JOINT TRANSPORTATION RESEARCH PROGRAM

FHWA/IN/JTRP-2009/34

Final Report

INNOVATIVE BRIDGE CONSTRUCTION

PROGRAM: IMPLEMENTATION OF FULL-DEPTH BRIDGE DECK PANELS IN INDIANA

Robert Frosch

Julio Ramirez

Stephen Price

March 2010 


\section{TECHNICAL Summary}

Technology Transfer and Project Implementation Information

\section{Innovative Bridge Construction Program: Implementation of Full Depth Bridge Deck Panels in Indiana}

\section{Introduction}

The interest in full-depth, precast bridge deck panels has been steadily increasing over the past 50 years because they offer several benefits over traditional cast-in-place construction. This type of system eliminates the need for cast-in-place formwork and, as such, reduces cost, construction time, and environmental/economic impact. In addition, precast panels are constructed in a controlled environment which leads to a more durable, high quality product.

Since 1964, more than 15 states have used fulldepth precast bridge deck panels in deck replacement projects and new construction. From the successful use of full-depth deck panels on steel girders over the last four decades and recent research involving concrete girders, the use of these systems is expected to increase. However, there are limitations with the current design approach that need to be addressed before these systems will be fully adopted. One of the main limitations with the current system is penetration of the full-depth of the deck by the grout pockets and shear keys. In addition, non-shrink grout is typically used to fill the pockets and shear keys and, consequently, shrinkage cracking is commonly observed around the pockets. This may eventually lead to deterioration of the deck, superstructure, and substructure through leakage.

There has been a considerable amount of research and experience with full-depth precast concrete deck panels installed on steel girders. However, research on full-depth precast concrete deck panels installed on prestressed concrete girders has been limited. This research evaluated the use of precast bridge deck panels on new and existing precast, prestressed concrete girders. In addition, a new system was developed to address durability and ease of construction issues that are problematic with current joint details.

\section{Findings}

The research program was conducted in four phases. First, the New England Region (NER) system was evaluated in a series of large scale tests in which the panels were placed on a $40 \mathrm{ft}$ prestressed concrete girder and subjected to three point loading to evaluate its constructability and composite behavior. Second, the strength and geometry of both the current and a new paneltogirder joint detail were evaluated and compared in a series of direct shear tests. Third, the strength and geometry of both the current and a new panelto-panel joint detail were evaluated and compared in a series of direct shear tests. Finally, a large scale specimen was designed, constructed, and evaluated to fully evaluate the new system. Based on the results of this research program the following conclusions were made: 
- Full-depth precast panels can be installed successfully on precast, prestressed concrete girders. In addition, postinstalled shear studs performed similar to cast-in-place shear studs.

- Partial-composite moment curvature analysis can be used to determine the area of steel required at the girder-deck panel interface.
- The horizontal force resisted by each stud can be estimated as Asfu for Grade 60 reinforcing steel.

- The new system demonstrated ease of construction and it minimizes full-depth penetrations of the deck, thereby increasing durability.

\section{Implementation}

The design and construction recommendations provided in this study can be implemented to improve the constructability and performance of precast bridge deck panels on precast, prestressed concrete girders. It is suggested that the recommendations be implemented in a field study to further evaluate constructability and long-term performance of such a structure. Through evaluation in the field, incorporation of these recommendations into the INDOT Design Manual can be considered. The improved constructability and durability of the new system not only has the potential to impact the way in which the aging highway system is rehabilitated and replaced but it may also decrease disruption to the traveling public.

\section{Contacts}

\section{For more information:}

\section{Prof. Robert Frosch}

Principal Investigator

School of Civil Engineering

Purdue University

West Lafayette IN 47907

Phone: (765) 494-5904

Fax: (765) 496-1105

E-mail: $\underline{\text { rosch@ecn.purdue.edu }}$

\section{Prof. Julio Ramirez}

Co-Principal Investigator

School of Civil Engineering

Purdue University

West Lafayette IN 47907

Phone: (765) 494-2716

Fax: (765) 496-1105

E-mail: ramirez@ecn.purdue.edu
Indiana Department of Transportation

Office of Research \& Development

1205 Montgomery Street

P.O. Box 2279

West Lafayette, IN 47906

Phone: (765) 463-1521

Fax: (765) 497-1665

\section{Purdue University}

Joint Transportation Research Program

School of Civil Engineering

West Lafayette, IN 47907-1284

Phone: (765) 494-9310

Fax: (765) 496-7996

E-mail: itrp@ecn.purdue.edu http://www.purdue.edu/jtrp 
Final Report

FHWA/IN/JTRP-2009/34

\title{
INNOVATIVE BRIDGE CONSTRUCTION PROGRAM: Implementation of Full-Depth Bridge Deck Panels in Indiana
}

\author{
by \\ Robert J. Frosch \\ Principal Investigator \\ Professor of Civil Engineering \\ Julio A. Ramirez \\ Co-Principal Investigator \\ Professor of Civil Engineering \\ and \\ Stephen Price \\ Graduate Research Assistant \\ School of Civil Engineering \\ Purdue University \\ Joint Transportation Research Program \\ Project No. C-36-56CC \\ File No. 7-4-80 \\ SPR-3024 \\ Conducted in Cooperation with the \\ Indiana Department of Transportation \\ and the Federal Highway Administration
}

The contents of this report reflect the views of the authors, who are responsible for the facts and the accuracy of the data presented herein. The contents do not necessarily reflect the official views or policies of the Indiana Department of Transportation or the Federal Highway Administration at the time of publication. This report does not constitute a standard, specification, or regulation.

Purdue University

West Lafayette, IN 47907

March 2010 


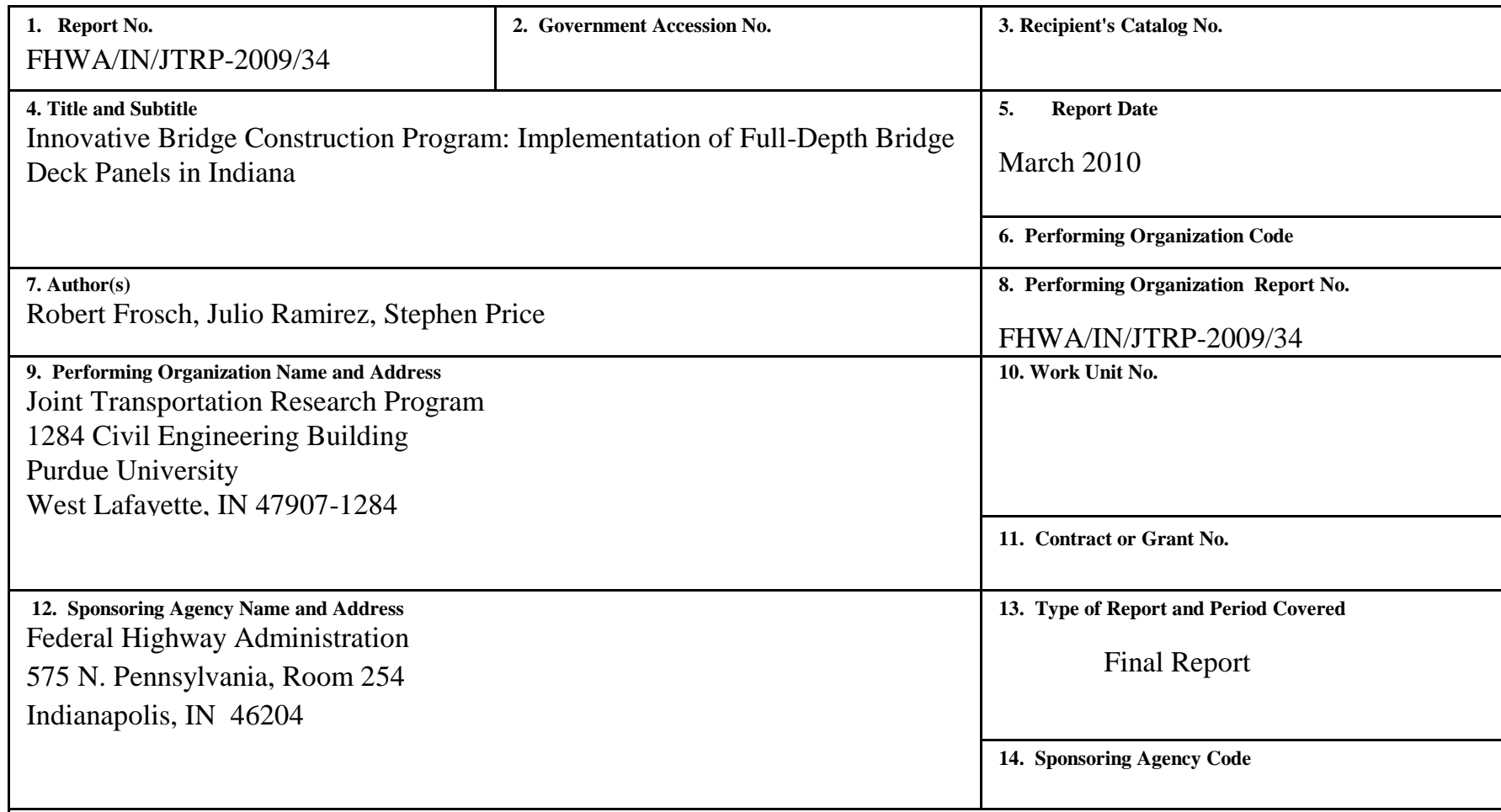

\section{Supplementary Notes}

Prepared in cooperation with the Federal Highway Administration and the Indiana Department of Transportation.

\section{Abstract}

This research evaluates the use of precast, prestressed bridge deck panels on new and existing precast, prestressed concrete girders. The evaluation focuses on the ease of construction and the ability of the system to develop composite action with the concrete girders. A system developed by the Connecticut Department of Transportation (CDOT) and Precast/Prestressed Concrete Institute New England Region (PCINER) was chosen for testing from available systems because it is representative of the current geometry of precast bridge deck panels. The CDOT system was evaluated in a series of large scale tests in which the panels were placed on a $40 \mathrm{ft}$ prestressed concrete girder and subjected to three point loading. The CDOT system is compared to a new system developed as part of the research program. The new system addresses durability and ease of construction issues that are problematic with current joint details. The strength and geometry of both the current and new joint details are evaluated and compared in a series of direct shear tests. A final, large scale specimen was designed, constructed, and loaded to evaluate the new system. It was concluded that the behavior of the new system is comparable to that of the CDOT system. In addition, the new system is easy to construct and minimizes deck penetrations, thereby enhancing durability. This research has the potential to impact the way in which the aging highway system is rehabilitated and replaced by reducing the associated time and costs of construction while decreasing disruption to the traveling public.

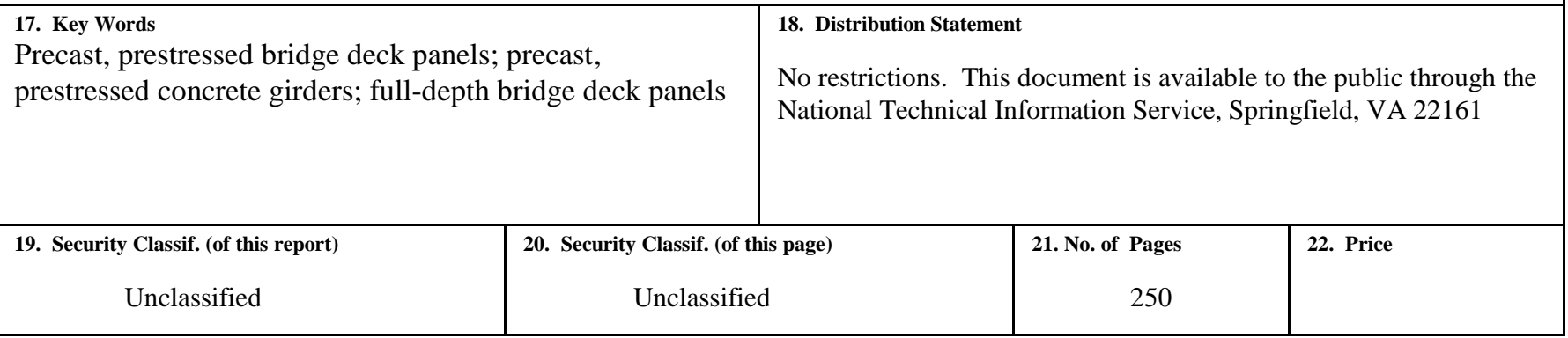




\section{ACKNOWLEDGEMENTS}

This work was supported by the Joint Transportation Research Program (JTRP) administered by the Indiana Department of Transportation (INDOT) and Purdue University through contract SPR-3024 as well as the Precast/Prestressed Concrete Institute (PCI) through the Daniel P. Jenny Research Fellowship Program. In addition, the project was supported through material donations from Prestresss Services Industries, LLC who donated a significant portion of the cost associated with the production and transportation of the prestressed girders, Unitex who donated segmental bridge adhesive, and Dayton Superior and Erico who donated the shear studs used in the project. The support of these sponsors and materials suppliers is gratefully acknowledged.

The authors would like to thank Dr. Tommy Nantung from the INDOT Division of Research for serving as Project Administrator and for his support throughout the project. In addition, thanks are extended to members of the JTRP Study Advisory Committee for their participation and thoughtful comments throughout the project. These members include Keith Hoernschemeyer, Don Leonard, Ed Spahr, Amanda Stevens, and Mike Wenning.

The authors would also like to thank Doug Sutton (chair), Don Meinheit, and Mark Lafferty for serving as members of the PCI Industry Advisory Group. Special thanks are extended to Neil Anderson and Maher Tadros from the PCI Research \& Development Committee for their helpful comments and support of the project. 
TABLE OF CONTENTS

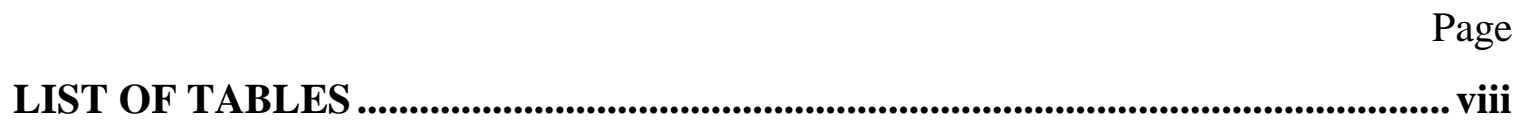

LIST OF FIGURES .............................................................................................................. iix

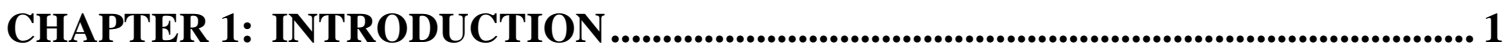

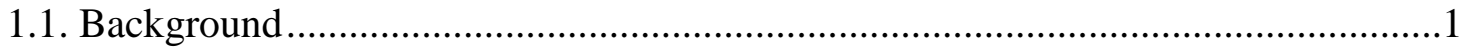

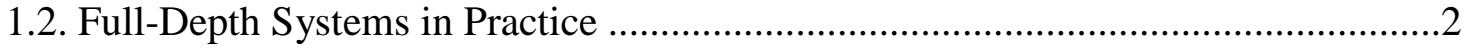

1.2.1. New England Region System ...............................................................

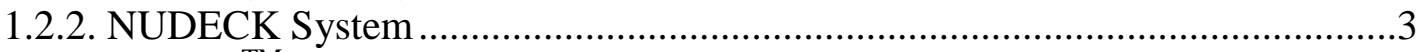

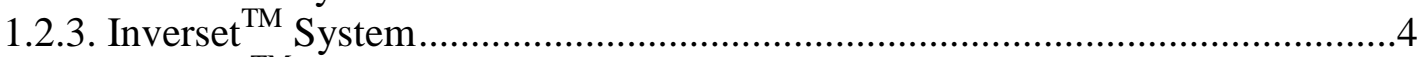

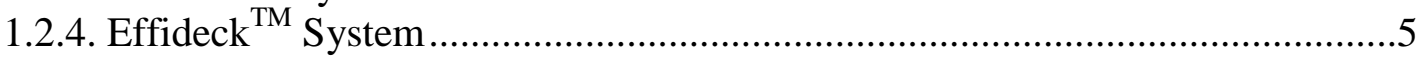

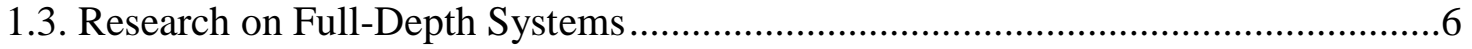

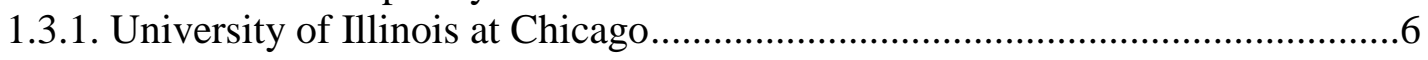

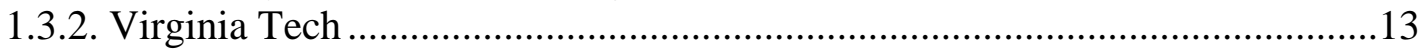

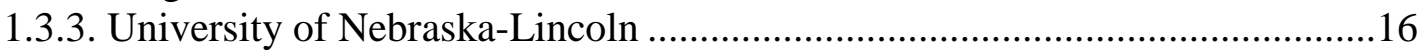

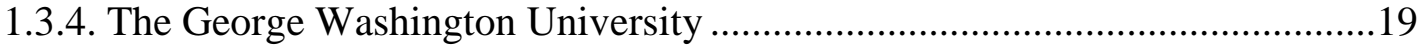

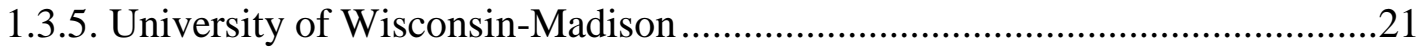

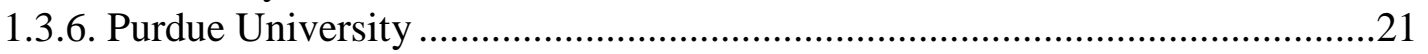

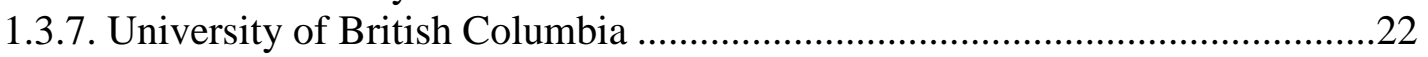

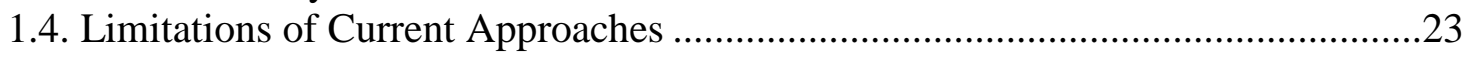

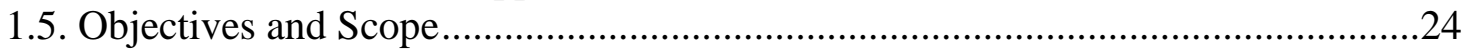

CHAPTER 2: NEW ENGLAND SYSTEM ON CONCRETE GIRDERS ............... 26

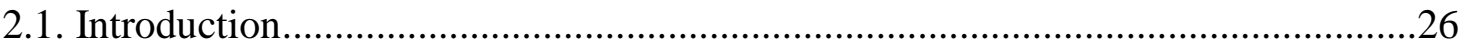

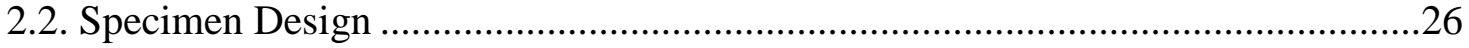

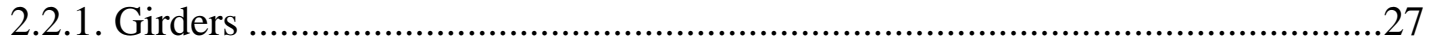

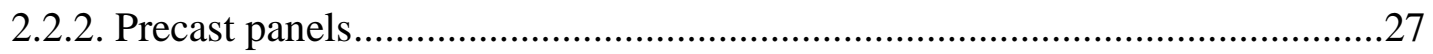

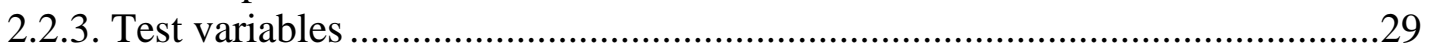

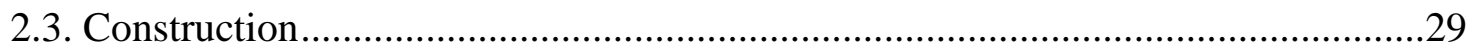

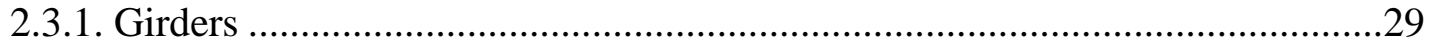

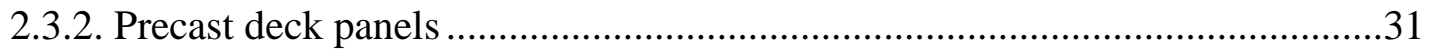

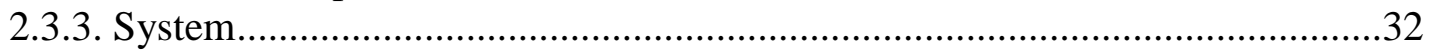




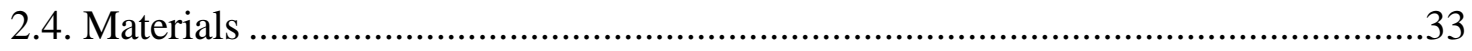

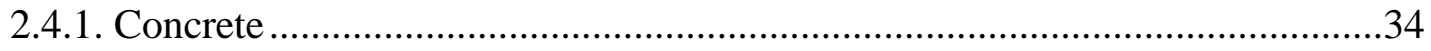

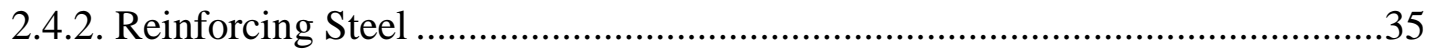

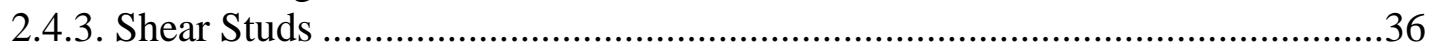

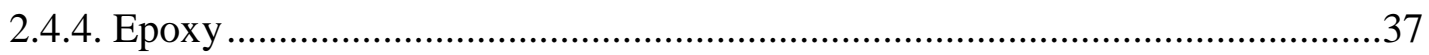

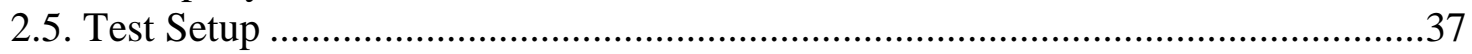

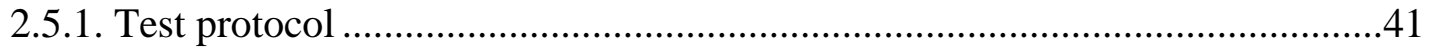

2.6. Test Results...............................................................................................

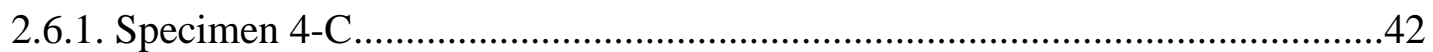

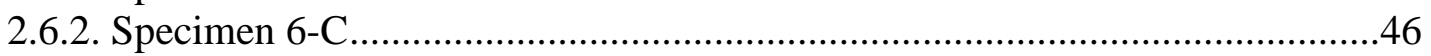

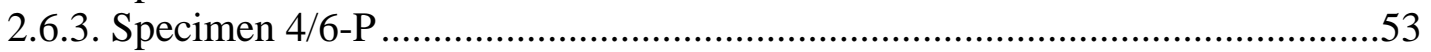

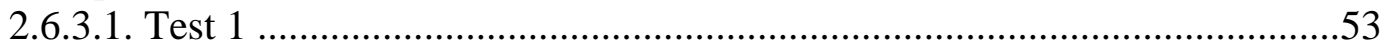

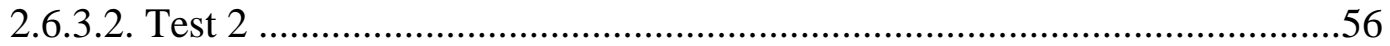

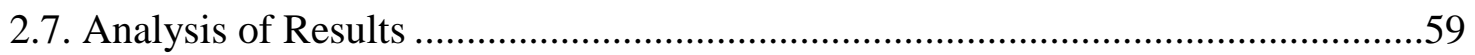

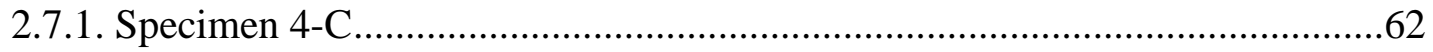

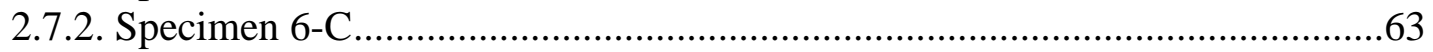

2.7.3. Specimen 4/6-P, Test 1 (\#6 studs) .................................................................64

2.7.4. Specimen 4/6-P, Test 2 (\#4 studs) ...............................................................66

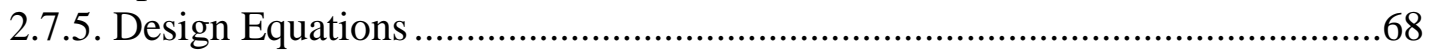

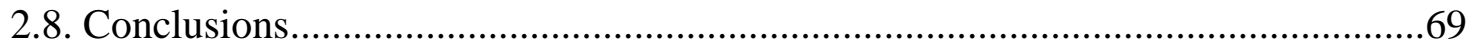

CHAPTER 3: PANEL-TO-GIRDER CONNECTION ............................................... 71

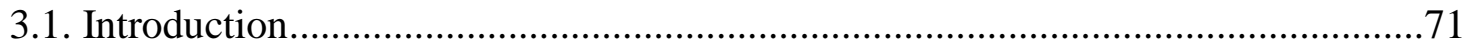

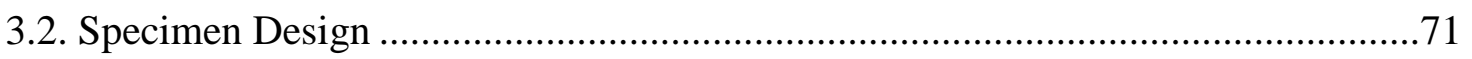

3.2.1. Girder section .........................................................................................71

3.2.2. Panel section ..........................................................................................75

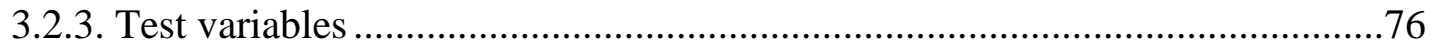

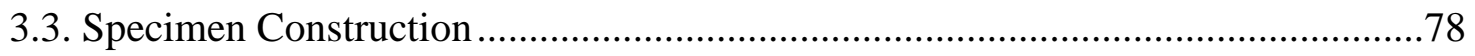

3.3.1. Girder section .......................................................................................78

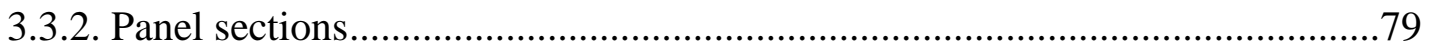

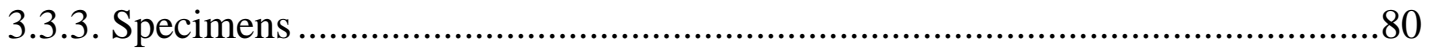

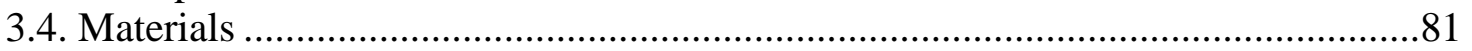

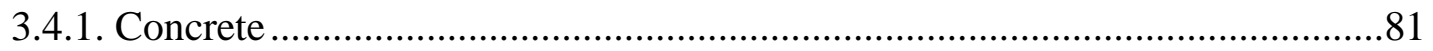

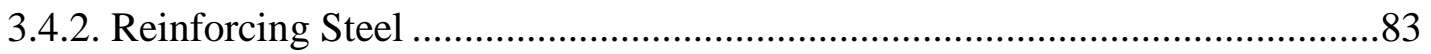

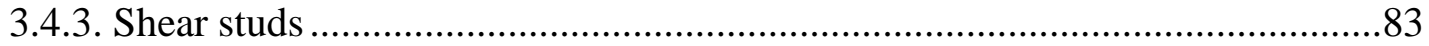

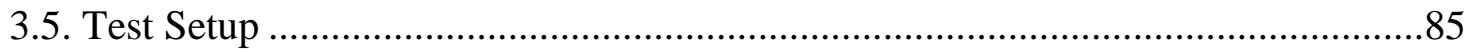

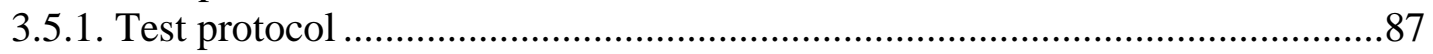

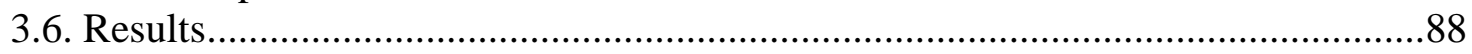

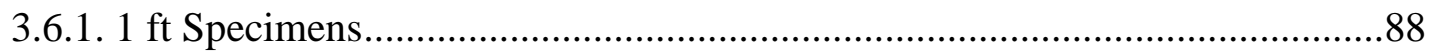

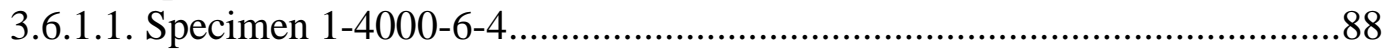

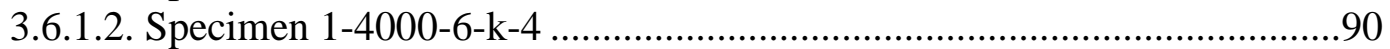

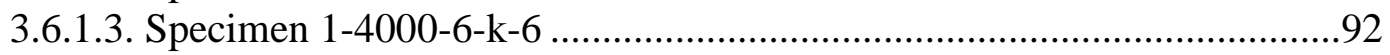

3.6.1.4. Specimen 1-4000-8-6..........................................................................94

3.6.1.5. Specimen 1-4000-8-k-6 ...................................................................95 


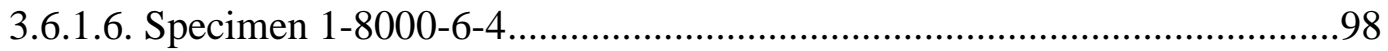

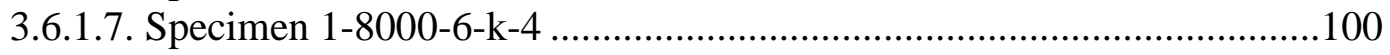

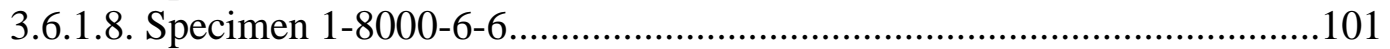

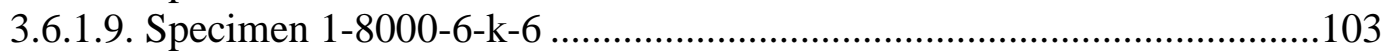

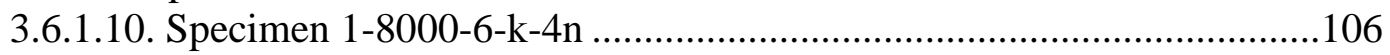

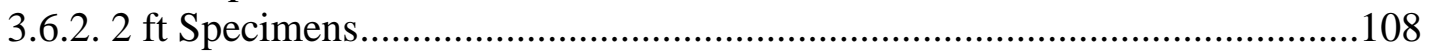

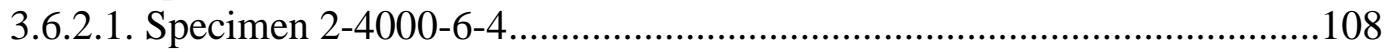

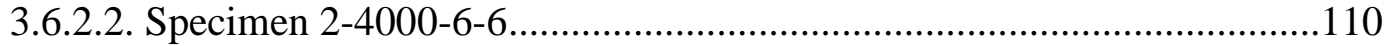

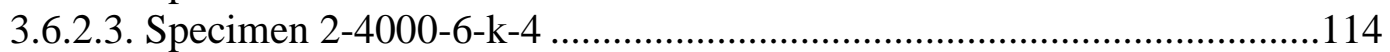

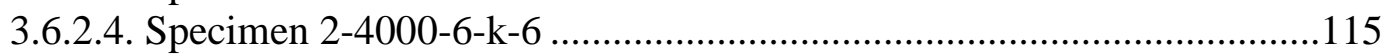

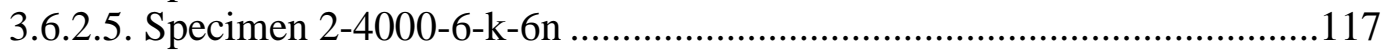

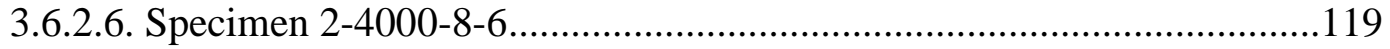

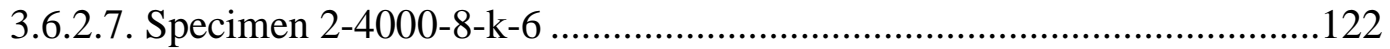

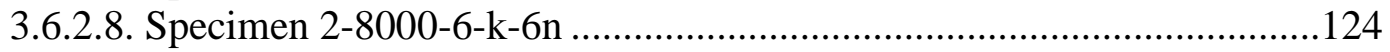

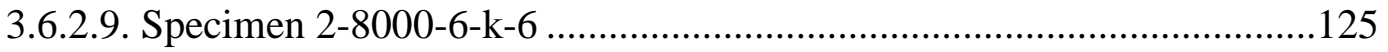

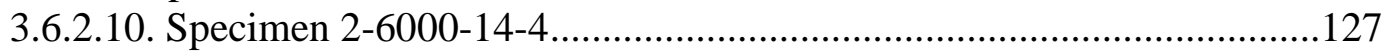

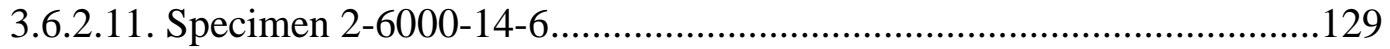

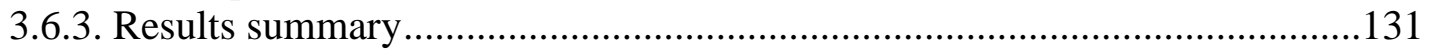

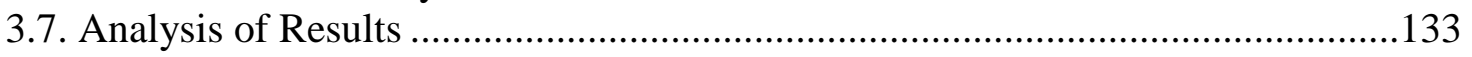

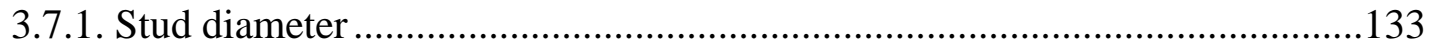

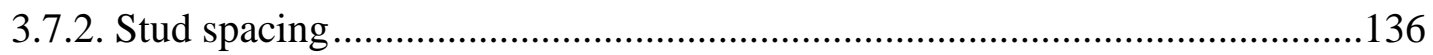

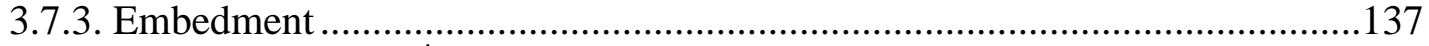

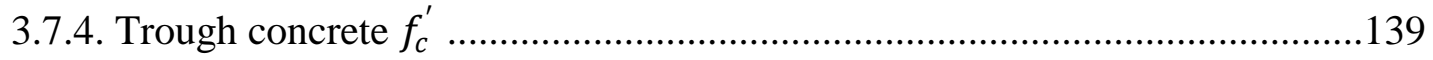

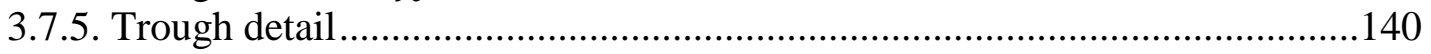

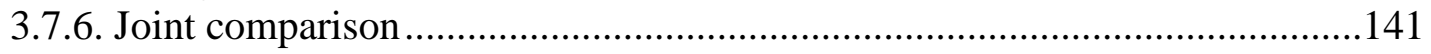

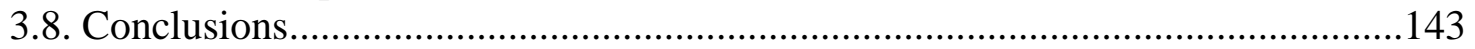

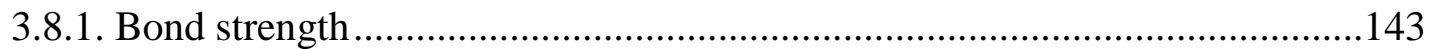

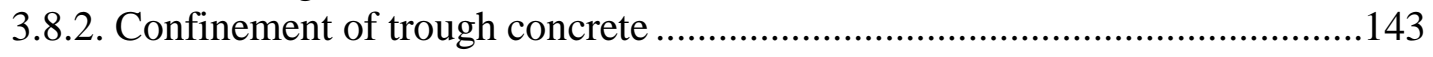

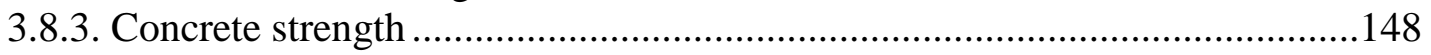

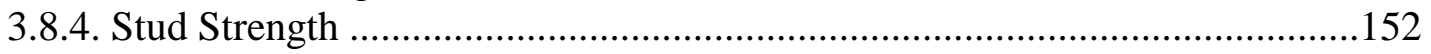

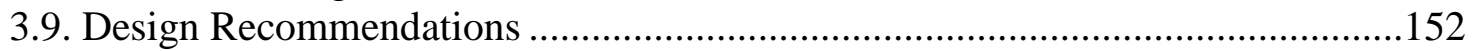

CHAPTER 4: PANEL-TO-PANEL CONNECTION.............................................. 153

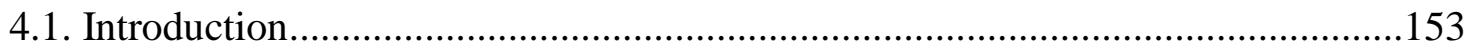

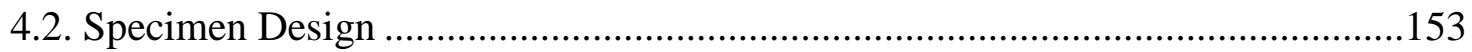

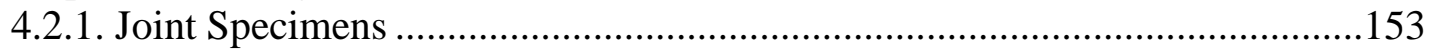

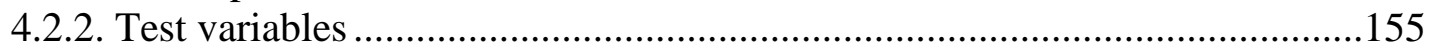

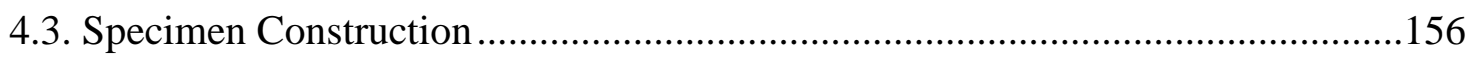

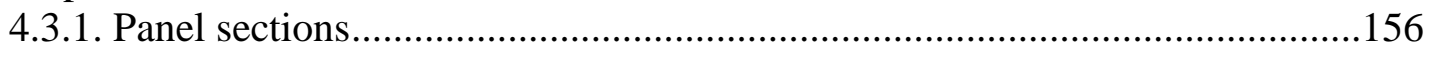

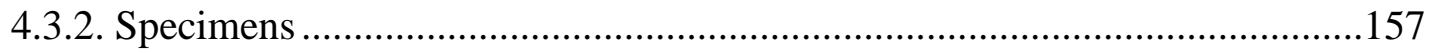

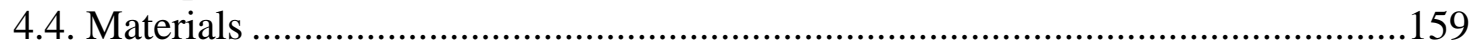

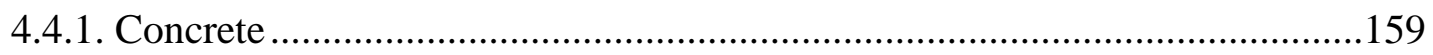

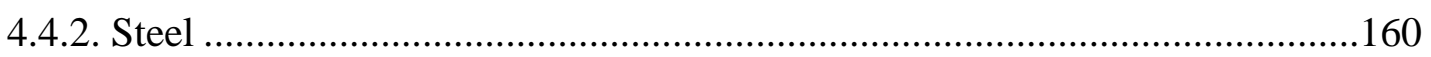

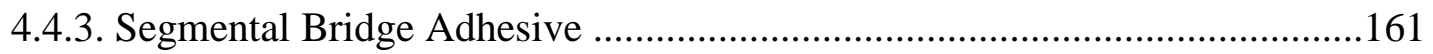




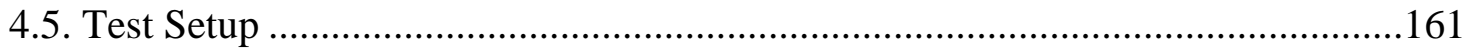

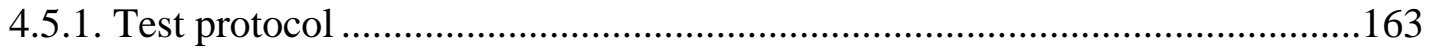

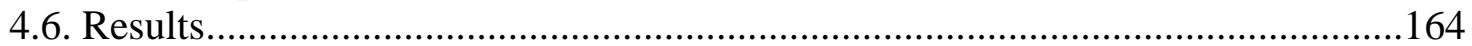

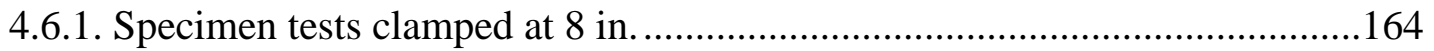

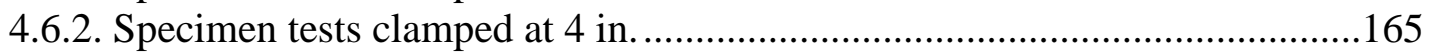

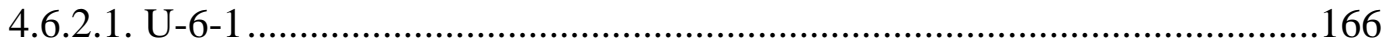

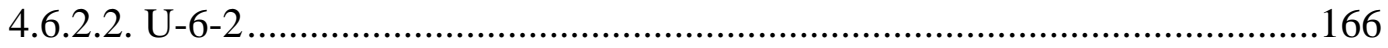

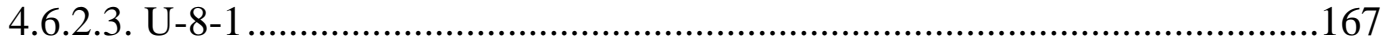

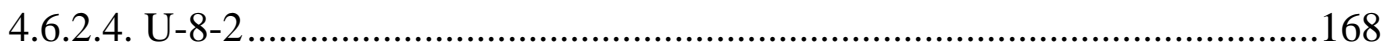

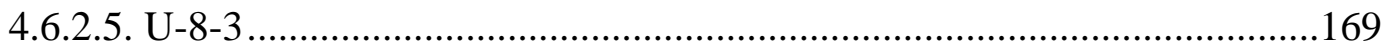

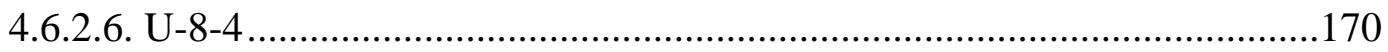

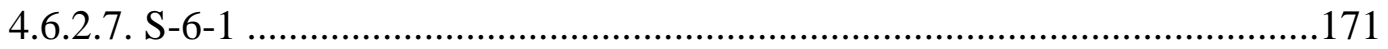

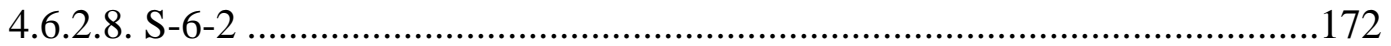

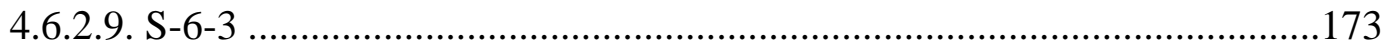

4.6.2.10. S-6-4 ....................................................................................174

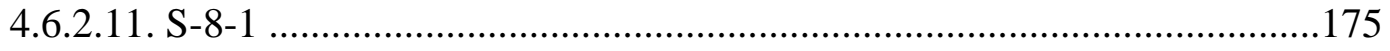

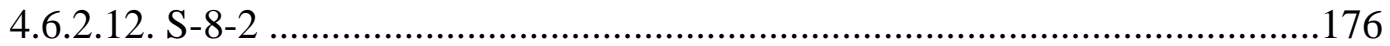

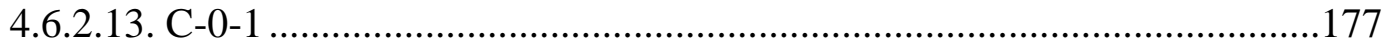

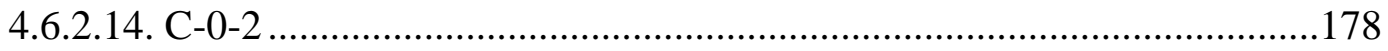

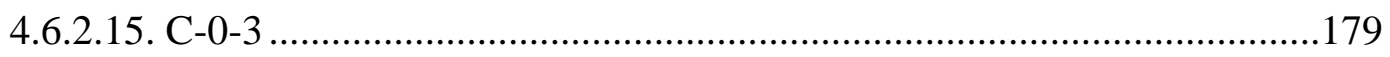

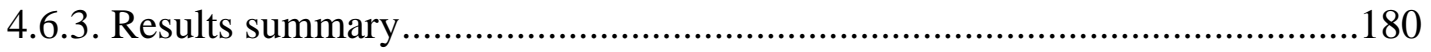

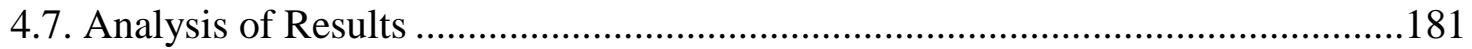

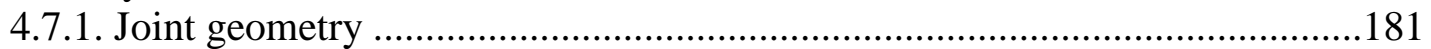

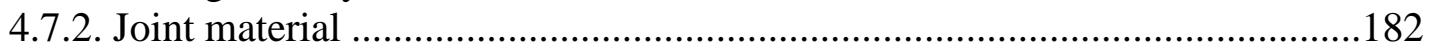

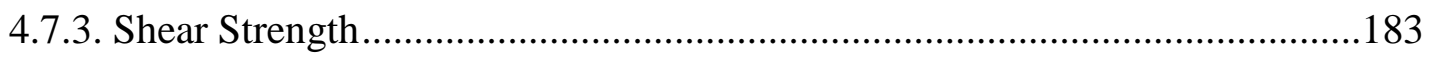

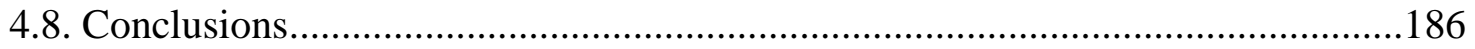

4.9. Design Recommendation..............................................................................187

CHAPTER 5: FULL-DEPTH DECK SYSTEM …................................................. 188

5.1. Introduction...........................................................................................188

5.2. Specimen Design .....................................................................................188

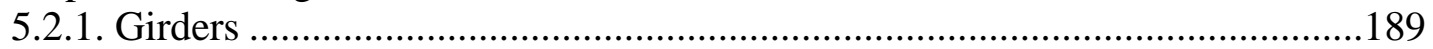

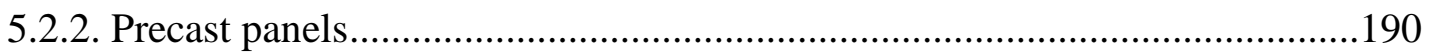

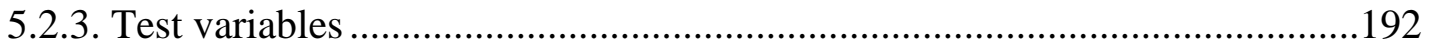

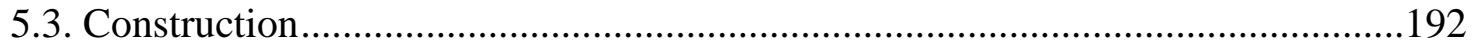

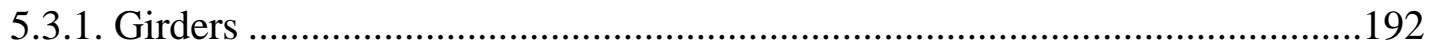

5.3.2. Precast deck panels ...................................................................................193

5.3.3. System........................................................................................................196

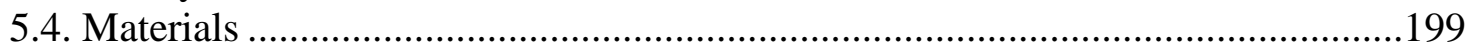

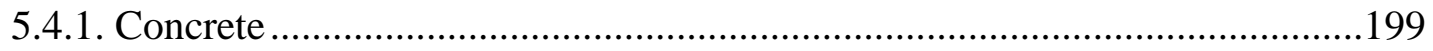

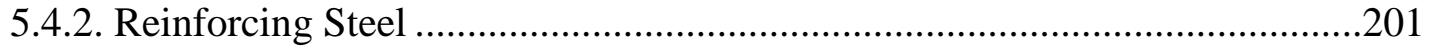

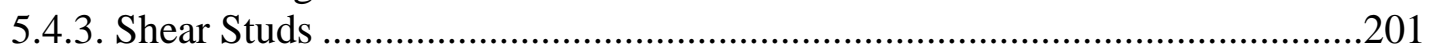

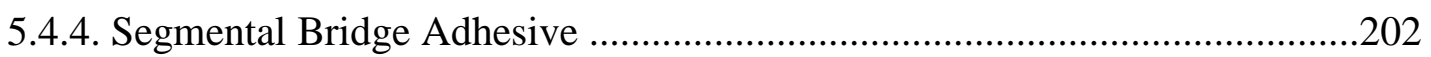

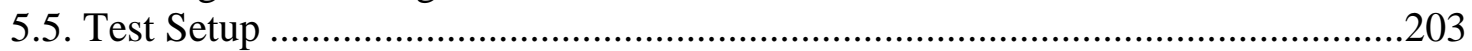




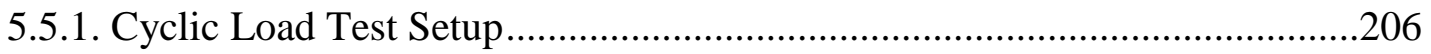

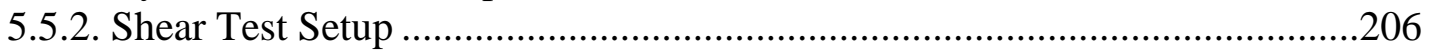

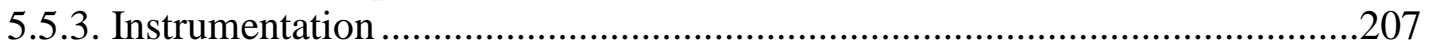

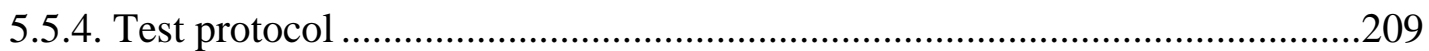

5.5.4.1. Cyclic Load Test.............................................................................209

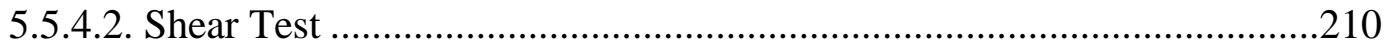

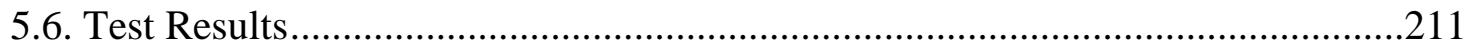

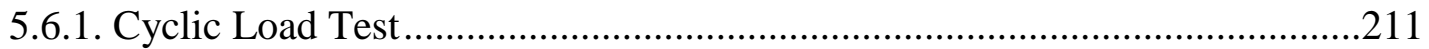

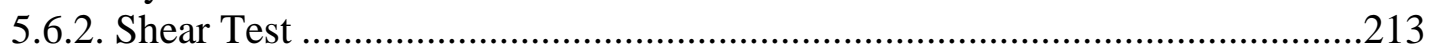

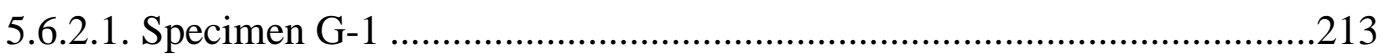

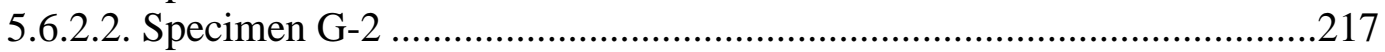

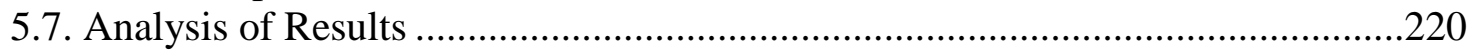

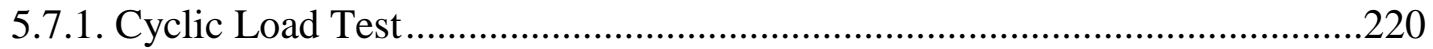

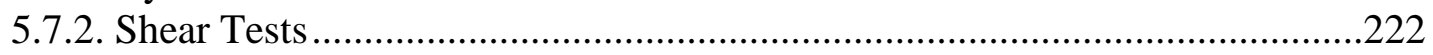

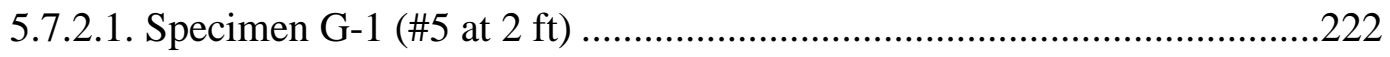

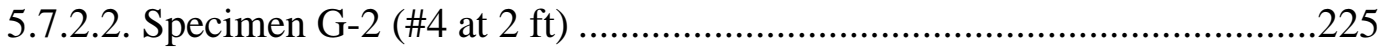

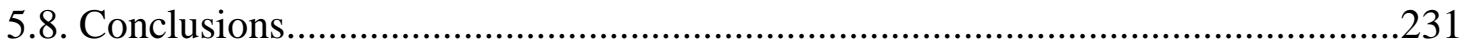

CHAPTER 6: SUMMARY AND CONCLUSIONS................................................. 232

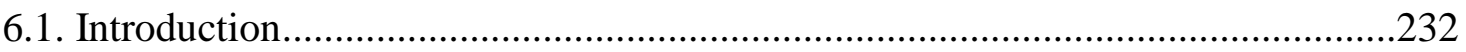

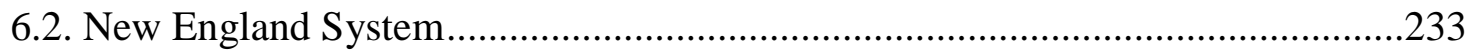

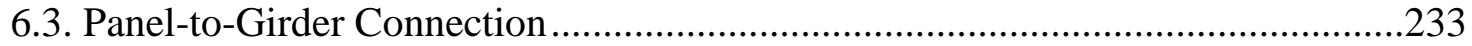

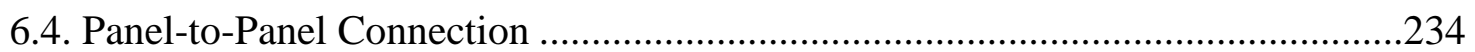

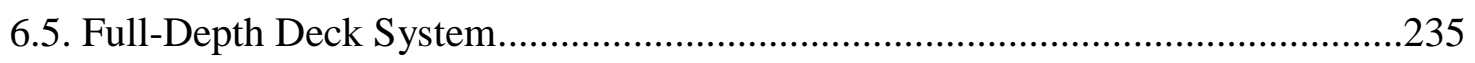

6.6. Design and Construction Recommendations ................................................236

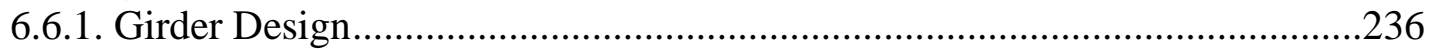

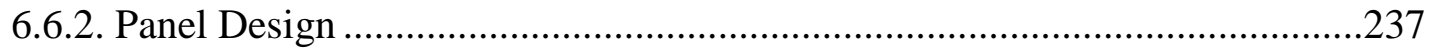

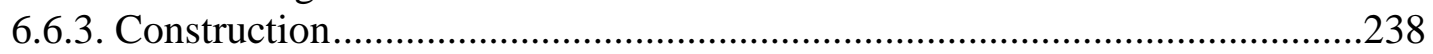

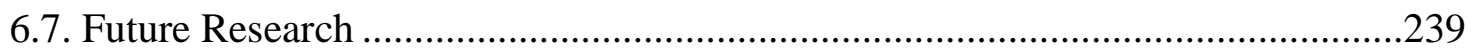

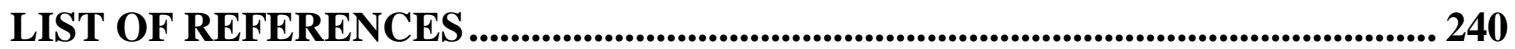

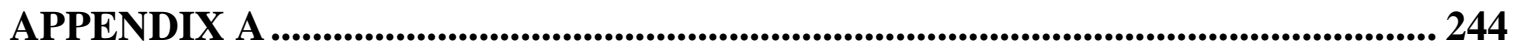




\section{LIST OF TABLES}

Table

2.1: Specimen variables

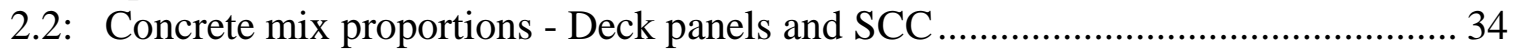

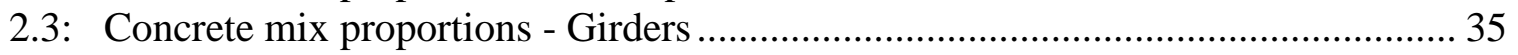

2.4: Average cylinder strengths on day of specimen test........................................... 35

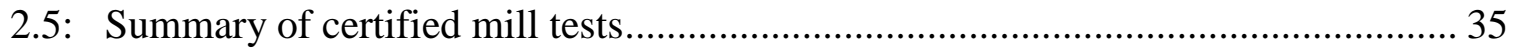

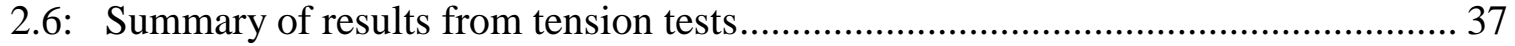

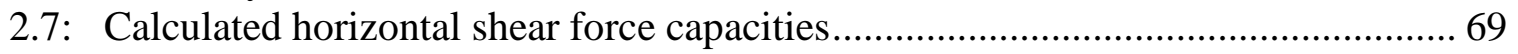

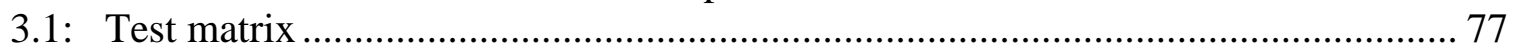

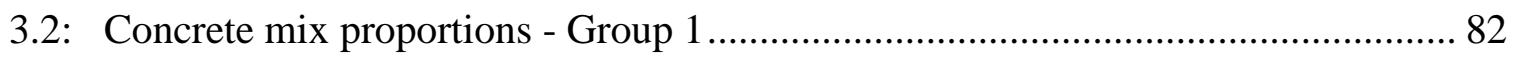

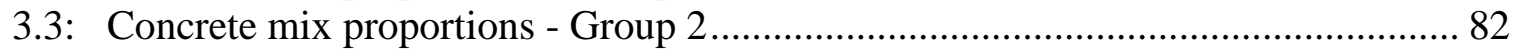

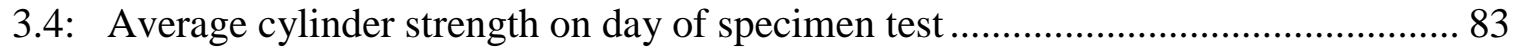

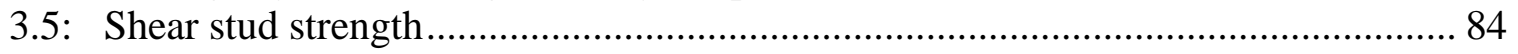

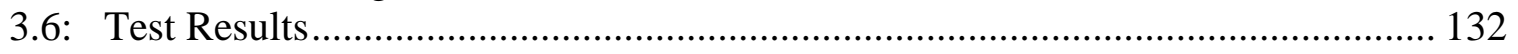

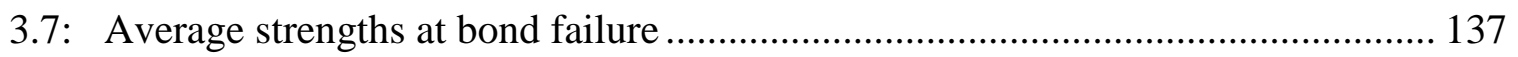

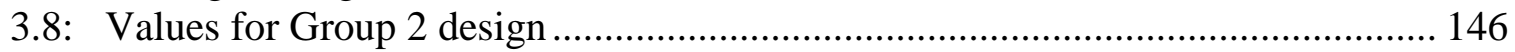

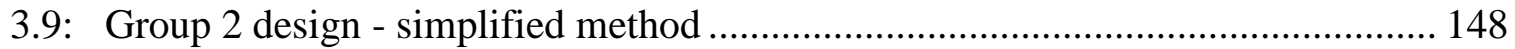

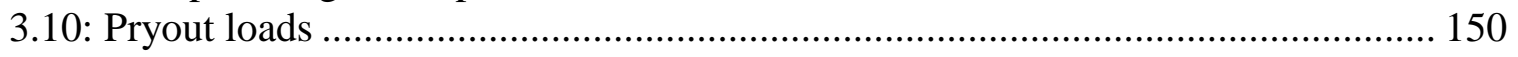

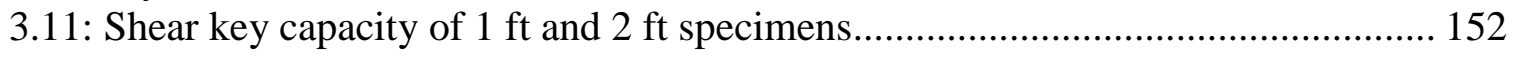

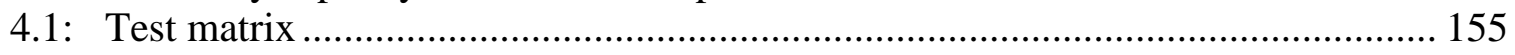

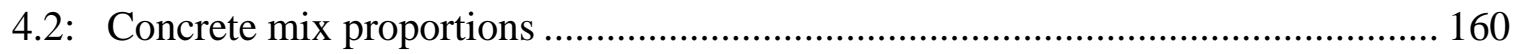

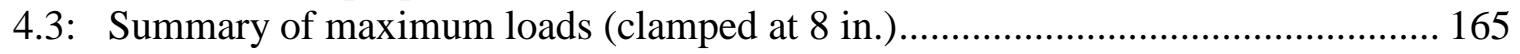

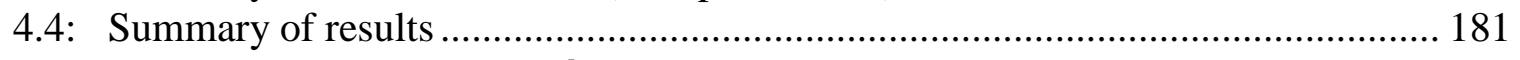

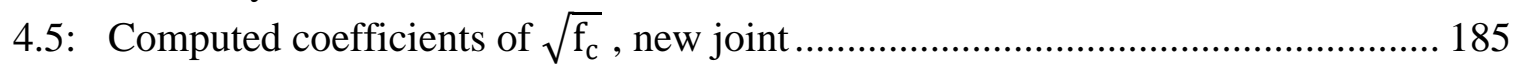

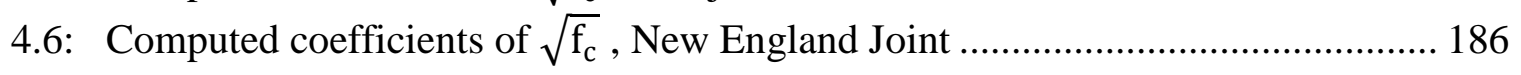

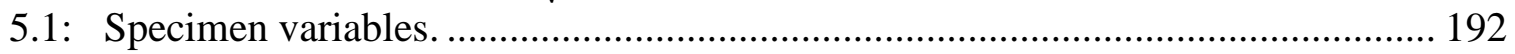

5.2: Concrete mix proportions - Deck panels and Trough......................................... 200

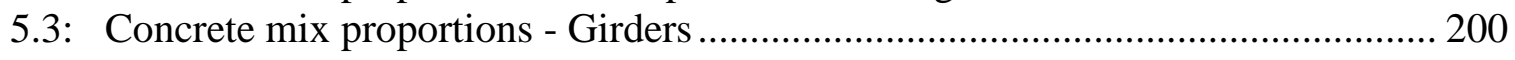

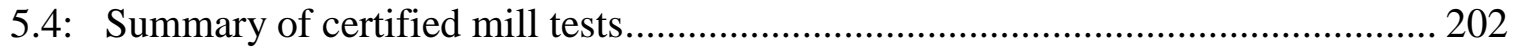

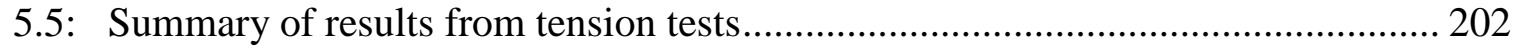

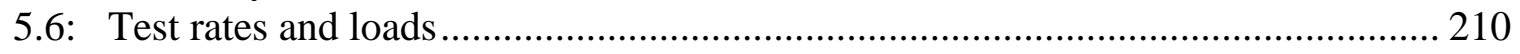

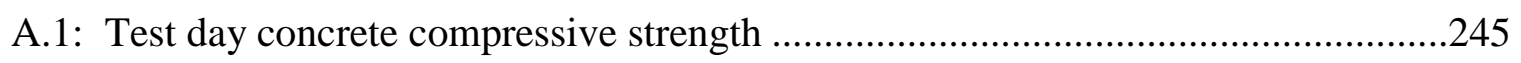




\section{LIST OF FIGURES}

Figure

1.1: $\quad$ Typical full-depth precast bridge deck panel system................................................. 2

1.2: Typical NUDECK panel (Fallaha et al. 2004)....................................................... 4

1.3: $\quad$ Typical Inverset ${ }^{\mathrm{TM}}$ unit (Fort Miller Co. 2008a) .................................................... 5

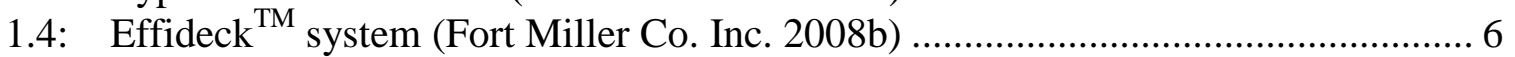

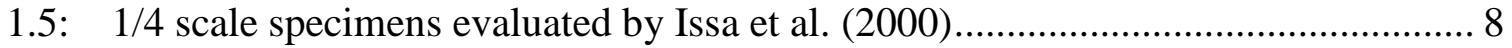

1.6: Small scale tests performed by Issa et al. (2003a) ............................................... 9

1.7: Example of one pocket full scale push-off specimen used by Issa et al. (2003b) 11

1.8: Example of push-off test performed by Issa et al. (2006) ..................................... 12

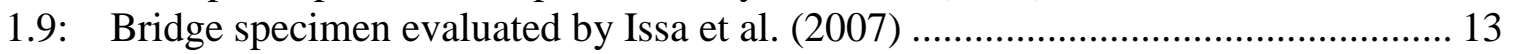

1.10: Push-off test setup (Menkulasi and Roberts-Wollmann 2005).............................. 14

1.11: Shear stud system developed at Virginia Tech (Scholz et al. 2007)...................... 15

1.12: Transverse joint geometries used by Sullivan (2007).......................................... 15

1.13: Plan view of deck system (Yamane et al. 1998) .................................................. 17

1.14: Sections A-A and B-B from Figure 1.13 (Yamane et al. 1998) ............................. 18

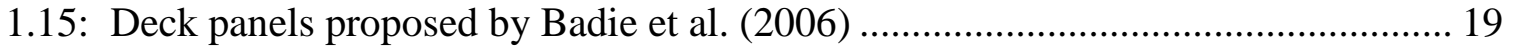

1.16: Transverse joint details proposed by Badie et al. (2006)..................................... 20

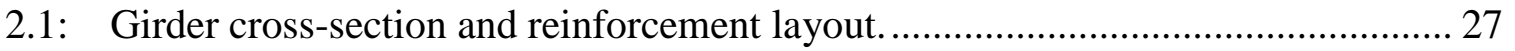

2.2: Panel dimensions and reinforcement details...................................................... 28

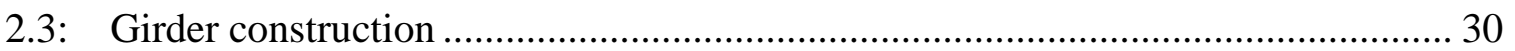

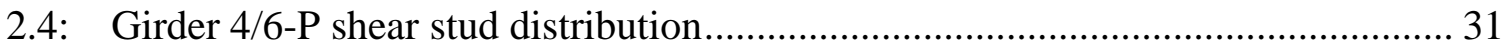

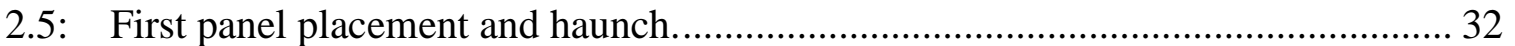

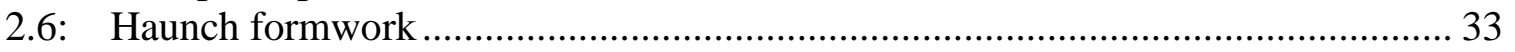

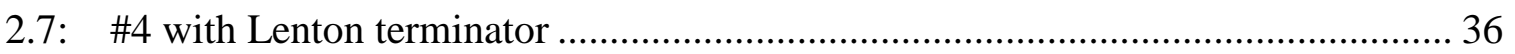

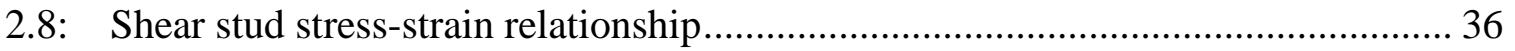

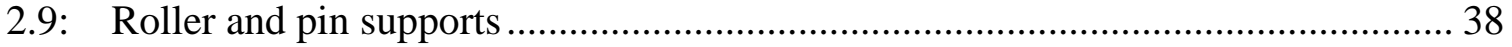

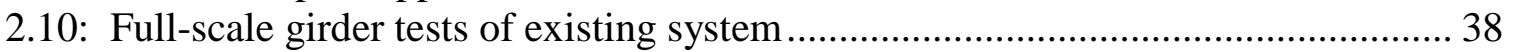

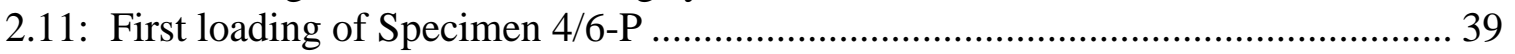

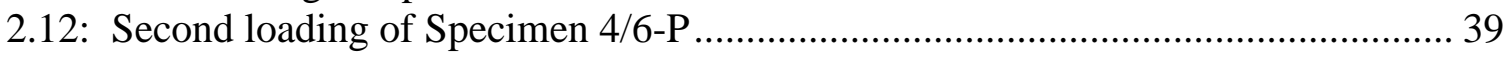

2.13: Location of external instrumentation on Specimens 4-C and 6-C .......................... 40

2.14: Location of external instrumentation on Specimen 4/6-P ................................... 41

2.15: Load vs Midspan deflection - Specimen 4-C ................................................... 42

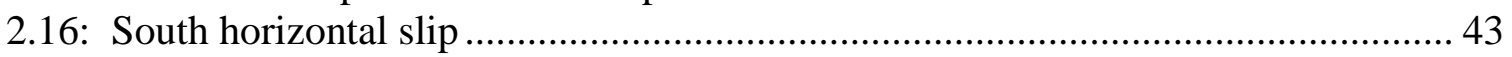

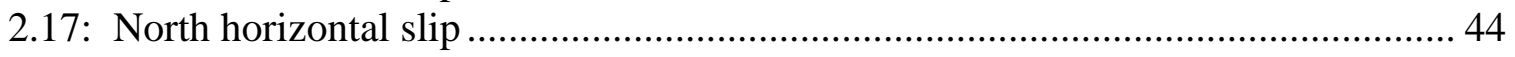

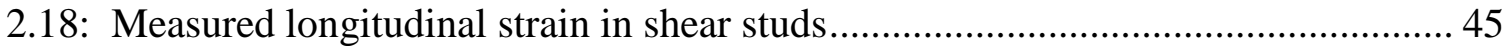

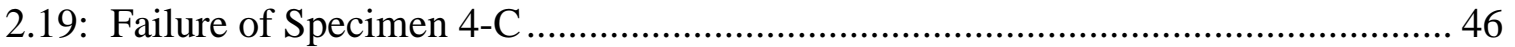

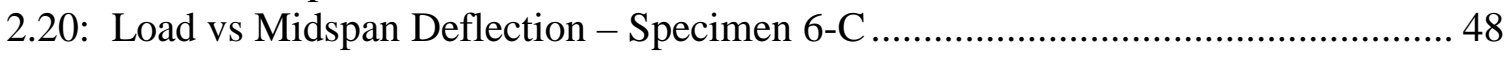




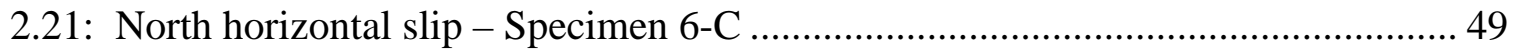

2.22: South horizontal slip - Specimen 6-C ............................................................... 50

2.23: Measured strain in shear studs - Specimen 6-C ................................................... 51

2.24: Load vs Midspan deflection for final loading to failure - Specimen 6-C ............... 51

2.25: Failure of Specimen 6-C ............................................................................... 52

2.26: Load vs deflection - Specimen 4/6-P, Test 1 ....................................................... 54

2.27: North horizontal slip - Specimen 4/6-P, Test 1................................................... 54

2.28: South horizontal slip - Specimen 4/6-P, Test 1 1.................................................. 55

2.29: Failure of Specimen 4/6-P, Test 1 ..................................................................... 56

2.30: Load vs deflection - Specimen 4/6-P, Test 2 ……………………………...... 57

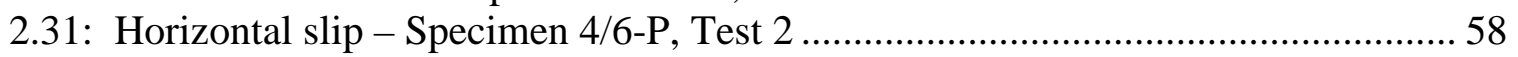

2.32: Failure of Specimen 4/6-P, Test 2 …………………………………………..... 59

2.33: Determining shear force at horizontal interface, full-composite .............................. 61

2.34: Determining shear force at horizontal interface, partial-composite ........................ 62

2.35: Specimen 4-C compared with computed load-deflection paths ................................ 63

2.36: Specimen 6-C compared with computed load-deflection paths ................................64 64

2.37: Specimen 4/6-P, Test 1, compared with computed load deflection paths ............... 66

2.38: Specimen 4-P, Test 2, compared with computed load-deflection paths ................... 67

3.1: Rebar layout for Group 1 specimens ................................................................... 73

3.2: Rebar layout for Group 2 specimens ……………............................................ 74

3.3: Shear key dimensions ....................................................................................... 75

3.4: Reinforcement layout for panel sections ............................................................. 76

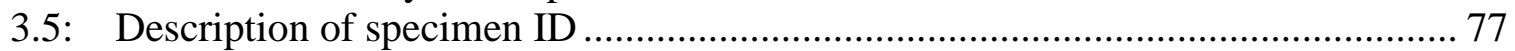

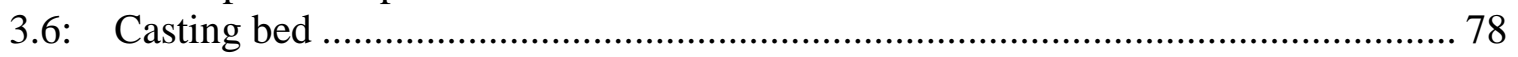

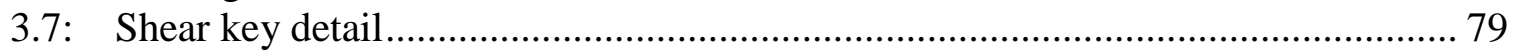

3.8: Examples of completed panel sections ……………........................................... 80

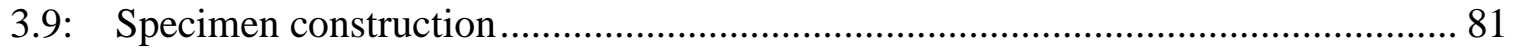

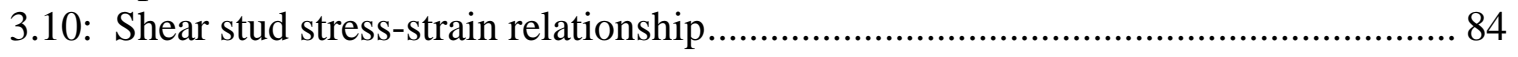

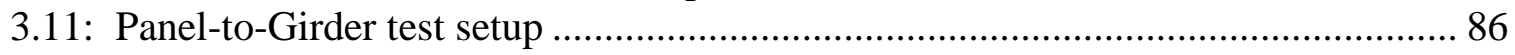

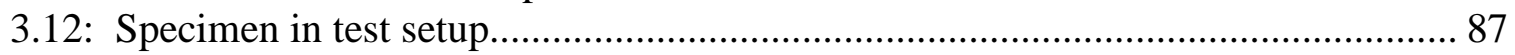

3.13: Load-slip response of Specimen 1-4000-6-4 ........................................................ 88

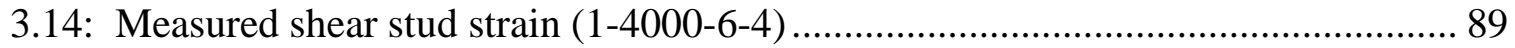

3.15: Specimen 1-4000-6-4 after bond failure............................................................. 90

3.16: Panel-haunch bond failure (1-4000-6-k-4) .......................................................... 91

3.17: Load-slip response of Specimen 1-4000-6-k-4 ………........................................ 91

3.18: Cracking of girder section (1-4000-6-k-4) ....................................................... 92

3.19: Load-slip response of Specimen 1-4000-6-k-6..................................................... 93

3.20: Cracking of girder section (1-4000-6-k-6)............................................................ 93

3.21: Load-slip response of Specimen 1-4000-8-6 ………............................................. 94

3.22: Panel rotation and cracking following bond failure (1-4000-8-6).......................... 95

3.23: Load-slip response of Specimen 1-4000-8-k-6 ................................................... 96

3.24: Cracking of Specimen 1-4000-8-k-6 after bond failure.......................................... 97

3.25: Cracking of Specimen 1-4000-8-k-6 ………….............................................. 97

3.26: Load-slip response of Specimen 1-8000-6-4 ....................................................... 98

3.27: Panel separation following bond failure (1-8000-6-4) ........................................... 99 
3.28: Measured shear stud strain (1-8000-6-4) ............................................................. 99

3.29: Load-slip response of Specimen 1-8000-6-k-4 …….......................................... 100

3.30: Cracking of girder section and trough (1-8000-6-k-4) .......................................... 101

3.31: Damage to trough concrete of Specimen 1-8000-6-k-4........................................ 101

3.32: Load-slip response of Specimen 1-8000-6-6 ..................................................... 102

3.33: Separated panel section...................................................................................... 103

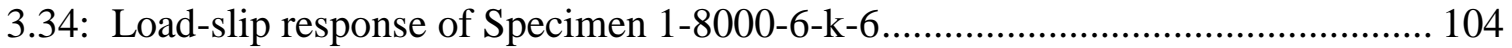

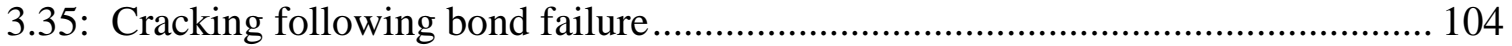

3.36: Measured shear stud strain (1-8000-6-k-6)......................................................... 105

3.37: Damage to trough concrete of Specimen 1-80000-6-k-6....................................... 106

3.38: Load-slip response for Specimen 1-8000-6-k-4n .............................................. 107

3.39: Shear stud failure of Specimen 1-8000-6-k-4n.................................................. 107

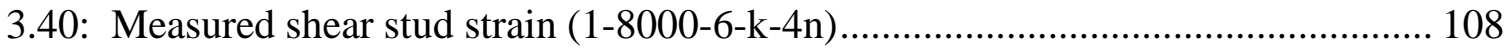

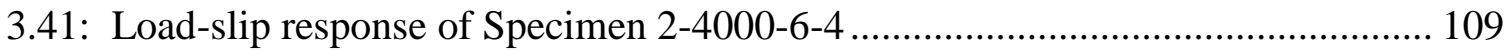

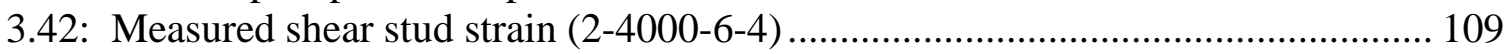

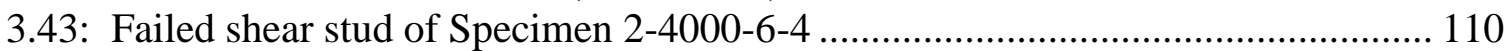

3.44: Load-slip response of Specimen 2-4000-6-6 .................................................... 111

3.45: Rotation of panel section following second bond failure (2-4000-6-6)................ 112

3.46: Pulling out of trough concrete from girder section (2-4000-6-6) .......................... 113

3.47: Measured shear stud strain (2-4000-6-6) .......................................................... 113

3.48: Load-slip response of Specimen 2-4000-6-k-4 …….......................................... 114

3.49: Failed shear stud of Specimen 2-4000-6-k-4 ..................................................... 115

3.50: Load-slip response of Specimen 2-4000-6-k-6................................................ 116

3.51: Trough deterioration of Specimen 2-4000-6-k-6 ............................................. 116

3.52: Measured shear stud strain (2-4000-6-k-6)...................................................... 117

3.53: Load-slip response for Specimen 2-4000-6-k-6n ................................................ 118

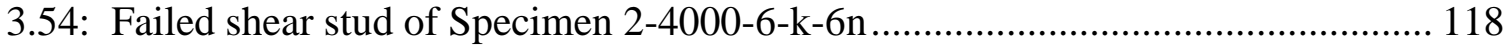

3.55: Measured shear stud strain (2-4000-6-k-6n) ........................................................ 119

3.56: Load-slip response of Specimen 2-4000-8-6 ................................................. 120

3.57: Voids in haunch of Specimen 2-4000-8-6 ...................................................... 121

3.58: Trough fracture of Specimen 2-4000-8-6 ………............................................. 121

3.59: Load-slip response for Specimen 2-4000-8-k-6 ................................................ 122

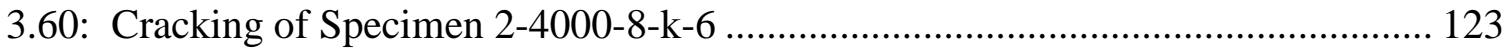

3.61: Measured shear stud strain (2-4000-8-k-6)........................................................ 123

3.62: Load-slip response of Specimen 2-8000-6-k-6n.................................................. 124

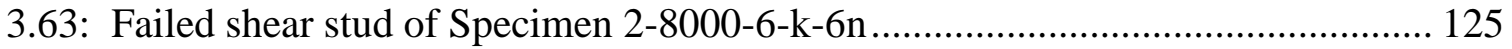

3.64: Load-slip response of Specimen 2-8000-6-k-6.................................................. 126

3.65: Girder section cracking and haunch void (2-8000-6-k-6) ..................................... 126

3.66: Trough and girder cracking of Specimen 2-8000-6-k-6 ....................................... 127

3.67: Load-slip response of Specimen 2-6000-14-4 ................................................... 128

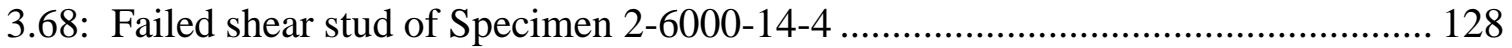

3.69: Measured shear stud strain (2-6000-14-4) ....................................................... 129

3.70: Load-slip response of Specimen 2-6000-14-6 ................................................... 130

3.71: Failed shear stud of Specimen 2-6000-14-6 ……….......................................... 130

3.72: Incomplete interface bond failure of Specimen 1-4000-8-6 .................................. 133 
3.73: Maximum load, after bond failure, on specimens with stud failure .................... 135

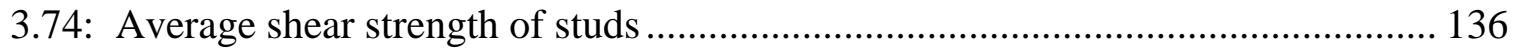

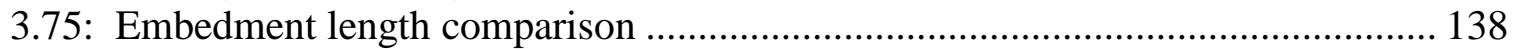

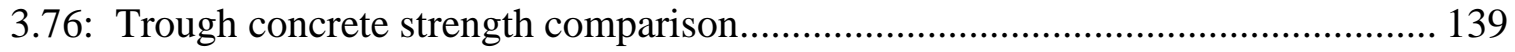

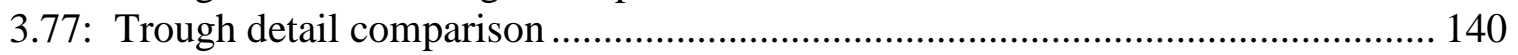

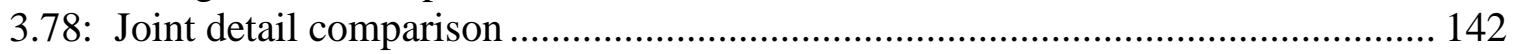

3.79: Loading and design for trough confinement reinforcement ............................. 145

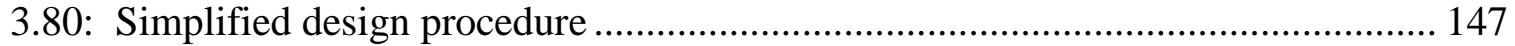

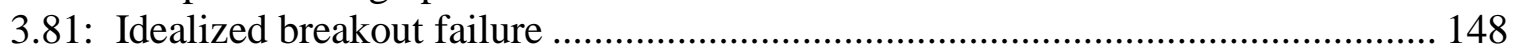

3.82: Additional idealized failure modes ................................................................. 149

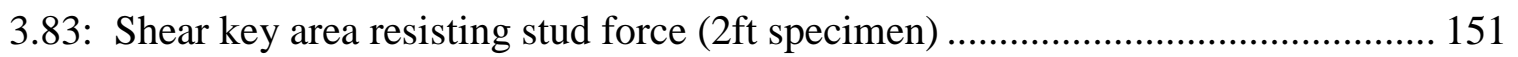

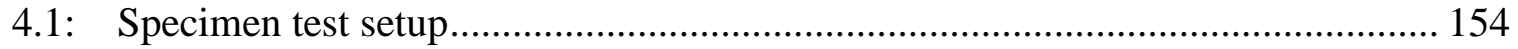

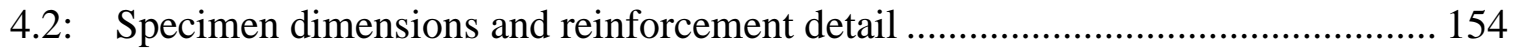

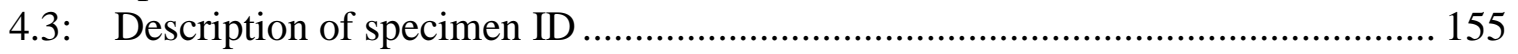

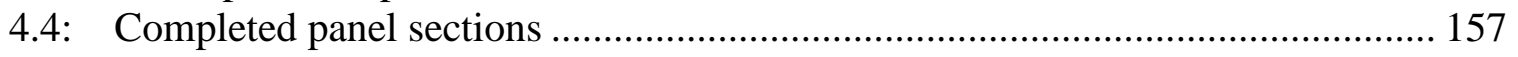

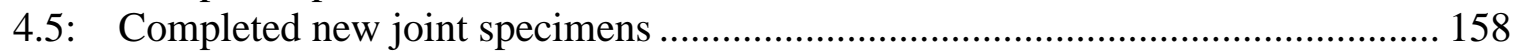

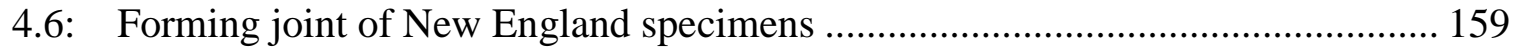

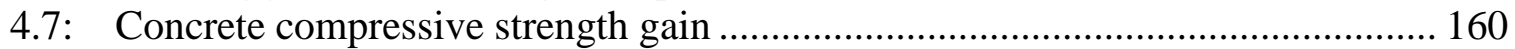

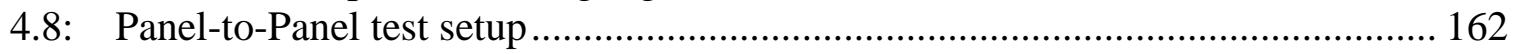

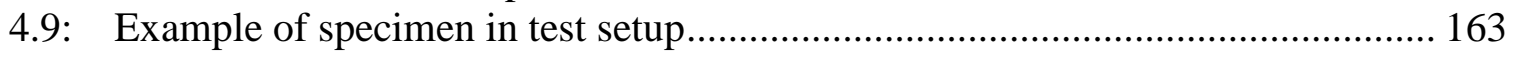

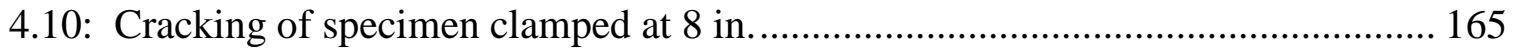

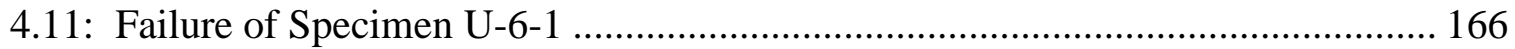

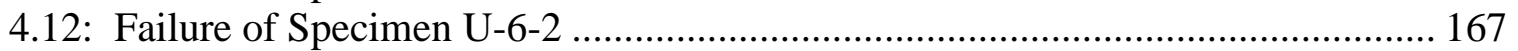

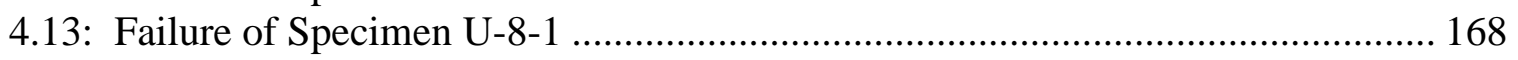

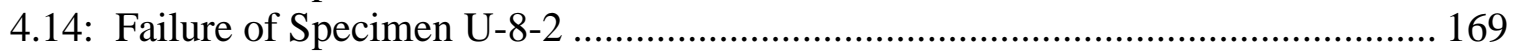

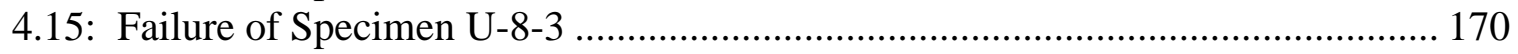

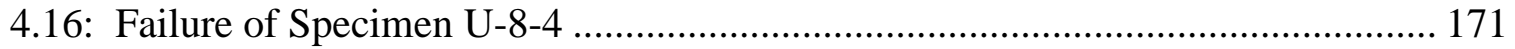

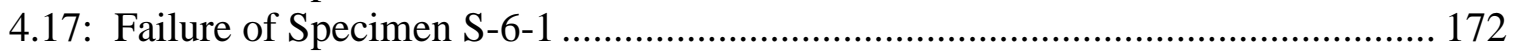

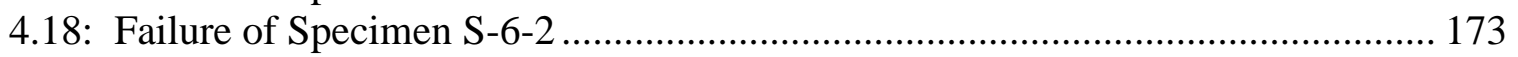

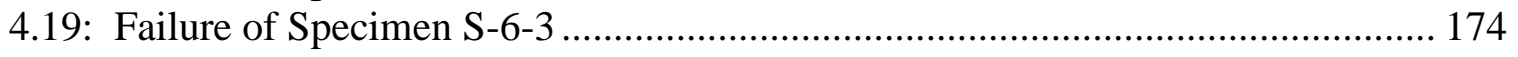

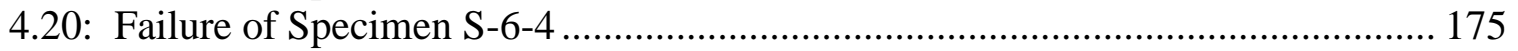

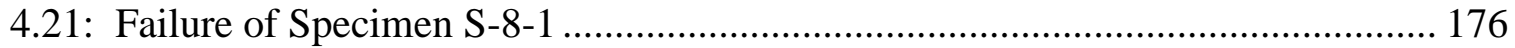

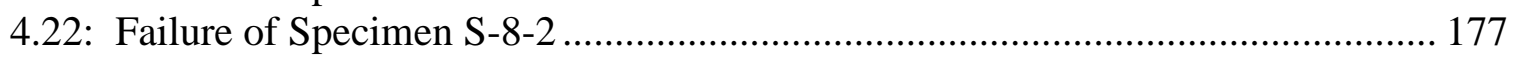

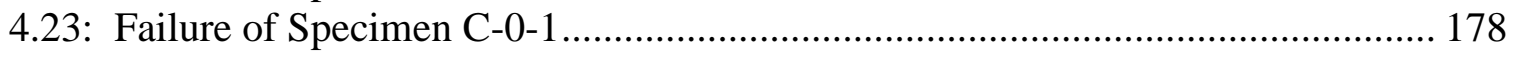

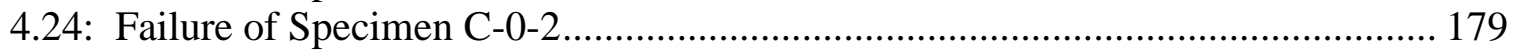

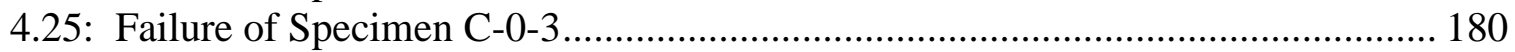

4.26: Average ultimate strength, comparing joint geometry ...................................... 182

4.27: Average ultimate strength, comparing joint material ....................................... 183

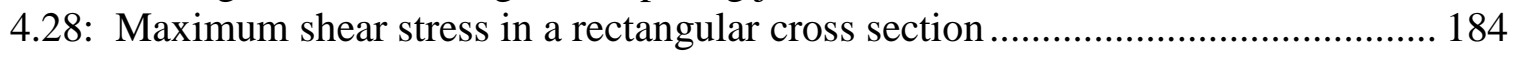

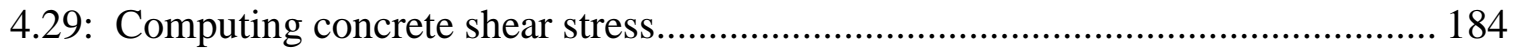

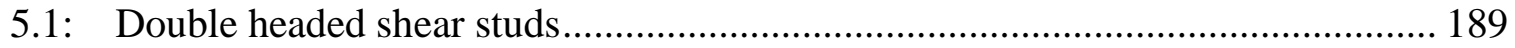

5.2: Girder cross-section and reinforcement layout.............................................. 190

5.3: Panel dimensions and reinforcement details................................................. 191

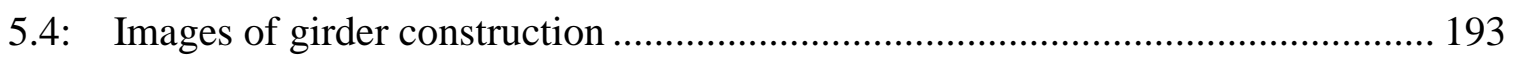

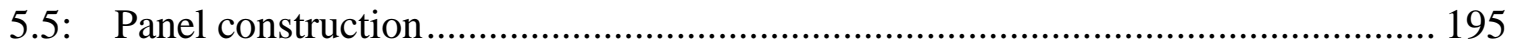




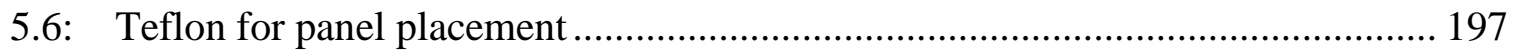

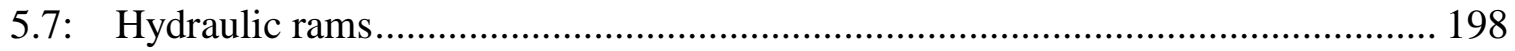

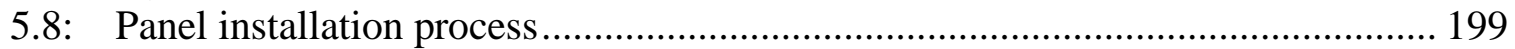

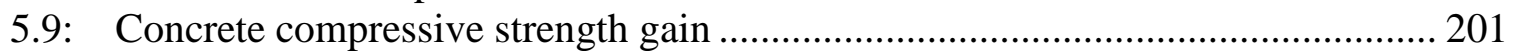

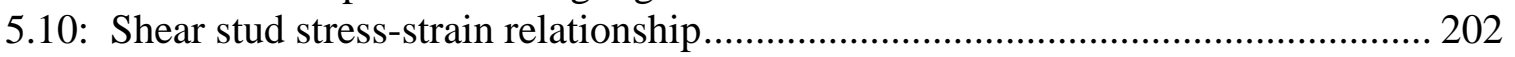

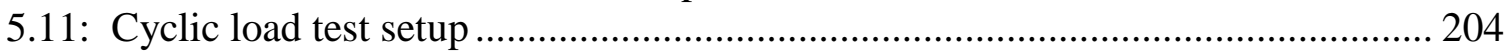

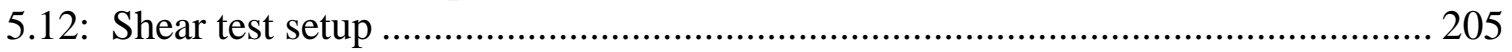

5.13: Cyclic load specimen to Specimens G-1 and G-2 ………………………......... 205

5.14: Roller and pin supports .................................................................................... 206

5.15: Stud size and spacing for ultimate load test.................................................... 207

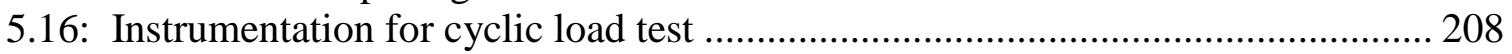

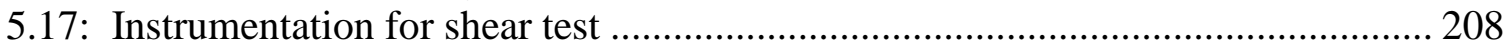

5.18: Static service wheel load-deflection response before cyclic loading .................... 212

5.19: Static service wheel load-deflection response after cyclic loading ....................... 212

5.20: Static ultimate wheel load-deflection response ……………….............................. 213

5.21: Load vs deflection - Specimen G-1................................................................ 214

5.22: North horizontal slip - Specimen G-1 ……………….................................... 215

5.23: South horizontal slip - Specimen G-1 ............................................................. 215

5.24: Measured strain in shear studs - Specimen G-1 ................................................ 216

5.25: Failure of Specimen G-1 .............................................................................. 216

5.26: Load vs deflection - Specimen G-2 ……………........................................ 217

5.27: North horizontal slip - Specimen G-2 …………….......................................... 218

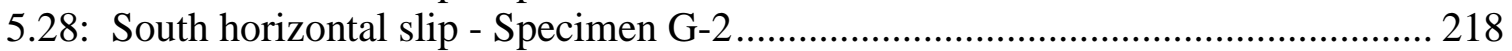

5.29: Measured strain in shear studs - Specimen G-2................................................ 219

5.30: Failure of Specimen G-2............................................................................. 219

5.31: Girder static service load response comparison.................................................... 220

5.32: Panel static service load response comparison ................................................... 221

5.33: Typical horizontal slip response ........................................................................ 221

5.34: Specimen G-1 compared with calculated load-deflection paths.......................... 224

5.35: North support (28 ft section of Specimen G-1) ………………............................ 224

5.36: Adjusted response (Specimen G-1) .................................................................... 225

5.37: Specimen G-2 compared with calculated load-deflection paths............................ 227

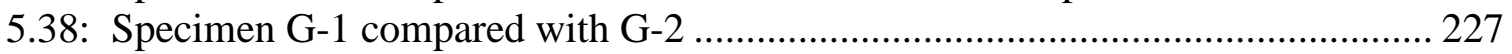

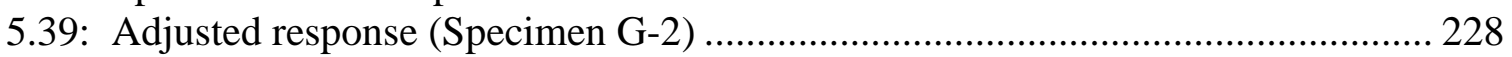

5.40: Load location-Specimen G-2 ……………………..................................... 228

5.41: Slip response of Specimens G-1 and G-2 ………........................................ 229

5.42: End slip of Specimens G-1 and G-2 ………….......................................... 230

A.1: Concrete compressive strength gain for Phase I deck panels .................................244

A.2: Concrete compressive strength gain for Phase I girders .........................................244

A.3: Concrete compressive strength gain for Phase I SCC ...........................................245

A.5: Internal strain gauge layout (Phase I specimens)...................................................246

A.6: Concrete compressive strength gain for Group 1 panel sections ............................247

A.7: Concrete compressive strength gain for Group 1 girder sections ..........................247

A.8: Concrete compressive strength gain for 4000 psi trough concrete .........................248 
A.9: Concrete compressive strength gain for Group 1, 8000 psi trough concrete and girder section of Specimens 2-8000-6-k-6, 1-8000-6-k-4n, and 2-8000-6-k-6n..

A.10: Concrete compressive strength gain for panels of Specimens

2-8000-6-k-6, 1-8000-6-k-4n, and 2-8000-6-k-6n

A.11: Concrete compressive strength gain for New England specimen

SCC and Specimen 2-4000-6-k-6n

A.12: Concrete compressive strength gain for Specimens 2-8000-6-k-6, 1-8000-6-k-4n, and 2-8000-6-k-6n

A.13: Concrete compressive strength gain of trough concrete in

Specimen 2-4000-6-k-6n 


\section{CHAPTER 1: INTRODUCTION}

\subsection{Background}

The interest in full-depth, precast bridge deck panels has been steadily increasing over the past 50 years because they offer several benefits over traditional cast-in-place construction. This type of system eliminates the need for cast-in-place formwork and, as such, reduces cost, construction time, and environmental/economic impact. In addition, precast panels are constructed in a controlled environment which leads to a more durable, high quality product.

There has been a considerable amount of research and experience with full-depth precast concrete deck panels installed on steel girders. The earliest use found in the literature was the replacement of two lanes of the Oakland-San Francisco Bridge in California with lightweight concrete deck panels in 1964 (Issa et al. 1995a). Since 1964, more than 15 states have used full-depth precast bridge deck panels in deck replacement projects and new construction (Issa et al. 1995b). The geometry of the panels and transverse joints varied between the reported projects. The panel-to-girder connection details also varied, consisting of welded studs, bolted studs, or deck tie downs (Issa et al. 1995b). There was no standard panel geometry or connections at the time. The development of full-depth, precast deck panel systems with standardized geometry and connection details began to take place in the 1980's.

A schematic of a typical precast panel system is shown in Figure 1.1. As illustrated, precast deck panels are typically constructed with the full design depth of the deck and span the full transverse width of the bridge. In the longitudinal direction, panels are typically $8 \mathrm{ft}$ in length because of transportation limitations. The connection between adjacent panels is accomplished by the use of shear keys. For connection to the girder, block outs in the panels, referred to as shear stud pockets, are commonly provided. 


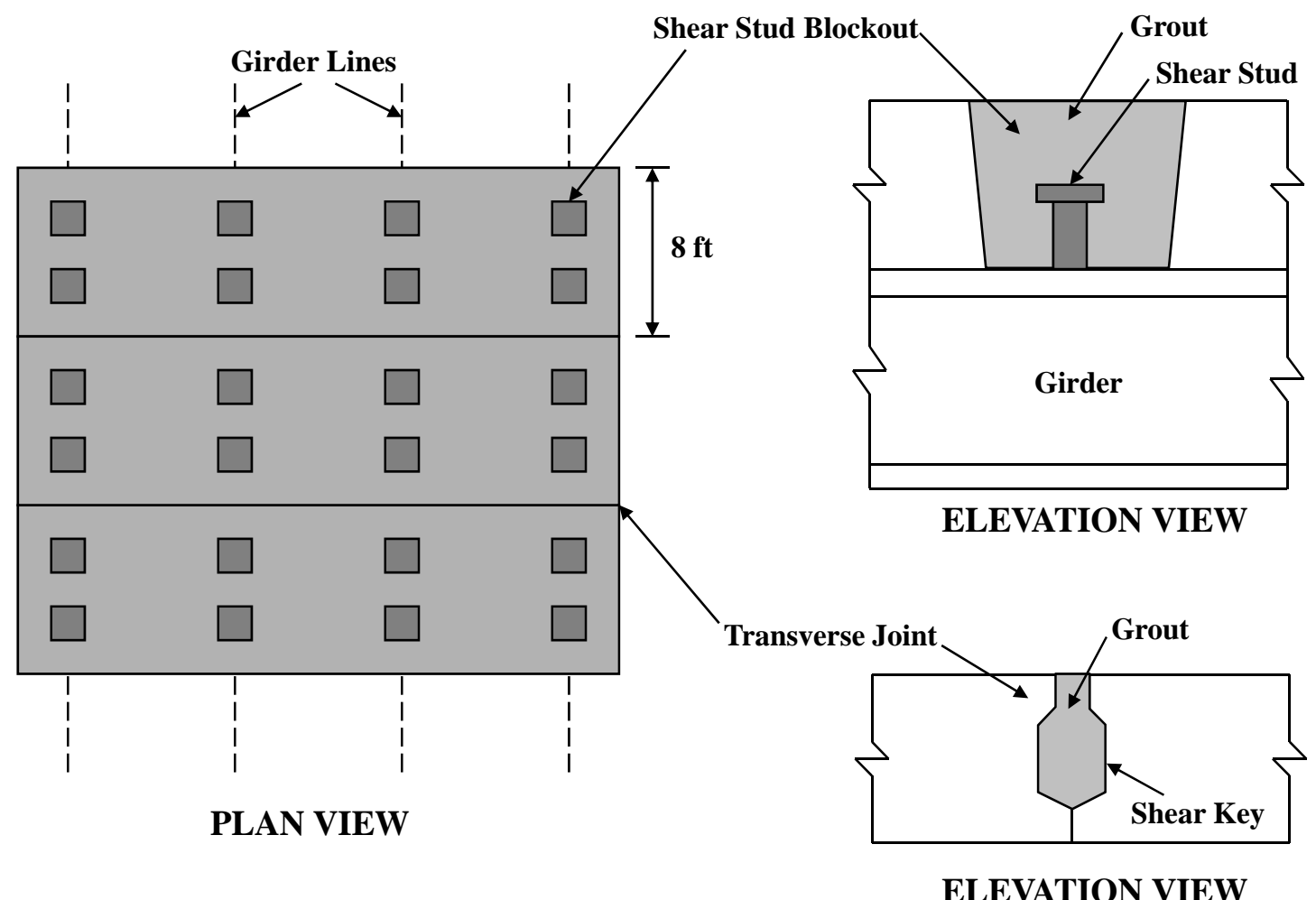

Figure 1.1: Typical full-depth precast bridge deck panel system

\subsection{Full-Depth Systems in Practice}

Several full-depth deck panel systems have been developed in the last three decades. The most notable of these systems include the following:

\subsubsection{New England Region System}

The details of this non-proprietary system were developed by the Connecticut Department of Transportation (CDOT) (Versace 2003). Design guidelines based on those details were approved by the Precast/Prestressed Concrete Institute New England Region (PCINER) Technical Committee in 2002 (PCINER 2002). The panels have details similar to the ones shown in Figure 1.1. The thickness of the panels can vary depending on the application, but are typically 8 in. The connection to the supporting 
structure is accomplished through square tapered pockets. This system does not require the use of prestressing of the deck panels.

\subsubsection{NUDECK System}

This non-proprietary system was developed at the University of Nebraska (Badie et al. 1998). The system was originally a continuous partial depth system, but quickly evolved into a full-depth system (Versace 2003). The deck panels are typically 6 in. thick and use a female-to-female transverse joint similar to that shown in Figure 1.1. The connection to the supporting structure is accomplished through an 8 in. wide gap over the girder that runs the length of the panel. This system requires prestressing in the transverse directions because of the reduced thickness. A typical NUDECK panel is shown in Figure 1.2. 


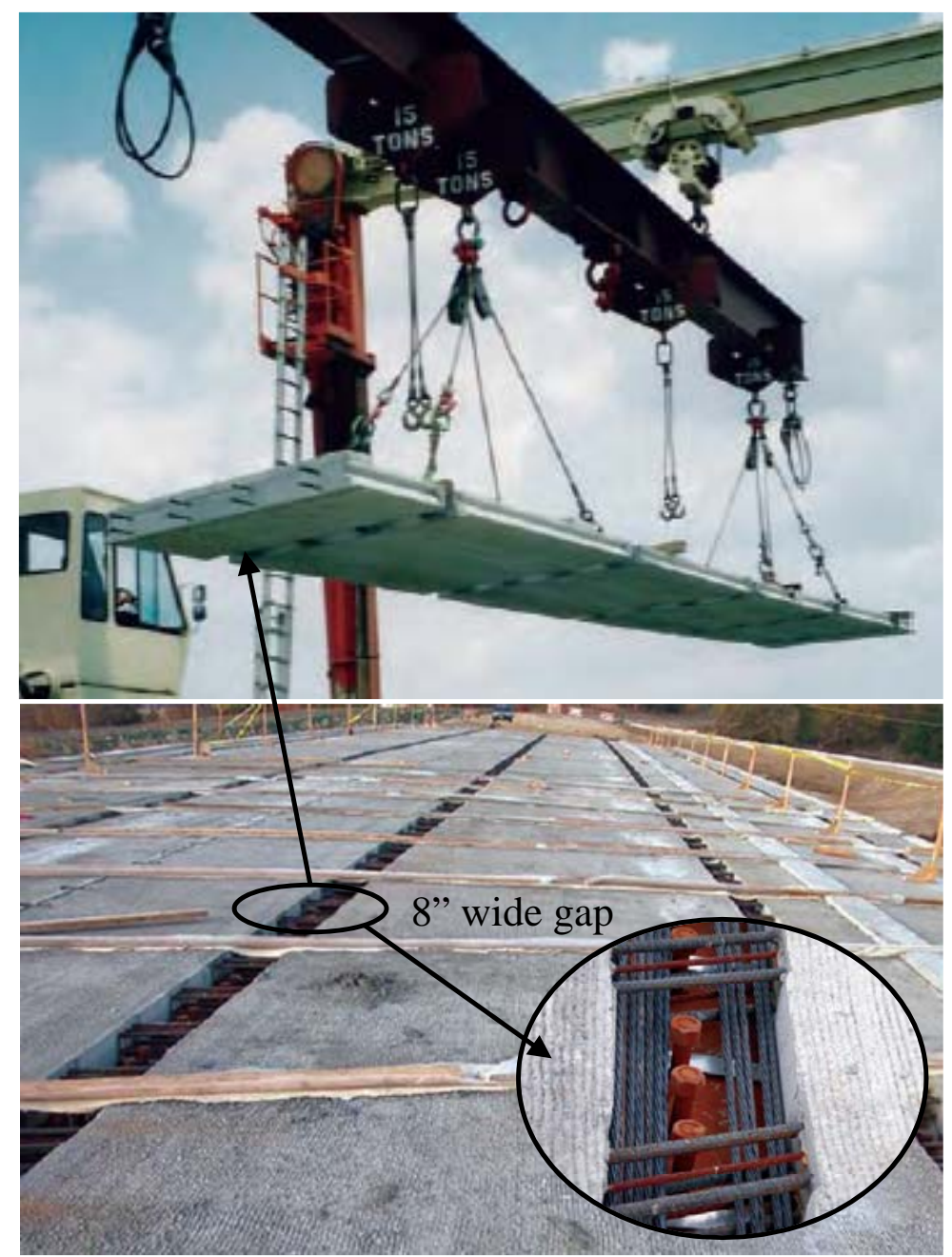

Figure 1.2: Typical NUDECK panel (Fallaha et al. 2004)

\subsubsection{Inverset ${ }^{T M}$ System}

This patented system was developed by Stanley Grossman in the early 1980’s (Versace 2003). The formwork for the deck is suspended from steel beams that are part of the composite superstructure. The steel beams become prestressed during casting due to the weight of the concrete in the formwork. When the deck system is righted, the concrete deck is prestressed by the steel beams. The system has been used on more than 145 bridges (Fort Miller Co. Inc. 2008a). A typical Inverset unit is shown in Figure 1.3. 

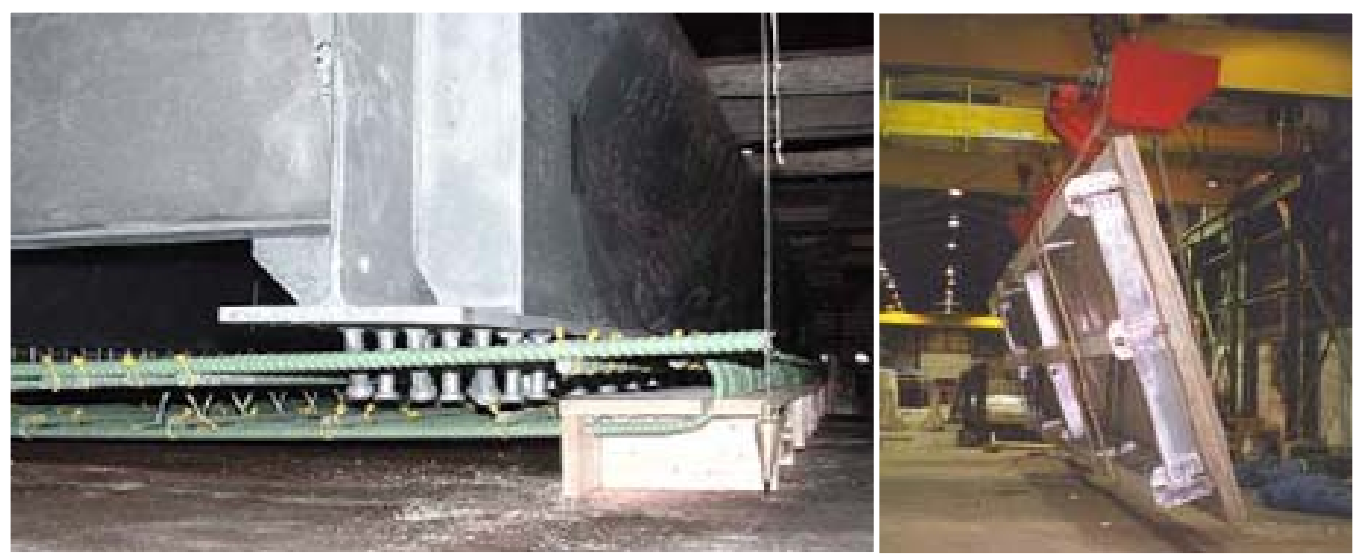

Figure 1.3: Typical Inverset ${ }^{\mathrm{TM}}$ unit (Fort Miller Co. 2008a)

\subsubsection{Effideck ${ }^{T M}$ System}

This proprietary system was developed in the late 1990's by the Fort Miller Company (Versace 2003). The precast modular deck system consists of a 5 in. thick slab supported by hollow steel tubes, as shown in Figure 1.4. The system can be used non-composite or composite with the supporting structure. Composite action in achieved through the use of shear studs and grout pockets, similar to that presented in Figure 1.1, though pocket geometry may differ. The panel-to-panel connections are made by bolting a connector plate to adjacent steel tubes. The welding of shear studs and bolting of connections are performed from atop the deck, so there are full-depth openings throughout the deck. The openings are filled with non-shrink grout. The system has been used on bridges in New York, Vermont and Massachusetts (Fort Miller Co. Inc. 2008b). 

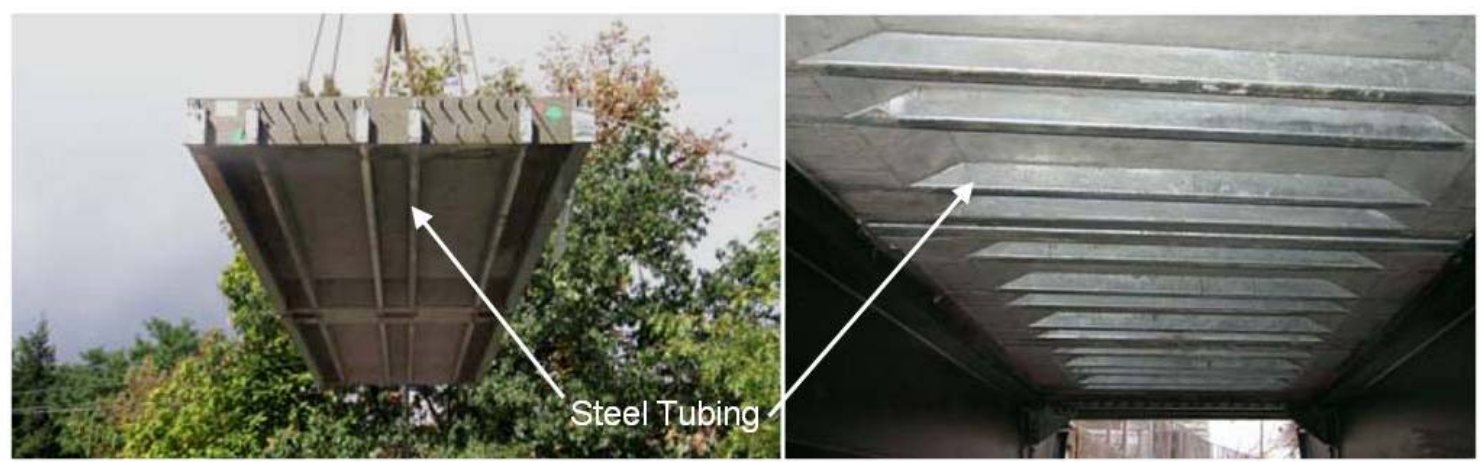

Figure 1.4: Effideck $^{\mathrm{TM}}$ system (Fort Miller Co. Inc. 2008b)

\subsection{Research on Full-Depth Systems}

The use of full-depth, precast panel systems installed on steel girders has been widespread. However, the use of these systems with concrete girders has been very limited, and only a small number of research programs have evaluated the connection of precast deck panels to concrete girders. Relevant research regarding the connection of precast panels to one another and connection of the panels to both steel and concrete girders is highlighted.

\subsubsection{University of Illinois at Chicago}

Issa et al. (1995a) performed a survey of DOT's around the U.S. and Ontario, Canada to determine experience and use of full-depth precast bridge panels. The main problems reported in this survey were leaking, cracking, and deterioration of the joints, mainly caused by construction procedures. As a follow-up to the survey, Issa et al. (1995b) conducted an investigation of the field performance of precast bridge deck panels in various states. The investigation consisted of field inspections of bridges in ten states and the District of Columbia and discussions with state engineers regarding the use of precast concrete bridge deck panels. From this investigation, it was concluded that inadequate performance is usually attributed to the poor connection between the panels and supporting system, adjacent joint configuration, lack of longitudinal post tensioning, construction procedures, and materials used. In addition, it was suggested that haunches 
be provided to account for dimensional irregularities or volume change and that transverse prestressing be used for handling purposes. Finally, it was observed that fewer problems were encountered with bridge decks supported on concrete elements because they are generally stiffer.

Issa et al. (1998) performed finite element modeling of both a simply supported and continuous bridge span. The purpose was to determine the amount of longitudinal post-tensioning required to keep the transverse joints of precast bridge deck panels in compression. The modeled simple span bridge was the Culpeper Bridge in VA, which spans $54.5 \mathrm{ft}$ and is $30 \mathrm{ft}$ wide. The modeled continuous span bridge was the Welland River Bridge, located near the city of Niagara Falls. Both modeled bridges had steel girders as the deck support structure. Based on the finite element models, it was determined that a minimum compressive stress in the deck of 200 psi is required for simply supported spans and $450 \mathrm{psi}$ for the interior supports of continuous spans. The design recommendations have been used by the Illinois Department of Transportation in at least five bridge deck replacement projects.

Issa et al. (2000) constructed a $1 / 4$ scale prototype bridge consisting of full-depth precast deck panels and two steel beams (Figure 1.5). The prototype bridge was modeled after a continuous four span bridge in Virginia. A total of three specimens were constructed. The deck of one specimen was not post-tensioned longitudinally. The decks of the other two specimens were post-tensioned to 208 psi and 380 psi. The specimens were subjected to static and fatigue loading consistent with AASHTO HS20 truck loads. The first cracking observed in the specimen that was not post-tensioned was at the transverse joint near the central support. Similar cracking was observed in the posttensioned specimens. However, the initial crack occurred at 3 times the load and cracking was better distributed throughout the panel. It was concluded that longitudinal post-tensioning is beneficial to crack control in negative moment regions. 


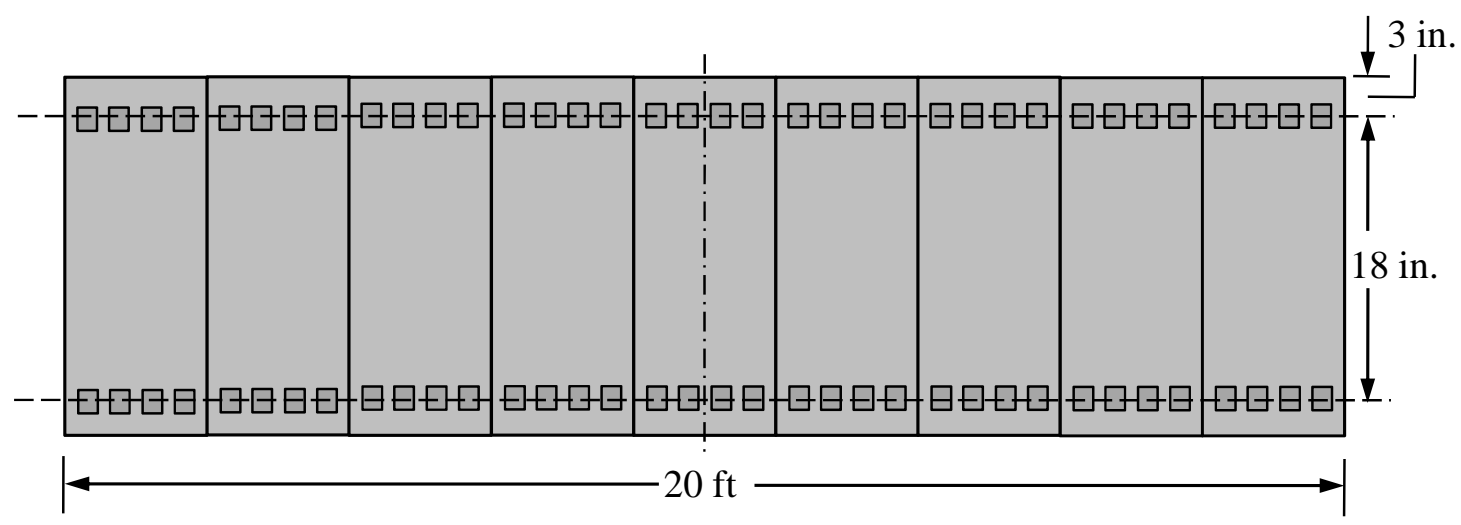

Plan

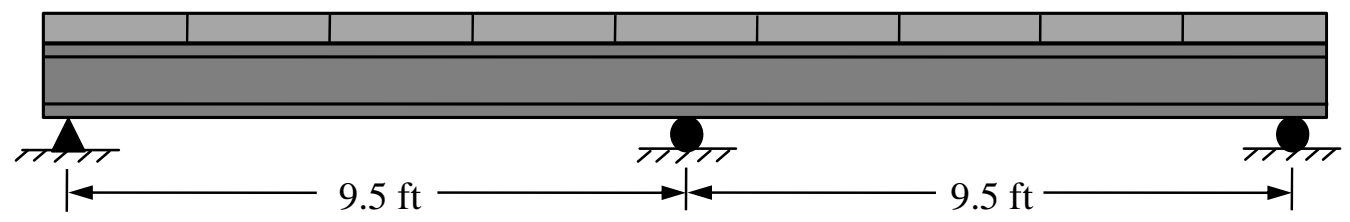

Elevation

Figure 1.5: 1/4 scale specimens evaluated by Issa et al. (2000)

Issa et al. (2003a) performed 36 small-scale shear tests, direct tension tests, and flexural tests to evaluate transverse joint material, as shown in Figure 1.6. A female-tofemale joint similar in geometry to that shown in Figure 1.1 was used in this study. 

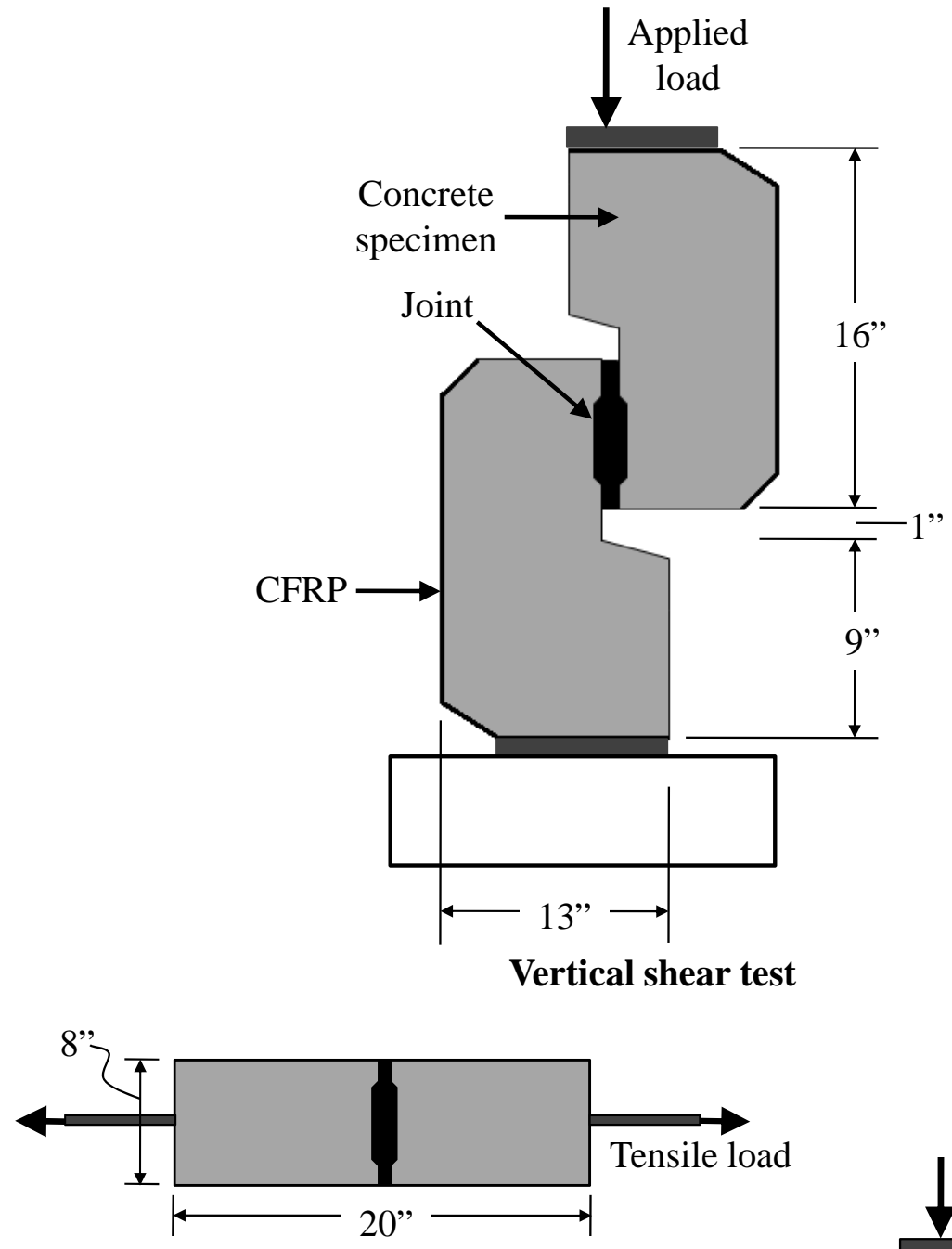

Direct tension test

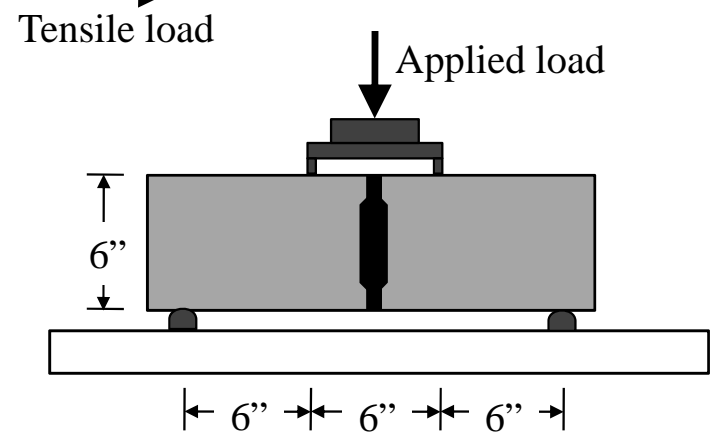

Flexural test

Figure 1.6: Small scale tests performed by Issa et al. (2003a)

Several different grout materials were used to fill the transverse joint: Set 45, Set 45 HW, Set Grout, and Emaco 2020. In addition to the load tests, chloride permeability and shrinkage tests were conducted on each grout material following ASTM C 1202-97 
and ASTM C 157, respectively. In the shear strength tests, the specimens failed at the joint with the exception of the specimens with Emaco 2020, which failed in the concrete away from the joint. From the results, it was concluded that the Emaco 2020 performed best overall and was recommended for use in critically stressed joints.

Issa et al. (2003b) conducted 28 push-out tests consisting of 14 full scale and 14 quarter scale specimens. The precast panels were connected to each flange of an A36 steel beam using welded shear studs, as shown in Figure 1.7. The variables tested include the number of shear studs in each pocket and also the number of pockets present on the specimen. The pocket spacing was kept consistent at $2 \mathrm{ft}$. Therefore, as the number of pockets increased, so did the length of the specimen. The study provided several findings. First, the number of shear studs in each pocket does not proportionally increase the load capacity. Second, the load necessary to induce slippage is affected by the configuration and number of studs in the pocket. Third, the ultimate strength increases with an increase in the number of shear pockets. However, the rate of increase is dependent on the number of shear studs per pocket. Finally, the AASHTO LRFD specifications are conservative in determining horizontal shear resistance of shear connectors. The authors also stated that push-off specimens with up to two grout pockets are reliable in evaluating composite behavior. 


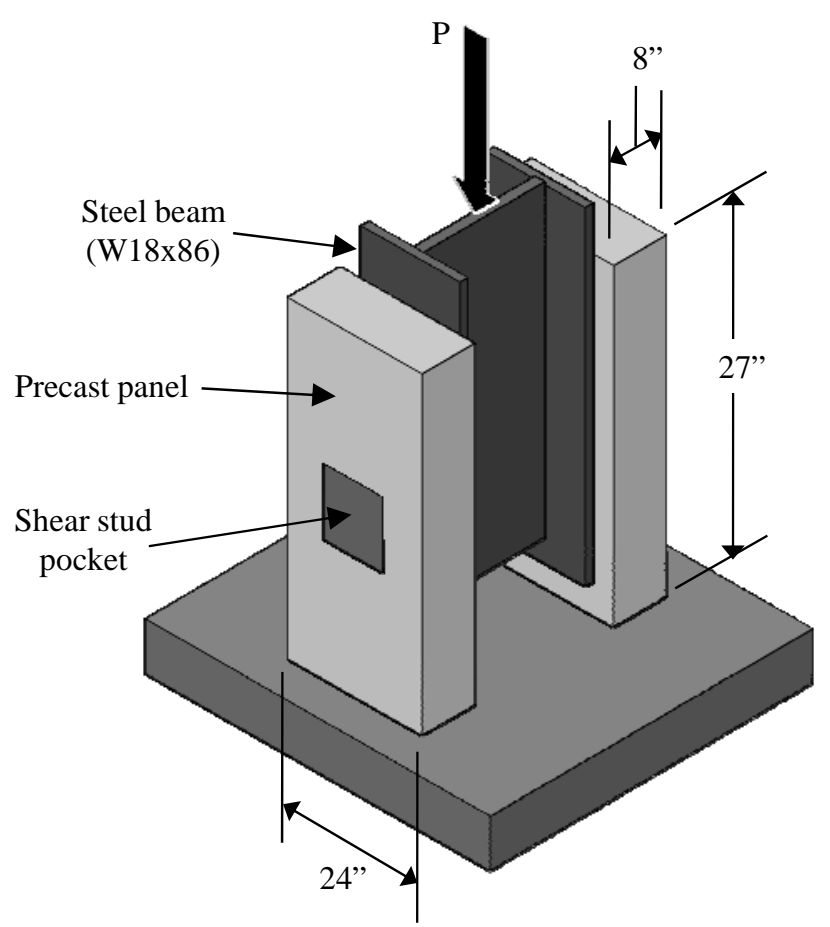

Figure 1.7: Example of one pocket full scale push-off specimen used by Issa et al. (2003b)

Issa et al. (2006) conducted 11 small scale tests on a panel-to-concrete girder connection. The specimens consisted of a concrete girder section with a precast panel attached to either side, as shown in Figure 1.8. The tests evaluated the effect of the number and configuration of shear studs per pocket on the shear strength of the connection, as well as embedment depth of the shear stud in the panel. The test results provided several findings. First, the shear strength of the connection increased proportionally with the number of studs. The first finding appears to be contradictory to that found by Issa et al. (2003b). However, in the aforementioned research article, the authors were referring specifically to a 1:1 relationship between the number of shear studs and the increase in load capacity. Second, the configuration of shear studs in the pocket affected the load at which slippage was induced. Third, the embedment depth of the shear stud in the panel affected the amount of slippage the specimen could undergo before failure. Finally, it was concluded that a threaded bolt used in the tests could be used as a shear stud for use with concrete girders. 


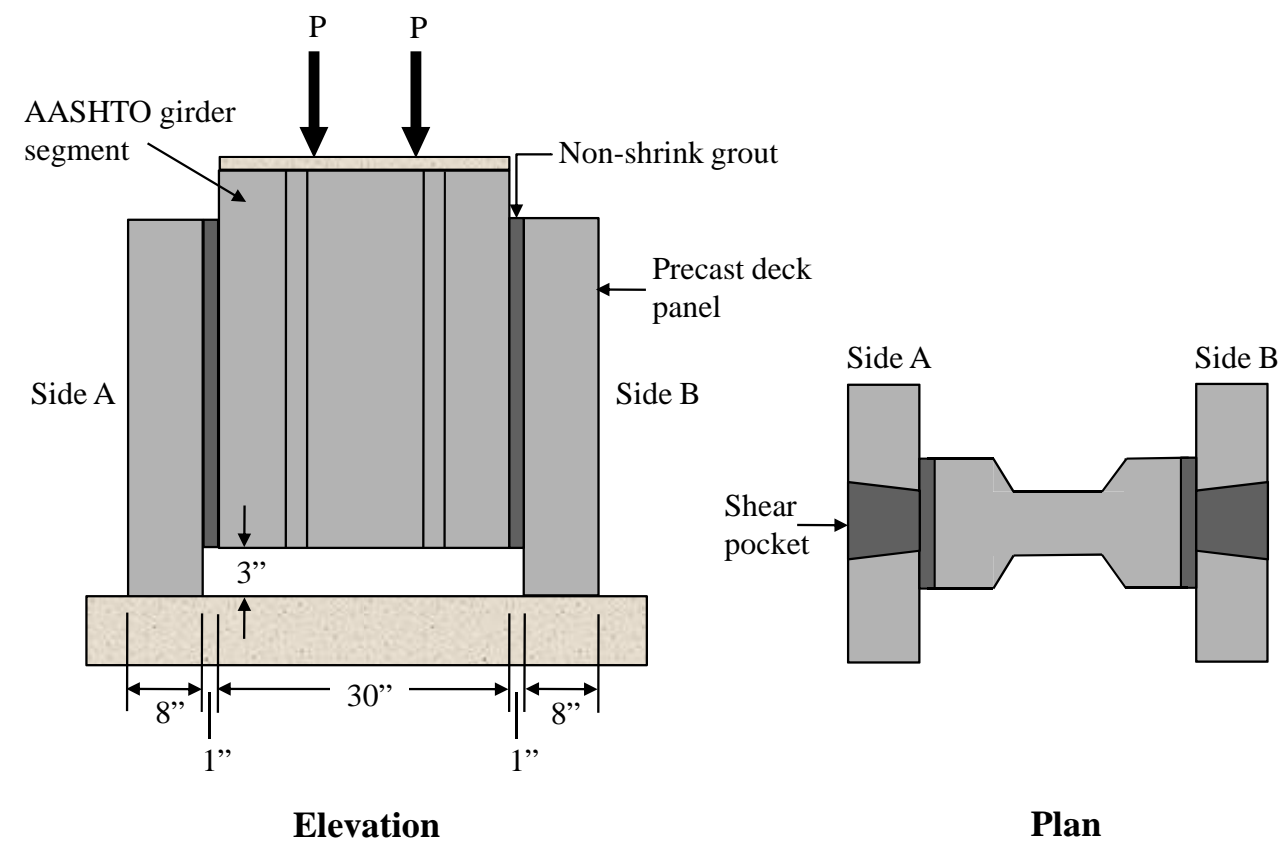

Figure 1.8: Example of push-off test performed by Issa et al. (2006)

Issa et al. (2007) constructed and tested a full-scale, continuous, two span prototype bridge to evaluate the constructability and behavior of a precast bridge deck system (Figure 1.9). The bridge was $82 \mathrm{ft}$ long and $18 \mathrm{ft}$ wide, supported by three $\mathrm{W}$ shape girders (W18x86). The deck consisted of 11 precast deck panels constructed with mild reinforcement. The deck was post-tensioned to a stress of approximately 500 psi over the central support. 


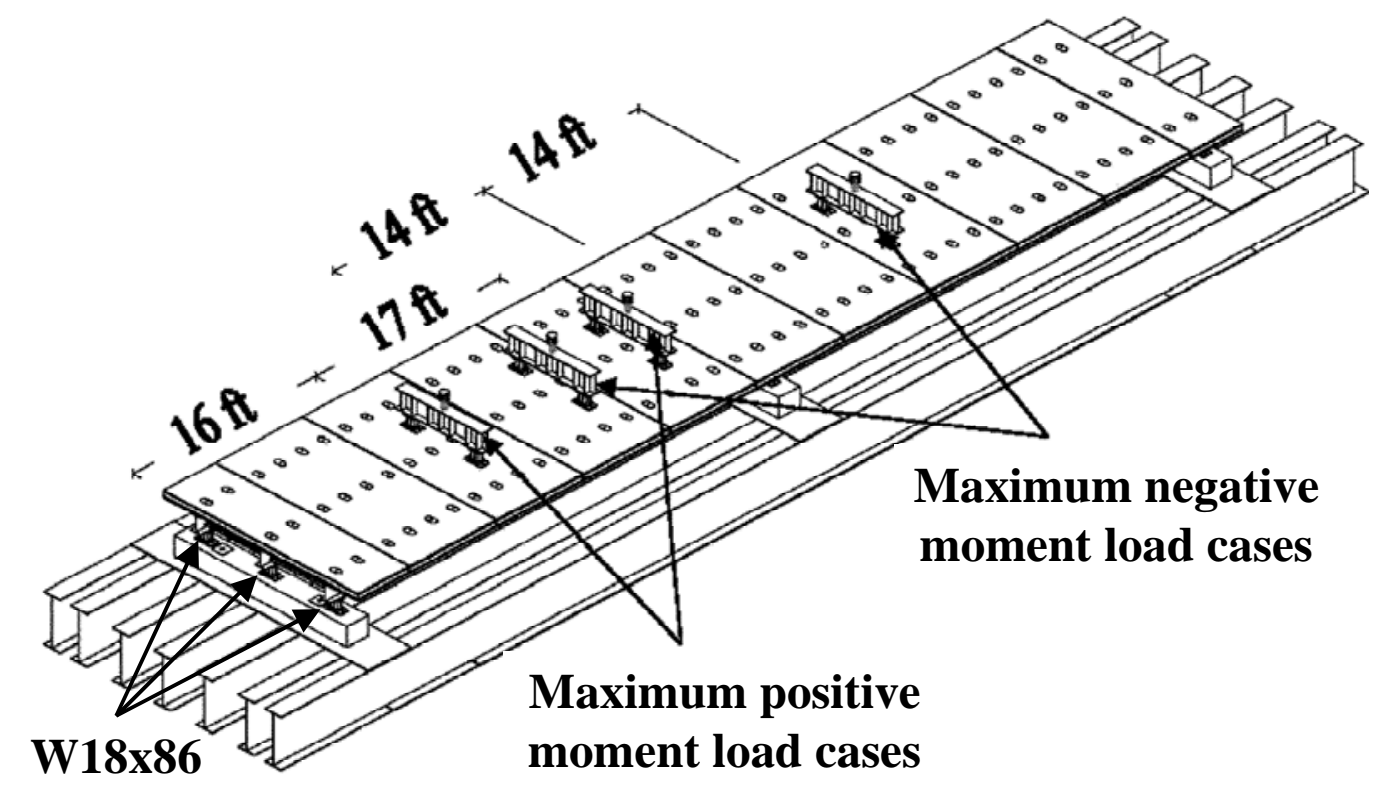

Figure 1.9: Bridge specimen evaluated by Issa et al. (2007)

The required number of shear studs per pocket to ensure full composite behavior was determined using the 1994 AASHTO LRFD specifications and the 1996 AASHTO standard specifications, 16th edition. Once welded shear studs were placed, the panels were secured on the girders by filling the shear stud pockets with non-shrink grout. The specimen was subjected to three static load cases. First, the HS20 AASHTO truck service load plus 30\% impact. Second an overload case of twice the service load. Finally, the ultimate load which was approximately 7.7 times the service load. Longitudinal and diagonal cracking of the deck was observed near the central support and loading points in the overload case. However, no cracks were observed in the transverse joints or haunch. From the results, it was determined that the specimen maintained full composite action throughout testing, indicating that the AASHTO code provisions were adequate for design of precast deck panels and shear connectors.

\subsubsection{Virginia Tech}

Menkulasi and Roberts-Wollmann (2005) conducted small-scale tests of the panel-to-girder connection to evaluate the effect of different grouts and haunch height on 
the shear strength of the connection. The small scale test specimens are shown in Figure 1.10 .

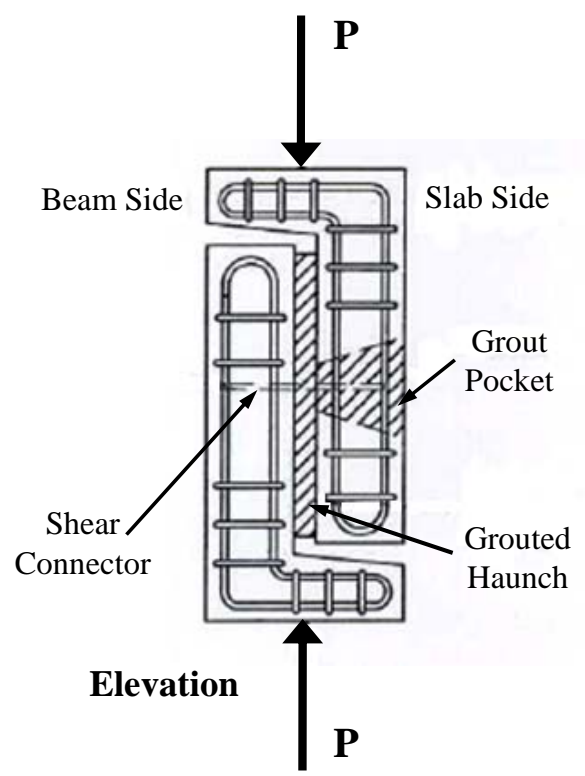

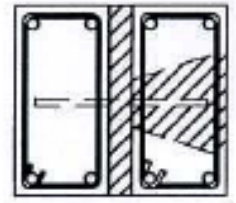

Section

Figure 1.10: Push-off test setup (Menkulasi and Roberts-Wollmann 2005)

From the results, it was shown that Set $\mathbf{4 5}$ grout and a latex modified grout performed the best. There was no significant difference in strength due to variable haunch heights between 1 in. and 3 in. The primary shear connector used in these tests were U-shaped stirrups, however, two additional shear connectors were tested and included post-installed hooked anchors and Dayton-Richmond 6 in. flared coil inserts with 3/4 in. diameter coil bolts. Both of the additional shear connectors tested exhibited ductile behavior and could be used as an alternative to U-shaped stirrups.

Additional small scale shear tests performed at Virginia Tech evaluated a new panel-to-girder connection detail for concrete girders and a hidden shear stud pocket detail (Wallenfelsz 2006). The new connection detail is presented in Figure 1.11. The connection consisted of welding shear studs to one side of a steel plate and embedding those studs into the top flange of the girder so that the plate was flush with the top of the girder. Shear studs welded to the exposed side of the plate are used to connect the panels to the girders. The pocket is grouted from the grout tubes on the top side of the panel. The new connection was ductile and demonstrated a proportional increase in shear 
strength with additional studs per pocket. The strength of the hidden pocket was similar to that of the normal pocket.

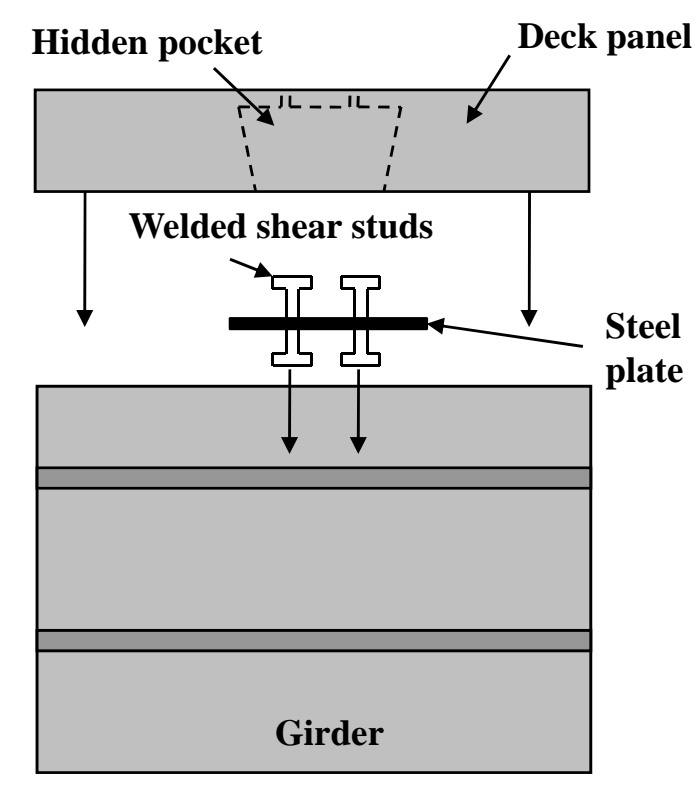

Figure 1.11: Shear stud system developed at Virginia Tech (Scholz et al. 2007)

Sullivan (2007) performed a full scale test of precast deck panels on concrete girders. The specimen was design according to the 3rd edition of the AASHTO LRFD specifications and was constructed using two $40 \mathrm{ft}$ long, Type II AASHTO girders spaced $8 \mathrm{ft}$ apart. The precast deck panels were $14 \mathrm{ft}$ wide and $8 \mathrm{in}$. deep. Two types of transverse joints and shear stud details were evaluated in the test program. The transverse joints evaluated were a grouted female-to-female type joint and an epoxied male-to-female joint, as shown in Figure 1.12. The shear studs evaluated were rebar hooks and a detail similar to that shown in Figure 1.11.

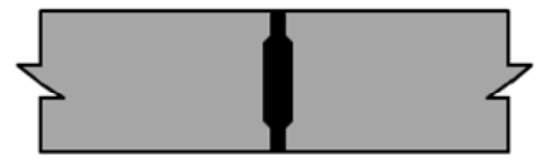

Grouted female to female joint

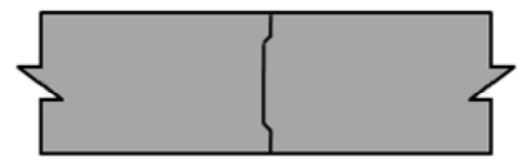

Epoxied male to female joint

Figure 1.12: Transverse joint geometries used by Sullivan (2007) 
The specimen was subjected to several static load cases and a fatigue loading of two million cycles at $2 \mathrm{~Hz}$. The design loads used to evaluate the behavior of the specimen were determined from AASHTO HS20 truck loads. From the results, it was concluded that the grouted female-to-female joint was easy to construct and encountered no problems throughout testing. It was found that the male-to-female epoxied joint was more difficult to construct due to bowing of the panels. In addition, the epoxied joint had minor leaking while under load when water was ponded over the joint. The results showed that both of the shear stud details had measured strains less than $50 \%$ of yield, indicating that design was adequate. The author concluded that the 2006 AASHTO LRFD specifications were conservative.

\subsubsection{University of Nebraska-Lincoln}

Yamane et al. (1998) developed a new precast, prestressed, bridge deck panel system in an effort to provide a high quality bridge deck very rapidly. The panels had a very efficient cross-section resulting in a light-weight and slender panel, as shown in Figure 1.13 and Figure 1.14. 


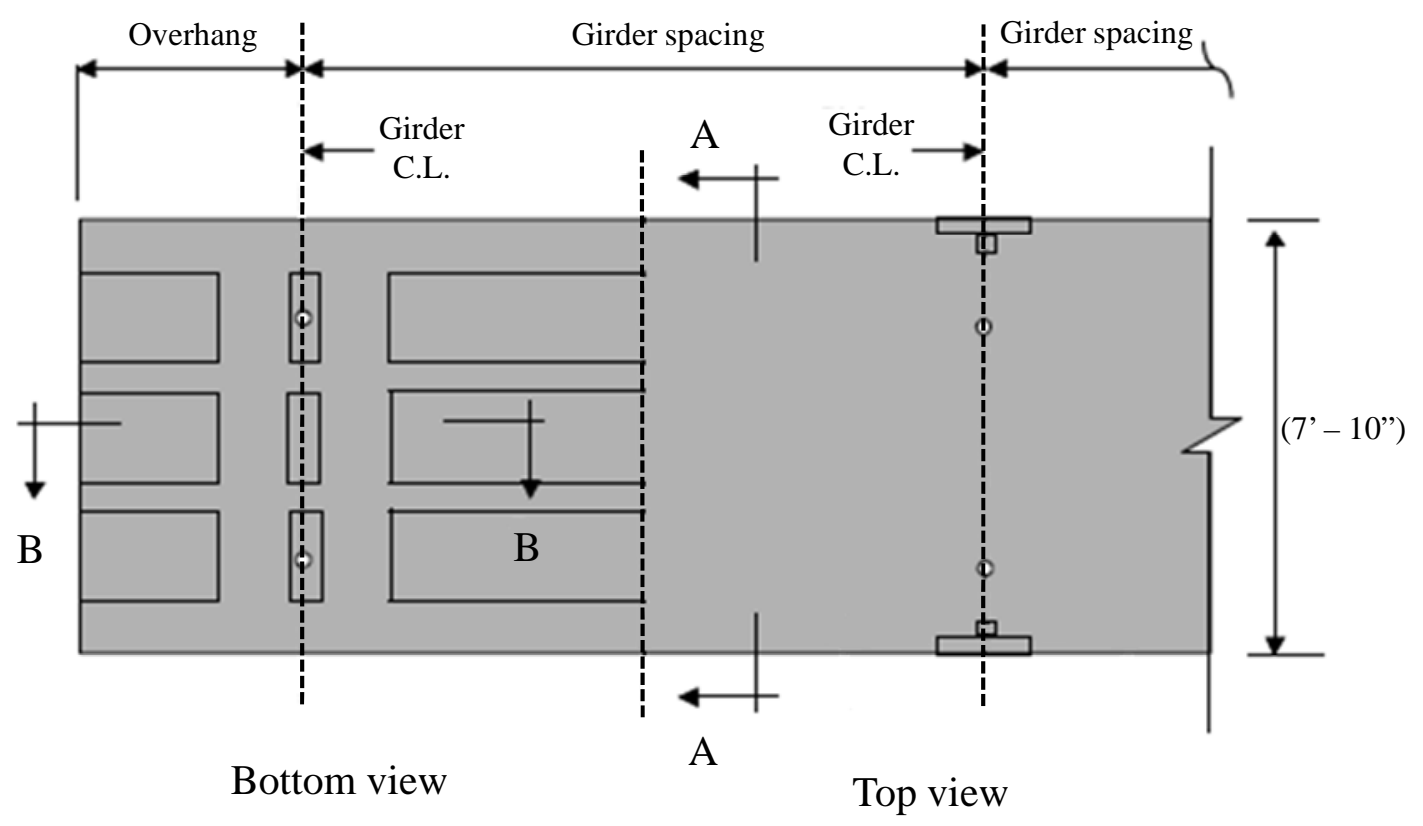

\section{Plan View}

Figure 1.13: Plan view of deck system (Yamane et al. 1998) 


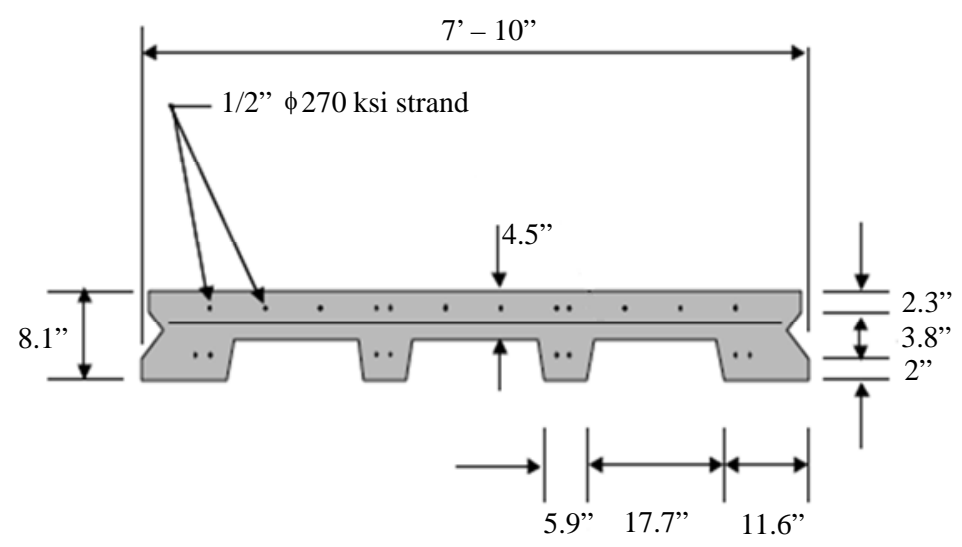

Section A-A

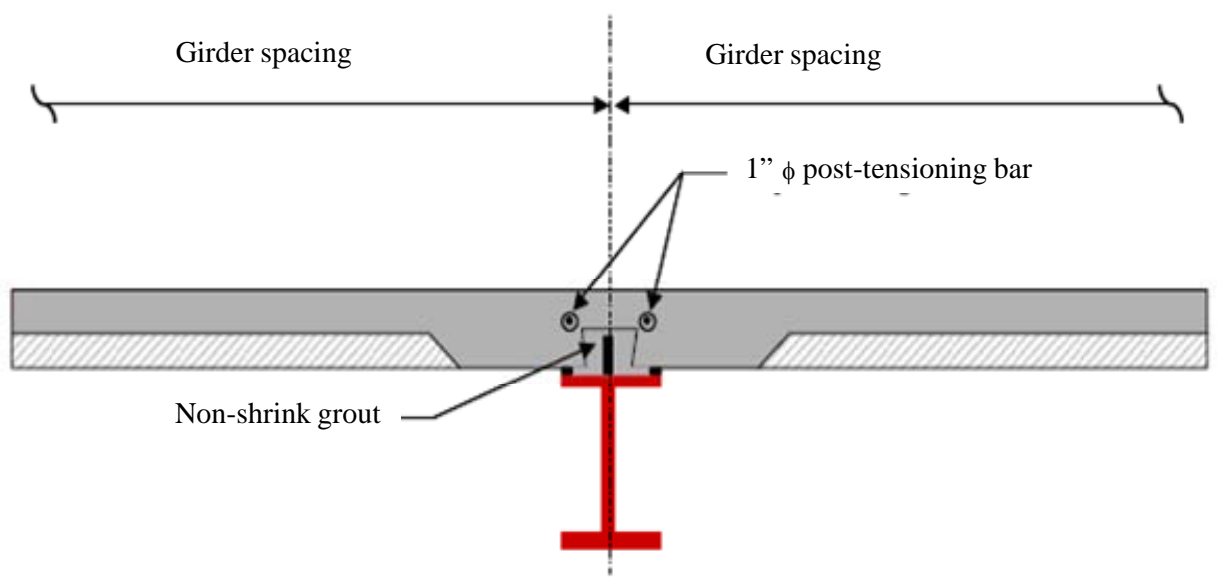

Section B-B

Figure 1.14: Sections A-A and B-B from Figure 1.13 (Yamane et al. 1998)

A prototype specimen that consisted of two $26 \mathrm{ft}$ long steel girders and three $8 \mathrm{ft}$ by $20 \mathrm{ft}$ precast panels was constructed to evaluate the system. The transverse joint between adjacent panels was a female-to-female joint filled with a grout material. The deck panels were prestressed transversely and post-tensioned together longitudinally. Welded headed studs and welded threaded studs with nuts were used as shear connectors to develop full composite behavior. The specimen was loaded with a simulated HS25 truck loading plus impact. In addition, a fatigue loading of 2 million cycles was performed. The magnitude of the fatigue load is unclear from the literature. The final 
loading was an ultimate load test in which punching shear was the mode of failure at $190 \%$ of the AASHTO requirement. From the results, it was concluded that the proposed deck system met all structural requirements for bridge decks.

\subsubsection{The George Washington University}

Badie et al. (2006) developed a means of connecting adjacent panels with just mild reinforcement to eliminate the need for post-tensioning. The system used HSS tubes cast in the panels to provide confinement to fully develop the mild reinforcement between adjacent panels, as shown in Figure 1.15. A more detailed view of the transverse joints is presented in Figure 1.16.

1 in. diameter grouting pipe

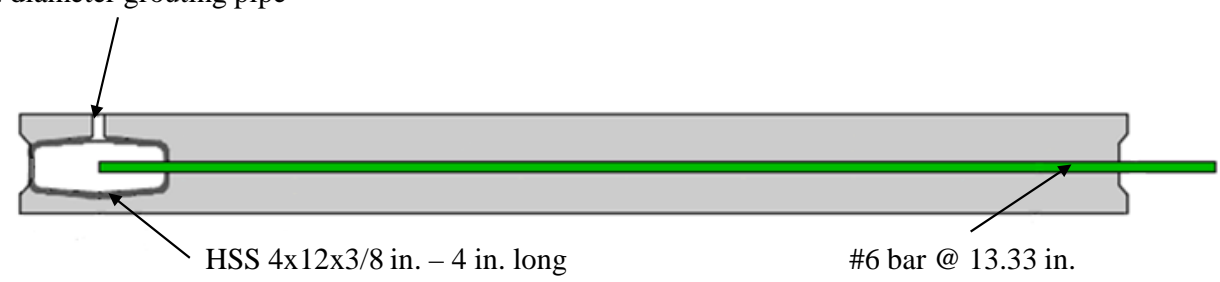

First connection detail

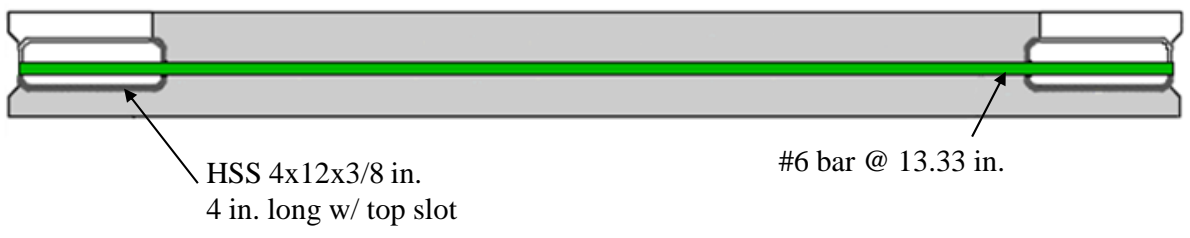

Second connection detail

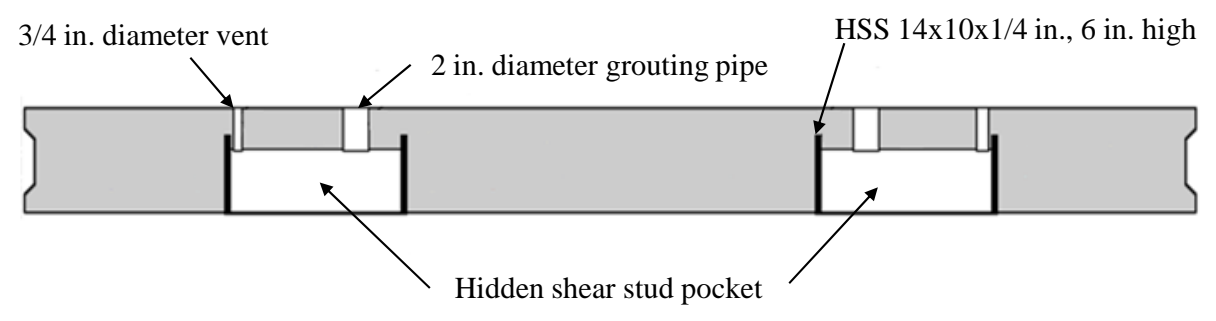

Panel pocket detail

Figure 1.15: Deck panels proposed by Badie et al. (2006) 


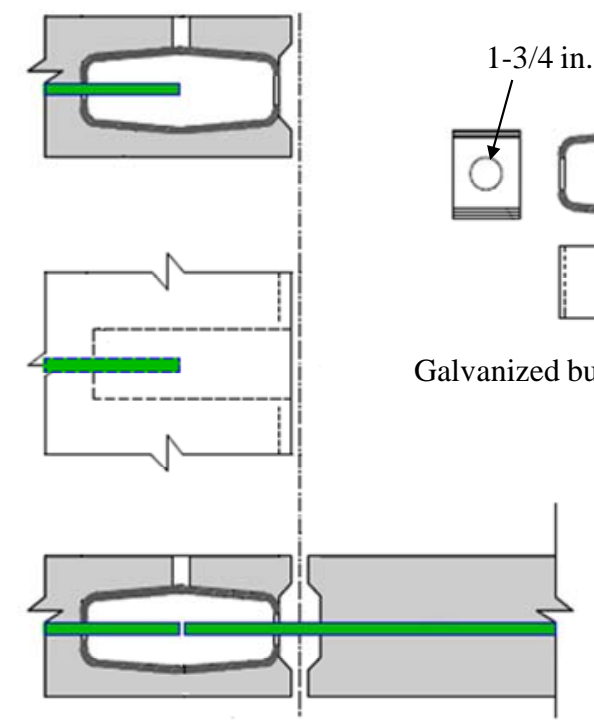

\section{First connection detail}

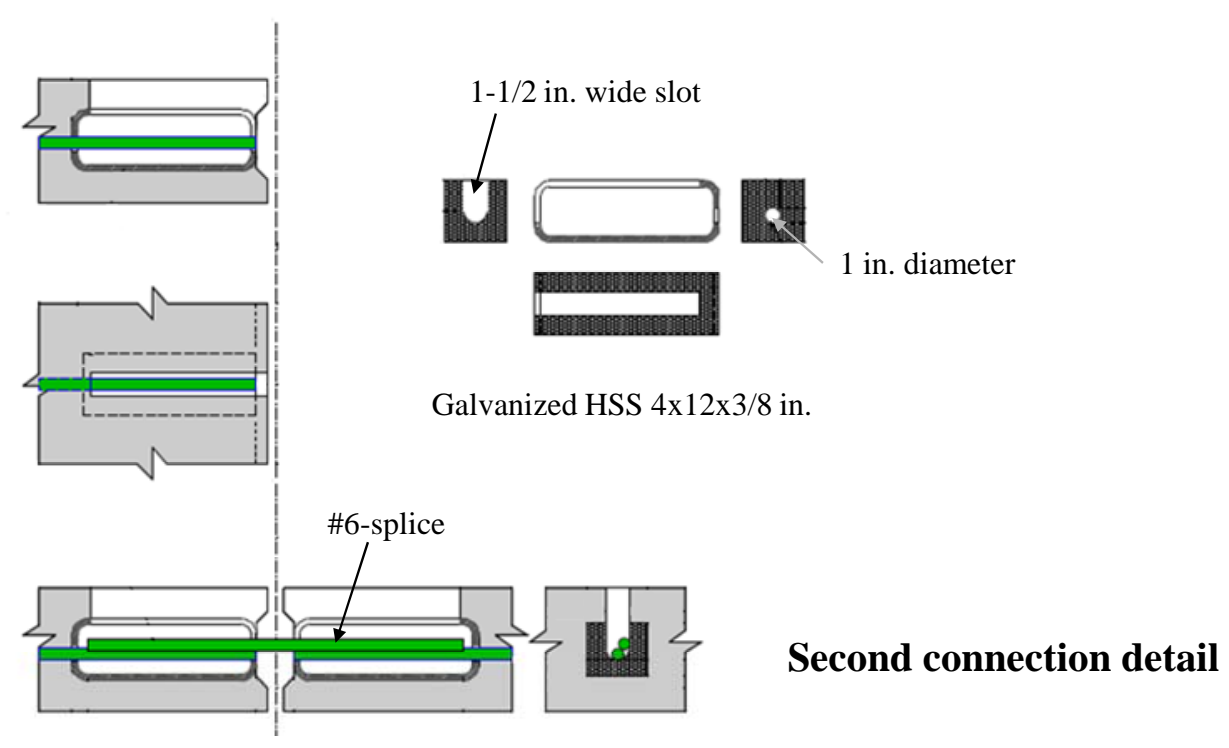

Figure 1.16: Transverse joint details proposed by Badie et al. (2006)

In addition, the research evaluated the use of 1-1/4 in. diameter shear studs to increase the maximum shear stud spacing to $48 \mathrm{in}$. on both steel and concrete girders. To evaluate the proposed connections, an extensive testing program was undertaken consisting of direct tension pullout tests, small scale shear push-off tests, two full-scale beam specimens, and one full-scale bridge specimen. The full-scale beam and bridge 
specimens consisted of precast concrete panels and steel girders. From the results several conclusions were made. First, full-depth precast deck panels can be connected effectively using the proposed panel-to-panel connection. Second, the panel-to-girder connection details using 1-1/4 in. shear stud clusters spaced at 48 in. were found to be sufficient if certain recommendations are followed. Finally, Article 5.8.4.1 in the 2006 AASHTO LRFD specifications can be used to estimate the horizontal shear capacity of the proposed panel-to-girder detail on both concrete and steel girders.

\subsubsection{University of Wisconsin-Madison}

Markowski (2005) evaluated the use of full-depth precast deck panels on highway bridges for the Wisconsin Department of Transportation and Federal Highway Administration. A series of tests were conducted to evaluate several aspects of deck panel behavior including (1) the behavior of the deck panels under edge loading, (2) the level of post-tensioning required across transverse and longitudinal joints, and (3) the composite behavior of deck panels placed on a steel plate girder with shear studs spaced a 24 in. and 48 in. The panel edge loading behavior and required post-tensioning levels were evaluated using full-scale panels. The composite behavior of the system was evaluated using a $1 \frac{1}{2}$ scale model subjected to fatigue and static loading. From the results, the following conclusions were made. First, punching shear is the failure mode of panel edge loading. Second, the required level of post-tensioning for transverse and longitudinal joints is 250 psi and 370 psi, respectively, to prevent any cracking at service loads. Finally, the behavior of the $1 / 2$ scale specimen indicated that a stud spacing of 48 in. can develop full composite behavior in both the elastic and inelastic loading range.

\subsubsection{Purdue University}

Kropp (1973) reported the results of continued monitoring of two bridges in Indiana that had precast deck panels installed in the summer of 1970. There was an existing bridge on SR 37 near Bloomington, Indiana the required a deck replacement and a new bridge on SR 140 near Knightstown, Indiana. The precast panels used on both bridges were approximately $4 \mathrm{ft}$ wide longitudinally, the full width of the bridge, and 
varied in thickness. The bridge on SR 37 had a deck panel thickness of 6.25 in., while the deck panel thickness varied from 7 in. to 10 in. on the SR 140 bridge due to the incorporated roadway crown. The transverse panel joint was a male to female joint similar in geometry to that shown in Figure 1.12. However, instead of epoxy, a 3/8 in. polychloroprene backer rod was placed the full length of the joint $0.5 \mathrm{in}$. from the top of the panel. In addition, a 1/16 in. thick neoprene strip was bonded to the bottom 4.75 in. of the joint to minimize stress concentrations due to an uneven surface. The panels were post-tensioned longitudinally to a nominal stress of 80 psi to prevent leaking of the transverse joints. Once post-tensioned, the panels were clamped to the top flange of the steel stringers using 115-RE-F railroad clips and 3/4 in. diameter bolts. Then the joints were cleaned with compressed air, brushed and sealed with a polyurethane elastomeric joint sealant. The 33 panels used on the SR 37 bridge and the 52 panels used on the SR 140 bridge were placed in two days. However, up to an additional two weeks were needed to secure the panels to the steel stringers and seal the joints. Both bridges were load tested at several intervals after their construction using a tandem axle dump truck. The results indicated that there were no changes in deck performance. However, after two years of service both bridges had transverse joint leakage.

\subsubsection{University of British Columbia}

LaRose and Elwood (2006) conducted 15 push-off tests to evaluate the ultimate capacity of clusters of shear studs. The specimens consisted of shear studs welded to a 350AT steel plate, which simulated the flange of a steel girder, and a precast concrete slab with a circular shear stud pocket. The studs were arranged in a circular pattern with the number of studs in each cluster varying between six and ten. The precast panels were attached to the steel plates using Target Traffic Patch Coarse Mix, a high early strength grout mixture. Nine specimens were loaded statically to determine ultimate strength. The remaining six specimens were subjected to cyclic loads to evaluate the effect of repeated loading on the ultimate strength. The results indicated that there is a reduction in the ultimate strength of stud clusters subjected to repeated loads. In addition, the 
ultimate strength of the stud clusters increased linearly in relation to the number of shear studs.

\subsection{Limitations of Current Approaches}

From the successful use of full-depth deck panels on steel girders over the last four decades and recent research involving concrete girders, the use of these systems is expected to increase. However, there are some limitations with the current design approach that need to be addressed before these systems will be fully adopted. One of the main limitations with the current system is penetration of the full-depth of the deck by the grout pockets and shear keys. The full-depth pockets provide an opening of approximately 64 in. $^{2}$ on the top surface of the panel every $2 \mathrm{ft}$ along the girder. In addition, the shear keys provide a $1 / 2$ in. opening that runs the full width of the bridge every $8 \mathrm{ft}$. Several researchers have proposed a hidden shear stud pocket to reduce the exposed surface area of the pocket (Badie et al. 2006 and Wallenfelsz 2006). Although the use of hidden pockets does reduce the surface of the full-depth penetration, it is cumbersome to form and visualizing the grout and assuring quality of placement is difficult.

Typically non-shrink grout is used to fill the pockets and shear keys, however, shrinkage cracking is commonly observed around the pockets, which may eventually lead to deterioration of the deck, superstructure, and substructure through leakage (Scholz et al. 2007). These grouts also present several placement issues. Typical set times are less than 40 minutes (Barde et al. 2006), which makes mixing and placing of large quantities

difficult. Furthermore, these grouts are not typically available from ready-mix plants, so each $50 \mathrm{lb}$ bag must be mixed on site, which presents quality control concerns. As a secondary issue, the grout generally has a different color than the concrete deck, which disrupts the appearance of the deck. Many of these issues have been addressed by providing an overlay or wearing surface.

While full-depth precast decks have been used as an experimental system on several structures across the country, specific design guidelines have not been developed. 
Several researchers have suggested that the AASHTO LRFD provisions are conservative for designing the horizontal connection between full-depth deck panel systems and concrete girders. However, this was concluded largely on results from small scale shear specimens. To-date, only one large scale concrete girder specimen has been tested (Sullivan, 2007) and failure of the shear studs did not occur. As a result, the behavior of large scale concrete specimens at ultimate strength of the panel to girder interface is still unclear.

\subsection{Objectives and Scope}

The objective of this research program was to develop an improved full-depth precast deck system for use on concrete girders that can result in improved durability and constructability of the system. To accomplish this objective, research was conducted in four phases.

1. Extend New England System: The connection system used in the New England System was extended for use with precast, prestressed concrete girders. This phase was intended to provide a benchmark for behavior of improved design schemes as this deck system has general acceptance in the field. Furthermore, this system has advantages for the redecking of existing bridges.

2. Develop Improved Panel to Girder Details: New details for the connection between precast deck panels and precast, prestressed concrete girders were developed and evaluated. The focus of the connection system was on eliminating penetrations in the deck surface.

3. Develop Improved Panel to Panel Details: New details for the connection between adjacent precast deck panels were developed and evaluated. The focus of this connection system was on increasing the speed of construction, minimizing the use of grout, and minimizing joint width. 
4. Evaluate Performance of the New Deck System: The joint system developed in Phases 2 and 3 was evaluated to confirm performance of the entire bridge system. In addition, this phase evaluated constructability of the system. 


\section{CHAPTER 2: NEW ENGLAND SYSTEM ON CONCRETE GIRDERS}

\subsection{Introduction}

The deck system outlined by PCINER (2002) was chosen for this research program because it incorporates design details that are representative of current design practice, such as the female-to-female joint and the tapered shear stud pocket. This system is also versatile because it can be designed to accommodate super-elevated, crowned, skewed, and curved bridge designs. In addition, PCINER provides design guidelines for using the deck system on steel and prestressed concrete girders. The design guidelines include details for standard rebar hooks as the horizontal shear reinforcement on concrete girders. However, the use of standard hooks can cause congestion within the pocket and tolerance issues with panel placement. This test series evaluated a modification of the system that makes use of single headed rebar studs as the horizontal shear reinforcement. The use of single headed studs alleviates congestion and tolerance issues. In addition, the specimens provide a benchmark for comparison of a new deck system that will be developed as part of this research program.

\subsection{Specimen Design}

To evaluate the structural behavior of the system with prestressed concrete girders and have a means of comparing new design details to current details, three large scale tests were designed. The objective of the tests was to evaluate the strength of the girderto-panel connection and composite behavior of the system. Each of the three test specimens was designed to be $40 \mathrm{ft}$ long using AASHTO Type-I prestressed concrete girders. The precast deck panels were designed to be $6 \mathrm{ft}$ in the transverse direction resulting in $3 \mathrm{ft}$ on either side of the center line of the girder, representing a bridge with a 
$6 \mathrm{ft}$ girder spacing. Each girder required nine deck panels, eight panels were $4 \mathrm{ft}$ in length and one was $8 \mathrm{ft}$ in length. The $8 \mathrm{ft}$ panel was placed in the middle of the span. Shear stud pockets were spaced every $2 \mathrm{ft}$ along the length of the panel. Details of the girder and precast panel designs are presented in the following sections.

\subsubsection{Girders}

The AASHTO Type I girders were designed with an overall length of $40 \mathrm{ft}$. Cross-section details are provided in Figure 2.1. Prestressing steel was specified as Grade 270, 1/2 in.-special, 7-wire, low-lax strand and was placed on a 2 in. grid.
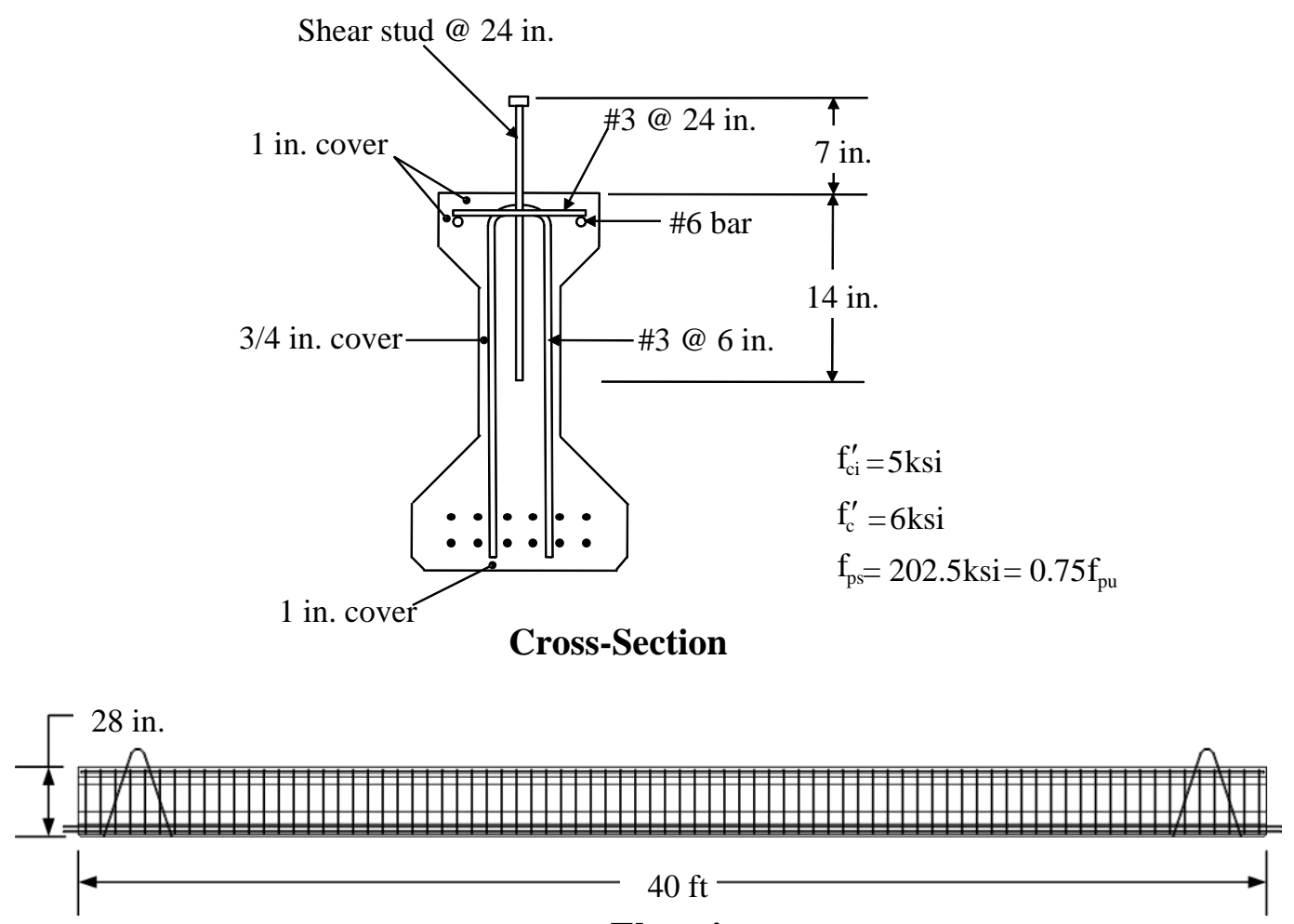

Elevation

Figure 2.1: Girder cross-section and reinforcement layout.

\subsubsection{Precast panels}

Each of the AASHTO Type-I girders required nine precast bridge deck panels. Eight of the precast deck panels were 47-3/4 in. in length, 72 in. in width, and 8 in. thick. 
The remaining precast deck panel was 95-3/4 in. in length, 72 in. in width, and 8 in. thick. The larger deck panel was placed at midspan to avoid having a panel joint at the loading location. Each of the panels had shear stud pockets spaced $2 \mathrm{ft}$ along the length. The reinforcement in the deck panels consisted of two mats of \#4 reinforcing bars. A detailed drawing showing the dimensions of the panels, locations of the pockets, and spacing of the mild reinforcement is presented in Figure 2.2.

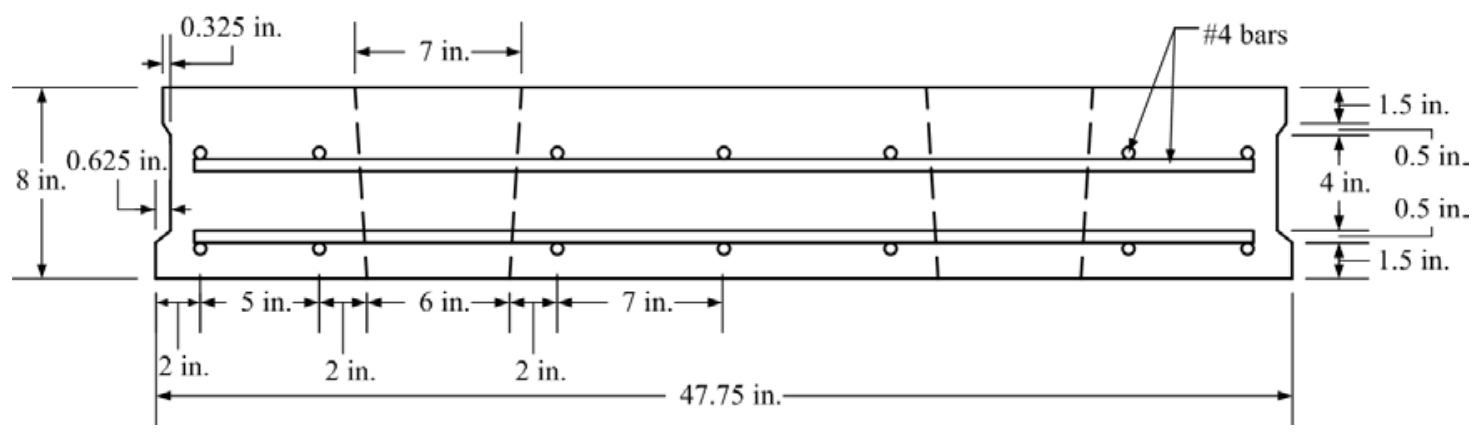

\section{Elevation - Longitudinal (4 ft panel)}

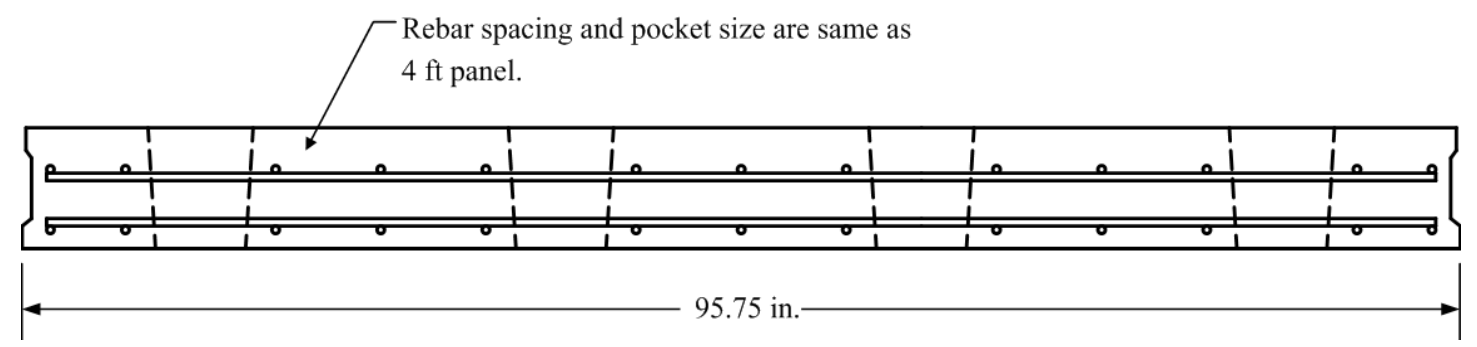

Elevation - Longitudinal (8 ft panel)

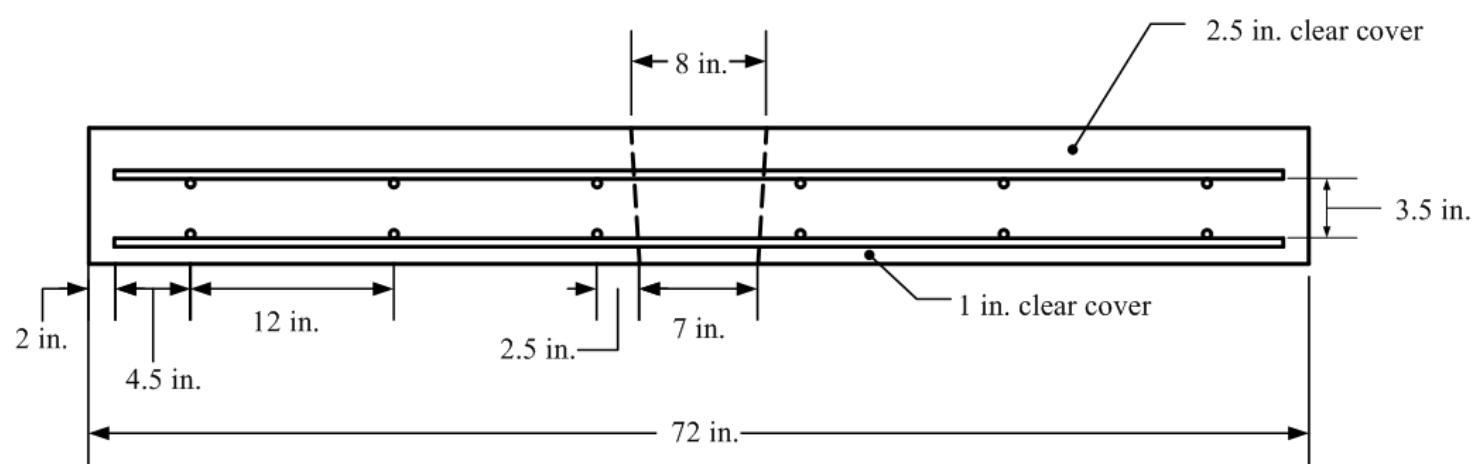

Elevation - Transverse

Figure 2.2: Panel dimensions and reinforcement details 


\subsubsection{Test variables}

Test variables for the test series consisted of two parameters.

1. Size of shear stud: The shear stud size was varied to evaluate its influence on shear transfer strength. Two sizes were considered, \#4 and \#6 reinforcing bars.

2. Shear stud installation method: Two methods were considered. First, studs were installed during girder fabrication to evaluate new construction. Second, studs were installed using a drill and epoxy adhesive to evaluate rehabilitation of existing structures where deck replacement is needed.

The specimens were identified by the size of the shear stud followed by a C or $\mathrm{P}$, indicating whether the studs were cast-in or post-installed, respectively. Specimen labels and variables are presented in Table 2.1. The shear studs in each specimen are numbered 1 through 20 beginning at the north end of the specimen. The shear stud number will be preceded by the specimen identification (e.g. "4-C-3” is the third shear stud of Specimen $4-\mathrm{C})$

Table 2.1: Specimen variables

\begin{tabular}{|c|c|c|}
\hline Specimens & Shear stud size & Shear stud installation \\
\hline $4-C$ & $\# 4$ & Cast-in \\
\hline $6-C$ & $\# 6$ & Cast-in \\
\hline $4 / 6-P$ & $\# 4$ and $\# 6$ & Epoxy \\
\hline
\end{tabular}

\subsection{Construction}

The following subsections describe the processes by which the precast components required for each specimen were constructed. The construction process for the specimens is also described.

\subsubsection{Girders}

The girders were constructed by Prestress Services Industries LLC. Once casting was completed, the top surface of the girders received a flat float finish. The strands 
were detensioned symmetrically once the concrete reach a nominal compressive strength of 5 ksi. Images from the girder construction process are presented in Figure 2.3.

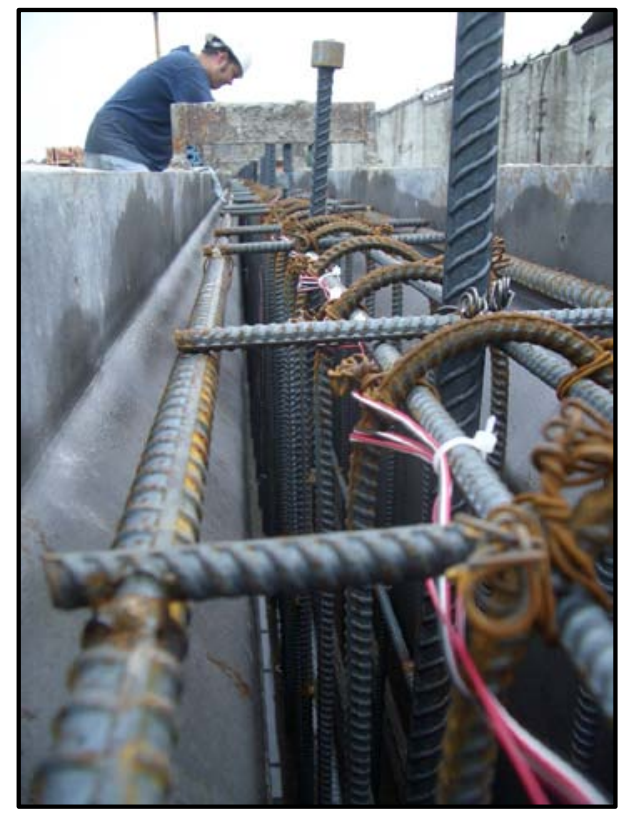

Rebar and Instrumentation

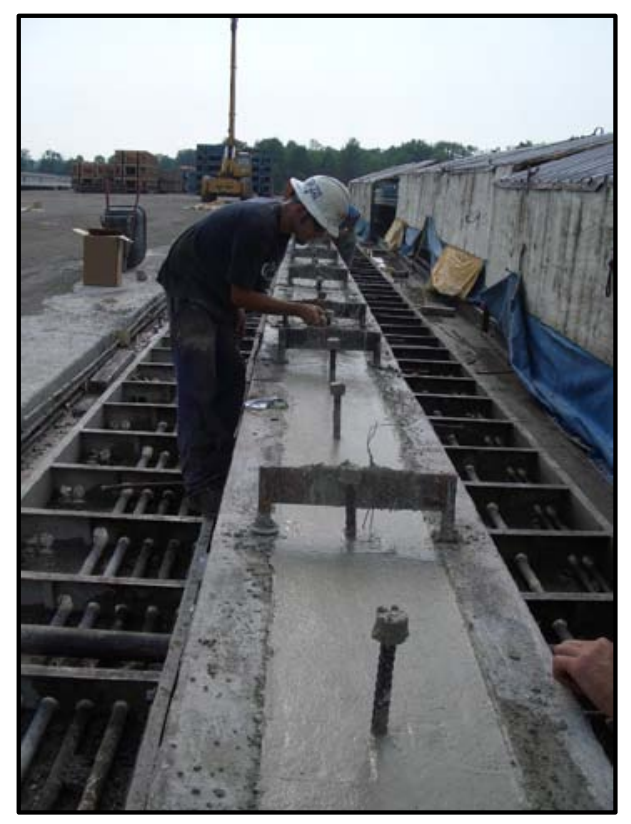

Surface finishing

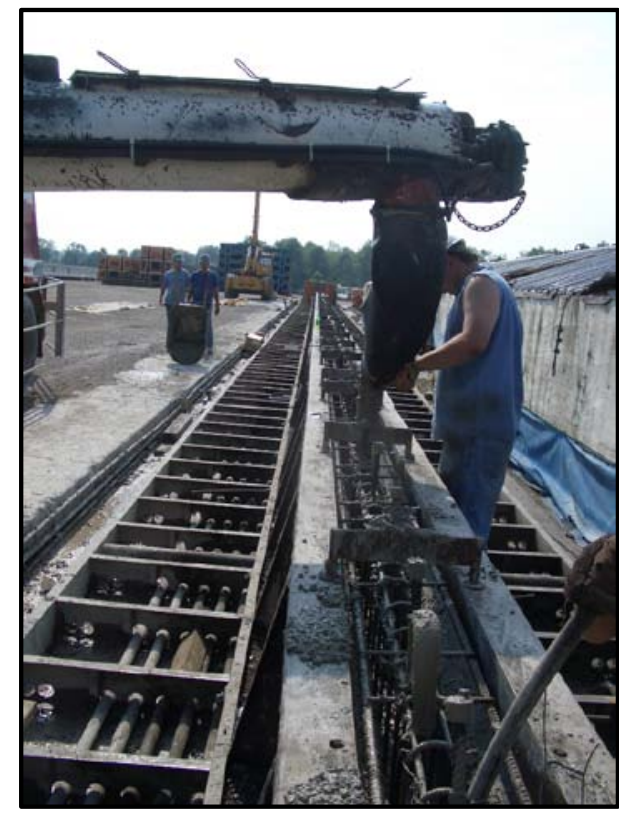

Casting

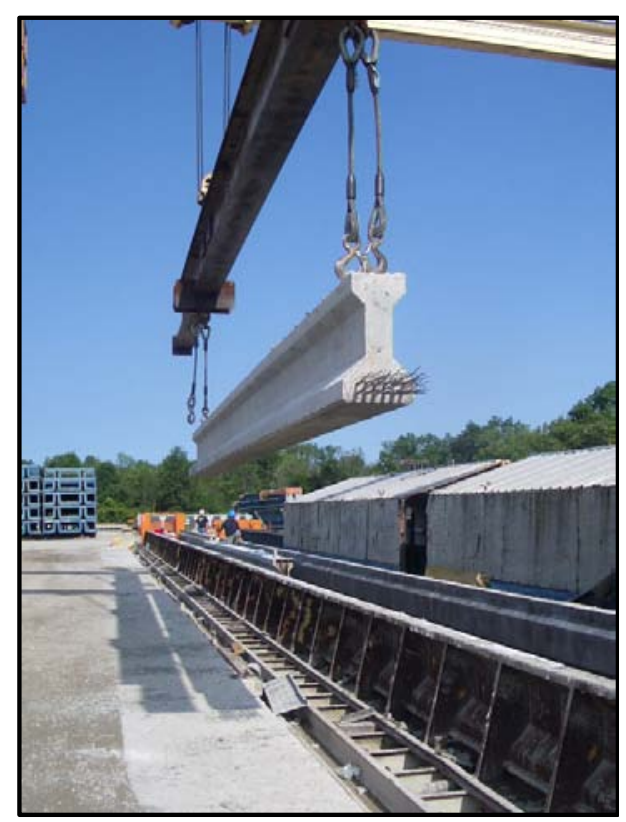

Removal from casting bed

Figure 2.3: Girder construction 
Girders 4-C and 6-C were cast with the shear studs in place, as shown in Figure 2.3. However, Girder 4/6-P was cast without shear studs. The shear studs were postinstalled at the Bowen Lab by drilling holes in the top flange of the girder and securing the studs with epoxy. The shear stud spacing was the same as Girders 4-C and 6-C. The distribution of the shear studs is illustrated in Figure 2.4. The holes were 1/8 in. larger in diameter than the shear stud being installed. The depth of the holes for the \#4 studs and \#6 studs were 6 in. and 9 in., respectively. These depths were recommended by the epoxy manufacturer to develop the full tensile strength of the rebar. Once drilled, the holes were blown-out with compressed air, wire brushed, and blown-out once more to remove laitance. The epoxy adhesive was injected into the base of the hole and the shear stud was placed by twisting and pushing until it came in contact with the base of the hole. There was sufficient epoxy placed in each hole so that there was excess epoxy present once the shear stud was in place. Any excess epoxy was removed prior to setting.

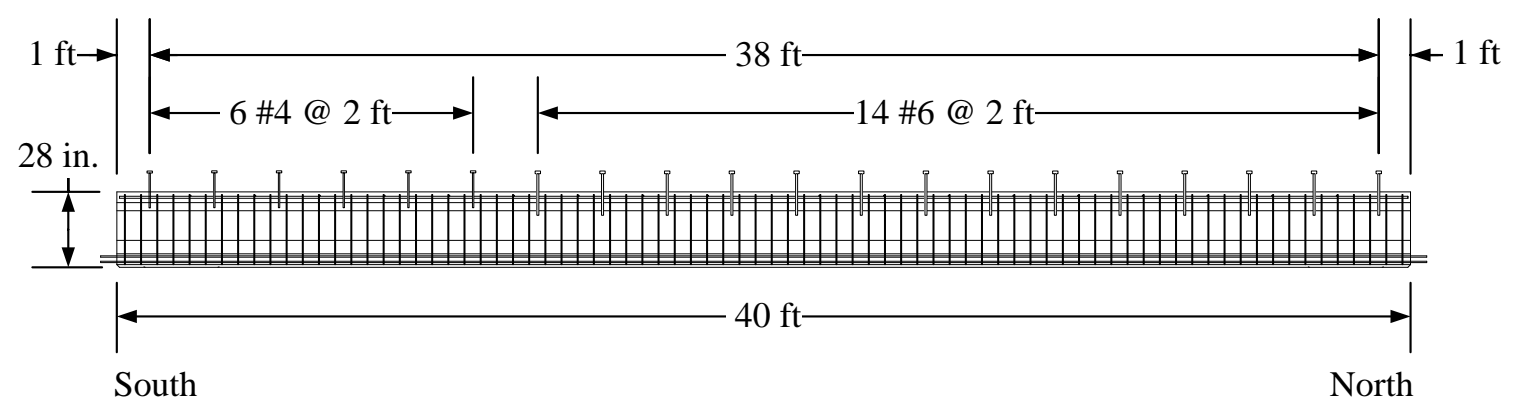

Figure 2.4: Girder 4/6-P shear stud distribution

\subsubsection{Precast deck panels}

The precast deck panels were constructed in the Bowen Laboratory at Purdue University on three separate occasions. Each set of nine panels required for a girder were cast using the same batch of concrete. The concrete was obtained from a local ready-mix supplier. The mix specified for the precast panels was INDOT Class C, which has a minimum compressive strength of $4 \mathrm{ksi}$ at 28 days. After casting, the deck panels were wet cured for 7 days. Once removed from the formwork, the transverse joint and shear 
stud pocket surfaces were cleaned with a wire brush and compressed air to remove laitance.

\subsubsection{System}

Once the girder was placed on the supports, the precast deck panels were placed. Each panel was centered on the girder to within a $1 / 4$ in. The deck panels were elevated above the top surface of the girder using 1 in. lengths of 2x4 lumber to form a 1 in. haunch. The placement of the first panel and haunch on Specimen 4-1 is shown in Figure 2.5 .

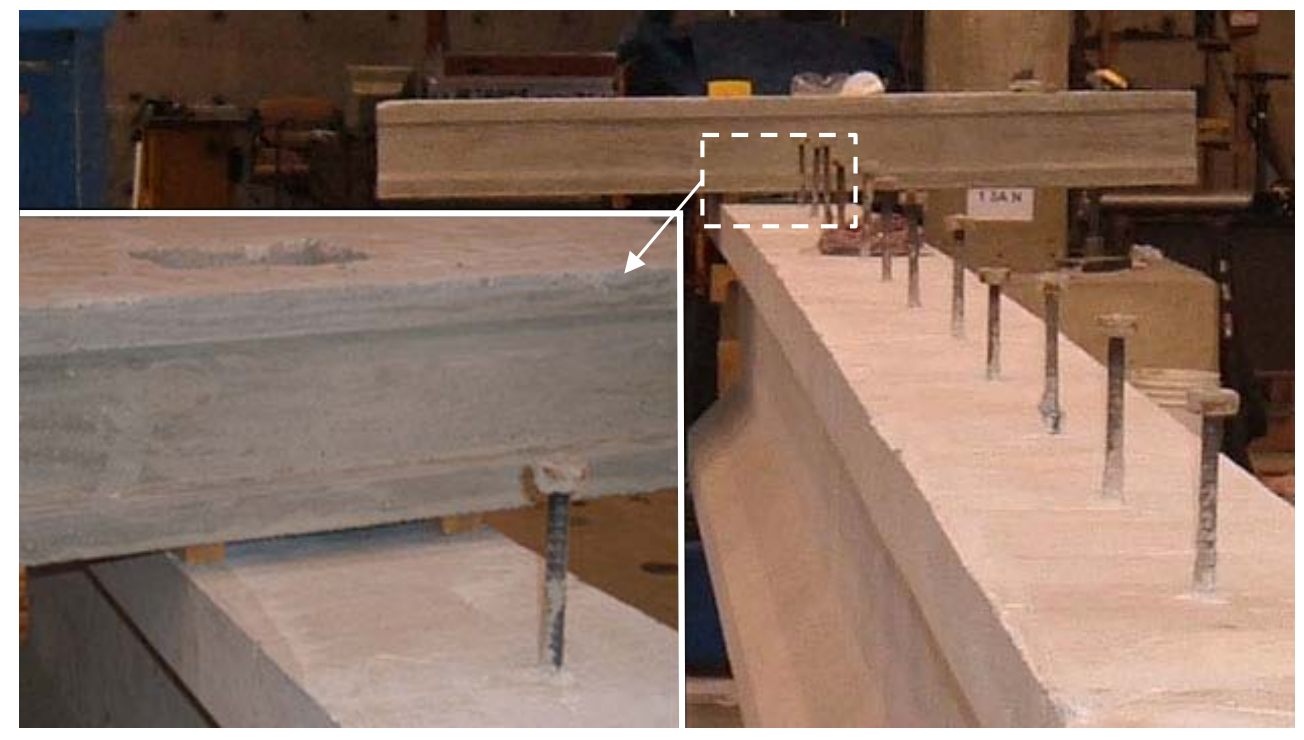

Figure 2.5: First panel placement and haunch.

Each successive panel was placed such that a gap of approximately $1 / 4 \mathrm{in}$. existed between panels. Once all of the panels were in place, they were leveled by shimming. Actual bridge deck panels have two leveling bolts embedded within either end of the panel over each girder to produce the proper elevation. However, since the specimens consisted of just one girder, leveling bolts were not required. Once the panels were leveled and in position, the haunch was formed with plywood and threaded rods, as shown in Figure 2.6. 


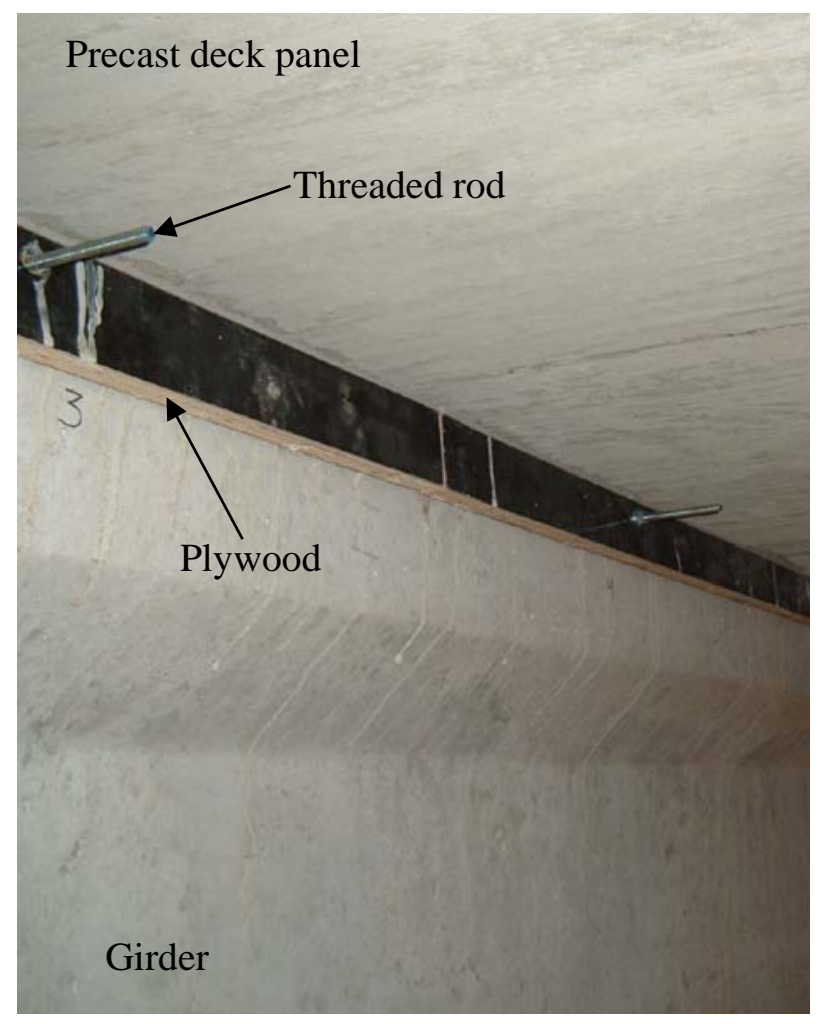

Figure 2.6: Haunch formwork

After forming was complete, the shear stud pockets and transverse joints were filled with self consolidating concrete (SCC). Using SCC on the three girder specimens had several benefits. The SCC mix used was available from a local ready-mix facility and the set time was several hours, so the material was consistent and easy to place. The pockets and transverse joints were filled with SCC starting from midspan and moving out toward the ends of the girder. Filling outward from midspan allows the SCC to flow downward due to the camber of the girder. After casting, the SCC was wet cured for 7 days.

\subsection{Materials}

Standard strength testing was performed on the materials used in the construction of the specimens according to applicable ASTM standards. All testing was performed in the Bowen Laboratory at Purdue University. 


\subsubsection{Concrete}

Concrete for the precast panels and the SCC was obtained from a local ready-mix supplier. The concrete for the girders was supplied by Prestress Services Industries LLC (PSI). Concrete mix proportions delivered for the deck panels and SCC are presented in Table 2.2. Concrete mix proportions provided by PSI are presented in Table 2.3. Compression tests were performed on $6 \times 12$ in. cylinders for the precast panels and SCC and $4 \times 8$ in. cylinders for the girders. The strength gain curves of the concrete compression tests and concrete age on the day of testing are presented in Appendix A. The results of the concrete compression tests for the day of testing are presented in Table 2.4 .

Table 2.2: Concrete mix proportions - Deck panels and SCC

\begin{tabular}{|c|c|c|c|c|c|c|c|}
\hline \multirow{2}{*}{ Material } & \multirow{2}{*}{ Unit } & \multicolumn{7}{|c|}{ Specimen } \\
\cline { 3 - 8 } & & \multicolumn{2}{|c|}{ 4-C } & \multicolumn{2}{|c|}{ 6-C } & \multicolumn{2}{c|}{ 4/6-P } \\
\cline { 3 - 8 } & & Panels & SCC & Panels & SCC & Panels & SCC \\
\hline Cement (Type I) & lbs/cy & 658 & 678 & 655 & 680 & 655 & 675 \\
\hline Pea-gravel & lbs/cy & --- & 1430 & --- & 875 & --- & 1430 \\
\hline \#8 stone & lbs/cy & 1790 & --- & 1793 & 575 & 1763 & --- \\
\hline \#23 sand & lbs/cy & 1265 & 1400 & 1265 & 1365 & 1244 & 1380 \\
\hline Fly-ash (Class C) & lbs/cy & --- & 195 & --- & 170 & --- & 160 \\
\hline Super (Glenium ${ }^{(B)}$ 3030 NS) & oz/cy & 19.7 & 102 & 19.9 & --- & 13.2 & 102 \\
\hline Air (Micro Air ${ }^{(B)}$ ) & oz/cy & 3.3 & 2 & 3.9 & 2.6 & 3.3 & 1.3 \\
\hline Water & lbs/cy & 186 & 165 & 215 & 147 & 192 & 148 \\
\hline
\end{tabular}


Table 2.3: Concrete mix proportions - Girders

\begin{tabular}{|c|c|c|}
\hline Material & Unit & Girders \\
\hline Cement (Type III) & lbs/cy & 658 \\
\hline Coarse Aggregate & lbs/cy & 1778 \\
\hline Fine Aggregate & lbs/cy & 1256 \\
\hline Super (Russtech 2000RM) & oz/100 wt. & 65.8 \\
\hline Reducer (Russtech LC-400R) & oz/100 wt. & 19.7 \\
\hline Air (Russtech RSA-10) & oz/cy & 6 \\
\hline Water & lbs/cy & 310 \\
\hline
\end{tabular}

Table 2.4: Average cylinder strengths on day of specimen test

\begin{tabular}{|c|c|c|c|}
\hline \multirow{2}{*}{ Specimen } & \multicolumn{3}{|c|}{ Test $\boldsymbol{f}_{\boldsymbol{c}}$ (psi) } \\
\cline { 2 - 4 } & Girder & Precast Panel & SCC \\
\hline $4-C$ & 9020 & 6360 & 5980 \\
\hline $6-C$ & 8320 & 4660 & 6870 \\
\hline $4 / 6-P$ & 8630 & 4590 & 7790 \\
\hline
\end{tabular}

\subsubsection{Reinforcing Steel}

The mild steel used throughout the girder sections and precast panels was ASTM A615 Grade 60. The prestressing steel was ASTM A416 seven-wire strand Grade 270. The seven-wire strand and mild steel used in the girder sections and precast panels was not tested because it was not a primary variable. However, certified mill test reports were provided for the seven-wire strand and mild steel used in the girder sections. A summary of those reports is presented in Table 2.5.

Table 2.5: Summary of certified mill tests

\begin{tabular}{|c|c|c|c|}
\hline Steel & $\mathbf{f}_{\mathbf{y}}(\mathbf{k s i})$ & $\mathbf{f}_{\mathbf{u}} \mathbf{( k s i )}$ & Elongation (\%) \\
\hline $\begin{array}{c}\text { Seven-wire strand } \\
(1 / 2 \text { in. special) }\end{array}$ & 261 & 284 & 5 \\
\hline \#3 bar & 69 & 102 & 12.5 \\
\hline \#6 bar & 72 & 106 & 11.3 \\
\hline
\end{tabular}




\subsubsection{Shear Studs}

Standard tension testing outlined in ASTM A370 was performed on the mild steel used for the shear studs. A total of four lots of rebar were used as shear studs in this test series. All studs were single headed studs with Lenton terminators, as presented in Figure 2.7. The stress-strain curves for each lot are presented in Figure 2.8; where the lots are identified by the specimen in which they were installed. A summary of the number of test samples, yield, and ultimate stress is presented in Table 2.6.

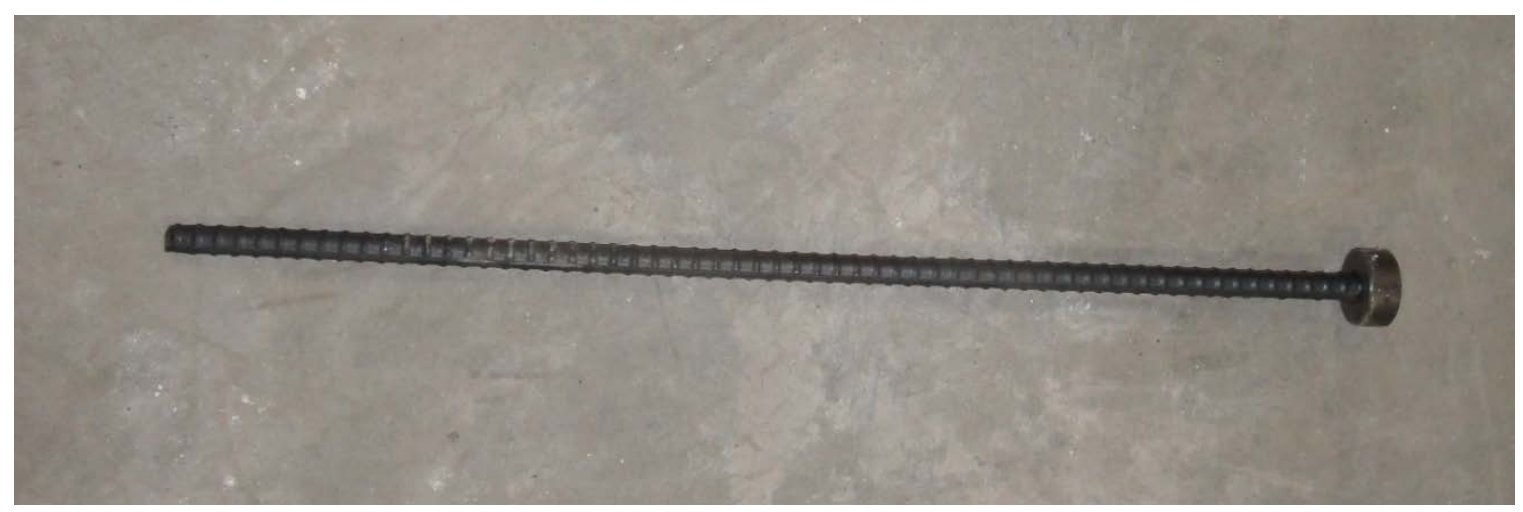

Figure 2.7: \#4 with Lenton terminator

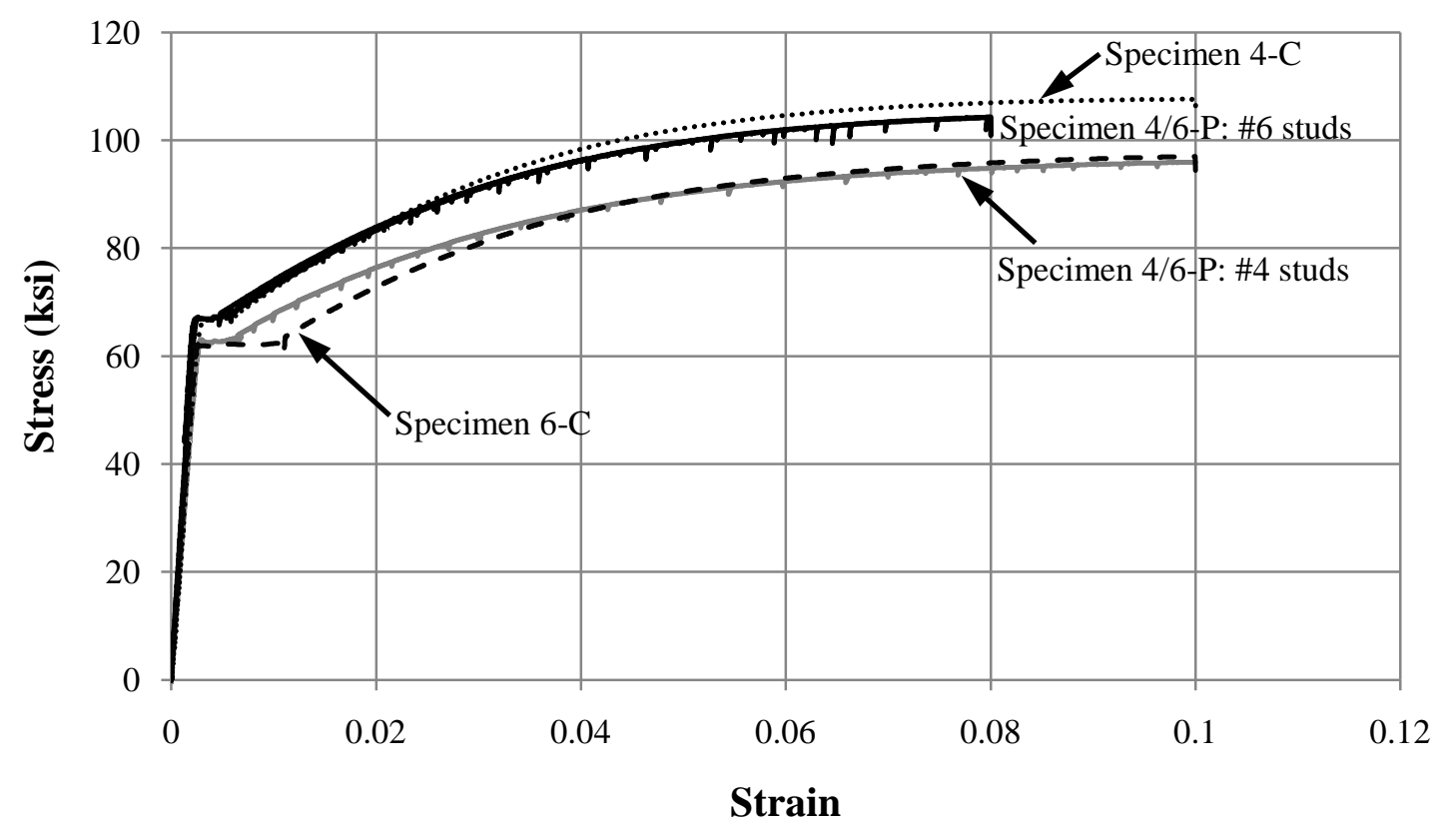

Figure 2.8: Shear stud stress-strain relationship 


\section{Table 2.6: Summary of results from tension tests}

\begin{tabular}{|c|c|c|}
\hline Specimen ID & $\mathbf{f}_{\mathbf{y}} \mathbf{( k s i )}$ & $\mathbf{f}_{\mathbf{u}} \mathbf{( k s i )}$ \\
\hline $4-C$ & 67 & 107 \\
\hline 6-C & 62 & 97 \\
\hline 4/6-P: \#4 & $63^{*}$ & $95^{*}$ \\
\hline 4/6-P: \#6 & $65^{*}$ & $105^{*}$ \\
\hline
\end{tabular}

*indicates an average value

\subsubsection{Epoxy}

The epoxy used to attach the shear studs in Specimen 4-P was HIT-RE 500, an epoxy adhesive product supplied by Hilti Corp. Material testing was not performed on this product because it was not a primary variable. Installation guidelines supplied by the manufacturer to develop the rebar were followed, and failure of the epoxy was not expected.

\subsection{Test Setup}

The test setup for this series of tests consisted of a loading system anchored to the strong floor and two supports spaced $1 \mathrm{ft}$ from either end of the girder. One support was a roller and the other a pin, as illustrated in Figure 2.9. Specimens 4-C and 6-C were subjected to three point loading with the load being applied at midspan, as shown in Figure 2.10. 


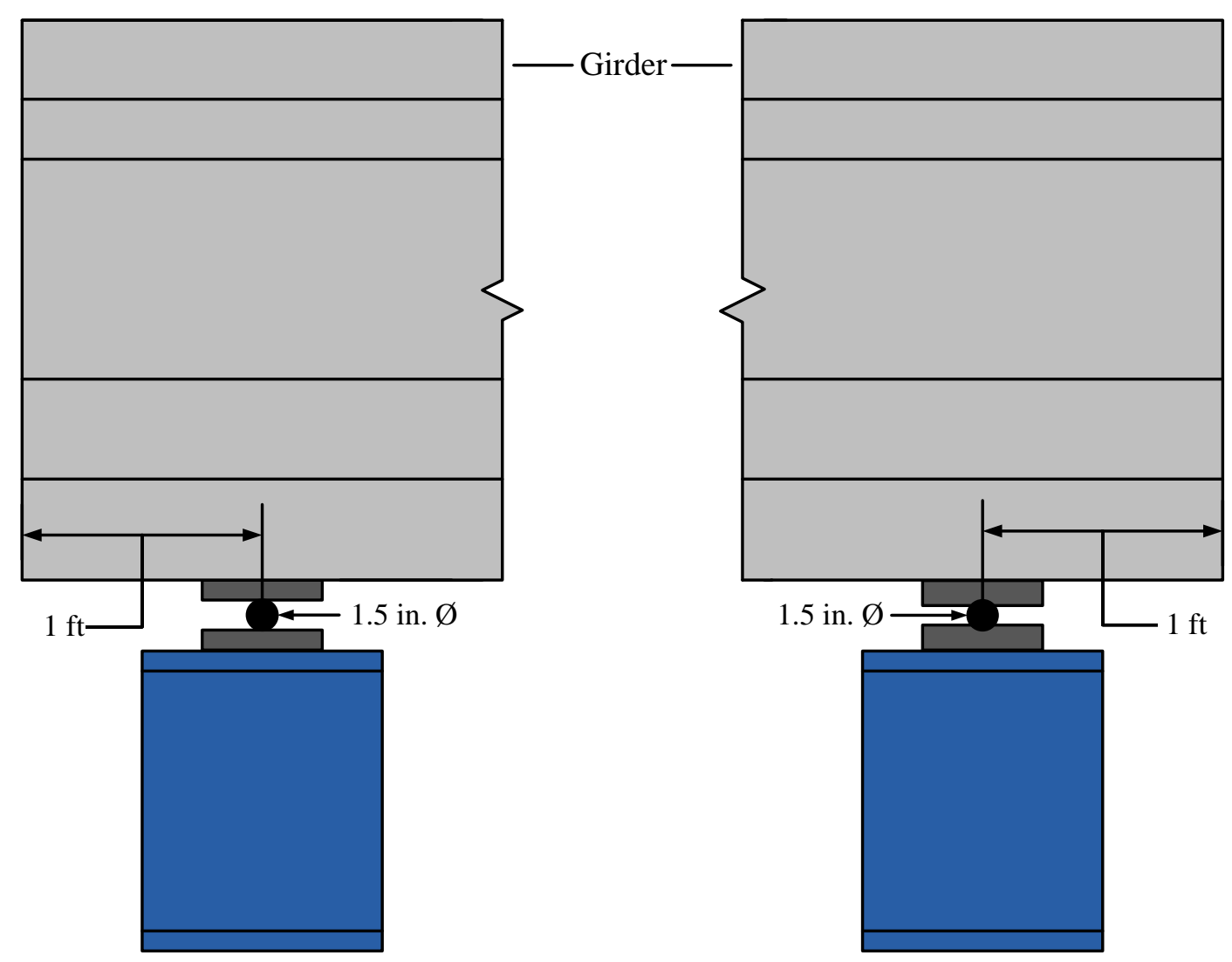

Roller Support

Pin Support

Figure 2.9: Roller and pin supports

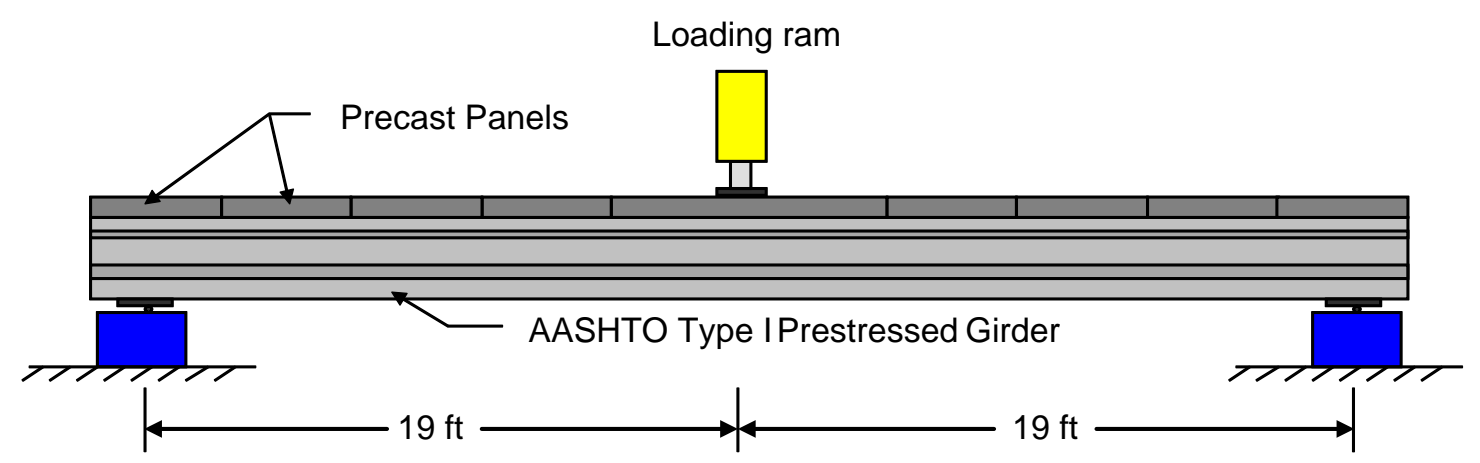

Figure 2.10: Full-scale girder tests of existing system

Specimen 4/6-P was subjected to three point loading with the load being applied $11 \mathrm{ft}$ from one of the supports. This specimen was loaded twice to evaluate the shear strength of each end of the girder which contained different size shear studs (Figure 2.11 
and Figure 2.12). A reduced shear span was used to subject the shear studs to higher shears and provide additional information regarding the behavior of both \#4 and \#6 studs. The north end of the specimen was loaded first because the ultimate strength of the \#6 studs was of primary interest (Figure 2.11). During the first loading, failure of the specimen occurred by crushing of the compression region in the partial composite section. The failed section was removed prior to loading the specimen a second time, resulting in a specimen of reduced length, shown in Figure 2.12.

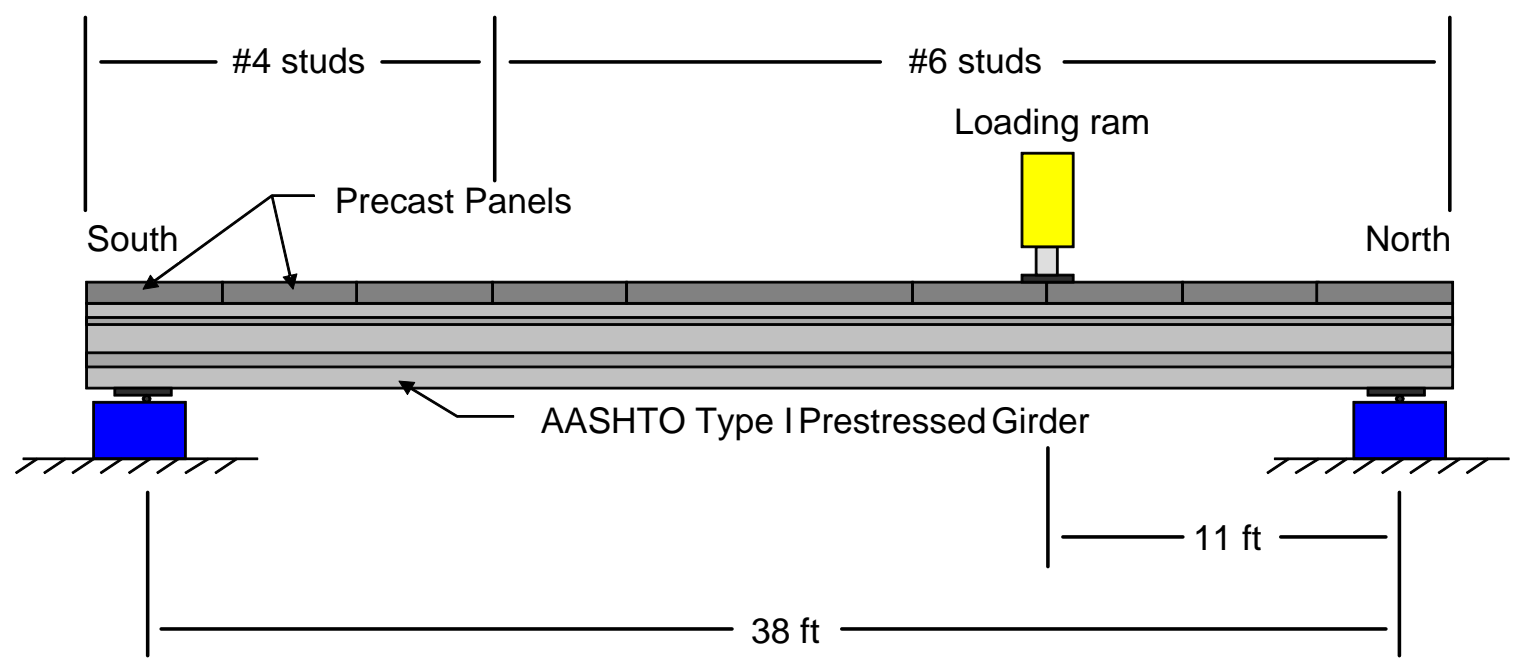

Figure 2.11: First loading of Specimen 4/6-P

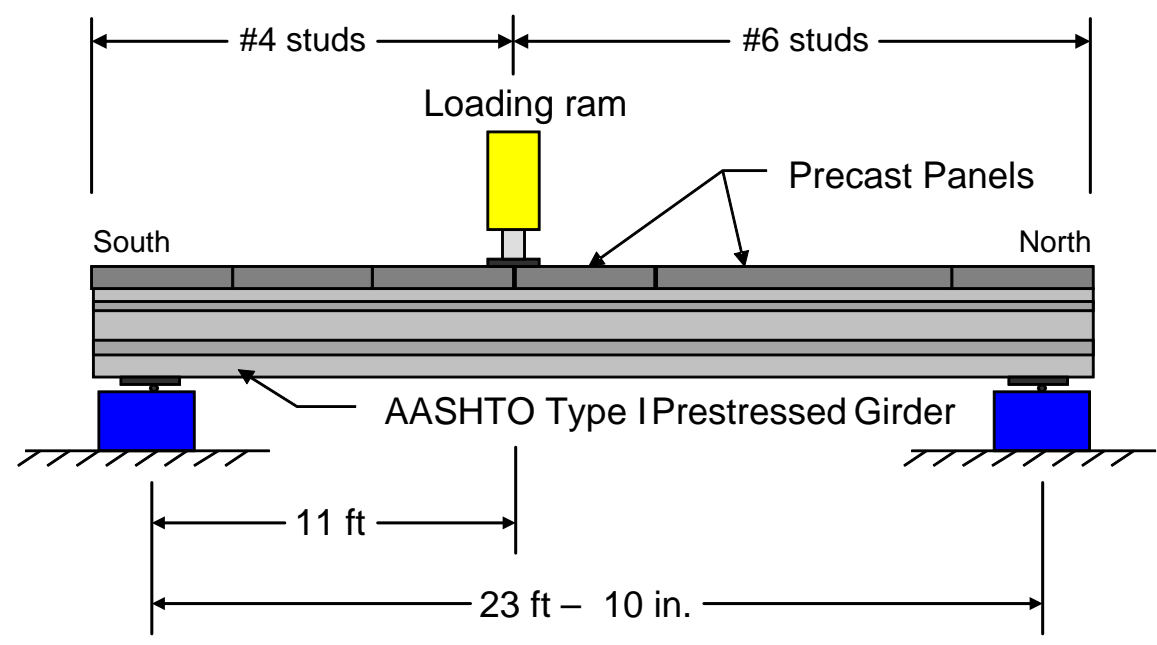

Figure 2.12: Second loading of Specimen 4/6-P 
Vertical displacement was measured from the girder bottom flange relative to the strong floor using linear variable differential transformers (LVDT) and linear potentiometers. Horizontal displacement of the panels was measured relative to the top flange of the girder using $1 \mathrm{in}$. linear potentiometers. The $1 \mathrm{in}$. potentiometers were mounted to the top flange of the girder and measurements were referenced to angle brackets mounted to the bottom of the panels. Loads were measured using a 300 kip load cell mounted between the ram and load frame. The locations of external instrumentation used on Specimens 4-C and 6-C are presented in Figure 2.13. The locations of external instrumentation differed on Specimen 4/6-P and are presented in Figure 2.14.

External strain gauges were surface mounted on the top and bottom of the deck panel at the load location, as shown in Figure 2.13 and Figure 2.14. Four gauges were used at each load location on Specimen 4/6-P because the presence of a deck joint. Two gauges were placed on either side of the joint. Each gauge was placed 18 in. from the edge of the deck panel. Each specimen had additional internally mounted strain gauges. A total of 30 strain gauges were placed on the mild reinforcement, shear studs, and prestressing steel of Specimens 4-C and 6-C. Specimen 4-P had only 20 strain gauges because it was cast without shear studs. The locations of the remaining gauges within the girder section are the same as Specimens 4-C and 6-C. All strain gauges were aligned along the longitudinal axis of the reinforcement to which they were attached. Detailed drawings of internal gauge locations are provided in Appendix A, Figure A.5.

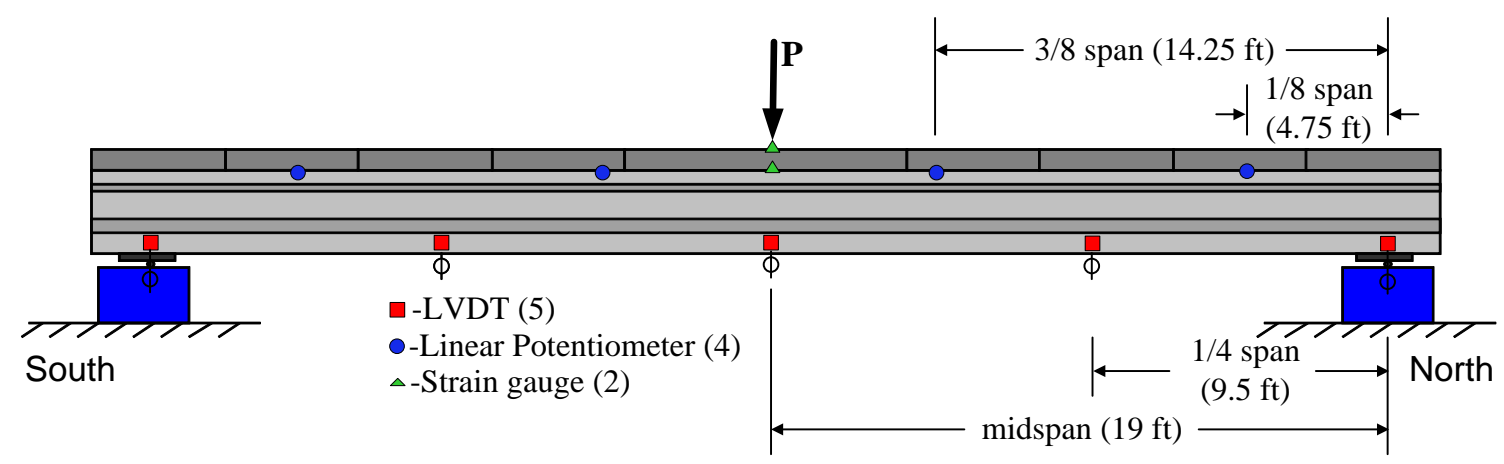

Figure 2.13: Location of external instrumentation on Specimens 4-C and 6-C 


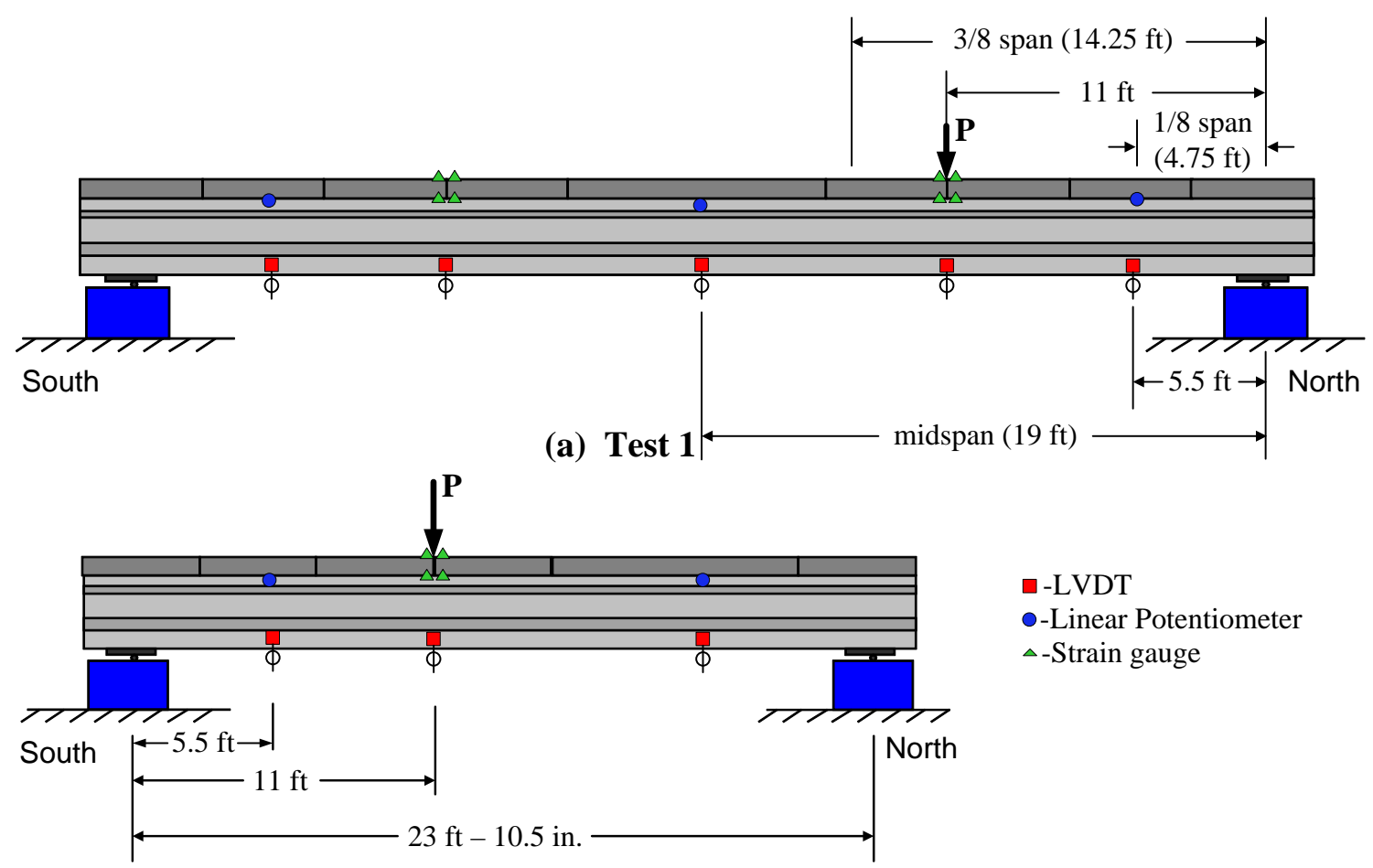

(b) Test 2

Figure 2.14: Location of external instrumentation on Specimen 4/6-P

\subsubsection{Test protocol}

The specimens were loaded at midspan using a 400 kip hydraulic ram until failure or excessive deflection occurred. Load was applied statically in specified load increments using a hydraulic pump. All instrumentation was monitored throughout testing and recorded at two second increments. In addition, cracks were monitored and marked at each loading increment.

\subsection{Test Results}

The following subsections present the results obtained from the test procedures described in Section 2.5. A summary of the results is provided for each specimen. 


\subsubsection{Specimen 4-C}

The load-deflection response for Specimen 4-1 is presented in Figure 2.15. As evident, the specimen behaved as a composite section up to a load of approximately 89 kips at which bond failure occurred at the girder-haunch interface along the south half of the specimen. Bond failure is evident in considering the horizontal slip on the south side of midspan (Figure 2.16). Loading of the specimen continued to 127 kips at which bond failure occurred at the girder-haunch interface along the north half of the specimen. Again, bond failure on this side is evident in considering the horizontal slip on the north side of midspan (Figure 2.17). A maximum measured slip, prior to failure, of $0.68 \mathrm{in}$. occurred at the 1/8 north span. Measured strains (Figure 2.18) indicate that the shear studs yielded prior to specimen failure. Failure of the specimen occurred at 119 kips and 9.5 in. midspan deflection. Final failure occurred by failure of the shear studs along the north side of the specimen, as shown in Figure 2.19, which was immediately followed by flexural failure of the girder due to crushing of the compression zone. It should be noted that crushing of the panels was not observed.

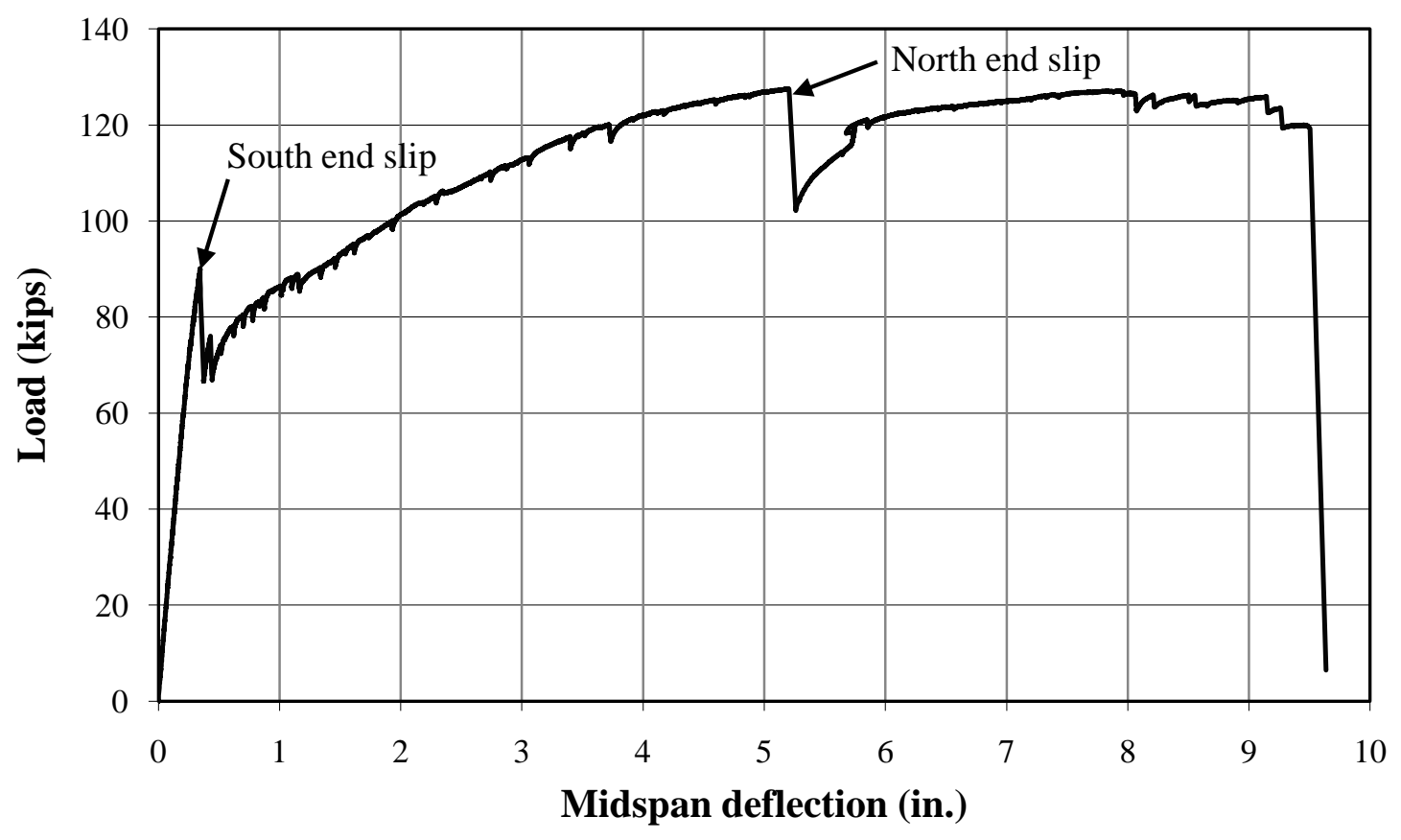

Figure 2.15: Load vs Midspan deflection - Specimen 4-C 


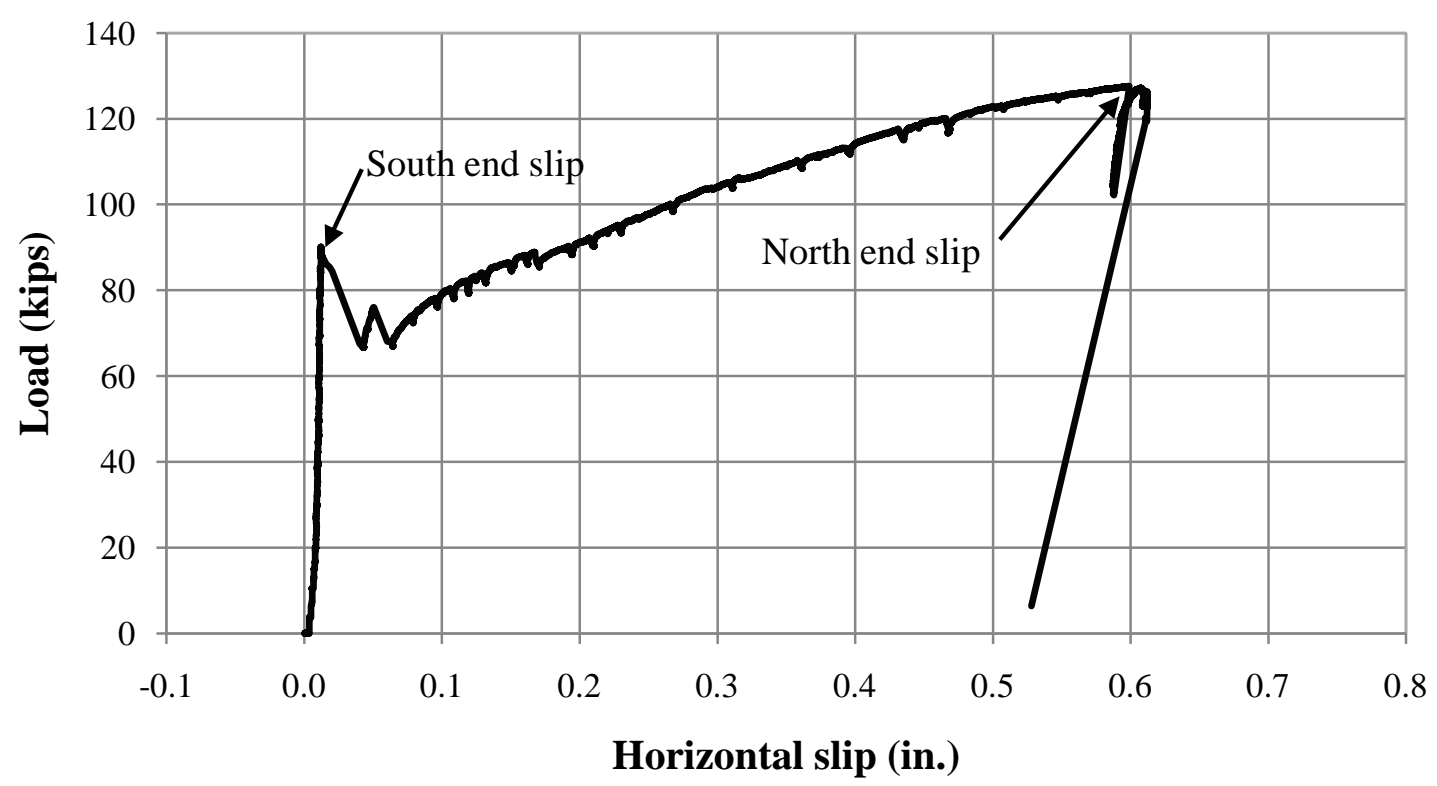

(a) $1 / 8$ span

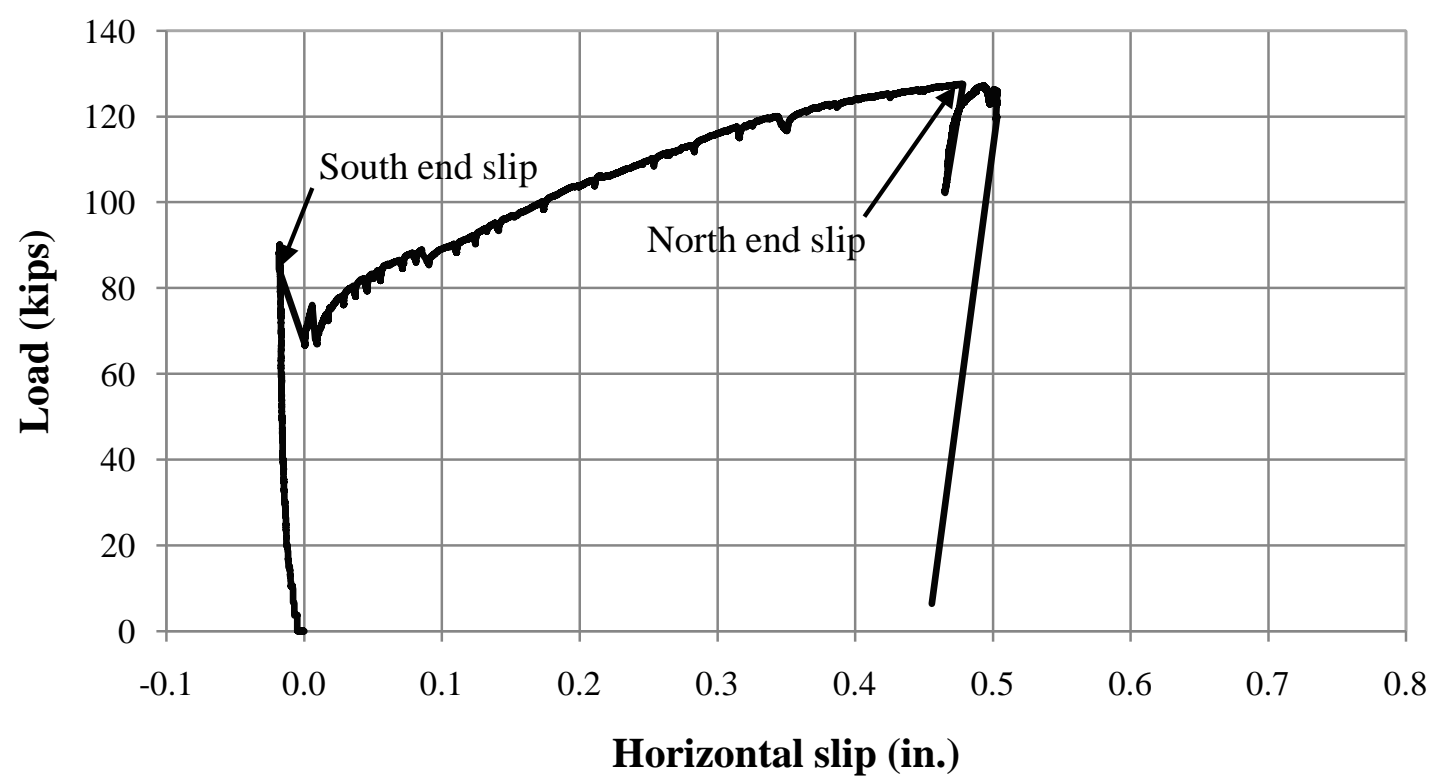

(b) $3 / 8$ span

Figure 2.16: South horizontal slip 


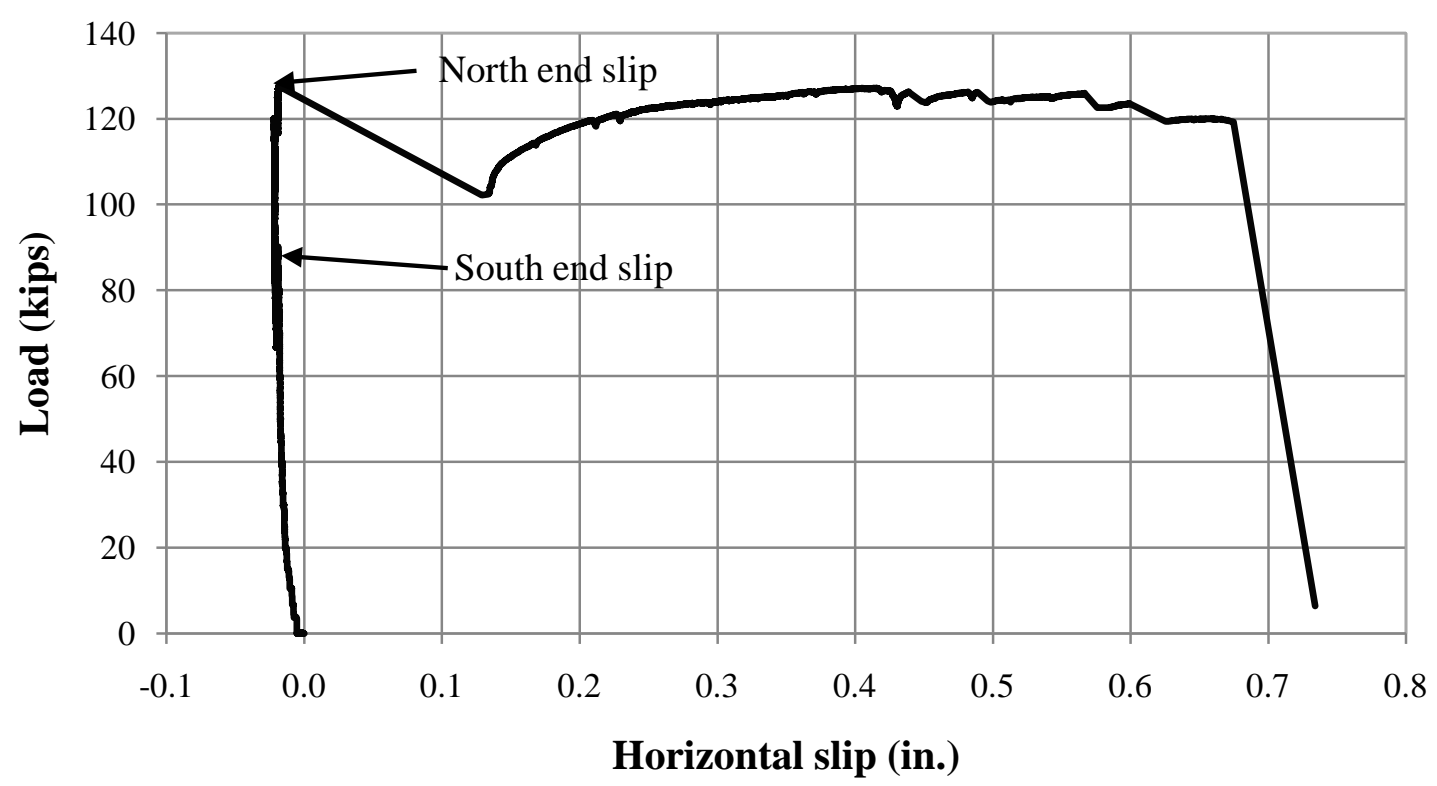

(a) $1 / 8$ span

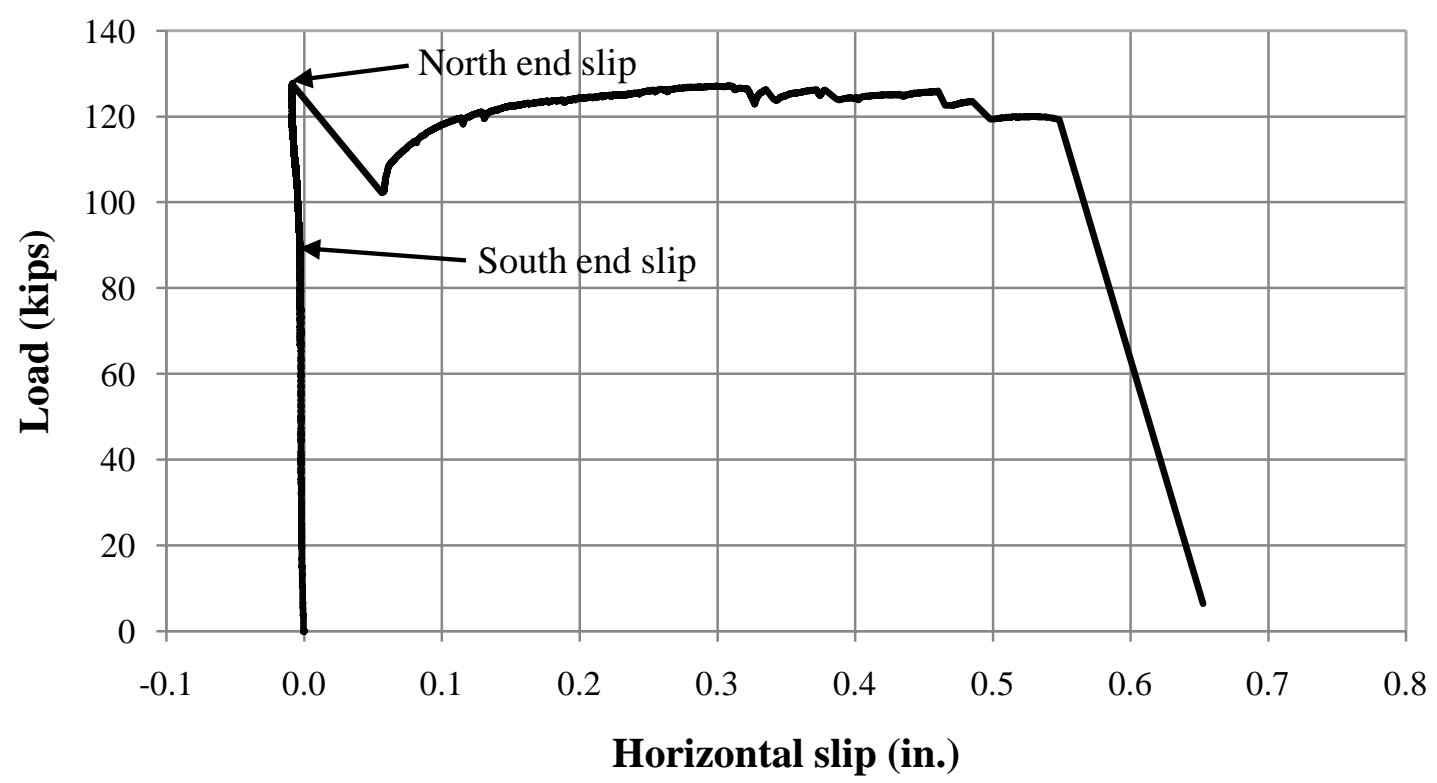

(b) $3 / 8$ span

Figure 2.17: North horizontal slip 


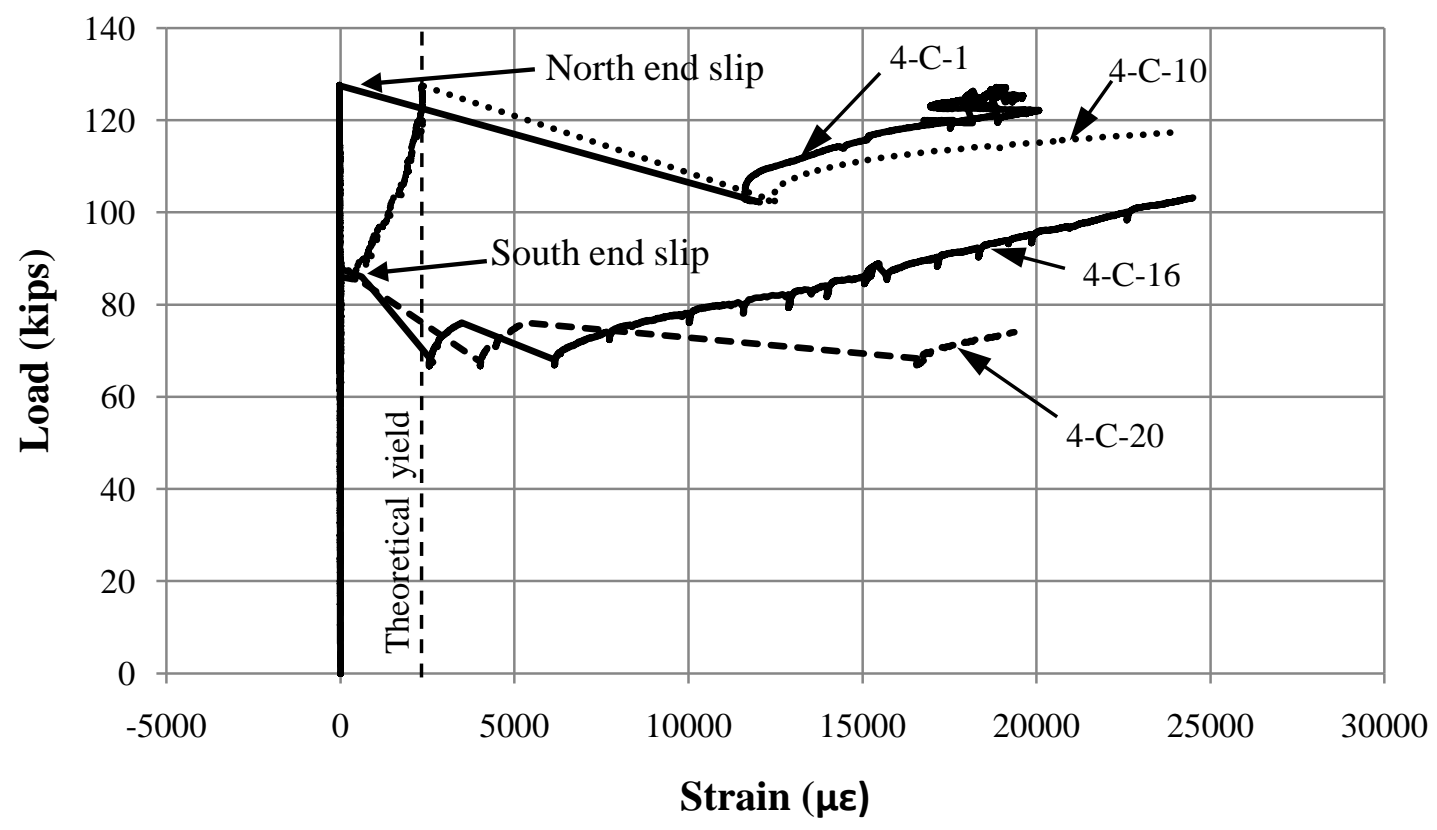

Figure 2.18: Measured longitudinal strain in shear studs 


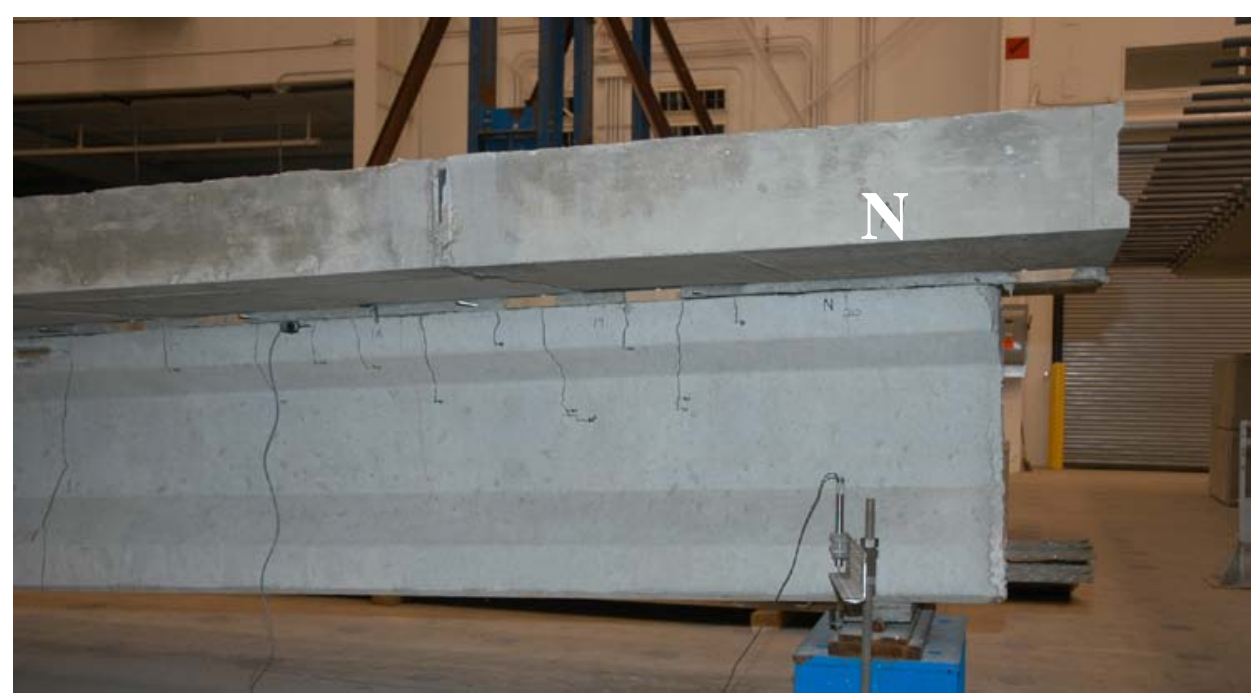

a) stud failure at North end

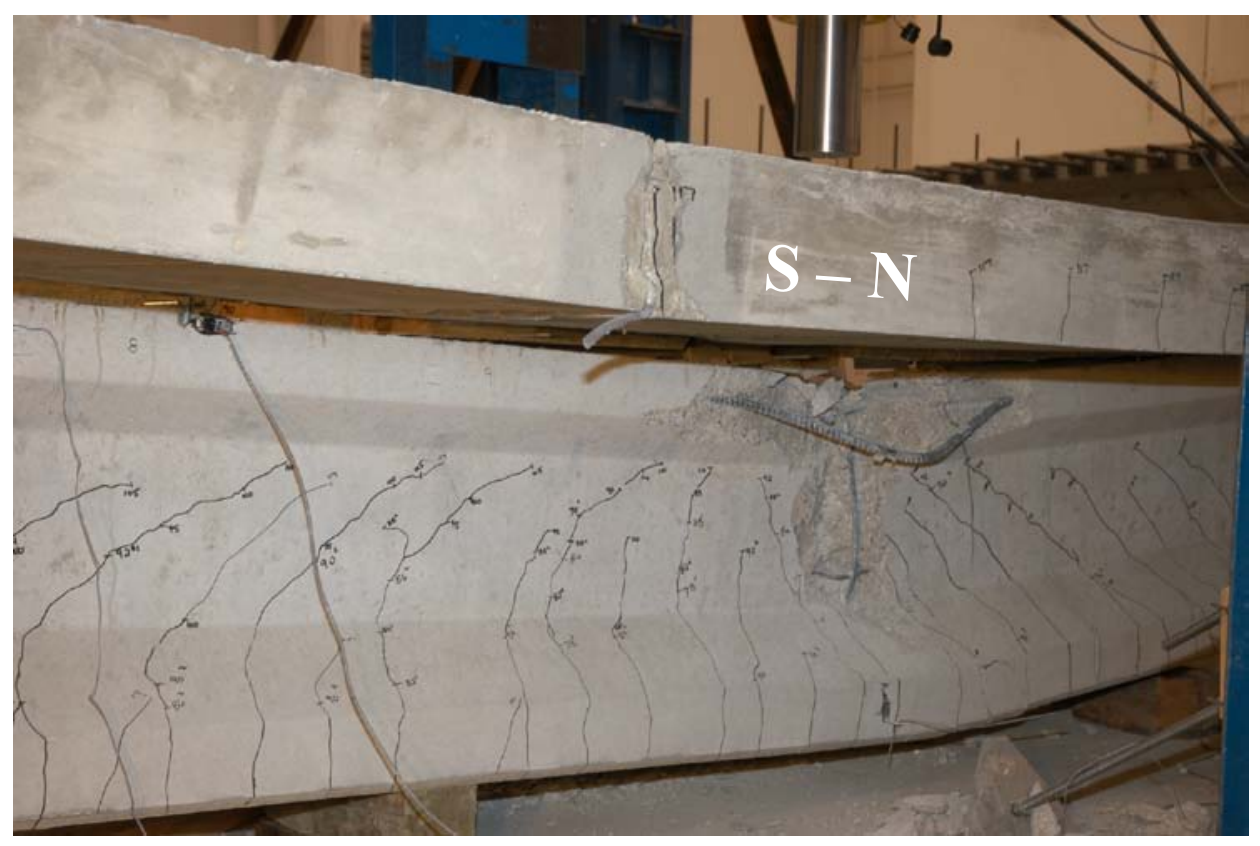

b) girder compression zone

Figure 2.19: Failure of Specimen 4-C

\subsubsection{Specimen 6-C}

The load-deflection response for Specimen 6-C is presented in Figure 2.20. As evident, the specimen behaved as a composite section up to a load of approximately 106 kips at which bond failure occurred at the panel-haunch interface along the north half of 
the specimen. Bond failure is evident in considering the horizontal slip on the north side of midspan (Figure 2.21). Loading of the specimen continued to 120.6 kips at which bond failure occurred at the panel-haunch interface along the south half of the specimen. Again, bond failure on this side is evident in considering the horizontal slip on the south side of midspan (Figure 2.22). A maximum measured slip of 0.83 in. occurred the 1/8 north span slip gauge at a load of 139 kips. The maximum measured slip occurred after the peak load of 142 kips was reached. Measured strains (Figure 2.23) indicate that the shear studs yielded prior to reaching the peak load.

At 6.71 in. of midspan deflection, the loading ram ran out of displacement capacity; therefore, the specimen was unloaded and steel plates were placed on top of the loading plate to provide increased displacement range. The specimen was reloaded to a maximum load of approximately 136 kips at which time the loading ram would not extend any further, so the specimen was unloaded. The loading cycle is clearly shown in Figure 2.21 through Figure 2.23; however, deflection data is unavailable because the midspan LVDT measured off-scale. The midspan LVDT was repositioned three times throughout the test because it ran out of stroke at the following approximate deflections: $1.2 \mathrm{in.,} 3.1 \mathrm{in}$. and $5 \mathrm{in}$. While unloading the specimen, it returned to $5 \mathrm{in}$. of midspan deflection at which point the LVDT measured offscale (Figure 2.20). The LVDT was repositioned for reloading the specimen, but malfunctioned during loading.

Prior to resuming testing the following day, the midspan LVDT was replaced with a linear potentiometer and an additional steel spacing plate was installed between the load-cell and frame. The load-deflection response of the final loading is presented in Figure 2.24. The specimen was loaded to approximately 126 kips at which time the load decreased to 113 kips. The specimen continued to be loaded to approximately 115 kips, at which time failure occurred. The midspan deflection of 0 in. in Figure 2.24 does not correspond to the 0 in. of midspan deflection in Figure 2.20. There was residual deflection of the specimen from the previous days' test. However, because the midspan LVDT malfunctioned in the first test, the residual deflection is unknown.

Final failure occurred in flexure due to crushing of the compressive zone in both the top of the precast panel as well as the top flange of the girder (Figure 2.25). As 
evident from the flexural cracks at the bottom of the precast panel, the girder and deck were not acting fully composite at this stage. Shear failure of shear studs was not observed.

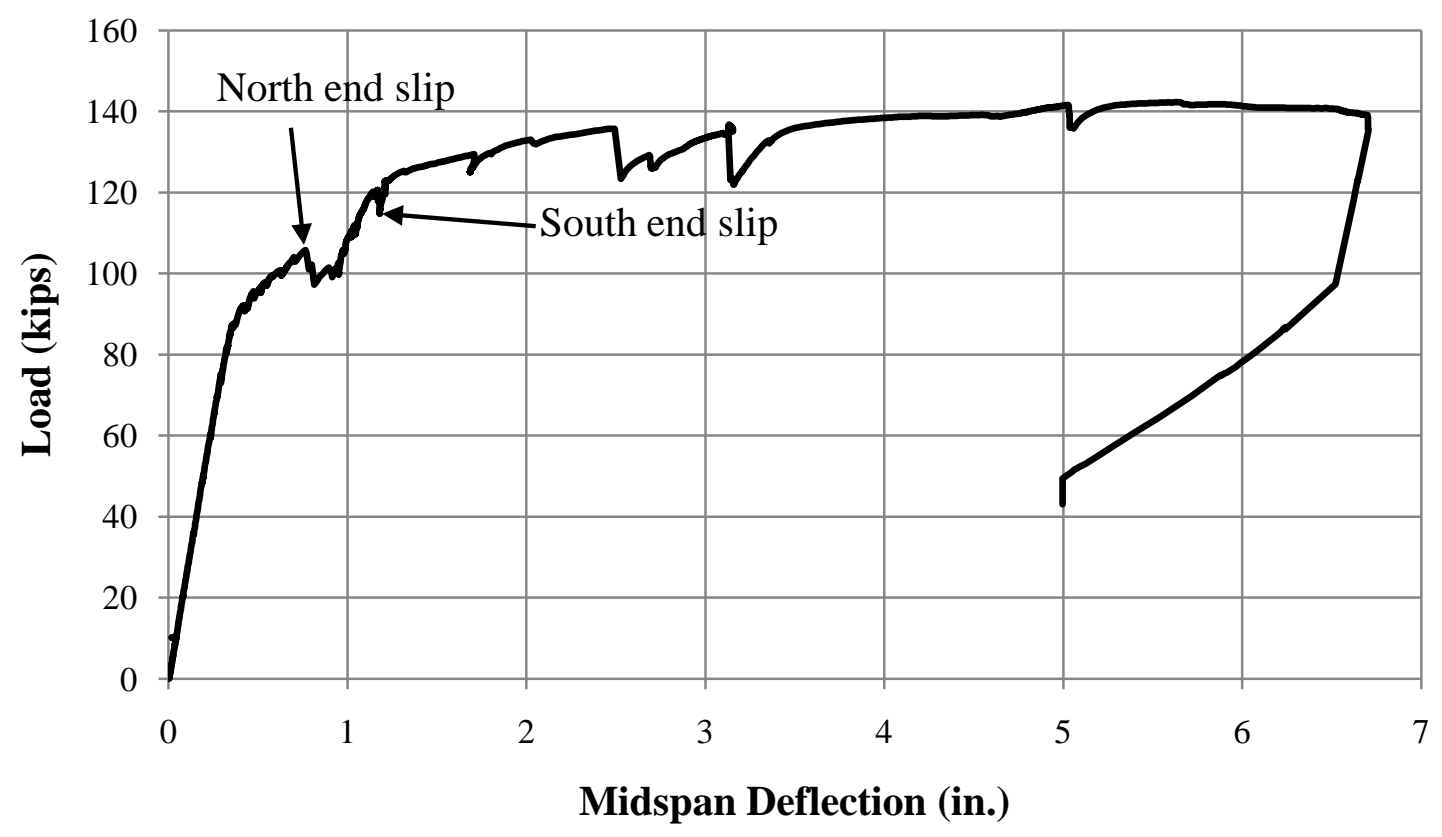

Figure 2.20: Load vs Midspan Deflection - Specimen 6-C 


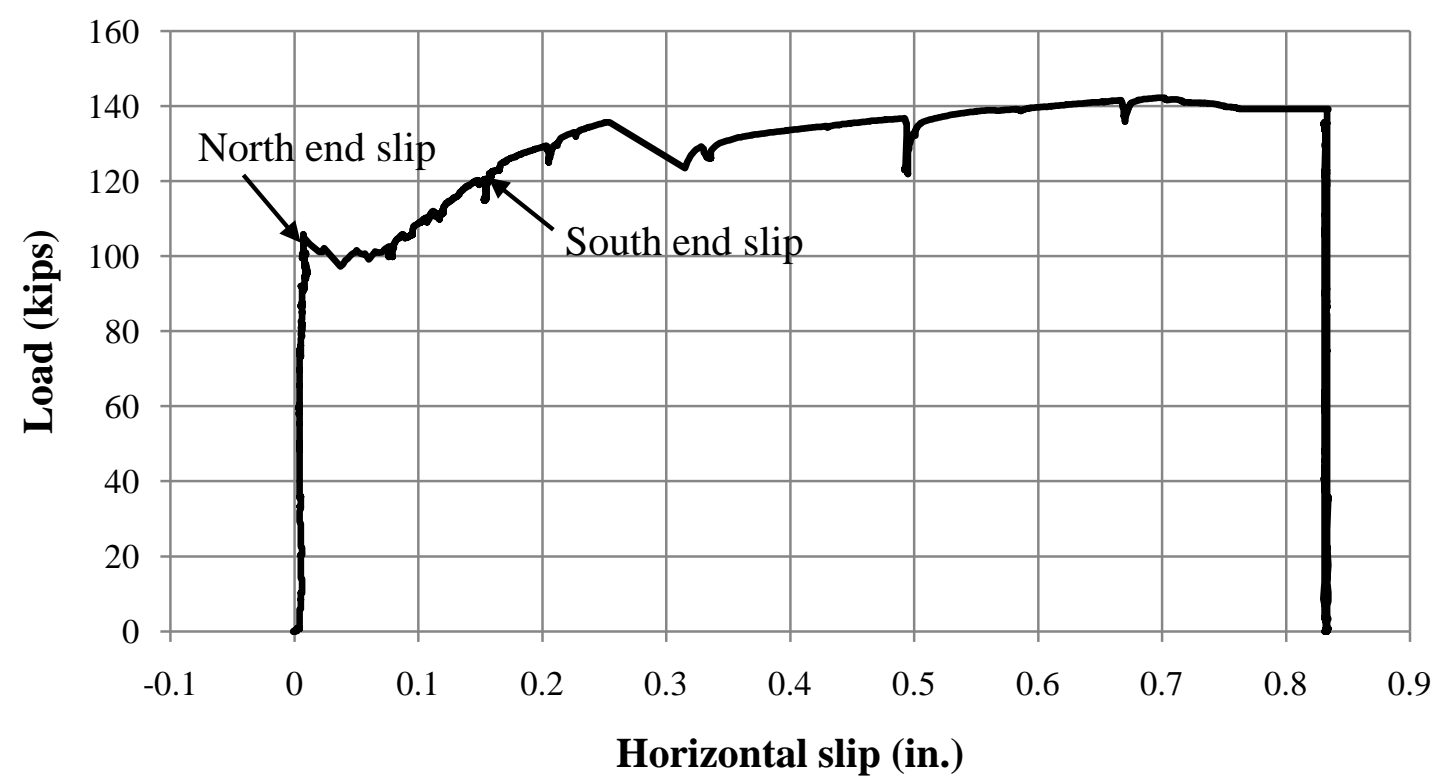

(a) 1/8 span

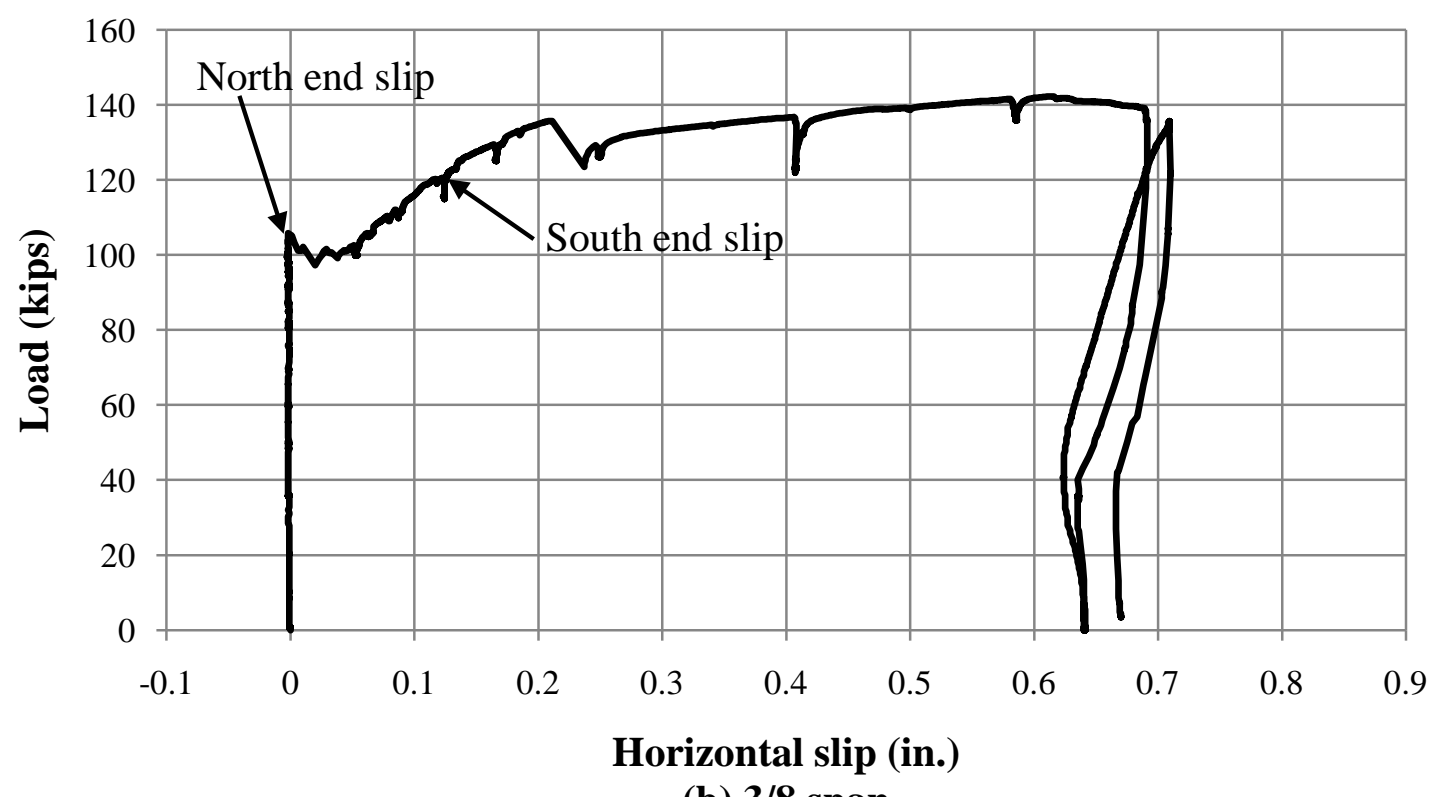

(b) $3 / 8$ span

Figure 2.21: North horizontal slip - Specimen 6-C 


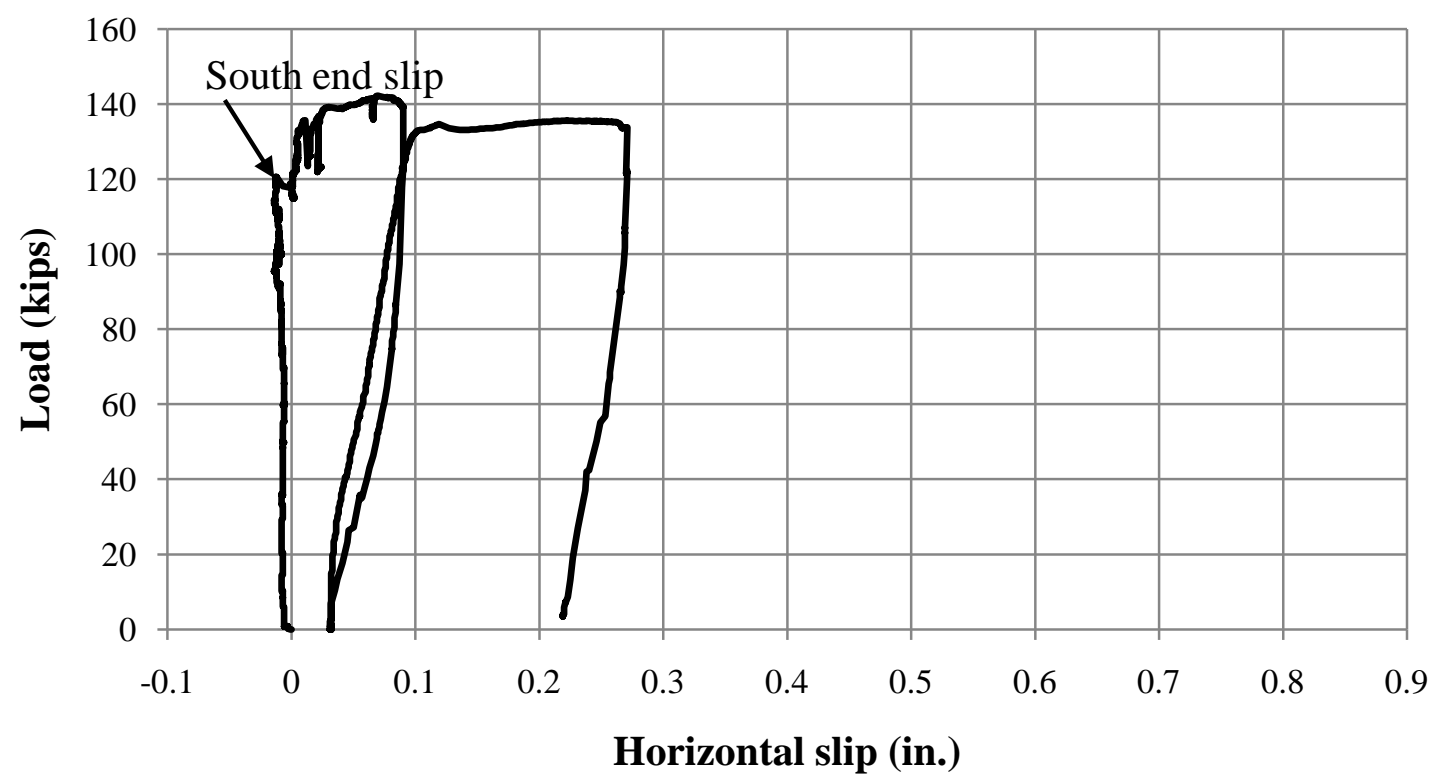

(a) 1/8 span

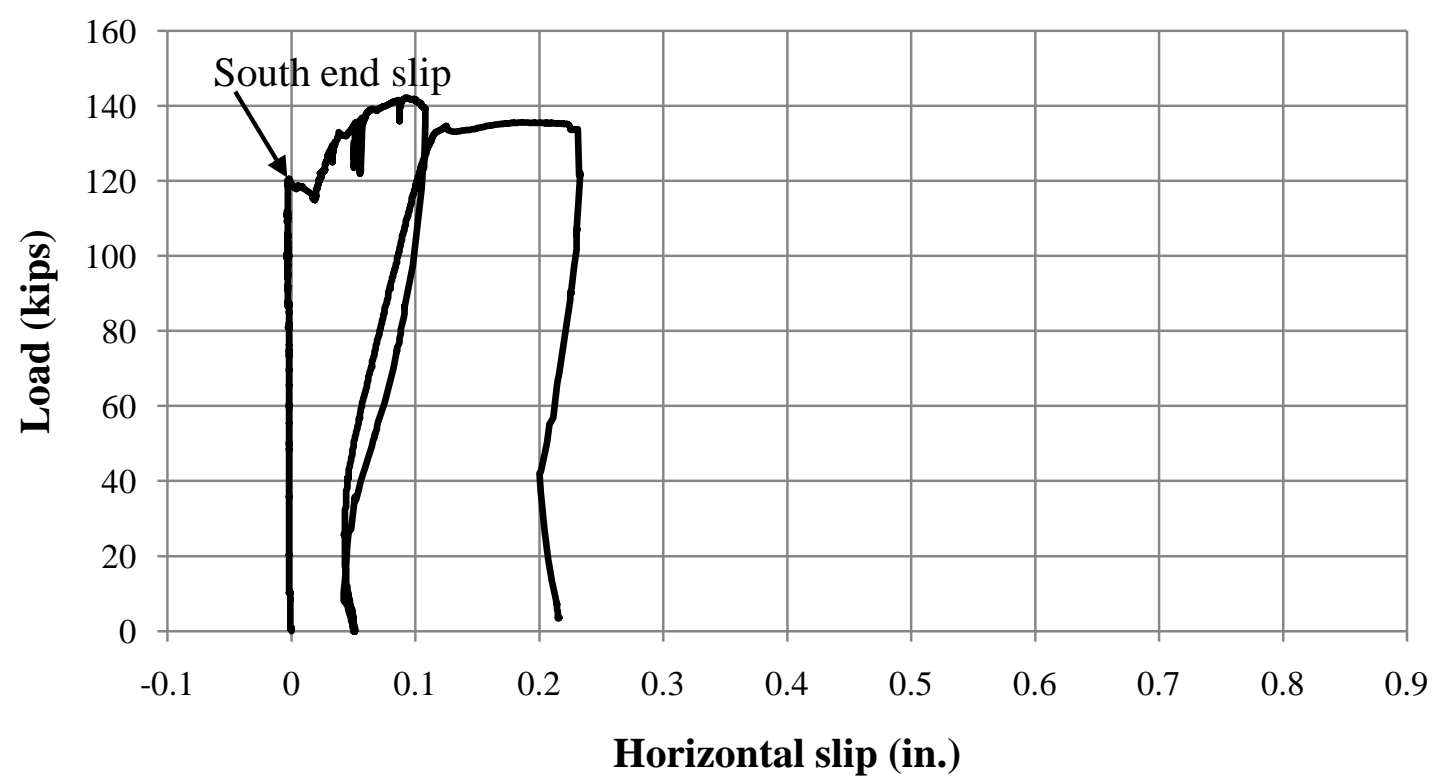

(b) 3/8 span

Figure 2.22: South horizontal slip - Specimen 6-C 


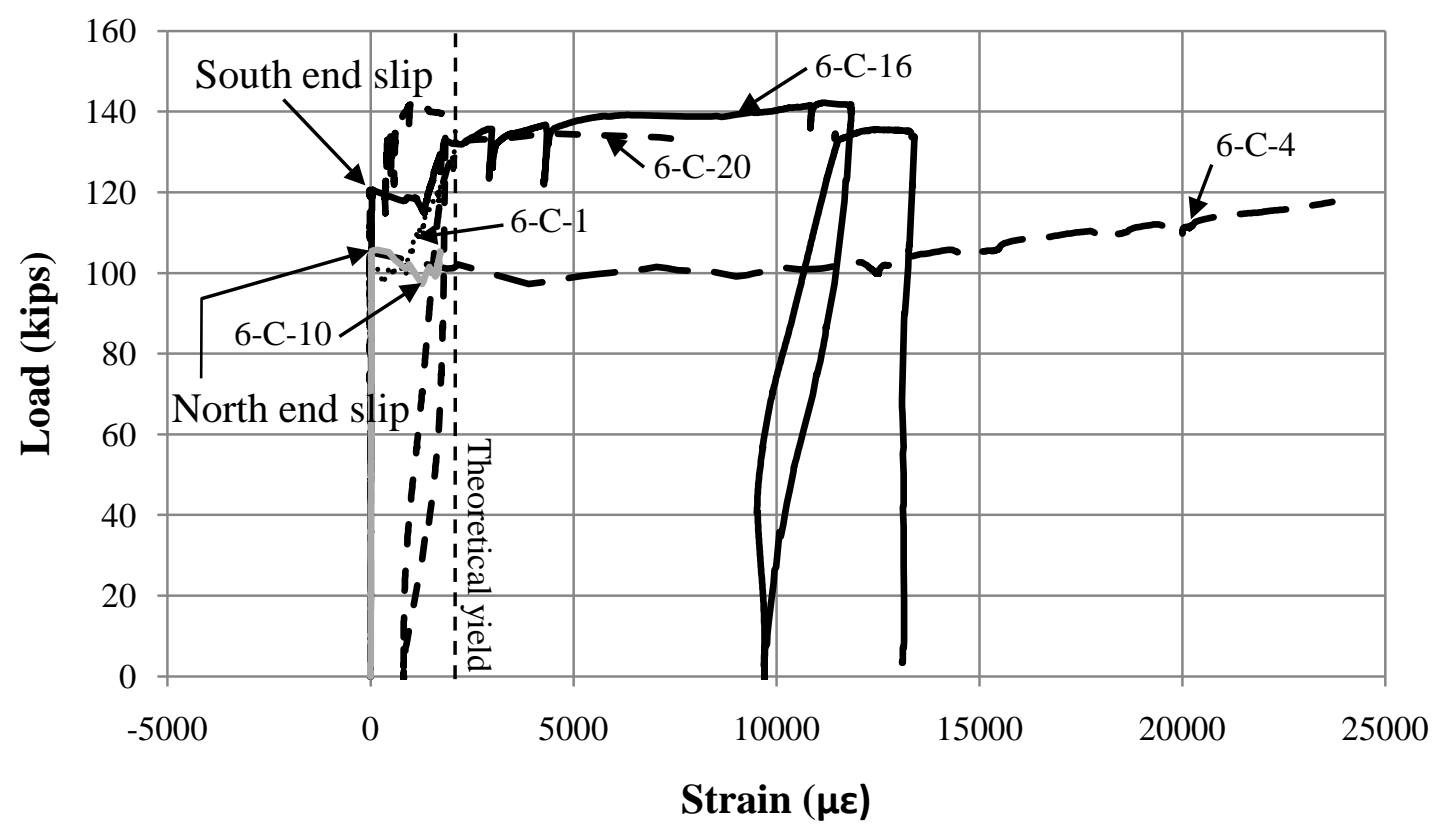

Figure 2.23: Measured strain in shear studs - Specimen 6-C

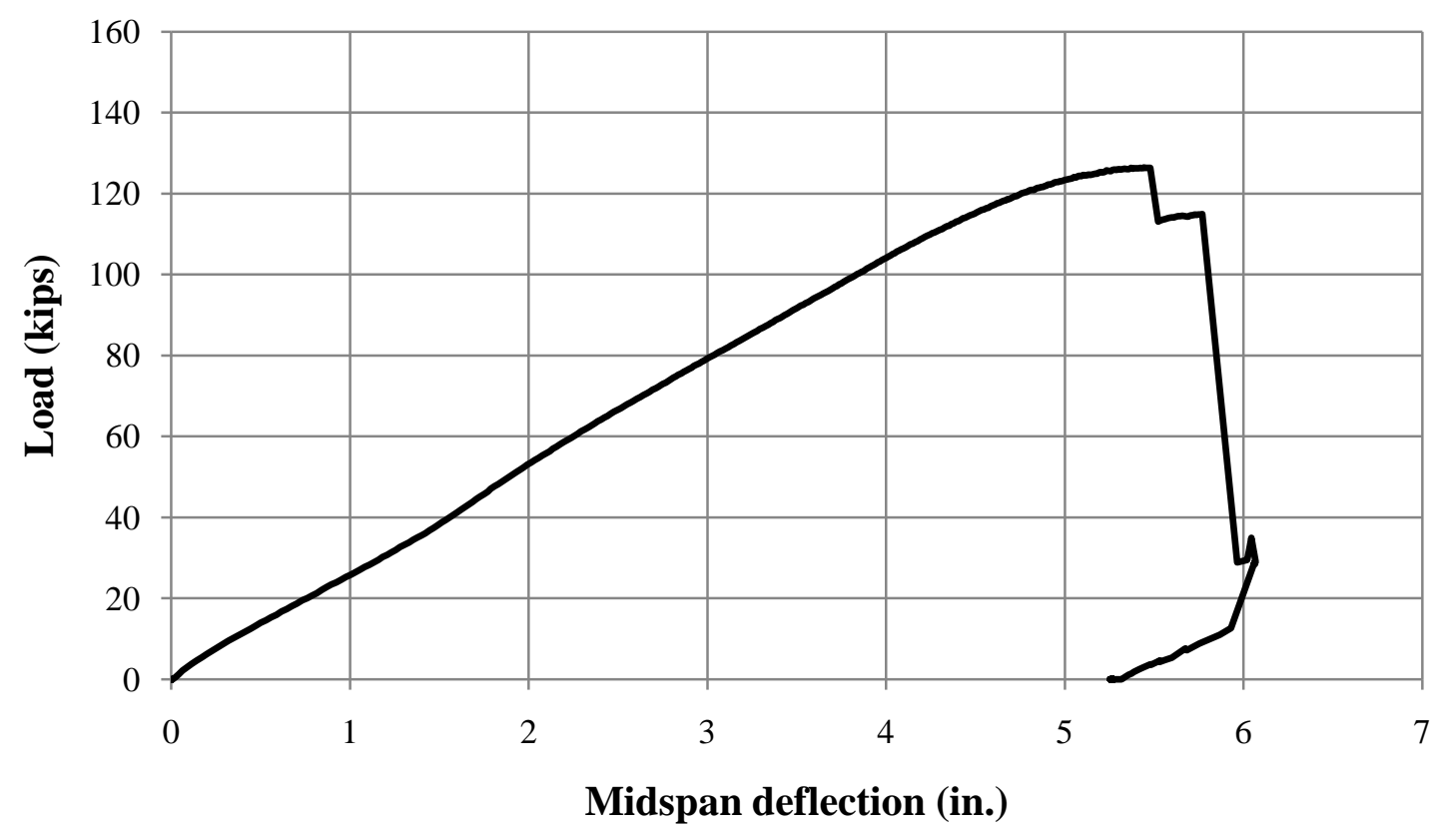

Figure 2.24: Load vs Midspan deflection for final loading to failure - Specimen 6-C 


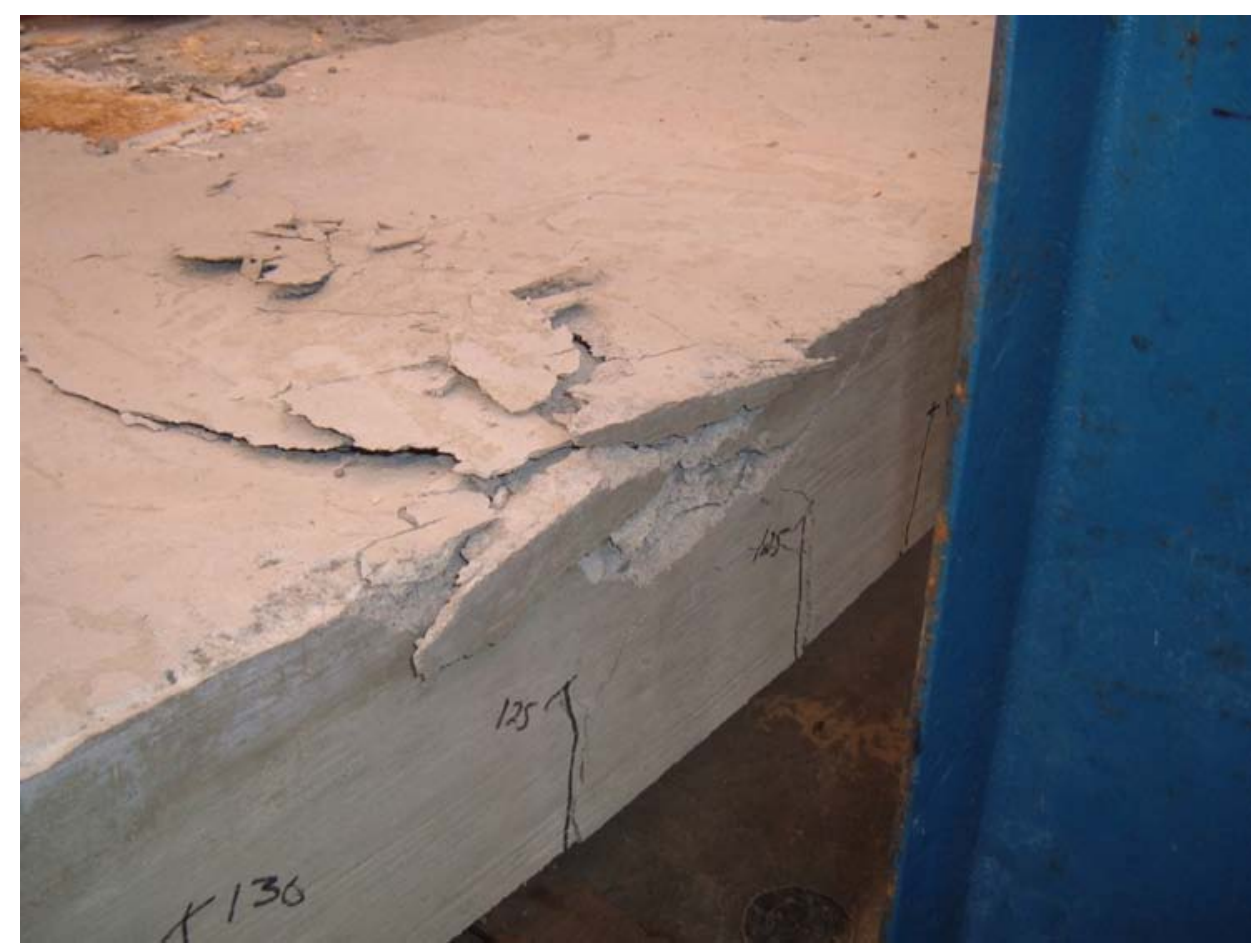

(a) deck panel compression zone

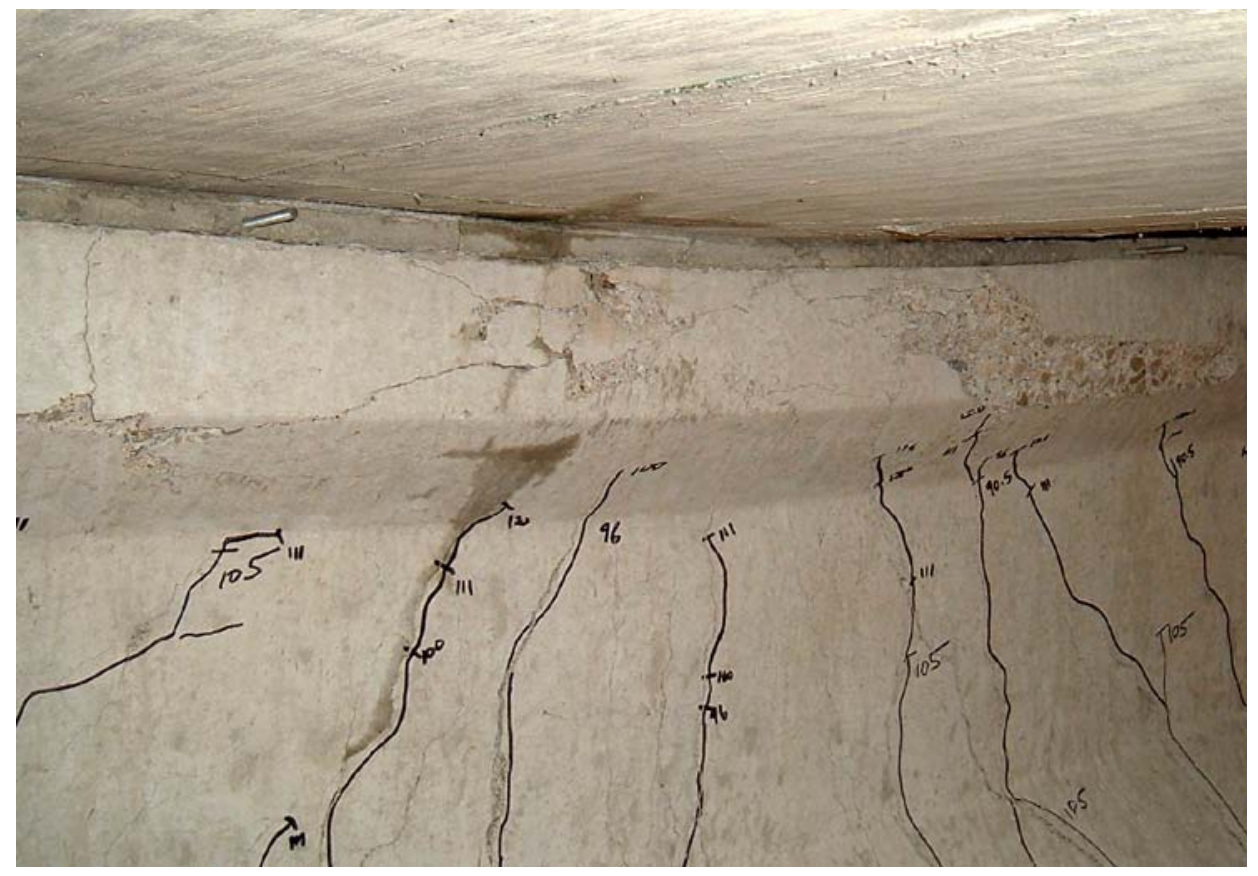

(b) girder compression zone

Figure 2.25: Failure of Specimen 6-C 


\subsubsection{Specimen 4/6-P}

As previously discussed (Section 2.5), Specimen 4/6-P was tested twice with the load applied $11 \mathrm{ft}$ from the support at each end. The north end of the specimen was tested first. During this test, failure of the specimen occurred by crushing of the compression regions in the partial composite section. The failed section was removed prior to loading the specimen on the south end. A summary of the results from both tests is provided below.

\subsubsection{Test 1}

The load-deflection response from Test 1 of Specimen 4/6-P is presented in Figure 2.26. The specimen behaved as a composite section up to a load of approximately 30 kips at which bond failure occurred at the girder-haunch interface along the north side of the load location. Bond failure is evident in considering the horizontal slip on the north end of the specimen (Figure 2.27). Loading of the specimen continued to approximately 97 kips at which bond failure occurred along the south end. Again, bond failure is evident in considering the horizontal slip on the south end (Figure 2.28). Loading of the specimen continued to a maximum load of 152 kips. A maximum measured slip, prior to failure, of 0.59 in. occurred at the north slip gauge. Failure of the specimen occurred at 148 kips and 2.8 in. of deflection at the load location. Final failure resulted from failure of the compression zone of the girder section, as shown in Figure 2.29. No crushing was observed in the precast panel. In addition, shear failure of the shear studs was not observed. 


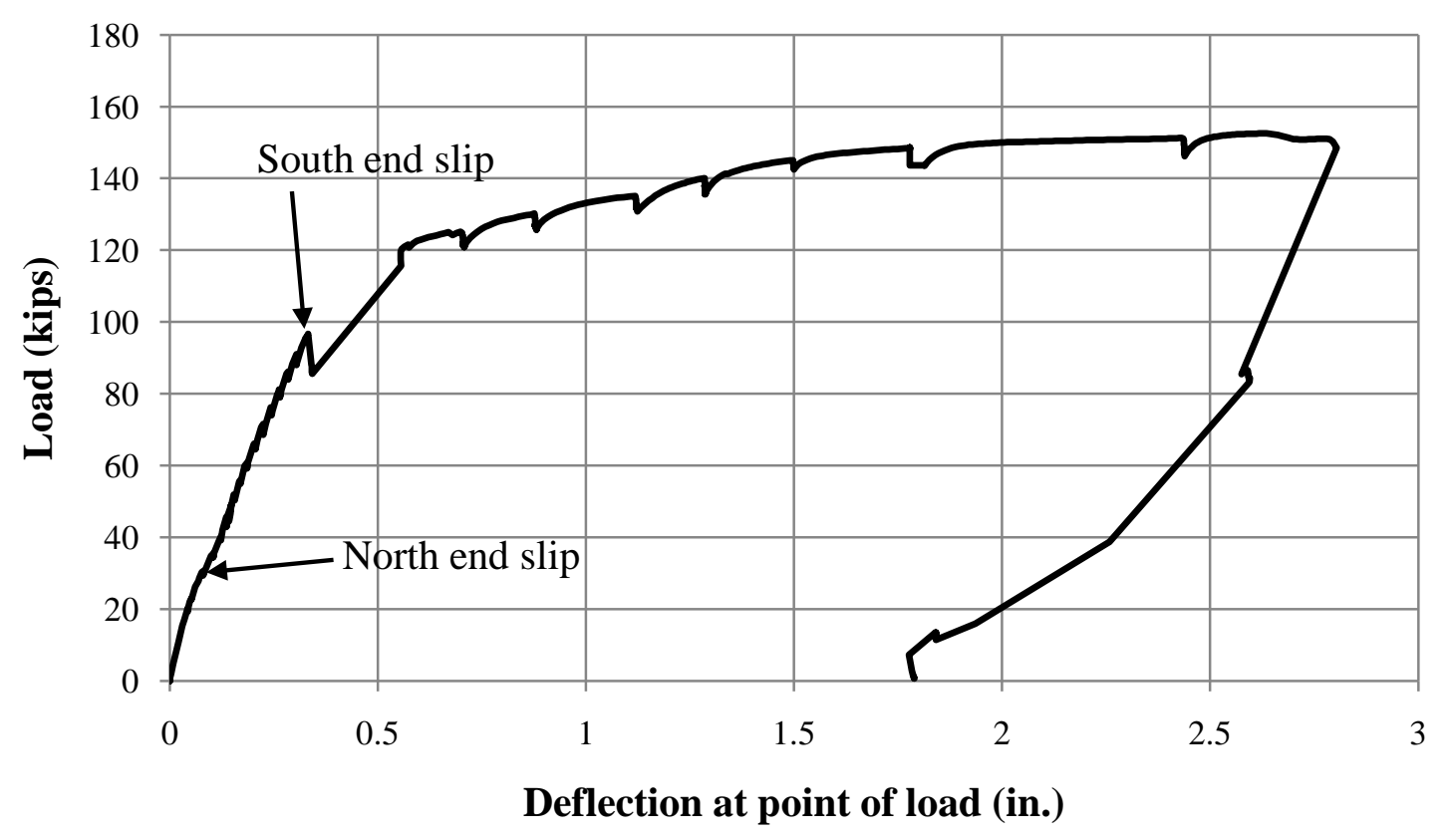

Figure 2.26: Load vs deflection - Specimen 4/6-P, Test 1

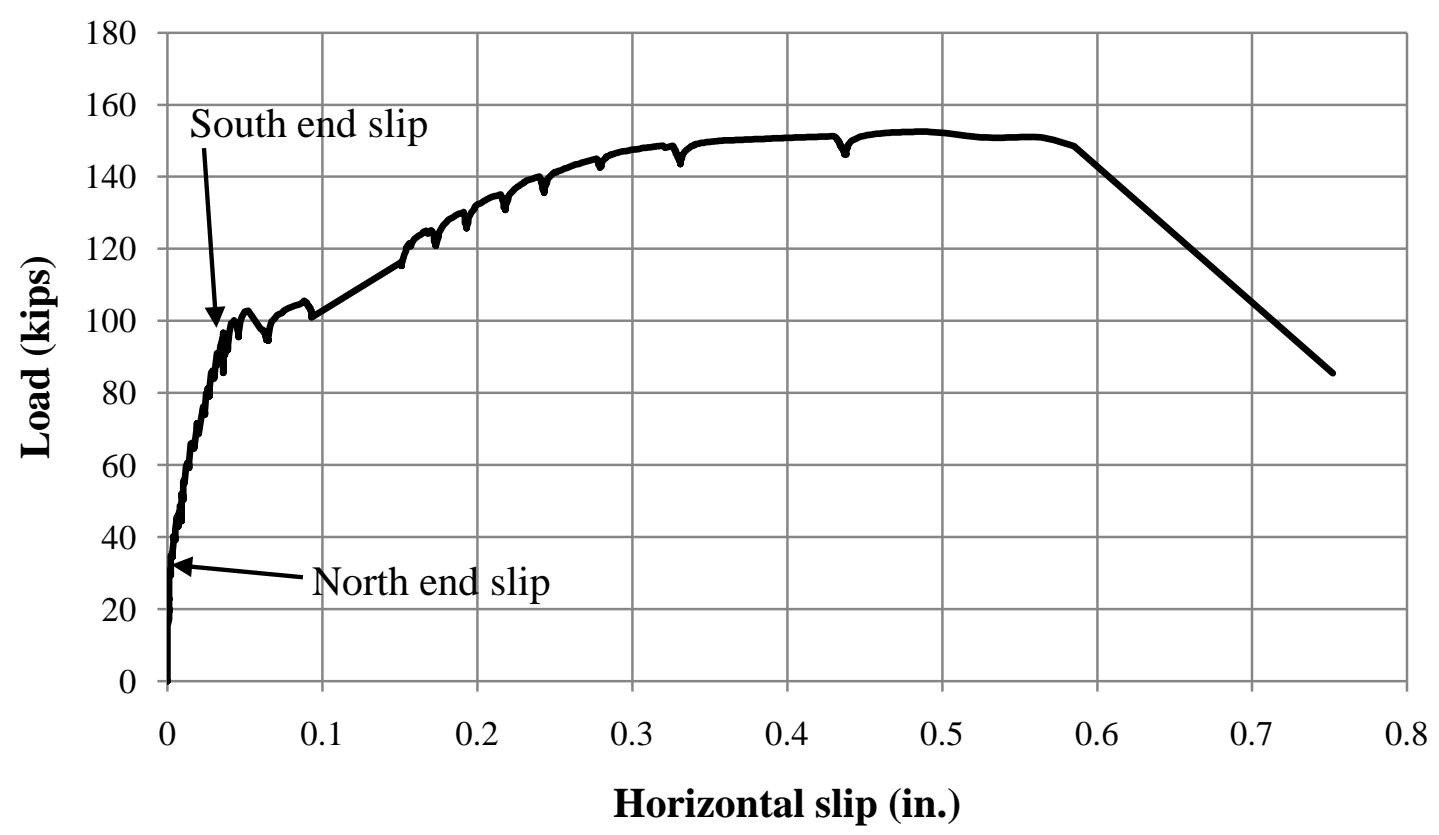

Figure 2.27: North horizontal slip - Specimen 4/6-P, Test 1 


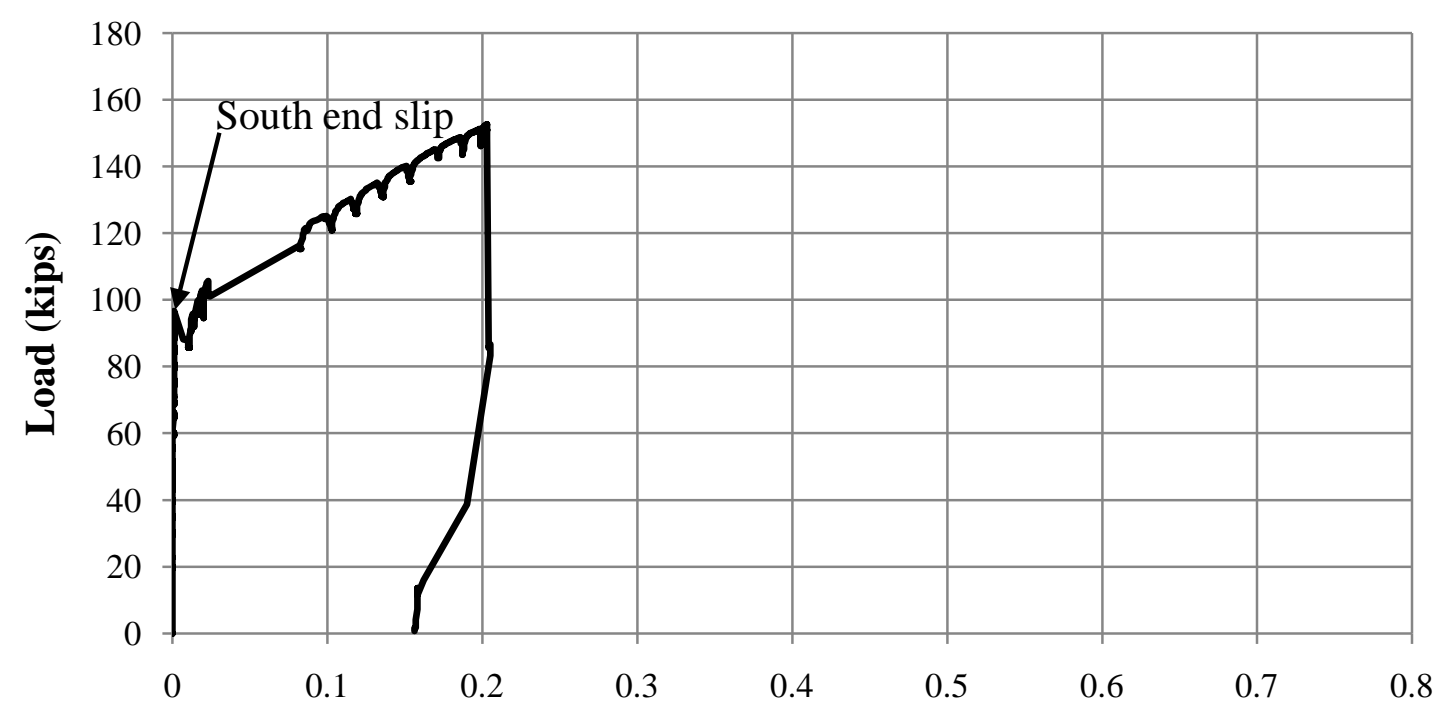

Horizontal slip (in.)

(a) midspan

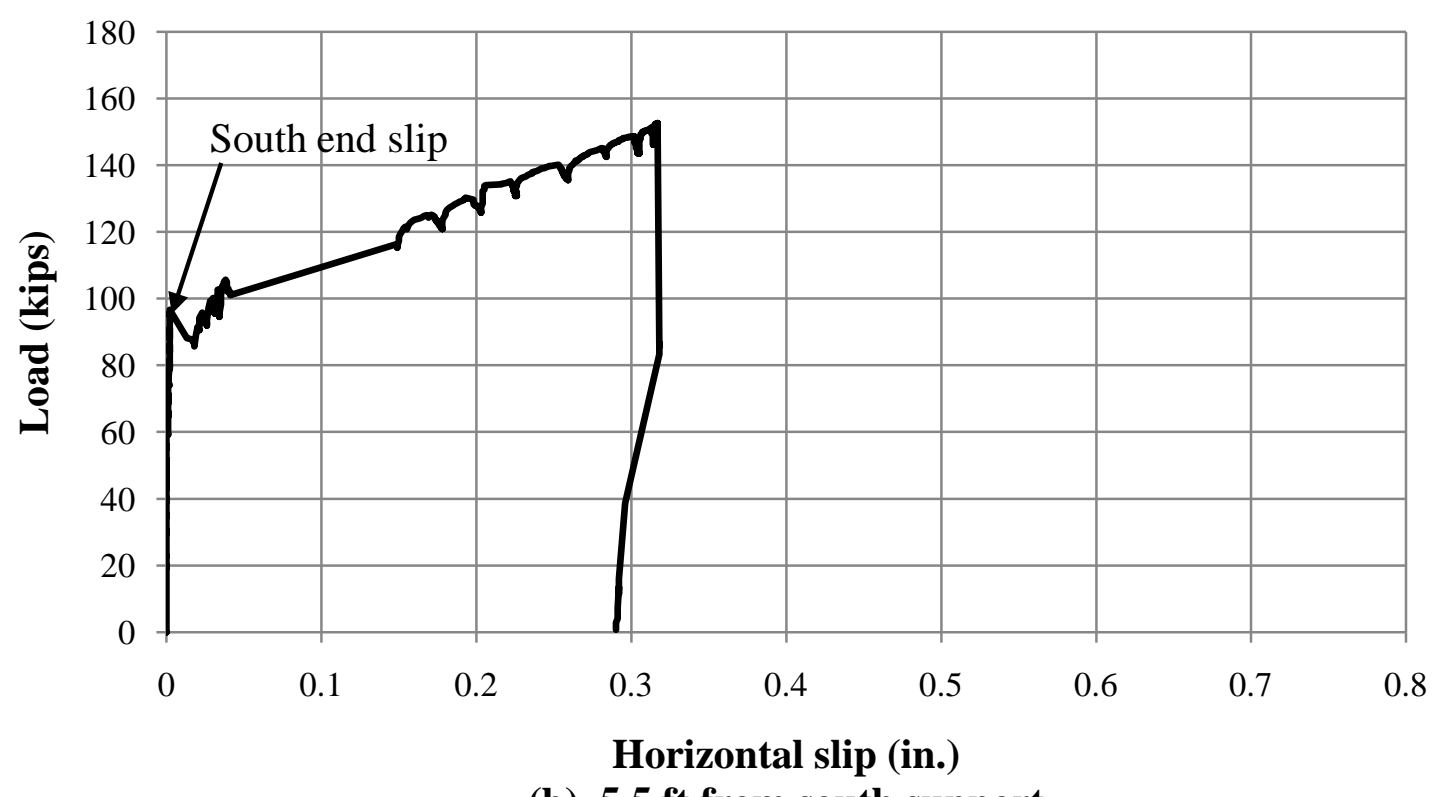

(b) $5.5 \mathrm{ft}$ from south support

Figure 2.28: South horizontal slip - Specimen 4/6-P, Test 1 


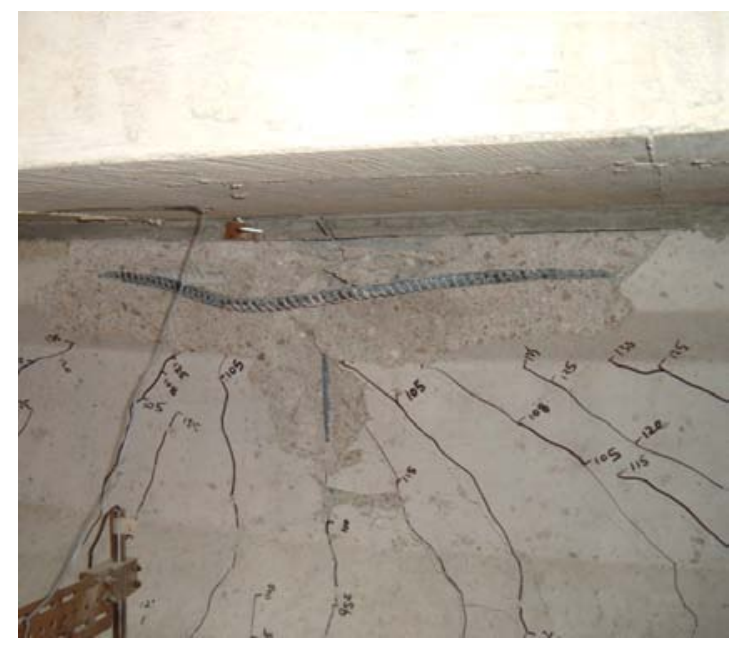

girder compression zone

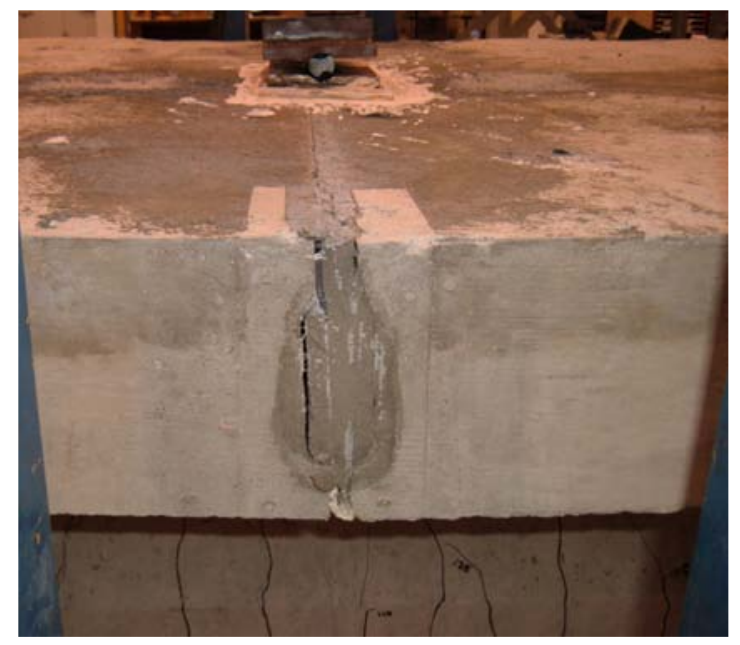

transverse deck joint

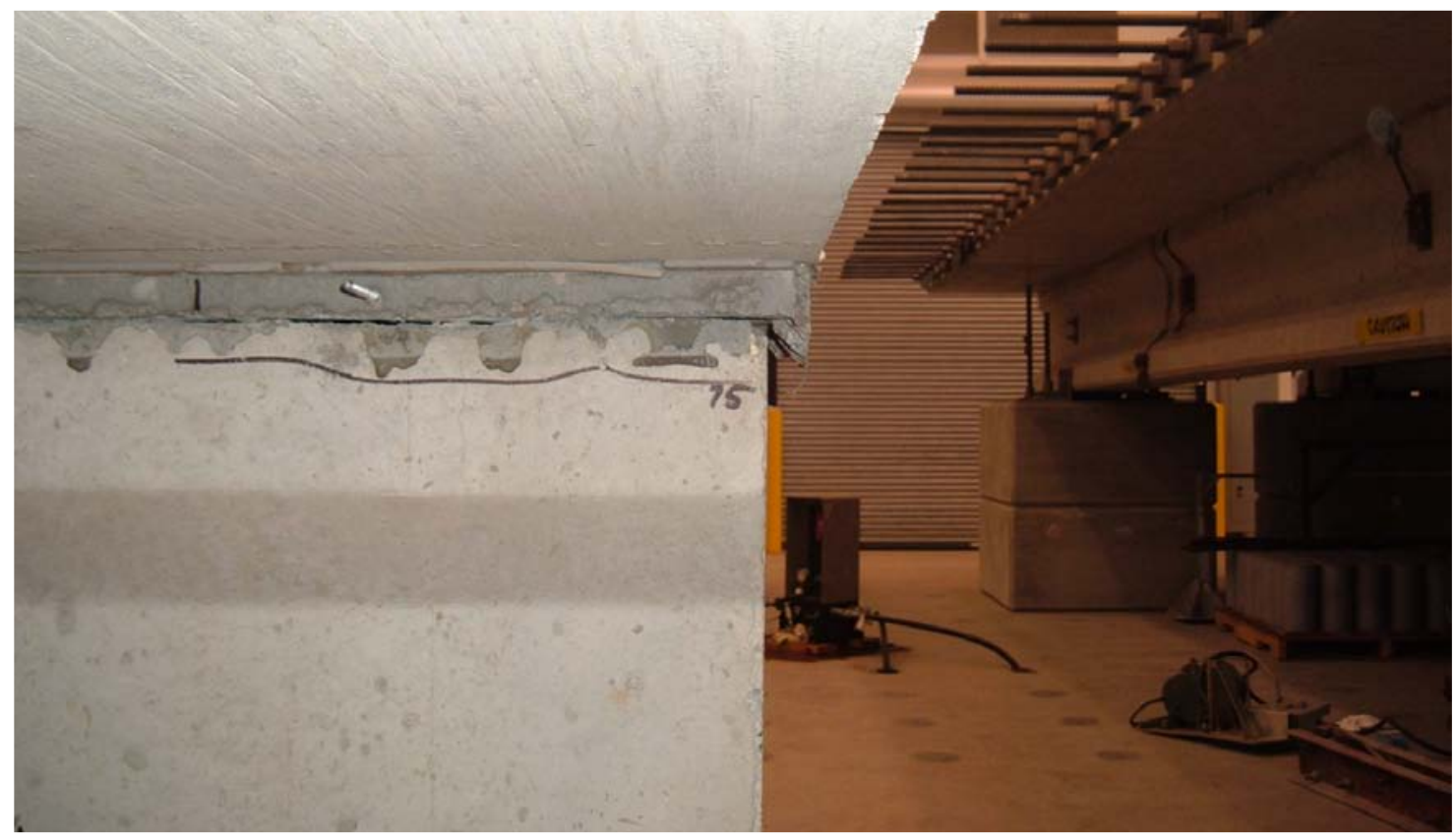

slip at North end of specimen

Figure 2.29: Failure of Specimen 4/6-P, Test 1

\subsubsection{Test 2}

The load-deflection response from Test 2 of Specimen 4/6-P is presented in Figure 2.30. The specimen was a partially composite section because bond failure had previously occurred along the entire span in the first test. This behavior is evident from 
the horizontal slip measured on both the north and south sides of the loading point (Figure 2.31). The starting displacement of each slip measurement (Figure 2.31) is from the residual of Test 1 (Figure 2.28). The specimen was loaded to a maximum load of approximately 189 kips. A maximum measured slip, prior to failure, of 0.7 in. occurred at the south slip gauge. Failure of the specimen occurred at 183 kips and 2.3 in. of deflection at the loading location. Final failure occurred by shear failure of the studs along the south shear span, as shown in Figure 2.32. This failure was immediately followed by flexural failure of the girder due to crushing of the compression zone. No crushing of the deck panels was observed.

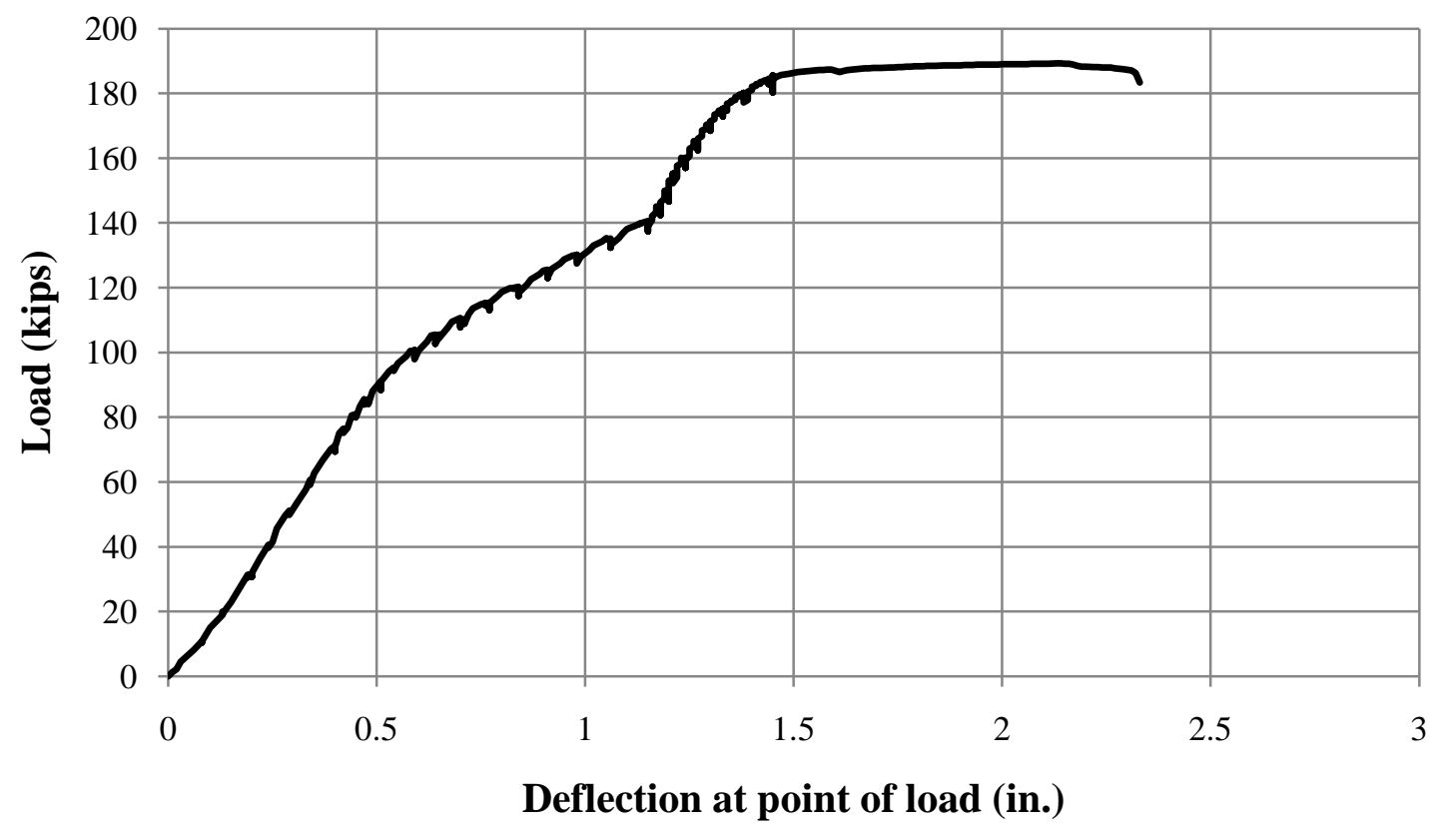

Figure 2.30: Load vs deflection - Specimen 4/6-P, Test 2 


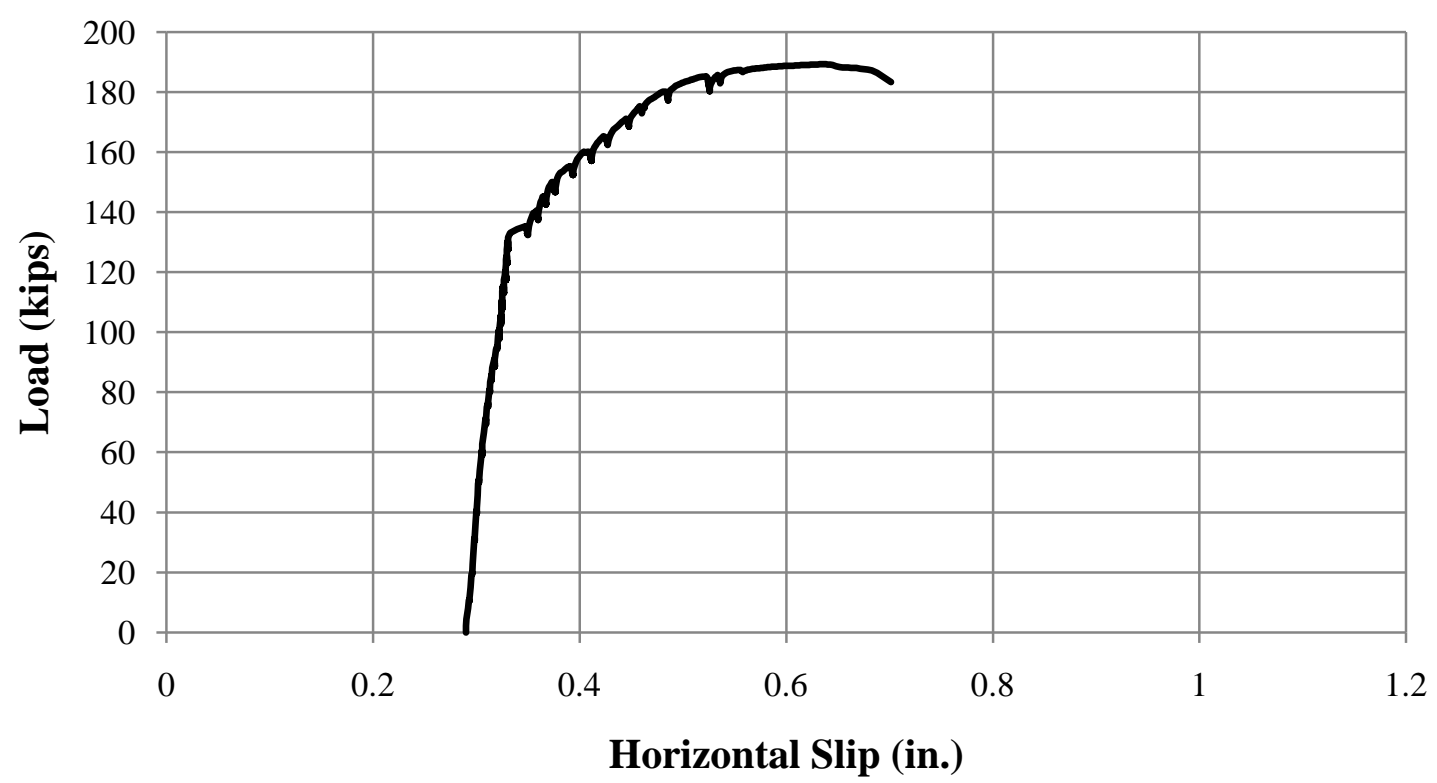

(a) South

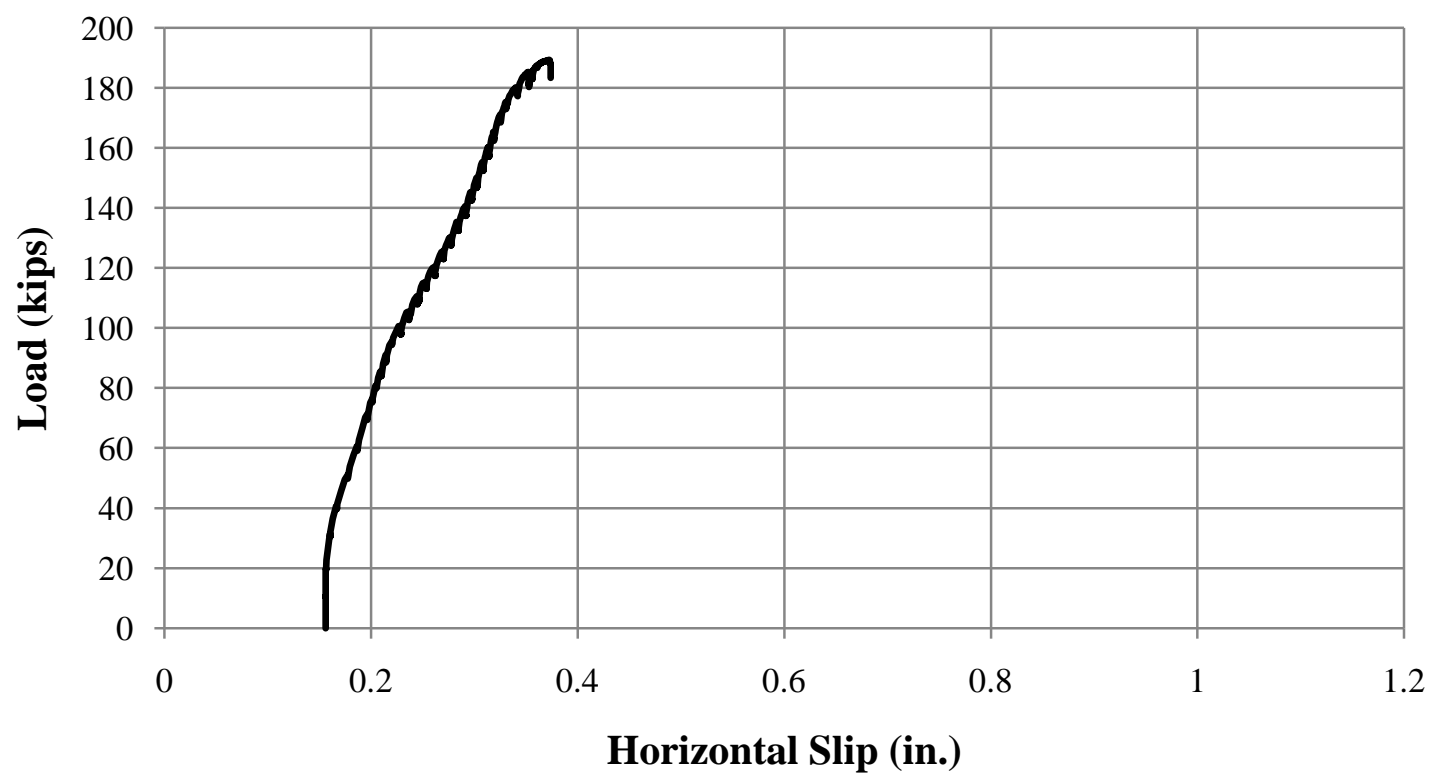

(b) North

Figure 2.31: Horizontal slip - Specimen 4/6-P, Test 2 

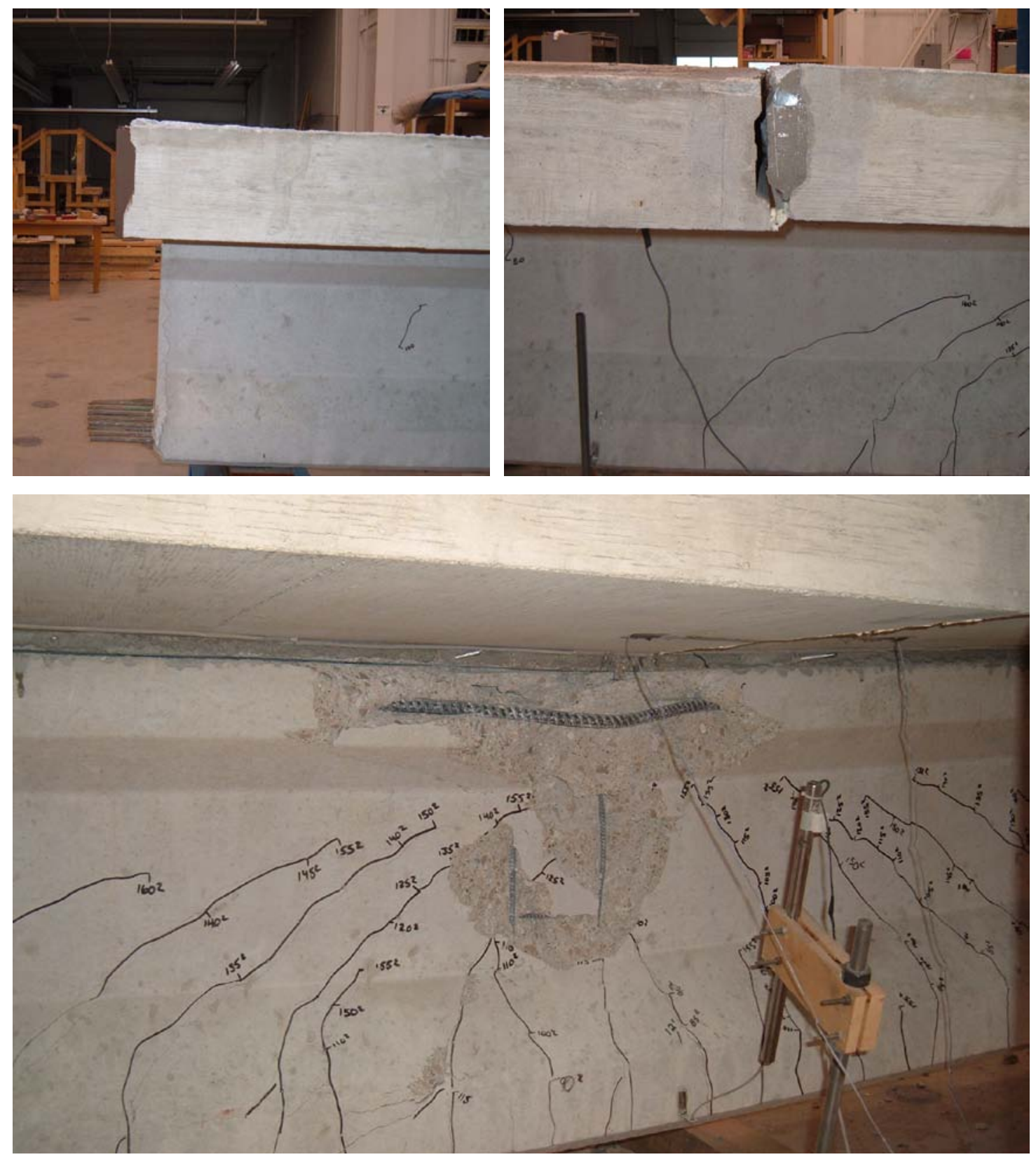

Figure 2.32: Failure of Specimen 4/6-P, Test 2

\subsection{Analysis of Results}

The load-deflection results for each test were analyzed to evaluate the composite response as well as the shear force resisted by the shear studs. A moment-curvature (MC) analysis was performed on the full-composite and girder cross-sections to construct 
an upper bound and lower bound for the response of the specimens. Ritter's parabola, as presented by Hognestad (1951), was used in modeling the stress-strain curve of the concrete compression region. The maximum concrete strain in the extreme compression fiber was assumed to be 0.004. A typical seven wire, low-relaxation strand stress-strain curve provided in the PCI Design Handbook (PCI 2004) was used in modeling the prestressing strand. From MC analysis the compressive force that must be transferred across the horizontal interface of half the span in a full-composite section can be obtained (Figure 2.33).

A MC analysis of the partial-composite section was performed to estimate the shear force at the interface based on the failure load of the test specimens. In determining the MC diagram for a partial-composite section, the MC analysis for the full-composite section was used up until the approximate point at which bond failure of the horizontal interface was observed during testing. Once the section was partially-composite, a value of 0.004 was assumed for $\varepsilon_{\mathrm{c}}$ at the extreme compression fiber of the girder section. Then, a value $A_{s} f_{u}$ was assumed for $V_{h i}$ to start the calculation, where $f_{u}$ was assumed as $90 \mathrm{ksi}$. Once $\varepsilon_{\mathrm{c}}$ and $\mathrm{V}_{\mathrm{hi}}$ were assumed, the procedure presented in Figure 2.34 was followed to determine an ultimate moment capacity and associated load. The calculated load was compared to the ultimate load obtained during testing. If the calculated load capacity differed by more than \pm 1 kip, $V_{\text {hi }}$ was adjusted and the ultimate load capacity was recalculated. Using the procedure presented in Figure 2.34, the force transferred across the horizontal interface in a partial-composite section can be obtained. Once $V_{h i}$ is determined, it can be used to compute the moment capacity of the partial-composite section at lower $\varepsilon_{\mathrm{c}}$ values to construct the remaining MC diagram starting from the cracking moment of the full-composite section to $\varepsilon_{\mathrm{c}}=0.004$. Using a single value of $\mathrm{V}_{\mathrm{hi}}$ for lower $\varepsilon_{\mathrm{c}}$ values assumes that all studs are yielded once the section is partiallycomposite. This assumption is in agreement with strain gauge data obtained during testing. The analysis results for each specimen are presented in the following sections.

The partial-composite analysis described can also be used to determine the area of steel required across the shear plane to develop the full-composite capacity of the section. The area can be determined by computing the full-composite capacity and then 
conducting a partial-composite analysis; varying $\mathrm{V}_{\mathrm{hi}}$ until the full-composite capacity is obtained. Once $\mathrm{V}_{\mathrm{hi}}$ is determined, the area of steel can be calculated by dividing $\mathrm{V}_{\mathrm{hi}}$ by $\mathrm{f}_{\mathrm{u}}$.
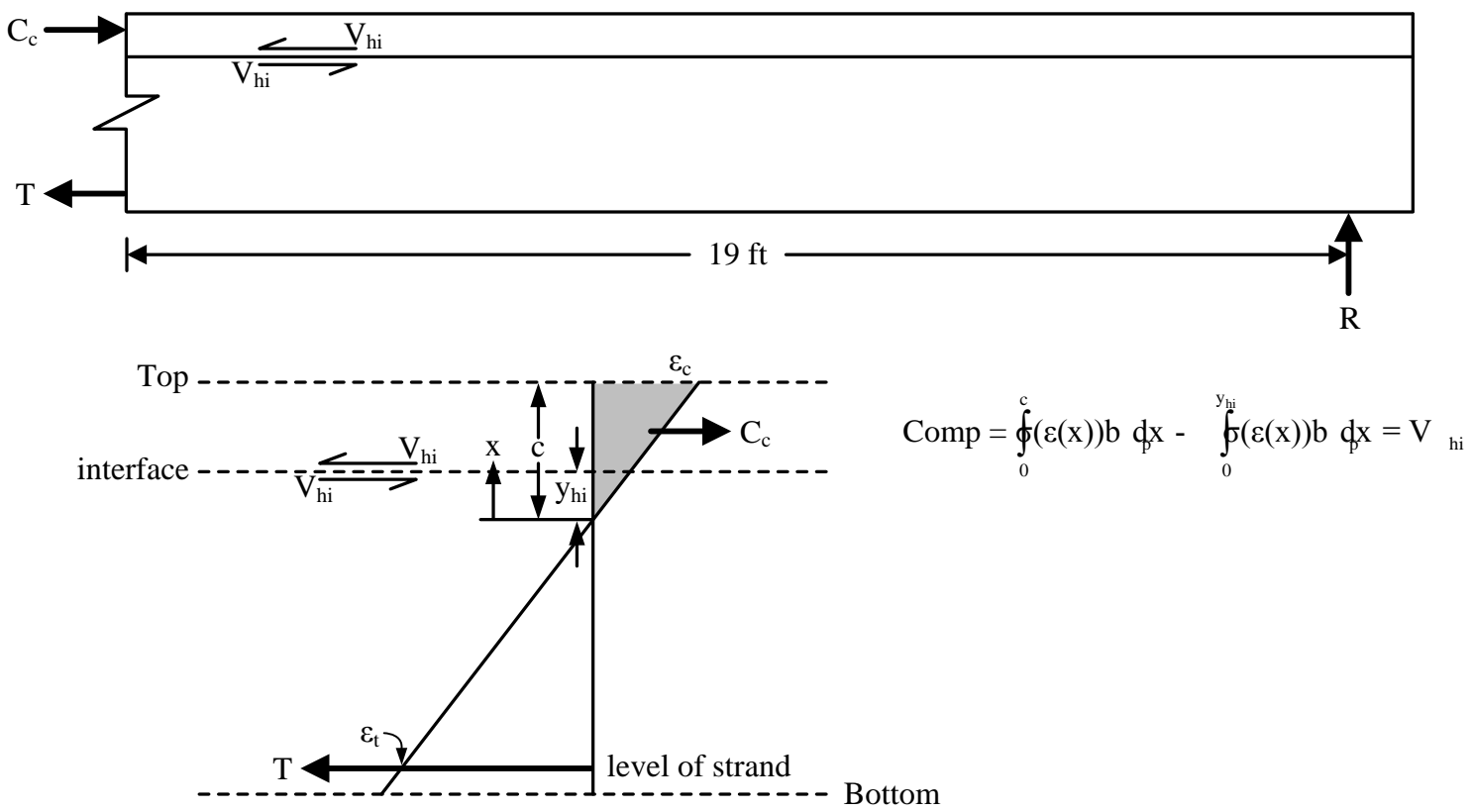

Strain Distribution

Figure 2.33: Determining shear force at horizontal interface, full-composite 


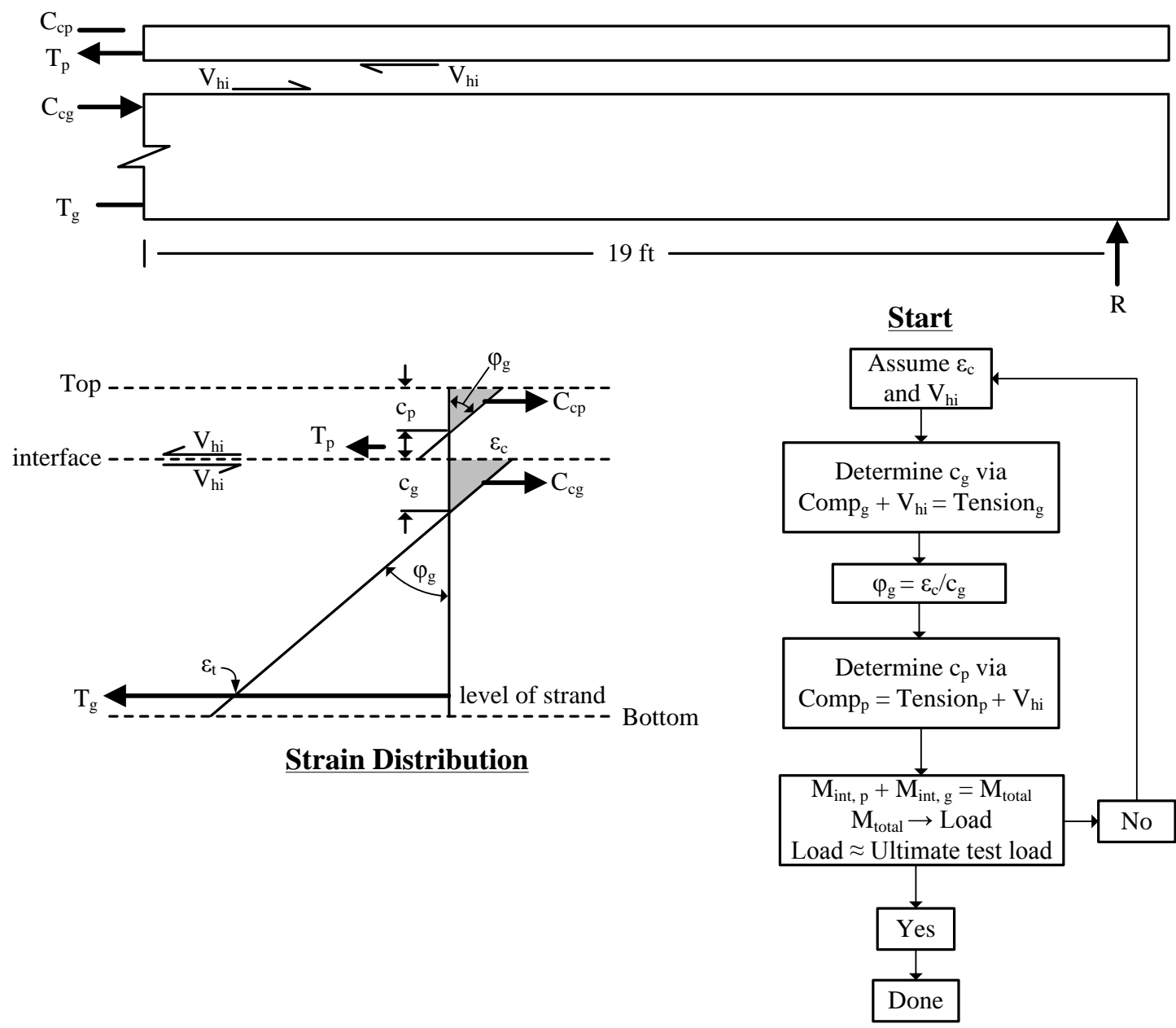

Figure 2.34: Determining shear force at horizontal interface, partial-composite

\subsubsection{Specimen 4-C}

The load-deflection results were compared with the calculated load-deflection paths of the full-composite, partial-composite, and girder sections (Figure 2.35). As evident, the specimen did not reach the calculated full-composite section capacity of 140 kips. The maximum load applied to the specimen was 127.6 kips, approximately $92 \%$ of the ultimate capacity. The specimen followed the analytical load-deflection path until bond failure in the south end of the specimen at which point the specimen behaved as a partial-composite section. As expected, the load-deflection behavior of the partialcomposite section tracks within the bounds formed by the full-composite and girder 
section theoretical load-deflection paths. It is evident that the assumed strain capacity of 0.004 is conservative, as the theoretical curves discontinue at this value.

The partial-composite load path is also presented and was determined using the procedure described in the previous section. The force transferred at the horizontal interface $\left(\mathrm{V}_{\mathrm{hi}}\right)$ was initially taken as 180 kips and was incrementally increased to 285 kips which resulted in an associated load capacity of 128 kips. There were 10 studs in each half span, therefore, each stud is computed to resist 28.5 kips assuming all studs have yielded and are contributing equally.

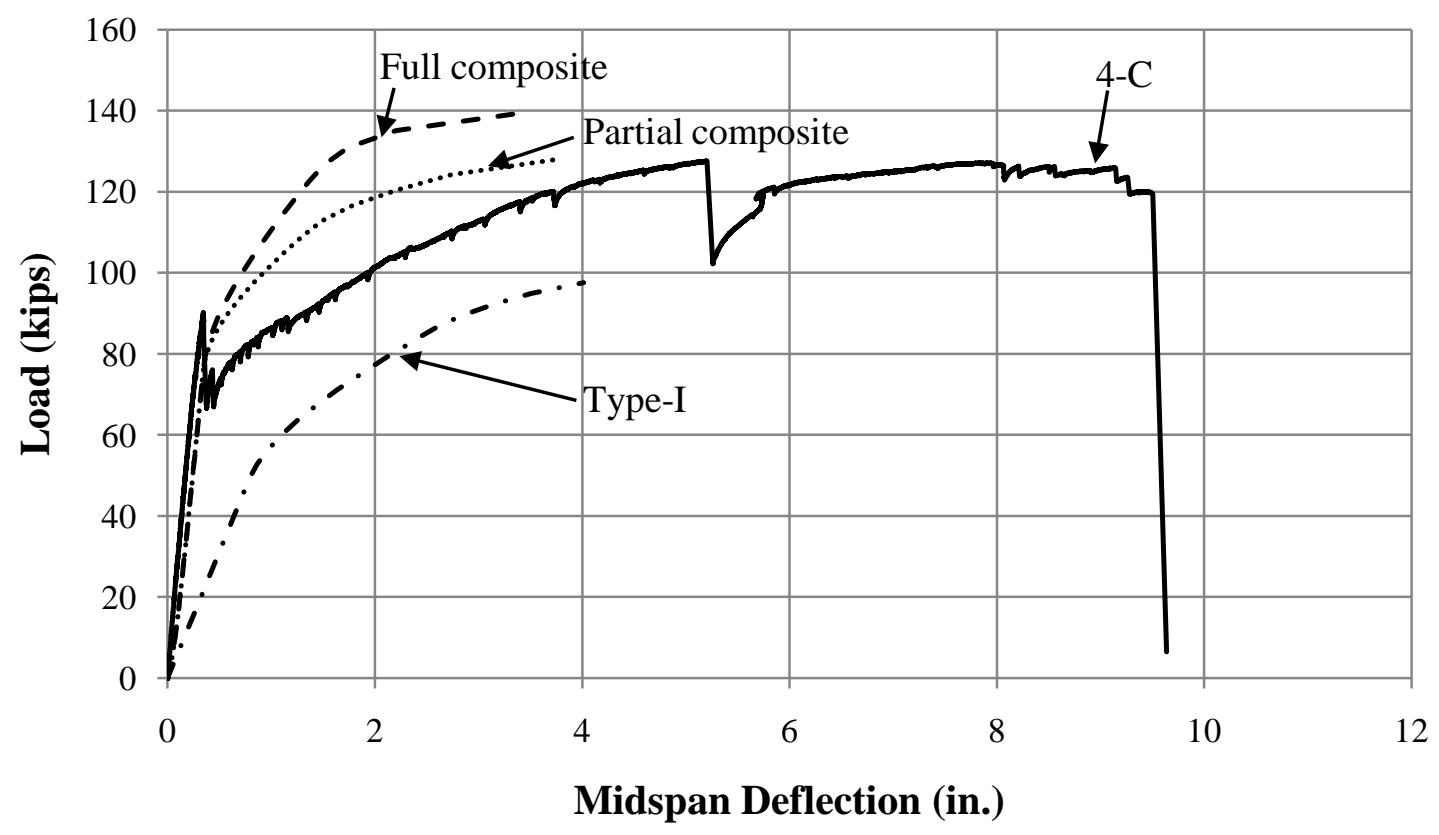

Figure 2.35: Specimen 4-C compared with computed load-deflection paths

\subsubsection{Specimen 6-C}

The load-deflection results were compared with the calculated load-deflection paths of the full-composite, partial-composite, and girder sections (Figure 2.36). As evident, the specimen reached the calculated full-composite section capacity of 140 kips. The maximum load applied to the specimen was 142.2 kips, approximately $102 \%$ of the calculated ultimate capacity. The specimen behavior followed the analytical results 
throughout the test. This result was unexpected since the specimen was partial-composite once bond failure occurred in the north end of the specimen. However, from MC analysis of the partial-composite section, it is evident that the ultimate load capacity of the full-composite section can be achieved. The required horizontal shear capacity at the interface of the partial-composite section is 380 kips to obtain an ultimate load equal to that of the specimen. There were 10 studs in each half span, therefore, 380 kips equates to $38 \mathrm{kips} / \mathrm{stud}$ assuming the studs have yielded and contribute equally. The amount of horizontal force required to reach the full-composite load of 140 kips was 365 kips which equates to 36.5 kips/stud.

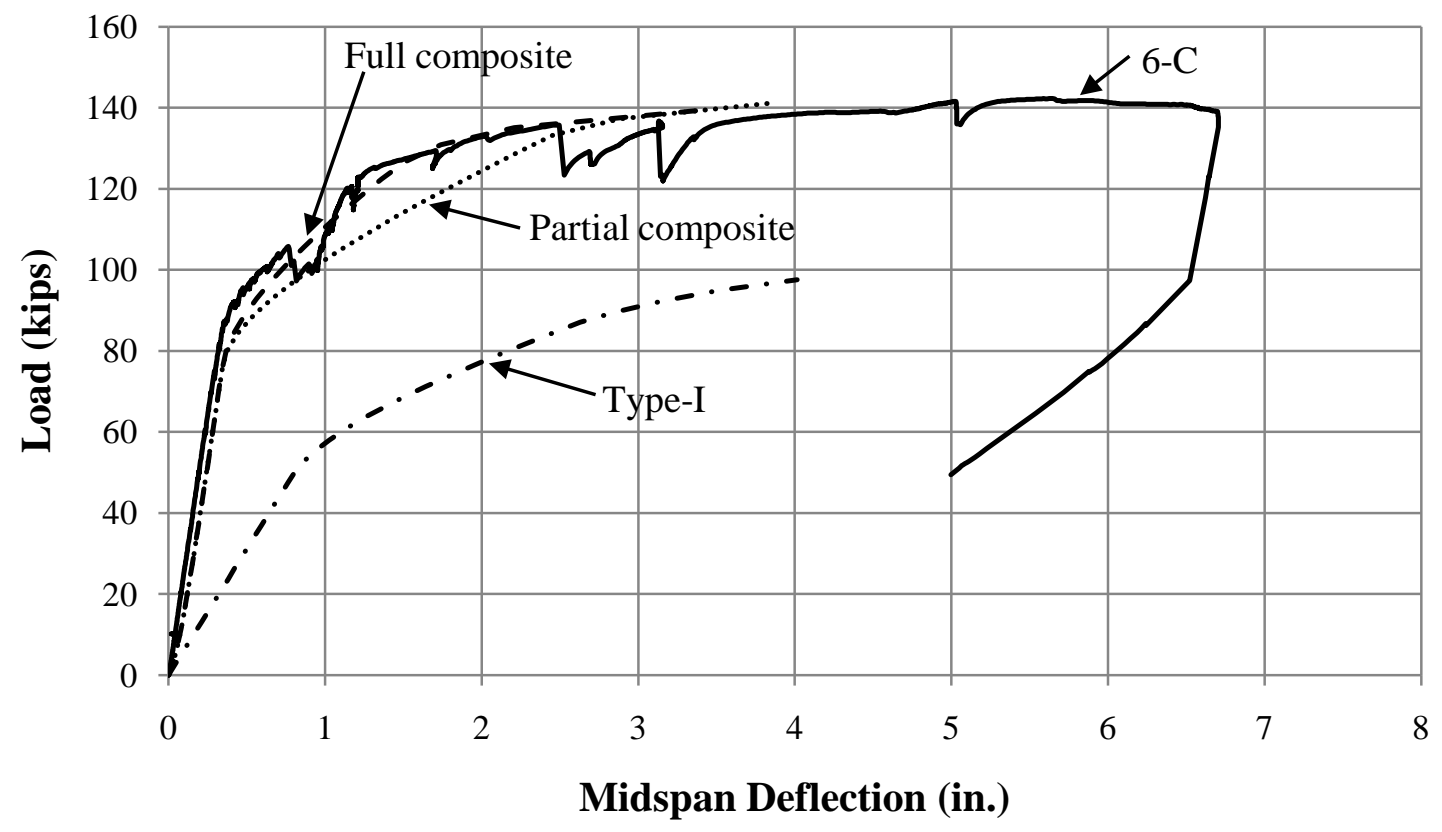

Figure 2.36: Specimen 6-C compared with computed load-deflection paths

\subsubsection{Specimen 4/6-P, Test 1 (\#6 studs)}

The load-deflection results were compared with the calculated load-deflection paths of the full-composite, partial-composite, and girder sections (Figure 2.37). As evident, the specimen did not reach the calculated full-composite section capacity of 170 kips. The maximum load applied to the specimen was 152.6 kips, approximately $90 \%$ of 
the ultimate capacity. The specimen followed the analytical load-deflection path until bond failure in the north end of the specimen (30 kips) at which point the specimen behaved as a partial-composite section. As expected, the load-deflection behavior of the partial-composite section tracks within the bounds formed by the full-composite and girder section load-deflection paths. The calculated load-deflection path of the partialcomposite section is followed by the measured response up to a deflection of approximately $0.6 \mathrm{in}$. at which point the test response began to deviate by more than $10 \%$. The result of the partial-composite MC analysis indicate that the force transferred at the horizontal interface $\left(\mathrm{V}_{\mathrm{hi}}\right)$ was 275 kips which gave an associated load capacity of 152 kips. There were 6 studs in the $11 \mathrm{ft}$ shear span, therefore, each stud carried 45.8 kips assuming all studs have yielded and are contributing equally. This force is similar in magnitude to the $38 \mathrm{kips} / \mathrm{stud}$ from Specimen 6-C. The amount of horizontal force required to reach the full-composite load of 170 kips was 365 kips which equates to 60.8 kips/stud. It should be noted that calculated force/stud does not represent the ultimate strength of the studs because the \#6 studs did not fail in either test. Therefore, these forces should be considered lower bounds.

As discussed previously, the shear studs in Specimen 4/6-P were post-installed using epoxy. The shear studs showed no indication of being deficient to the cast-in-place studs. 


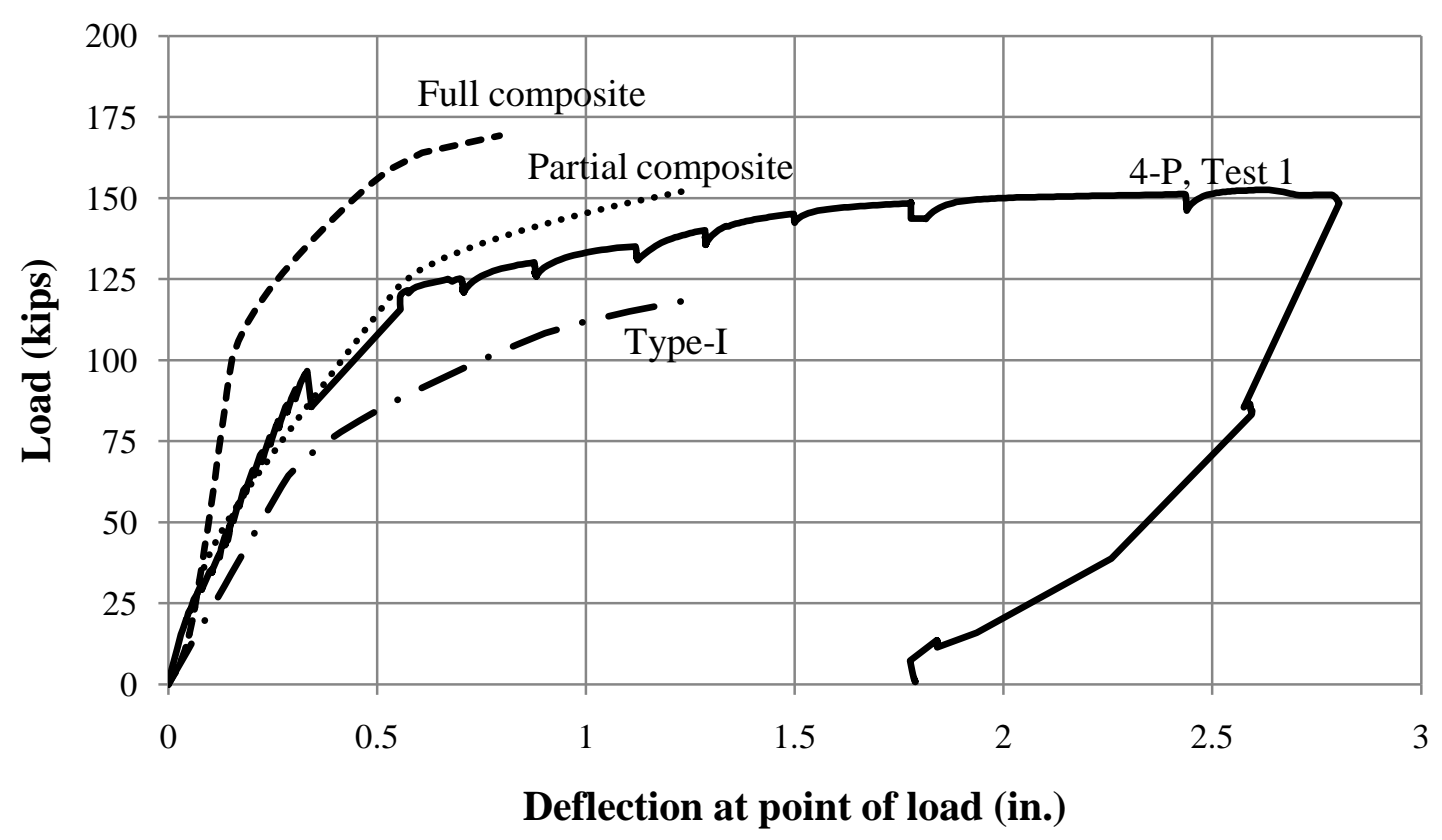

Figure 2.37: Specimen 4/6-P, Test 1, compared with computed load deflection paths

\subsubsection{Specimen 4/6-P, Test 2 (\#4 studs)}

The load-deflection results were compared with the calculated load-deflection paths of the full-composite, partial-composite, girder, and cracked girder sections (Figure 2.38). As evident, the specimen did not reach the calculated full-composite section capacity of 240 kips. The maximum load applied to the specimen was 189.2 kips, approximately $79 \%$ of the ultimate capacity. The specimen did not follow the analytical load-deflection because it was partially-composite and the section was cracked from the previous test. Initially, the load-deflection behavior of the specimen tracked below both the full-composite and girder section load-deflection paths. However, it does track above the cracked girder section load-deflection path, and prior to failure, the specimen maintained load between the full-composite and girder section theoretical loads.

The cracked girder load-deflection path incorporates the effects of cracking and plastic elongation of the strand from the previous loading. The maximum residual strain measurement, after unloading, of $1690 \mu \varepsilon$ from strain gauges installed on the strand was used to estimate loss of prestress due to plastic elongation of the strand. A loss in 
prestress of $48.2 \mathrm{ksi}$ was subtracted from the initial prestress force of $153.4 \mathrm{ksi}$. The resulting value of $105.2 \mathrm{ksi}$ was used in the MC analysis of the cracked section.

The partial-composite load path is also presented and was determined using the procedure described in Section 2.7. The force transferred at the horizontal interface $\left(\mathrm{V}_{\mathrm{hi}}\right)$ was initially taken as 108 kips and was incrementally increased to 145 kips which resulted in an associated load capacity of 189.4 kips, similar to the maximum load applied to the specimen (189.2 kips). There were 6 studs in the $11 \mathrm{ft}$ shear span, therefore, each stud carried 24.2 kips assuming all studs have yielded and are contributing equally. This value is similar to the $28.5 \mathrm{kips} / \mathrm{stud}$ from Specimen 4-C. However, if the developed strength per stud in Specimens 4-C and 4/6-P are normalized by the ratio of $\mathrm{f}_{\mathrm{u}}$ of the studs (107 ksi for 4-C and $95 \mathrm{ksi}$ for 4/6-P (\#4 studs)), the difference in developed yield strength is reduced from 4.3 kips to 1.1 kips. It should be noted that in both tests, failure of the \#4 studs occurred. These results show excellent correlation in the forces carried.

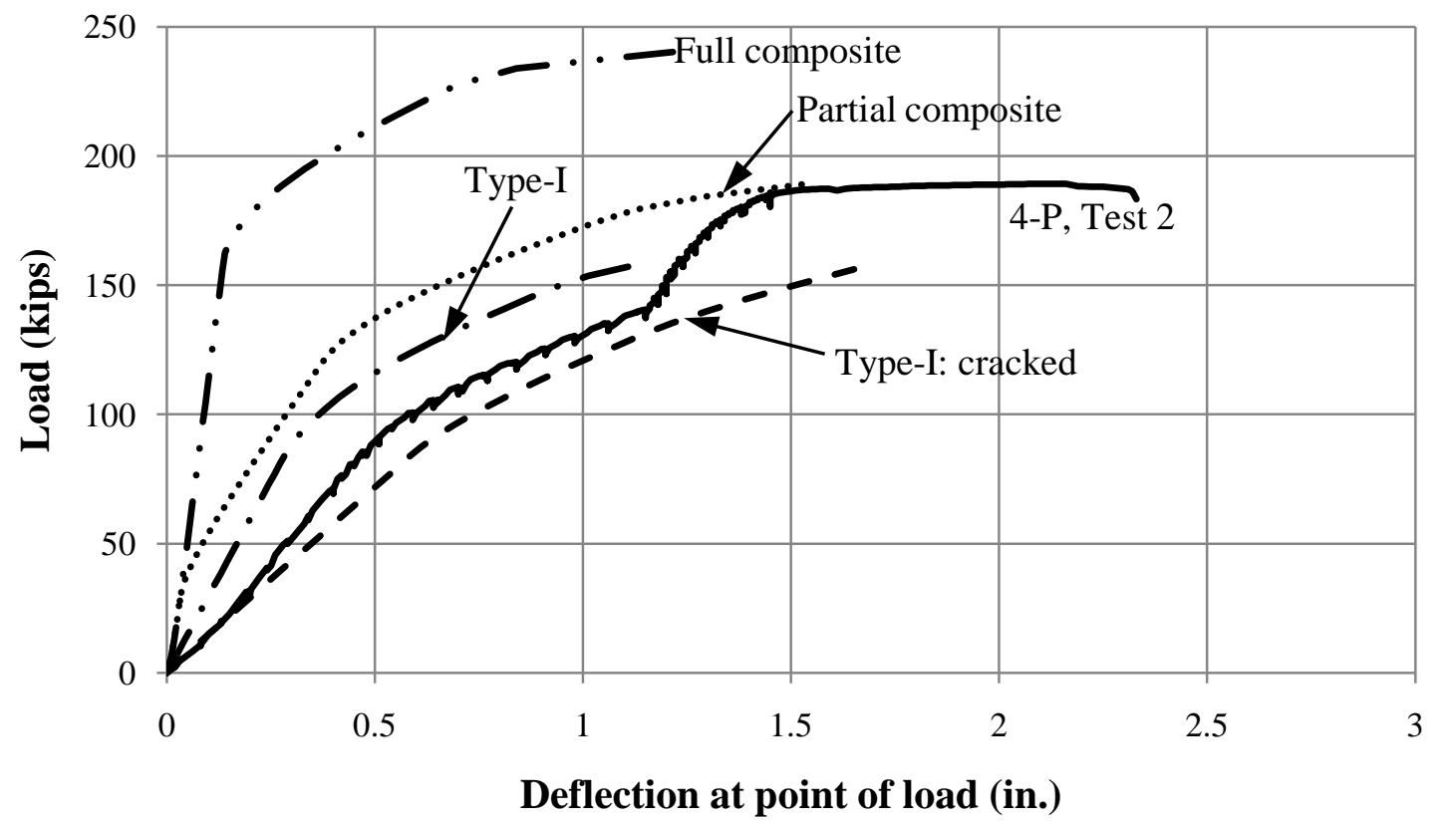

Figure 2.38: Specimen 4-P, Test 2, compared with computed load-deflection paths 


\subsubsection{Design Equations}

Both AASHTO and ACI provide design equations regarding transfer of shear force across a shear plane with reinforcement perpendicular to the shear plane; referred to as the shear-friction design method. The design equations from AASHTO (2007) and ACI (2008) are presented as Equations (2.1) and (2.2), respectively. The shear friction equation presented in ACI (2008) is similar to that of AASHTO (2007); however, the $\left(\mathrm{cA}_{\mathrm{cv}}\right)$ term is omitted from the ACI equation. It should be noted that considerably different estimates of shear strength are obtained because the $\left(\mathrm{cA}_{\mathrm{cv}}\right)$ term of the AASHTO expression contributes more than 129 kips to $\mathrm{V}_{\mathrm{ni}}$.

In computing the capacity of the horizontal interface using Equations (2.1) and (2.2), the magnitude of $\mathrm{P}_{c}$ was determined from the panel dead weight along the length of girder being considered. The term $\mathrm{A}_{\mathrm{cv}}$ was determined by multiplying the width of the haunch (12 in.) by the length from the loading location to the closest girder end. The results from Equations (2.1) and (2.2) applied to this test series are compared with values obtained from the partial-composite MC analysis and are presented in Table 2.7.

$$
\begin{gathered}
\text { AASHTO: } V_{n i}=c A_{c v}+\mu\left(A_{v f} f_{y}+P_{c}\right) \\
\text { ACI: } V_{n i}=\left(A_{v f} f_{y}+P_{c}\right) \mu
\end{gathered}
$$

where:

$$
\begin{aligned}
& V_{n i}=\text { nominal shear resistance } \\
& c=\text { cohesion factor }(\mathrm{ksi})=0.0075 \mathrm{ksi} \\
& A_{c v}=\text { area of concrete section resisting shear transfer (in. }{ }^{2} \text { ) } \\
& \mu=\text { coefficient of friction }=0.6 \\
& \text {-concrete placed against hardened concrete not intentionally roughened } \\
& A_{v f}=\text { area of shear friction reinforcement (in. }{ }^{2} \text { ) } \\
& f_{y}=\text { specified minimum yield strength of reinforcing bars }(\mathrm{ksi})=60 \mathrm{ksi} \\
& P_{c}=\text { Permanent net compressive force (kip) }
\end{aligned}
$$


Sample calculation (half-span):

AASHTO:

$$
\begin{aligned}
& V_{n i}=(0.075 \mathrm{ksi})\left(2,880 \mathrm{in}^{2}\right)+0.6\left(10 * 0.2 \mathrm{in}^{2} * 60 \mathrm{ksi}+12 \mathrm{kips}\right) \\
& V_{n i}=295 \mathrm{kips}
\end{aligned}
$$

ACI:

$$
V_{n i}=\left(10 * 0.2 \text { in. }^{2} * 60 \text { ksi }+12 \text { kips }\right) 0.6=79 \text { kips }
$$

Table 2.7: Calculated horizontal shear force capacities

\begin{tabular}{|c|c|c|c|}
\hline \multirow{2}{*}{ Specimen } & \multicolumn{3}{|c|}{ Total Interface Shear (kips) } \\
\cline { 2 - 4 } & Eq. 2.1 & Eq. 2.2 & Partial-Composite MC \\
\hline 4-C & $295^{*}$ & 79 & $285=28.5 /$ stud $-(10$ studs $)$ \\
\hline $6-C$ & 381 & 165 & $380=38 /$ stud - (10 studs) \\
\hline 4/6-P (Test 1) \#6 studs & 229 & 99 & $275=45.8 /$ stud - (6-studs) \\
\hline 4/6-P (Test 2) \#4 studs & $177^{*}$ & 47 & $145=24.2 /$ stud - (6 studs) \\
\hline
\end{tabular}

*area of shear reinforcement perpendicular to the shear plane is less than that required by AASHTO (2007)

It is evident from the values presented in Table 2.7 that the ACI design equation is conservative. When used within the limits presented by AASHTO (2007), Equation (2.1) is conservative. The expression (Eq. 2.1) matched the results of 6-C and was conservative for 4/6-P (Test 1). For specimen's 4-C and 4/6-P (Test 2) the expression (Eq. 2.1) was unconservative. However, the reinforcement amounts are below those recommended by AASHTO.

\subsection{Conclusions}

Several conclusions were drawn from the results of this series of tests.

1. Once full-composite action was lost due to bond failure at the interface, shear studs across the interface yielded.

2. The ultimate strength of the \#4 studs were approximately 24 kips/stud for $f_{u}$ of $95 \mathrm{ksi}$. This corresponds to a design strength of approximately $1.25 \mathrm{~A}_{\mathrm{v}} \mathrm{f}_{\mathrm{u}}$.

3. Cast in place headed shear studs can be used successfully as a means of connecting precast deck panels to precast, prestressed concrete girders. The level 
of composite action can be varied based on the amount of reinforcement crossing the interface.

4. Post-installed shear studs performed similar to cast in place studs indicating the system could be used successfully in the redecking of existing bridges.

5. The area of steel required to achieve full-composite capacity of the section can be determined using the partial-composite MC analysis described in Section 2.7. 


\section{CHAPTER 3: PANEL-TO-GIRDER CONNECTION}

\subsection{Introduction}

The objective of the second phase of the research program was to develop a new connection between the precast deck panels and precast, prestressed girders. As previously discussed, the focus of the system is to eliminate penetrations of the deck panels. To evaluate the behavior and strength of the new detail, interface shear tests will be conducted. The New England System detail will also be tested in the same manner to evaluate and compare the behavior of the details.

\subsection{Specimen Design}

Each of the test specimens consisted of a concrete girder section with a trough and a precast deck panel with a shear stud. Details of the girder and precast panel designs are presented in the following sections.

\subsubsection{Girder section}

Each girder section was selected as rectangular with a width of 20 in. and a height of 32 in. The length of the section was either 12 inches or 24 inches. The 20 in. width of the girder section was chosen because it is the same width as an AASHTO Type IV girder top flange. The 32 in. height of the girder section was controlled by the spacing of anchor points on the strong floor. As the testing program progressed, the reinforcement layout of the girder sections needed modification. Therefore, the specimens were separated into two groups depending on the reinforcement layout used. The rebar layout for Group 1 is shown in Figure 3.1. The $1 \mathrm{ft}$ specimens in Group 1 had only the two outer stirrups shown. The two straight \#5 bars at the mid-height of the specimen were 
not present in the $1 \mathrm{ft}$ specimens. The rebar layout for Group 2 is presented in Figure 3.2. The $1 \mathrm{ft}$ specimens in Group 2 had 4 stirrups spaced at $2.5 \mathrm{in}$. while the $2 \mathrm{ft}$ specimens had 6 stirrups spaced at 3.75 in. The design compressive strength of the girder sections was selected as 8,000 psi to be consistent with that typically used in precast, prestressed girders.

Two specimens designed to test the New England System joint used the Group 1 rebar layout and no trough. The shear studs were designed for an embedment of 14 in. into the girder section. The studs were single headed with the non-headed end embedded in the girder section. The shear stud used in Specimen 2-6000-14-6 was fabricated with a friction welded head. The shear stud used in Specimen 2-6000-14-4 was fabricated with a threaded Lenton terminator. Both types of heads are designed by the manufacturer to develop the full tensile strength of the rebar. 


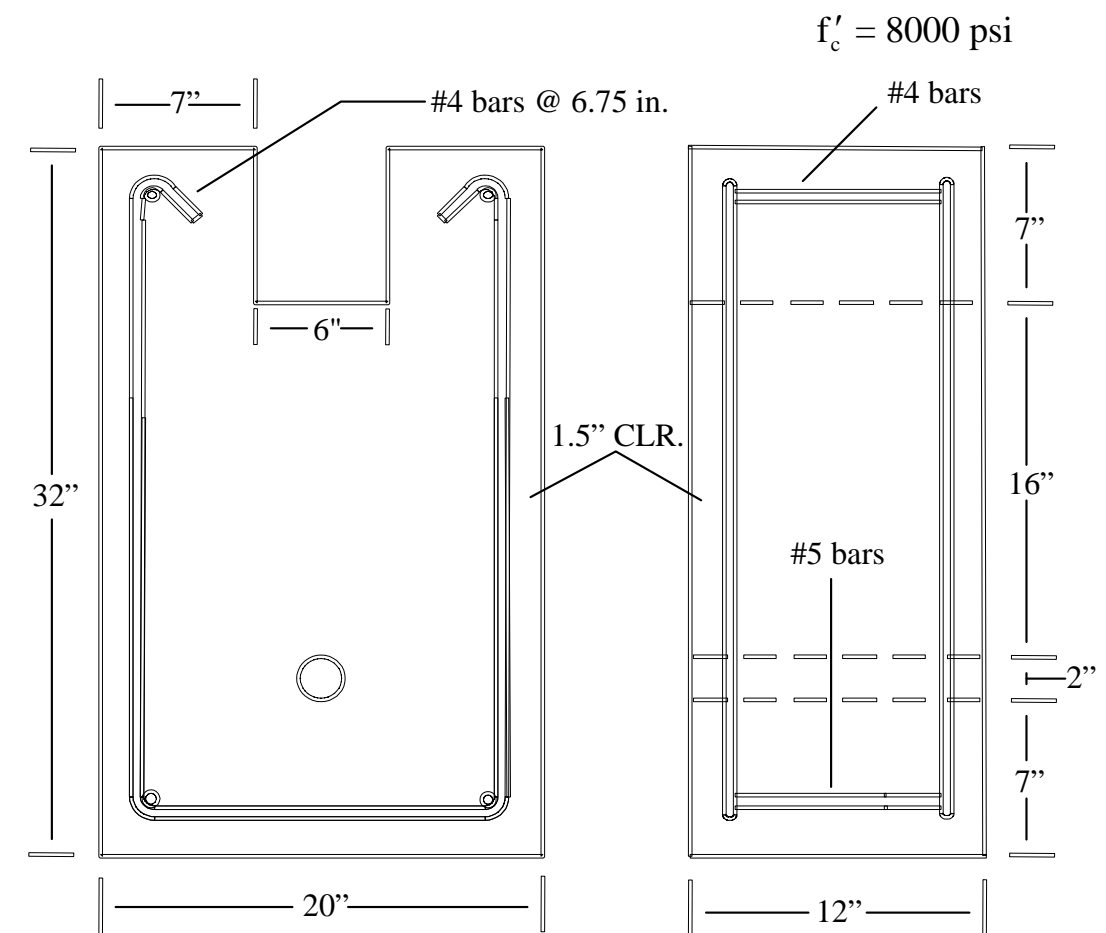

a) $1 \mathrm{ft}$

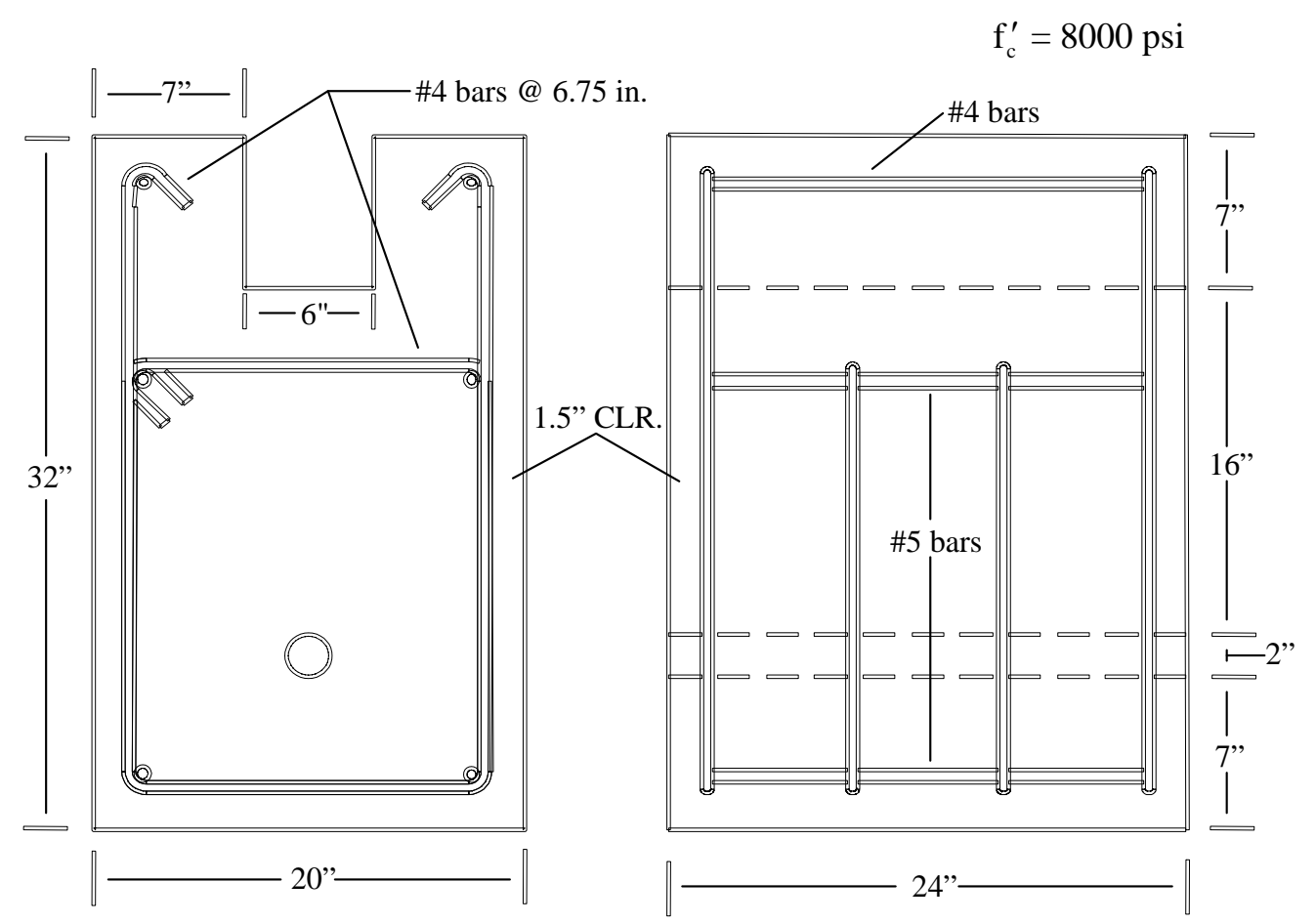

b) $2 \mathrm{ft}$

Figure 3.1: Rebar layout for Group 1 specimens 


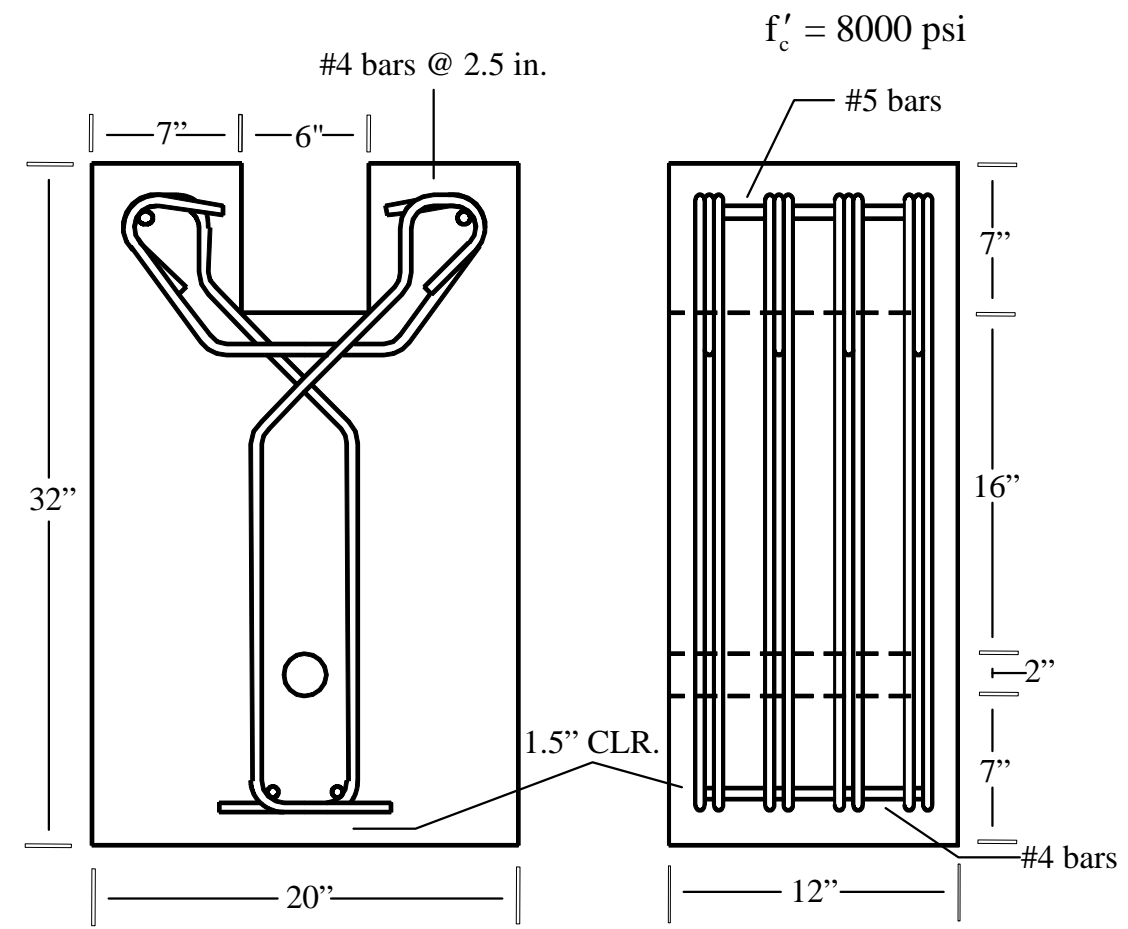

a) $1 \mathrm{ft}$

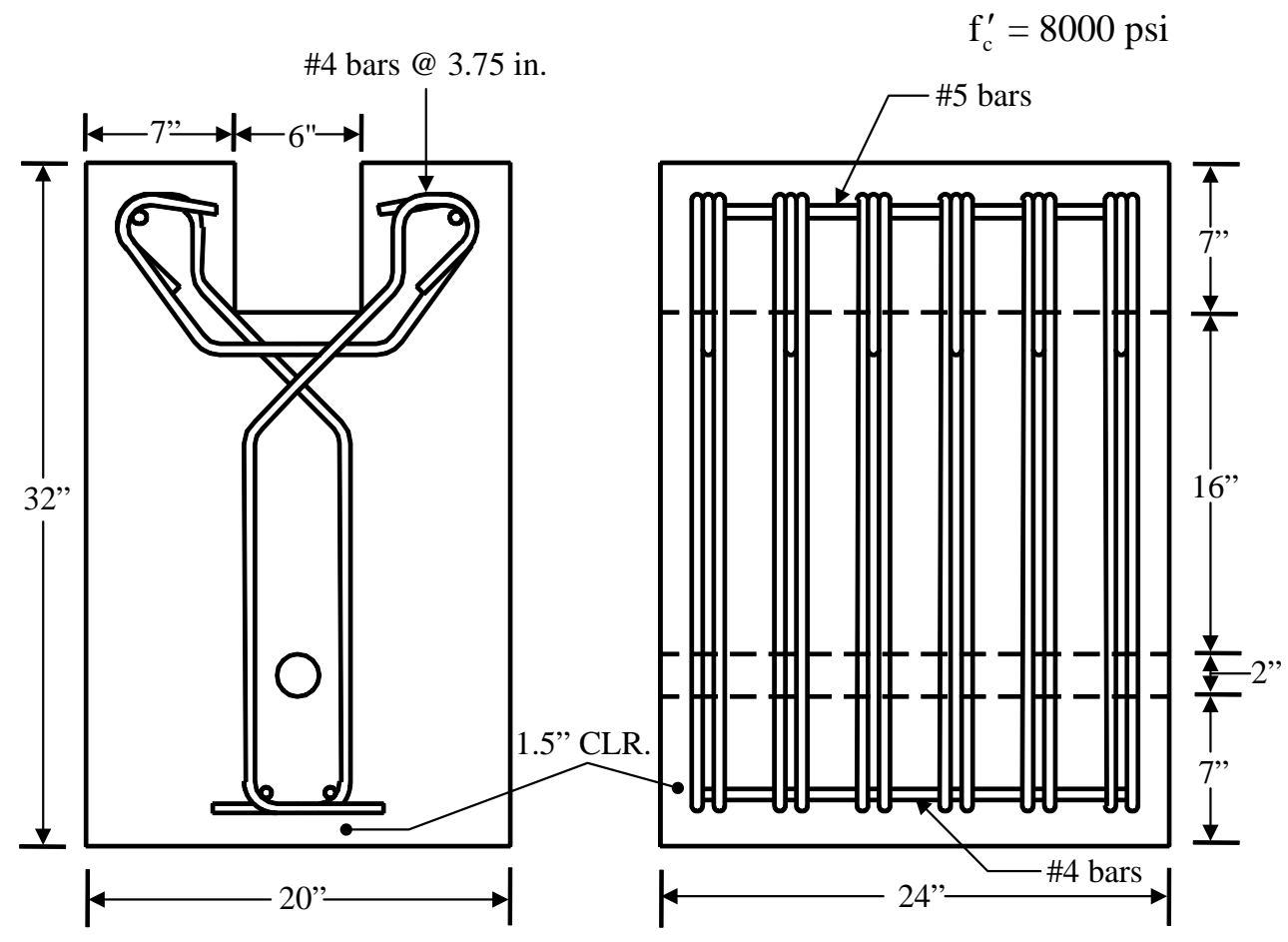

b) 2 ft

Figure 3.2: Rebar layout for Group 2 specimens 
Several of the specimens were designed with shear keys on the sides and bottom of the trough. The purpose of the shear keys is to mechanically transfer forces from the trough material to the girder section without the need for reinforcement crossing the interface. Dimensions of the shear keys located along the trough are presented in Figure 3.3. The shear key geometry selected was based on research by Frosch (1996). The dimensions are proportioned such that overriding of the keys should not be an issue.

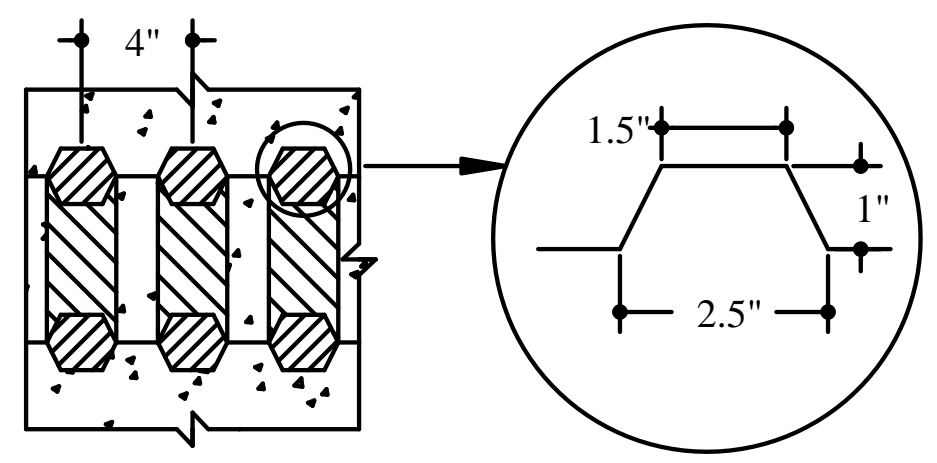

Figure 3.3: Shear key dimensions

\subsubsection{Panel section}

Each deck panel section was designed 20 in. in width and 8 in. in depth. The length of the section was either 14 in. or 26 in. for the $1 \mathrm{ft}$ and $2 \mathrm{ft}$ specimens, respectively. The additional 2 in. of panel length was to accommodate the loading system and allow the panel to slip up to 2 in. in the test setup. Each panel section had a double headed shear stud embedded 5.5 in., with exception of the New England System joint specimens, which had pockets. The double headed studs were purchased from a manufacturer and consisted of mild reinforcement with steel plates friction welded to each end. Each panel was designed with \#4 mild reinforcement. The rebar layout for the panel sections is illustrated in Figure 3.4. The design compressive strength of the panel sections was selected as 4,000 psi to be consistent with that typically used in bridge decks. 


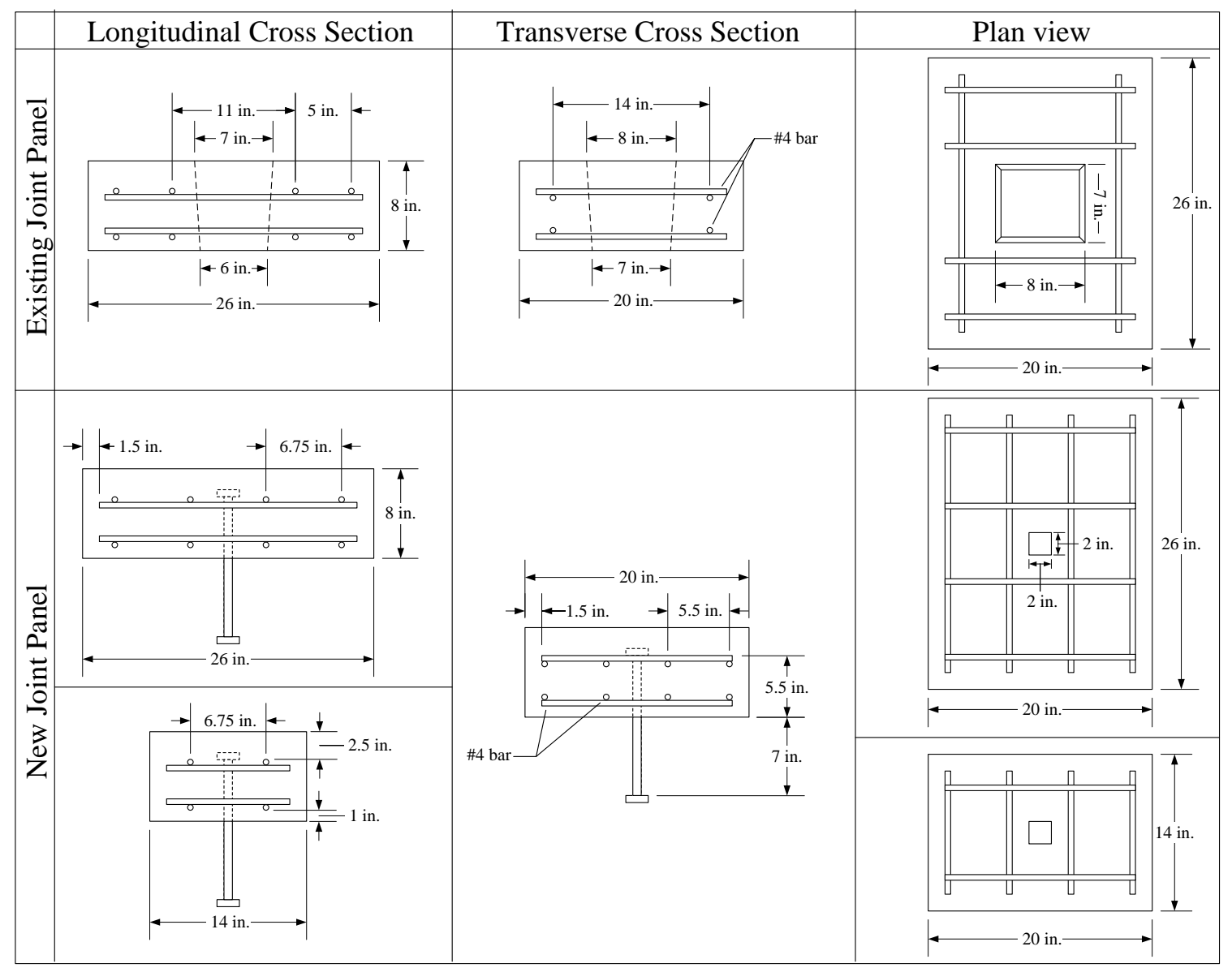

Figure 3.4: Reinforcement layout for panel sections

\subsubsection{Test variables}

The panel-girder tests consisted of a total of 21 specimens. The primary variables include the embedment length of the connector into the girder, compressive strength of the concrete used to fill the trough, stud spacing, stud diameter, and trough detail. For comparison purposes, two specimens were designed using the New England joint connection system. For these specimens, the SCC mix specified in Chapter 2 was selected to fill the pockets allowing comparison with the first phase of testing. The specimens are designated as shown in Figure 3.5. The test matrix of specimens is presented in Table 3.1. 


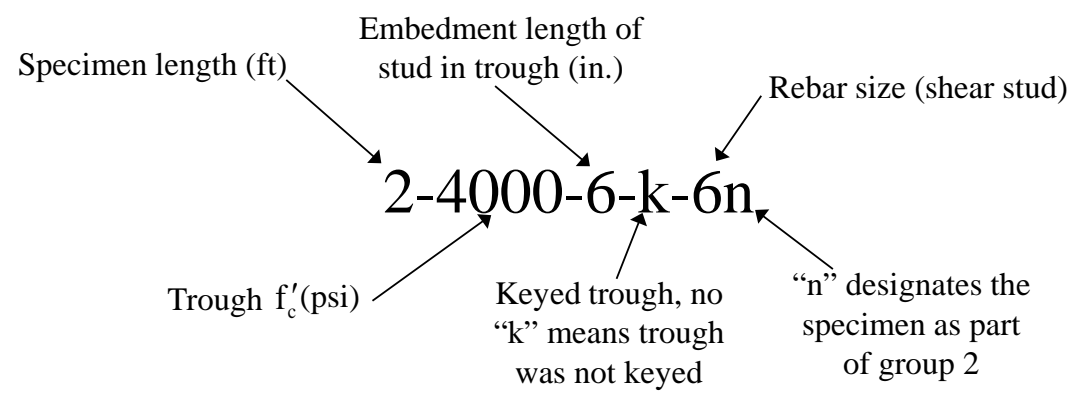

Figure 3.5: Description of specimen ID

Table 3.1: Test matrix

\begin{tabular}{|l|c|c|c|c|c|c|}
\hline \multicolumn{1}{|c|}{ Specimens } & Group & $\begin{array}{c}\text { Spacing } \\
\text { (ft) }\end{array}$ & $\begin{array}{c}\text { Trough } \boldsymbol{f}_{\boldsymbol{c}}^{\prime} \\
\text { (psi) }\end{array}$ & $\begin{array}{c}\text { Embedment } \\
\text { (in.) }\end{array}$ & $\begin{array}{c}\text { Trough } \\
\text { Detail }\end{array}$ & $\begin{array}{c}\text { Stud } \\
\text { Size }\end{array}$ \\
\hline $1-4000-6-4$ & 1 & 1 & 4000 & 6 & no key & $\# 4$ \\
\hline $1-4000-6-k-4$ & 1 & 1 & 4000 & 6 & key & $\# 4$ \\
\hline $1-4000-6-k-6$ & 1 & 1 & 4000 & 6 & key & $\# 6$ \\
\hline $1-4000-8-6$ & 1 & 1 & 4000 & 8 & no key & $\# 6$ \\
\hline $1-4000-8-k-6$ & 1 & 1 & 4000 & 8 & key & $\# 6$ \\
\hline $2-4000-6-4$ & 1 & 2 & 4000 & 6 & no key & $\# 4$ \\
\hline $2-4000-6-6$ & 1 & 2 & 4000 & 6 & no key & $\# 6$ \\
\hline $2-4000-6-k-4$ & 1 & 2 & 4000 & 6 & key & $\# 4$ \\
\hline $2-4000-6-k-6$ & 1 & 2 & 4000 & 6 & key & $\# 6$ \\
\hline $2-4000-8-6$ & 1 & 2 & 4000 & 8 & no key & $\# 6$ \\
\hline $2-4000-8-k-6$ & 1 & 2 & 4000 & 8 & key & $\# 6$ \\
\hline $1-8000-6-4$ & 1 & 1 & 8000 & 6 & no key & $\# 4$ \\
\hline $1-8000-6-k-4$ & 1 & 1 & 8000 & 6 & key & $\# 4$ \\
\hline $1-8000-6-6$ & 1 & 1 & 8000 & 6 & no key & $\# 6$ \\
\hline $1-8000-6-k-6$ & 1 & 1 & 8000 & 6 & key & $\# 6$ \\
\hline $2-6000-14-4$ & 1 & 2 & 6000 & 14 & New England & $\# 4$ \\
\hline $2-6000-14-6$ & 1 & 2 & 6000 & 14 & New England & $\# 6$ \\
\hline $2-8000-6-k-6$ & 1 & 2 & 8000 & 6 & key & $\# 6$ \\
\hline $1-8000-6-k-4 n$ & 2 & 1 & 8000 & 6 & key & $\# 4$ \\
\hline $2-8000-6-k-6 n$ & 2 & 2 & 8000 & 6 & key & $\# 6$ \\
\hline $2-4000-6-k-6 n$ & 2 & 2 & 4000 & 6 & key & $\# 6$ \\
\hline
\end{tabular}




\subsection{Specimen Construction}

The following subsections describe the process by which the precast components required for each specimen were constructed. The construction process for the specimen as a unit is also described.

\subsubsection{Girder section}

The girder sections were constructed in the Bowen Laboratory on two occasions. The casting bed with completed girder sections from the first casting is shown in Figure 3.6. The concrete was obtained from a local ready-mix supplier. The mix specified for the girder sections had a nominal compressive strength of $8 \mathrm{ksi}$ at 28 days, with the exception of one specimen (2-4000-6-k-6n). The girder section of Specimen 2-4000-6-k6n was constructed with the SCC mix used in filling the pockets of Specimens 2-600014-6 and 2-6000-14-4. Mix designs are provided in Section 3.4. After casting, the girder sections were wet cured for 7 days. Once removed from the formwork, the trough surfaces were cleaned with a wire brush and compressed air to remove laitance. An example of a completed $2 \mathrm{ft}$ keyed girder section is shown in Figure 3.7.

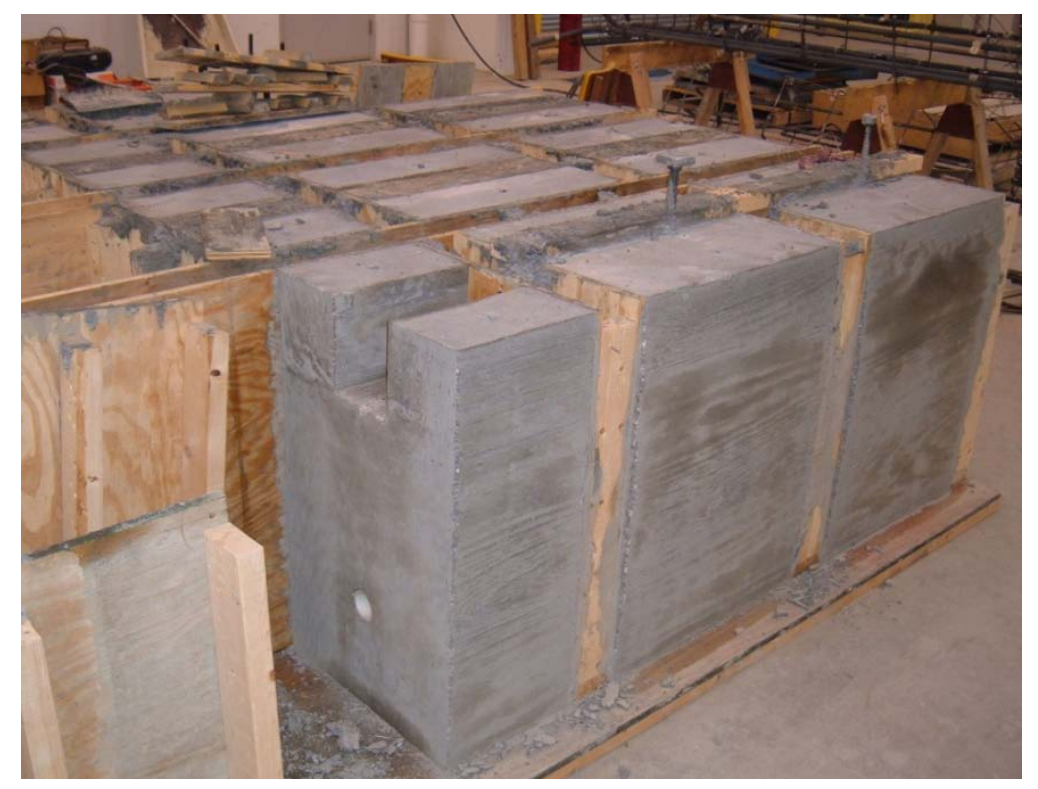

Figure 3.6: Casting bed 


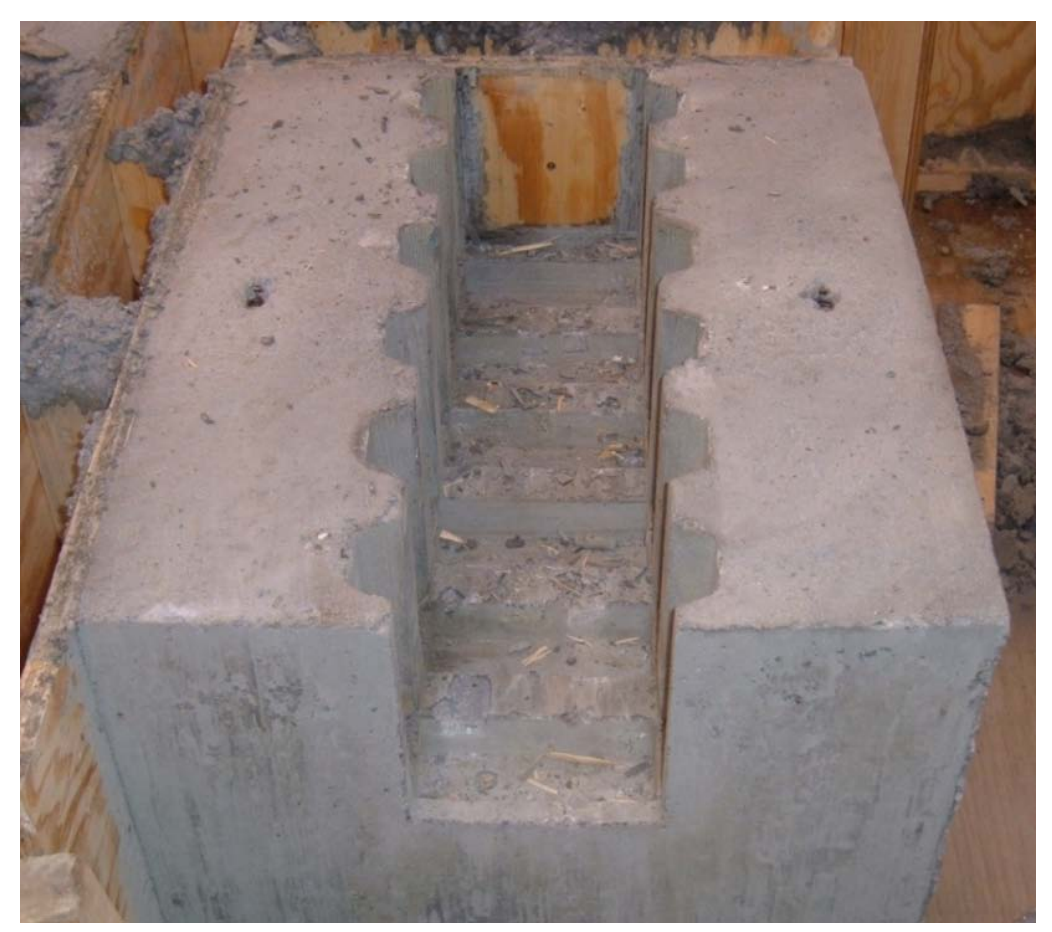

Figure 3.7: Shear key detail

\subsubsection{Panel sections}

The panel sections were constructed in the Bowen Laboratory on two occasions. The concrete was obtained from a local ready-mix supplier. The mix specified for the panel sections was INDOT Class C, which has a nominal compressive strength of $4 \mathrm{ksi}$ at 28 days, with exception of one specimen (2-4000-6-k-6n). The panel section of specimen 2-4000-6-k-6n was constructed with the SCC mix used in filling the pockets of Specimens 2-6000-14-6 and 2-6000-14-4. Mix designs are provided in Section 3.4. After casting, the panel sections were wet cured for 7 days. Once removed from the formwork, the pocket surfaces of the New England System panels were cleaned with a wire brush and compressed air to remove laitance. Examples of completed panel sections are shown in Figure 3.8. 


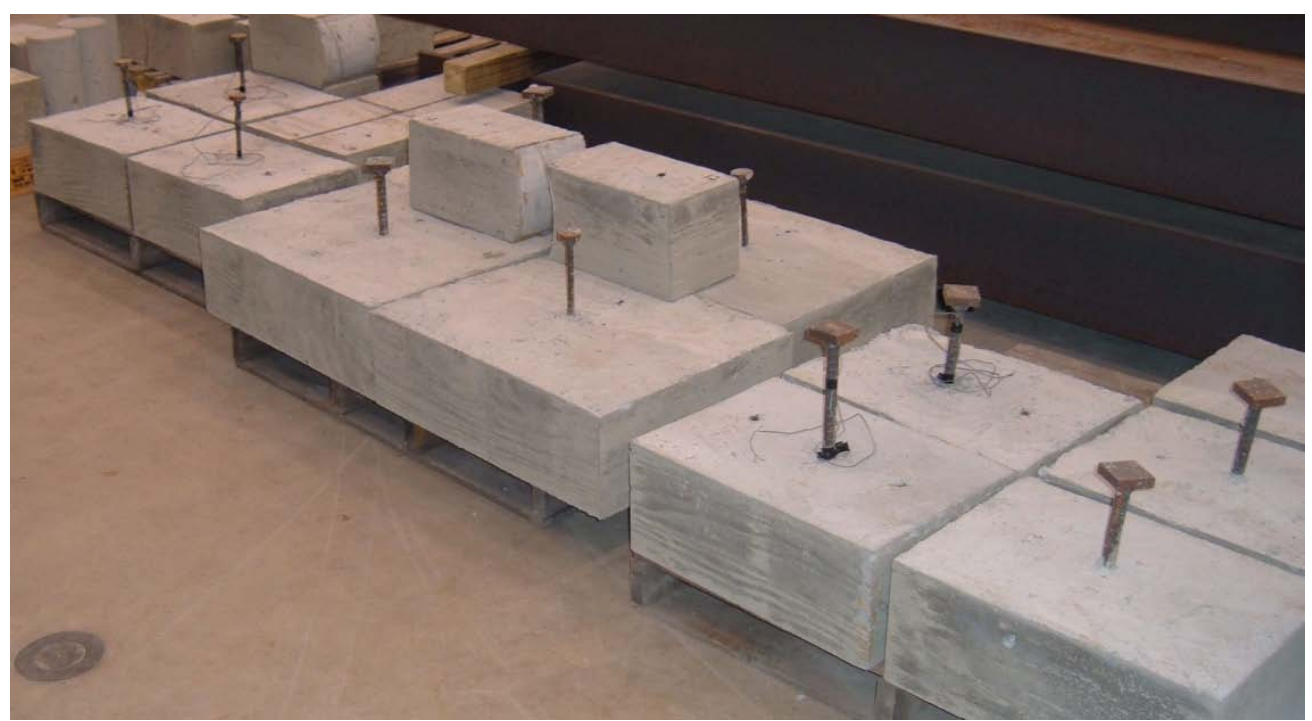

Figure 3.8: Examples of completed panel sections

\subsubsection{Specimens}

Once the girder and panel sections of the specimen were constructed, they were placed on their sides as illustrated in Figure 3.9. Each panel was positioned to give the specimen an overall depth of $41 \mathrm{in}$. and then shimmed to ensure the bottom surface of the panel was vertical. The sides of the specimen haunch were formed with $1 / 2$ in. foam. Once formed, the appropriate concrete strength was ordered from a local ready-mix supplier. The concrete was poured into the trough from above. After casting, the trough concrete was wet cured for 7 days. 


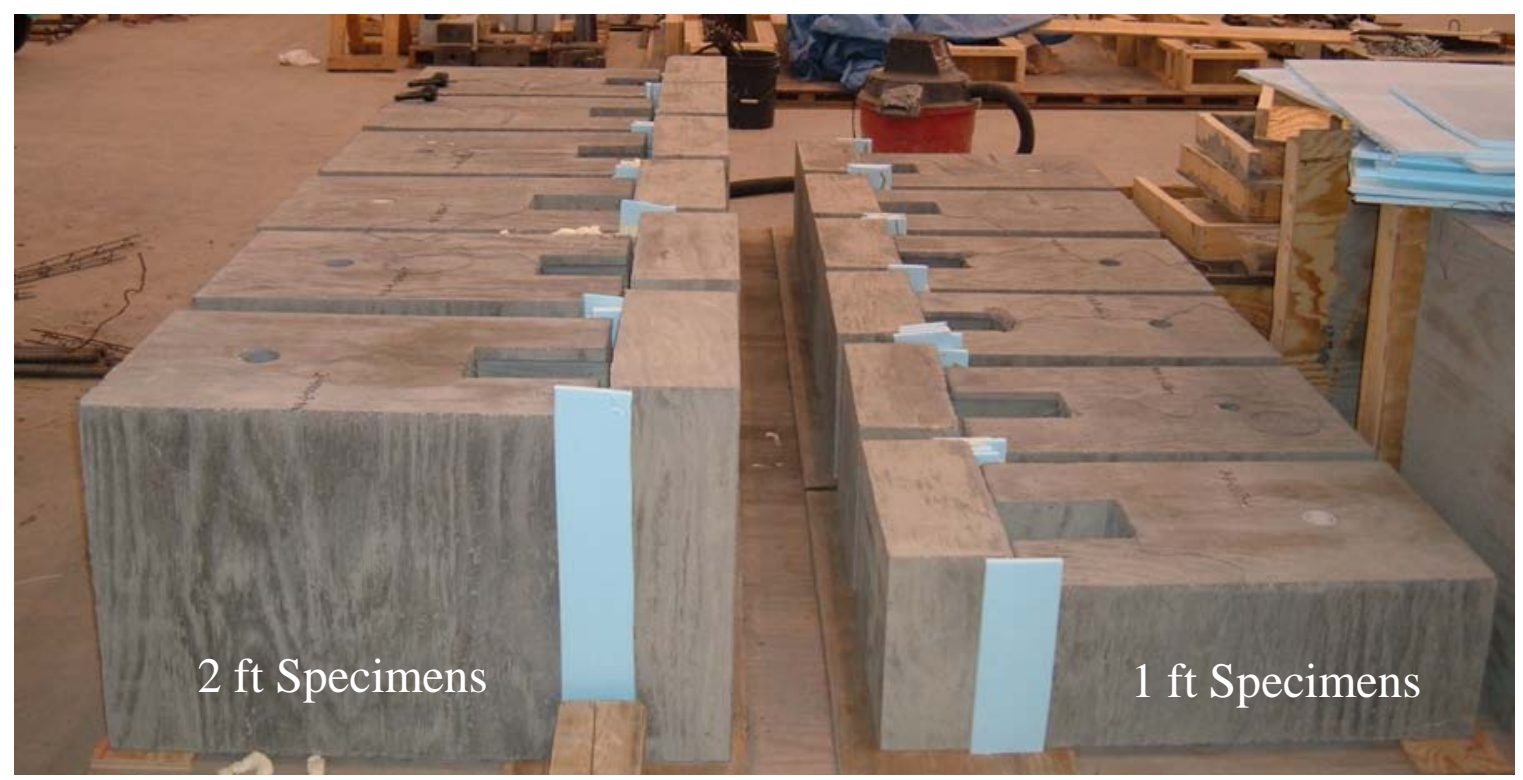

Figure 3.9: Specimen construction

\subsection{Materials}

Standard testing was performed on the materials used in the construction of the specimens according to applicable ASTM standards. All testing was performed in the Bowen Laboratory at Purdue University.

\subsubsection{Concrete}

Concrete for the specimens was obtained from a local ready-mix supplier. The mix proportions delivered for the specimen components of Group 1 and 2 are presented in Table 3.2 and Table 3.3, respectively. Compression tests were performed on 6”x12” cylinders for all concretes used in the specimens. The strength gain curves of the concrete compression tests are provided in Appendix A. The results of the concrete compression tests for the day of testing are presented in Table 3.4. 
Table 3.2: Concrete mix proportions - Group 1

\begin{tabular}{|c|c|c|c|c|c|c|}
\hline \multirow[b]{2}{*}{ Material } & \multirow[b]{2}{*}{ Unit } & \multicolumn{5}{|c|}{ Specimen Component } \\
\hline & & Panel & $\begin{array}{c}\text { Trough } \\
f_{c}^{\prime}=4 \mathrm{ksi}\end{array}$ & $\begin{array}{c}\text { Trough } \\
f_{c}^{\prime}=8 \mathrm{ksi}\end{array}$ & SCC & Girder \\
\hline Pea-gravel & $\mathrm{lb} / \mathrm{cy}$ & --- & --- & 1607 & 1450 & 1596 \\
\hline \#8 stone & $\mathrm{lb} / \mathrm{cy}$ & 1769 & --- & --- & --- & --- \\
\hline \#11 stone & $\mathrm{lb} / \mathrm{cy}$ & --- & 1480 & --- & --- & --- \\
\hline \#23 sand & $\mathrm{lb} / \mathrm{cy}$ & 1253 & 1550 & 1273 & 1350 & 1295 \\
\hline Cement (Type I) & $\mathrm{lb} / \mathrm{cy}$ & 656 & 480 & 757 & 675 & 756 \\
\hline Fly-ash (Class C) & $\mathrm{lb} / \mathrm{cy}$ & --- & 95 & 143 & 175 & 142 \\
\hline $\begin{array}{l}\text { Super Plasticizer } \\
\left.\text { (Glenium }^{\circledR} 3030 \mathrm{NS}\right)\end{array}$ & oz/cy & 13.3 & 11.5 & 62.7 & 102.0 & 63.3 \\
\hline Air Entrainer (Micro Air ${ }^{(B)}$ ) & oz/cy & 4.4 & 5.3 & --- & 2.0 & --- \\
\hline Water & $\mathrm{lb} / \mathrm{cy}$ & 166 & 148 & 183 & 150 & 151 \\
\hline
\end{tabular}

Table 3.3: Concrete mix proportions - Group 2

\begin{tabular}{|c|c|c|c|c|c|c|}
\hline \multirow{3}{*}{ Material } & \multirow{3}{*}{ Unit } & \multicolumn{5}{|c|}{ Specimen Component } \\
\hline & & \multicolumn{2}{|c|}{ 2-4000-6-k-6n } & \multicolumn{3}{|c|}{ Other } \\
\hline & & $\begin{array}{c}\text { Panel and } \\
\text { Girder }\end{array}$ & $\begin{array}{c}\text { Trough } \\
f_{c}^{\prime}=4 \mathrm{ksi}\end{array}$ & Panel & $\begin{array}{c}\text { Trough } \\
f_{c}^{\prime}=8 \mathrm{ksi}\end{array}$ & Girder \\
\hline Pea-gravel & $\mathrm{lb} / \mathrm{cy}$ & 1450 & --- & --- & 1610 & 1607 \\
\hline \#8 stone & $\mathrm{lb} / \mathrm{cy}$ & --- & 1780 & 1760 & --- & --- \\
\hline \#11 stone & lb/cy & --- & --- & --- & --- & --- \\
\hline \#23 sand & $\mathrm{lb} / \mathrm{cy}$ & 1350 & 1230 & 1240 & 1270 & 1273 \\
\hline Cement (Type I) & $\mathrm{lb} / \mathrm{cy}$ & 675 & 655 & 660 & 758 & 757 \\
\hline Fly-ash (Class C) & $\mathrm{lb} / \mathrm{cy}$ & 175 & --- & --- & 145 & 143 \\
\hline $\begin{array}{l}\text { Super Plasticizer } \\
\text { (Glenium }{ }^{\circledR} 3030 \text { NS) }\end{array}$ & oz/cy & 102.0 & 13.0 & 13.5 & 64.0 & 62.7 \\
\hline $\begin{array}{l}\text { Air Entrainer } \\
\left(\text { Micro Air }{ }^{\circledR} \text { ) }\right.\end{array}$ & oz/cy & 2.0 & 4.5 & 4.8 & --- & --- \\
\hline Water & lb/cy & 150 & 188 & 171 & 166 & 183 \\
\hline
\end{tabular}


Table 3.4: Average cylinder strength on day of specimen test

\begin{tabular}{|c|c|c|c|}
\hline Specimens & \multicolumn{3}{|c|}{ Test $f_{c}$ (psi) } \\
\hline Group 1 & Panel & Trough & Girder \\
\hline $1-4000-6-4$ & \multirow{17}{*}{5490} & \multirow{11}{*}{5410} & \multirow{17}{*}{11700} \\
\hline $1-4000-6-k-4$ & & & \\
\hline 1-4000-6-k-6 & & & \\
\hline $1-4000-8-6$ & & & \\
\hline 1-4000-8-k-6 & & & \\
\hline $2-4000-6-4$ & & & \\
\hline 2-4000-6-6 & & & \\
\hline 2-4000-6-k-4 & & & \\
\hline 2-4000-6-k-6 & & & \\
\hline $2-4000-8-6$ & & & \\
\hline 2-4000-8-k-6 & & & \\
\hline $1-8000-6-4$ & & \multirow{4}{*}{8200} & \\
\hline $1-8000-6-k-4$ & & & \\
\hline 1-8000-6-6 & & & \\
\hline 1-8000-6-k-6 & & & \\
\hline $2-6000-14-4$ & & \multirow{2}{*}{9790} & \\
\hline 2-6000-14-6 & & & \\
\hline 2-8000-6-k-6 & 6420 & 10430 & 10720 \\
\hline \multicolumn{4}{|l|}{ Group 2} \\
\hline 1-8000-6-k-4n & \multirow{2}{*}{6420} & \multirow{2}{*}{10430} & \multirow{2}{*}{10720} \\
\hline 2-8000-6-k-6n & & & \\
\hline 2-4000-6-k-6n & 9910 & 3900 & 9910 \\
\hline
\end{tabular}

\subsubsection{Reinforcing Steel}

The mild steel used throughout the specimens was ASTM A615 Grade 60. The mild steel was not tested because it was not a primary variable.

\subsubsection{Shear studs}

Standard tension testing was performed on the mild steel used for the shear studs. There were four heats of mild reinforcement used in this test series, two for both the \#4 and \#6 studs. The stud used in Specimen 2-6000-14-4 was from the same heat as the \#4 studs used in Specimen 4-C. The stud had a taper threaded D16 Lenton Terminator on the end which enters the panel. The remaining studs were ASTM A706 Grade 60 and 
headed at both ends. The heads were a HRC 120 for \#6 studs and a HRC 150 for \#4 studs. The heads were friction welded to the rebar.

The results of tension tests on the four heats are presented in Figure 3.10. The load-strain relationship for the studs used in the 6 in. embedment specimens ends prematurely because the testing machine halted collection of strain data at 0.04 . While the stress-strain curve after that point is unavailable, the ultimate load capacity was still recorded. The strain at which strain data collection halted was increased after that heat was tested. Yield and ultimate strength values are summarized in Table 3.5.

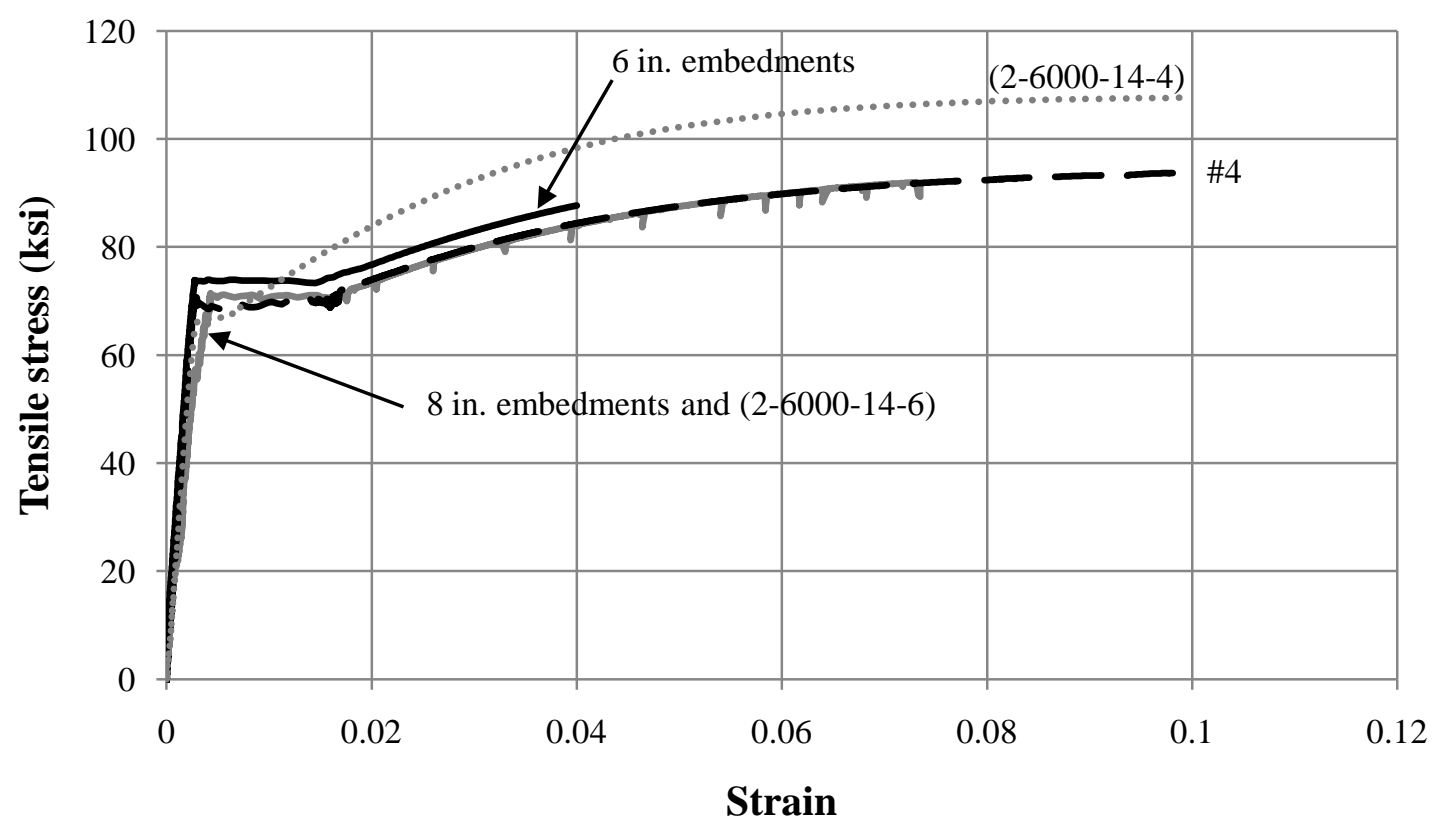

Figure 3.10: Shear stud stress-strain relationship

Table 3.5: Shear stud strength

\begin{tabular}{|c|c|c|c|}
\hline Bar & Specimens & $\mathbf{f}_{\mathbf{y}}(\mathbf{k s i})$ & $\mathbf{f}_{\mathbf{u}}(\mathbf{k s i})$ \\
\hline$\# 6$ & 6 in. embedments & 73 & 97 \\
\hline$\# 6$ & $\begin{array}{c}\text { 8 in. embedments and } \\
\text { 2-6000-14-4 }\end{array}$ & 70 & 95 \\
\hline$\# 4$ & All except (2-6000-14-4) & 69 & 94 \\
\hline$\# 4$ & $(2-6000-14-4)$ & 67 & 107 \\
\hline
\end{tabular}




\subsection{Test Setup}

The test setup consisted of a loading system anchored to the strong floor and a specimen support block. The support block and specimen were post-tensioned to the strong floor using a $1.5 \mathrm{in}$. diameter bar tensioned to $21.5 \mathrm{ksi}$ (38 kips). The support block was constructed with the same outer dimensions as a $2 \mathrm{ft}$ specimen (Section 3.2.1). The trough of the support block was 7 in. in width and 9 in. in depth. The extra width and depth of the trough was provided to avoid any contact of the specimen trough concrete with the support block which would provide confinement. The panel section of the specimen was clamped with two 1.5 in. plates secured together using two $1.5 \mathrm{in}$. diameter threaded rods, one on either side. The load was centered over the panel-girder interface to produce a plane through the interface where the applied load is only causing shear stresses. Load was measure using a 150 kip load-cell positioned between the ram and loading frame. A strain gauge was installed on the shear stud $1 / 4$ in. above the panel prior to casting the specimens. Potentiometers were positioned on each side of the panel to measure displacement relative to the strong floor. An LVDT was positioned at the center of the base of the girder section to measure possible rotation of the specimen relative to the strong floor. The test setup for the $1 \mathrm{ft}$ and $2 \mathrm{ft}$ specimens and locations of the potentiometers and LVDT are presented in Figure 3.11. An example of a test specimen prior to testing is presented in Figure 3.12. 


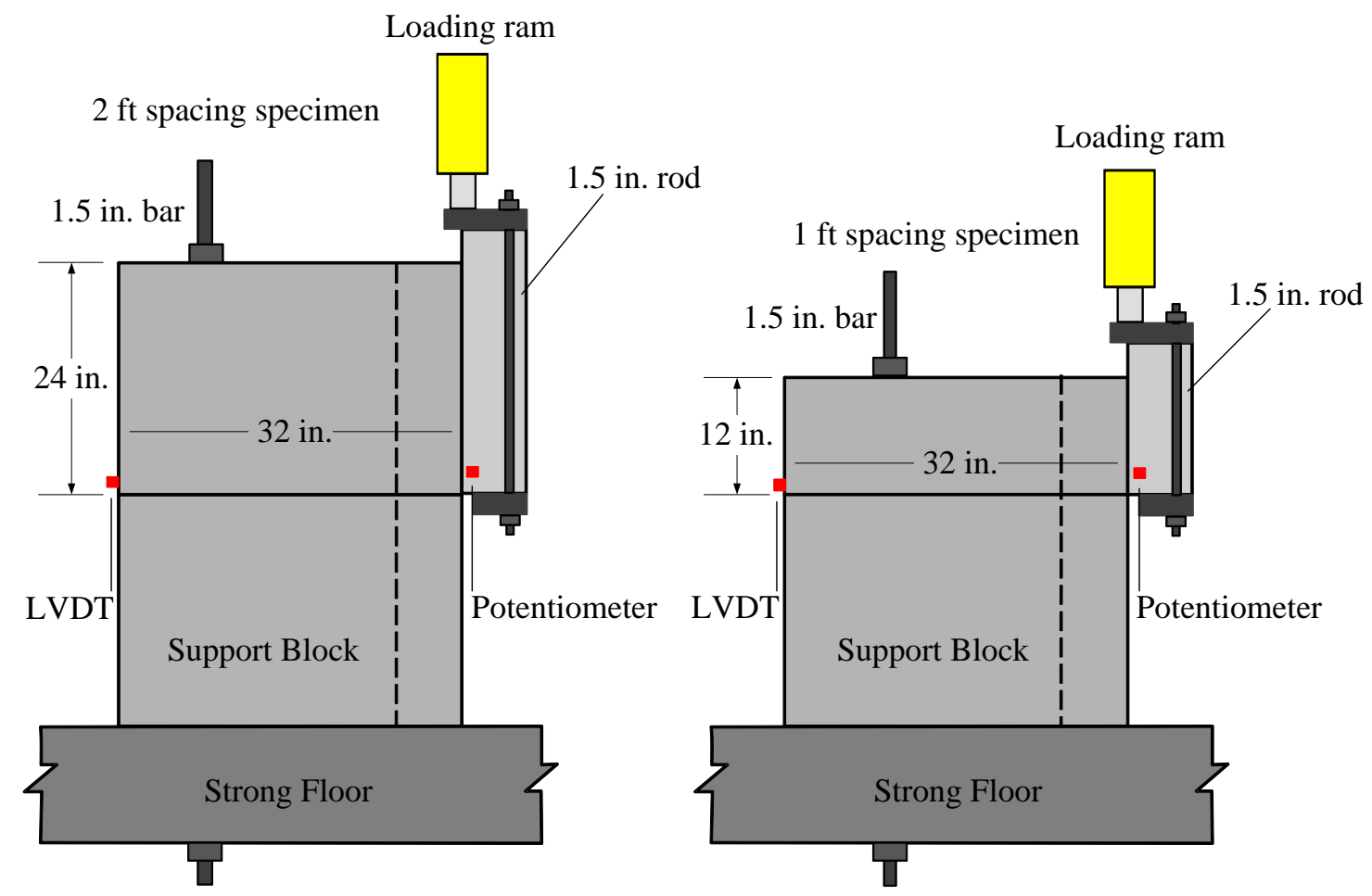

Figure 3.11: Panel-to-Girder test setup 


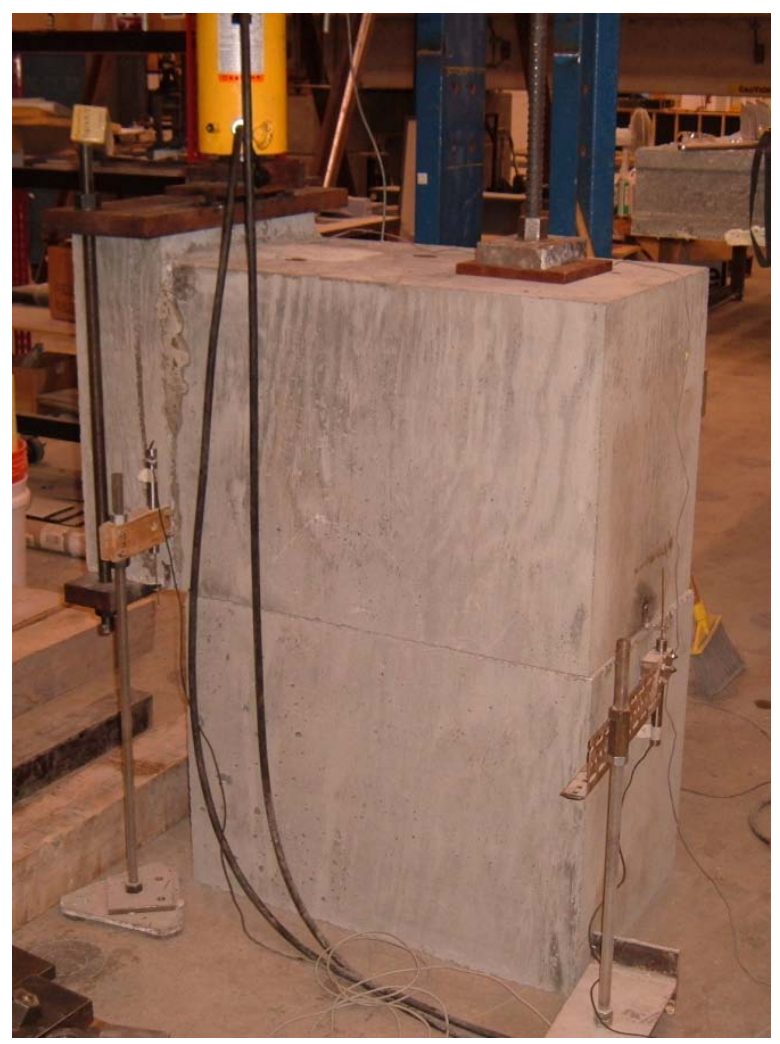

Figure 3.12: Specimen in test setup

\subsubsection{Test protocol}

The specimens were loaded using a 200 kip hydraulic ram until either failure of the shear stud occurred or the specimen could no longer sustain load. Load was applied using a manually operated hydraulic pump. All instrumentation was monitored throughout testing and recorded at 0.5 second increments. Cracks were also monitored and marked. 


\subsection{Results}

The following subsections present the results obtained from the test described in Section 3.5. A summary of the results is provided for each specimen.

\subsubsection{1 ft Specimens}

\subsubsection{Specimen 1-4000-6-4}

The load-slip response for Specimen 1-4000-6-4 is presented in Figure 3.13. The specimen behaved as a composite section up to a load of approximately $64.3 \mathrm{kips}$ at which bond failure occurred at the trough-girder section interface. No cracking was observed prior to bond failure. A maximum measured shear stud strain of $509 \mu \varepsilon$ occurred immediately after bond failure (Figure 3.14). The deck section fell away from the girder section following bond failure (Figure 3.15). Measured strains indicate that the shear stud did not yield.

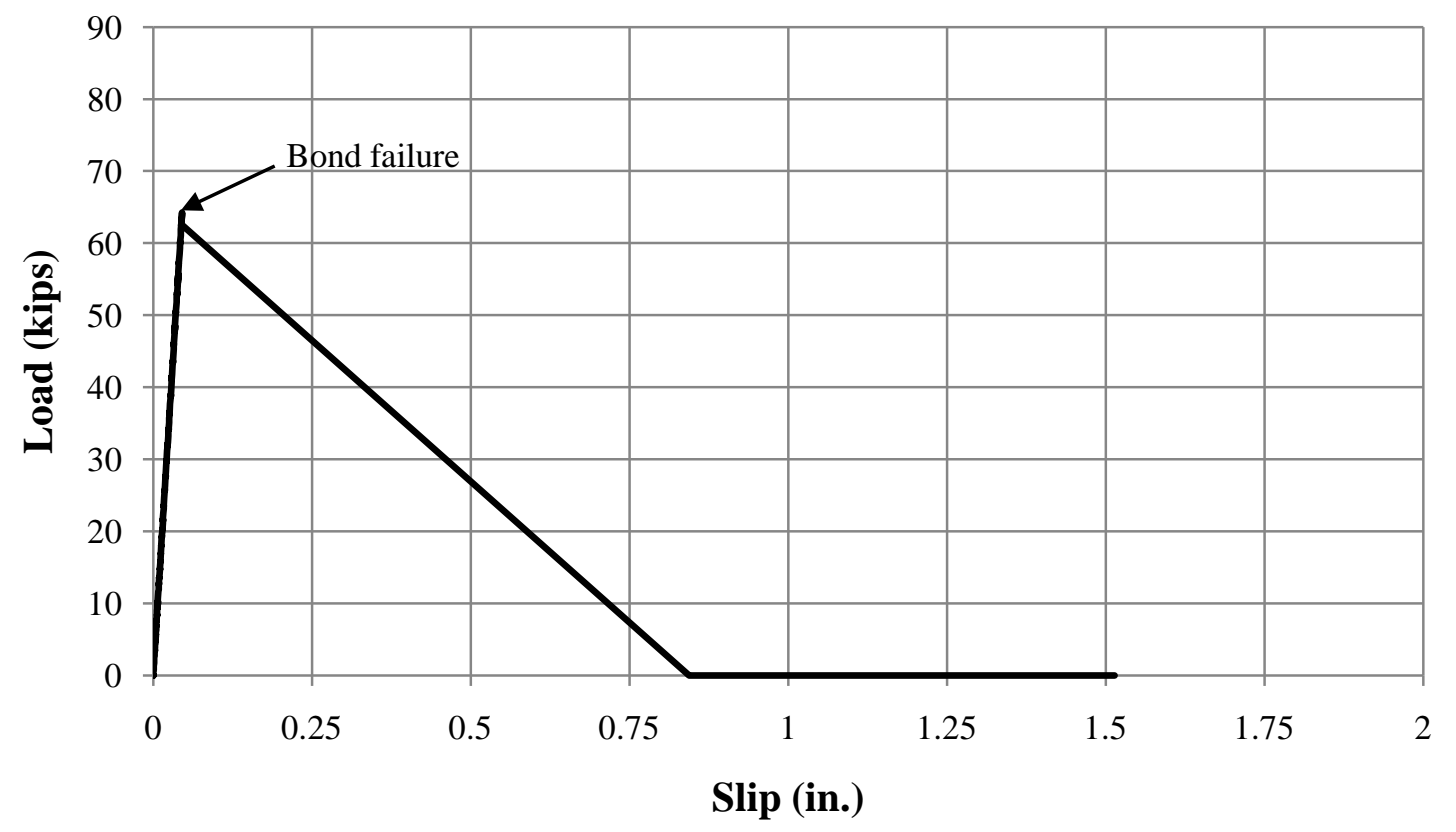

Figure 3.13: Load-slip response of Specimen 1-4000-6-4 


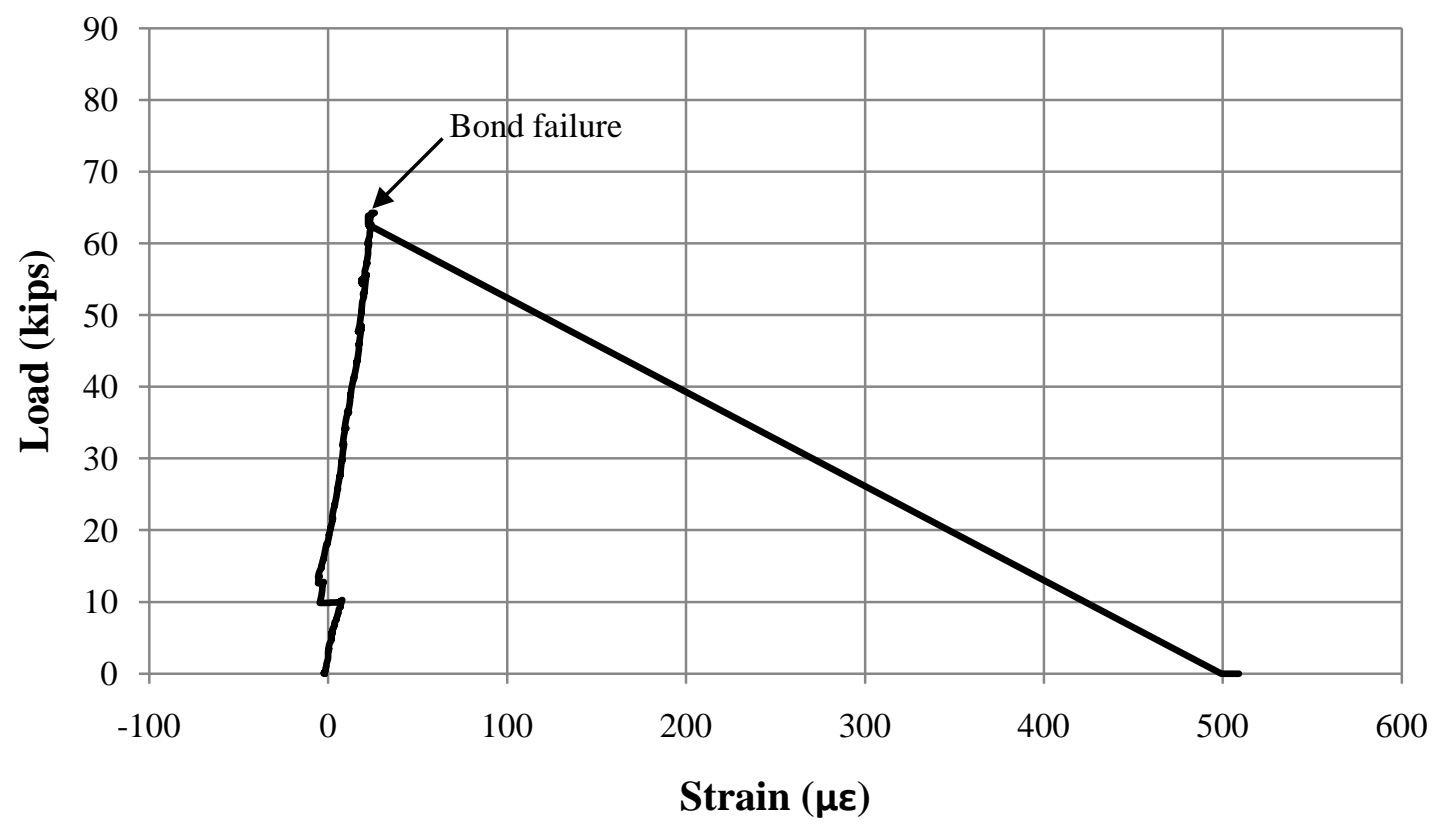

Figure 3.14: Measured shear stud strain (1-4000-6-4) 


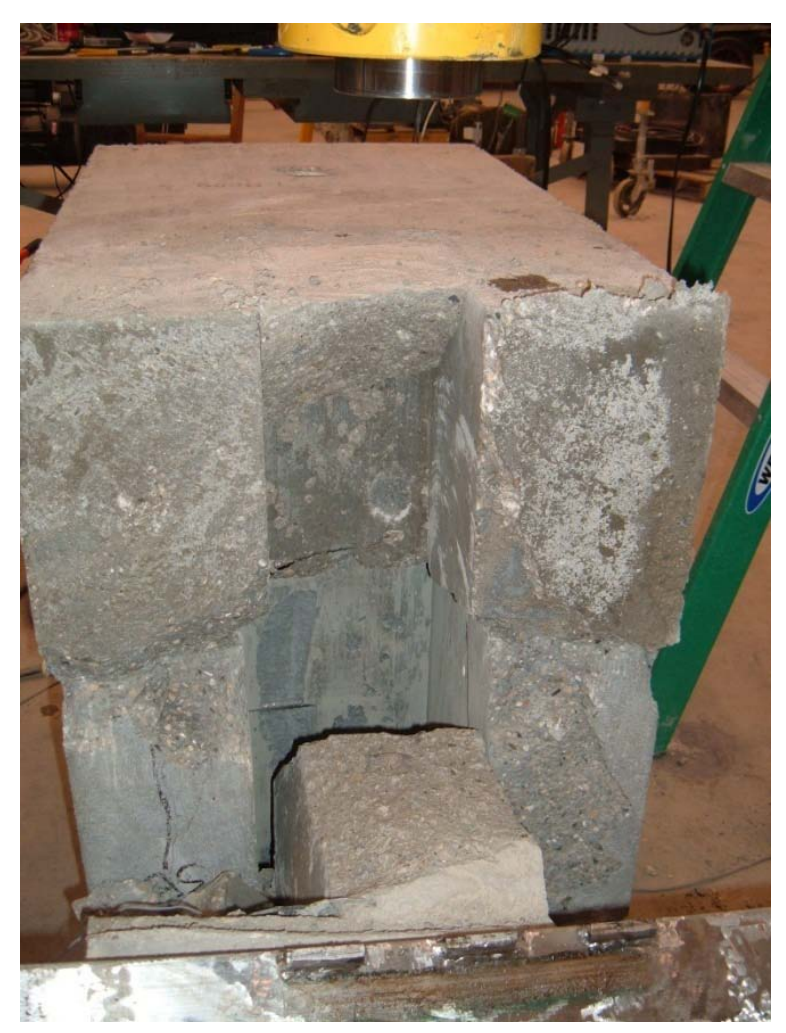

Figure 3.15: Specimen 1-4000-6-4 after bond failure

\subsubsection{Specimen 1-4000-6-k-4}

The load-slip response for Specimen 1-4000-6-k-4 is presented in Figure 3.17. The specimen behaved as a composite section up to a load of approximately 52.6 kips at which bond failure occurred at the panel-haunch interface, as illustrated in Figure 3.16. No cracks were observed prior to or immediately following bond failure. A maximum measured shear stud strain of $74 \mu \varepsilon$ occurred immediately prior to bond failure. The strain gauge failed once bond failure occurred. Loading of the specimen continued and cracking of the trough material was first observed at 17 kips. Cracking of the trough material is evident in considering Figure 3.17. Upon continued loading, cracks developed around the perimeter of the trough and in the girder section. The cracks in the girder section initiated at the inside corners of the trough (Figure 3.18). Testing was stopped at approximately $1.75 \mathrm{in}$. of slip because of a decreased load capacity due to cracking of the specimen. 


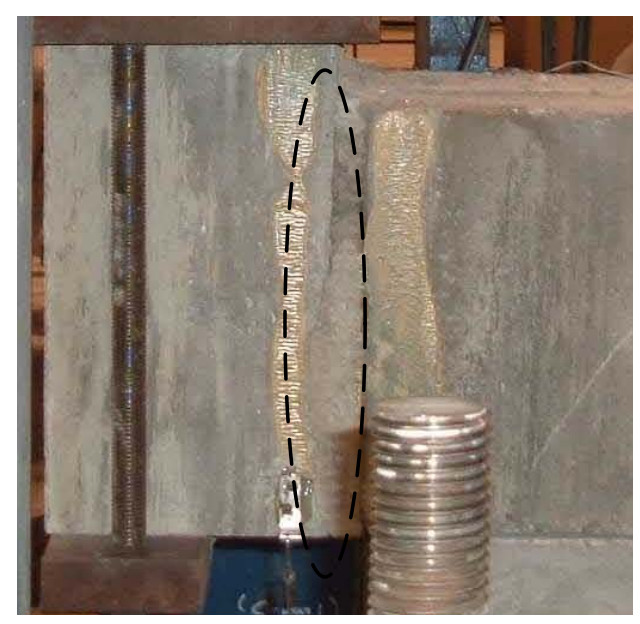

Prior to bond failure

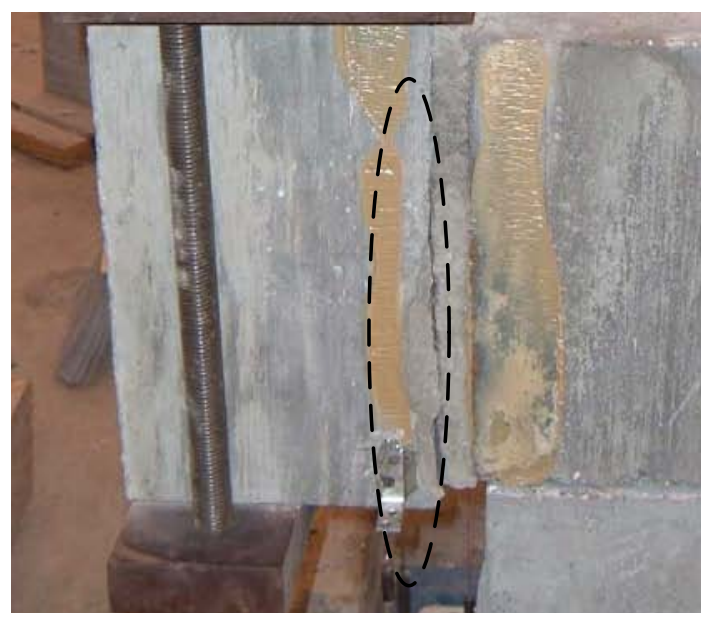

Interface bond failure

Figure 3.16: Panel-haunch bond failure (1-4000-6-k-4)

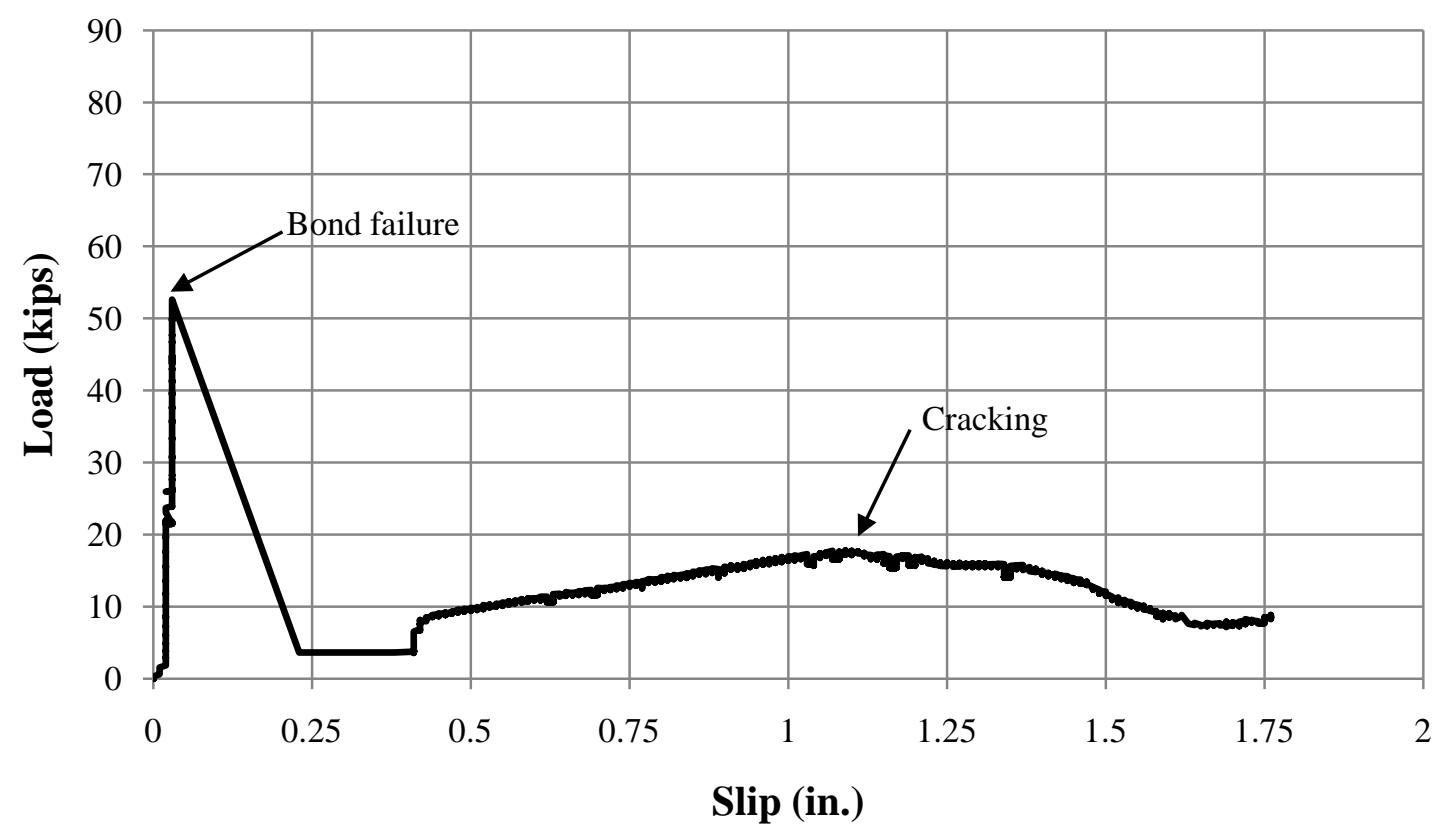

Figure 3.17: Load-slip response of Specimen 1-4000-6-k-4 


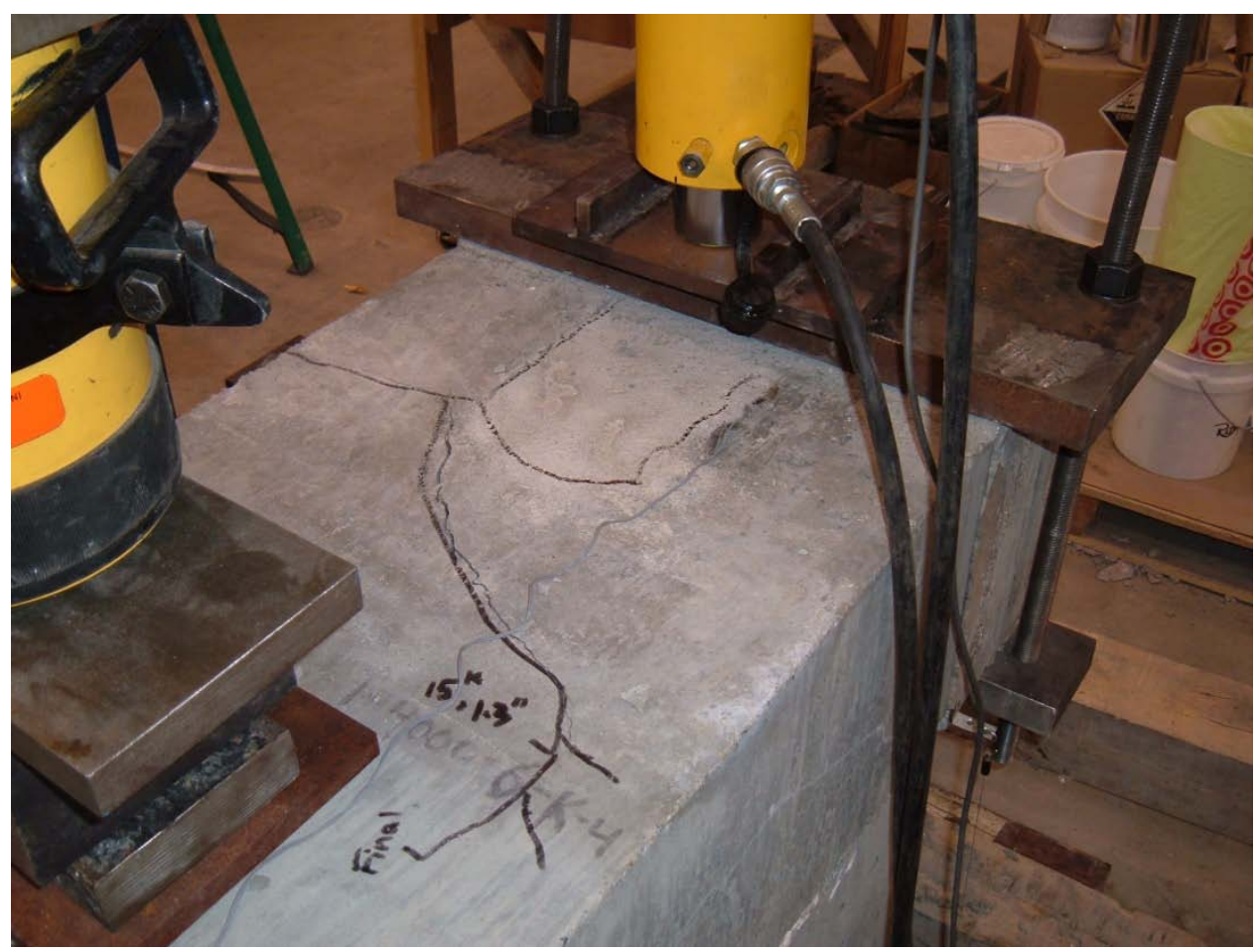

Figure 3.18: Cracking of girder section (1-4000-6-k-4)

\subsubsection{Specimen 1-4000-6-k-6}

The load-slip response for Specimen 1-4000-6-k-6 is presented in Figure 3.19. The specimen behaved as a composite section up to a load of approximately 81 kips at which bond failure occurred at the panel-haunch interface. Prior to bond failure, a crack was observed at the base of the trough at a load of 27 kips. The crack propagated into the girder section initiating at the inside corners of the trough. Additional cracks developed within the trough material immediately following bond failure. Loading of the specimen continued and cracks within the trough material widened (Figure 3.20). Deterioration of the trough capacity is evident in considering Figure 3.19. A maximum measured shear stud strain of $24 \mu \varepsilon$ occurred immediately prior to bond failure. The strain gauge failed once bond failure occurred. 


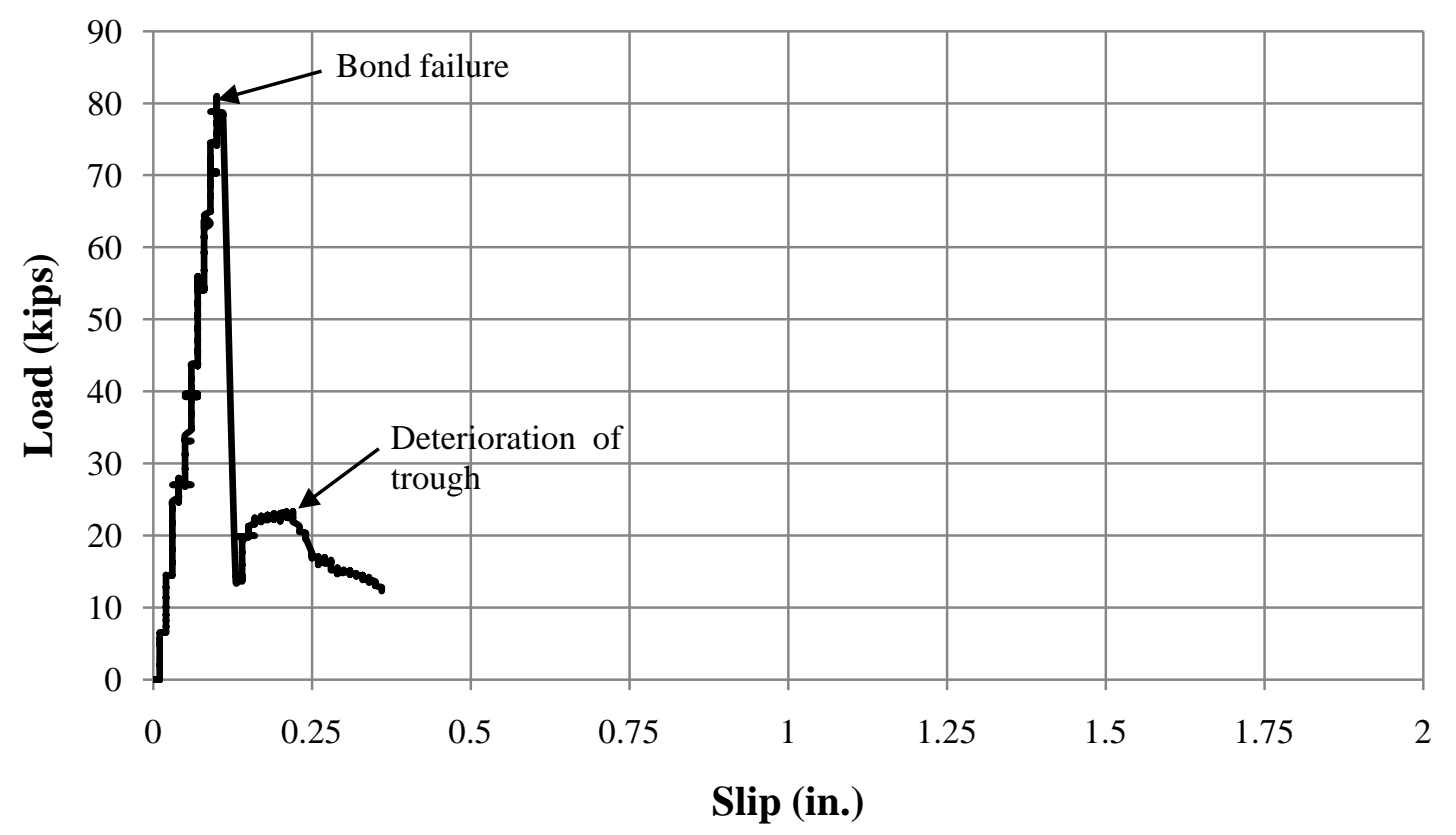

Figure 3.19: Load-slip response of Specimen 1-4000-6-k-6

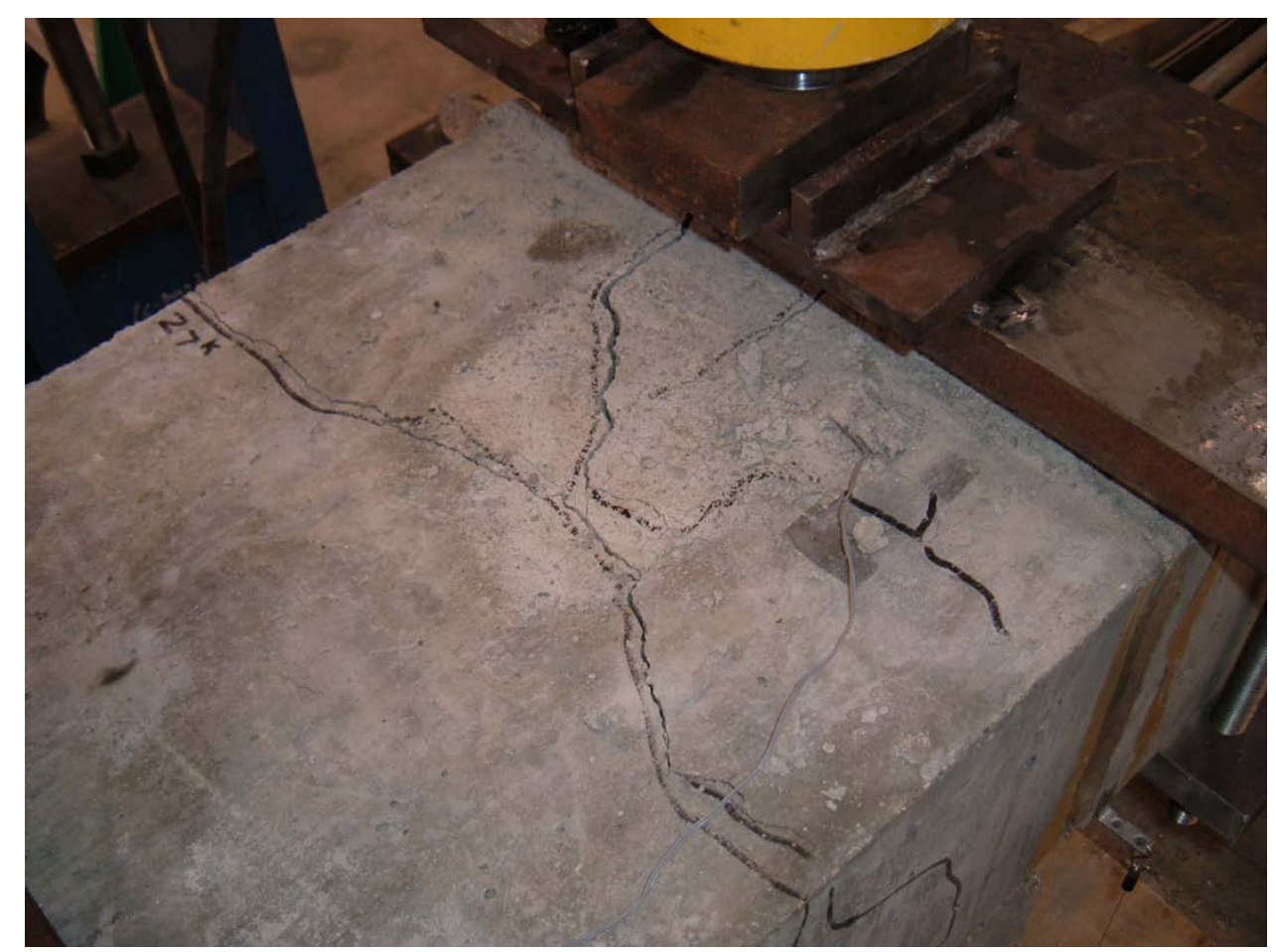

Figure 3.20: Cracking of girder section (1-4000-6-k-6) 


\subsubsection{Specimen 1-4000-8-6}

The load-slip response for Specimen 1-4000-8-6 is presented in Figure 3.21. The specimen was loaded to a maximum load of approximately 29 kips at which bond failure occurred at the trough-girder section interface. Prior to bond failure, a crack was observed at the base of the trough. The crack propagated into the girder section initiating at the inside corners of the trough. Following bond failure, the panel section began to rotate away from the girder section (Figure 3.22). The panel section continued to rotate without an increase in applied load. The test was halted once the rotation of the panel section exceeded the limits of the test setup. A maximum measured shear stud strain of $795 \mu \varepsilon$ occurred after bond failure. Measured strains indicate that the shear stud did not yield.

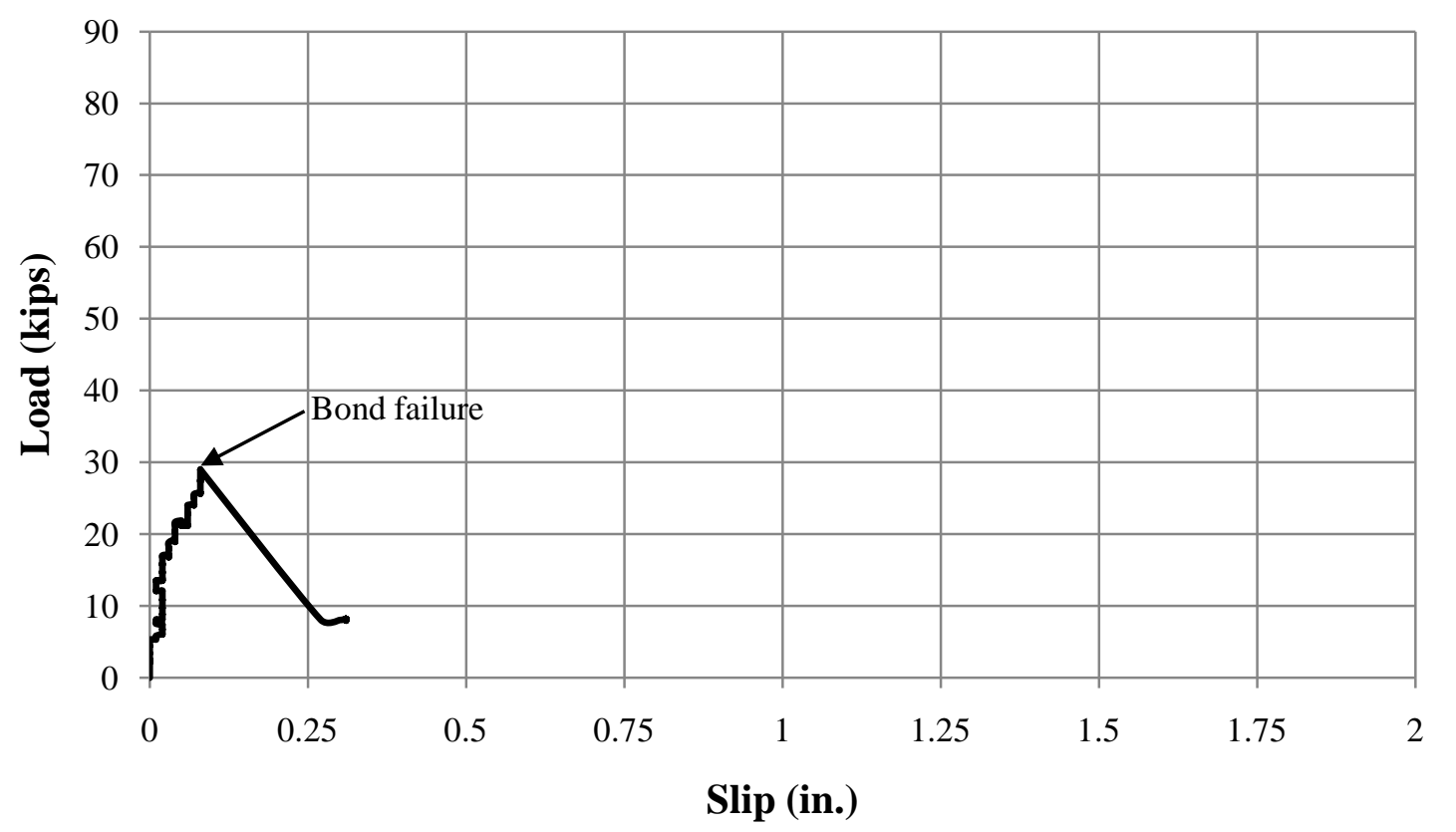

Figure 3.21: Load-slip response of Specimen 1-4000-8-6 


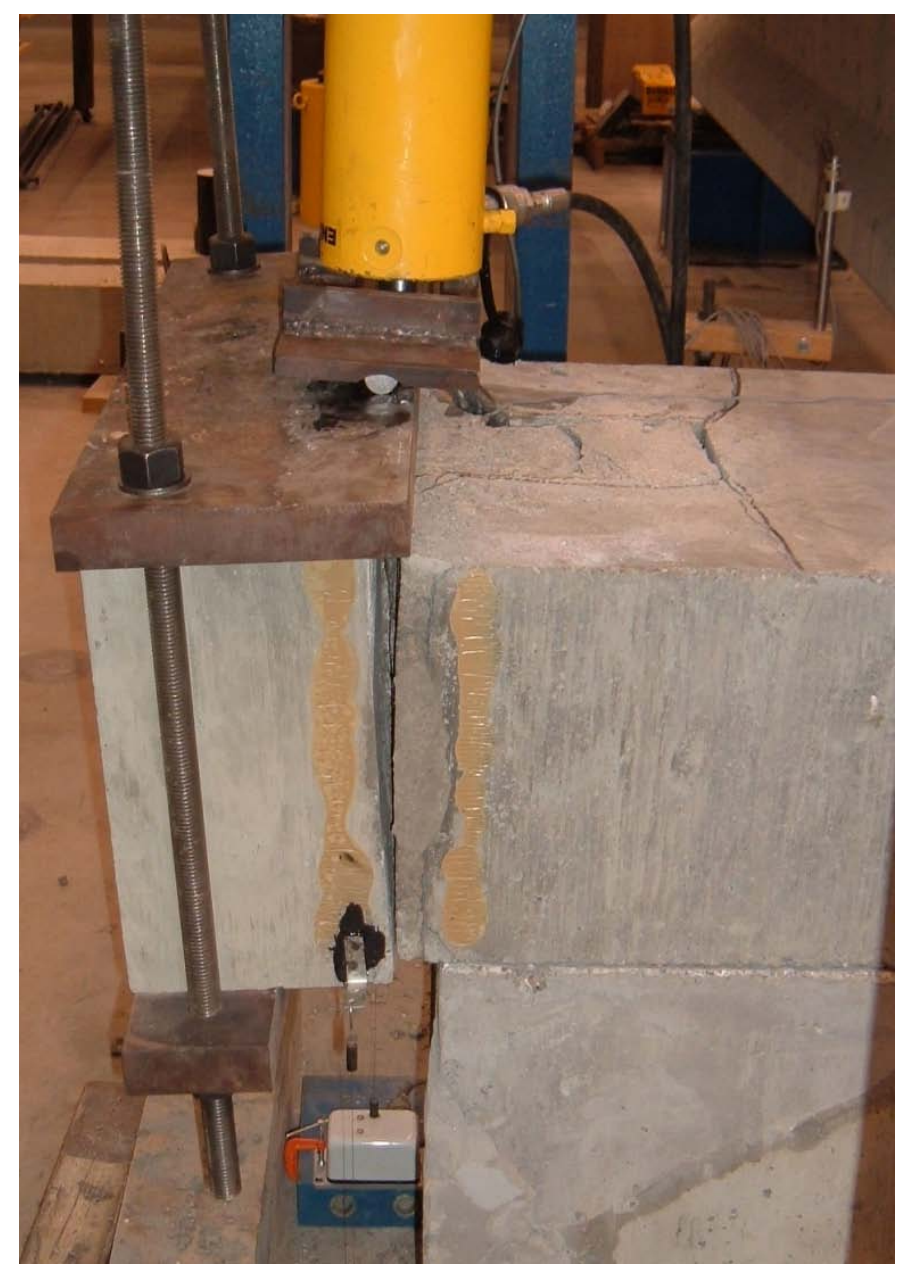

Figure 3.22: Panel rotation and cracking following bond failure (1-4000-8-6)

\subsubsection{Specimen 1-4000-8-k-6}

The load-slip response for Specimen 1-4000-8-k-6 is presented in Figure 3.23. The specimen behaved as a composite section up to a load of approximately 50.8 kips at which bond failure occurred at the panel-haunch interface. No cracks were observed prior to bond failure. Cracks developed at the mid-height of the trough, base of the trough, and girder section immediately following bond failure (Figure 3.24). The cracking in the girder section initiated at the inside corners of the trough. Loading of the specimen continued and vertical cracking of the trough material was observed at 15 kips. Deterioration of the capacity is evident in considering Figure 3.23, which was due to excessive cracking of the specimen, as illustrated in Figure 3.25. A maximum measured 
shear stud strain of $98 \mu \varepsilon$ occurred immediately prior to bond failure. The strain gauge failed once bond failure occurred.

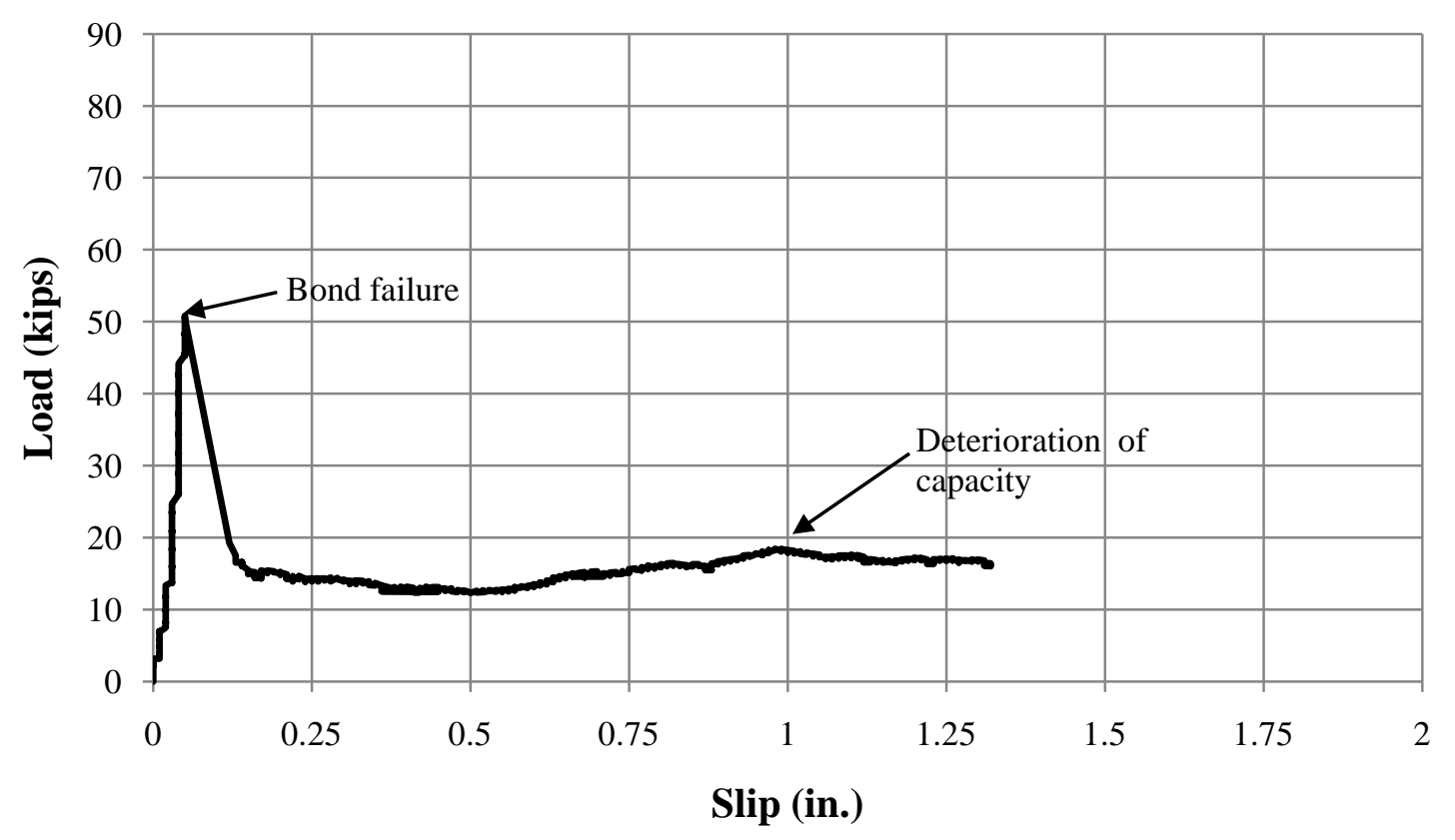

Figure 3.23: Load-slip response of Specimen 1-4000-8-k-6 


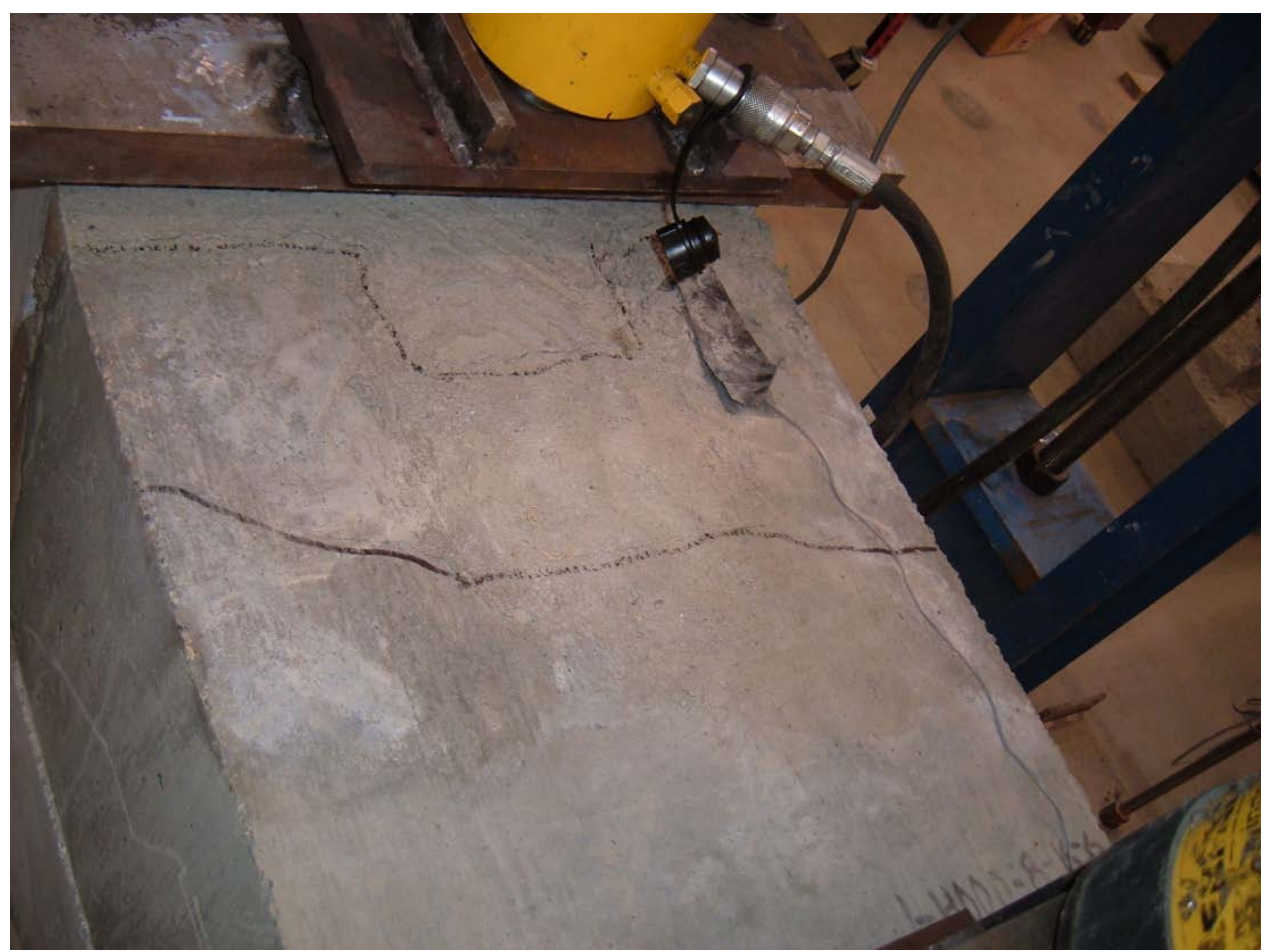

Figure 3.24: Cracking of Specimen 1-4000-8-k-6 after bond failure

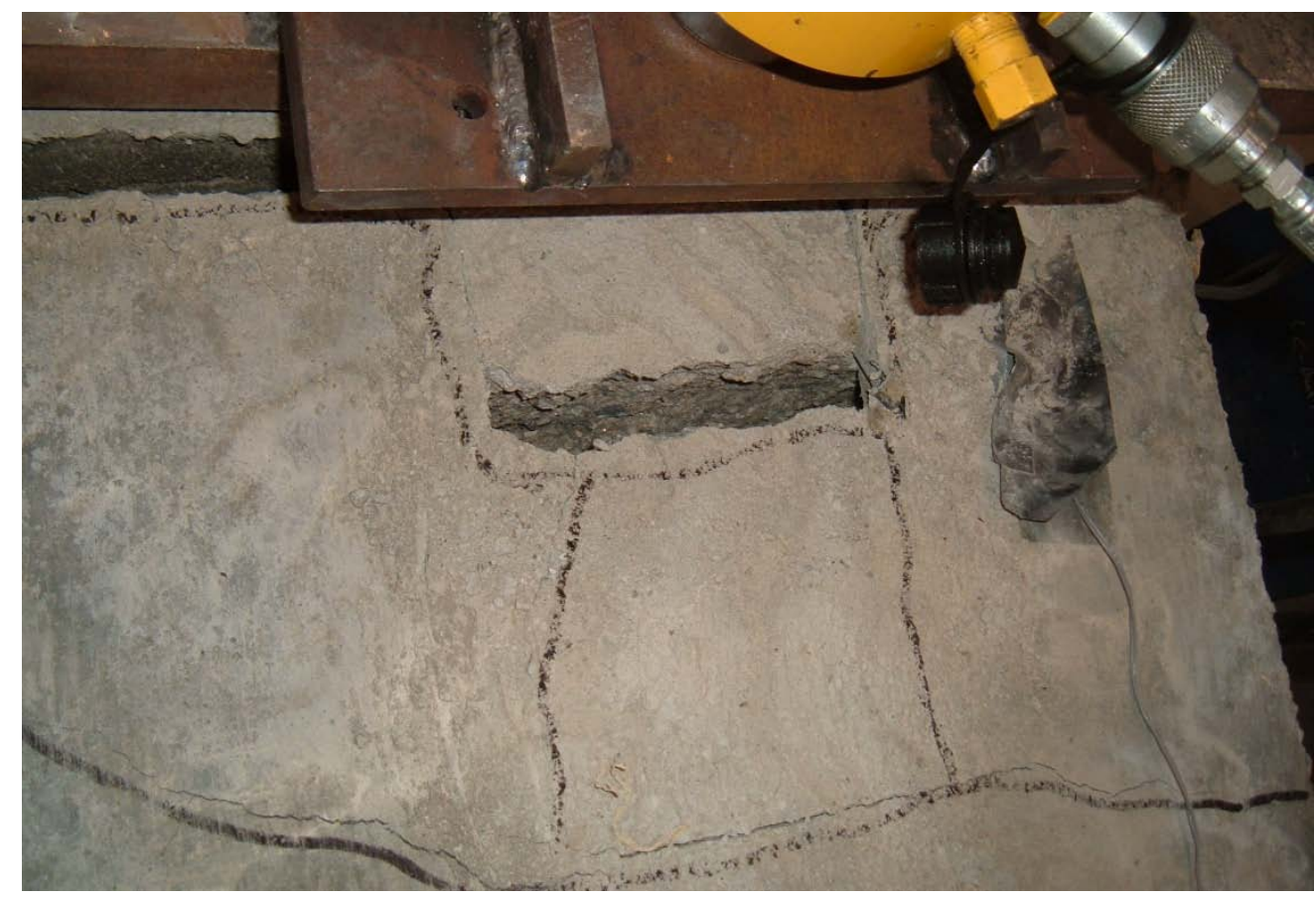

Figure 3.25: Cracking of Specimen 1-4000-8-k-6 


\subsubsection{Specimen 1-8000-6-4}

The load-slip response for Specimen 1-8000-6-4 is presented in Figure 3.26. The specimen behaved as a composite section up to a load of approximately 45.9 kips at which bond failure occurred at the trough-girder section interface. The panel and trough material completely separated from the girder section (Figure 3.27). A maximum measured shear stud strain of $7216 \mu \varepsilon$ occurred after bond failure (Figure 3.28). A flexural crack was observed in the girder section at 25 kips due to uneven seating of the specimen on the support block. However, no other cracks were observed prior to bond failure.

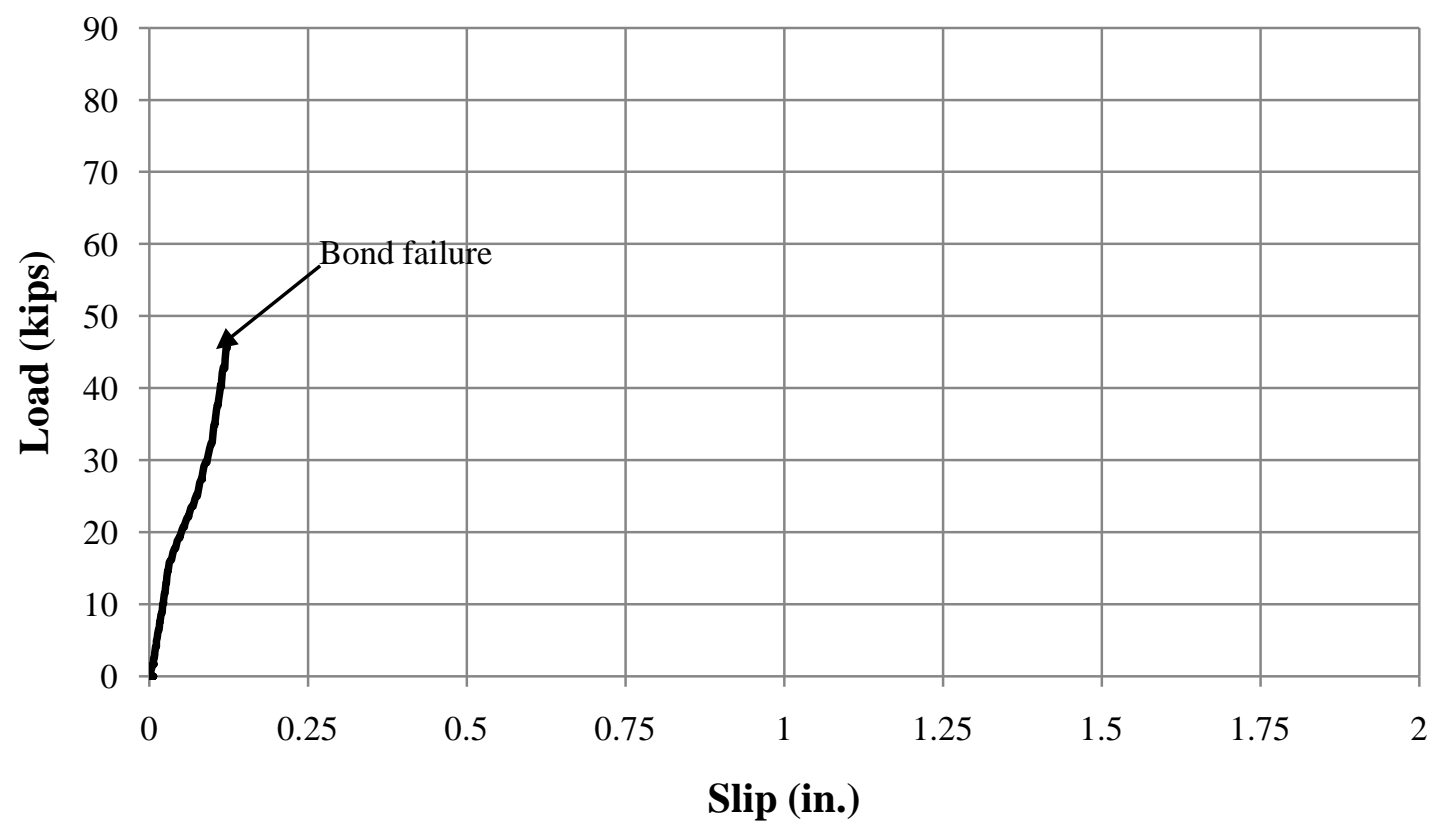

Figure 3.26: Load-slip response of Specimen 1-8000-6-4 


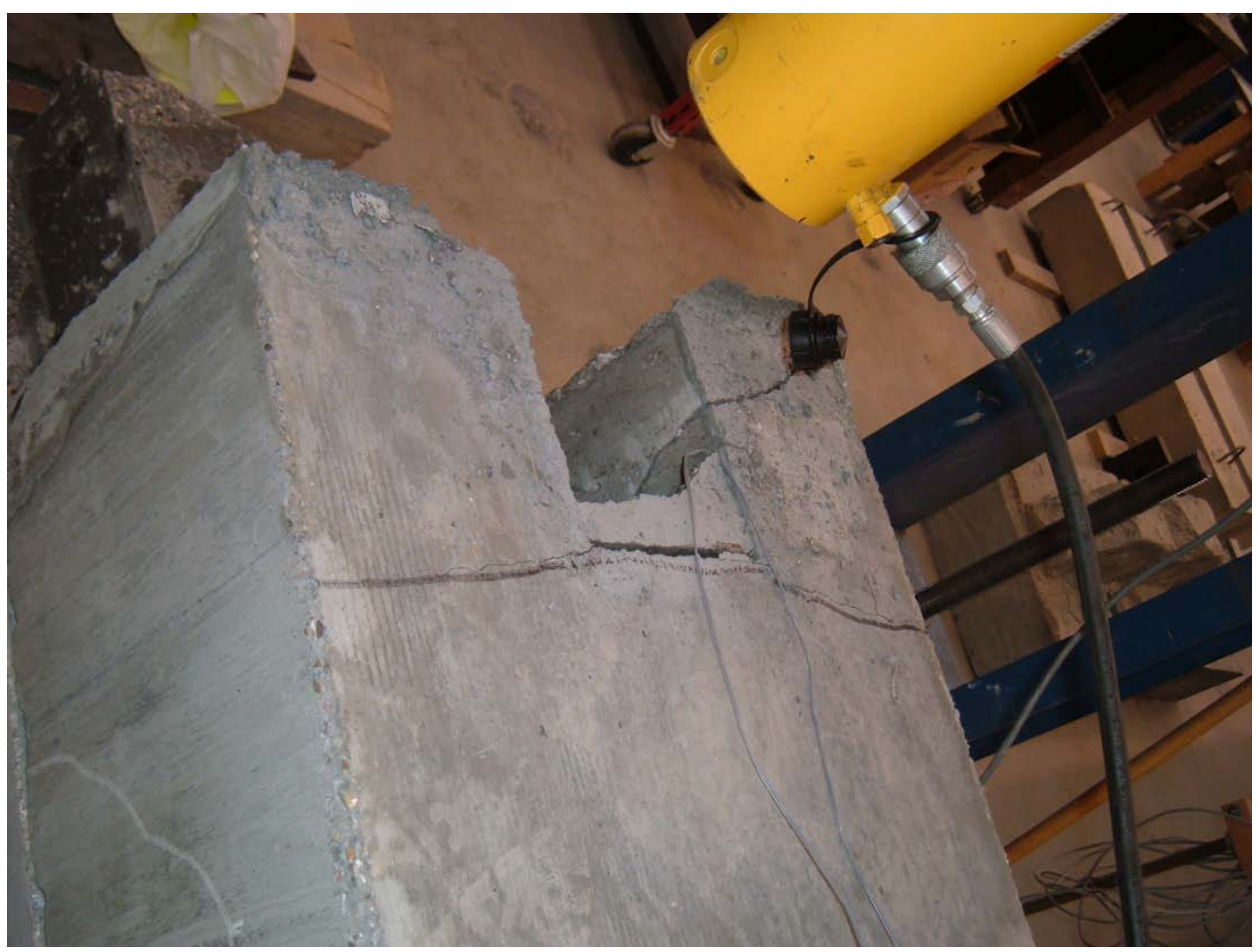

Figure 3.27: Panel separation following bond failure (1-8000-6-4)

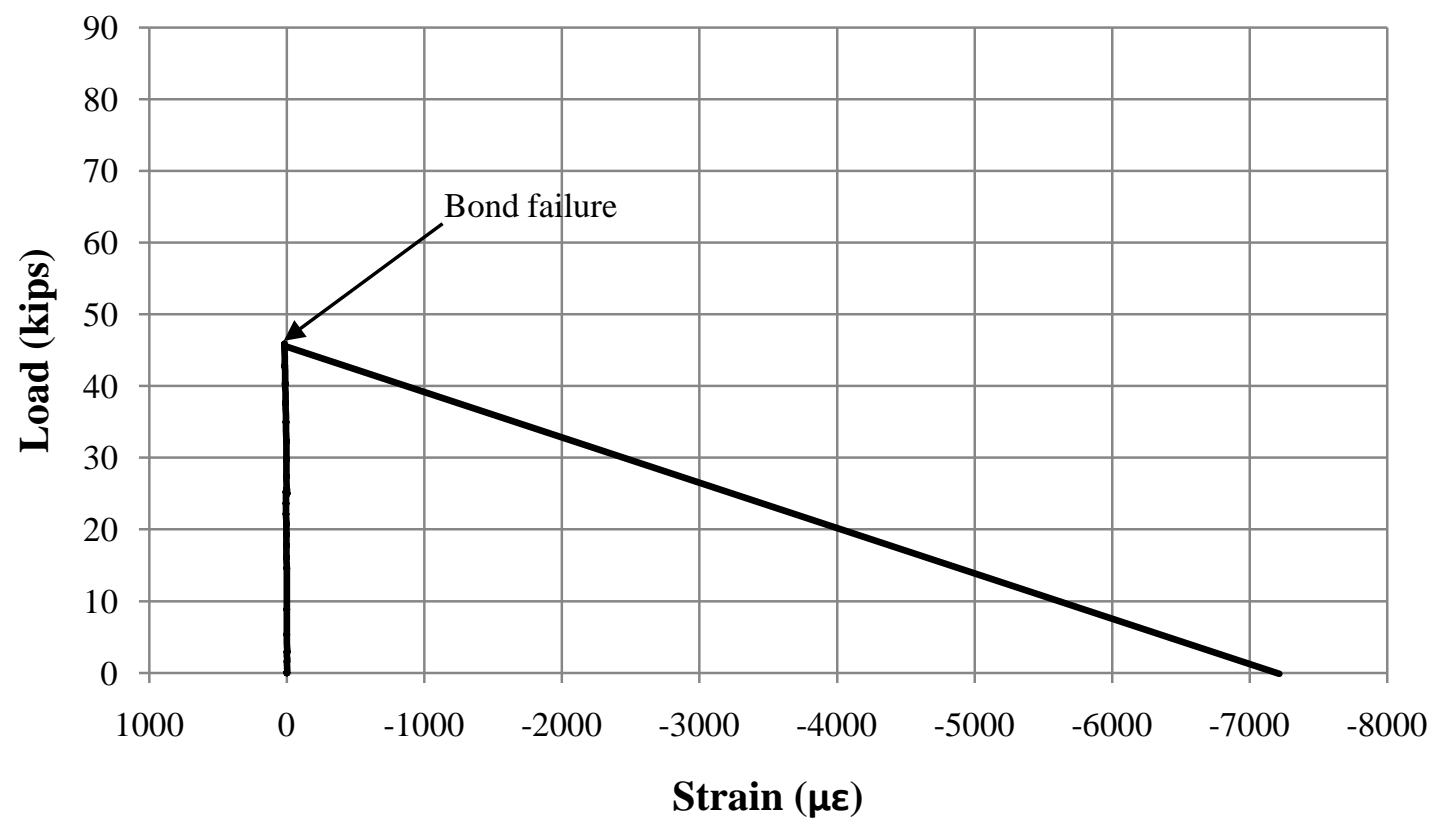

Figure 3.28: Measured shear stud strain (1-8000-6-4) 


\subsubsection{Specimen 1-8000-6-k-4}

The load-slip response for Specimen 1-8000-6-k-4 is presented in Figure 3.29. The specimen behaved as a composite section up to a load of approximately 77.4 kips at which bond failure occurred at the panel-haunch interface. Loading of the specimen continued to a second peak of 10.4 kips at which a horizontal crack formed at the midheight of the trough. Continued loading produced a vertical crack down the middle of the trough (Figure 3.30). The panel continued to deflect with no increase in applied load. Although the panel section did not fall away from the girder section during testing the damage to the trough material was evident during specimen removal. The panel section was easily removed from the girder section because of the damage to the trough, as presented in Figure 3.31. A maximum measured shear stud strain of $57 \mu \varepsilon$ occurred immediately prior to bond failure. The strain gauge failed once bond failure occurred.

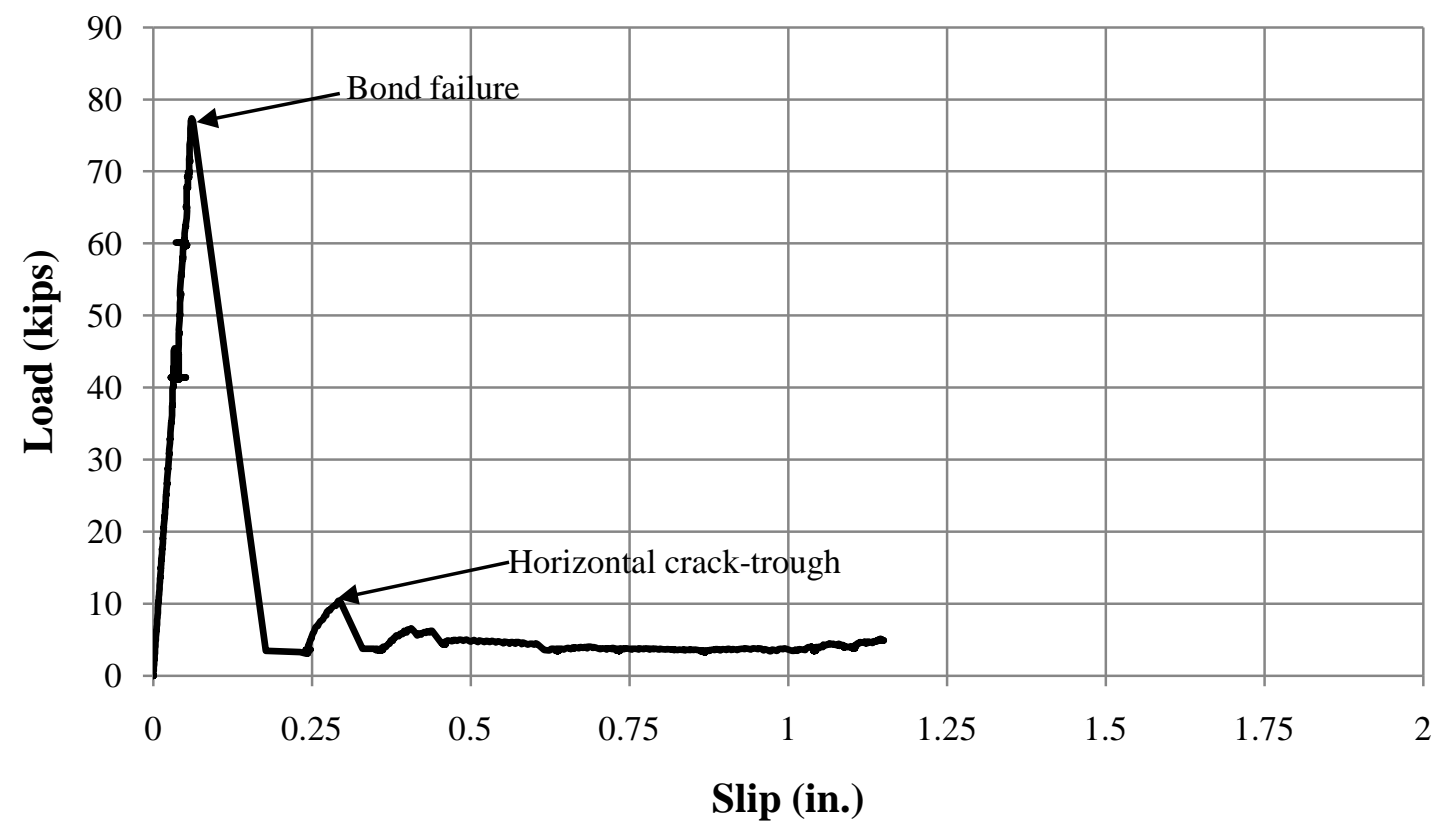

Figure 3.29: Load-slip response of Specimen 1-8000-6-k-4 


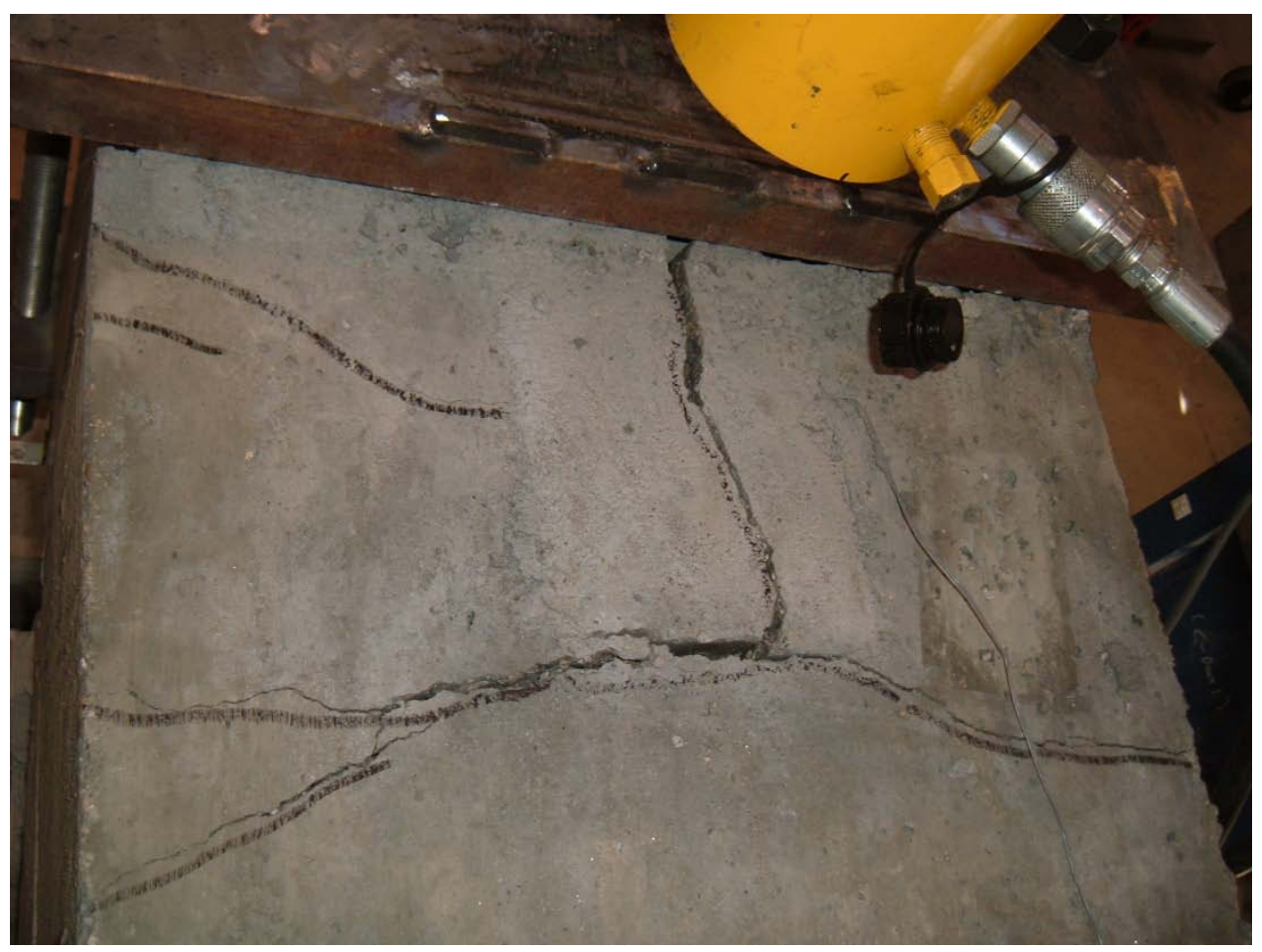

Figure 3.30: Cracking of girder section and trough (1-8000-6-k-4)

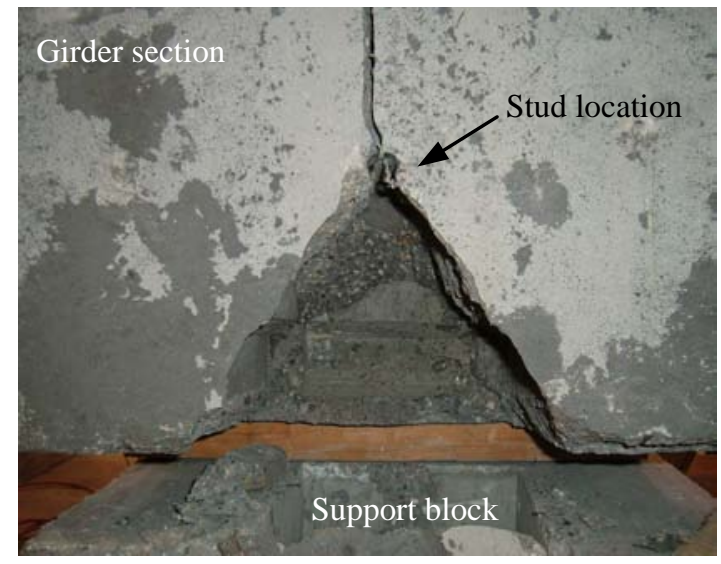

Girder section

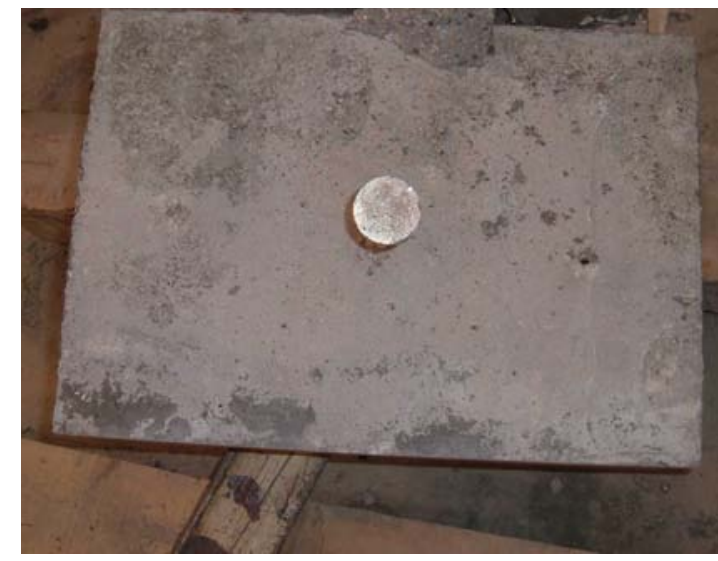

Panel section

Figure 3.31: Damage to trough concrete of Specimen 1-8000-6-k-4

\subsubsection{Specimen 1-8000-6-6}

The load-slip response for Specimen 1-8000-6-6 is presented in Figure 3.32. The specimen behaved as a composite section up to a load of approximately 58.6 kips at 
which bond failure occurred at the trough-girder section interface. The panel and trough material completely separated from the girder section. No cracks were observed prior to bond failure. A maximum measured shear stud strain of $69 \mu \varepsilon$ occurred immediately prior to bond failure. The strain gauge failed once bond failure occurred.

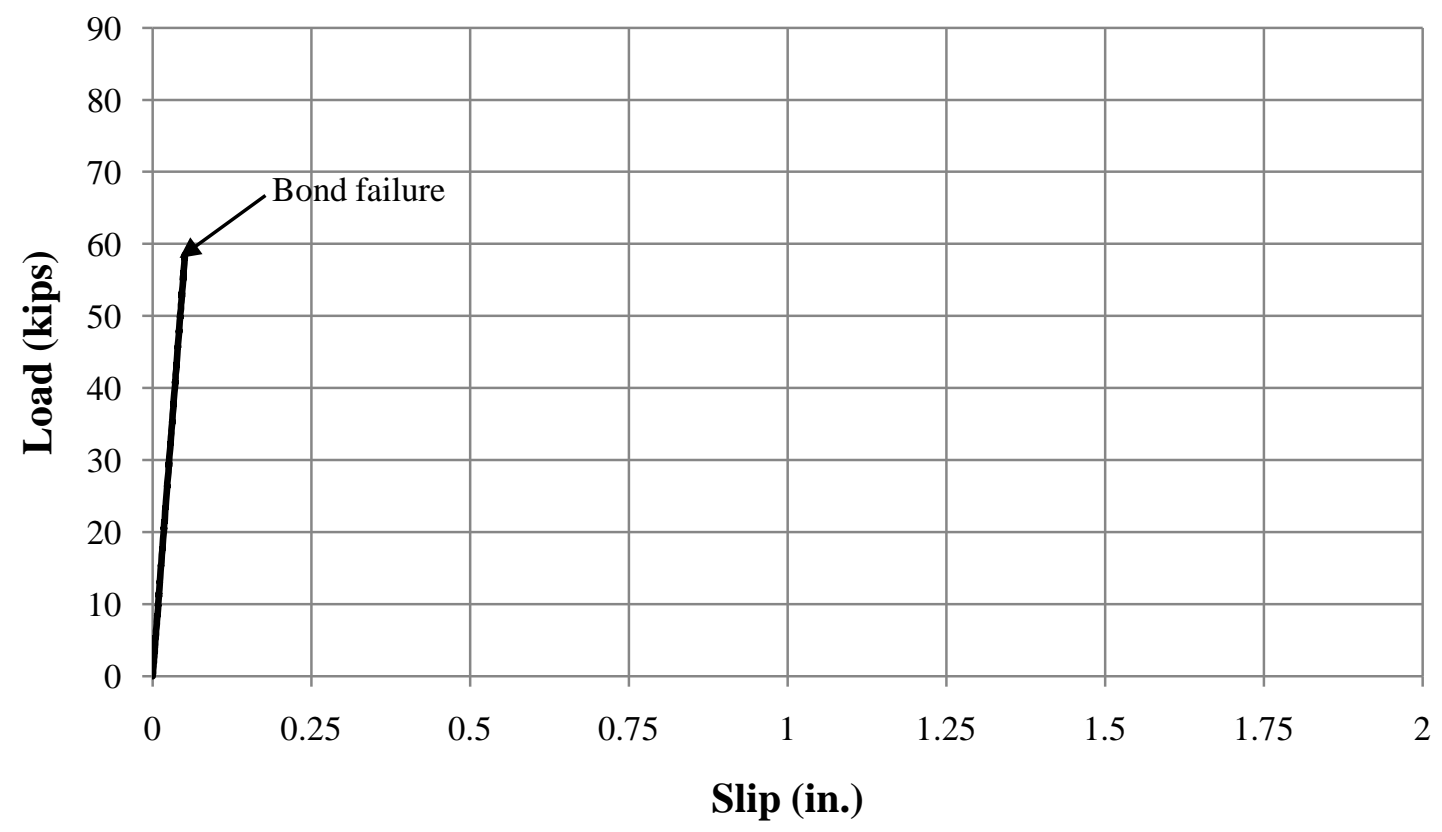

Figure 3.32: Load-slip response of Specimen 1-8000-6-6 


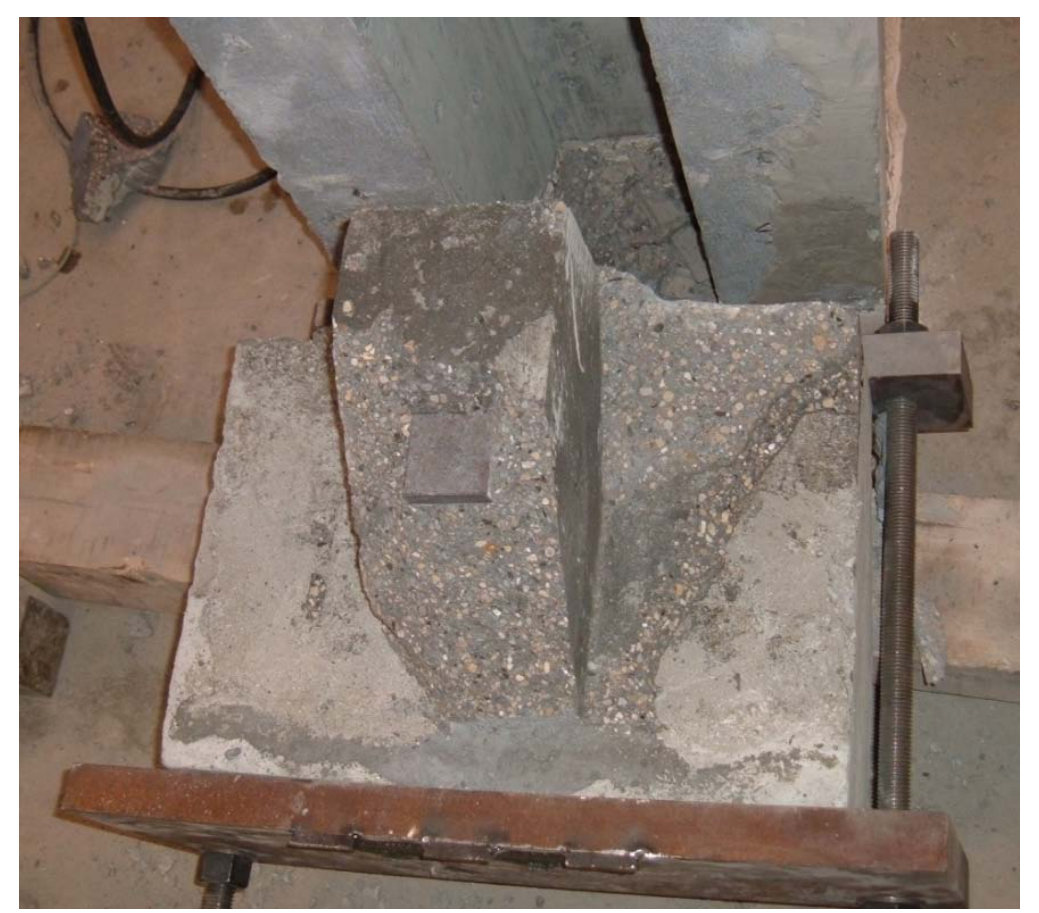

Figure 3.33: Separated panel section

\subsubsection{Specimen 1-8000-6-k-6}

The load-slip response for Specimen 1-8000-6-k-6 is presented in Figure 3.34. The specimen behaved as a composite section up to a load of approximately 56.3 kips at which bond failure occurred at both the trough-girder section and panel-haunch interfaces. This failure mechanism was evident from cracks along both interfaces after bond failure and prior to continued loading. Also, a crack was observed in the girder section following bond failure, which initiated at the bottom corner of the trough, as presented in Figure 3.35. No cracks were observed prior to the initial bond failure. A maximum measured shear stud strain of $8284 \mu \varepsilon$ occurred immediately after the bond failure (Figure 3.36). Measured strains indicate that the shear stud yielded. The strain gauge failed following that measurement. Loading of the specimen continued and the panel continued to deflect with no increase in applied load. Testing was halted at approximately 1.25 in. of slip due to increasing damage to the trough material and decrease in load capacity. Although the panel section did not fall away from the girder section during testing the damage to the trough material was evident during specimen 
removal. The panel section was easily removed from the girder section because of the damage to the trough, as presented in Figure 3.37.

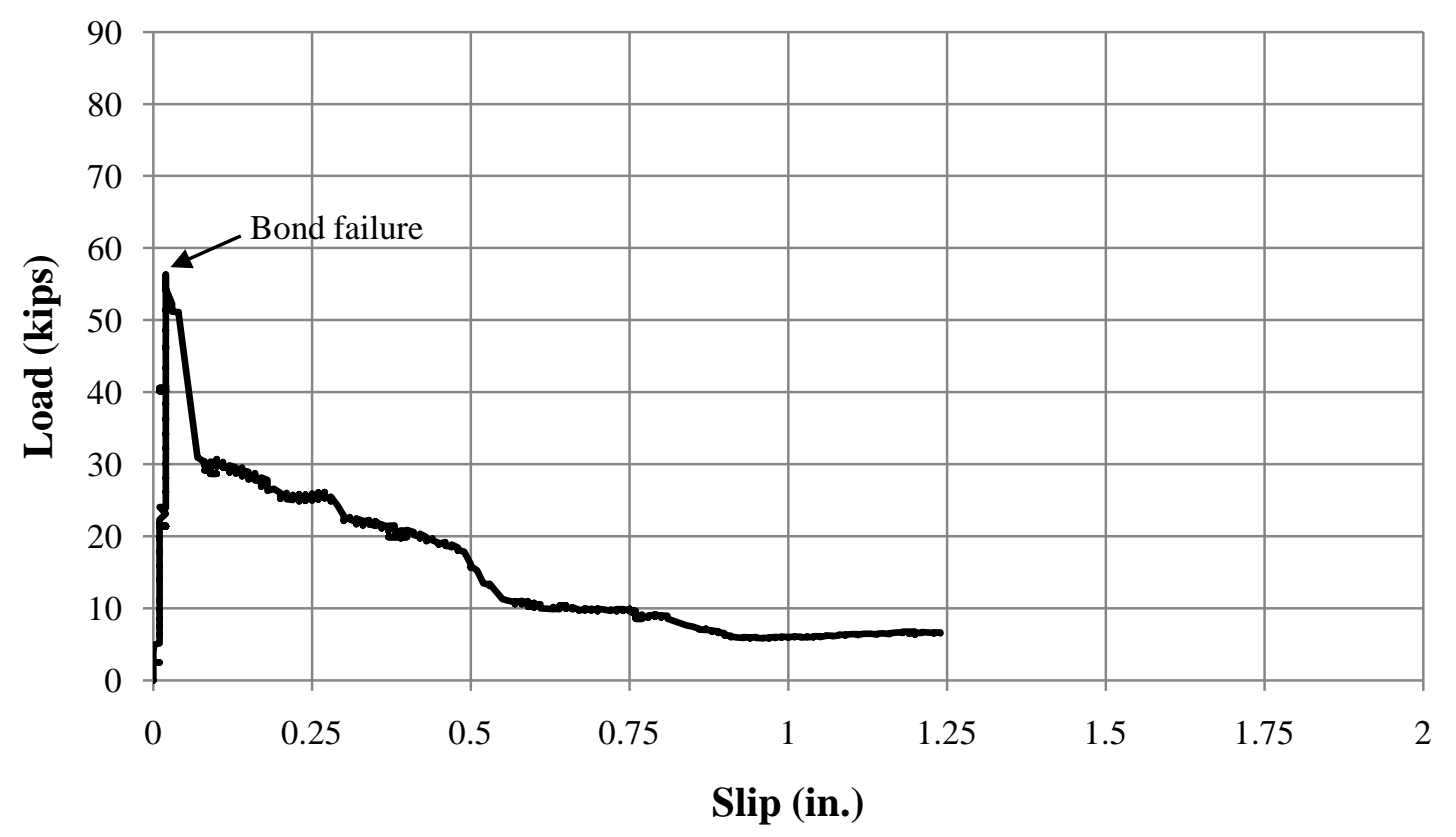

Figure 3.34: Load-slip response of Specimen 1-8000-6-k-6

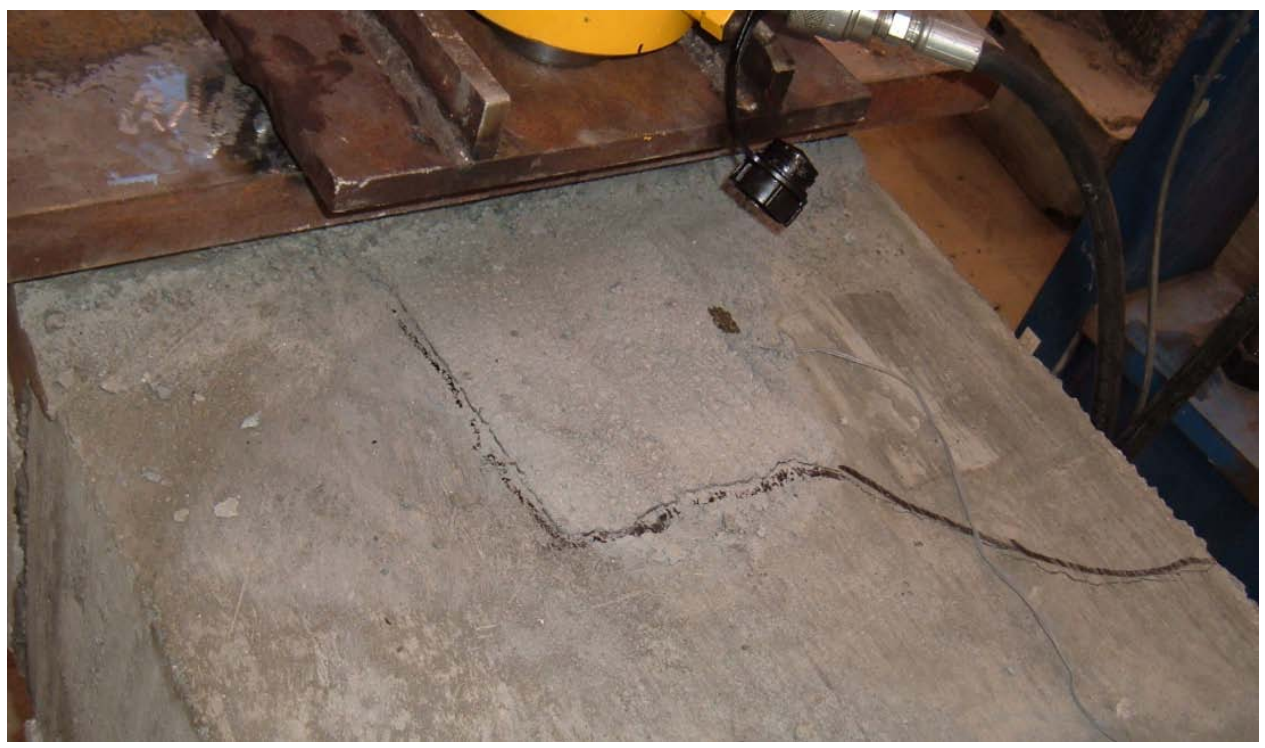

Figure 3.35: Cracking following bond failure 


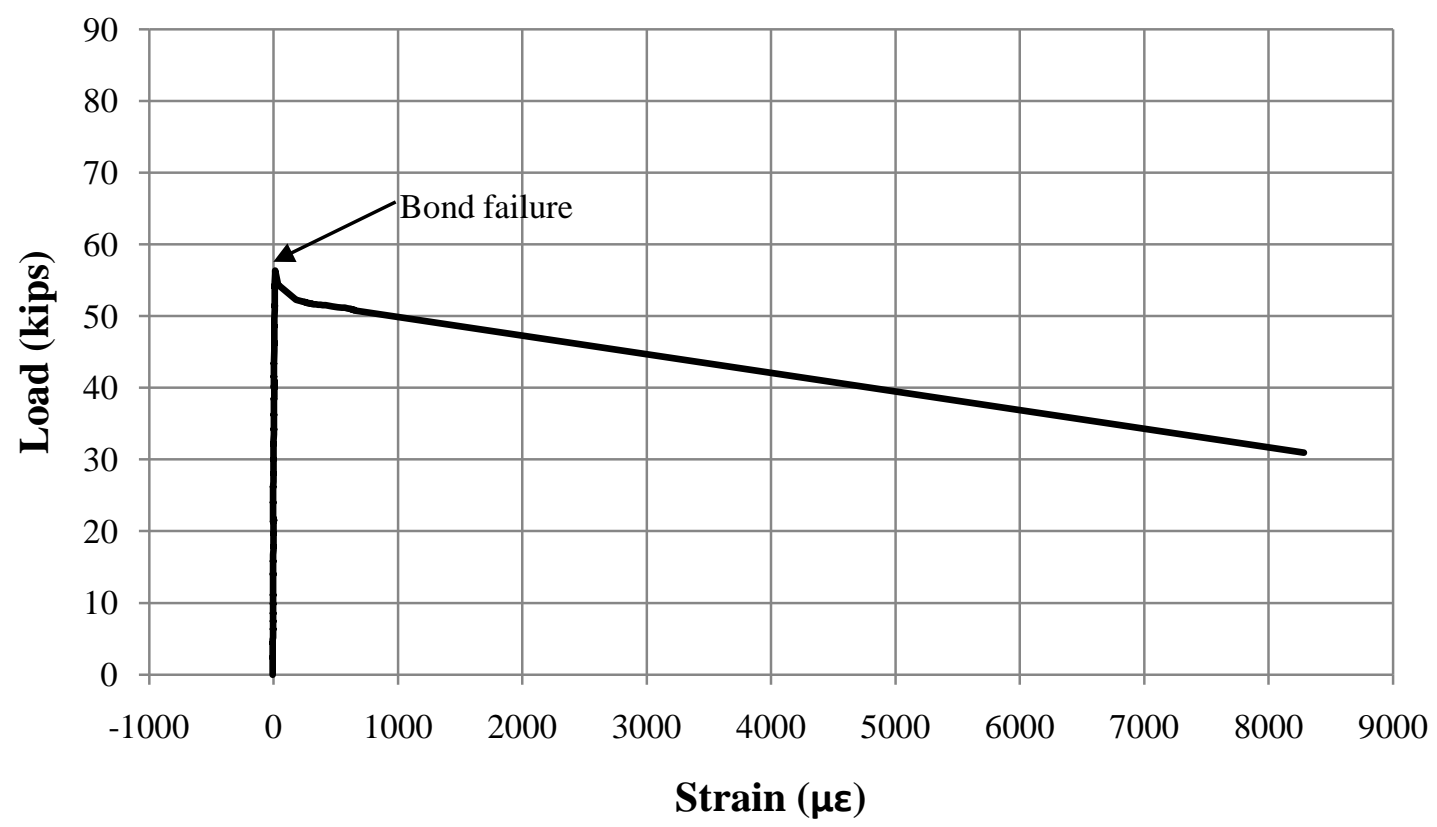

Figure 3.36: Measured shear stud strain (1-8000-6-k-6) 


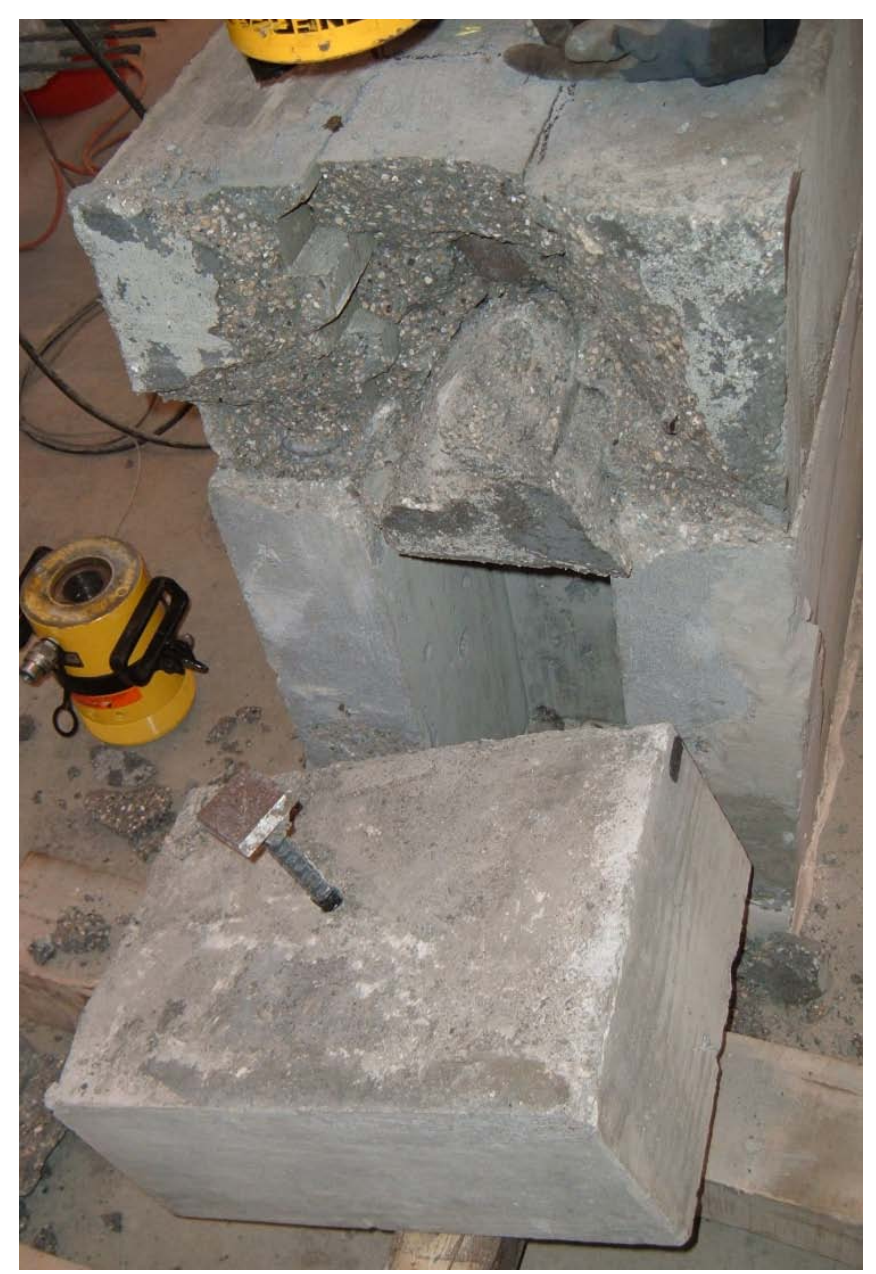

Figure 3.37: Damage to trough concrete of Specimen 1-80000-6-k-6

\subsubsection{Specimen 1-8000-6-k-4n}

The load-slip response for Specimen 1-8000-6-k-4n is presented in Figure 3.38. The specimen behaved as a composite section up to a load of approximately 47.2 kips at which bond failure occurred at the panel-haunch interface. No cracking was observed prior to or following bond failure. Loading of the specimen continued until failure of the shear stud. As shown, after the significant decrease in capacity following bond failure, load was increased with increasing slip until the shear stud failed at a load of 21.2 kips. The panel section and failed shear stud are presented in Figure 3.39. A maximum measured strain of $8681 \mu \varepsilon$ occurred immediately prior to shear stud failure (Figure 3.40). 


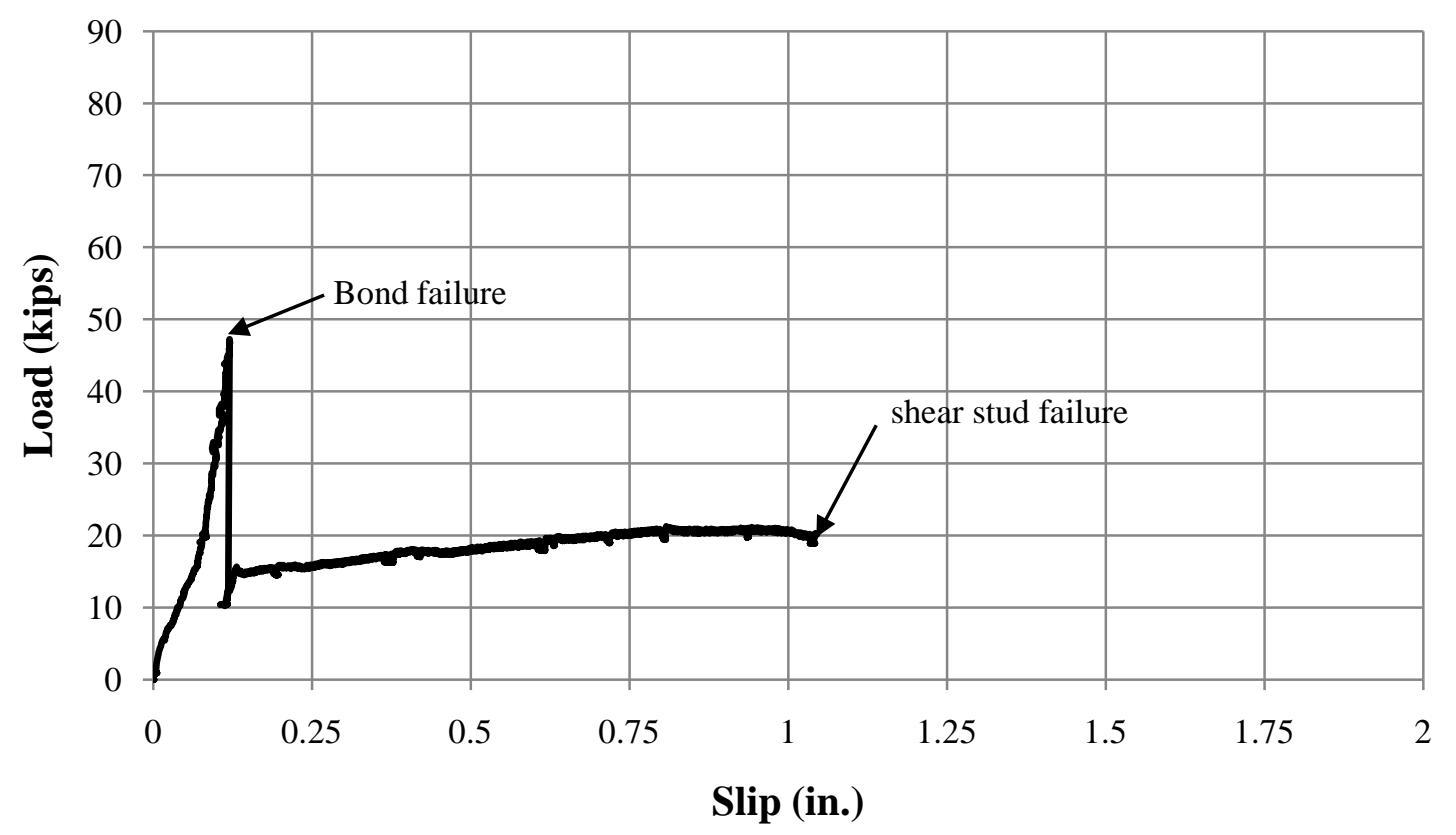

Figure 3.38: Load-slip response for Specimen 1-8000-6-k-4n

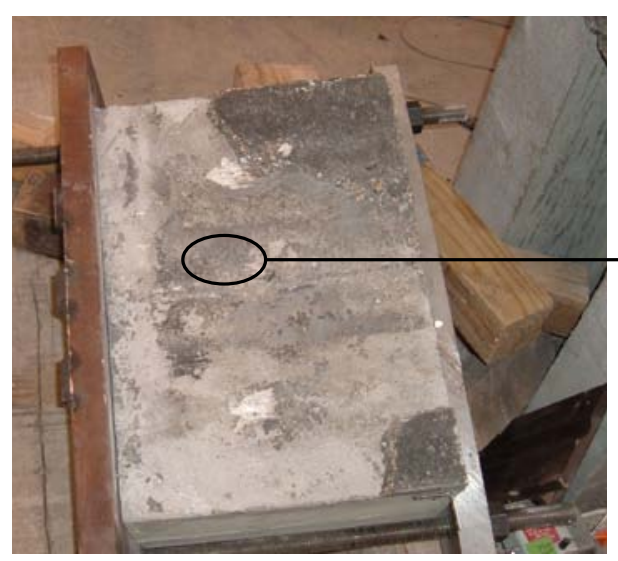

Panel section

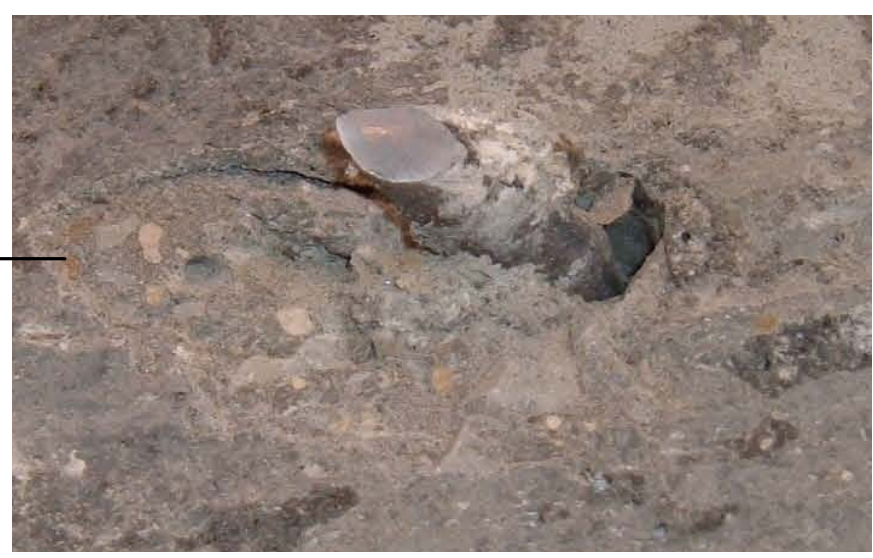

\#4 stud

Figure 3.39: Shear stud failure of Specimen 1-8000-6-k-4n 


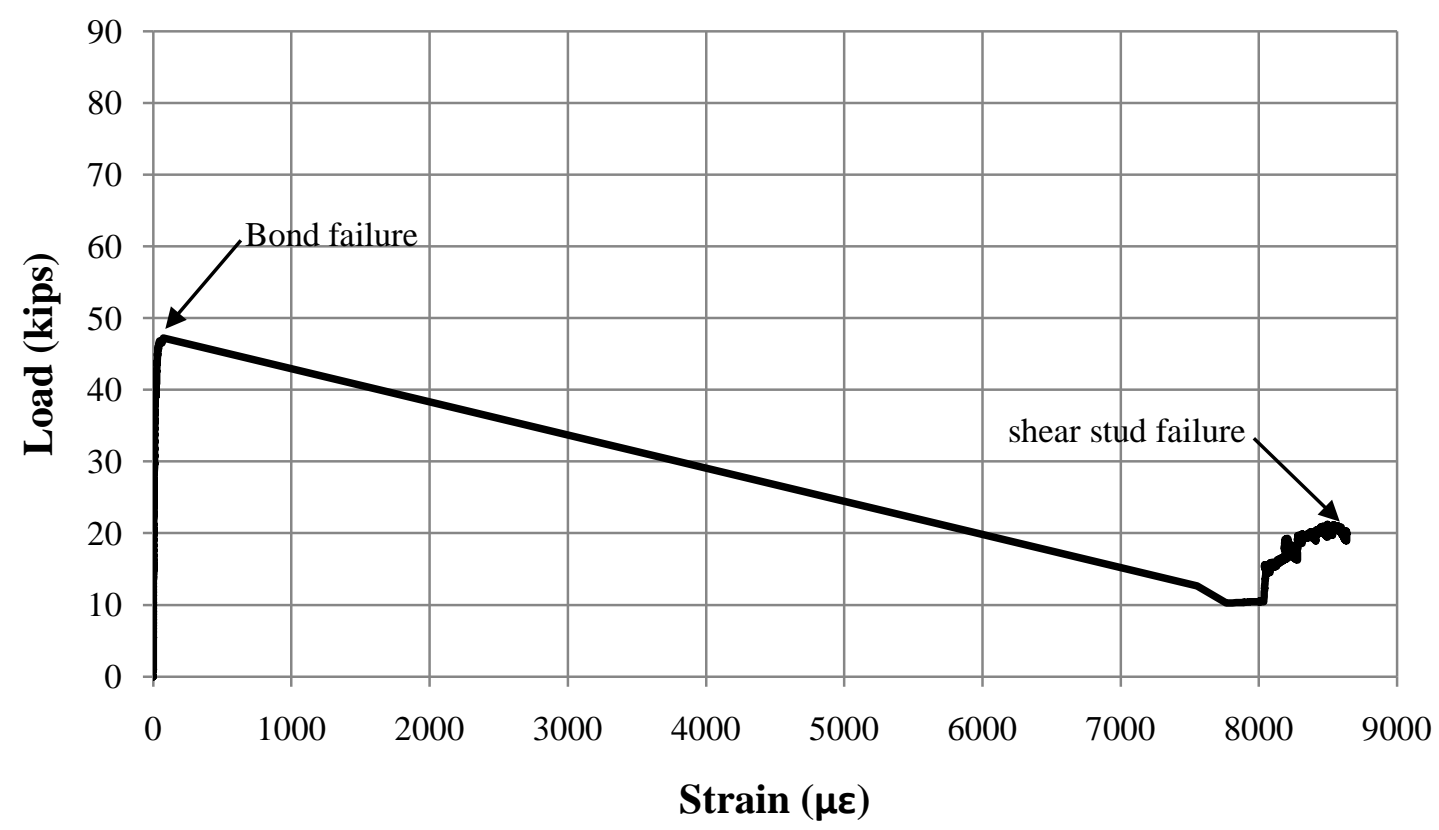

Figure 3.40: Measured shear stud strain (1-8000-6-k-4n)

\subsubsection{2 ft Specimens}

\subsubsection{Specimen 2-4000-6-4}

The load-slip response for Specimen 2-4000-6-4 is presented in Figure 3.41. The specimen behaved as a composite section up to a load of approximately 90.9 kips at which bond failure occurred at the panel-haunch interface. No cracking was observed prior to, or following bond failure. Loading of the specimen continued until failure of the shear stud. A maximum measured shear stud strain of $6543 \mu \varepsilon$ occurred immediately prior to failure of the shear stud (Figure 3.42). Measured strains indicate that the shear stud yielded. The panel section with failed shear stud is presented in Figure 3.43. 


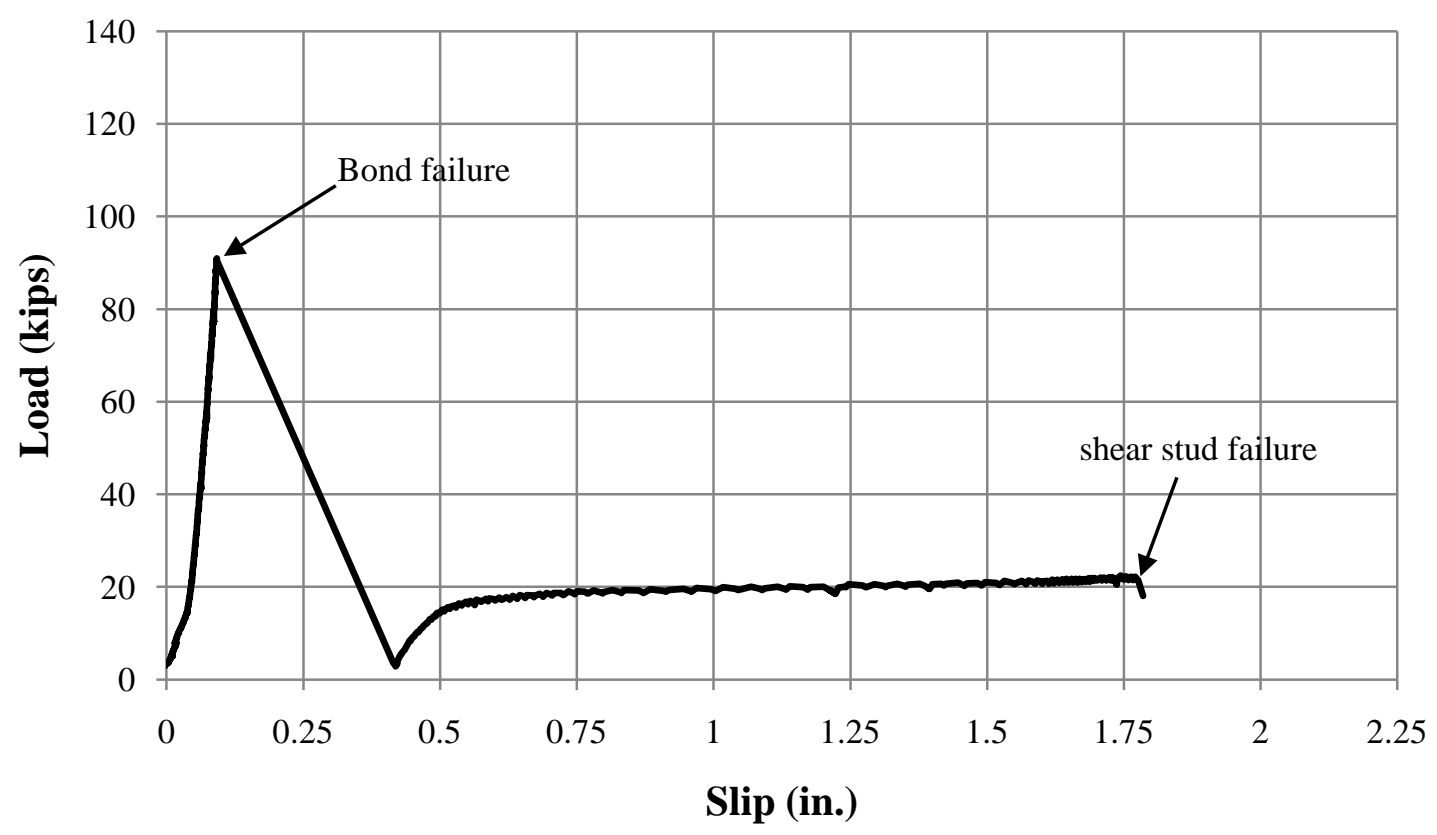

Figure 3.41: Load-slip response of Specimen 2-4000-6-4

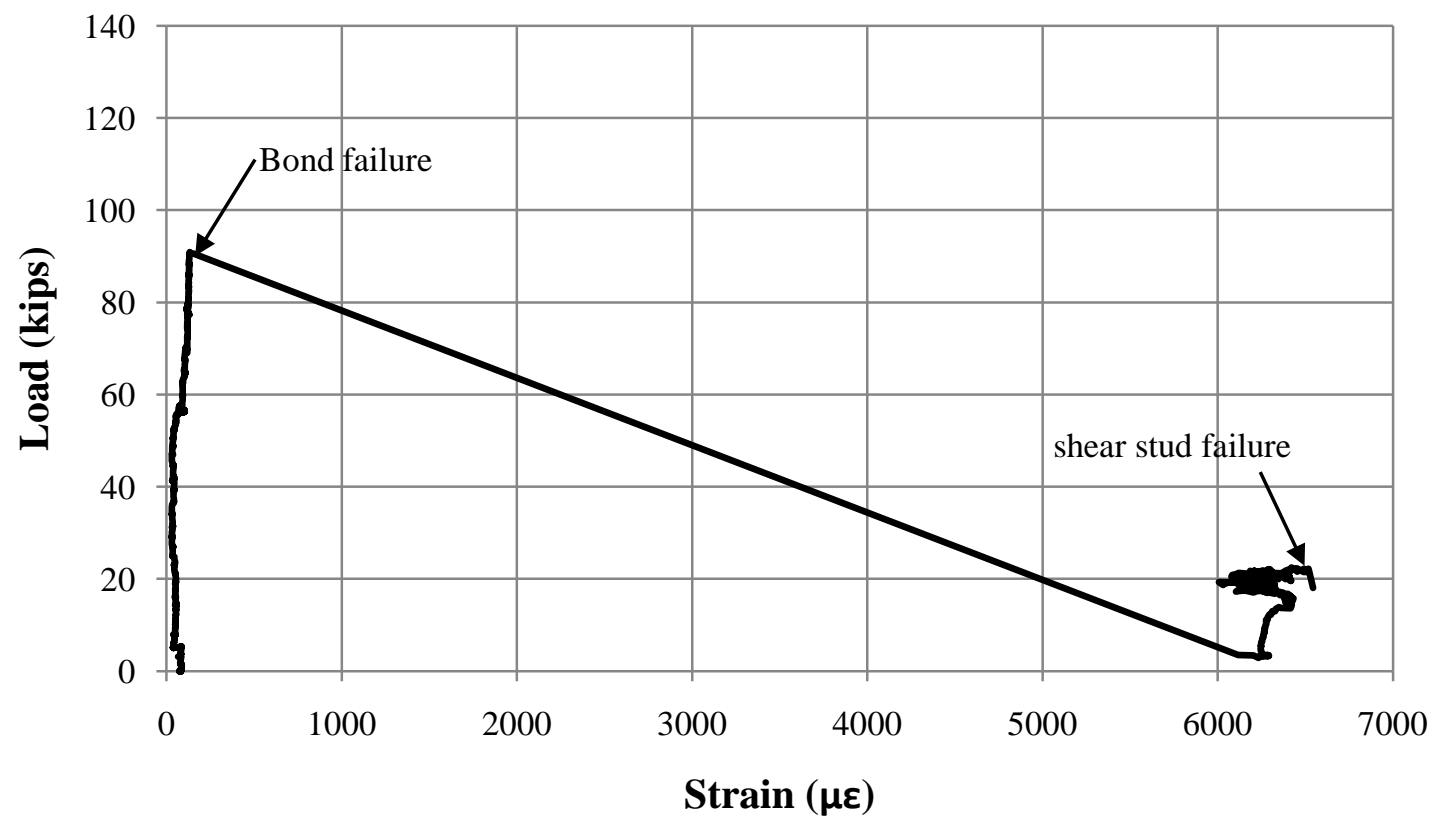

Figure 3.42: Measured shear stud strain (2-4000-6-4) 


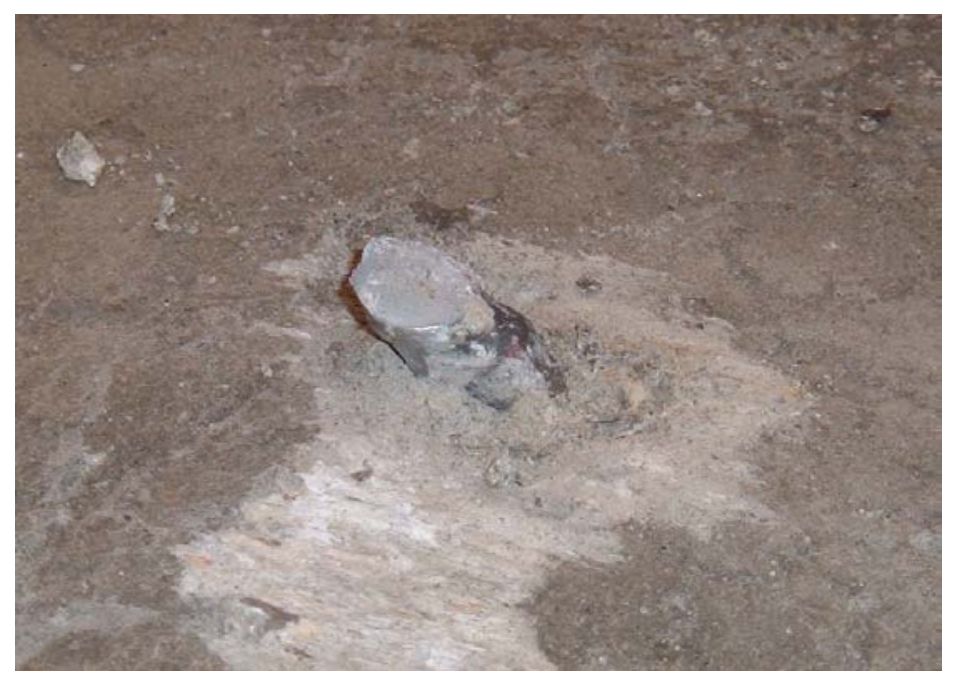

Figure 3.43: Failed shear stud of Specimen 2-4000-6-4

\subsubsection{Specimen 2-4000-6-6}

The load-slip response for Specimen 2-4000-6-6 is presented in Figure 3.44. The specimen behaved as a composite section up to a load of approximately 133.1 kips at which bond failure occurred at the panel-haunch interface. No cracking was observed prior to or immediately following bond failure. Loading of the specimen continued until bond failure of the trough-girder section interface. Following the second bond failure, the panel section began to rotate away from the girder section (Figure 3.45) as the trough was being pulled from the girder section, as presented in Figure 3.46. The test was halted due to the decreasing load capacity and rotation of the panel section. A maximum measured shear stud strain of $3913 \mu \varepsilon$ occurred immediately after failure of the panelhaunch interface (Figure 3.47). Measured strains indicate that the shear stud yielded. 


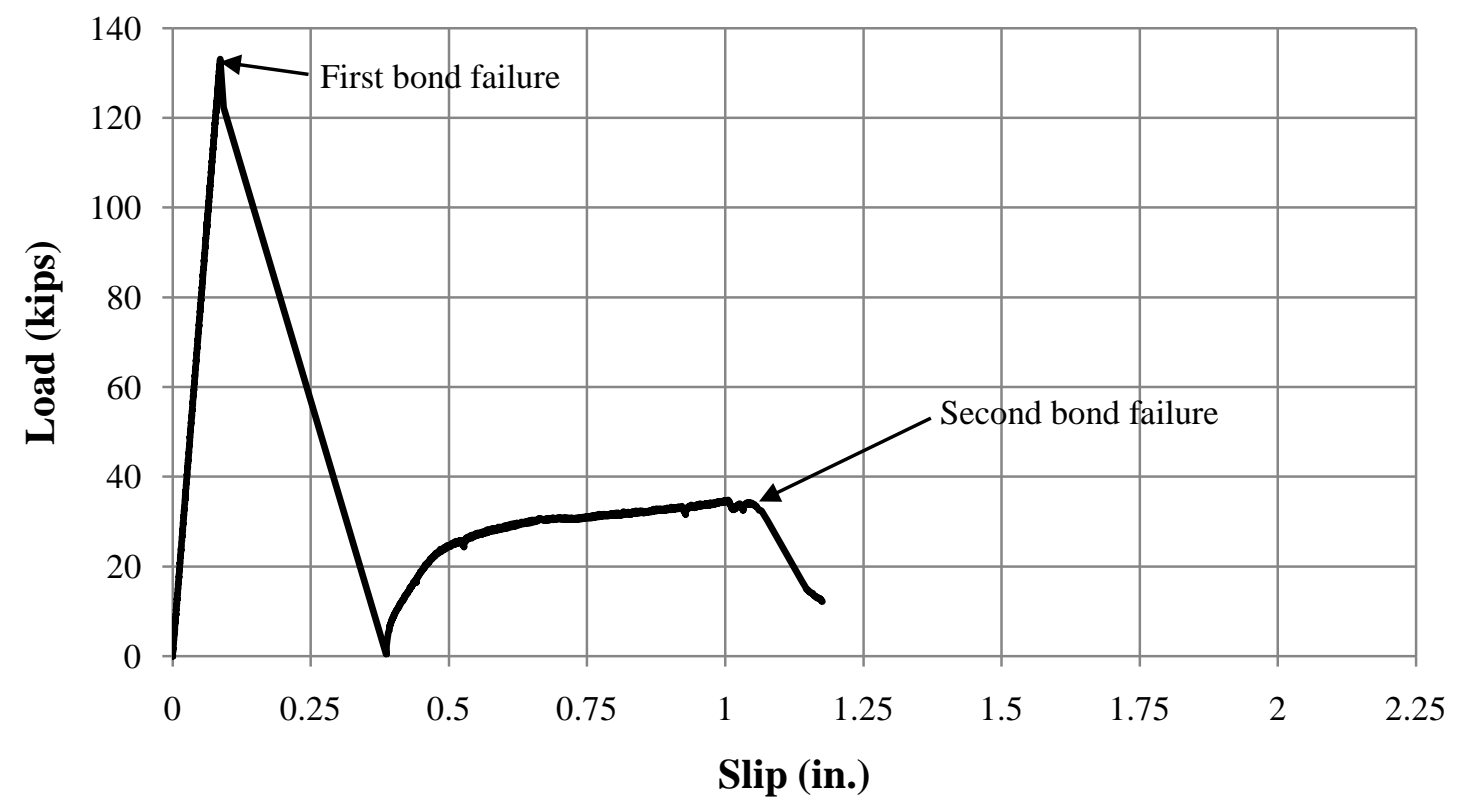

Figure 3.44: Load-slip response of Specimen 2-4000-6-6 


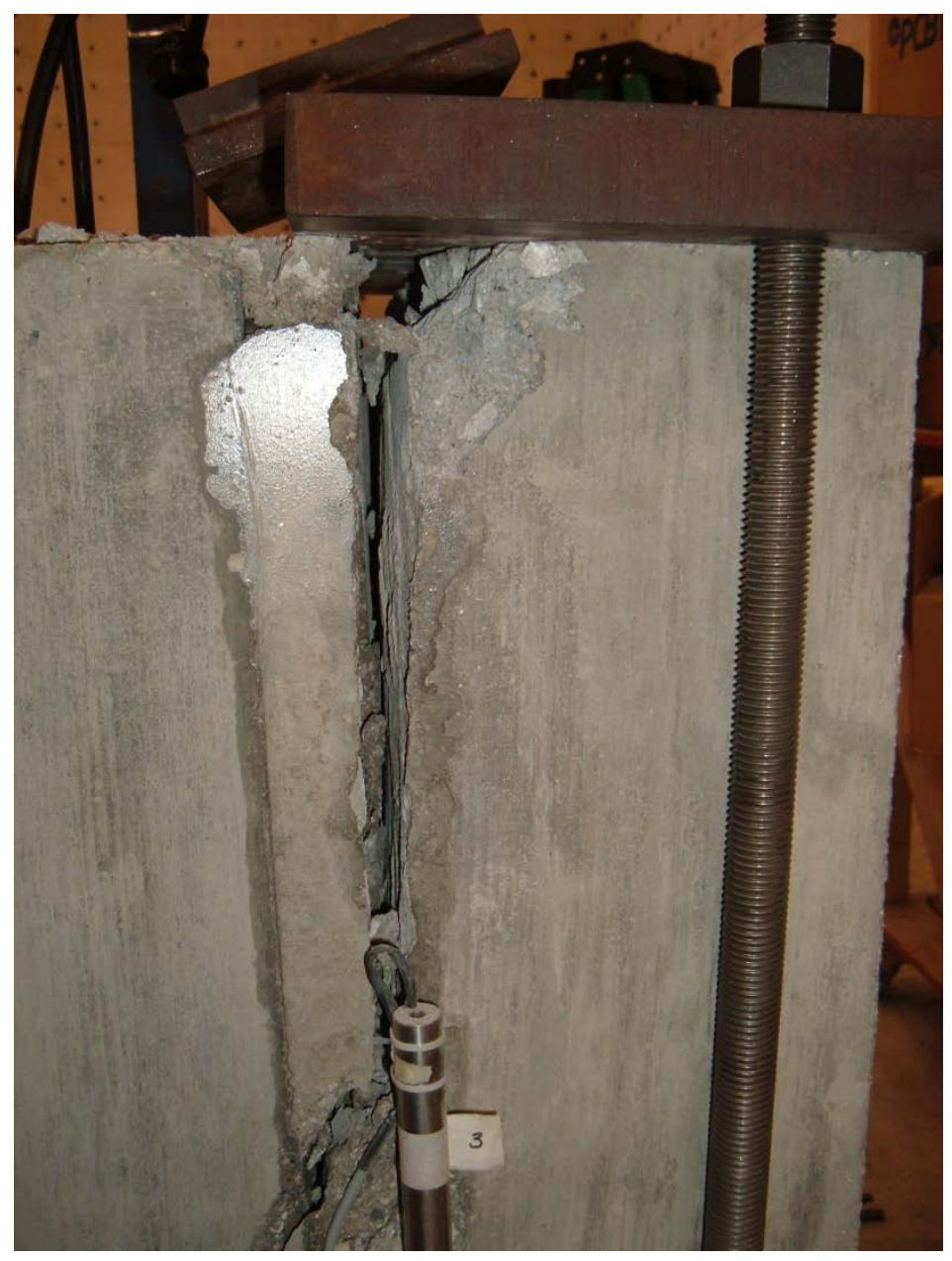

Figure 3.45: Rotation of panel section following second bond failure (2-4000-6-6) 


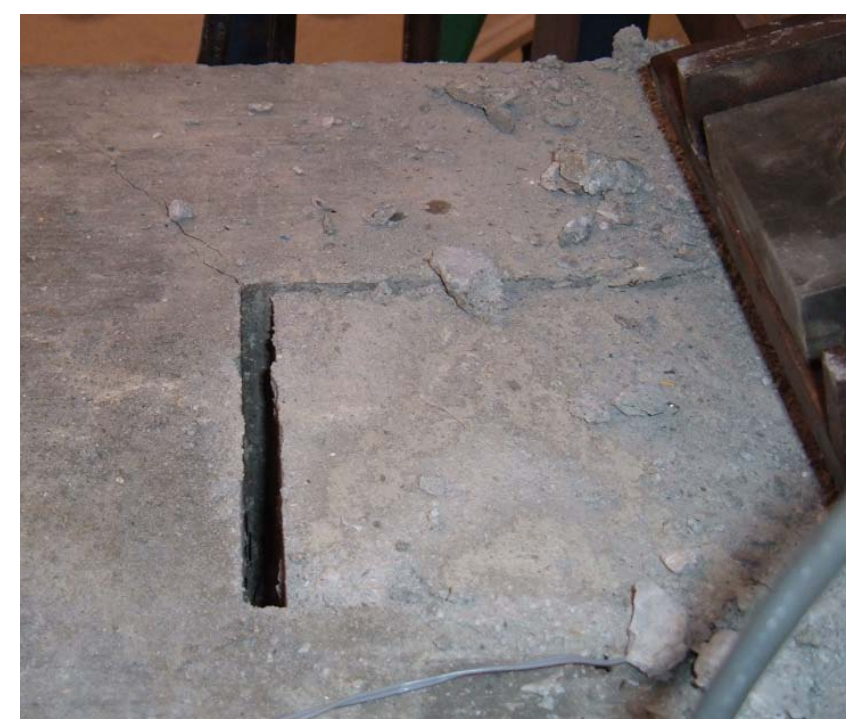

Figure 3.46: Pulling out of trough concrete from girder section (2-4000-6-6)

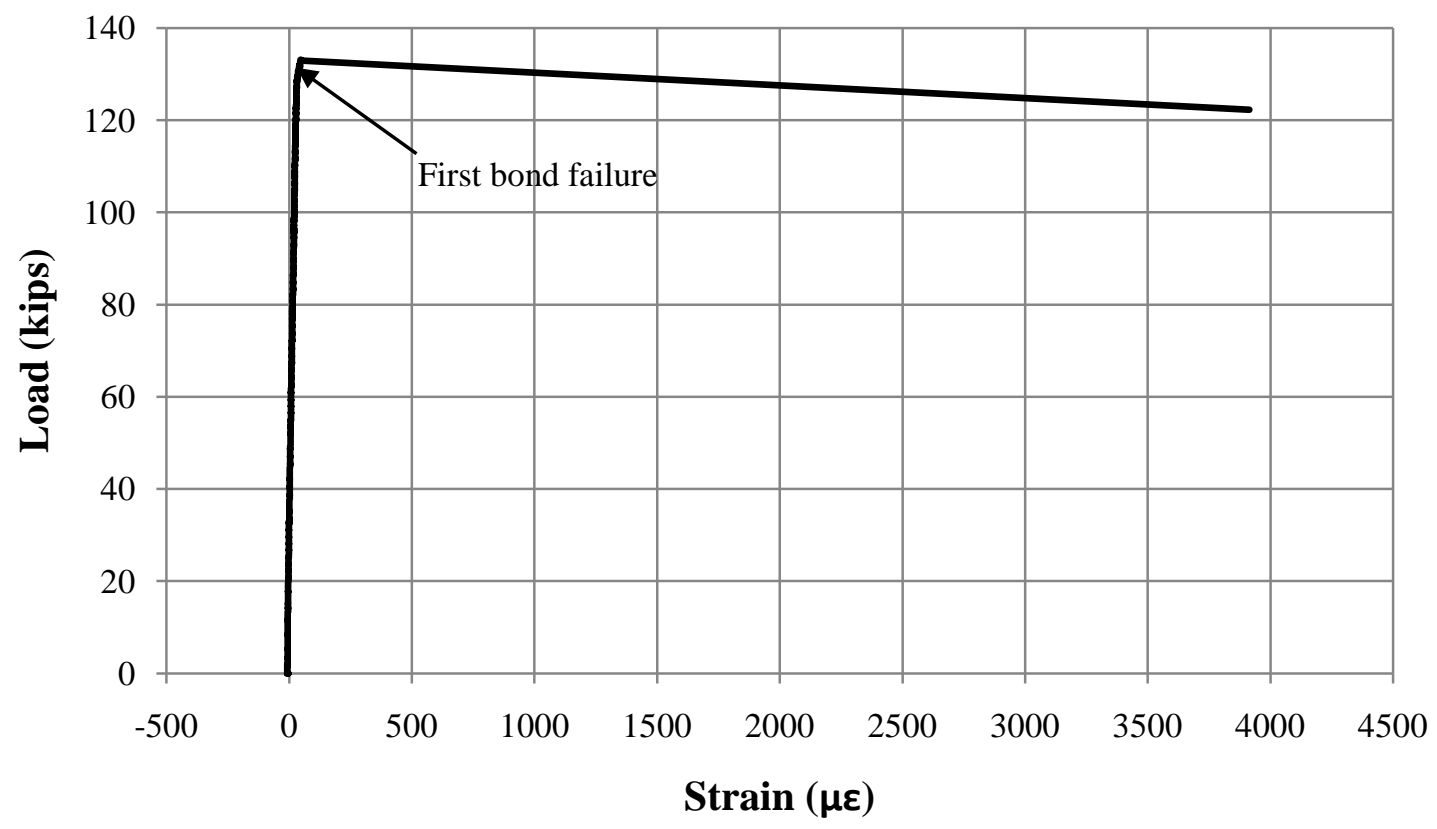

Figure 3.47: Measured shear stud strain (2-4000-6-6) 


\subsubsection{Specimen $2-4000-6-k-4$}

The load-slip response for Specimen 2-4000-6-k-4 is presented in Figure 3.48.

The specimen behaved as a composite section up to a load of approximately 110.8 kips at which bond failure occurred at the panel-haunch interface. No cracking was observed prior to, or following bond failure. Loading of the specimen continued until failure of the shear stud, as presented in Figure 3.49. A maximum measured shear stud strain of $56 \mu \varepsilon$ occurred prior to bond failure. The strain gauge went off-scale once bond failure occurred.

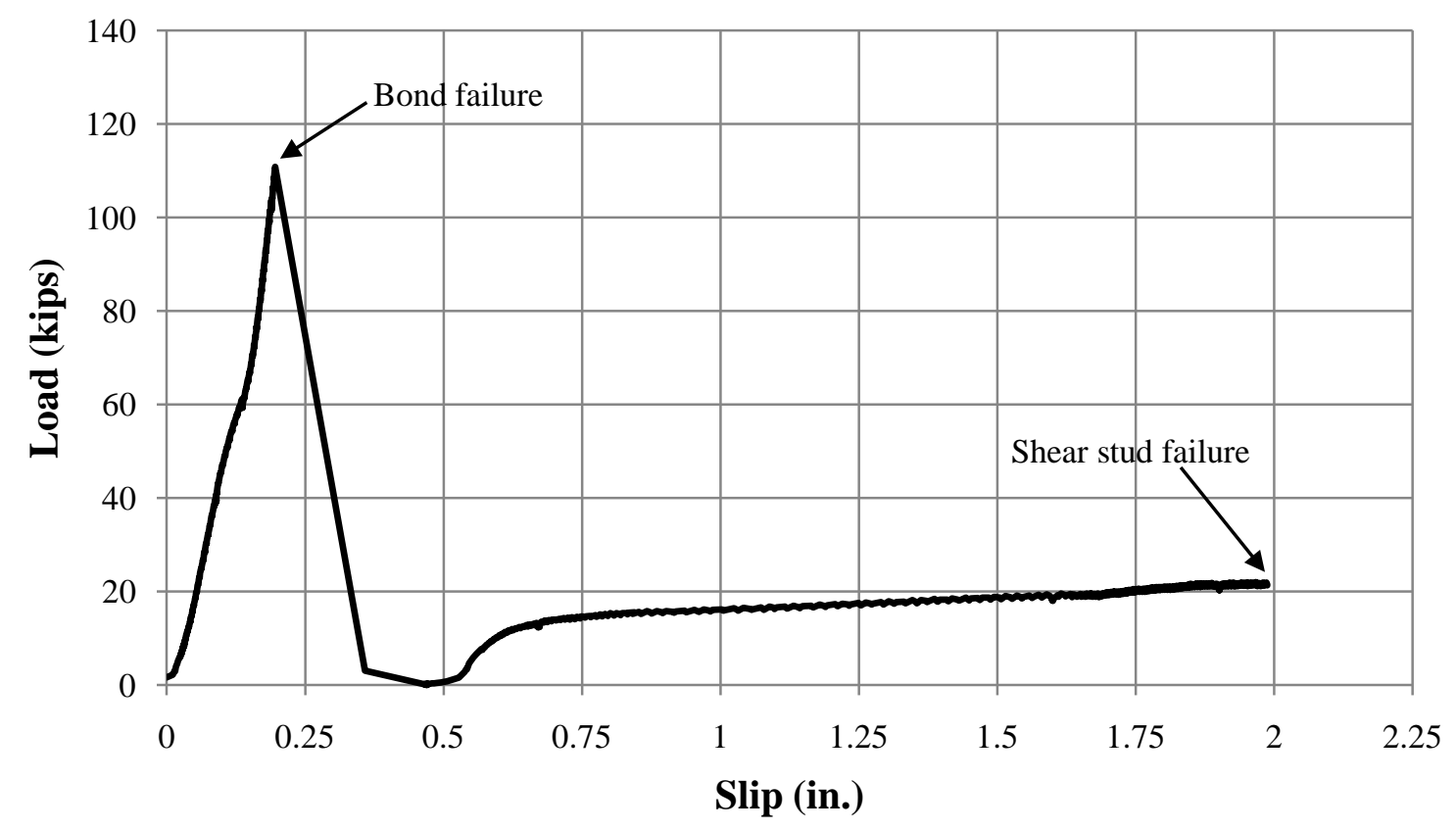

Figure 3.48: Load-slip response of Specimen 2-4000-6-k-4 


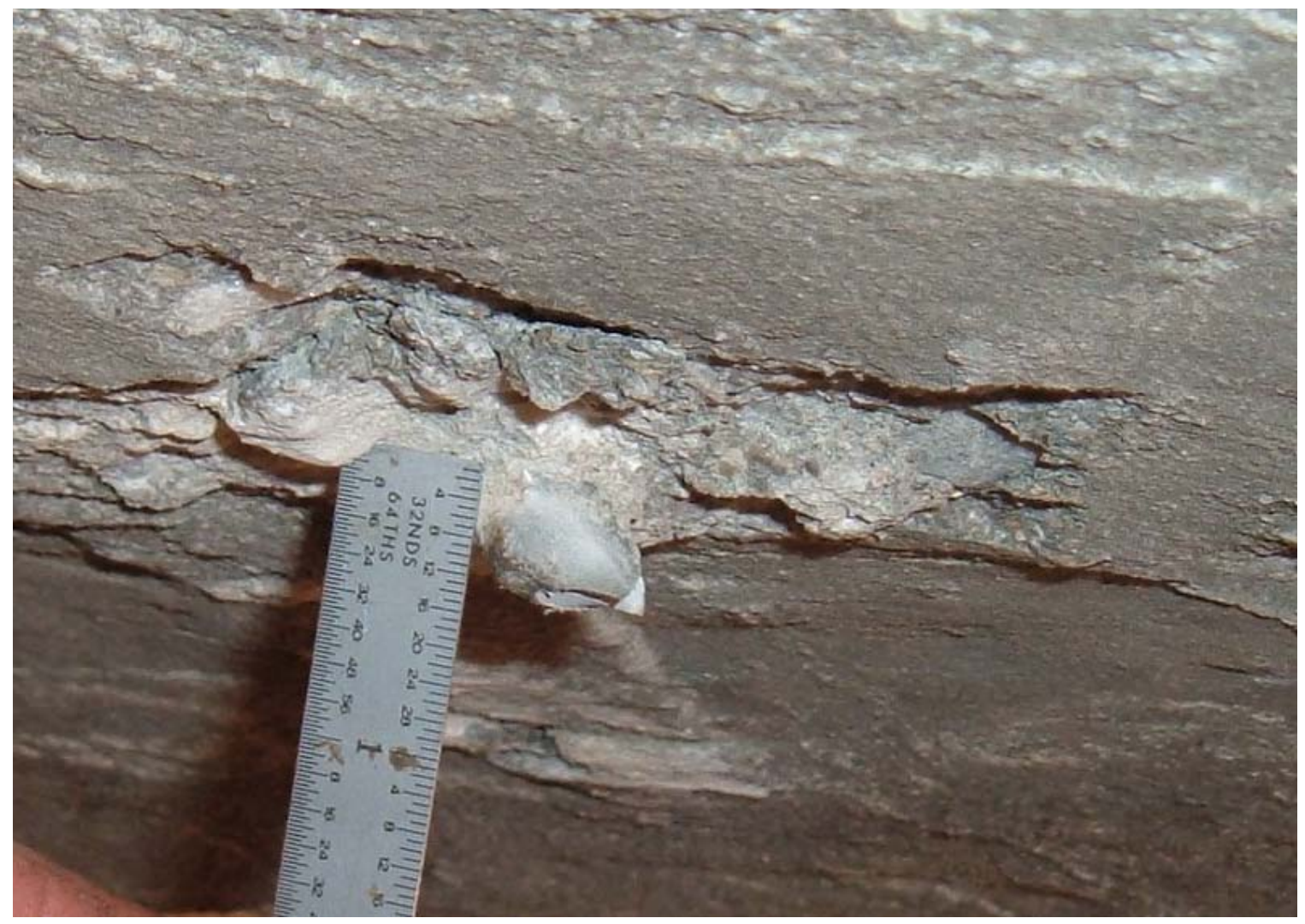

Figure 3.49: Failed shear stud of Specimen 2-4000-6-k-4

\subsubsection{Specimen 2-4000-6-k-6}

The load-slip response for Specimen 2-4000-6-k-6 is presented in Figure 3.50. The specimen behaved as a composite section up to a load of approximately 86.2 kips at which bond failure occurred at the panel-haunch interface. No cracking was observed prior to, or immediately following bond failure. However, after continued loading, a crack was observed at the base of the trough at approximately 40 kips. The crack propagated into the girder section, initiating at the inside corners of the trough. Loading of the specimen continued to a second peak load of $44.9 \mathrm{kips}$, at which time the trough material lost load capacity due to deterioration (Figure 3.51). A maximum measured shear stud strain of $4546 \mu \varepsilon$ occurred at 40.6 kips (Figure 3.52). The strain gauge failed prior to the second peak load. Measured strains indicate that the shear stud yielded. 


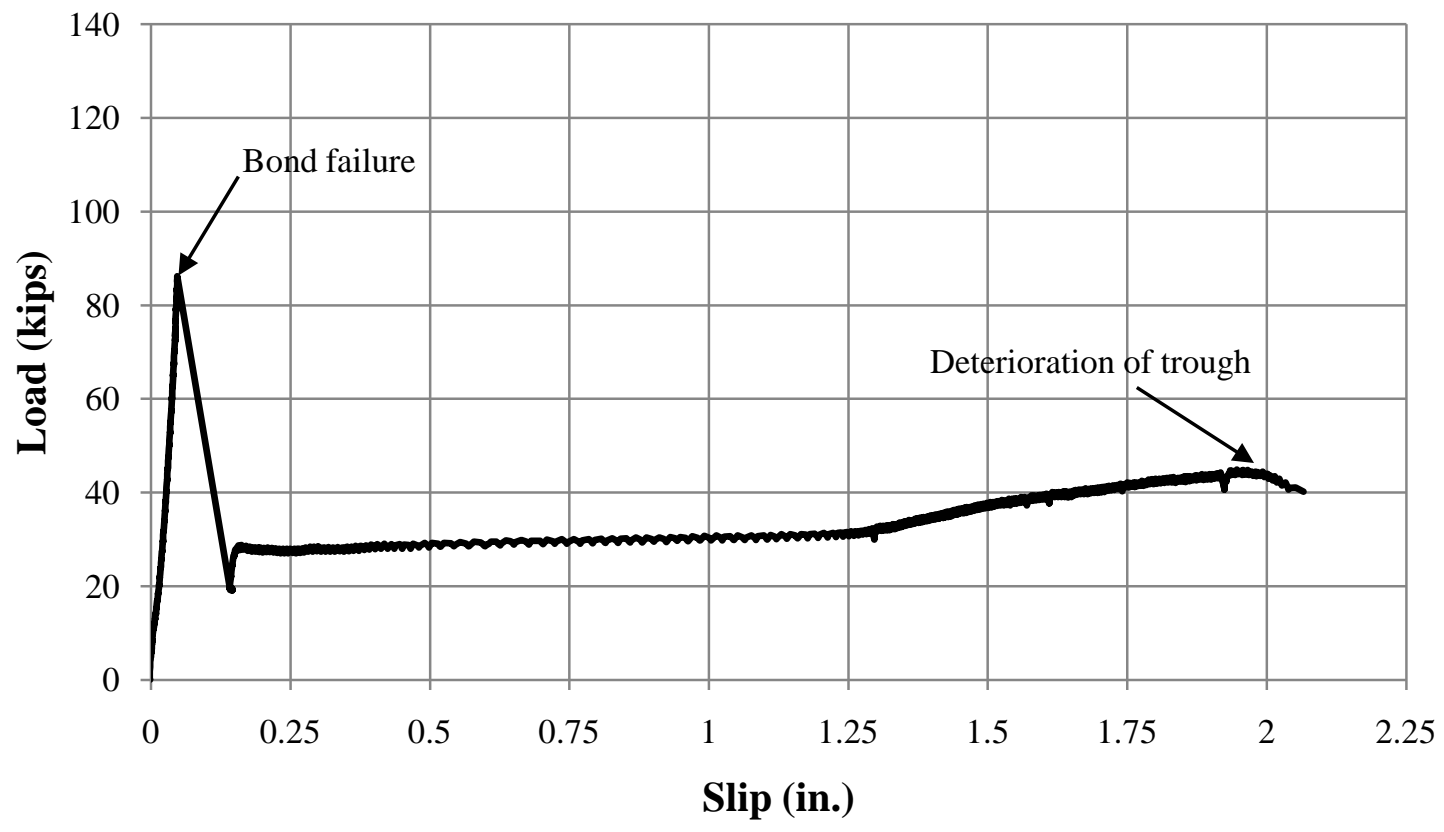

Figure 3.50: Load-slip response of Specimen 2-4000-6-k-6

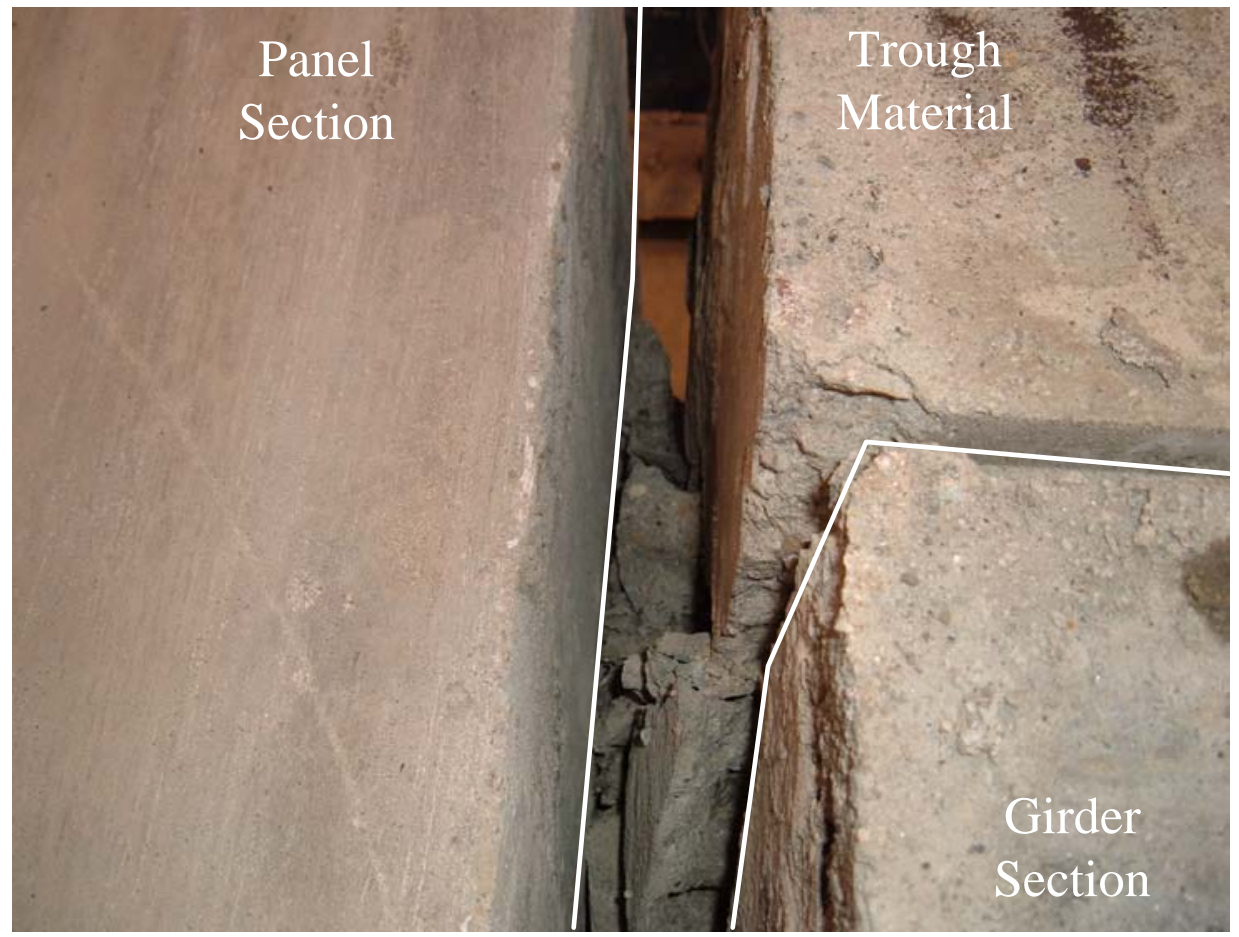

Figure 3.51: Trough deterioration of Specimen 2-4000-6-k-6 


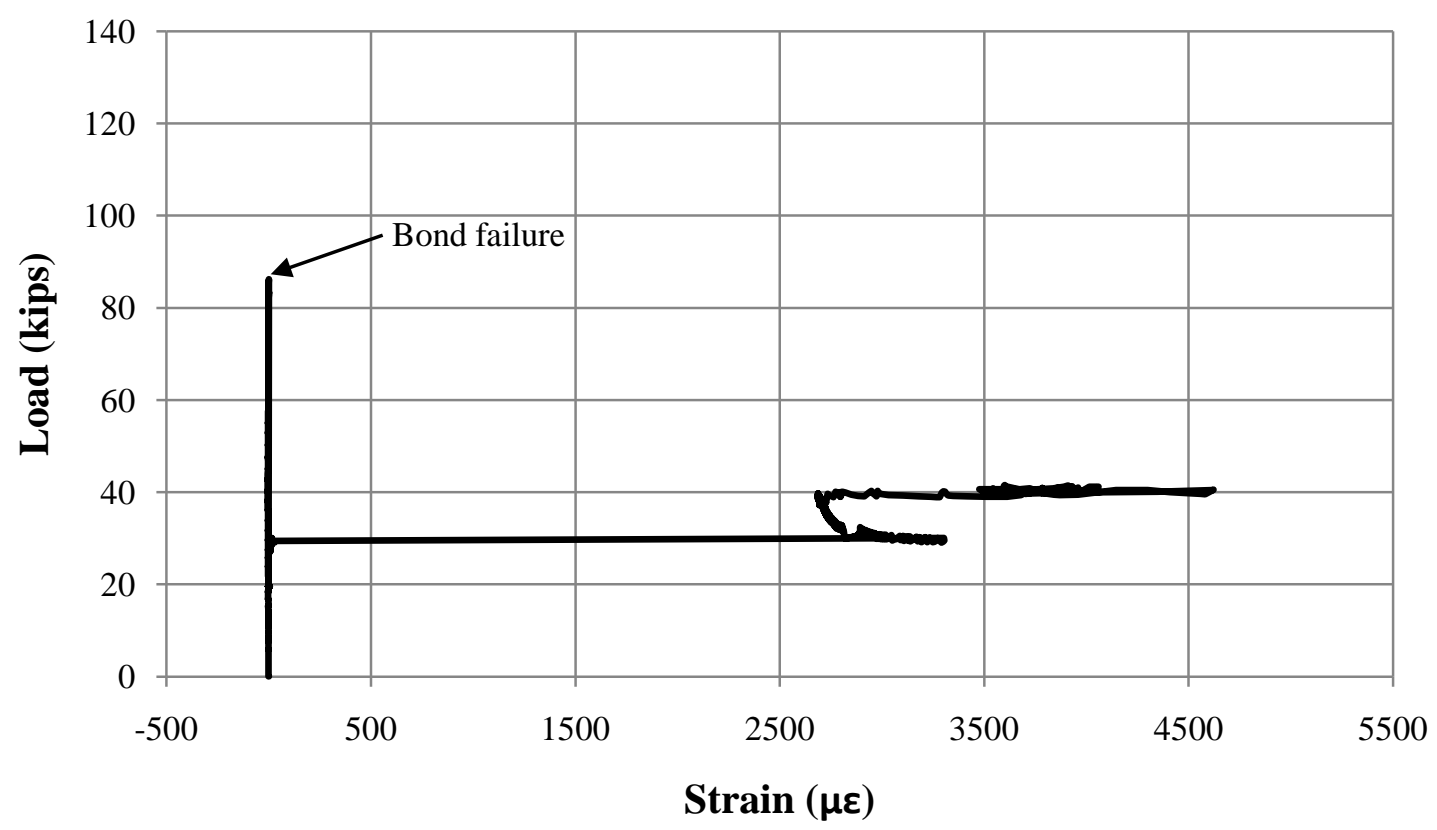

Figure 3.52: Measured shear stud strain (2-4000-6-k-6)

\subsubsection{Specimen 2-4000-6-k-6n}

The load-slip response for Specimen 2-4000-6-k-6n is presented in Figure 3.53. The specimen behaved as a composite section up to a load of approximately 107.6 kips at which bond failure occurred at the panel-haunch interface. The non-linear response at approximately 100 kips was due to damage accumulation in the support block under the load location, which caused some spalling of the support block. No cracking of the specimen was observed prior to, or immediately following bond failure. Loading of the specimen continued to the maximum deflection of the test setup. The specimen was unloaded and a 2 in. spacing plate was installed under the loading plate to provide for additional deflection capacity of the test setup. The specimen was reloaded to 49.2 kips at which failure of the shear stud occurred (Figure 3.54). A maximum measured shear stud strain prior to unloading the specimen was $6161 \mu \varepsilon$, indicating that the shear stud had yielded (Figure 3.55). Upon reloading of the specimen, the strain gauge provided inconsistent readings and was considered unreliable. 


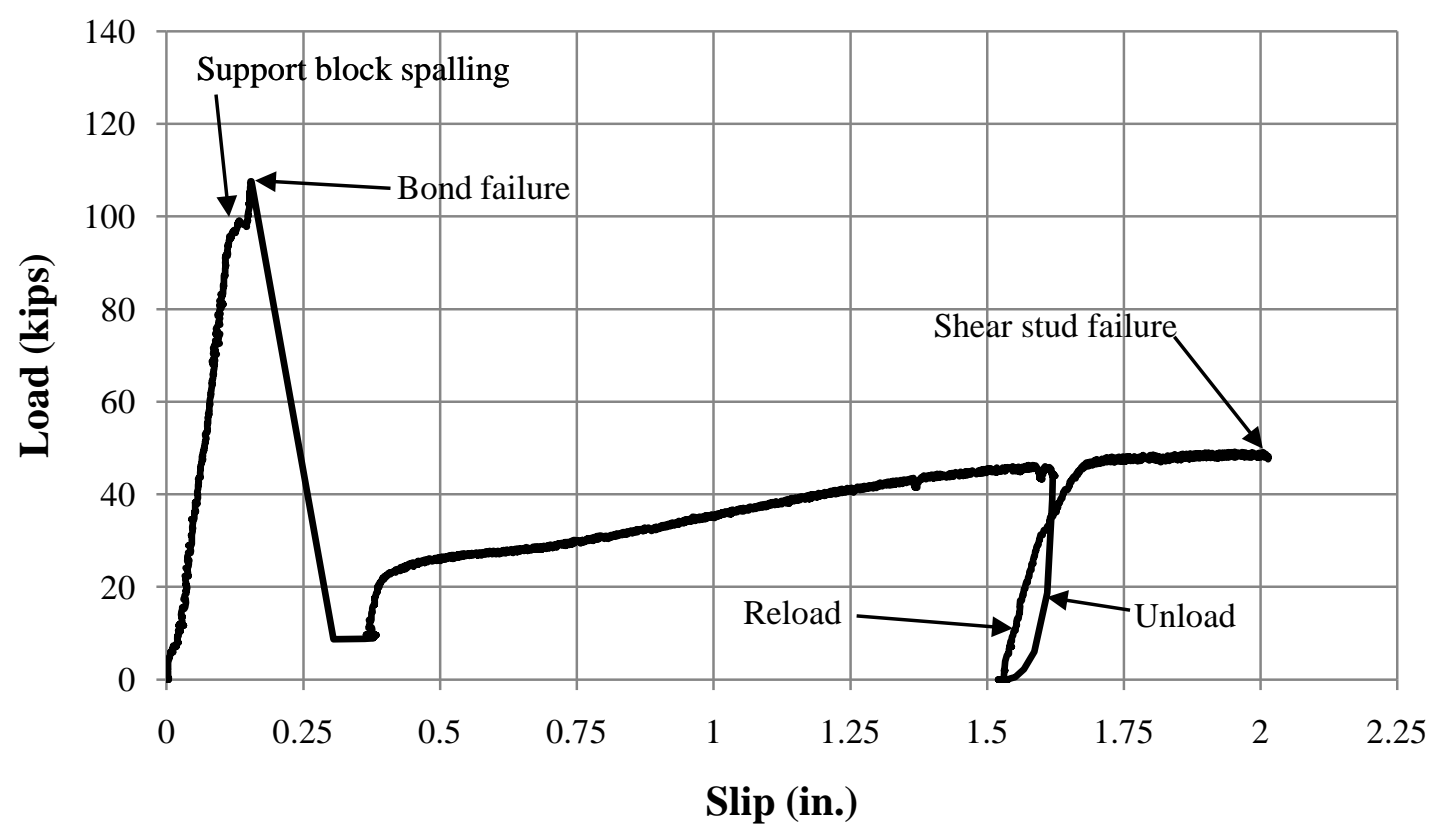

Figure 3.53: Load-slip response for Specimen 2-4000-6-k-6n

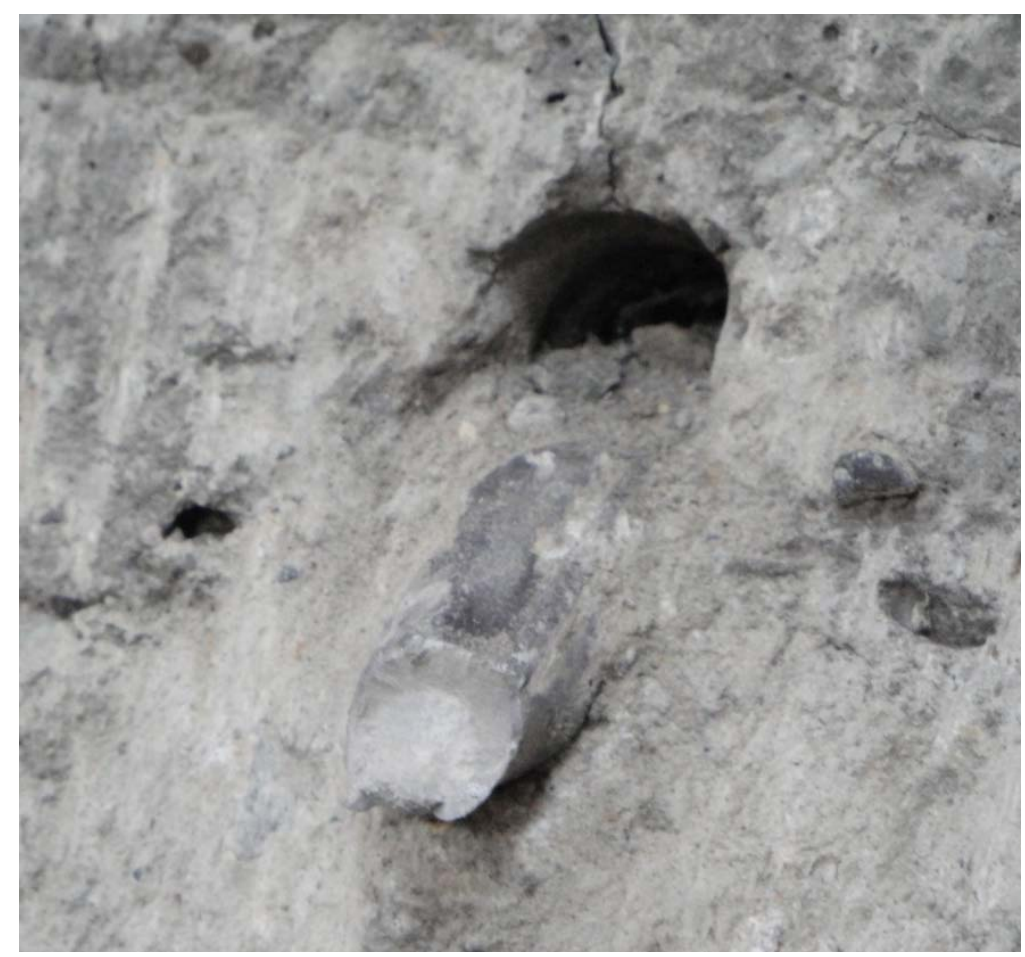

Figure 3.54: Failed shear stud of Specimen 2-4000-6-k-6n 


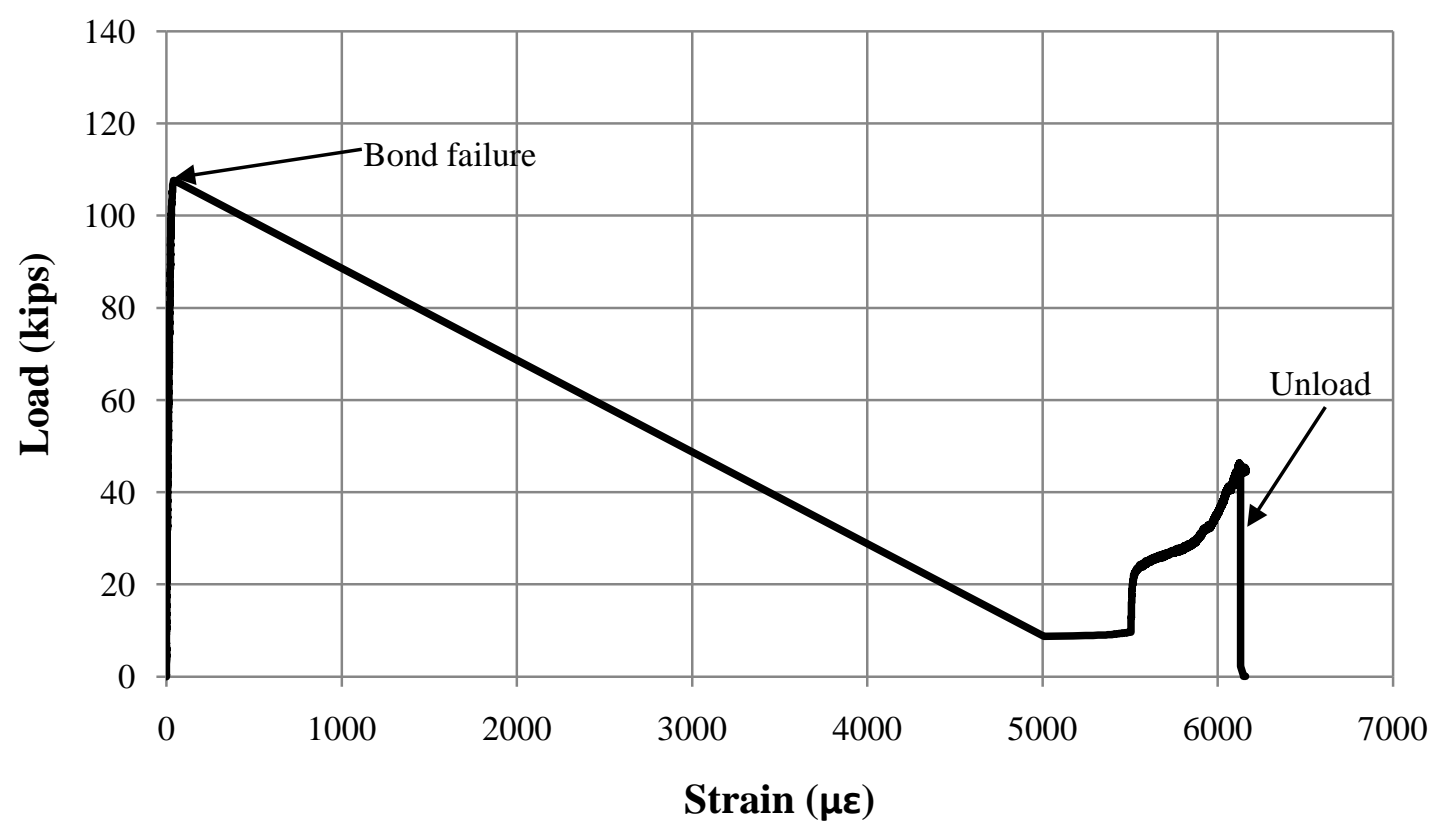

Figure 3.55: Measured shear stud strain (2-4000-6-k-6n)

\subsubsection{Specimen 2-4000-8-6}

The load-slip response for Specimen 2-4000-8-6 is presented in Figure 3.56. The specimen behaved as a composite section up to a load of approximately 66 kips at which bond failure occurred at the panel-haunch interface. It should be noted that the haunch contained voids which resulted in a decreased bonding area (Figure 3.57). No cracking was observed prior to, or immediately following bond failure. Loading of the specimen continued to a second peak load of 40.5 kips. Upon reaching the second peak load, a bond failure occurred between the trough-girder section interface and the trough fractured at its mid-height (Figure 3.58). A maximum measured shear stud strain of $2189 \mu \varepsilon$ occurred immediately following the initial panel-haunch interface failure. 


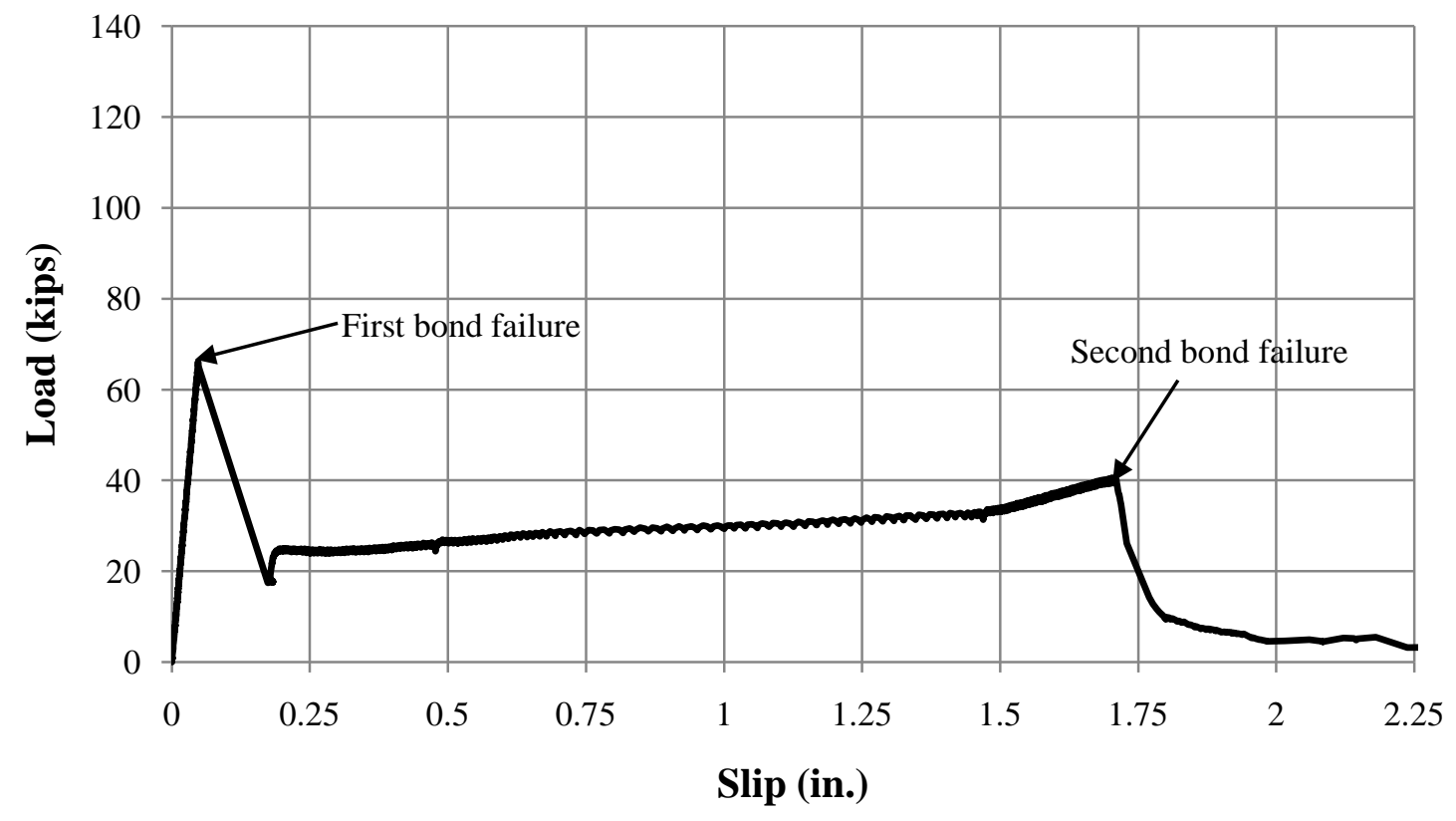

Figure 3.56: Load-slip response of Specimen 2-4000-8-6 


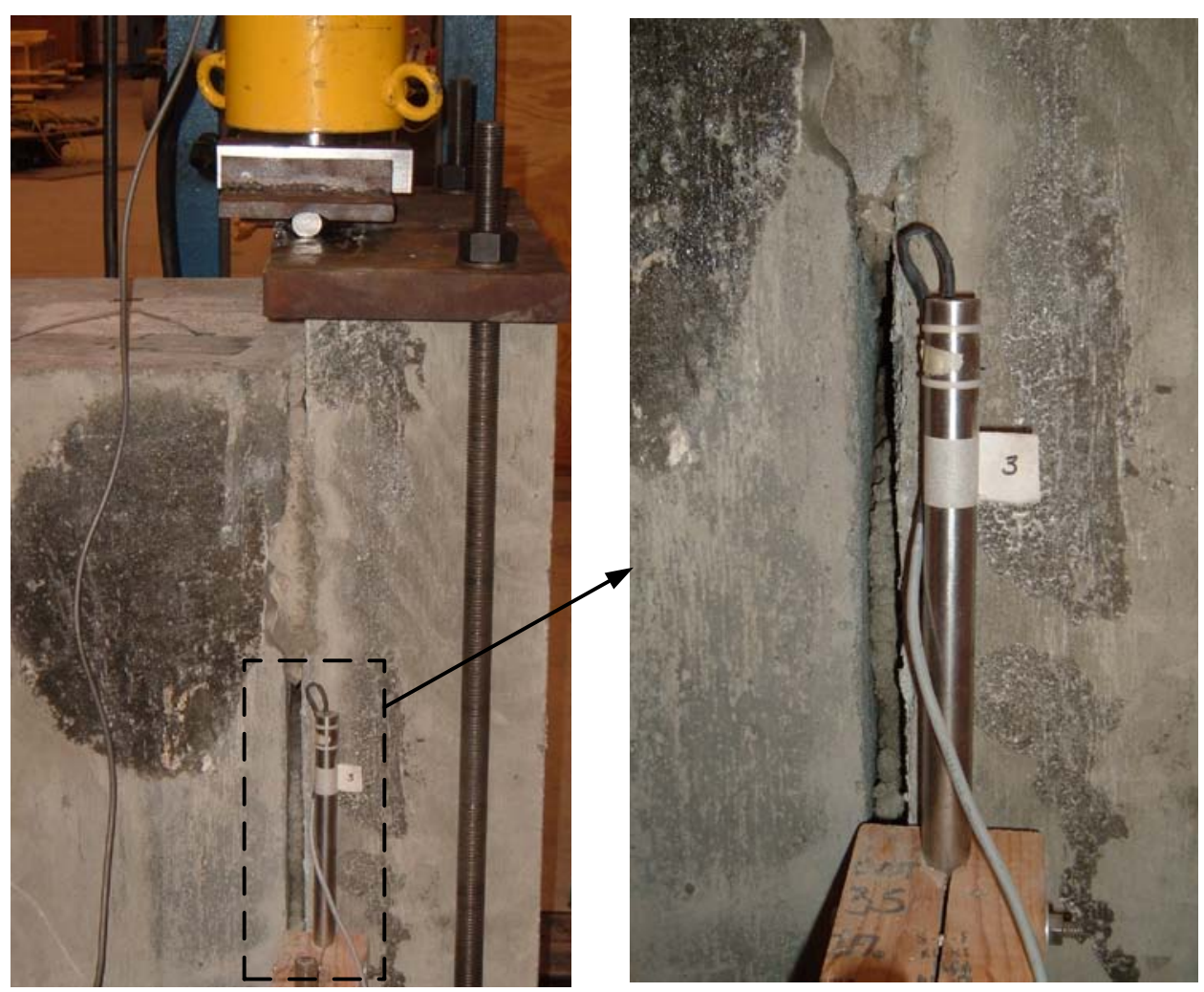

Figure 3.57: Voids in haunch of Specimen 2-4000-8-6

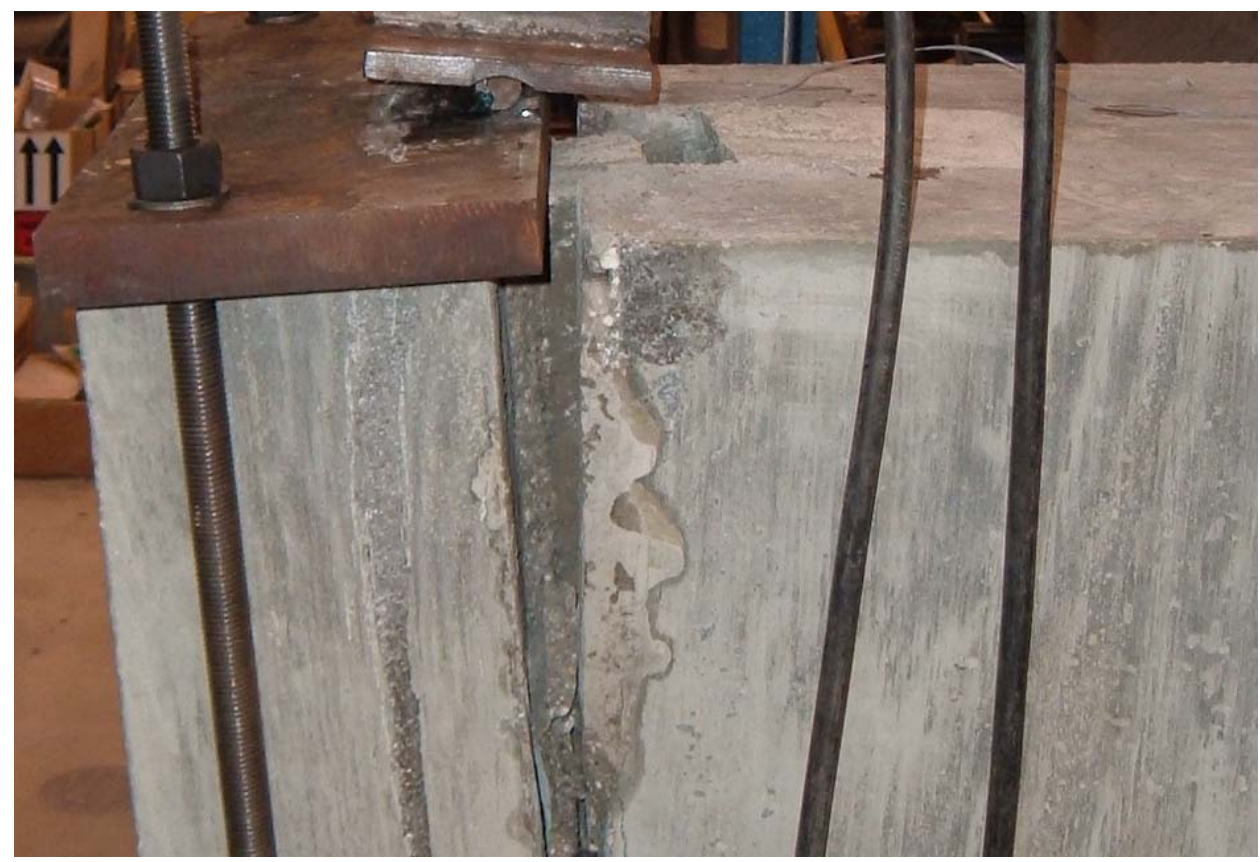

Figure 3.58: Trough fracture of Specimen 2-4000-8-6 


\subsubsection{Specimen 2-4000-8-k-6}

The load-slip response for Specimen 2-4000-8-k-6 is presented in Figure 3.59. The specimen behaved as a composite section up to a load of approximately 82 kips at which bond failure occurred at the panel-haunch interface. No cracking was observed prior to, or immediately following bond failure. Loading of the specimen continued to a second peak load of 46 kips. Cracks were observed at the base of the trough and propagated into the girder section, initiating at the inside corners of the trough. Cracks also appeared at the mid-height of the trough material (Figure 3.60). Testing was stopped due to decreasing load capacity and cracking of the trough and girder section. A maximum measured shear stud strain of 13,994 $\mu \varepsilon$ occurred at a load of 31.5 kips after interface bond failure (Figure 3.61). The strain gauge measured off-scale for the remainder of the test. Measured strains indicate that the shear stud yielded.

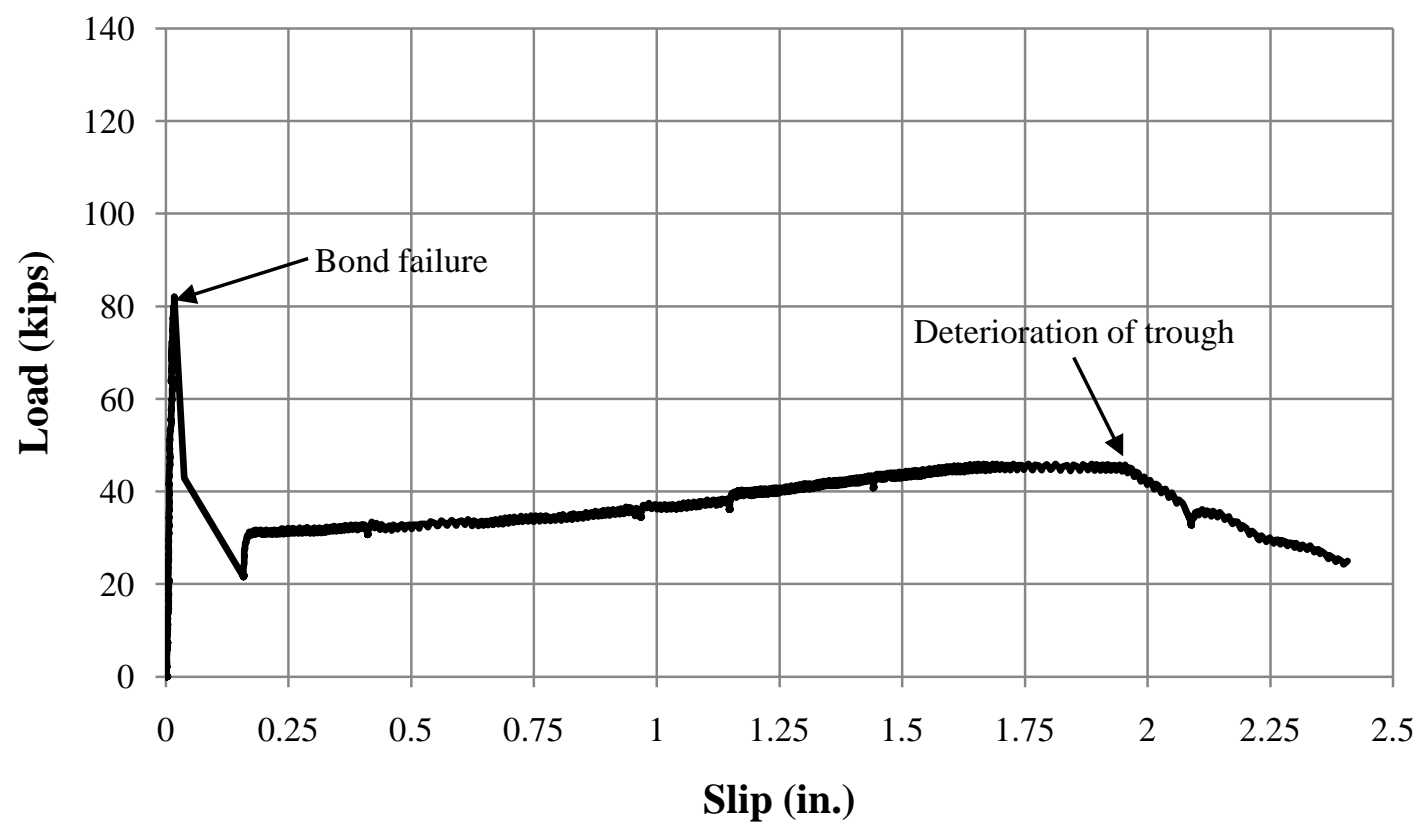

Figure 3.59: Load-slip response for Specimen 2-4000-8-k-6 


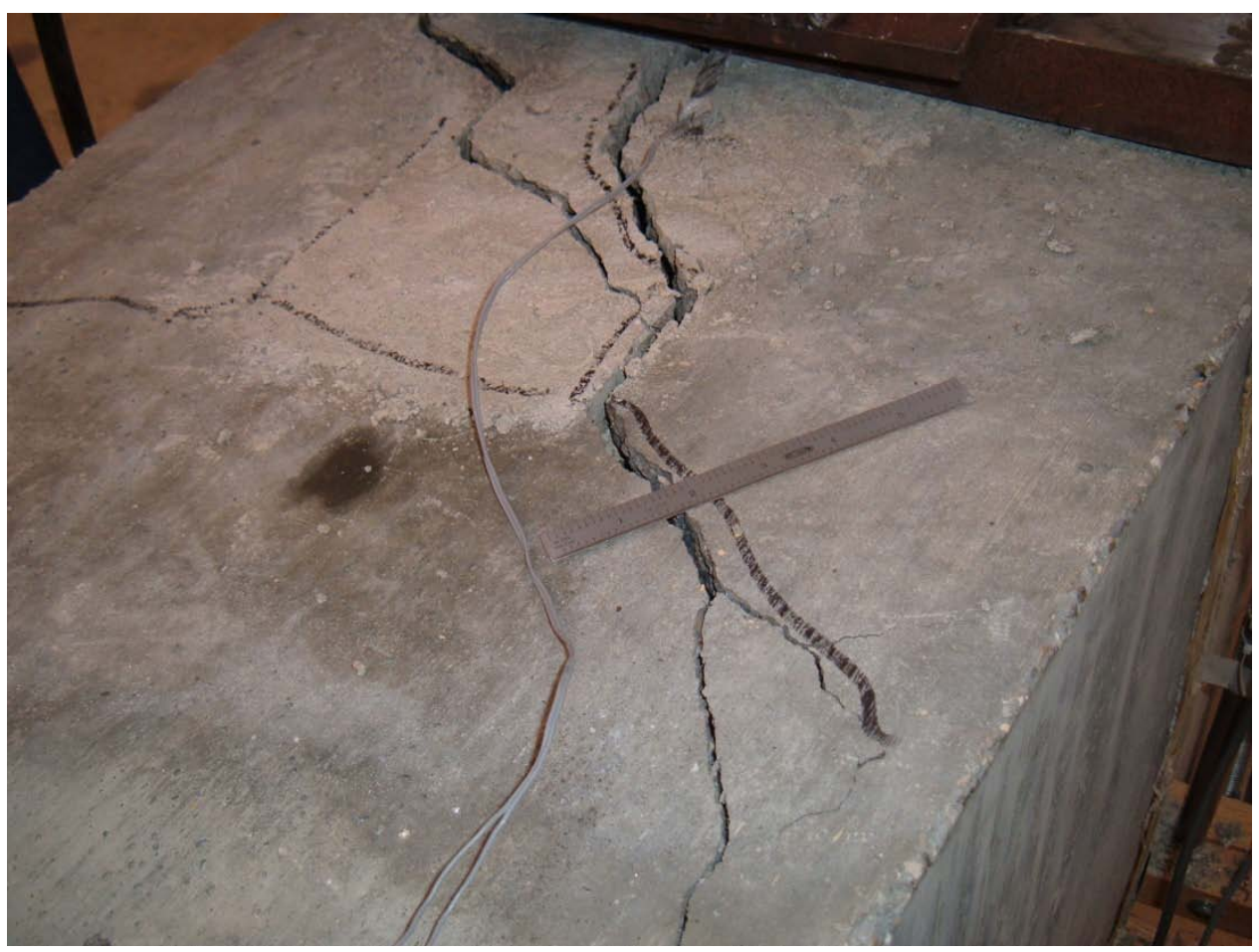

Figure 3.60: Cracking of Specimen 2-4000-8-k-6

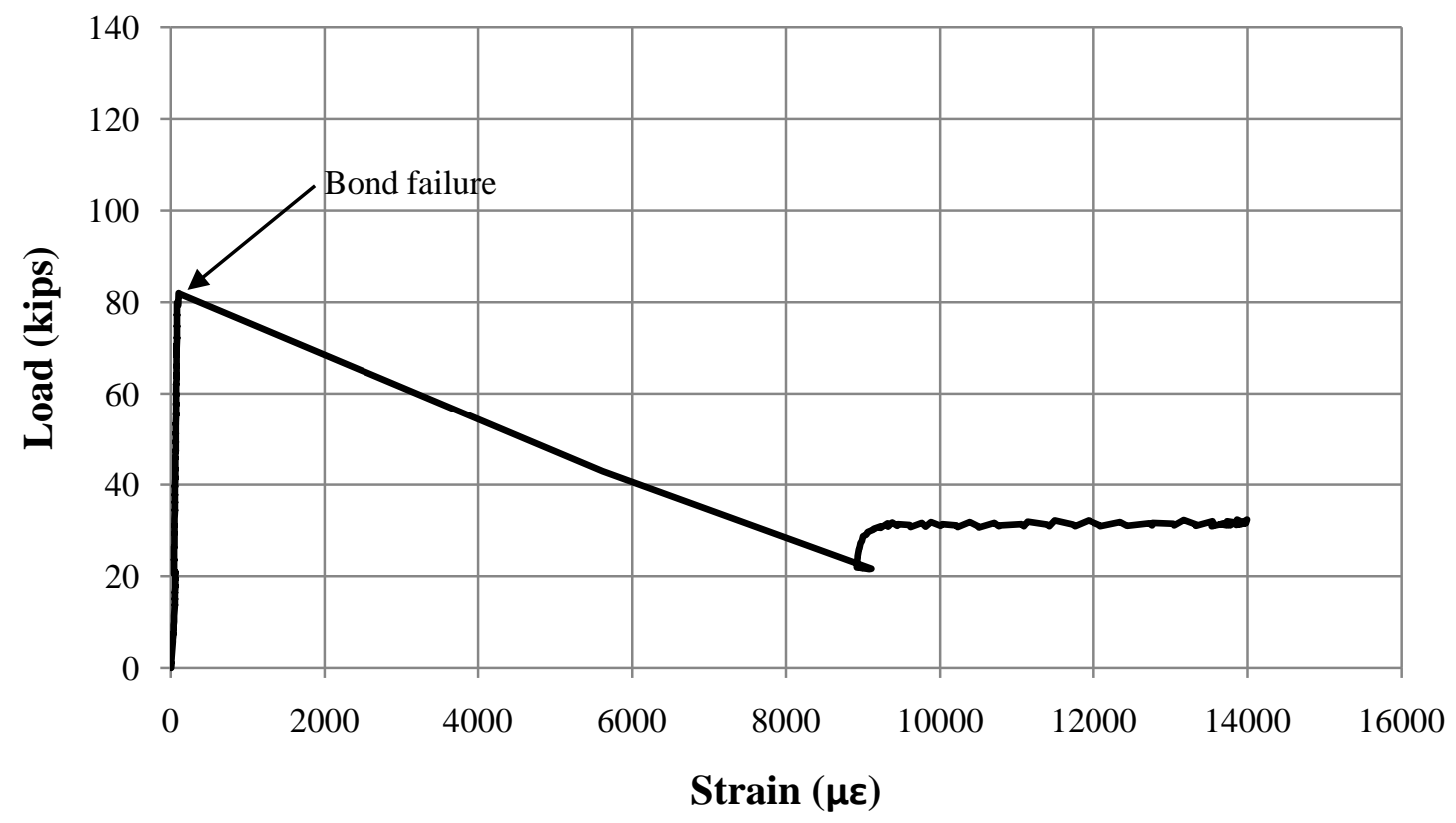

Figure 3.61: Measured shear stud strain (2-4000-8-k-6) 


\subsubsection{Specimen 2-8000-6-k-6n}

The load-slip response for Specimen 2-8000-6-k-6n is presented in Figure 3.62. The specimen behaved as a composite section up to a load of approximately 75.7 kips at which bond failure occurred at the panel-haunch interface. No cracking was observed prior to, or following bond failure. Loading of the specimen continued to the maximum deflection capacity of the test setup. The specimen was unloaded and a 2 in. spacing plate was installed under the loading plate to provide for additional deflection capacity. The specimen was reloaded to 44.5 kips at which failure of the shear stud occurred (Figure 3.63). A maximum measured shear stud strain of $100 \mu \varepsilon$ occurred immediately prior to bond failure. The strain gauge failed following bond failure.

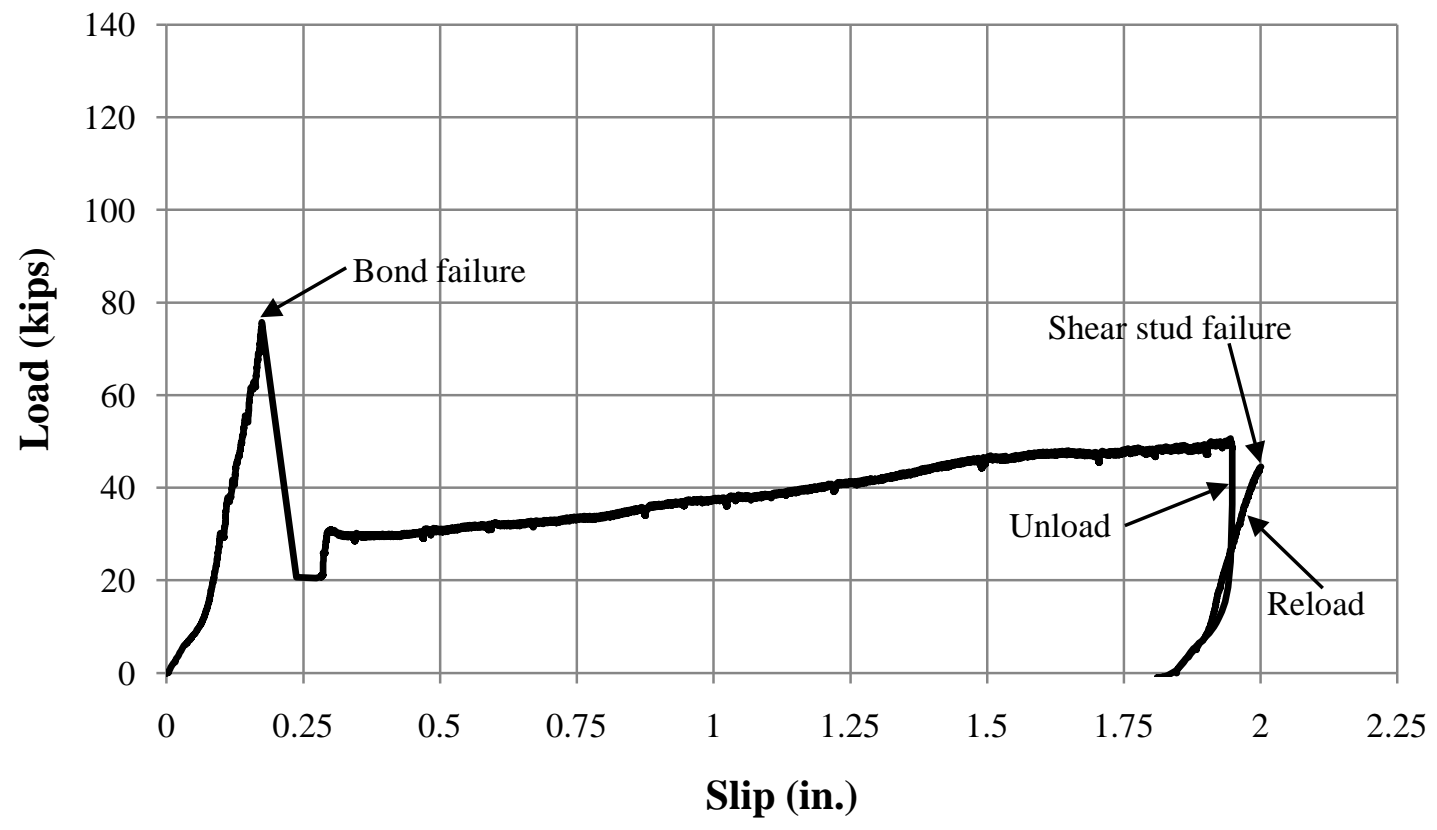

Figure 3.62: Load-slip response of Specimen 2-8000-6-k-6n 


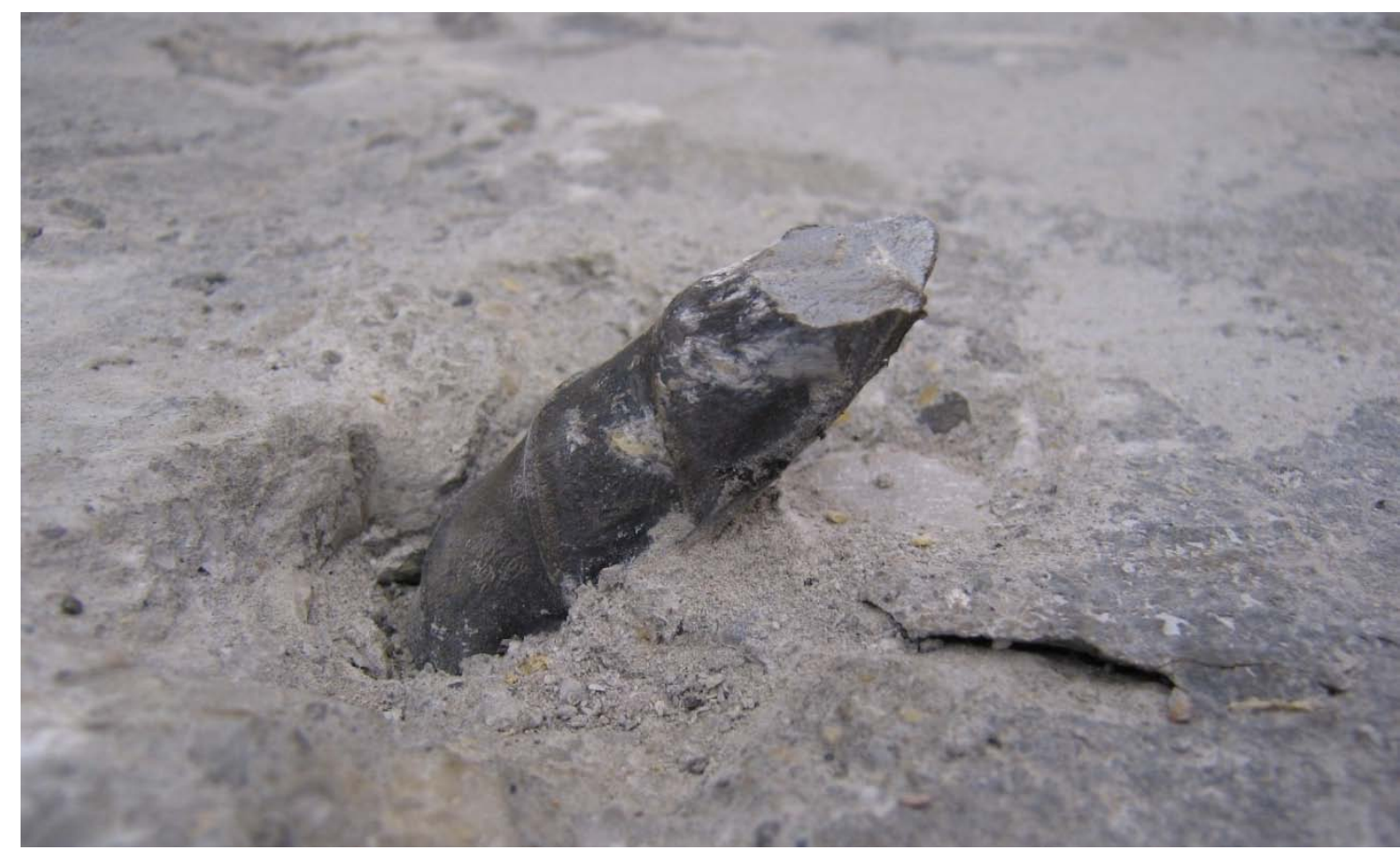

Figure 3.63: Failed shear stud of Specimen 2-8000-6-k-6n

\subsubsection{Specimen 2-8000-6-k-6}

The load-slip response for Specimen 2-8000-6-k-6 is presented in Figure 3.64. The specimen behaved as a composite section up to a load of approximately 68 kips at which bond failure occurred at the panel-haunch interface. It should be noted that the haunch contained voids which resulted in a decreased bonding area (Figure 3.65). No cracking was observed prior to, or immediately following bond failure. Loading of the specimen continued to 36 kips where a crack in the girder section initiated at the bottom right corner of the trough. Loading continued to a second peak load of 47.5 kips was reached at which point the trough material cracked. The specimen continued to carry load. However, the initial cracks continued to widen and elongate (Figure 3.66). As loading continued the panel began to move away from the girder section, at which point the test was discontinued. A maximum measured shear stud strain of $59 \mu \varepsilon$ occurred just prior to bond failure. The strain gauge failed once bond failure occurred. 


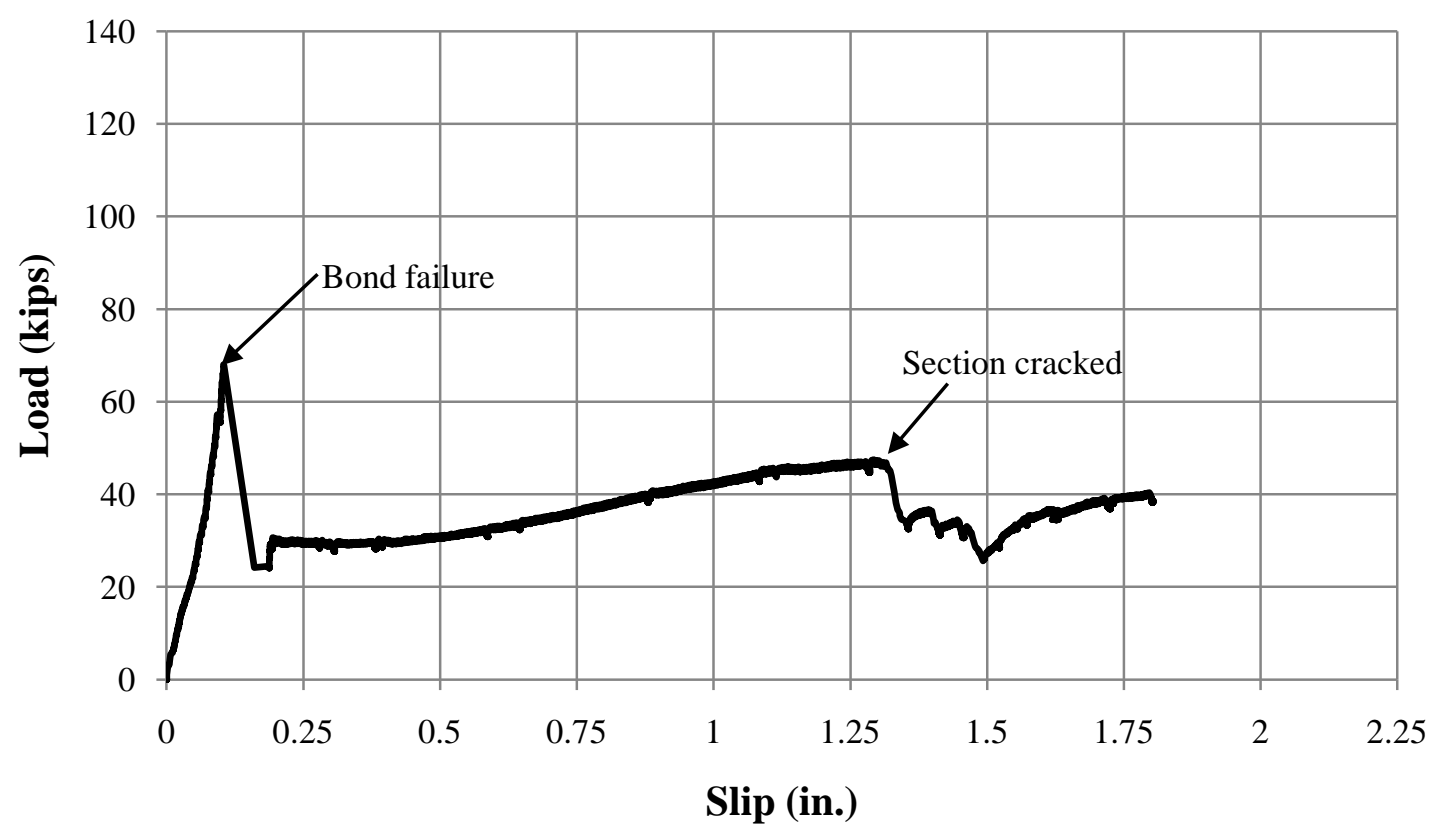

Figure 3.64: Load-slip response of Specimen 2-8000-6-k-6
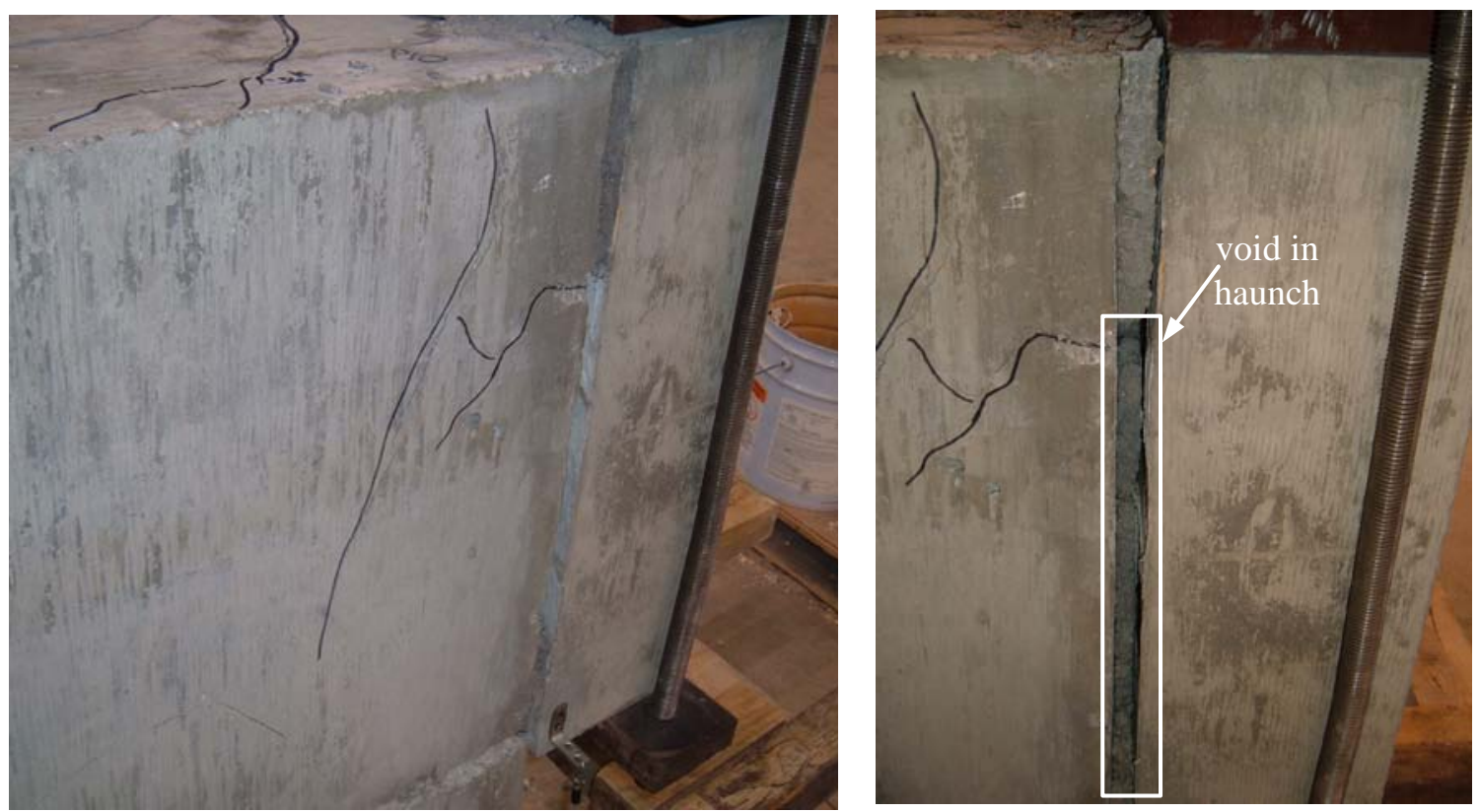

Figure 3.65: Girder section cracking and haunch void (2-8000-6-k-6) 


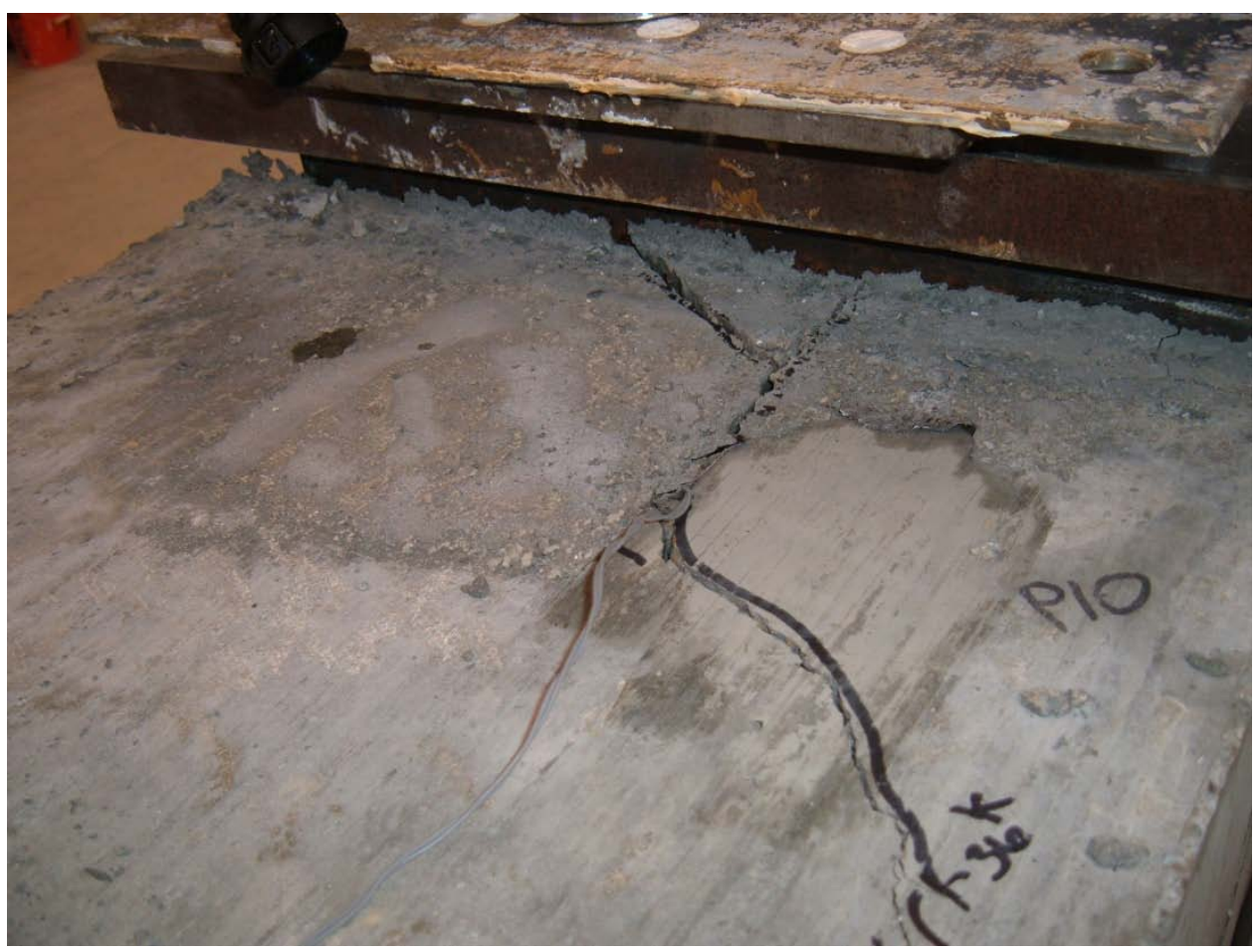

Figure 3.66: Trough and girder cracking of Specimen 2-8000-6-k-6

\subsubsection{Specimen 2-6000-14-4}

The load-slip response for New England system Specimen 2-6000-14-4 is presented in Figure 3.67. The specimen behaved as a composite section up to a load of approximately 114.8 kips at which failure occurred at the panel-haunch interface. No cracking was observed prior to, or following bond failure. Loading of the specimen continued to a second peak load of 27.2 kips at which point the shear stud failed. The panel section with failed shear stud is presented in Figure 3.68. A maximum measured shear stud strain of $3470 \mu \varepsilon$ occurred immediately following bond failure (Figure 3.69). The strain gauge measured off-scale for the remainder of the test. 


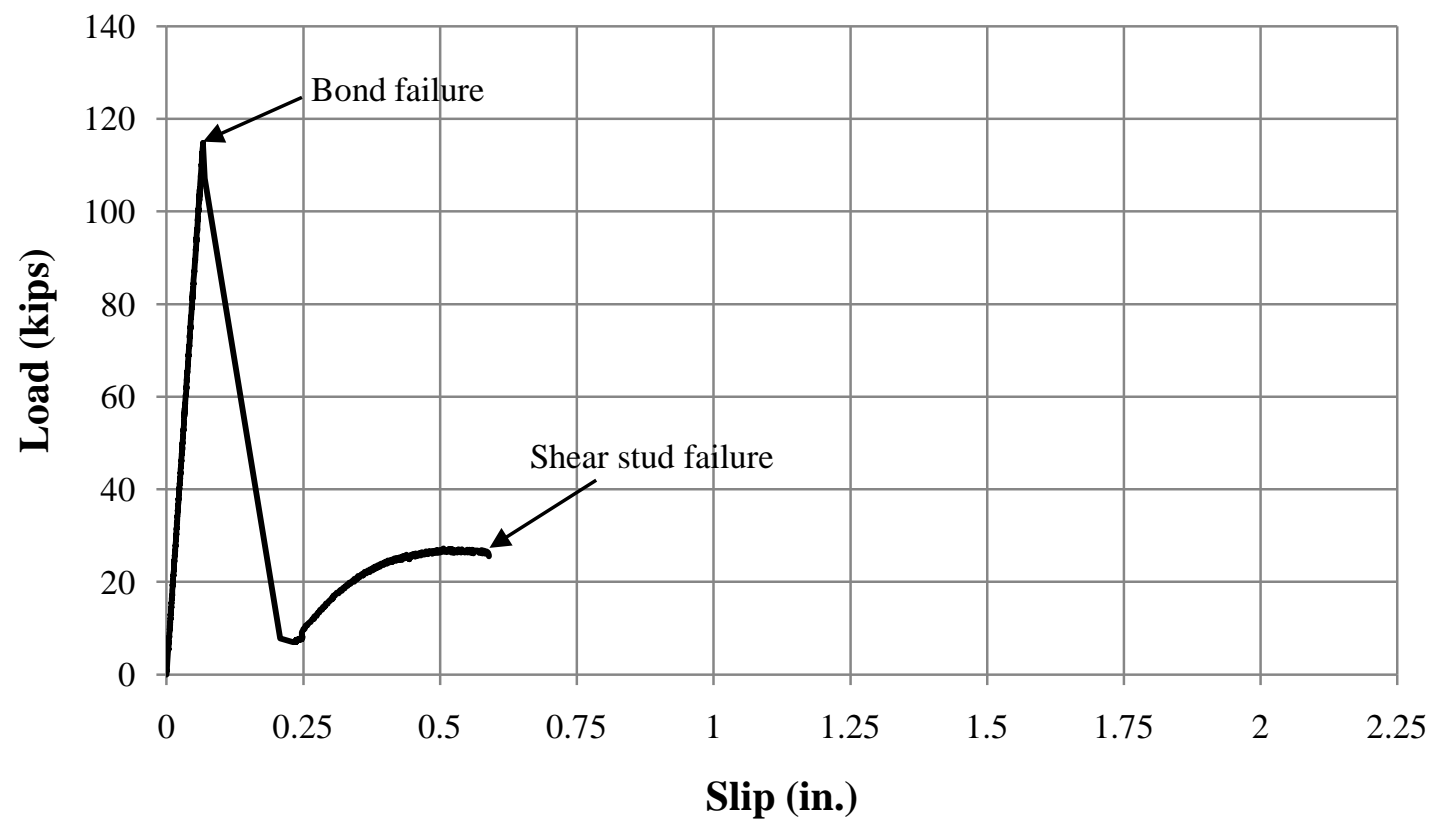

Figure 3.67: Load-slip response of Specimen 2-6000-14-4

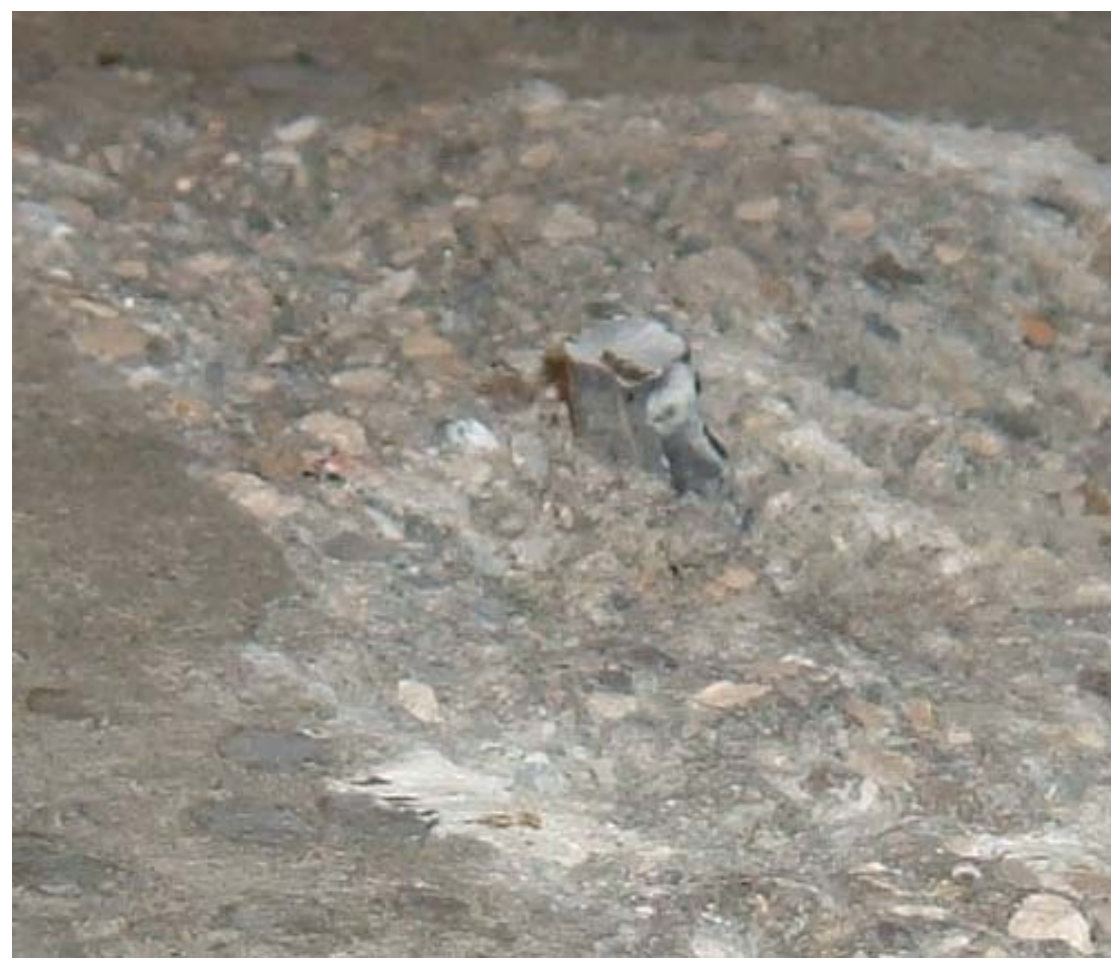

Figure 3.68: Failed shear stud of Specimen 2-6000-14-4 


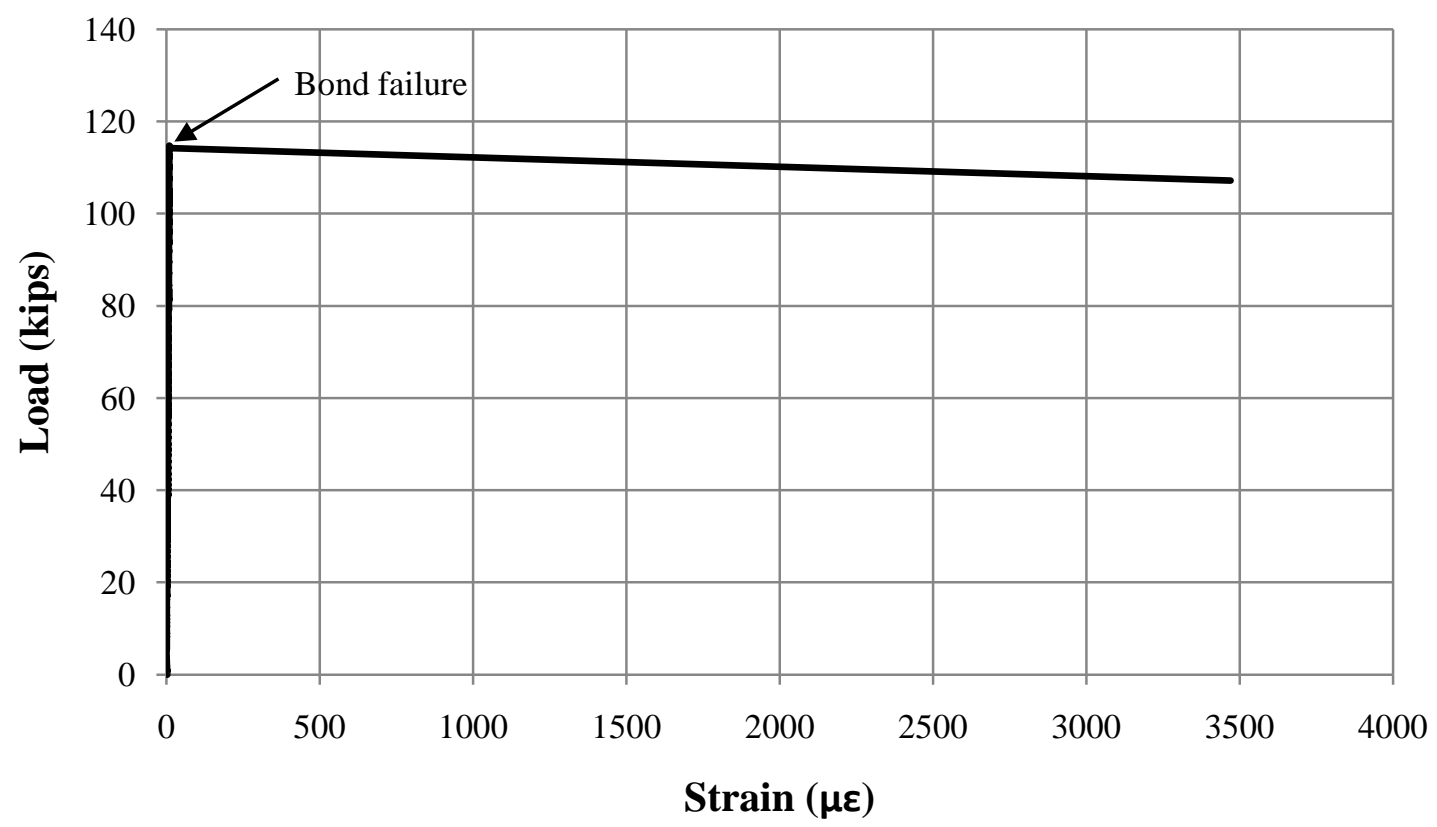

Figure 3.69: Measured shear stud strain (2-6000-14-4)

\subsubsection{Specimen 2-6000-14-6}

The load-slip response for New England system Specimen 2-6000-14-6 is presented in Figure 3.70. The specimen behaved as a composite section up to a load of approximately 137.7 kips at which failure occurred at the panel-haunch interface. No cracking was observed prior to, or following bond failure. Loading of the specimen continued to a second peak load of 49.5 kips. Shear stud failure occurred at a load of 41.8 kips, following the second peak. The panel section with failed shear stud is presented in Figure 3.71. A maximum measured shear stud strain of $120 \mu \varepsilon$ occurred just prior to bond failure. The strain gauge measured off-scale for the remainder of the test. 


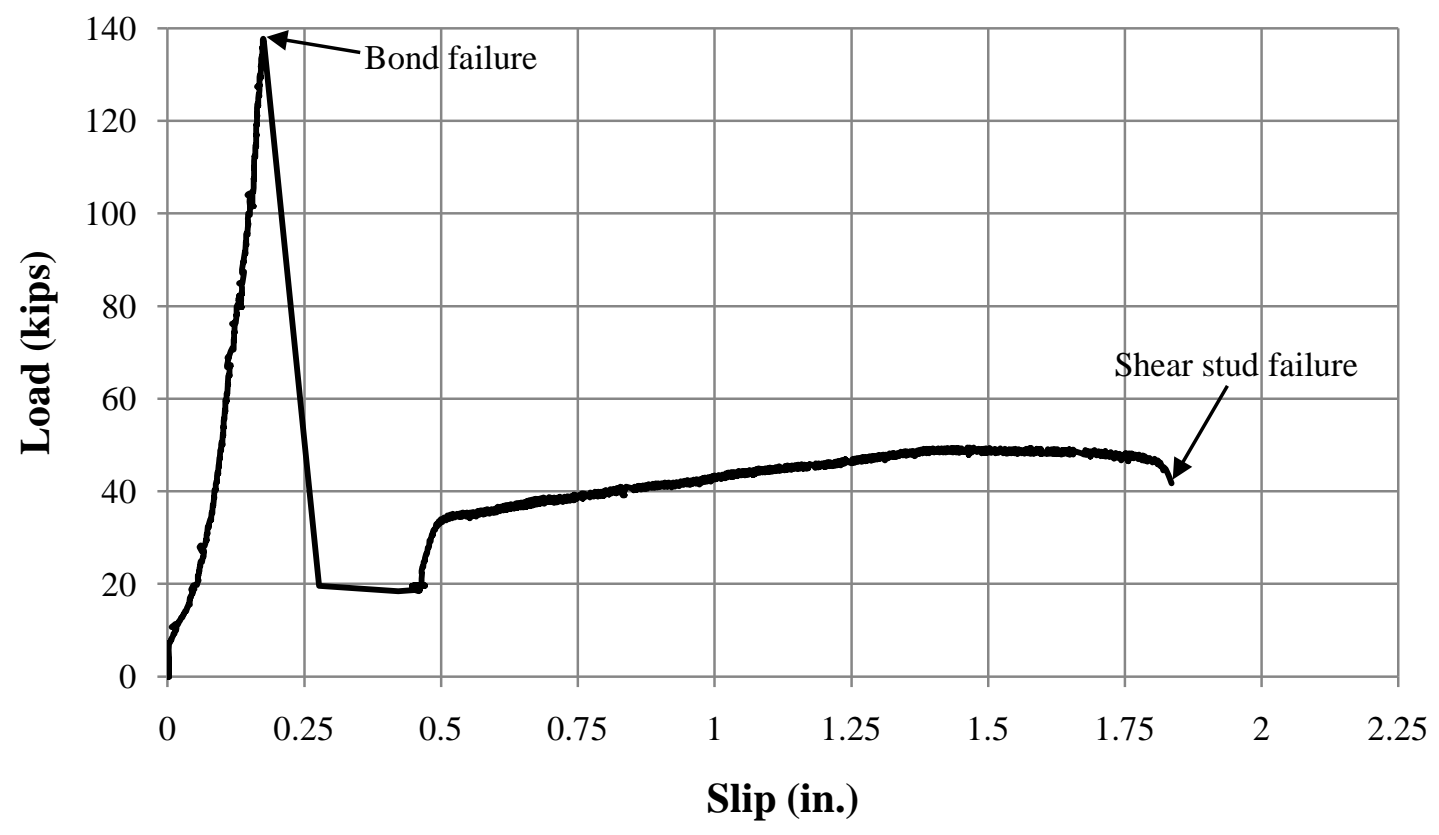

Figure 3.70: Load-slip response of Specimen 2-6000-14-6

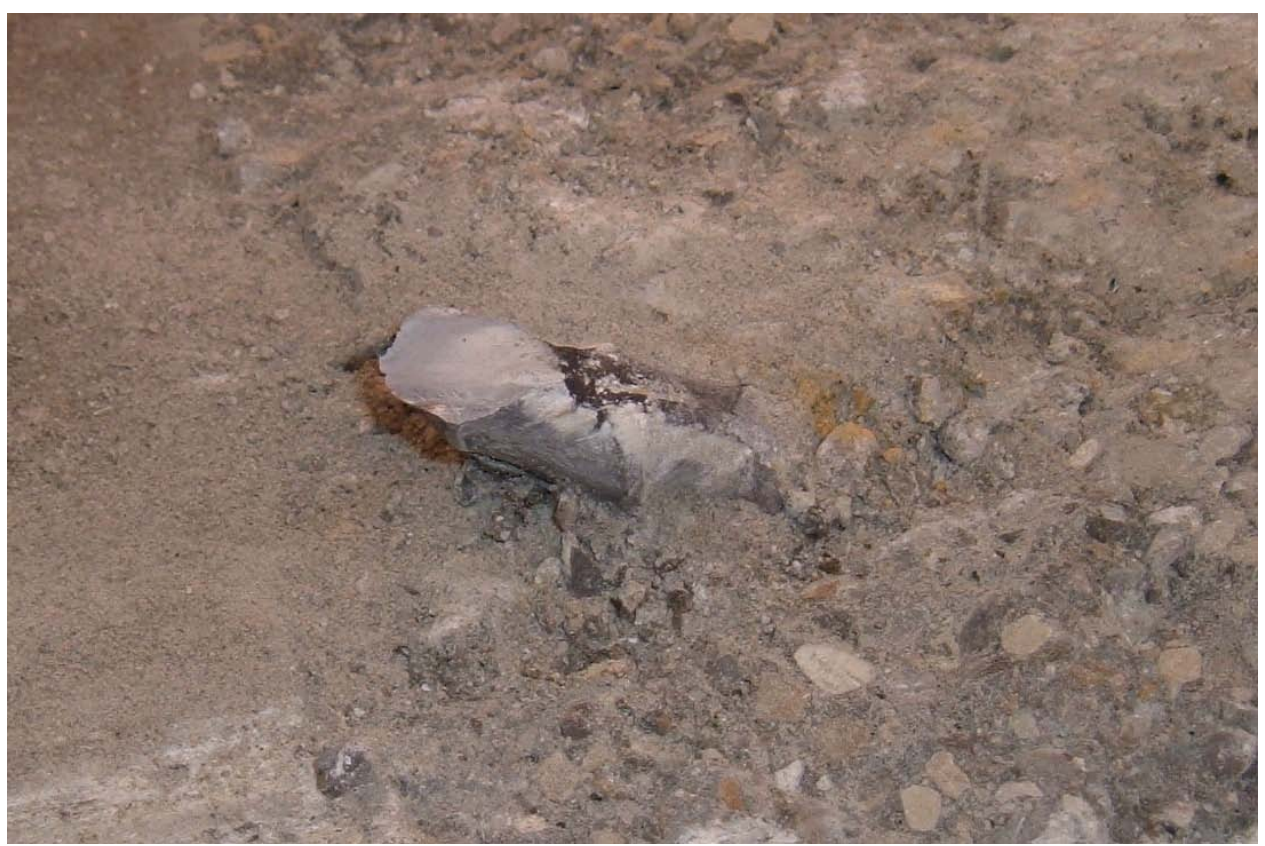

Figure 3.71: Failed shear stud of Specimen 2-6000-14-6 


\subsubsection{Results summary}

The initial failure of all specimens occurred as an interface bond failure through either the panel-haunch interface or the trough-girder interface. Final failure can be classified as three types:

1: Bond failure of the trough-girder section interface.

2: Cracking and deterioration of the trough material which could no longer sustain load.

3: Fracture of the shear stud.

When the specimen experienced trough-girder section interface bond failure, the trough material and panel fell out and away from the girder section. This failure only occurred in specimens without shear keys in the trough.

Trough material failure occurred when the trough material was not sufficiently confined by the girder section. This reduced confinement allowed for cracking of the trough concrete. This failure mode was typical of the keyed, Group 1 specimens because of the reinforcement detail in the girder section. The reinforcement detail in the section adjacent to the trough (Figure 3.1) did not intersect the crack that initiated at the corner of the trough. In addition, due to the lack of reinforcement, there was a lack of lateral stiffness which allowed the trough to spread laterally, decreasing confinement of the trough concrete which resulted in a reduced specimen capacity.

Shear stud fracture occurred if the girder section provided sufficient confinement to the trough material. This failure mode was observed in the existing joint specimens and the keyed Group 2 specimens, because of the improved reinforcement detail in the girder section (Figure 3.2).

The failure modes and test results are summarized in Table 3.6. Average shear stress was calculated based on the interface area that experienced bond failure. A few specimens had bond failure occur at the trough-girder interface. In those cases, the bonding surface that failed had an area larger than the panel-haunch interface. Therefore, the larger area was used in calculating average shear stress at bond failure. If the unbonded interface area was indeterminable due to incomplete interface failure or voids in the haunch, the average stress was not calculated. For instance, Specimen 1-4000-8-6 
experienced bond failure at the trough-girder interface. However, the crack did not occur along the entire length of the interface. It propagated through a portion of the girder section (Figure 3.72). The area of the cracked girder section is unknown; therefore, the average shear stress was not calculated.

Table 3.6: Test Results

\begin{tabular}{|c|c|c|c|c|c|}
\hline Specimen ID & Failure & $\begin{array}{c}\text { Load at } \\
\text { bond failure } \\
\text { (kip) } \\
\end{array}$ & $\begin{array}{l}\tau_{\text {avg }} \text { at bond } \\
\text { failure (psi) }\end{array}$ & $\begin{array}{c}\text { Max. } \\
\text { measured } \\
\text { strain }(\mu \varepsilon) \\
\end{array}$ & $\begin{array}{c}\text { Stud } \\
\text { failure } \\
\text { load (kip) } \\
\end{array}$ \\
\hline $1-4000-6-4$ & $\begin{array}{c}\text { Girder } \\
\text { Interface }\end{array}$ & 64.3 & 158 & 509 & --- \\
\hline $1-4000-6-k-4$ & Trough & 52.6 & 219 & 74 & --- \\
\hline 1-4000-6-k-6 & Trough & 81.0 & 337 & 24 & --- \\
\hline $1-4000-8-6$ & $\begin{array}{c}\text { Girder } \\
\text { Interface }\end{array}$ & 29.1 & --- & 795 & --- \\
\hline $1-4000-8-k-6$ & Trough & 50.8 & 212 & 98 & --- \\
\hline 2-4000-6-4 & Shear Stud & 90.9 & 189 & 6543 & 22.5 \\
\hline 2-4000-6-6 & Trough & 133.1 & 277 & 3913 & --- \\
\hline 2-4000-6-k-4 & Shear Stud & 110.8 & 231 & 56 & 22.0 \\
\hline 2-4000-6-k-6 & Trough & 86.2 & 180 & 4546 & $\begin{array}{l}-- \\
\end{array}$ \\
\hline $2-4000-8-6$ & Trough & 66.0 & --- & 2189 & --- \\
\hline 2-4000-8-k-6 & Trough & 82.0 & 171 & 13994 & --- \\
\hline $1-8000-6-4$ & $\begin{array}{c}\text { Girder } \\
\text { Interface }\end{array}$ & 45.9 & 112 & 7216 & --- \\
\hline 1-8000-6-k-4 & Trough & 77.4 & 322 & 57 & --- \\
\hline $1-8000-6-6$ & $\begin{array}{c}\text { Girder } \\
\text { Interface }\end{array}$ & 58.6 & 144 & 69 & --- \\
\hline 1-8000-6-k-6 & Trough & 56.3 & --- & 8284 & --- \\
\hline $2-6000-14-4$ & Shear Stud & 114.8 & 239 & 3470 & 27.2 \\
\hline 2-6000-14-6 & Shear Stud & 137.7 & 287 & 120 & 49.5 \\
\hline 2-8000-6-k-6 & Trough & 68.0 & --- & 59 & --- \\
\hline $1-8000-6-k-4 n$ & Shear Stud & 47.2 & 197 & 8681 & 21.2 \\
\hline 2-8000-6-k-6n & Shear Stud & 75.7 & 158 & 100 & 50.6 \\
\hline $2-4000-6-k-6 n$ & Shear Stud & 107.6 & 224 & 6161 & 49.2 \\
\hline
\end{tabular}




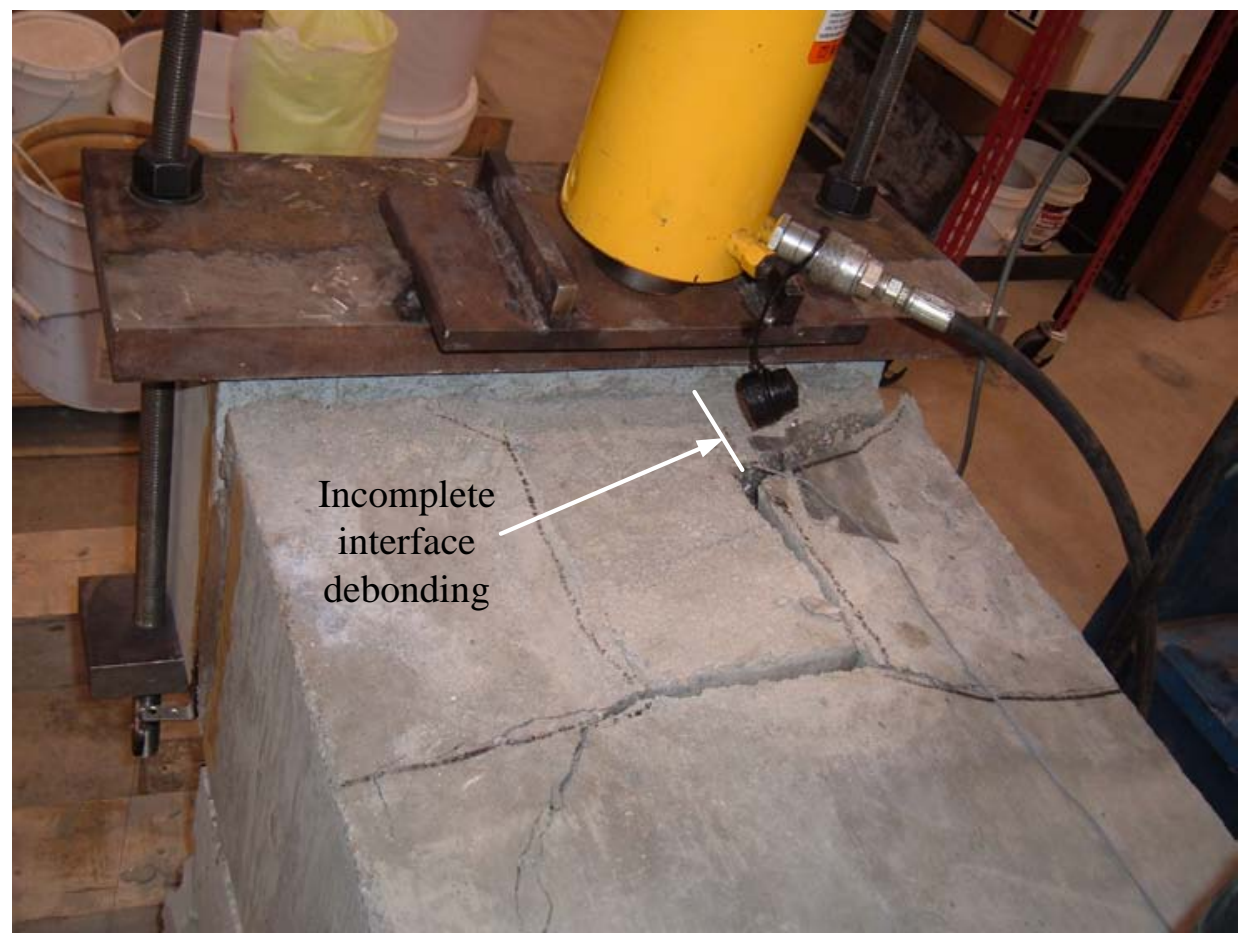

Figure 3.72: Incomplete interface bond failure of Specimen 1-4000-8-6

\subsection{Analysis of Results}

The primary variables for this phase of testing included stud diameter, stud spacing, embedment length of the connector into the girder, compressive strength of the trough concrete, and trough detail. The test results were analyzed to determine the effects, if any, of those variables on specimen behavior. The analysis results are presented in the following sections.

\subsubsection{Stud diameter}

As expected, the stud diameter did not have an appreciable affect on the initial interface failure capacity. Prior to bond failure, the shear studs experienced less than 150 $\mu \varepsilon$, indicating little contribution to load resistance. For the specimens that experienced stud failure, the load at failure is compared in Figure 3.73 for \#4 and \#6 studs. In general, the shear capacities are approximately the same, as is to be expected. The ultimate 
strength of Specimen 2-6000-14-4 which represents the New England system, however, is slightly higher than that of the new connection even though the area of steel crossing the interface is identical. The mild reinforcement used for the shear stud in 2-6000-14-4 had a $\mathrm{f}_{\mathrm{u}}(107 \mathrm{ksi})$ value $12 \%$ higher than that used in the other specimens (Figure 3.10). Normalizing the ultimate load of 2-6000-14-4 to that of the other \#4 specimens by the ultimate strength of the studs results in a shear of 23.9 kips which is consistent with the other results. It is evident when comparing the ratio of the average failure loads of \#4 studs with \#6 studs (Figure 3.74) to the ratio of respective stud cross-sectional area that they are proportional as shown below. The ultimate load of each specimen was normalized using a shear stud strength of $\mathrm{f}_{\mathrm{u}}=94$ kips in the averages presented in Figure 3.74 .

$$
\frac{22.4 \text { kips }}{48.5 \text { kips }}: \frac{0.2 \text { in. }^{2}}{0.44 \text { in. }^{2}} \rightarrow 0.46: 0.45
$$

The average shear studs strengths obtained in this phase of testing are consistent with the strengths obtained from the analysis described in Chapter 2, Section 2.7. In Phase 1, the strength of a \#4 stud achieved at failure was estimated as 24 kips which matches well with 22.4 kips measured here. No \#6 studs failed during Phase 1 testing; however, the highest force per stud was estimated as 45.8 kips (Specimen 4/6-P) which is consistent with the average strength obtained in this phase of testing.

Based on the test results, a few comments are appropriate.

1. No. 6 studs had a higher instance of trough concrete failure due to the increased strength over the \#4 stud. Failure of the trough material was mitigated by modifying the girder reinforcement details to that of Group 2 (Figure 3.2).

2. While these tests support increased shear capacity by increasing stud crosssectional area, it must be noted that this relationship is for a single stud and may not exist for groups of shear studs. 


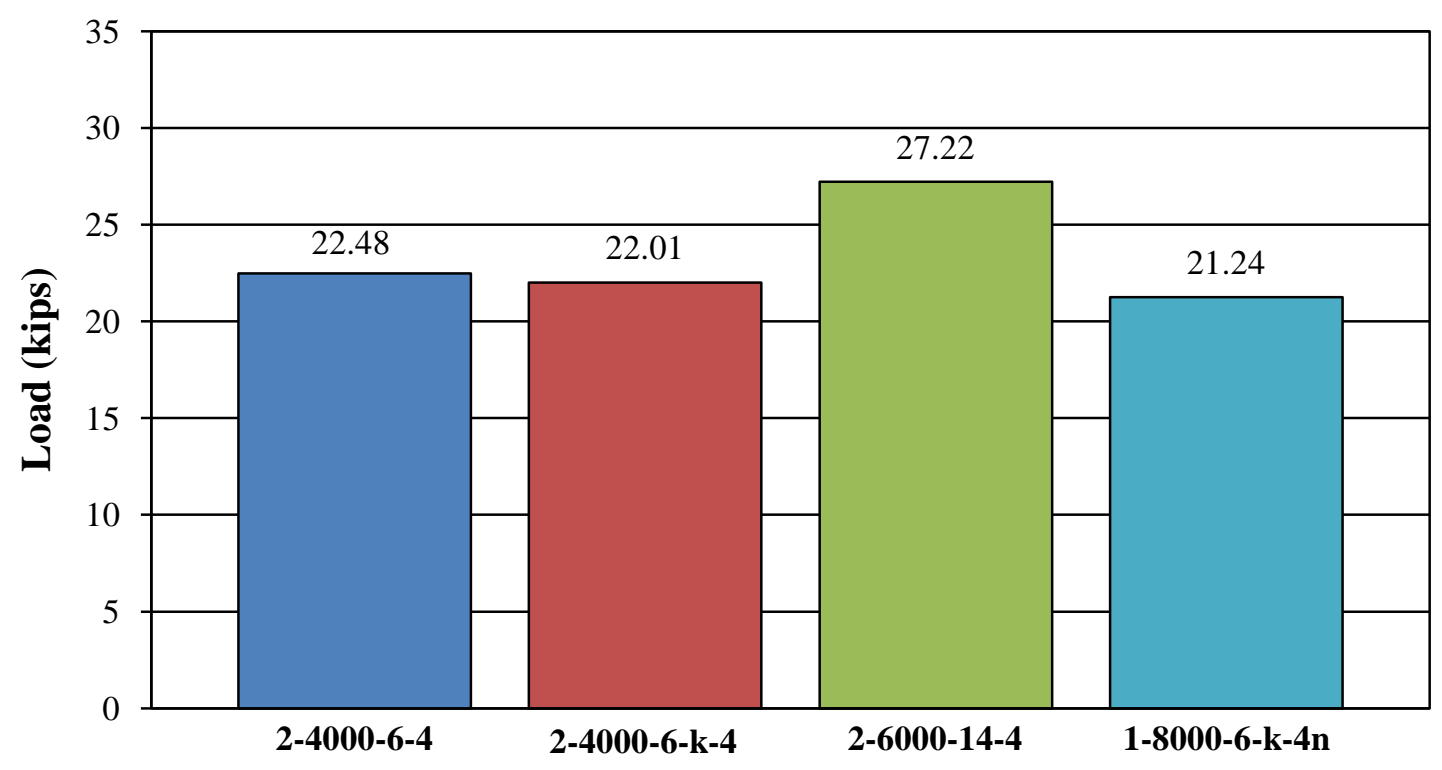

a) \#4 studs

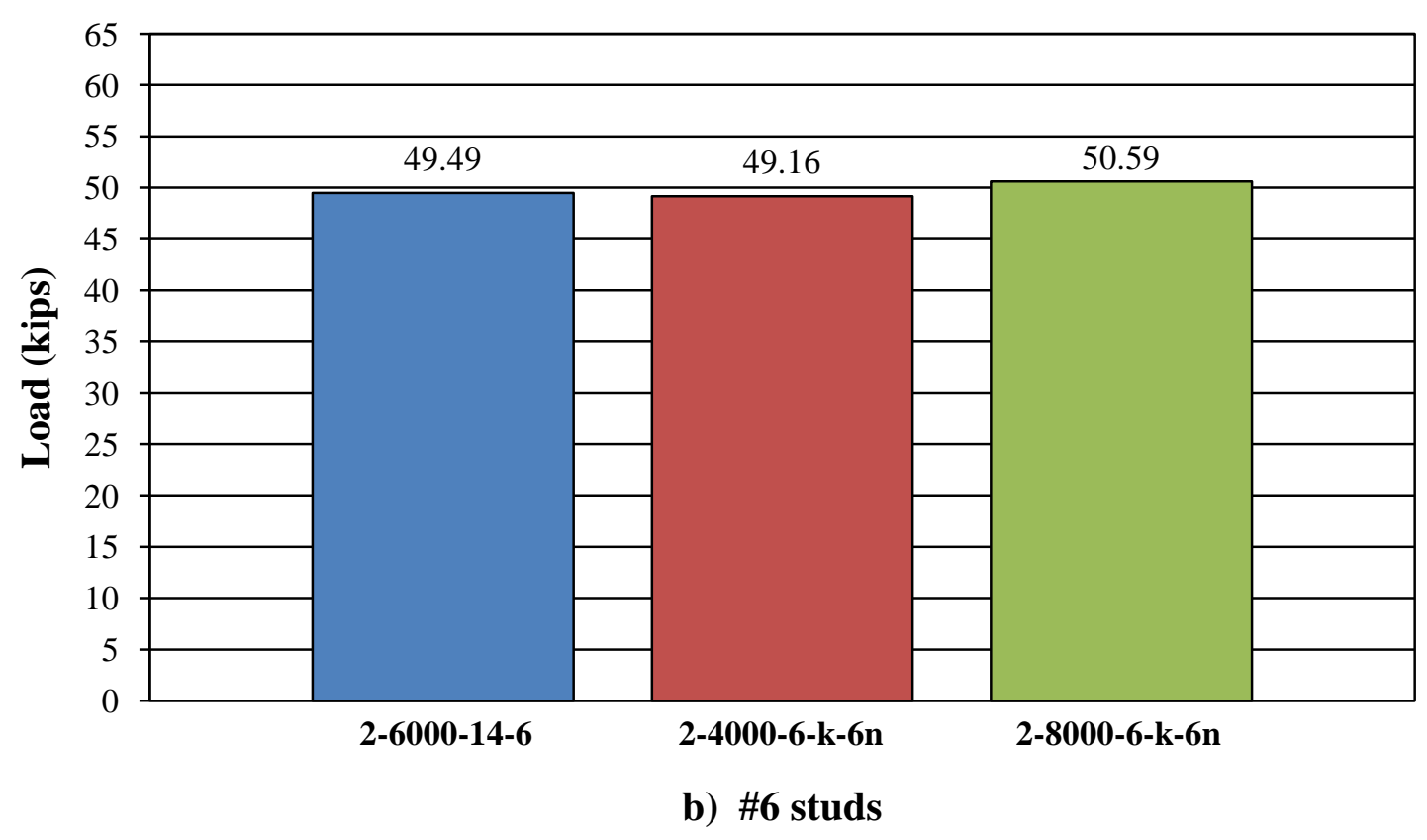

Figure 3.73: Maximum load, after bond failure, on specimens with stud failure 


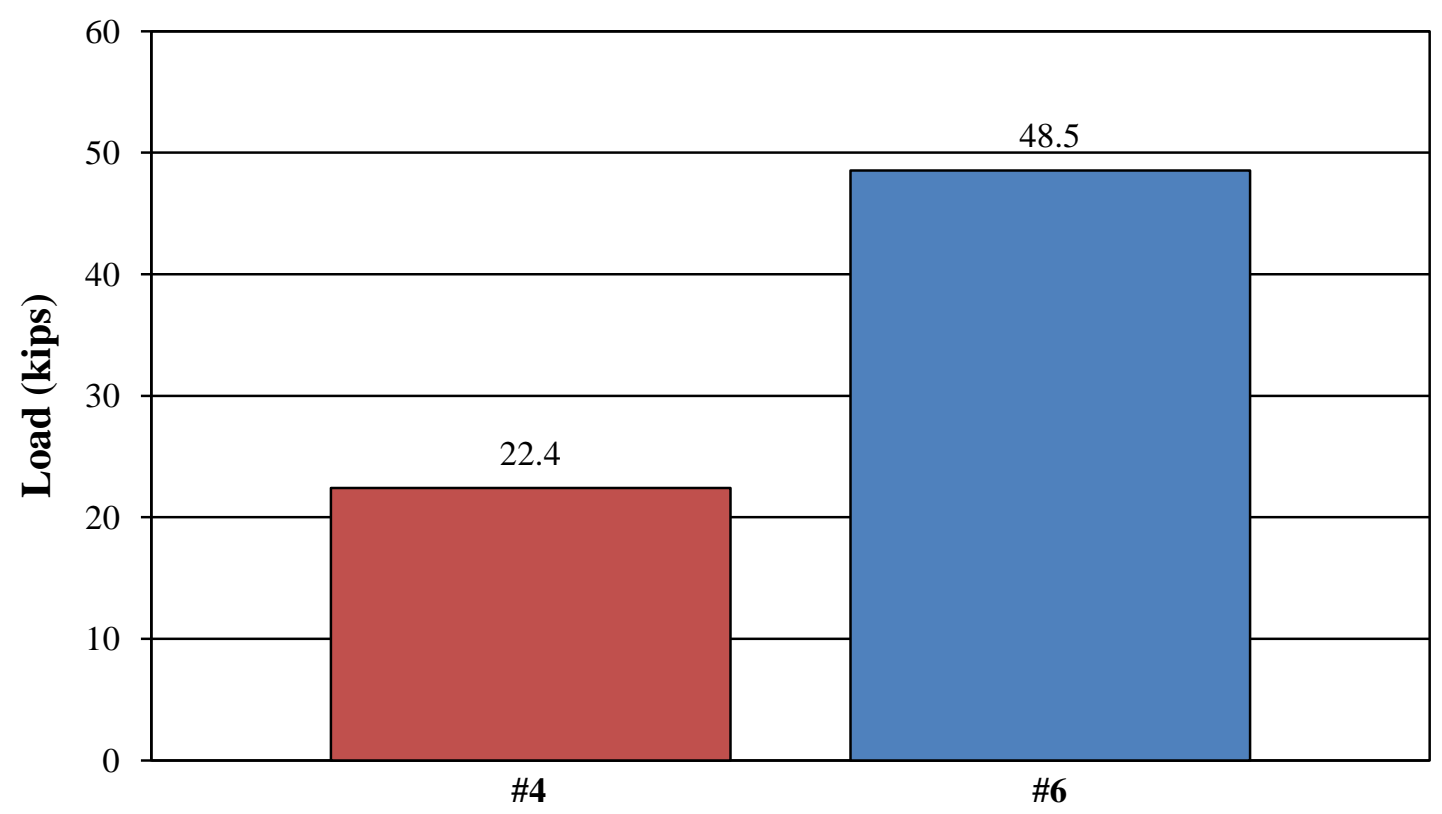

Figure 3.74: Average shear strength of studs

\subsubsection{Stud spacing}

As expected, the load at which initial bond failure occurred was dependent on the interface area. The $2 \mathrm{ft}$ specimens showed an average increase in load at bond failure of $42 \%$ over the $1 \mathrm{ft}$ specimens. However, this increase cannot be attributed to stud spacing but rather the increase in interface area. If compared in terms of stress, the average shear stress at bond failure of the $2 \mathrm{ft}$ specimens was in good agreement with the $1 \mathrm{ft}$ specimens, differing by $2 \%$. Average stresses, loads, and standard deviation are summarized in Table 3.7.

As evident from Figure 3.73a, the load at stud failure for both the $1 \mathrm{ft}$ and $2 \mathrm{ft}$ specimens are similar. This finding supports that the shear capacity is based primarily on the reinforcement crossing the interface and not the concrete surface area of the interface which provides frictional resistance. This finding is further supported by the results presented in Chapter 2, in which the estimated stud capacities are consistent with those in Figure 3.74 even though the concrete surface area of the interface differs by $40 \%$ per stud. 
Table 3.7: Average strengths at bond failure

\begin{tabular}{|c|c|c|c|c|}
\hline $\begin{array}{c}\text { Stud spacing } \\
\text { (ft) }\end{array}$ & $\begin{array}{c}\text { Avg. stress } \\
\text { (psi) }\end{array}$ & $\begin{array}{c}\text { Std. dev. } \\
\text { (psi) }\end{array}$ & $\begin{array}{c}\text { Avg. load } \\
\text { (kip) }\end{array}$ & $\begin{array}{c}\text { Std. dev. } \\
\text { (kip) }\end{array}$ \\
\hline 1 & 213 & 81 & 56 & 15 \\
\hline 2 & 217 & 46 & 98 & 25 \\
\hline
\end{tabular}

\subsubsection{Embedment}

As evident from Figure 3.75, increased embedment from 6 in. to 8 in. showed no increase in strength or improvement in behavior in either the $1 \mathrm{ft}$ or $2 \mathrm{ft}$ specimens. As shown in Figure 3.73, a 6 in. embedment is sufficient to provide a shear failure of a \#6 or smaller bar. This was possible because of the improved reinforcement detail in the girder sections of Group 2, which provided confinement for the trough concrete, and the keyed trough detail, which provided a mechanical connection to transfer shear forces to the girder section. This result is in agreement with previous research by Fuchs et al. (1995) regarding anchors in concrete loaded in shear near an edge. The results and design approach proposed by Fuchs et al. (1995) indicate that the variable with the most influence on anchor strength is the distance of the anchor from a free edge rather than embedment depth. 


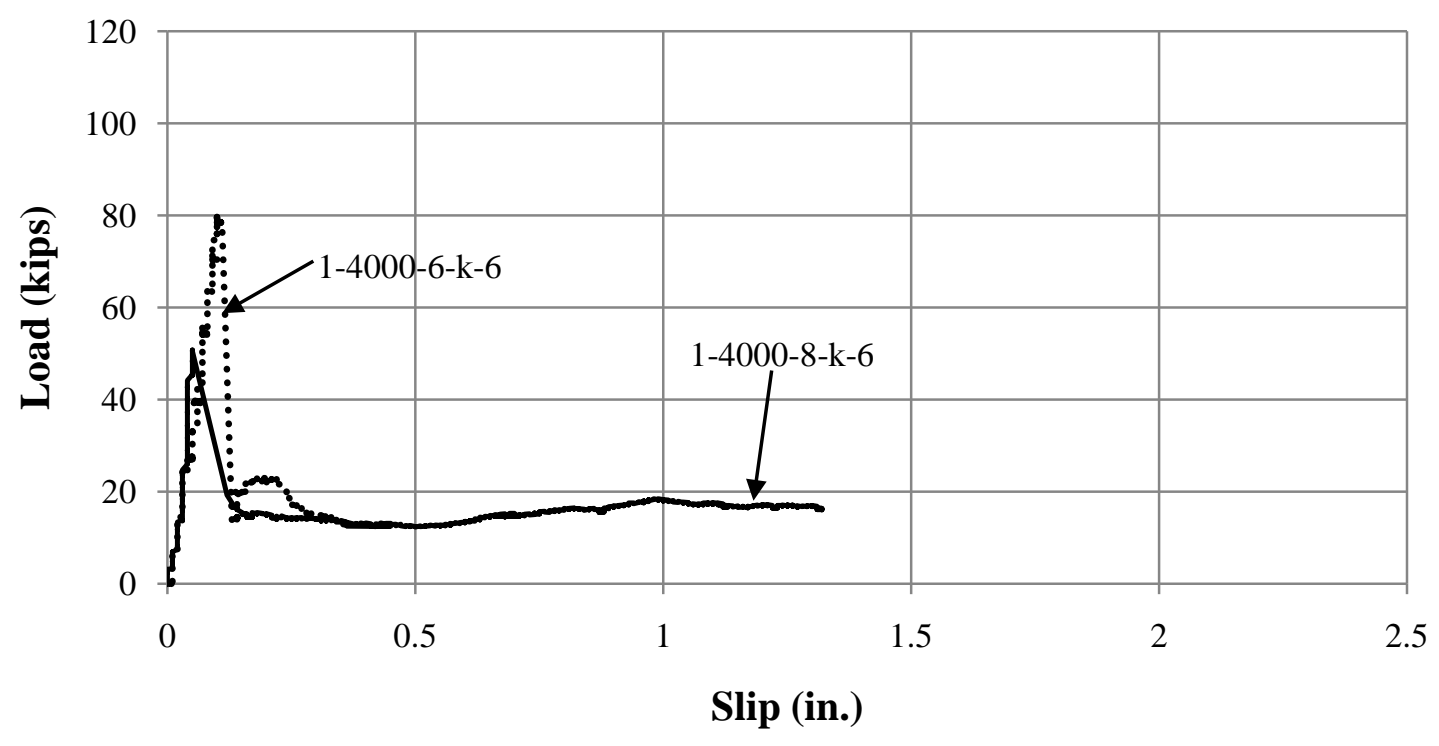

a) $1 \mathrm{ft}$ spacing

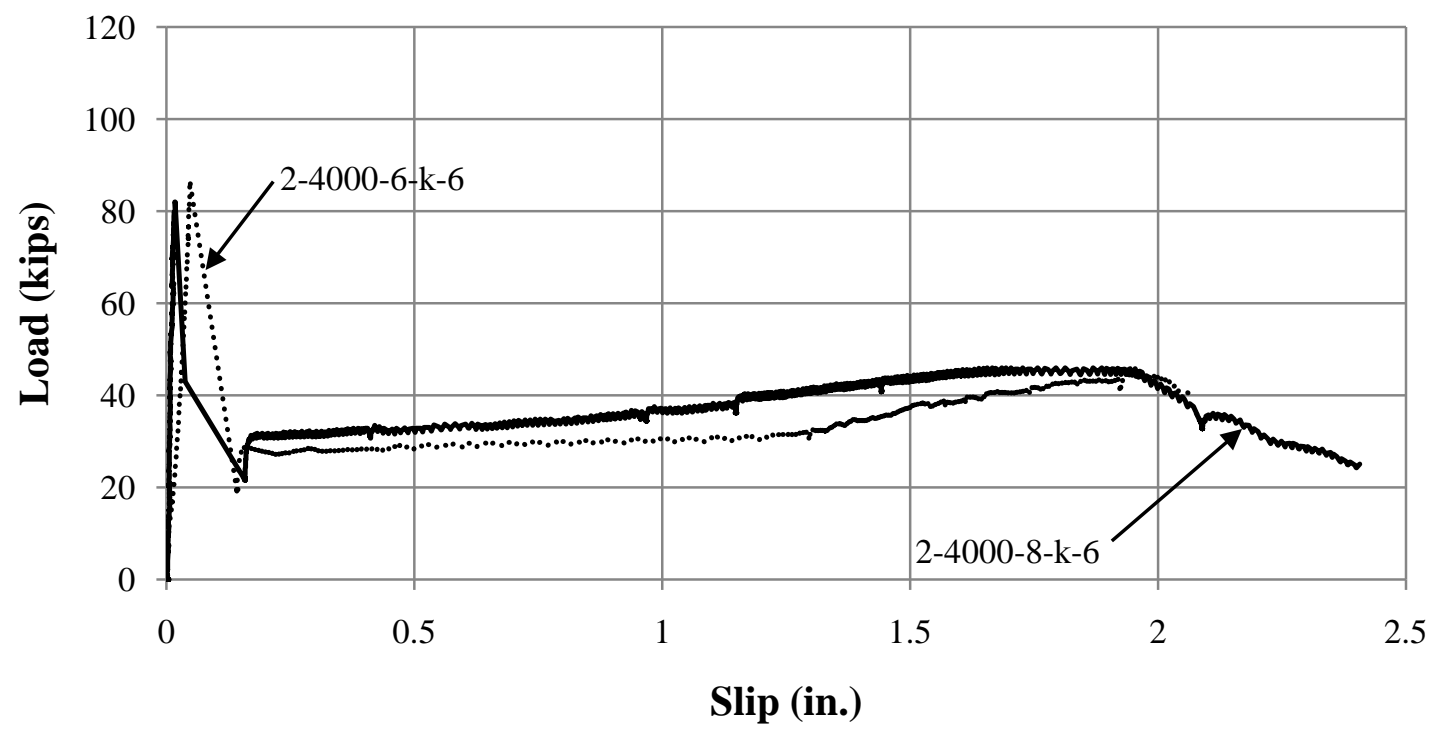

b) $2 \mathrm{ft}$ spacing

Figure 3.75: Embedment length comparison 


\subsubsection{Trough concrete $f_{c}^{\prime}$}

The strength of the trough concrete had no appreciable effect on the load at which initial bond failure occurred. The specimens with 4,000 psi concrete showed an increase in average interface shear stress at bond failure of 15\% over the specimens with 8,000 psi concrete. However, the average shear stress value for the specimens with 4,000 and 8,000 psi trough concrete had a standard deviation of approximately $25 \%$ and $44 \%$, respectively. Therefore, it is unclear whether the bond strength was influenced by the trough concrete strength.

As shown in Figure 3.76, varying the compressive strength of the concrete used to fill the trough from 4,000 psi to 8,000 psi had no discernable influence on the final capacity of the specimen at shear stud failure. This finding indicates that once a minimum compressive strength for shear stud failure is provided, any excess strength has little influence on the behavior of the horizontal interface. As shown in Figure 3.76, similar post peak behavior ( $>0.5$ in. slip) was observed up to final failure.

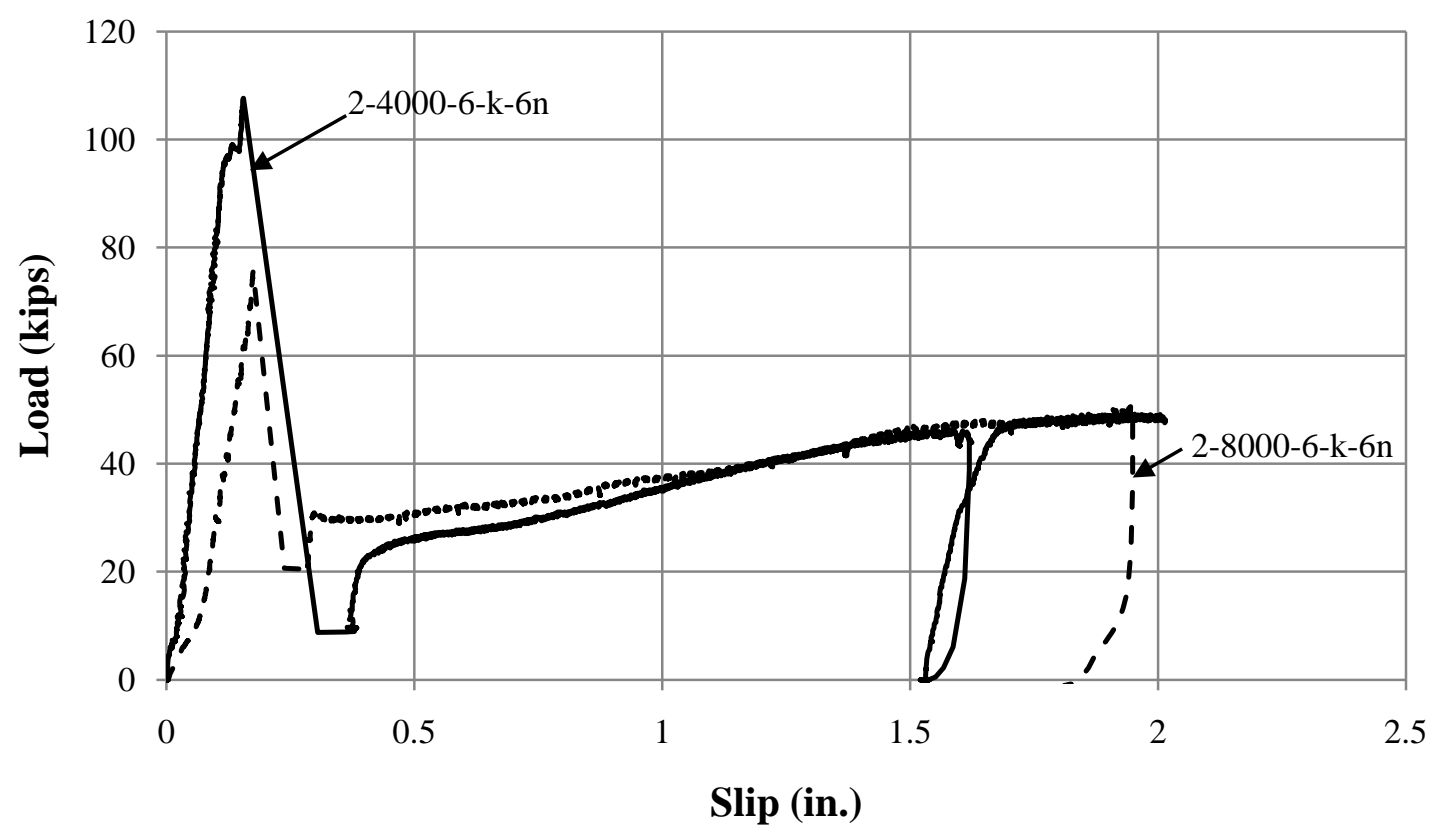

Figure 3.76: Trough concrete strength comparison 


\subsubsection{Trough detail}

Two trough details were evaluated in this series of tests. One detail was a plain surface and the other was a keyed surface. As evident from Figure 3.77, having a keyed surface in the trough is necessary for performance following initial bond failure of the interface and to prevent a rapid decrease in capacity. Without the keyed surface, the trough fell out of the specimens' girder section because resistance to shear forces was only provided by interface bond. The keyed surface provides for more "ductile” behavior in comparison to the smooth surface and allows for shear forces to be resisted mechanically.

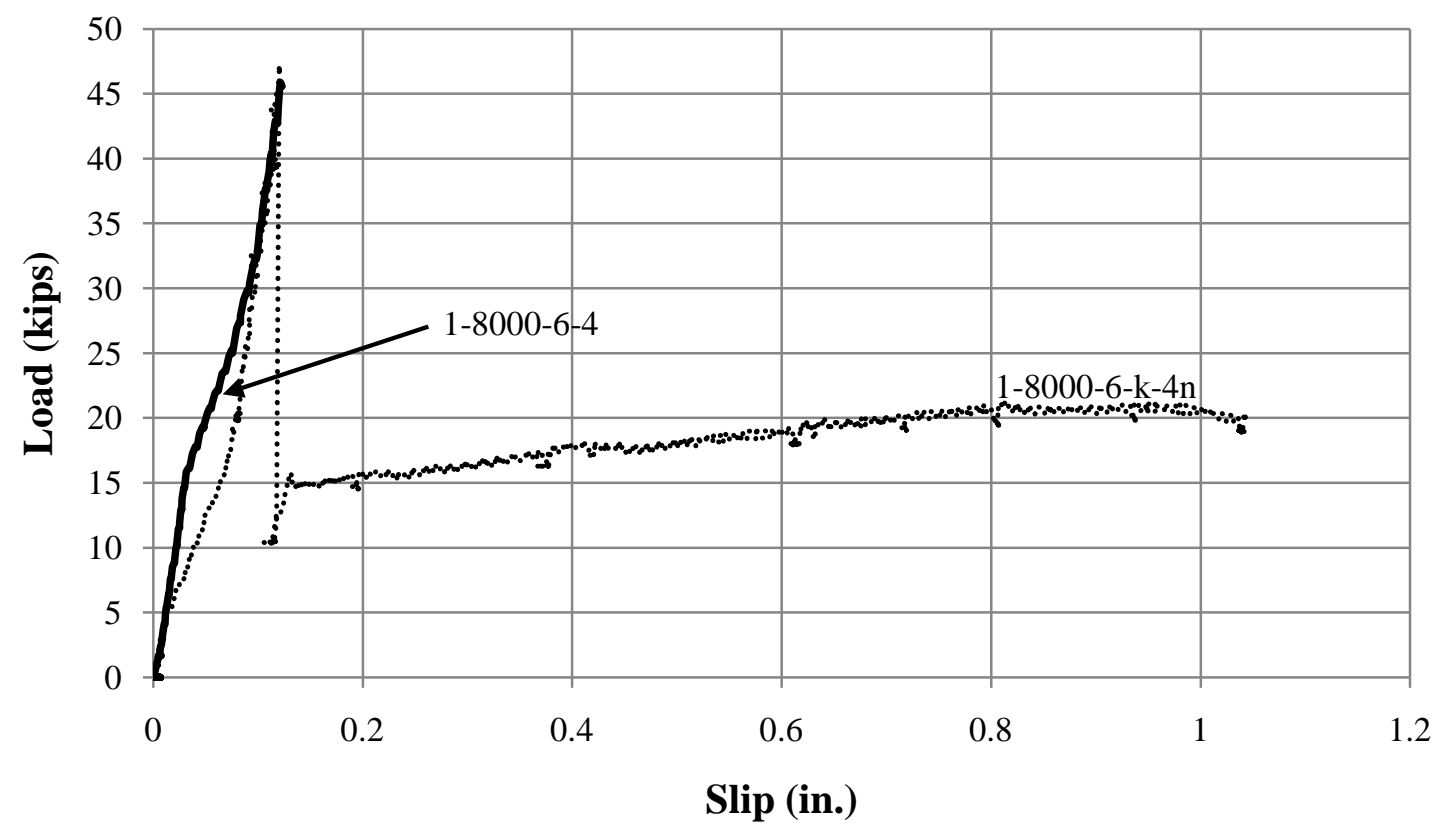

Figure 3.77: Trough detail comparison 


\subsubsection{Joint comparison}

The new joint and New England System joint details were compared to evaluate any differences in performance. The new joint specimens used for comparison were those from Group 2 because those represent the behavior of the improved reinforcement detail and keyed trough. It is evident from Figure 3.78, the \#4 and \#6 stud sizes were similar in strength at stud failure regardless of the joint detail. As previously discussed, the final failure load of Specimen 2-6000-14-4 was slightly higher because $f_{u}$ of the stud was greater than that used in 1-8000-6-k-4n. The findings indicate that the new joint detail is capable of producing equivalent behavior and strength as that of the New England System. 


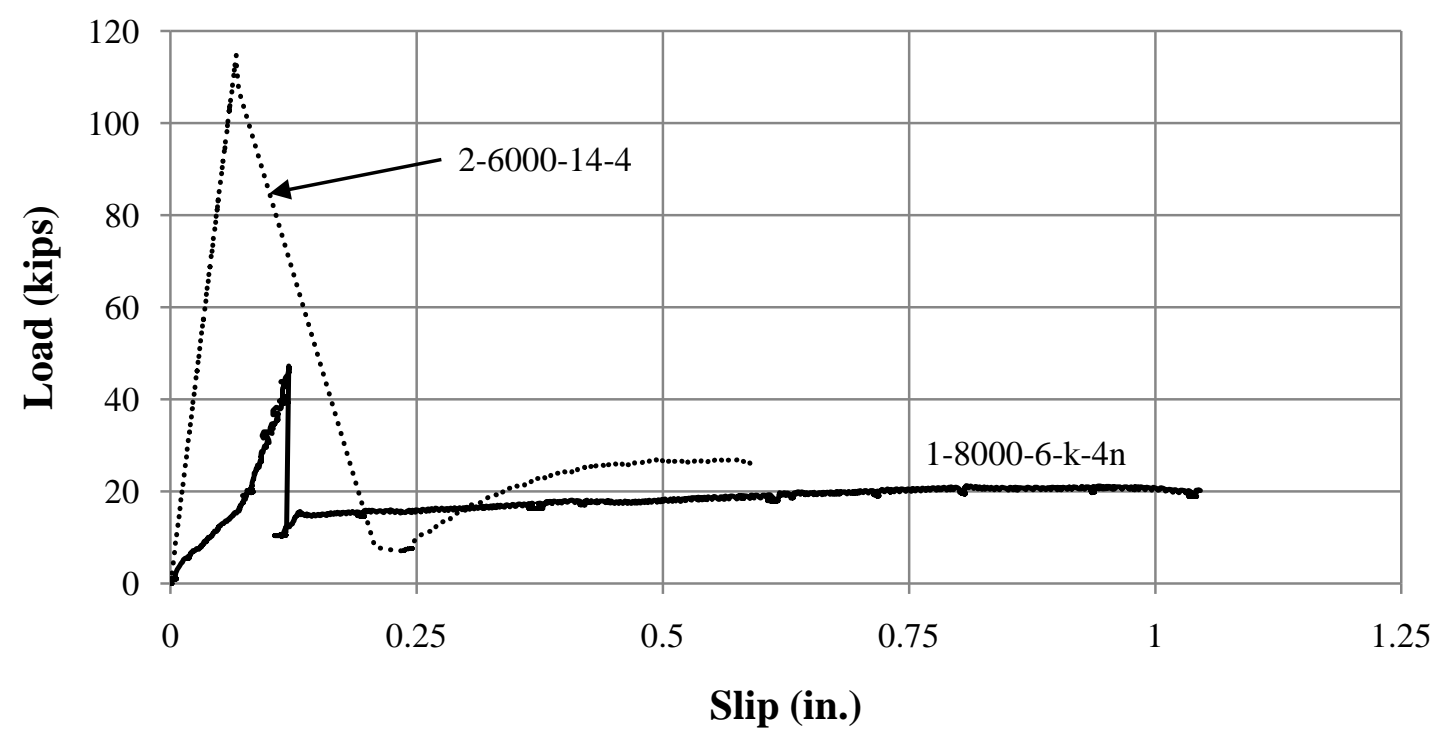

a) \#4 studs

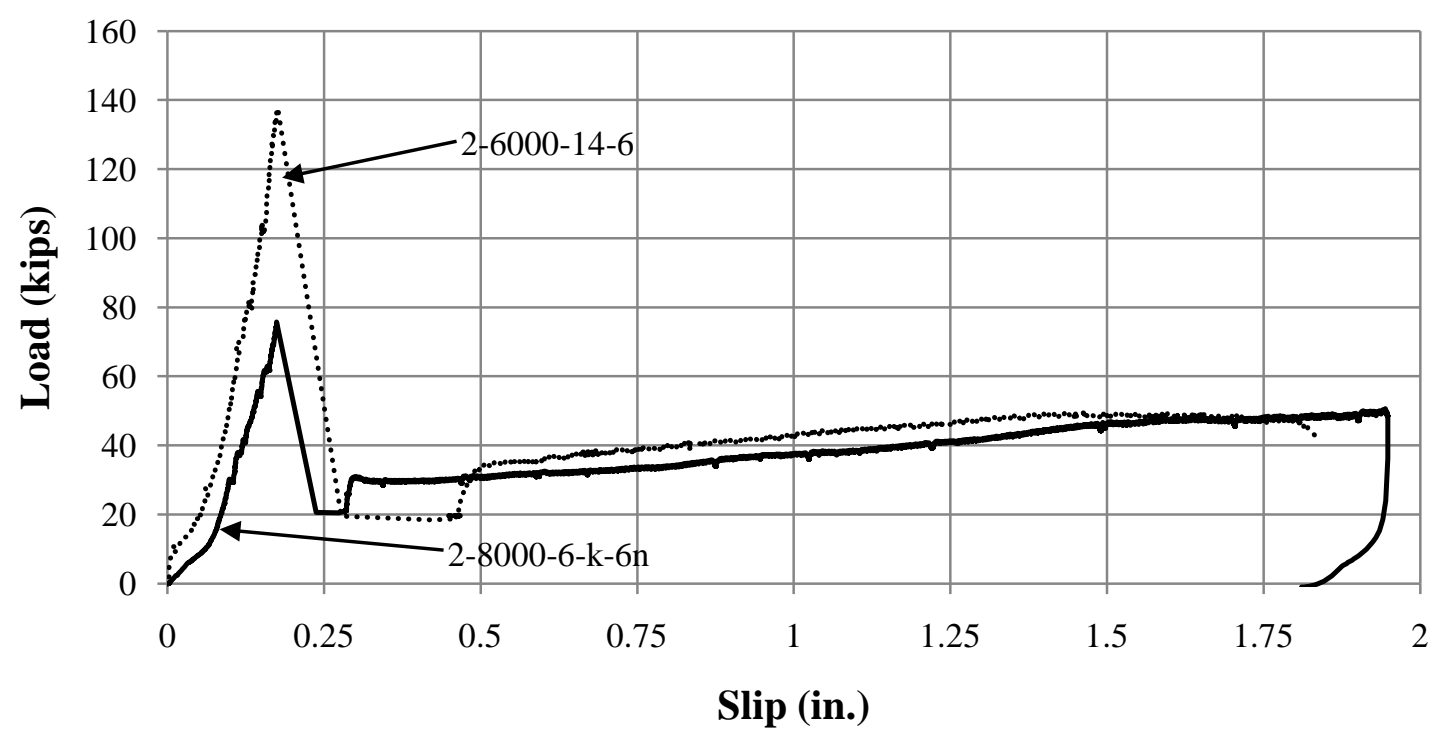

b) \#6 studs

Figure 3.78: Joint detail comparison 


\subsection{Conclusions}

There are four main factors governing the behavior and strength of the new joint detail assuming the trough has a keyed surface and the stud is embedded at least 6 in. into the trough material:
1) Bond strength
2) Confinement of trough concrete
3) Concrete strength
4) Stud strength

\subsubsection{Bond strength}

The bond strength between adjacent concrete surfaces is highly variable, and its failure is sudden. Therefore, relying on bond strength for capacity in a structure is undesirable. However, when it is necessary to model the behavior of a structure, an estimate of bond strength is required for approximating the transition from full-composite to partial-composite behavior. The average shear stress at bond failure for all the specimens where an interface bond failure occurred is 208 psi with a standard deviation of 58 psi. Taking the average shear stress minus two standard deviations yields 92 psi. Subtracting two standard deviations from the mean corresponds to 92 psi being conservative for at least $95 \%$ of the specimens. The lowest average shear stress at bond failure calculated from this phase of testing was 112 psi. It is recommended that 100 psi is a reasonable lower-bound value that can be used to estimate bond strength of the horizontal interface.

\subsubsection{Confinement of trough concrete}

It is evident from the comparison of the behavior of Group 1 and Group 2 specimens that providing sufficient reinforcement in the girder section is critical in preventing girder and trough concrete cracking, and for developing a shear stud failure. The girder section of Group 1 did not contain any reinforcement to resist the moments generated by loading. To design the reinforcement in the girder section, a lateral force 
$(\mathrm{H})$ must be determined. The force $(\mathrm{H})$ on the girder section was calculated by assuming the load on the stud was distributed to each side of the trough equally. The force of $\mathrm{p} / 2$ was further distributed along the sides of the trough-girder section interface, as illustrated in Figure 3.79a. It was assumed that the force would radiate from the stud linearly with a higher percentage of the load being carried by the interface closest to the stud. The smallest angle of the failure plane was limited to 35 degrees, which is the same angle used in calculating various failure cones for anchors in concrete (ACI 2008).

The percentage of the force carried at the trough-girder interface at a given distance from the edge of the specimen was assumed to vary linearly from 0 at the edge to $\alpha(\theta)=m\left(\theta-\theta_{1}\right)$. The value of $m$ can be determined by summing the vertical components of the distributed force and setting it equal to $\mathrm{P} / 2$. Once $\mathrm{m}$ is determined, the horizontal components can be summed to determine the force $(\mathrm{H})$. To determine the moment applied to the girder section $\left(\mathrm{M}_{\mathrm{ext}}\right)$, the force $(\mathrm{H})$ is multiplied by $\overline{\mathrm{y}}_{\mathrm{pa}}$, which is the neutral axis of the area projected on the side of the trough by the failure cone. Once $\mathrm{M}_{\mathrm{ext}}$ is calculated, the area and number of stirrups can be determined by assuming a plane section through the girder section at the base of the trough and determining the flexural capacity of the cross-section for a selected value of $A_{s}$ and $f_{s}$. This cross-section is assumed to be cracked for all values of $\mathrm{f}_{\mathrm{s}}$ because the reentrant corner at the base of the trough produces a stress concentration and is likely to be cracked prior to loading. The procedure discussed is presented in Figure 3.79b.

When designing the specimens of Group 2, an applied load of $\mathrm{P}=2 \mathrm{~A}_{\mathrm{s}} \mathrm{f}_{\mathrm{u}}$ was conservatively considered with the ultimate strength of the shear stud assumed to be $\mathrm{f}_{\mathrm{u}}=$ $100 \mathrm{ksi}$. In addition, $\mathrm{f}_{\mathrm{s}}$ was limited to $30 \mathrm{ksi}$ when determining $\mathrm{A}_{\mathrm{s}}$ of the stirrups and moment capacity of the girder section ( $\left.\mathrm{M}_{\mathrm{int}}\right)$ to resist $\mathrm{M}_{\mathrm{ext}}$ to limit the estimated lateral displacement $(\Delta)$ of the girder section at the top of the trough to the order of one thousandth of an inch (0.001 in.). The lateral displacement was calculated from the curvature of the considered cross-section associated with $\mathrm{M}_{\text {int }}$. The estimated lateral force $(\mathrm{H})$, moments ( $\mathrm{M}_{\mathrm{ext}}$ and $\left.\mathrm{M}_{\mathrm{int}}\right)$, and $\mathrm{A}_{\mathrm{s}}$ are summarized in Table 3.8 . 


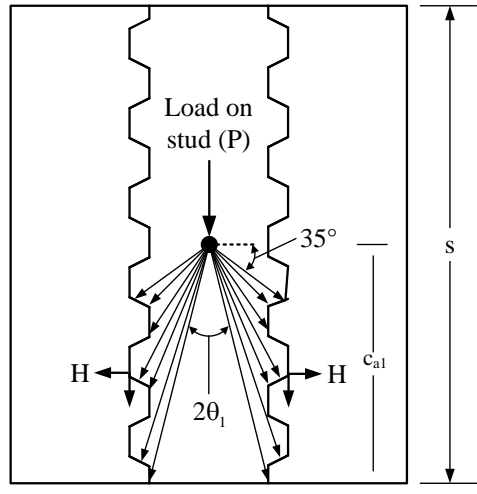

Elevation (Front)

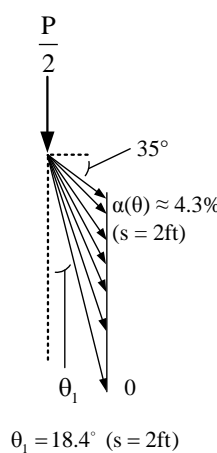

$\theta_{1}=18.4^{\circ}(\mathrm{s}=2 \mathrm{ft})$

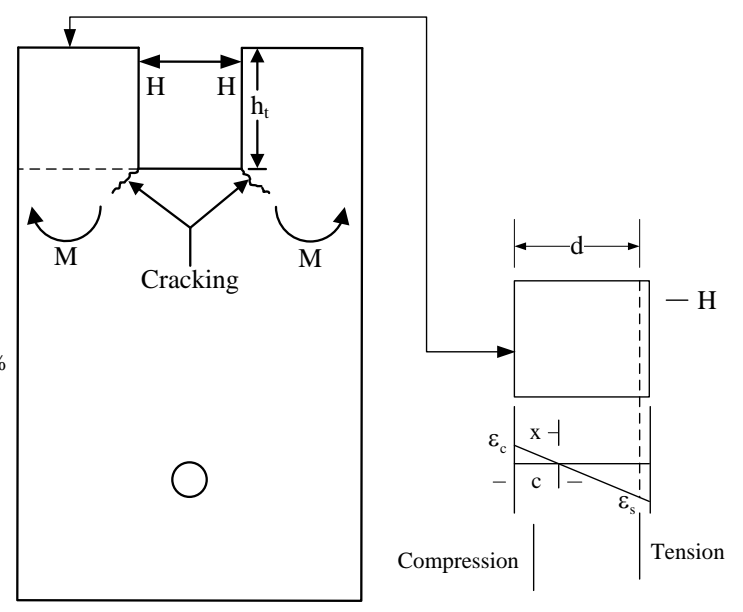

Plan

a) Moments in girder section due to loading

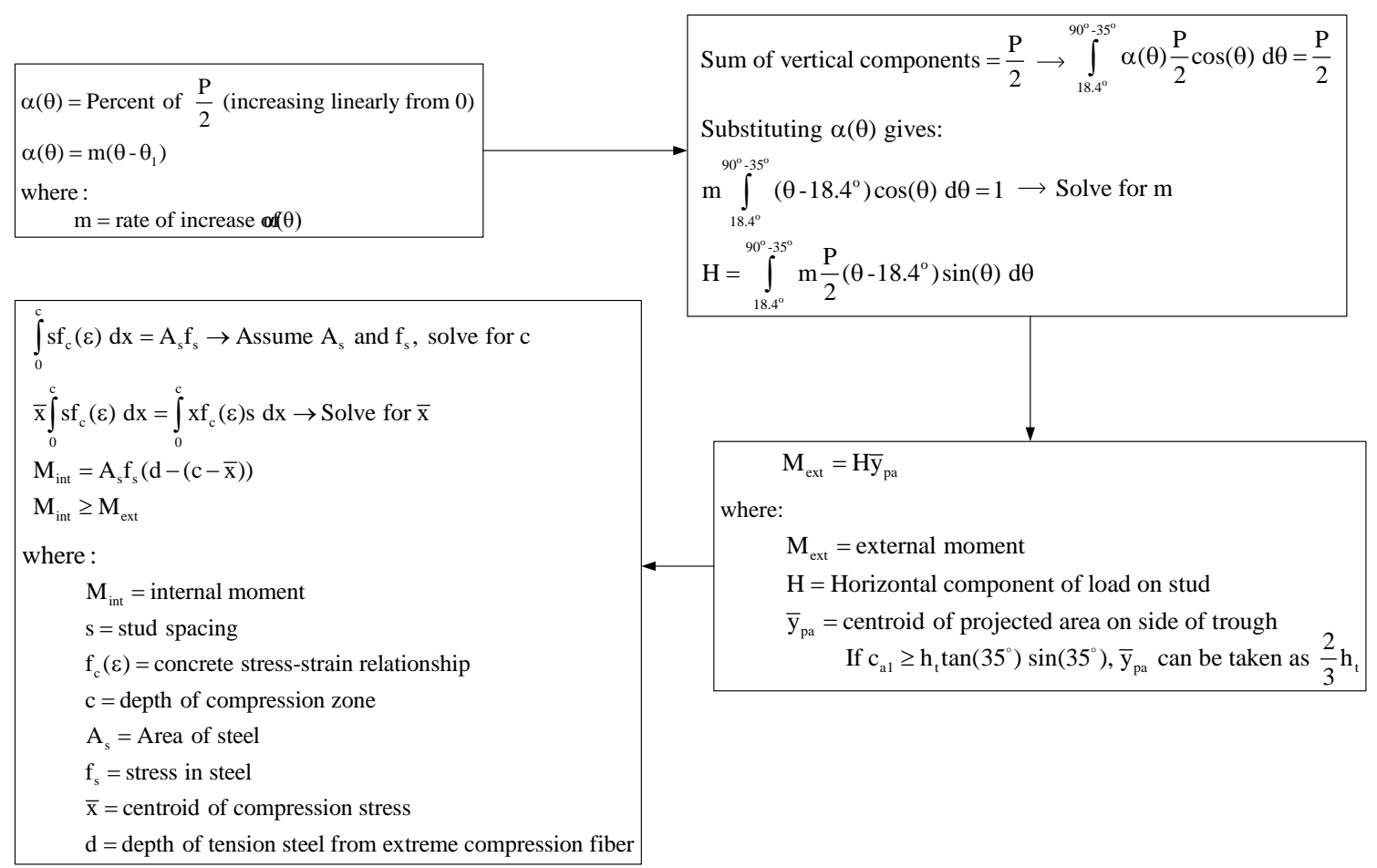

\section{b) Design procedure}

Figure 3.79: Loading and design for trough confinement reinforcement 
Table 3.8: Values for Group 2 design

\begin{tabular}{|c|c|c|c|c|c|c|}
\hline Stud Spacing (ft) & Stud Size & $\mathbf{H}$ (kip) & $\mathbf{M}_{\text {ext }}$ (in.-k) & $\mathbf{A}_{\mathbf{s}}$ (in. ${ }^{2}$ ) & $\mathbf{M}_{\text {int }}$ (in.-k) & $\Delta$ (in.) \\
\hline 1 & $\# 4$ & 20.4 & 95 & 0.8 & 110 & 0.002 \\
\hline \multirow{2}{*}{2} & $\# 4$ & 18.5 & 70 & 1.2 & 160 & 0.002 \\
\cline { 2 - 7 } & $\# 6$ & 40.8 & 150 & 1.2 & 160 & 0.002 \\
\hline
\end{tabular}

Due to the length of the procedure described above, a simplified method is desirable. The simplified method uses an applied stud force $P=\mathrm{A}_{\mathrm{s}} \mathrm{f}_{\mathrm{u}}$ divided by $2\left[\tan \left(35^{\circ}\right)\right]$, which results in the horizontal component of the stud force $(\mathrm{H})$ assuming a $35^{\circ}$ force cone projected from the stud, as presented in Figure 3.80. The ultimate strength of the shear stud was assumed to be $f_{u}=100 \mathrm{ksi}$. The force $(H)$ is multiplied by the conservative value $\left(h_{t}\right)$ to determine $M_{\text {ext }}$ on the girder section rather than $(2 / 3) h_{t}$. Then, $M_{\text {ext }}$ is used in determining the area of steel $\left(A_{s}\right)$ required to produce $M_{\text {int }}$ such that $M_{\text {int }} \geq M_{\text {ext }}$, as illustrated in Figure 3.79. It is assumed the full length (s) of the section resists $M_{\text {ext }}$. The estimated lateral force $(H)$, moments $\left(M_{\text {ext }}\right.$ and $\left.M_{i n t}\right)$, and $A_{s}$ from simplified design procedure are summarized in Table 3.9. As with the procedure illustrated in Figure 3.79, $\mathrm{f}_{\mathrm{s}}$ was limited to approximately $30 \mathrm{ksi}$ when calculating $\mathrm{M}_{\text {int }}$. This simplified procedure requires only slightly more reinforcement than that required by the complex procedure. 

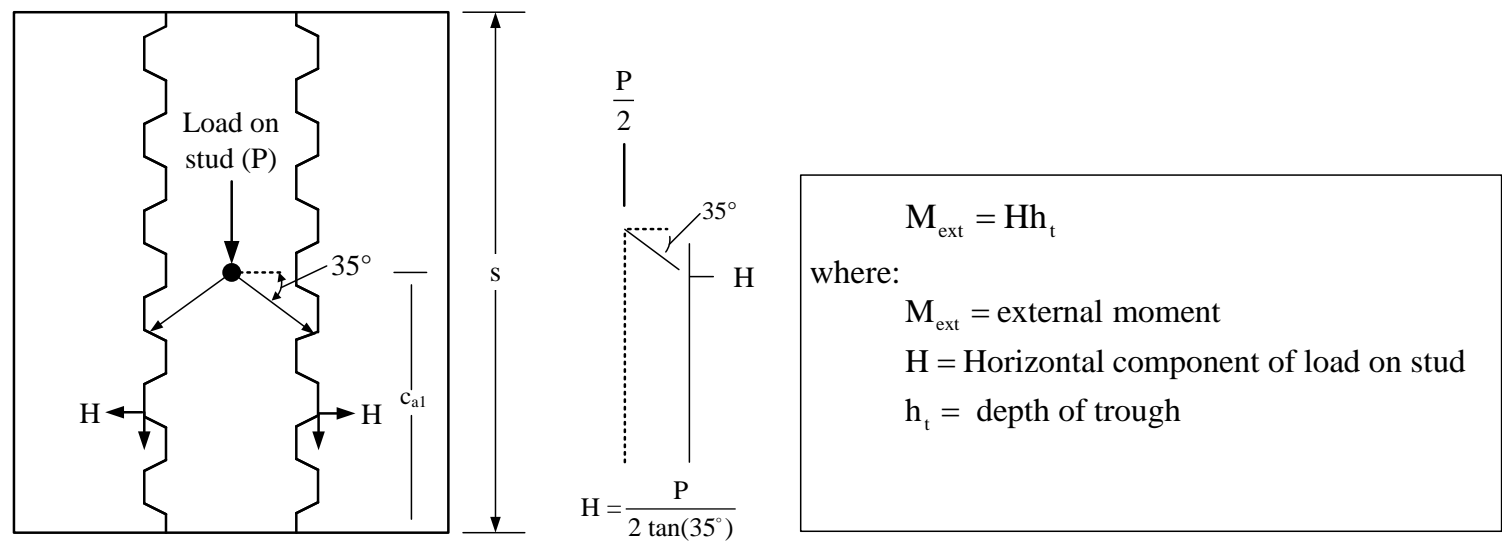

Elevation (Front)

Figure 3.80: Simplified design procedure 
Table 3.9: Group 2 design - simplified method

\begin{tabular}{|c|c|c|c|c|c|c|}
\hline Stud Spacing (ft) & Stud Size & $\mathbf{H}$ (kip) & $\mathbf{M}_{\text {ext }}$ (in.-k) & $\mathbf{A}_{\mathbf{s}}$ (in. ${ }^{\mathbf{2}}$ ) & $\mathbf{M}_{\text {int }}$ (in.-k) & $\Delta$ (in.) \\
\hline 1 & $\# 4$ & 14.3 & 110 & 0.8 & 110 & 0.002 \\
\hline \multirow{2}{*}{2} & $\# 4$ & 14.3 & 110 & 1.6 & 225 & 0.002 \\
\cline { 2 - 7 } & $\# 6$ & 31.4 & 220 & 1.6 & 225 & 0.002 \\
\hline
\end{tabular}

\subsubsection{Concrete strength}

Concrete breakout design provisions are provided in Appendix D of ACI (2008) for anchors in concrete. The design equations are very similar to those presented by Fuchs et al (1995) for determining concrete breakout strength, but simplified. The concrete breakout equations presented by Fuchs and ACI are not particularly valid for comparison with results of this test phase because of the type of edge condition present in the test setup. The projected breakout cone for the shear stud (Figure 3.81) is supported by the support block making concrete breakout unlikely because it was not a completely free edge. This is also unlikely in the full-scale structure.

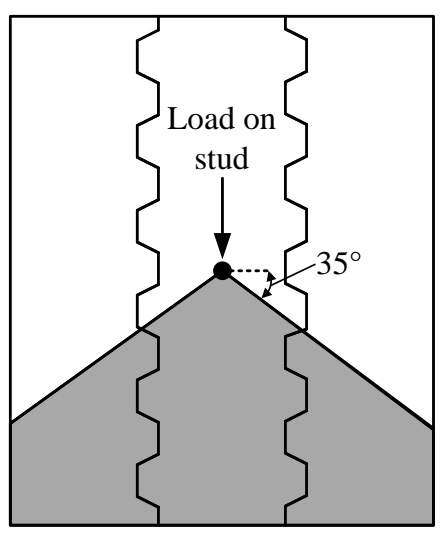

Elevation (Front)

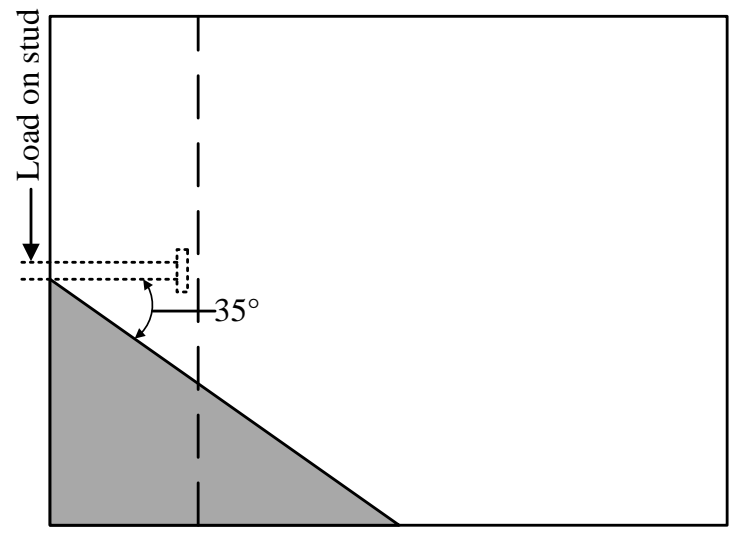

Elevation (Side)

Figure 3.81: Idealized breakout failure

Other possible modes of failure of the concrete include concrete pryout failure and shearing of the shear keys (Figure 3.82). The design equations for concrete pryout 
failure are applicable to this phase of testing because this mode of failure is primarily based on embedment depth of the stud rather than edge distance. For the specimens tested, the calculated concrete pryout load exceeded the stud capacity; therefore, this failure mode did not control, as summarized in Table 3.10.

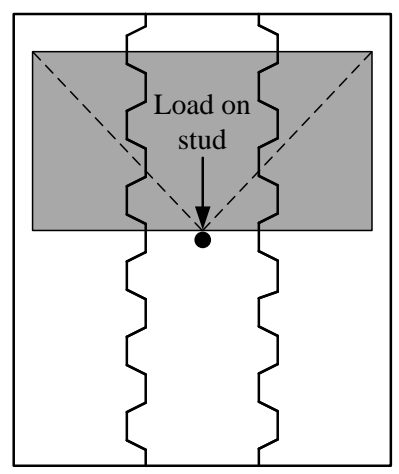

Elevation (Front)

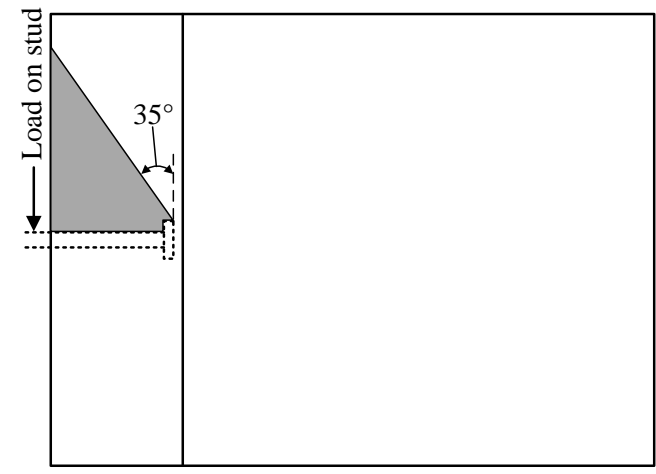

Elevation (Side)

a) Pryout Failure

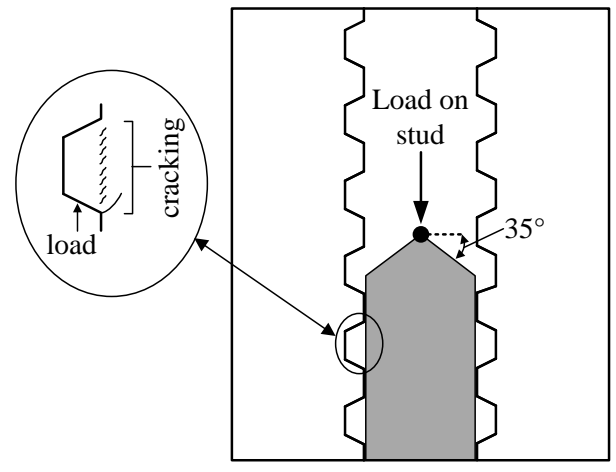

Elevation (Front)

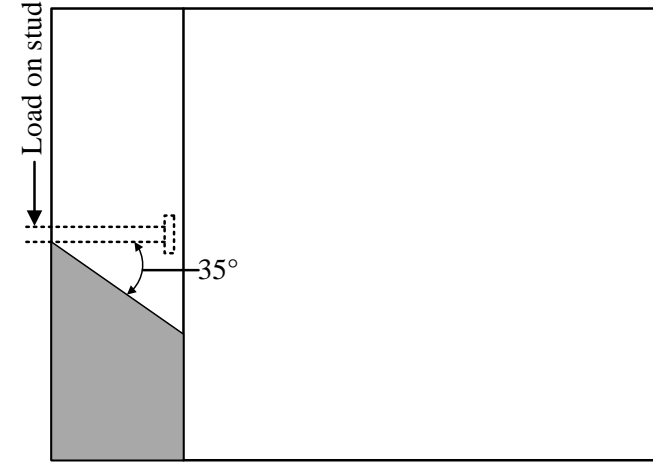

Elevation (Side)

b) Shear Key Failure

Figure 3.82: Additional idealized failure modes 
Table 3.10: Pryout loads

\begin{tabular}{|c|c|c|c|c|}
\hline \multirow{2}{*}{ Stud Spacing (ft) } & Stud Size & Stud $\mathbf{A}_{\mathbf{s}} \mathbf{f}_{\mathbf{u}}$ (kip) & \multicolumn{2}{|c|}{ Pryout load (kips) } \\
\cline { 3 - 5 } & $\mathbf{f}_{c}^{\prime}=\mathbf{4 0 0 0} \mathbf{~ p s i}$ & $\boldsymbol{f}_{\boldsymbol{c}}^{\prime}=\mathbf{8 0 0 0} \mathbf{~ p s i}$ \\
\hline 1 & $\# 4$ & 20 & 33.4 & 47.3 \\
\hline \multirow{2}{*}{2} & $\# 4$ & 20 & 55.8 & 78.9 \\
\cline { 3 - 4 } & $\# 6$ & 44 & & \\
\hline
\end{tabular}

The strength of the shear key is generally not the controlling failure, although, it must be checked. From AASHTO (1999), Section 12.2.21 the ultimate shear strength of a shear key can be calculated using Equation (3.1).

$$
V_{n j}=A_{k} \sqrt{f_{c}^{\prime}}\left(12+0.017 f_{p c}\right)+0.6 A_{s m} f_{p c}
$$

where:

$V_{n j}=$ Nominal shear strength of joint (psi)

$f_{c}^{\prime}=$ Compressive strength of concrete (psi)

$A_{k}=$ Total area of base of shear keys in the failure plane (in. ${ }^{2}$ )

$f_{p c}=$ Compressive stress from prestressing accounting for all prestress losses (psi)

$A_{s m}=$ Contact area between smooth surfaces on the failure plane (in. ${ }^{2}$ )

Canceling out the terms of the equation involving prestressing forces results in Equation (3.2). Issa et al (2007b) found Equation (3.1) to be conservative when used to calculate shear key capacity in the absence of prestressing force. In addition, the value is similar to that obtained from applying the rotating smeared-crack-band model (RSCBM) discussed by Kaneko et al (1993). The RSCBM model estimates an ultimate shear stress of $13 \sqrt{f_{c}^{\prime}}$ for $f_{c}^{\prime}=4000$ psi and a prestressing force of 0 psi normal to the key base. It is recommended that Equation (3.2) be used because it is slightly more conservative. The weaker of the trough or girder section material should be used in calculating shear key strength. 


$$
V_{n j}=12 \sqrt{f_{c}^{\prime}} A_{k}
$$

The projected area of the failure cone on the trough-girder interface was used to conservatively determine the area resisting the stud force (Figure 3.83). The area of the base of the shear keys present in the projected area was used in estimating shear key capacity. Shear key strength for the $1 \mathrm{ft}$ and $2 \mathrm{ft}$ specimens are presented in Table 3.11 for 4,000 psi trough material. For an actual girder the keys present within one stud spacing would be engaged in resisting a stud. Therefore, shear key capacity for studs spaced at $1 \mathrm{ft}$ in an actual girder would be calculated in a manner similar to the $2 \mathrm{ft}$ specimens from this phase of testing. Since the shear key capacity for a $1 \mathrm{ft}$ stud spacing is approximately 82 kips a maximum stud size of \#8 bar can be used without having to calculate shear key capacity, assuming $f_{u}=100$ ksi.

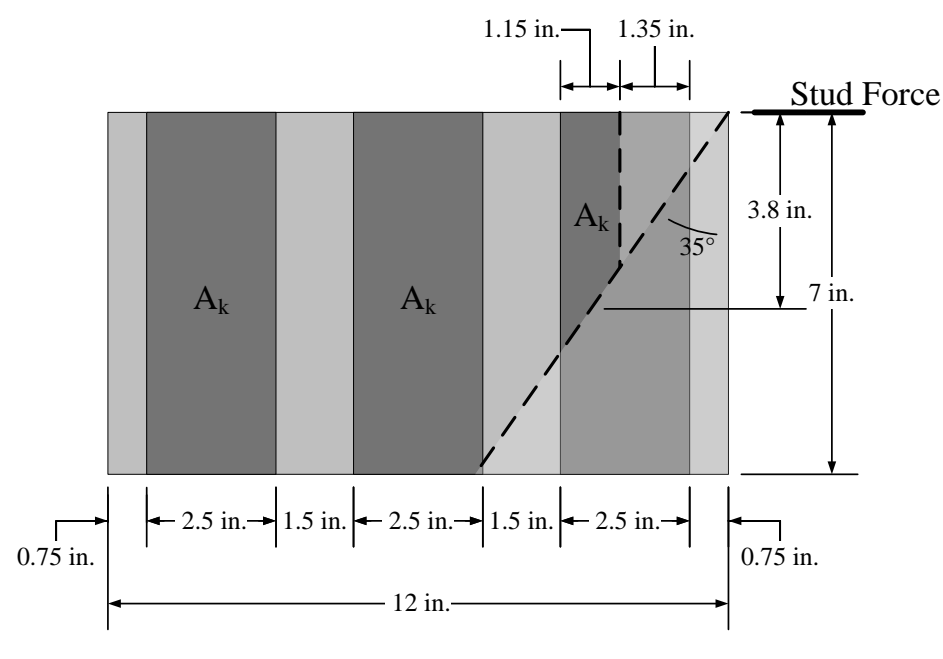

Elevation (trough side)

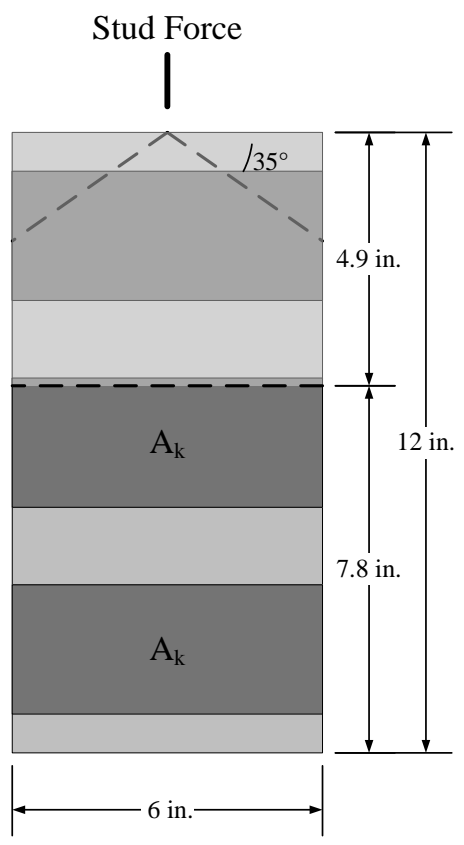

Plan (trough bottom)

$$
\begin{aligned}
& \text { Calculation of shear key capacity (2ft specimen): } \\
& \mathrm{A}_{\text {keys }}=\sum \mathrm{A}_{\mathrm{k}} \approx 2.5 \text { in. }(7 \text { in. }+7 \text { in. }+6 \text { in. }) 2+(1.15 \text { in. } \times 3.8 \text { in. }) 2 \approx 108 \text { in. }^{2} \\
& 12 \sqrt{f_{c}^{\prime}} \mathrm{A}_{\text {keys }}=12 \sqrt{4000} \text { psi } \times 108 \text { in. }^{2} \approx 82,000 \mathrm{lbs}
\end{aligned}
$$

Figure 3.83: Shear key area resisting stud force (2ft specimen) 
Table 3.11: Shear key capacity of $1 \mathrm{ft}$ and $2 \mathrm{ft}$ specimens

\begin{tabular}{|c|c|c|c|}
\hline Specimen stud spacing (ft) & $\begin{array}{c}\text { Base } \mathbf{A}_{\text {keys }} \text { (in. }^{2} \text { ) in } \\
\text { failure cone }\end{array}$ & $\mathbf{1 2 \sqrt { \mathbf { f } _ { \mathbf { c } } ^ { \prime } } \text { (psi) }}$ & Capacity (kip) \\
\hline 1 & 38 & 760 & 28 \\
\hline 2 & 108 & 760 & 82 \\
\hline
\end{tabular}

\subsubsection{Stud Strength}

Estimating the strength of the shear studs is important because it is the most "ductile" of the three failure modes. Therefore, it is desirable to promote this failure mode. The results from this phase of testing indicated that the shear stud strength is dependent on the cross-sectional area and $\mathrm{f}_{\mathrm{u}}$ of the stud. The strength of the shear studs can be approximated by multiplying the nominal area of the stud with $\mathrm{f}_{\mathrm{u}}$ as provided by Equation (3.3). For ASTM A615 reinforcement studs ( $f_{u}=90 \mathrm{ksi}$ min), this results in $\mathrm{V}_{\mathrm{n}}=18.0$ kips and $\mathrm{V}_{\mathrm{n}}=39.6$ kips for \#4 and \#6 studs, respectively. These values are conservative compared to those presented in Figure 3.74. This method for calculating stud strength is also consistent with ACI (2008), Section D.6.1.2.

$$
\mathrm{V}_{\mathrm{n}}=\mathrm{A}_{\mathrm{s}} \mathrm{f}_{\mathrm{u}}
$$

\subsection{Design Recommendations}

Based on the results of this phase of testing, the following design recommendations are provided.

1. Use keyed trough surface.

2. Minimum stud embedment 6 in. for \#4 - \#6 studs.

3. Provide minimum 4,000 psi concrete strength in trough.

4. Detail girder to resist outward thrust (Section 3.8.2).

5. The horizontal strength of the joint can be estimated based on the shear stud strength provided by $V_{n}=A_{s} f_{u}$. 


\section{CHAPTER 4: PANEL-TO-PANEL CONNECTION}

\subsection{Introduction}

The objective of the third phase of this research program was to develop a new connection between precast deck panels. As previously discussed, the focus of the system is to eliminate penetrations of the deck panels and minimize joint width. To evaluate the behavior and strength of the new detail, shear tests will be conducted. The New England System detail will also be tested in the same manner to evaluate and compare the behavior of the details.

\subsection{Specimen Design}

Each of the test specimens consisted of two precast deck panel sections. Details of the precast panel section design are presented in the following section.

\subsubsection{Joint Specimens}

Each specimen was designed 8 in. in width and 8 in. in depth. The total length of each specimen was 28 in. with the centroid of the joint placed at approximately 14 in. The length was determined by allowing for 8 in. from the loading plane in each direction plus 12 in. to secure the specimen in the test setup, as illustrated in Figure 4.1. Each specimen was designed with a semi-circular male-female joint, with exception of the New England System joint specimens, which were designed with the female-female shear key discussed in Section 2.2.2. Each panel was designed with \#3 and \#5 mild reinforcement. The rebar layout for the specimens is illustrated in Figure 4.2. The design compressive strength of the panel sections was selected as 4,000 psi to be consistent with that typically used on bridge decks. 


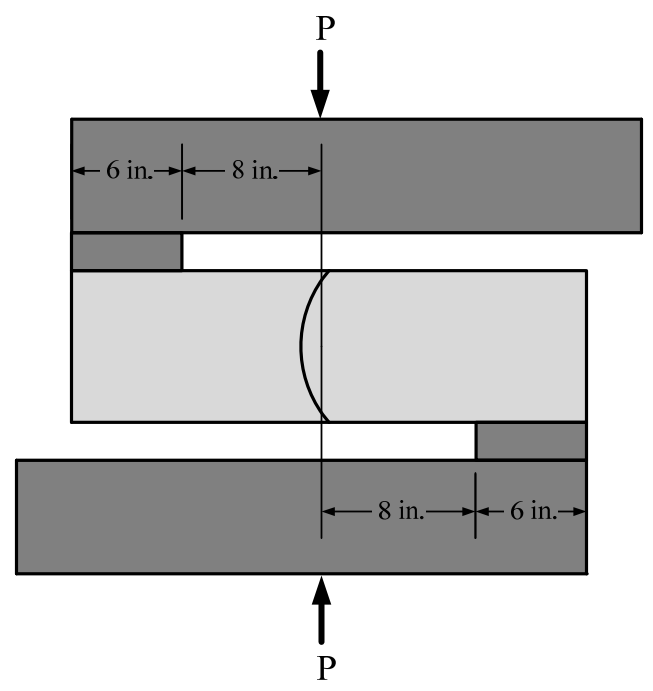

Elevation (side)

Figure 4.1: Specimen test setup
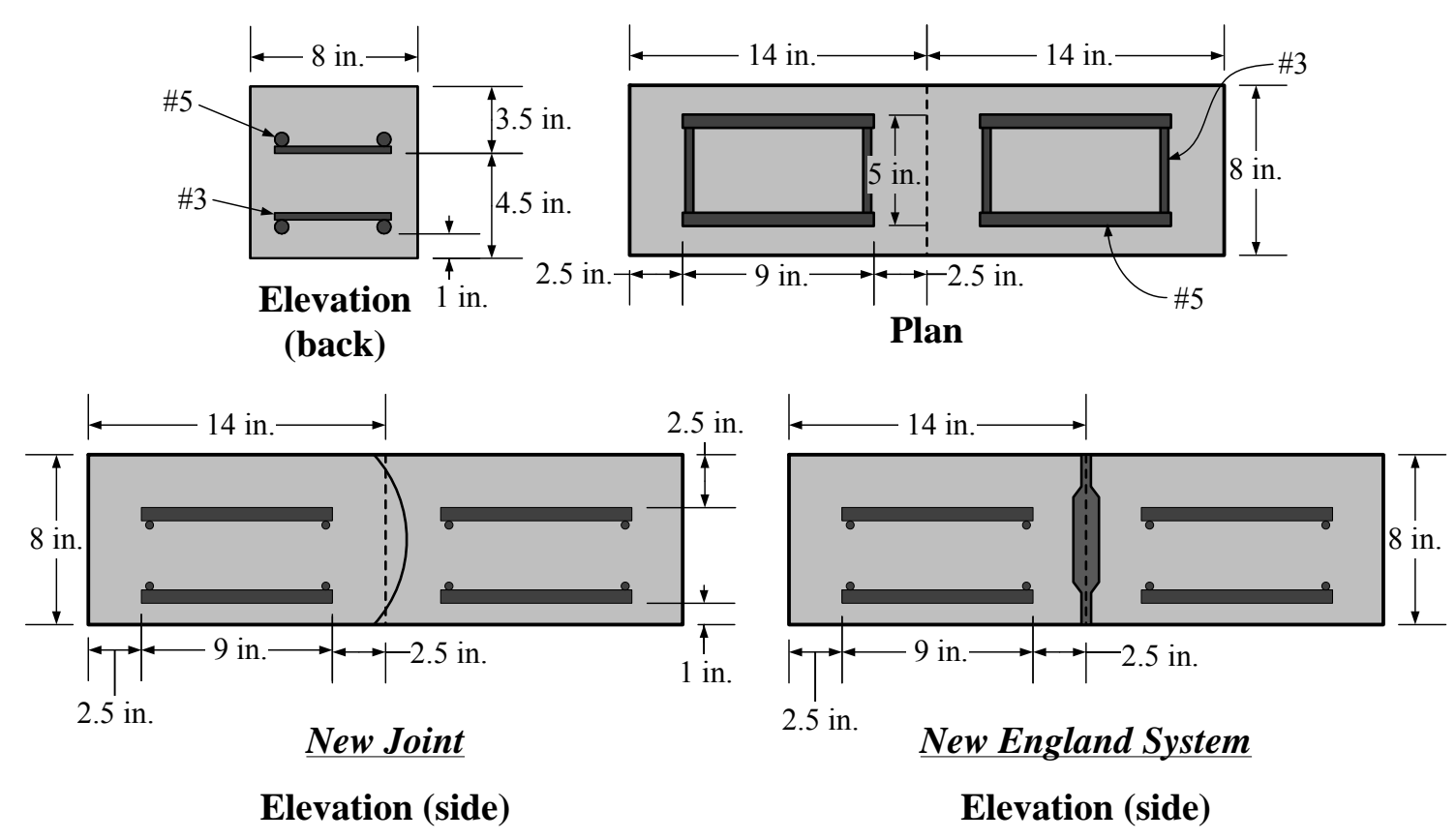

Figure 4.2: Specimen dimensions and reinforcement detail 


\subsubsection{Test variables}

The panel-panel tests consisted of a total of 15 specimens. The primary variables include the joint geometry and the joint material. Of the 15 specimens, 12 were designed with a semi-circular, male-female joint. The radius of this joint was either 6 in. or 8 in. For these specimens a segmental bridge adhesive (SBA) was specified to fill the joint. Two SBA's were chosen, Unitex Pro-Poxy SBA and Sikadur 31 slow set SBA. For comparison purposes, three specimens were designed using the New England joint. For these specimens, the SCC mix specified in Chapter 2 was selected to fill the shear key allowing comparison with the first phase of testing. The specimens are designated as shown in Figure 4.3. The test matrix of specimens is presented in Table 4.1.

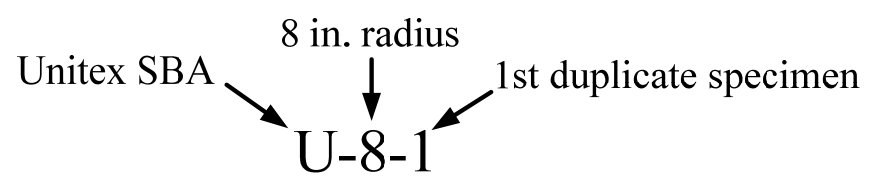

Figure 4.3: Description of specimen ID

Table 4.1: Test matrix

\begin{tabular}{|c|c|c|}
\hline Specimen ID & Joint Material & Joint Geometry \\
\hline U-6-1 & \multirow{6}{*}{ Unitex Pro-Poxy } & \multirow{2}{*}{6 in. radius male-female } \\
\hline U-6-2 & & \\
\hline U-8-1 & & \multirow{4}{*}{8 in. radius male-female } \\
\hline $\mathrm{U}-8-2$ & & \\
\hline U-8-3 & & \\
\hline U-8-4 & & \\
\hline S-6-1 & \multirow{6}{*}{ Sikadur 31 slow set } & \multirow{2}{*}{6 in. radius male-female } \\
\hline S-6-2 & & \\
\hline S-6-3 & & \multirow{4}{*}{8 in. radius male-female } \\
\hline S-6-4 & & \\
\hline S-8-1 & & \\
\hline $\mathrm{S}-8-2$ & & \\
\hline $\mathrm{C}-0-1$ & \multirow{3}{*}{$\mathrm{SCC}$} & \multirow{3}{*}{ Shear key female-female } \\
\hline $\mathrm{C}-0-2$ & & \\
\hline $\mathrm{C}-0-3$ & & \\
\hline
\end{tabular}




\subsection{Specimen Construction}

The following subsections describe the process by which the precast components required for each specimen were constructed. The construction process for the specimen as a unit is also described.

\subsubsection{Panel sections}

The panel sections were constructed in the Bowen Laboratory on two occasions. The concrete was obtained from a local ready-mix supplier. The two sides of each specimen were cast next to each other, where the sections of the new joint specimens were separated by a thin section of cardboard tubing used to form the joint radius. The New England joints were separated by a wood insert cut to form the profile of the shear key. The mix specified for the panel sections was INDOT Class $C$, which has a nominal compressive strength of $4 \mathrm{ksi}$ at 28 days. Mix designs are provided in Section 4.4. After casting, the panel sections were wet cured for 7 days. Once removed from the formwork, the joint surfaces were cleaned with a wire brush and compressed air to remove laitance. Examples of completed panel sections are shown in Figure 4.4. 


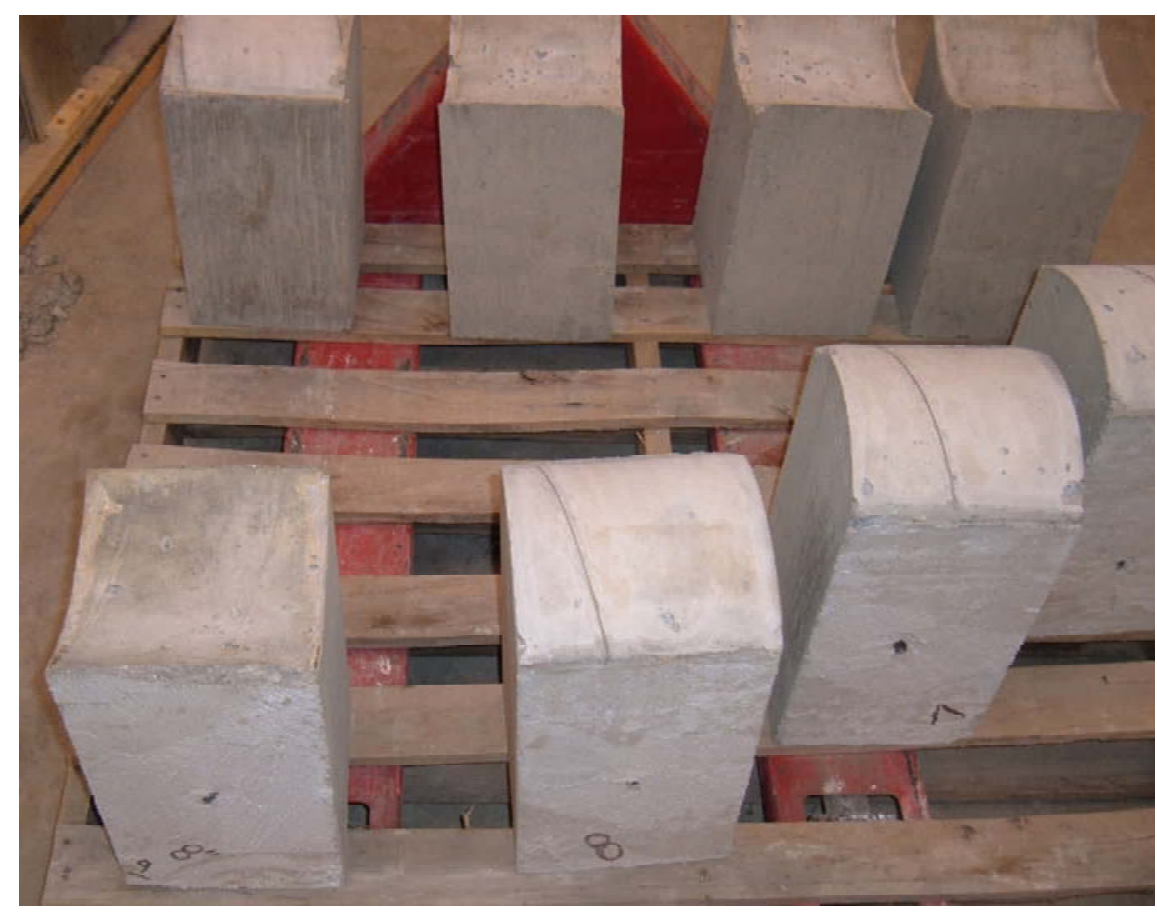

Figure 4.4: Completed panel sections

\subsubsection{Specimens}

Once the panel sections of the specimen were constructed, they were constructed together using the appropriate joint material. The new joint specimens were secured using SBA. The SBA was mixed according to the instructions provided and applied to both surfaces of the joint with a gloved hand. The two sections of the specimen were then aligned and squeezed together using pipe clamps. The sections were squeezed until a layer of SBA $1 / 8$ in. to 1/4 in.thick was present in the joint. The pipe clamps and excess SBA were removed prior to setting. The specimens were allowed to sit, undisturbed for 24 hours. Examples of complete specimens are shown in Figure 4.5. 


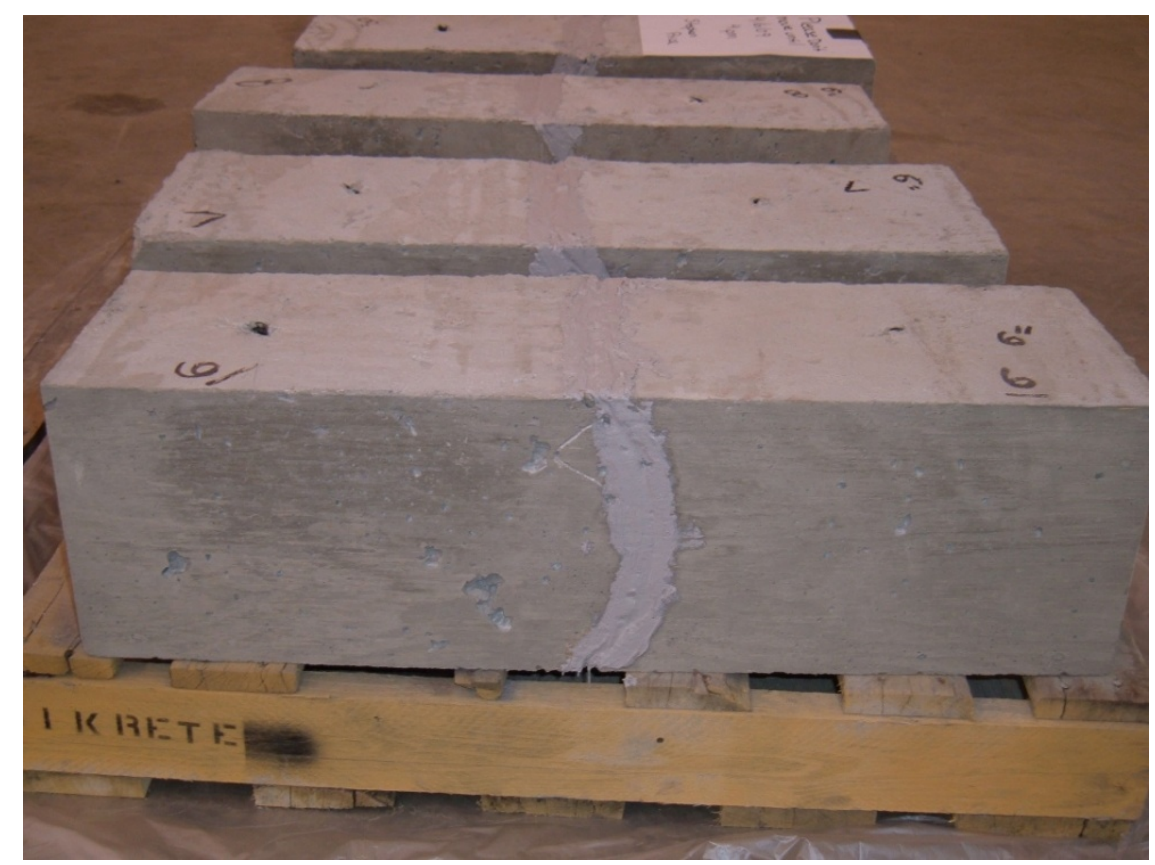

Figure 4.5: Completed new joint specimens

The New England joint was secured together using the SCC discussed in Chapter 2. The two sections of the specimens were positioned $1 / 4 \mathrm{in}$. apart and the sides of the joint were formed with 1/2 in. foam, as shown in Figure 4.6. Once formed, the SCC was ordered from a local ready-mix supplier. The concrete was poured into the joint from above. After casting, the concrete was wet cured for 7 days. 


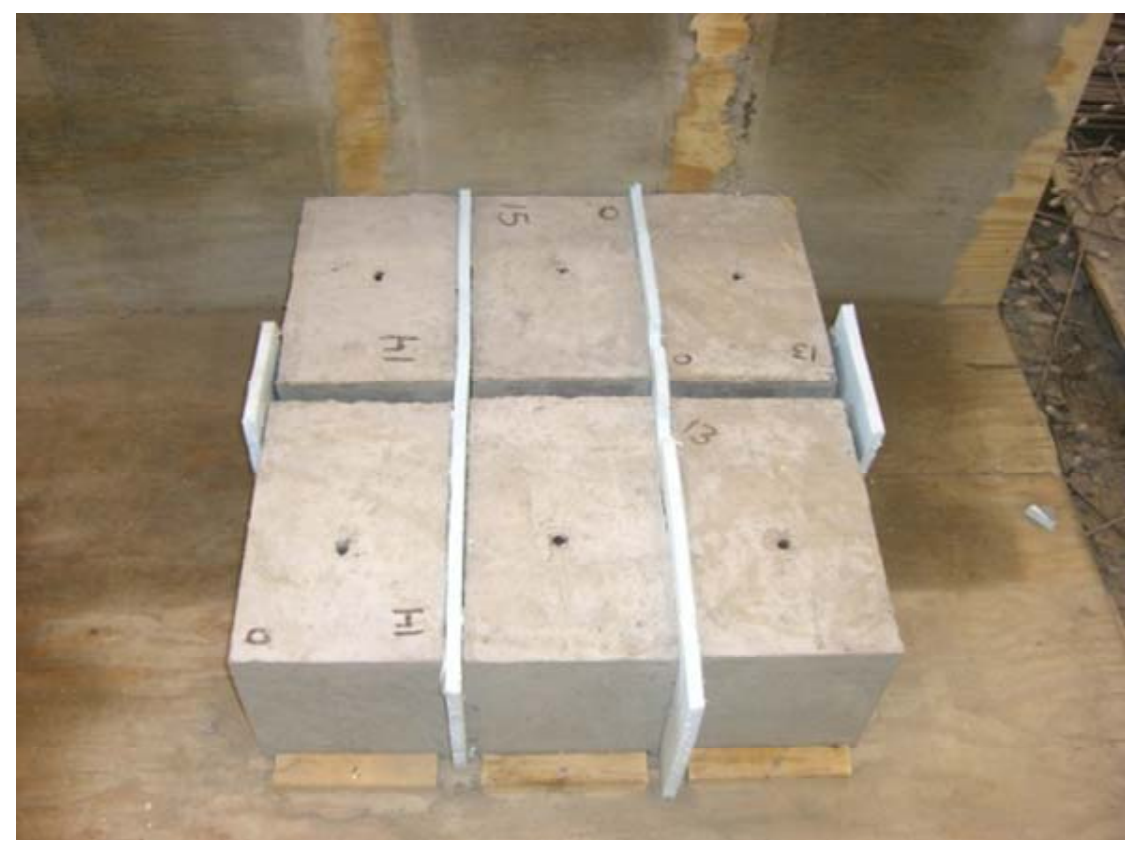

Figure 4.6: Forming joint of New England specimens

\subsection{Materials}

Standard testing was performed on the materials used in the construction of the specimens according to applicable ASTM standards. All testing was performed in the Bowen Laboratory at Purdue University.

\subsubsection{Concrete}

Concrete for the specimens was obtained from a local ready-mix supplier. The mix proportions delivered for the panel sections and SCC are presented in Table 4.2. Compression tests were performed on 6"x12" cylinders for all concretes used in the specimens. The strength-gain curves of the concrete compression tests are provided in Figure 4.7. 
Table 4.2: Concrete mix proportions

\begin{tabular}{|l|c|c|c|}
\hline Material & Unit & Panel sections & SCC \\
\hline Pea-gravel & lb/cy & --- & 1450 \\
\hline$\# 8$ stone & $\mathrm{lb} / \mathrm{cy}$ & 1769 & --- \\
\hline$\# 23$ sand & $\mathrm{lb} / \mathrm{cy}$ & 1253 & 1350 \\
\hline Cement (Type I) & $\mathrm{lb} / \mathrm{cy}$ & 656 & 675 \\
\hline Fly-ash (Class C) & $\mathrm{lb} / \mathrm{cy}$ & --- & 175 \\
\hline Super Plasticizer (Glenium $\left.{ }^{(B)} 3030 \mathrm{NS}\right)$ & $\mathrm{oz} / \mathrm{cy}$ & 13.3 & 102.0 \\
\hline Air Entrainer (Micro Air ${ }^{(B)}$ & $\mathrm{oz} / \mathrm{cy}$ & 4.4 & 2.0 \\
\hline Water & $\mathrm{lb} / \mathrm{cy}$ & 166 & 150 \\
\hline
\end{tabular}

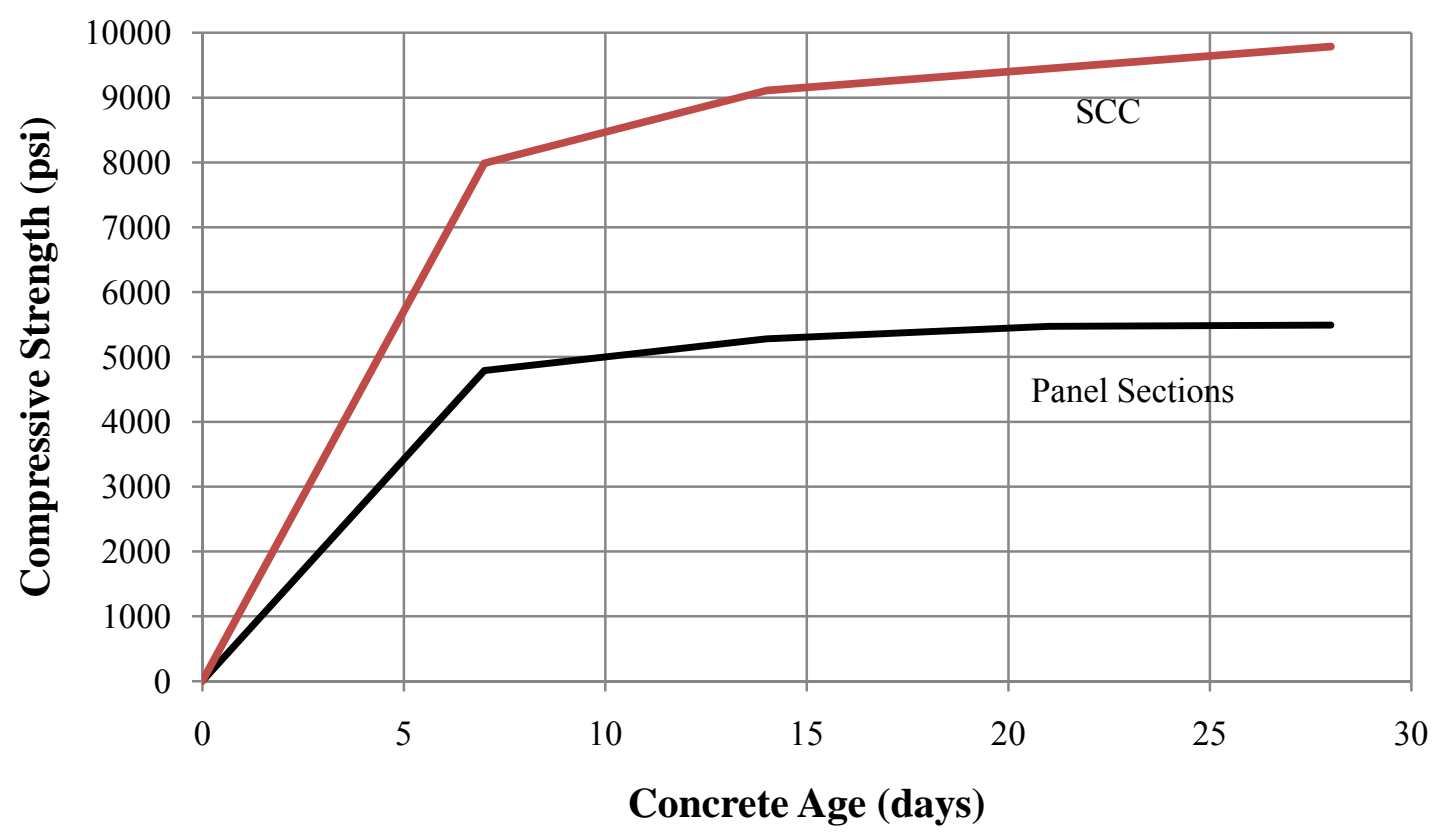

Figure 4.7: Concrete compressive strength gain

\subsubsection{Steel}

The mild steel used throughout the specimens was ASTM A615 Grade 60. The mild steel was not tested because it was not a primary variable. 


\subsubsection{Segmental Bridge Adhesive}

Two segmental bridge adhesives were chosen for this phase of testing, Unitex Pro-Poxy SBA and Sikadur 31 slow set SBA. The SBA was not tested because the results of standard tests are supplied by the manufacturer. In addition, the products were being tested in a manner that would provide the most relevant data to this research program.

\subsection{Test Setup}

The test setup for this series of tests consisted of a loading system attached to the strong floor, support block, and a loading frame containing the specimen. Each end of the specimen was clamped in the loading frame with a 0.5 in. plate secured together using four 0.5 in. diameter ASTM A354 threaded rods, two on either side. The specimens were initially clamped on each end 8 in. from the centroid of the joint. However, as the testing program progressed the clamping distance needed modification. The distance was shortened to 4 in. This reduced the span between supports from 16 to $8 \mathrm{in}$., which would allow for higher shear loads to be applied to the specimen prior to flexural cracking. The loading ram was positioned over the centroid of the panel-panel joint to produce a plane through the joint where the applied load causes pure shear stresses. Load was measured using a 150 kip load-cell positioned between the ram and loading frame. In addition, a potentiometer positioned at the mid-height of the joint was used to measure relative displacement of the panel sections. The test setup and location of the potentiometer are shown in Figure 4.8. An example of a test specimen prior to testing is presented in Figure 4.9. 


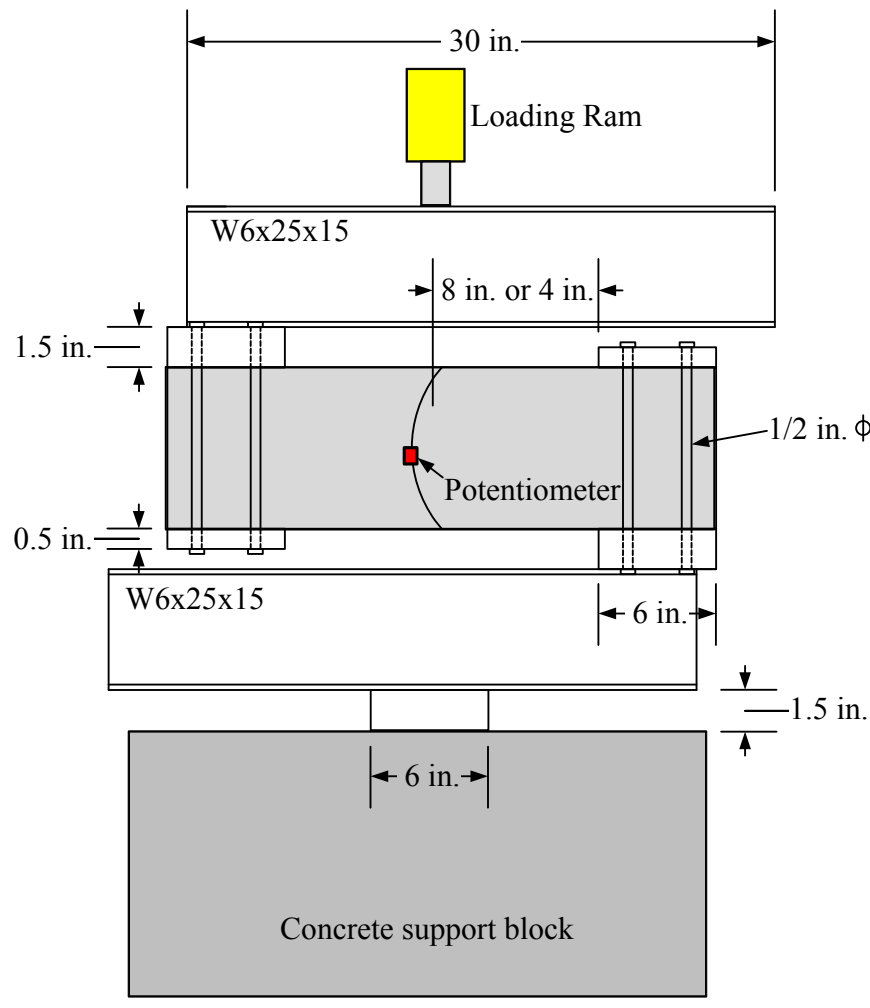

Elevation (side)
Loading Ram

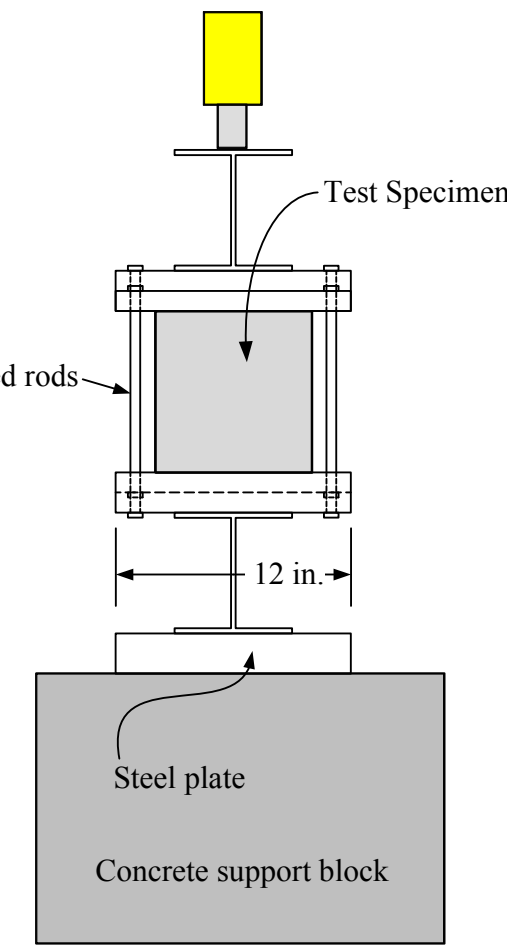

Elevation (front)

Figure 4.8: Panel-to-Panel test setup 


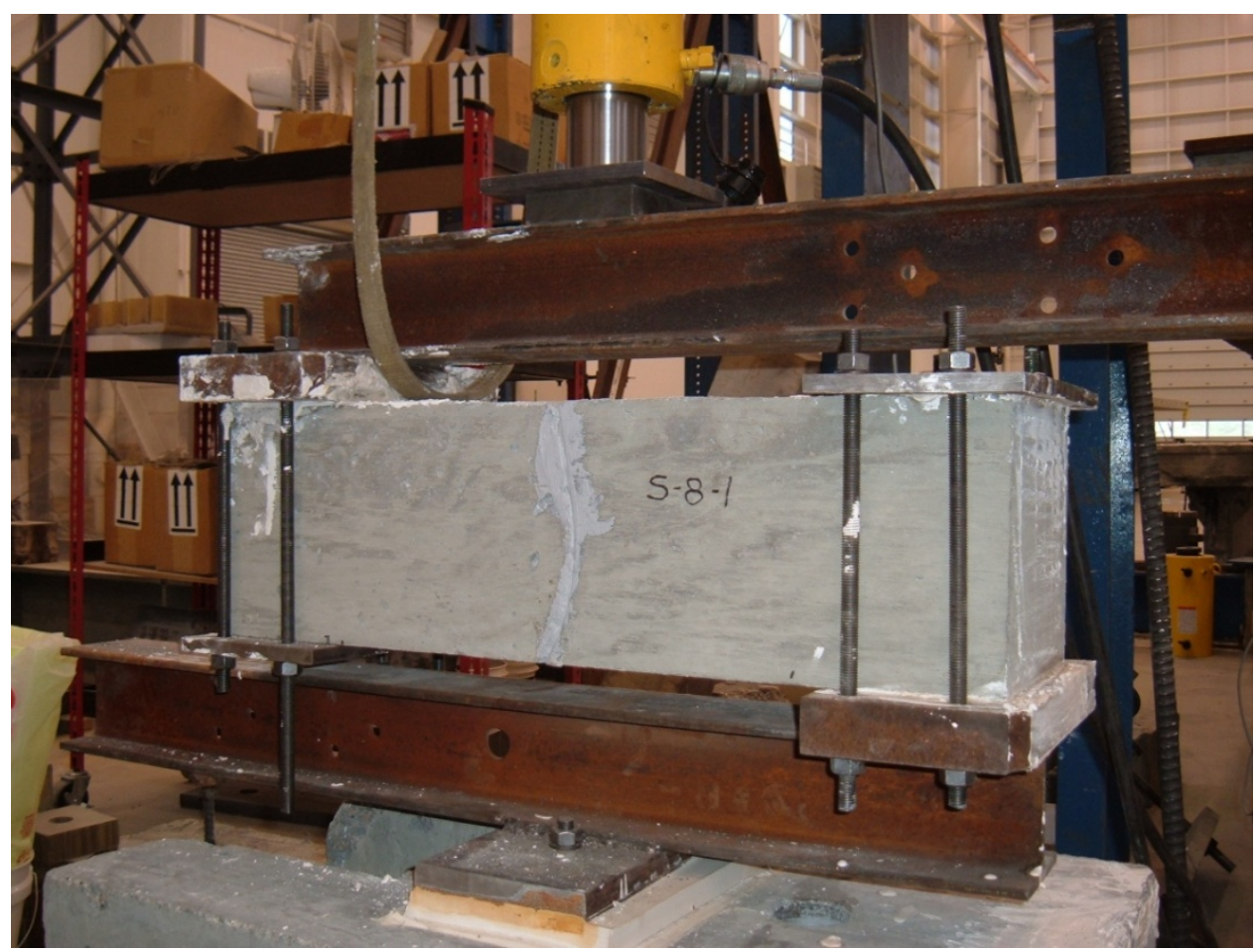

Figure 4.9: Example of specimen in test setup

\subsubsection{Test protocol}

The specimens were loaded using a 100 kip hydraulic ram until failure of the specimen occurred or maximum deflection of the setup was reached. Load was applied using a manually operated hydraulic pump. All instrumentation was monitored throughout testing and recorded at 0.4 second increments. Cracks were also monitored and marked. 


\subsection{Results}

The following subsections present the results obtained from the test described in Section 4.5.

\subsubsection{Specimen tests clamped at 8 in.}

Initially, the following specimens were clamped on each end 8 in. from the centroid of the joint: U-6-1, U-8-1, U-8-2, S-6-1, S-6-2, S-6-3, S-8-1, and S-8-2. The moments produced by loading led to cracking of the specimens near the supports, as shown in Figure 4.10. Cracking was similar in all specimens tested. Following cracking, the specimens continued to deflect with no increase in load until the maximum deflection of the test setup was reached. No cracking of the joint material was observed. The maximum load carried by each specimen is presented in Table 4.3. It should be noted that these values are not representative of the shear strength of the joint.

Due to the strength of the joint and flexural capacity of the specimens, it was necessary to reduce the clamping distance to $4 \mathrm{in}$. This modification allows for a reduction in the moment applied at the supports such that higher loads can be applied to the specimen enabling evaluation of the ultimate shear strength of the joint. 


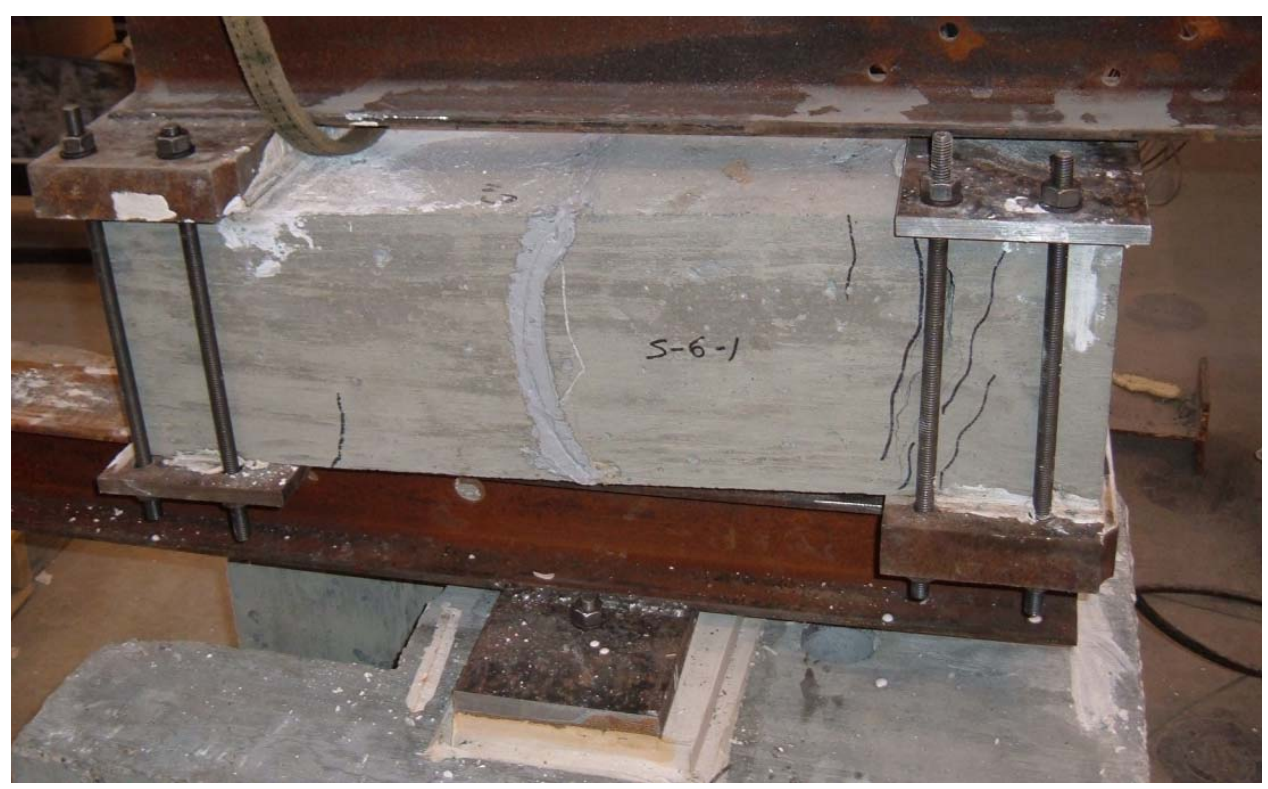

Figure 4.10: Cracking of specimen clamped at 8 in.

Table 4.3: Summary of maximum loads (clamped at 8 in.)

\begin{tabular}{|c|c|}
\hline Specimen ID & Maximum load (kips) \\
\hline U-6-1 & 13.2 \\
\hline U-8-1 & 13.2 \\
\hline U-8-2 & 11.3 \\
\hline S-6-1 & 10.2 \\
\hline S-6-2 & 11.8 \\
\hline S-6-3 & 12.3 \\
\hline S-8-1 & 12.7 \\
\hline S-8-2 & 11.7 \\
\hline
\end{tabular}

\subsubsection{Specimen tests clamped at 4 in.}

As previously discussed, the clamping distance from the centroid of the joint was reduced from 8 to 4 in. since shear failure of the specimens tested had not occurred. All specimens tested at the 8 in. clamping distance were able to be retested at 4 in. 


\subsubsection{U-6-1}

The failure of Specimen U-6-1 is shown in Figure 4.11. The specimen was loaded to 20.0 kips at which point sudden shear failure of the concrete occurred on the female side of the joint. The SBA remained bonded to both panel sections and had no observed damage. In addition, no cracking of the specimen was observed prior to failure. The potentiometer measured a maximum relative displacement of 0.0008 in. across the joint prior to failure.

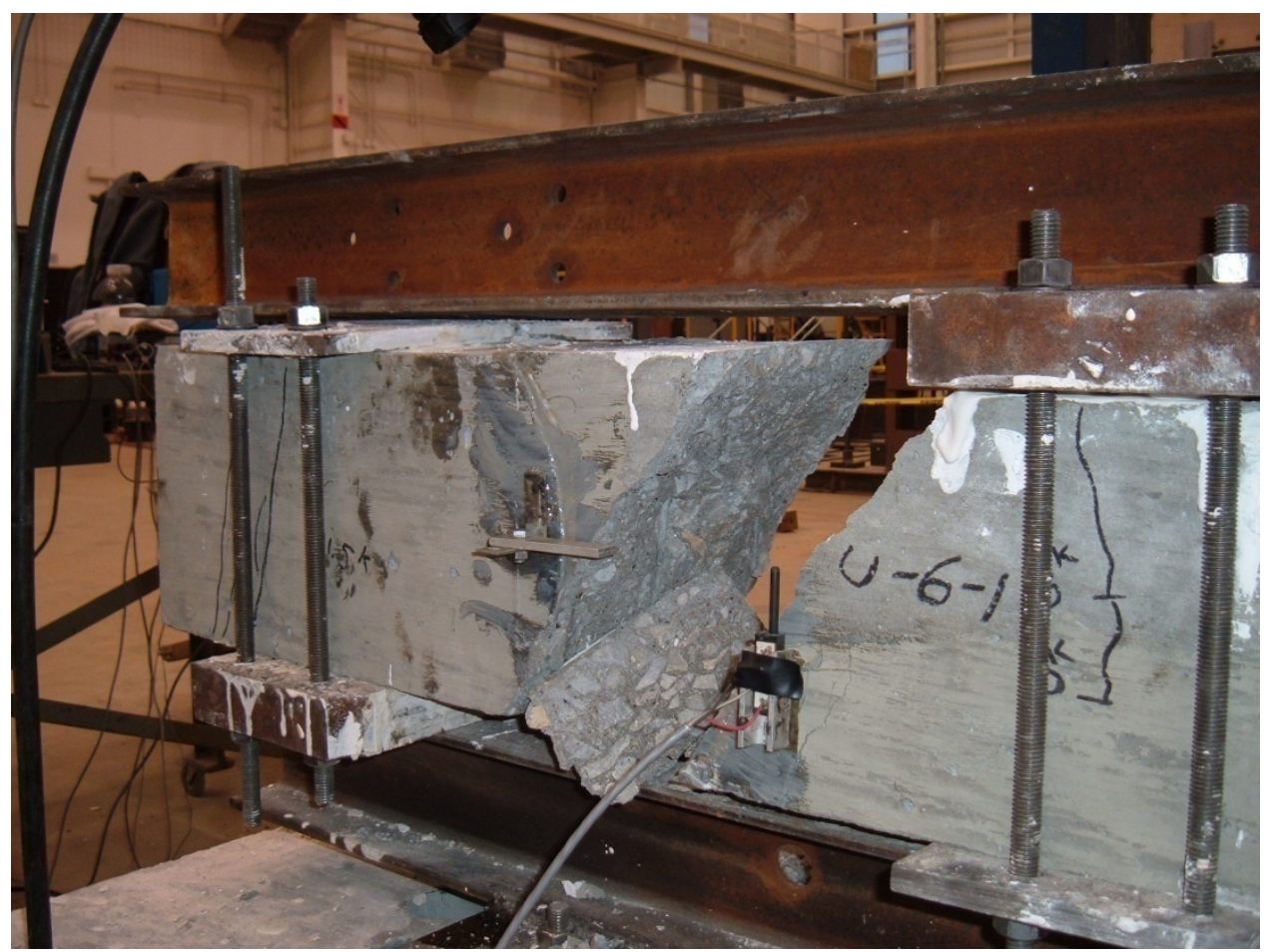

\section{Figure 4.11: Failure of Specimen U-6-1}

\subsubsection{2. $\underline{\mathrm{U}-6-2}$}

The failure of Specimen U-6-2 is shown in Figure 4.12. The specimen was loaded to 15.5 kips at which point sudden shear failure of the concrete occurred on the male side of the joint. The SBA remained bonded to both panel sections and had no observed damage. In addition, no cracking of the specimen was observed prior to failure. The potentiometer measured a maximum relative displacement of $0.003 \mathrm{in}$. across the joint prior to failure. Following failure of the concrete, loading of the specimen 
continued. The specimen carried a reduced load of approximately 5.4 kips until the maximum deflection of the test setup was reached.

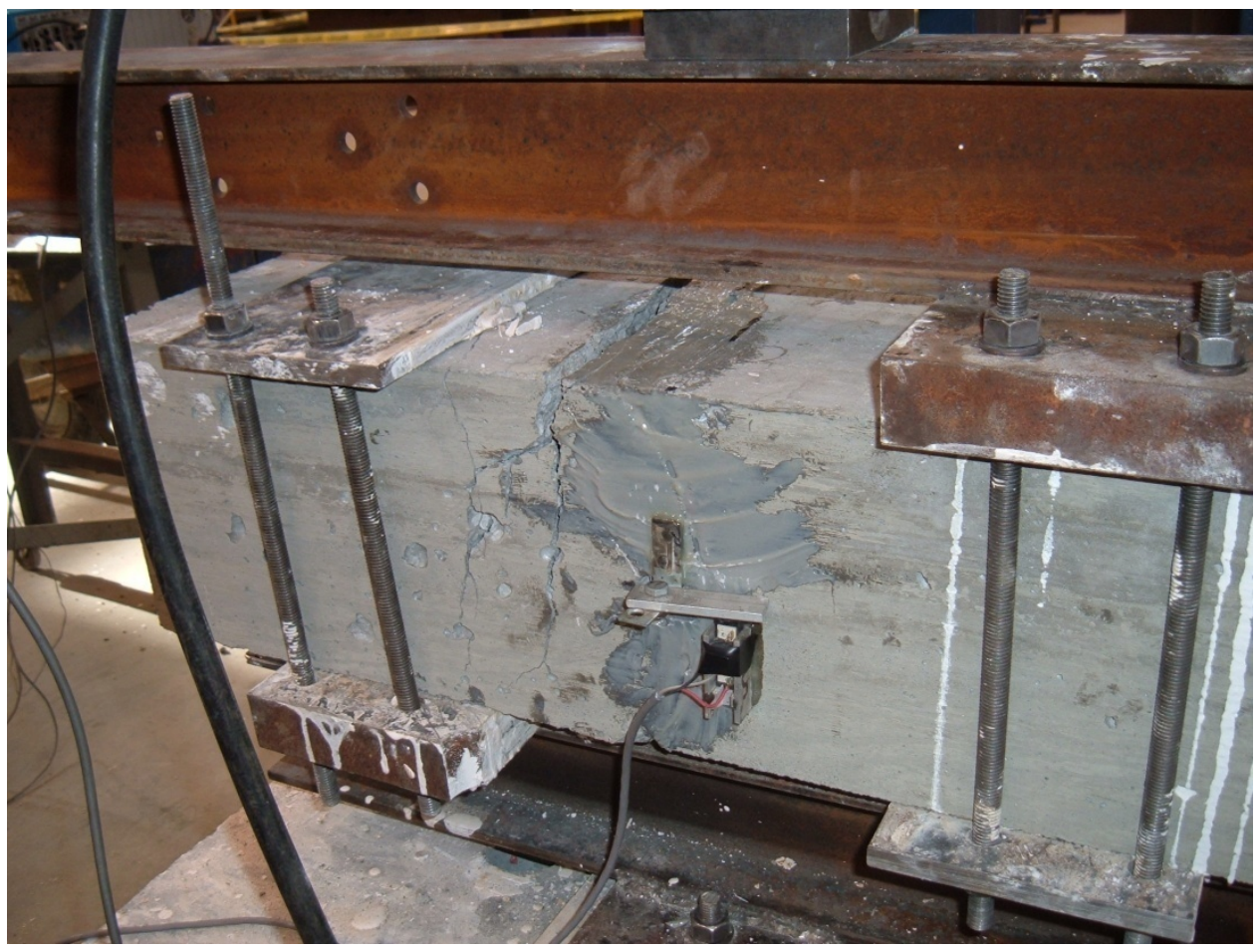

Figure 4.12: Failure of Specimen U-6-2

\subsubsection{3. $\underline{\mathrm{U}-8-1}$}

The failure of Specimen U-8-1 is shown in Figure 4.13. The specimen was loaded to 16.3 kips at which point sudden shear failure of the concrete occurred. The failure plane crossed the joint. The SBA remained bonded to both panel sections. In addition, no cracking of the specimen was observed prior to failure. The potentiometer measured a maximum relative displacement of 0.0007 in. across the joint prior to failure. 


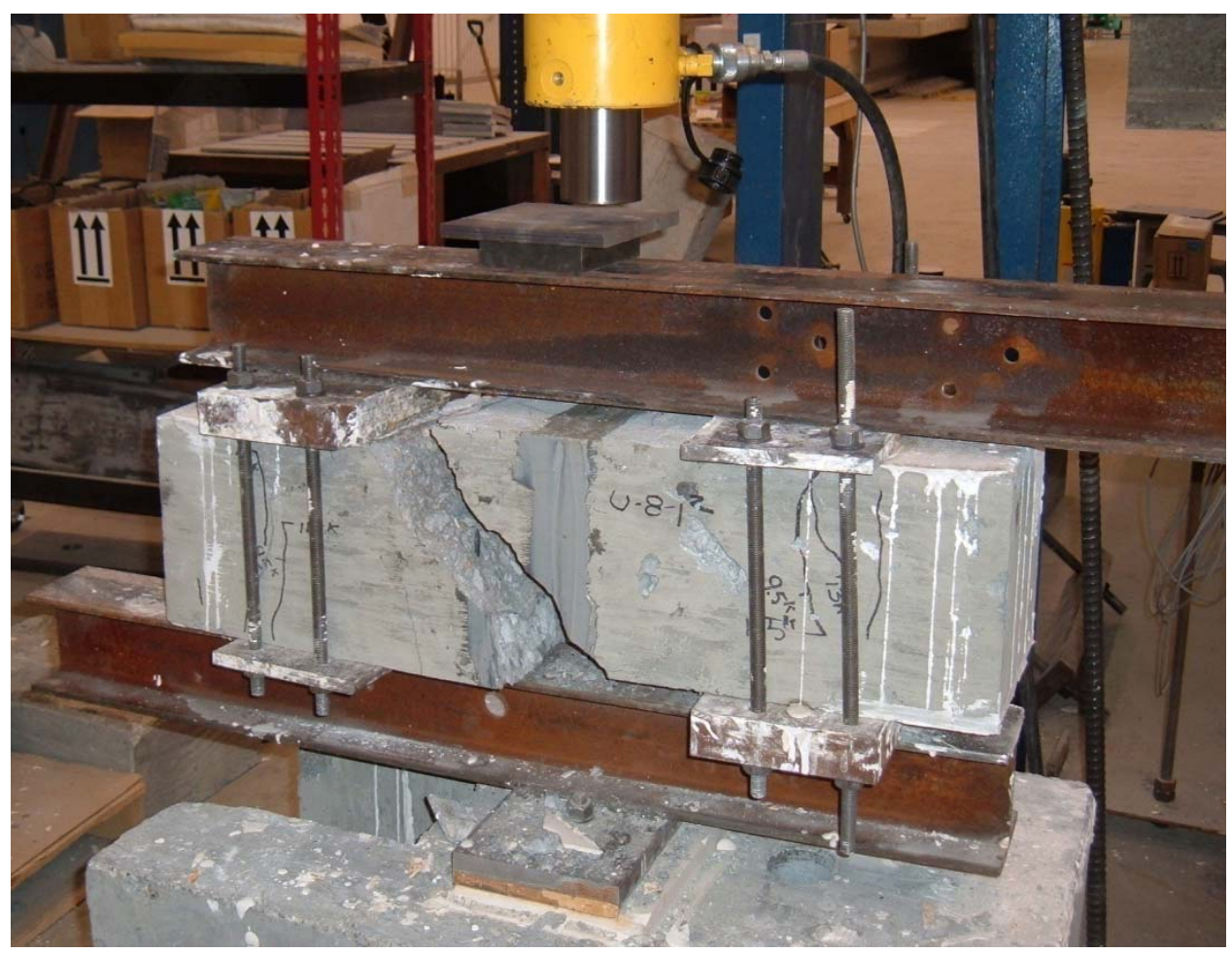

Figure 4.13: Failure of Specimen U-8-1

\subsubsection{4. $\underline{\mathrm{U}-8-2}$}

The failure of Specimen U-8-2 is shown in Figure 4.14. The specimen was loaded to 18.2 kips at which point sudden shear failure of the concrete occurred on the male side of the joint The SBA remained bonded to both panel sections and had no observed damage. In addition, no cracking of the specimen was observed prior to failure. The potentiometer measured a maximum relative displacement of 0.0009 in. across the joint prior to failure. Following failure of the concrete, loading of the specimen continued. The specimen carried a reduced load of approximately 10 kips until the maximum deflection of the test setup was reached. 


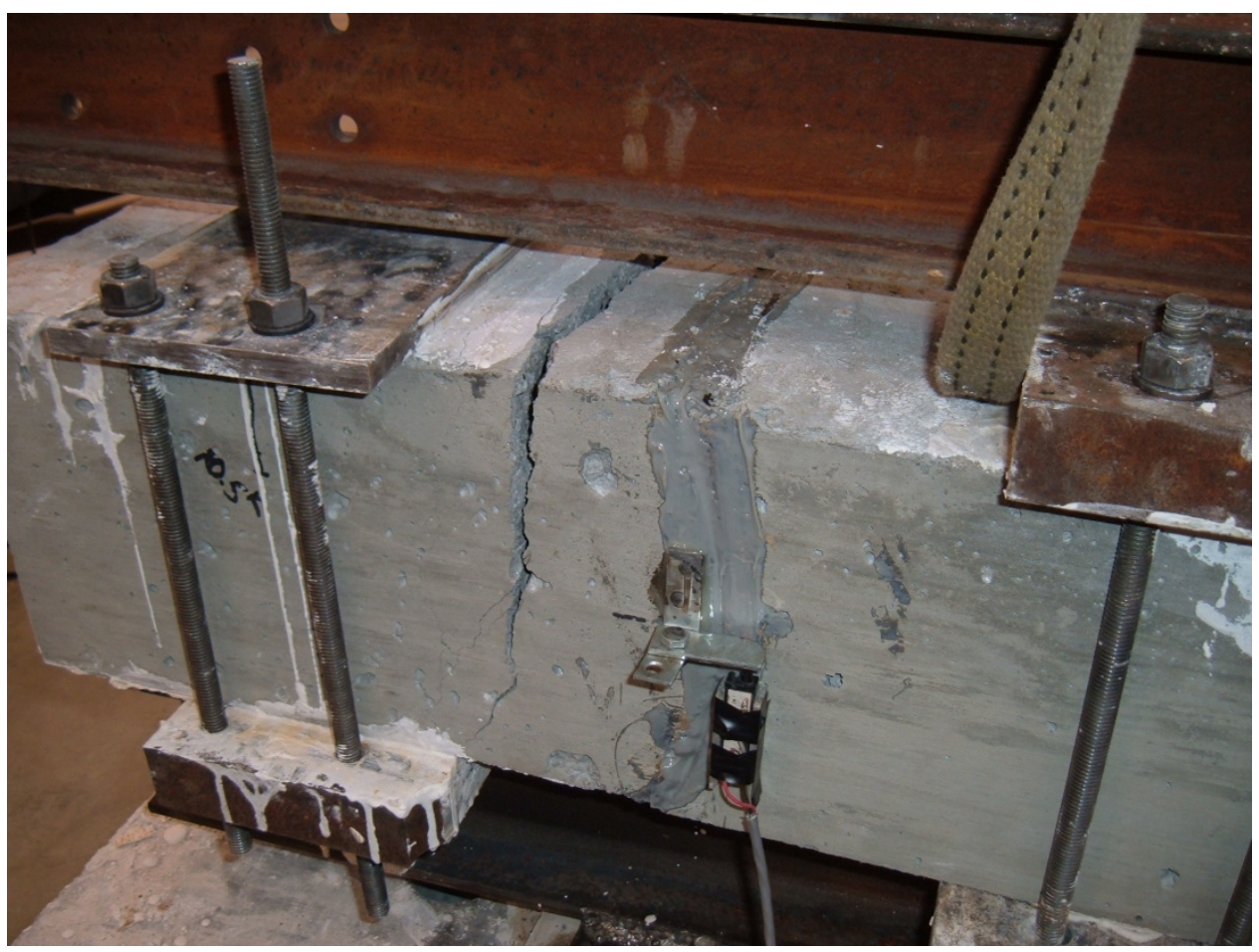

Figure 4.14: Failure of Specimen U-8-2

\subsubsection{5. $\underline{\mathrm{U}-8-3}$}

The failure of Specimen U-8-3 is shown in Figure 4.15. The specimen was loaded to 17.6 kips at which point sudden failure of the concrete occurred on the female side of the joint. The SBA remained bonded to both panel sections and had no observed damage. In addition, no cracking of the specimen was observed prior to failure. The potentiometer measured a maximum of 0.0015 in. of relative displacement across the joint prior to failure. Following initial failure of the concrete, loading of the specimen continued. The specimen carried a second peak load of 13 kips. After the second peak load was reached, a reduced load of approximately 2.7 kips was carried until the maximum deflection of the test setup was reached. 


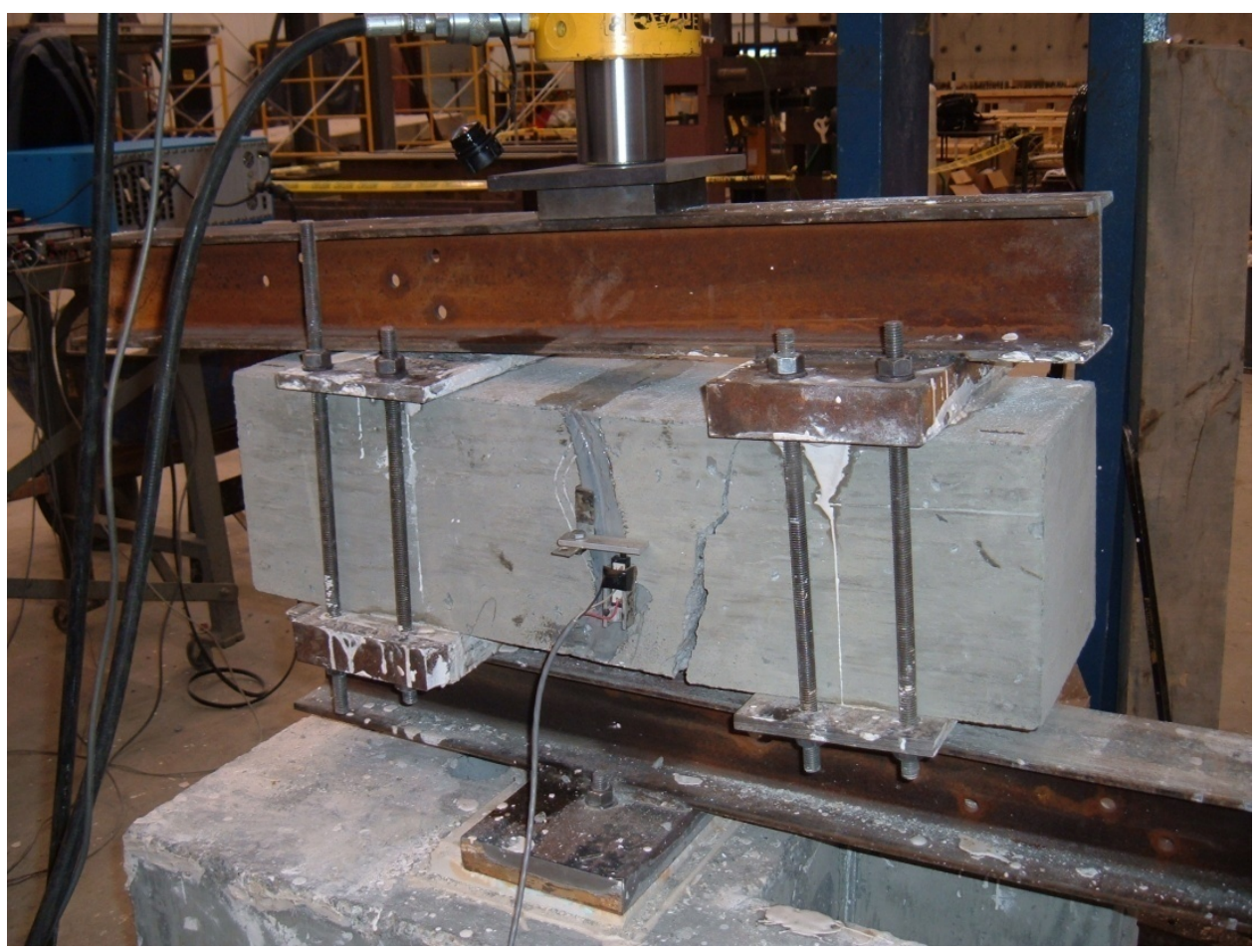

Figure 4.15: Failure of Specimen U-8-3

\subsubsection{6. $\underline{\mathrm{U}-8-4}$}

The failure of Specimen U-8-4 is shown in Figure 4.16. The specimen was loaded to 19.3 kips at which point sudden shear failure of the concrete occurred. The failure plane went across the joint. The SBA remained bonded to both panel sections. In addition, no cracking of the specimen was observed prior to failure. The potentiometer measured a maximum relative displacement of $0.0008 \mathrm{in}$. across the joint prior to failure. Following initial failure of the concrete, loading of the specimen continued. The specimen carried a second peak load of 13.8 kips. After the second peak load was reached, a reduced load of approximately 6 kips was carried until the maximum deflection of the test setup was reached. 


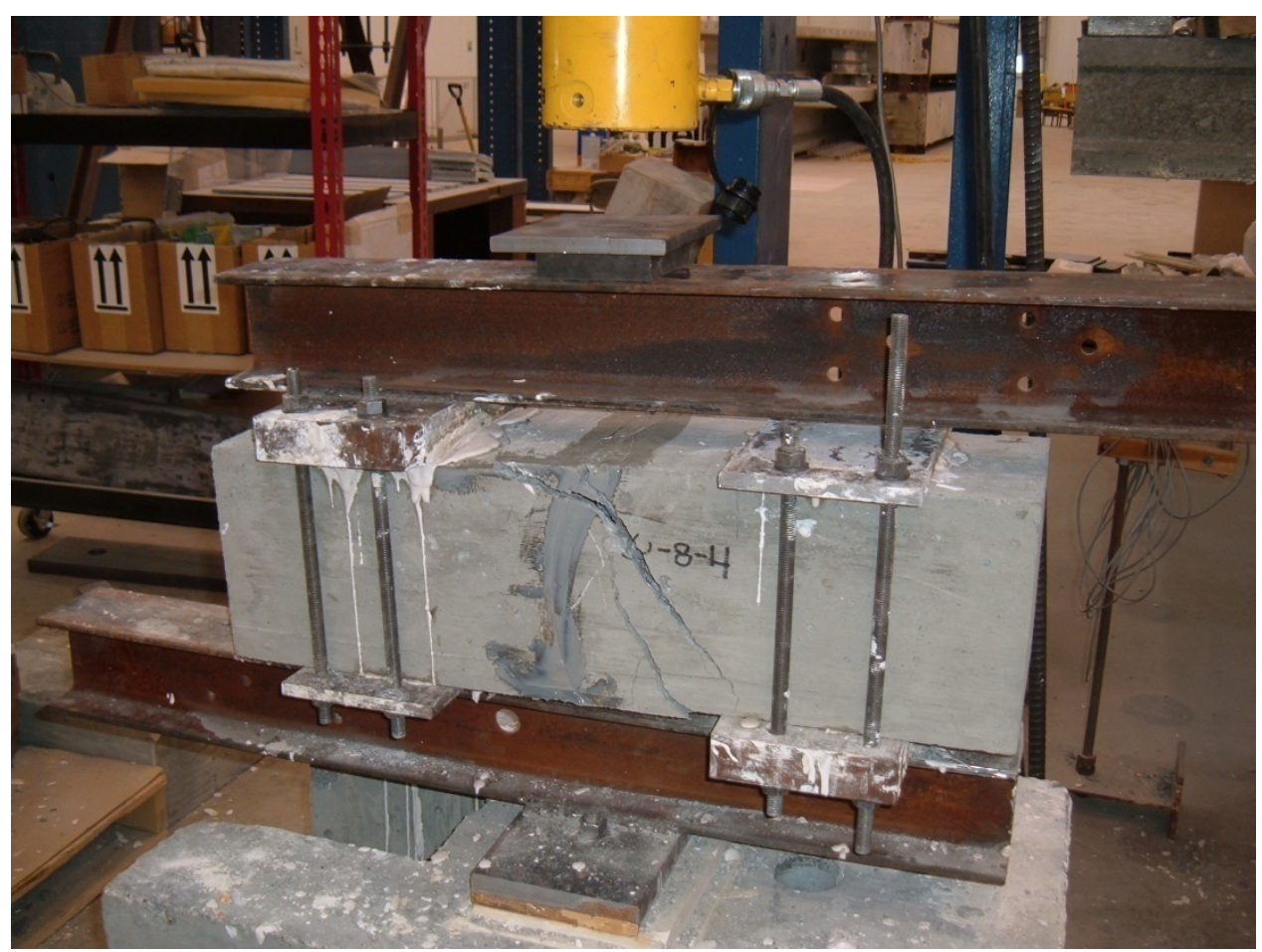

Figure 4.16: Failure of Specimen U-8-4

\subsubsection{7. $\underline{\mathrm{S}-6-1}$}

The failure of Specimen S-6-1 is shown in Figure 4.17. The specimen was loaded to 18.4 kips at which point sudden shear failure of the concrete occurred on the male side of the specimen. The SBA remained bonded to both panel sections and had no observed damage. In addition, no cracking of the specimen was observed prior to failure. The potentiometer provided displacement measurements inconsistent with specimen behavior throughout the loading. Therefore, the displacement measurements were considered unreliable. Following initial failure of the concrete, loading of the specimen continued. The specimen carried a second peak load of 12.6 kips. After the second peak load was reached, the specimen could no longer sustain load. 


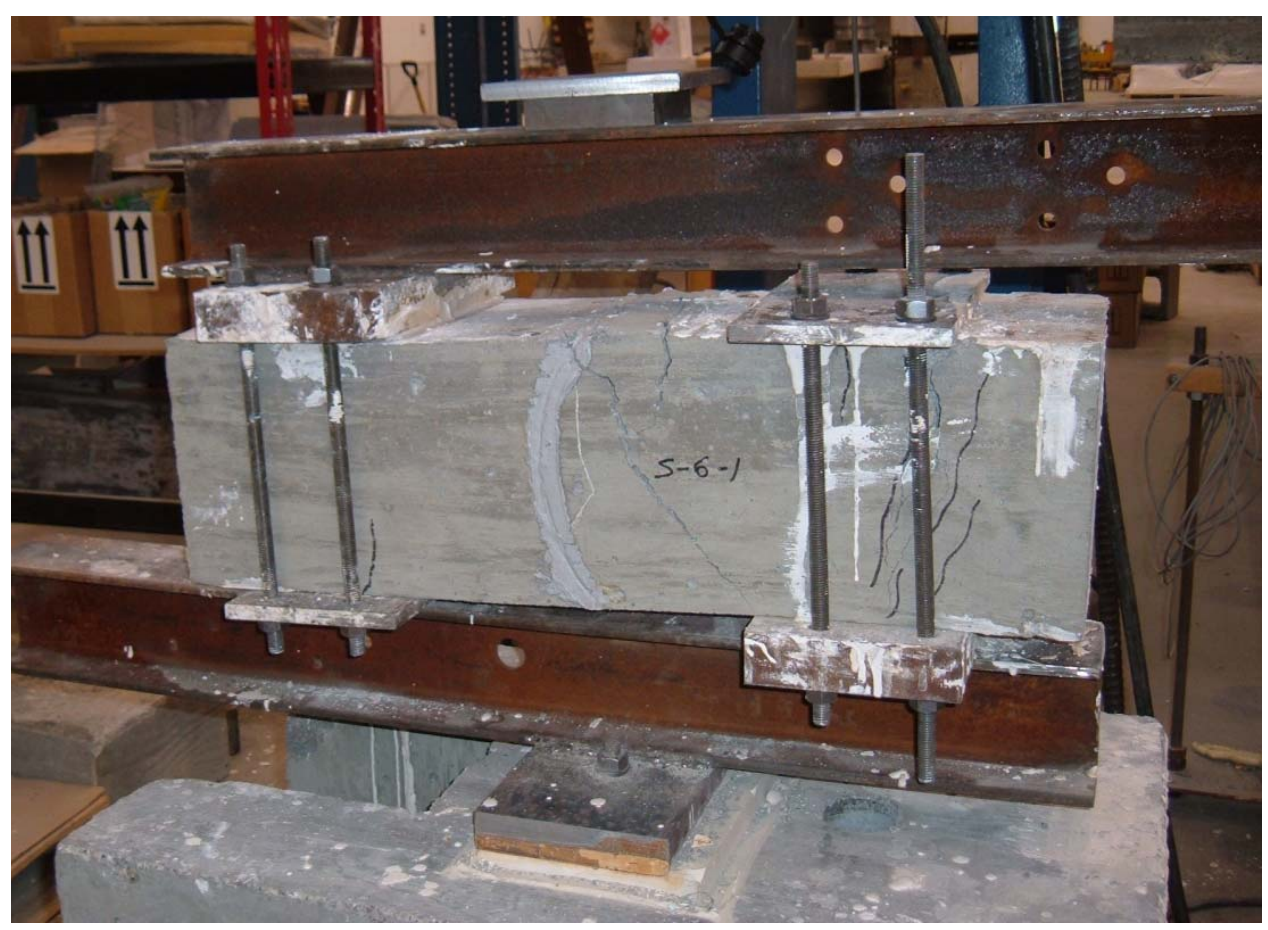

Figure 4.17: Failure of Specimen S-6-1

\subsubsection{8. $\underline{\text { S-6-2 }}$}

The failure of Specimen S-6-2 is shown in Figure 4.18. The specimen was loaded to 17.4 kips at which point sudden shear failure of the concrete occurred on the male side of the specimen. The SBA remained bonded to both panel sections and had no observed damage. In addition, no cracking of the specimen was observed prior to failure. The potentiometer measured a maximum relative displacement of 0.0016 in. across the joint prior to failure. Following initial failure of the concrete, loading of the specimen continued. The specimen carried a second peak load of 11 kips. After the second peak load was reached, a reduced load of approximately 8.6 kips was carried until the maximum deflection of the test setup was reached. 


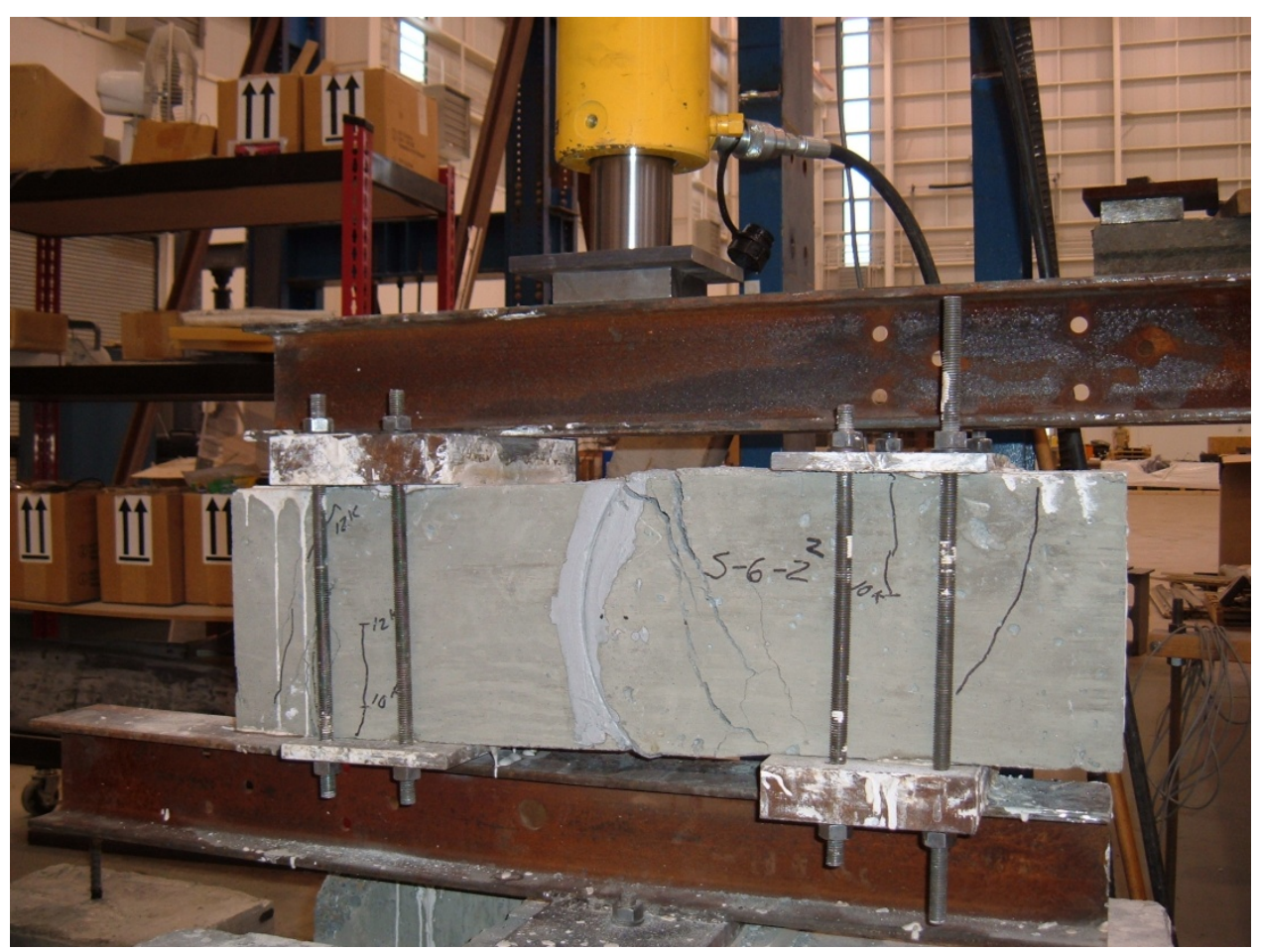

Figure 4.18: Failure of Specimen S-6-2

\subsubsection{S-6-3}

The failure of Specimen S-6-3 is shown in Figure 4.19. The specimen was loaded to 16.5 kips at which point sudden shear failure of the concrete occurred on the male side of the specimen. The SBA remained bonded to both panel sections and had no observed damage. In addition, no cracking of the specimen was observed prior to failure. The potentiometer measured a maximum relative displacement of 0.002 in. across the joint prior to failure. Following initial failure of the concrete, loading of the specimen continued. The specimen carried a second peak load of 13.1 kips. After the second peak load was reached, a reduced load of approximately 7.9 kips was carried until the maximum deflection of the test setup was reached. 


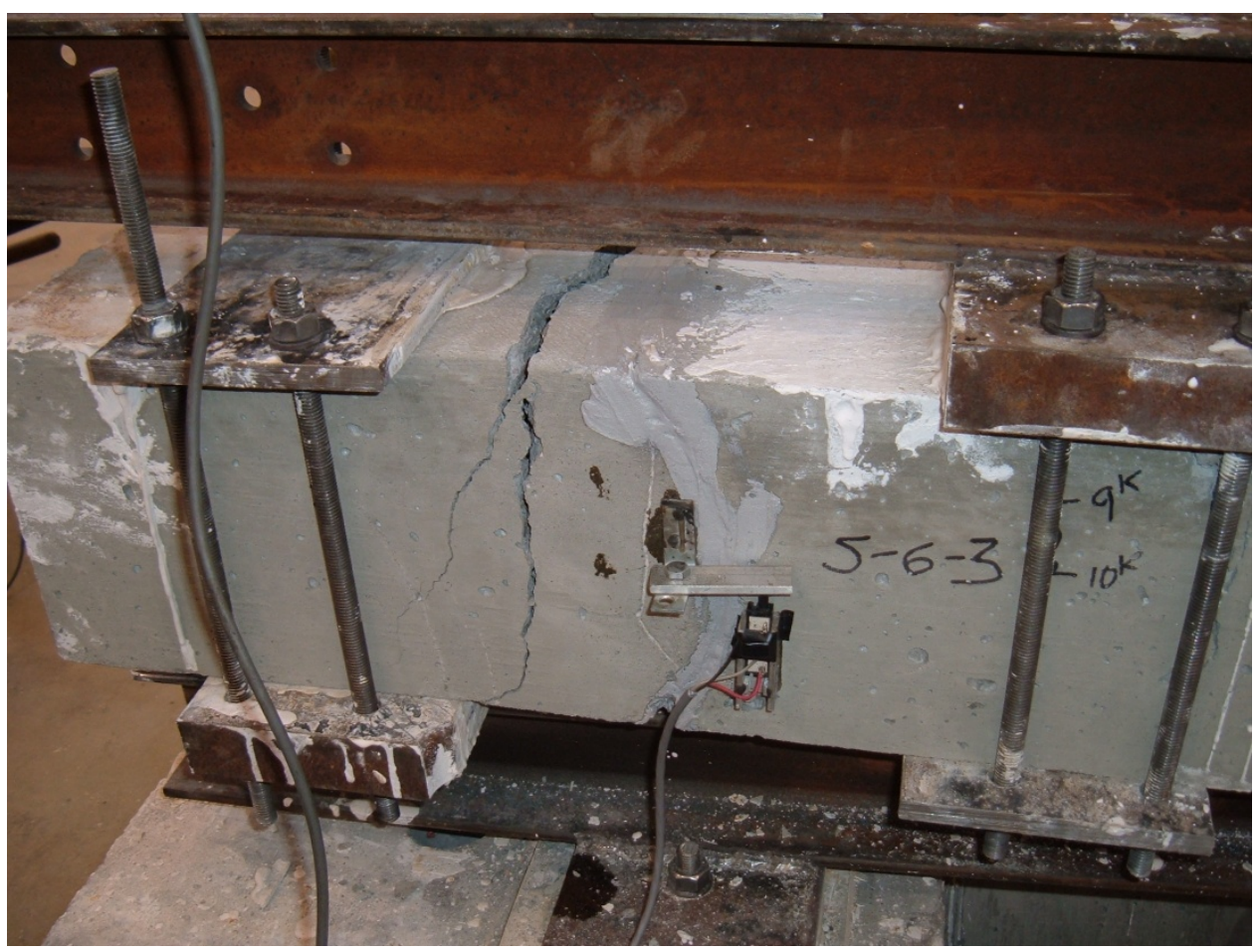

Figure 4.19: Failure of Specimen S-6-3

\subsubsection{0. $\underline{\text { S-6-4 }}$}

The failure of Specimen S-6-4 is shown in Figure 4.20. The specimen was loaded to 16.1 kips at which point sudden shear failure of the concrete occurred on the male side of the specimen. The SBA remained bonded to both panel sections and had no observed damage. In addition, no cracking of the specimen was observed prior to failure. The potentiometer measured a maximum relative displacement of $0.0013 \mathrm{in}$. across the joint prior to failure. Following initial failure of the concrete, loading of the specimen continued. The specimen carried a second peak load of 11.6 kips. After the second peak load was reached, a reduced load of approximately 5.4 kips was carried until the maximum deflection of the test setup was reached. 


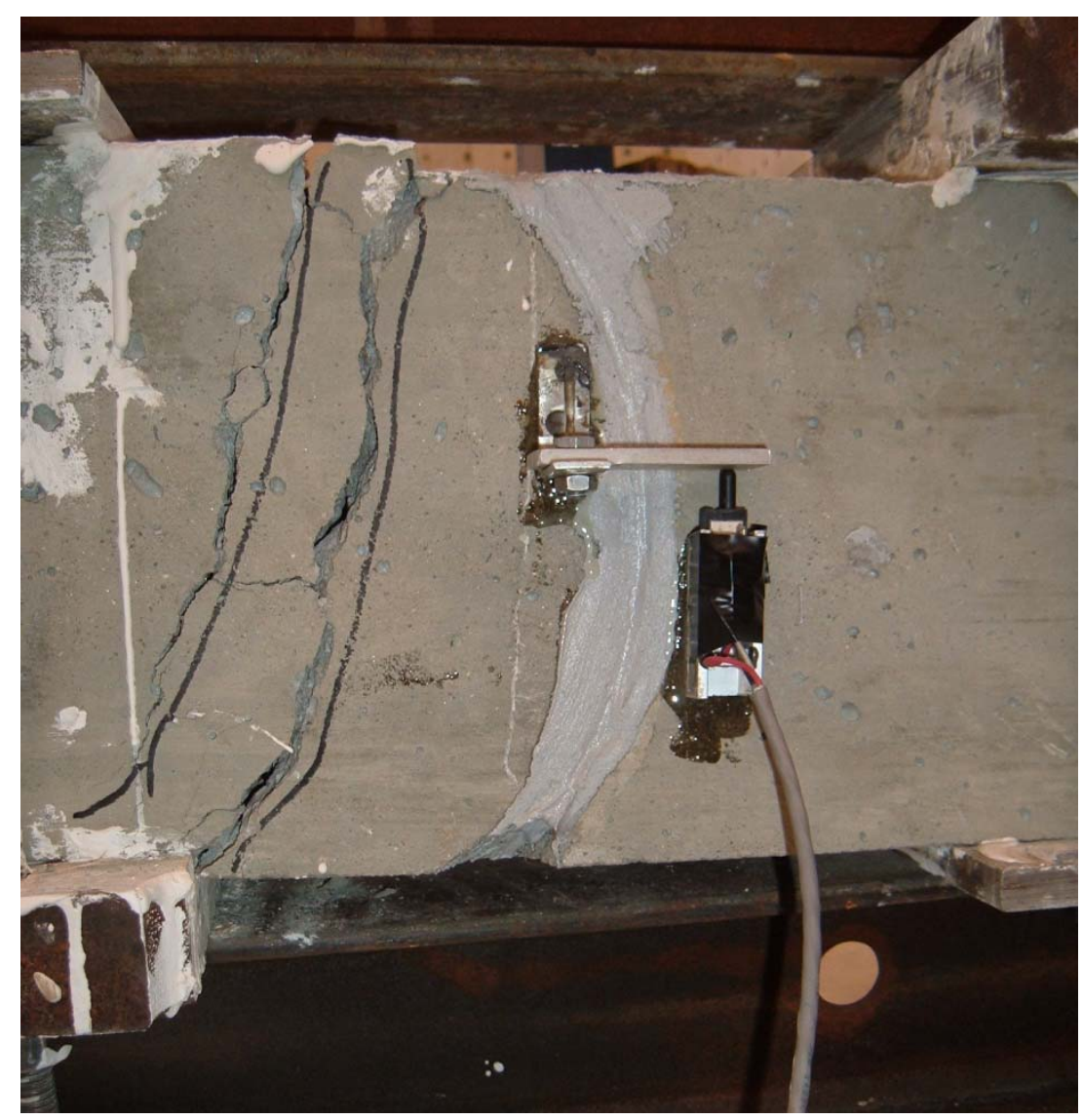

Figure 4.20: Failure of Specimen S-6-4

\subsubsection{1. $\underline{\mathrm{S}-8-1}$}

The failure of Specimen S-8-1 is shown in Figure 4.21. The specimen was loaded to 15.9 kips at which point sudden shear failure of the concrete occurred on the female side of the specimen. The SBA remained bonded to both panel sections and had no observed damage. In addition, no cracking of the specimen was observed prior to failure. The potentiometer measured a maximum relative displacement of $0.0022 \mathrm{in}$. across the joint prior to failure. 


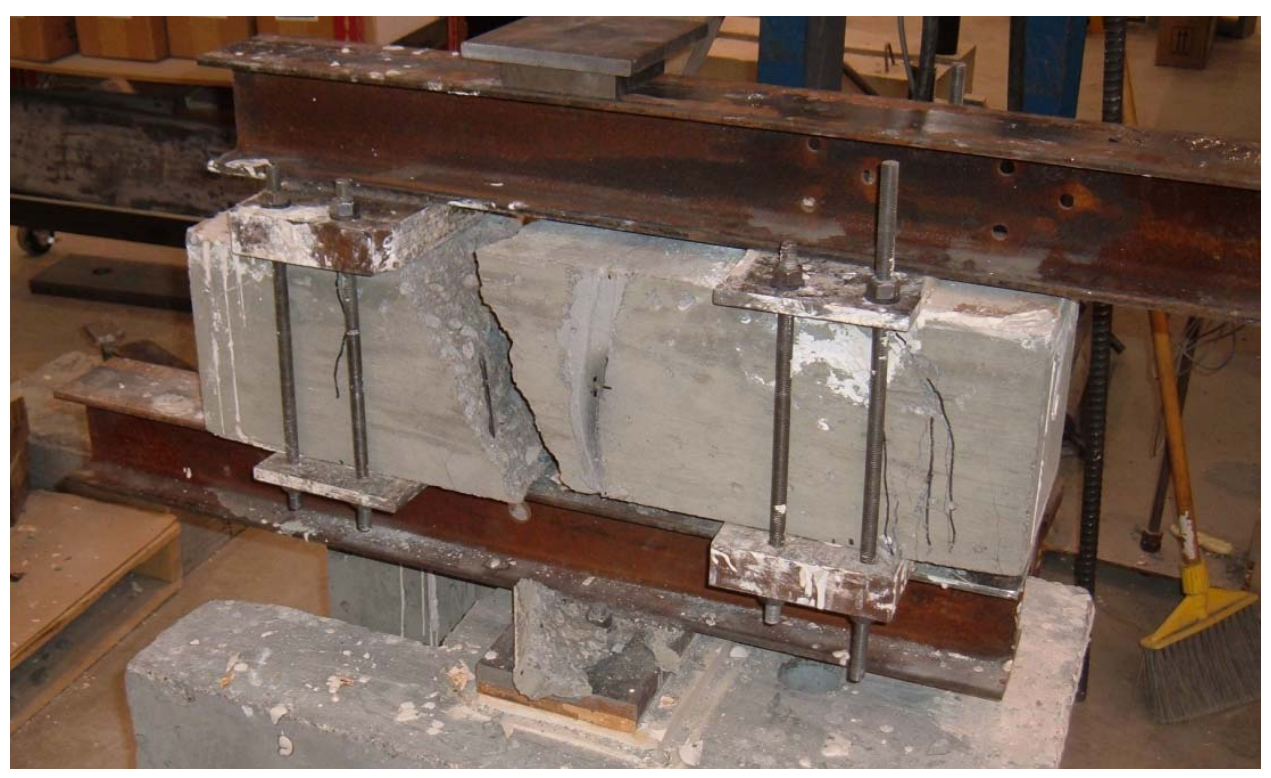

Figure 4.21: Failure of Specimen S-8-1

\subsubsection{2. $\underline{\text { S-8-2 }}$}

The failure of Specimen S-8-2 is shown in Figure 4.22. The specimen was loaded to 16.4 kips at which point sudden shear failure of the concrete occurred. The failure plane went across the joint. The SBA remained bonded to both panel sections. In addition, no cracking of the specimen was observed prior to failure. The potentiometer measured a maximum relative displacement of 0.0031 in. across the joint prior to failure. Following initial failure of the concrete, loading of the specimen continued. The specimen carried a second peak load of 15.2 kips. After the second peak load was reached, the specimen could no longer sustain load. 


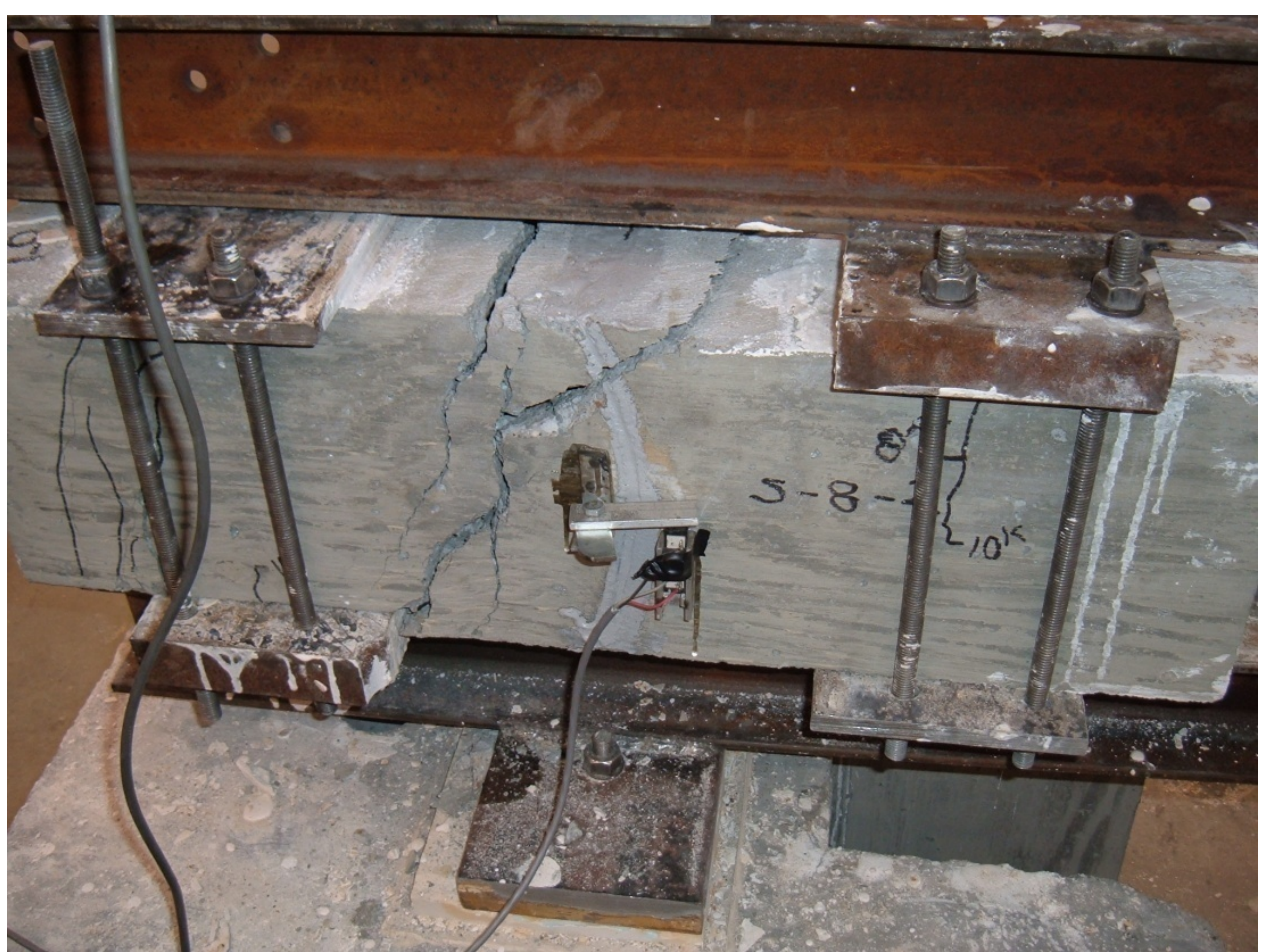

Figure 4.22: Failure of Specimen S-8-2

\subsubsection{3. $\underline{\mathrm{C}-0-1}$}

The failure of Specimen C-0-1 is shown in Figure 4.23. The specimen was loaded to 6.9 kips at which point sudden failure of the concrete and bond at the joint surface occurred. The SCC remained undamaged and bonded to one panel section. In addition, no cracking of the specimen was observed prior to failure. The potentiometer measured a maximum relative displacement of 0.001 in. across the center of the joint prior to failure. 


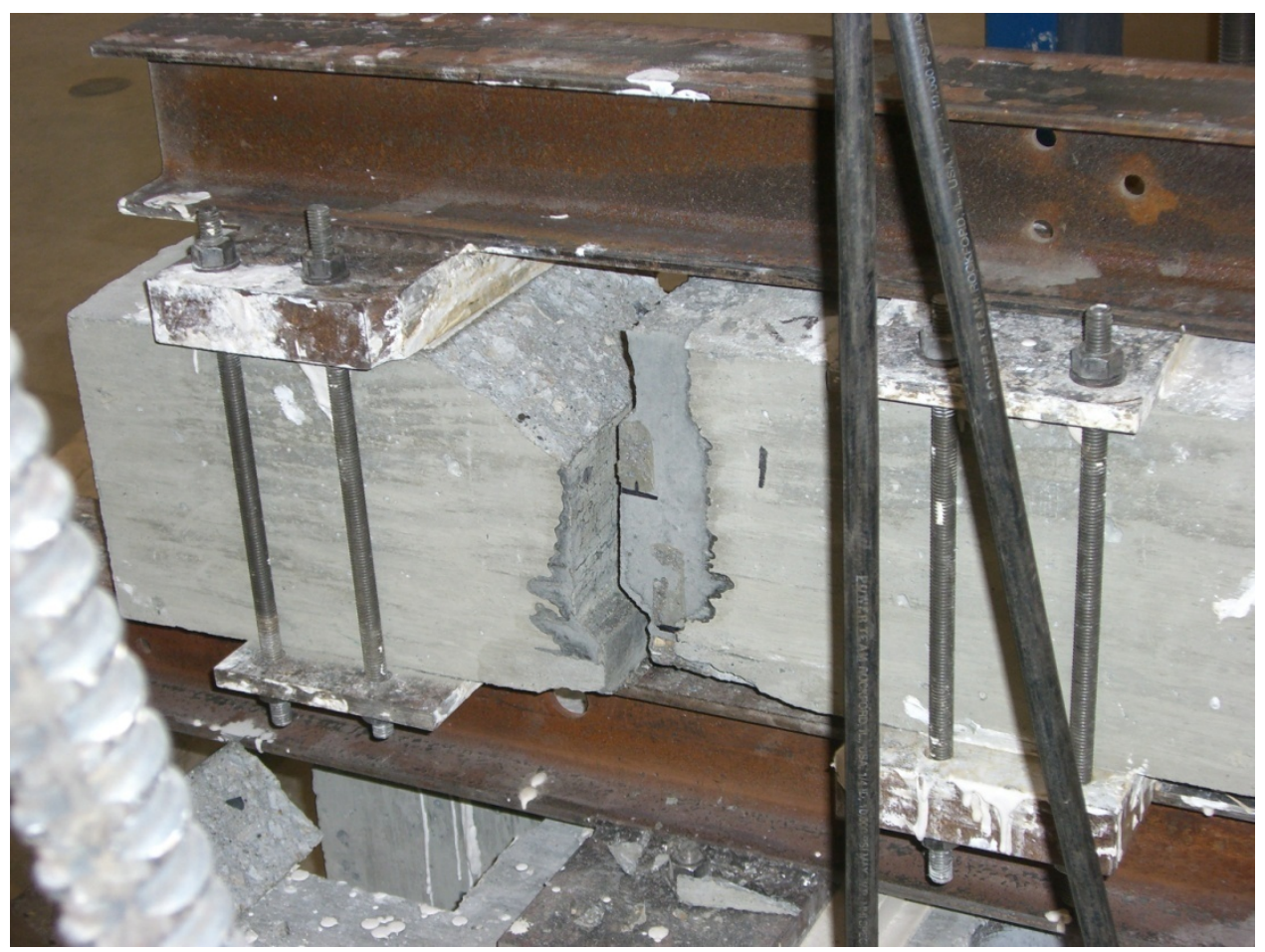

Figure 4.23: Failure of Specimen C-0-1

\subsubsection{4. $\underline{\text { C-0-2 }}$}

The failure of Specimen C-0-2 is shown in Figure 4.24. The specimen was loaded to 8.9 kips at which point sudden failure of the concrete and bond at the joint surface occurred. The SCC remained undamaged and bonded to one panel section and the portion of concrete that broke free from the other. In addition, no cracking of the specimen was observed prior to failure. The potentiometer measured a maximum relative displacement of 0.0005 in. across the center of the joint prior to failure. 


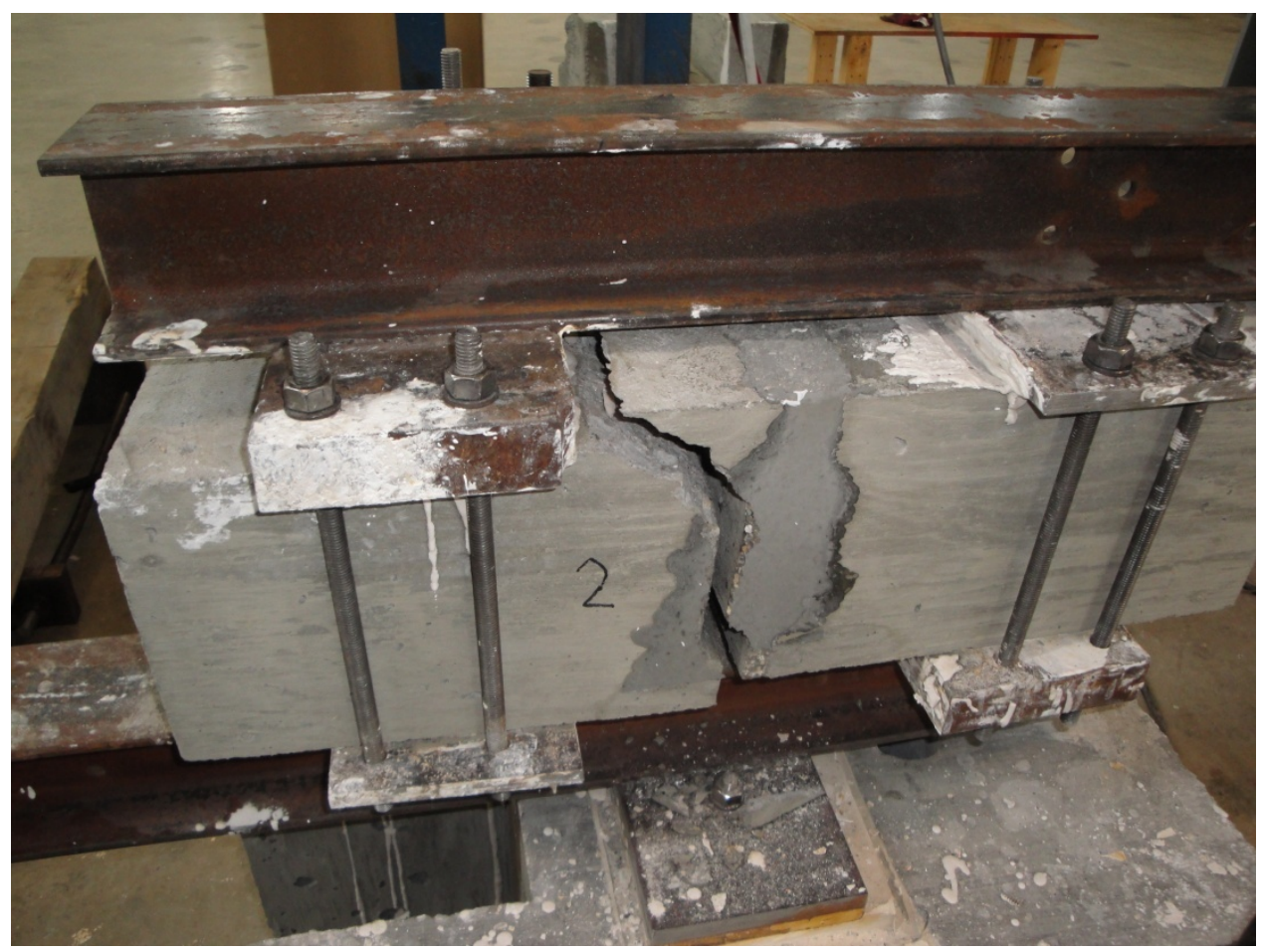

Figure 4.24: Failure of Specimen C-0-2

\subsubsection{5. $\underline{\mathrm{C}-0-3}$}

The failure of Specimen C-0-3 is shown in Figure 4.25. The specimen was loaded to 12.3 kips at which point sudden failure of the concrete and bond at the joint surface occurred. The SCC remained undamaged and bonded to one panel section. In addition, no cracking of the specimen was observed prior to failure. The potentiometer measured a maximum relative displacement of 0.0015 in. across the center of the joint prior to failure. 


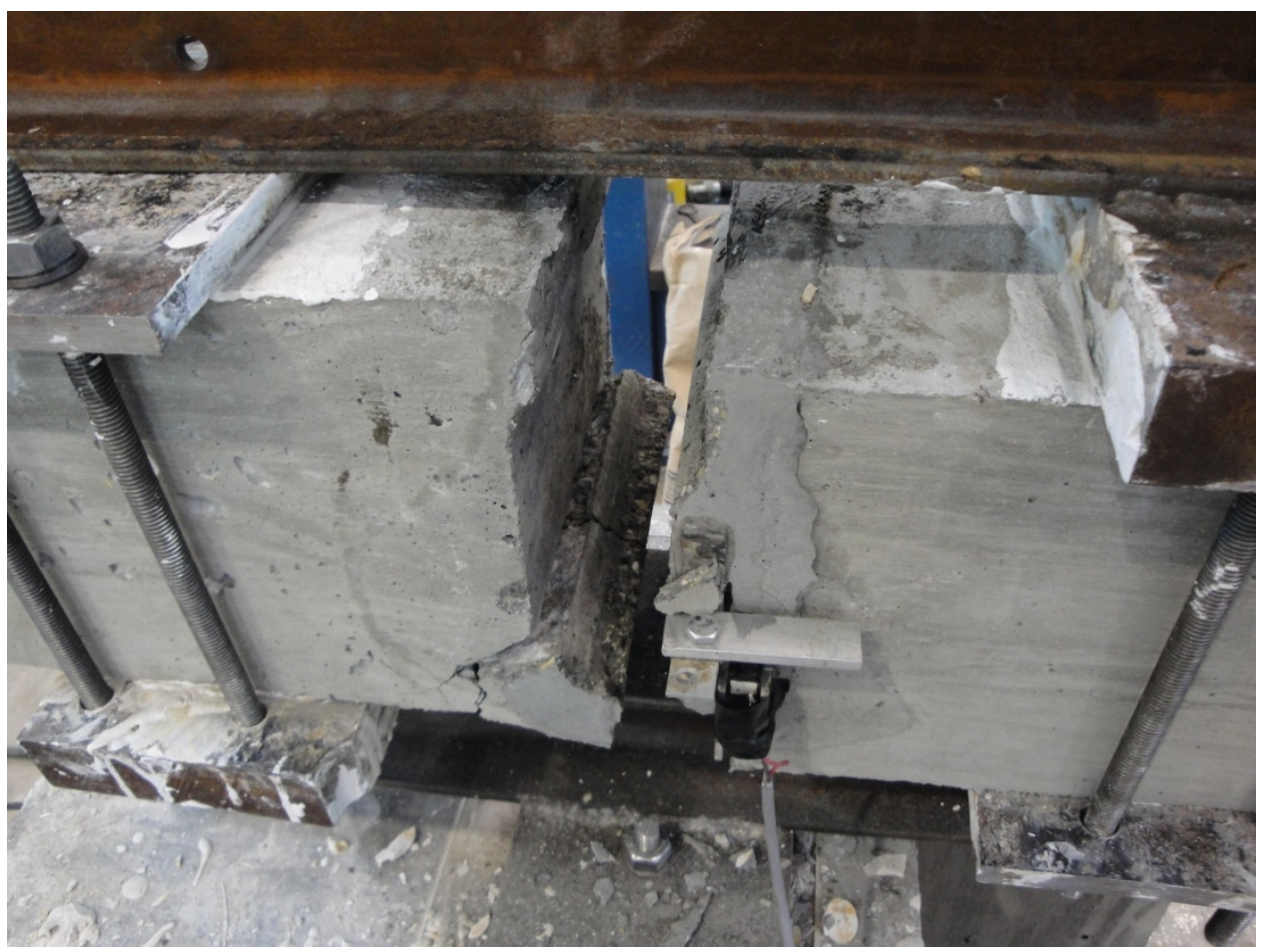

Figure 4.25: Failure of Specimen C-0-3

\subsubsection{Results summary}

All new joint specimens experienced a shear failure through the panel section. The New England joint experienced a bond failure at the panel-SCC interface and sheared a portion of the key provided from the panel section. Therefore, final failure can be classified as two types:

1: Shear failure through the panel section

2: Bond failure of the panel section-SCC interface

When the specimen experienced shear failure of the panel section, the peak load was reached at this failure load. Any load carrying capacity following the initial peak load occurred due to dowel action of the mild reinforcement. This failure occurred in all new joint specimens loaded at a clamping distance of 4 in.

When bond failure occurred at the panel section-SCC interface, the bond between one of the panel sections and SCC would remain intact while the other panel section fell away from the joint. The failure modes and test results are summarized in Table 4.4. 
Average shear stress was calculated based on the maximum load carried and the cross sectional area of the specimens, which was 64 in. $^{2}$

Table 4.4: Summary of results

\begin{tabular}{|c|c|c|c|}
\hline Specimen ID & Failure location & Ultimate load (kips) & Avg. shear stress (psi) \\
\hline U-6-1 & Panel section & 20 & 313 \\
\hline U-6-2 & Panel section & 15.5 & 242 \\
\hline U-8-1 & Panel section & 16.3 & 255 \\
\hline U-8-2 & Panel section & 18.2 & 284 \\
\hline U-8-3 & Panel section & 17.6 & 275 \\
\hline U-8-4 & Panel section & 19.3 & 302 \\
\hline S-6-1 & Panel section & 18.4 & 288 \\
\hline S-6-2 & Panel section & 17.4 & 272 \\
\hline S-6-3 & Panel section & 16.5 & 258 \\
\hline S-6-4 & Panel section & 16.1 & 252 \\
\hline S-8-1 & Panel section & 15.9 & 248 \\
\hline S-8-2 & Panel section & 16.4 & 256 \\
\hline C-0-1 & Joint & 6.9 & 108 \\
\hline C-0-2 & Joint & 8.9 & 139 \\
\hline C-0-3 & Joint & 12.3 & 192 \\
\hline
\end{tabular}

\subsection{Analysis of Results}

The primary variables include the joint geometry and the material in the joint. The test results were analyzed to determine the effects, if any, of those variables on specimen behavior. In addition, test results are compared with the concrete shear strength computed using basic mechanics. The analysis results are presented in the following sections.

\subsubsection{Joint geometry}

The joint geometries evaluated in this phase of testing consisted of the new joint, which is a semi-circular, male-female joint, and the New England joint, which is a female-female shear key. The new joint was evaluated using two radii, 6 in. and 8 in. The average ultimate strength of each radii as well as the New England joint is presented 
in Figure 4.26. It is evident that the average ultimate strengths of the 6 in. and 8 in. radii were the same with similar standard deviations. However, the strength of the New England joint was approximately $46 \%$ less than that of the new joint detail. These results indicate that the new joint has increased capacity over the New England joint. In addition, increasing the radius from 6 in. to 8 in. has no appreciable effect on the ultimate strength. This result is reasonable considering that failure of the specimens with both circular geometries resulted from failure of the panel concrete rather than the joint.

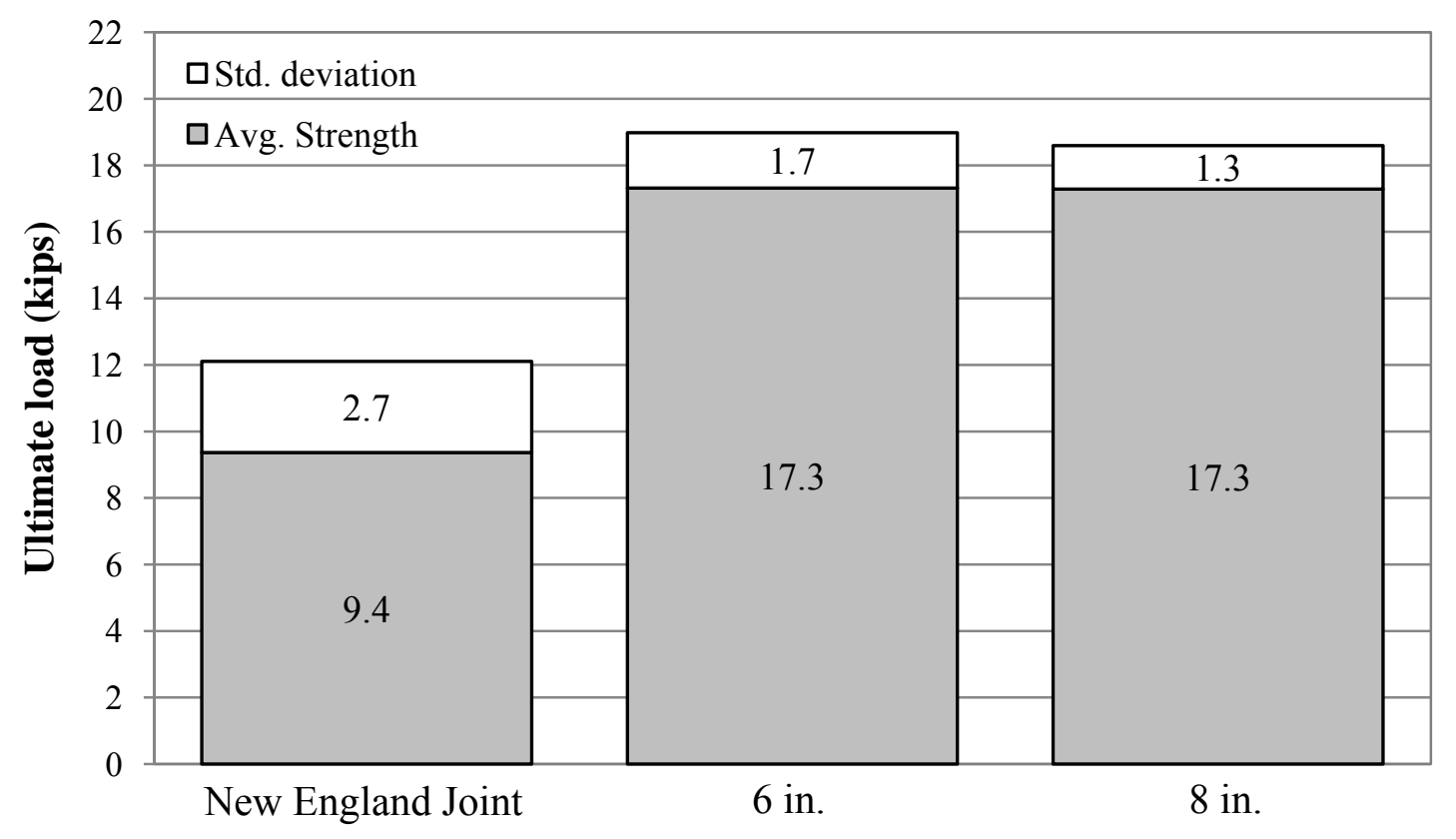

Figure 4.26: Average ultimate strength, comparing joint geometry

\subsubsection{Joint material}

The joint materials evaluated in this phase of testing consisted of two SBA's used in the new joint and SCC used in the New England joint. The two SBA's evaluated were Unitex Pro-Poxy and Sikadur 31 Slow Set. The average ultimate strength of each SBA as well as the New England joint is presented in Figure 4.27. It is evident that the average ultimate strengths of the two SBA's were similar. However, the strength of the New England joint was approximately 44\% less than the new joint. These results would indicate that the male-female joint secured together with SBA has increased capacity over 
the New England joint. For the new joint system, failure is controlled by the panel concrete rather than the geometry and adhesion of the joint.

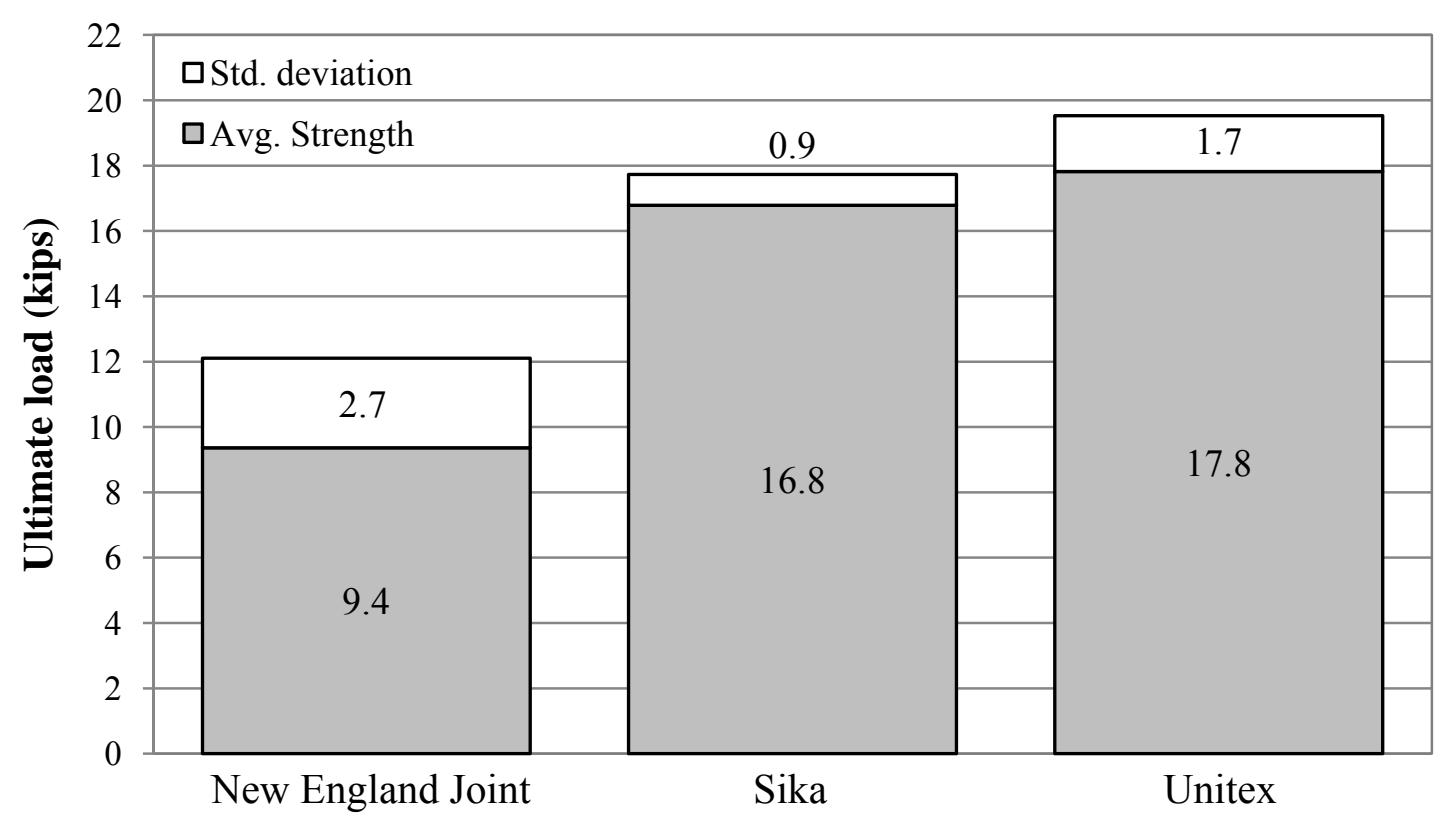

Figure 4.27: Average ultimate strength, comparing joint material

\subsubsection{Shear Strength}

Based on mechanics, the shear stress across a rectangular cross section can be determined as summarized in Figure 4.28. For a rectangular cross section V, I, and $t$ are constant. The quantity $Q$ varies over the height of the section and is maximum at $y=0$, which is the horizontal neutral axis of the cross section. Consequently, the maximum shear stress occurs at the neutral axis and is computed as:

$$
\tau_{\max }=\frac{3}{2} \frac{\mathrm{V}}{\mathrm{bh}}
$$




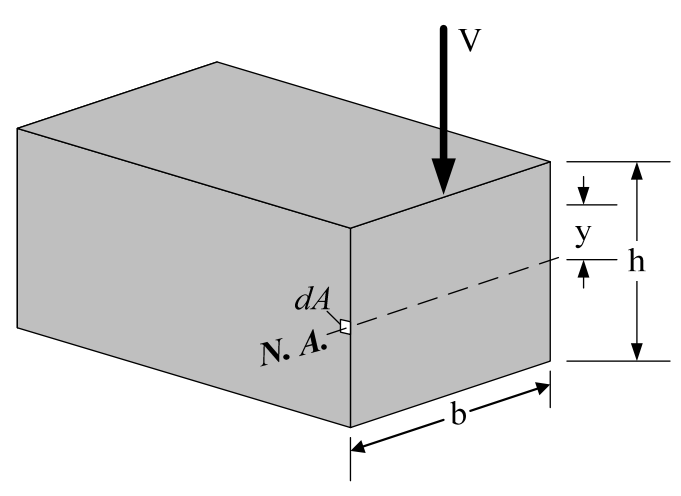

$$
\begin{aligned}
& \tau=\frac{\mathrm{VQ}}{\mathrm{It}} \quad(\text { Shear formula }) \\
& \text { For a rectangular cross section } \\
& \mathrm{Q}=\frac{1}{2}\left(\frac{\mathrm{h}^{2}}{4}-\mathrm{y}^{2}\right) \mathrm{b}, \quad \mathrm{I}=\frac{\mathrm{bh}^{3}}{12}, \text { and } \mathrm{t}=\mathrm{b} \\
& \tau \text { will be largest at } \mathrm{y}=0 \text { (the N.A.) } \\
& \tau_{\max }=\frac{3}{2} \frac{\mathrm{V}}{\mathrm{bh}}
\end{aligned}
$$

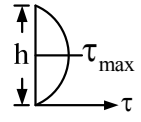

Figure 4.28: Maximum shear stress in a rectangular cross section

The equation for $\tau_{\max }$ was used in conjunction with Mohr's circle considering the tensile strength of concrete (approximately $6 \sqrt{f_{c}}$ ). For a very small area $(d A)$ of material located at the horizontal neutral axis (Figure 4.28), there are only shear stresses present, as illustrated in Figure 4.29. The element $d A$ has principle stresses oriented at an angle of $45^{\circ}$. If $\sigma_{\mathrm{t}}$ is set equal to $6 \sqrt{\mathrm{f}_{\mathrm{c}}}$ then, from Mohr's circle, the element $d A$ will be subjected to shear stress of the same magnitude. The shear stress on element $d A$ is the maximum shear stress that can be resisted in the cross section $\left(\tau_{\max }\right)$ prior to diagonal tension failure. Setting $\tau_{\max }$ equal to $\sigma_{t}$ and solving for $V$ yields a maximum shear stress of $4 \sqrt{f_{c}}$.

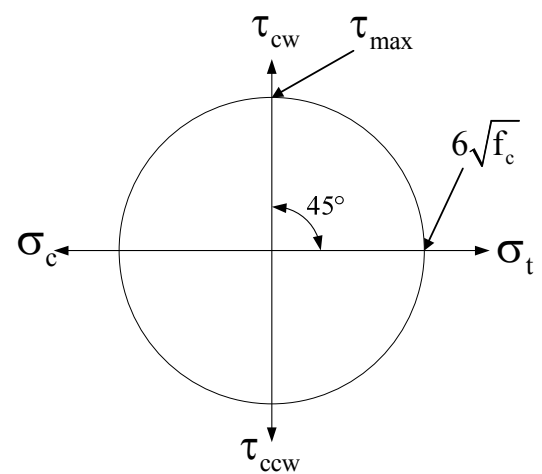

Mohr's Circle

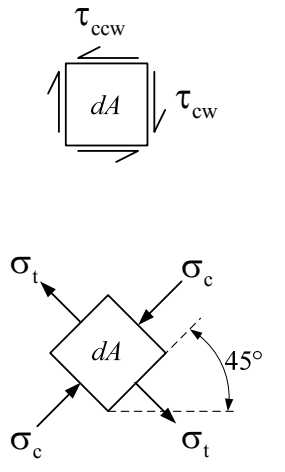

Figure 4.29: Computing concrete shear stress

The coefficient of $\sqrt{f_{c}}$ was computed for each specimen using the 42 day strength of the panel sections (5490 psi). The results are summarized in Table 4.5 and Table 4.6. 
The new joint specimens produced values in reasonable agreement with $4 \sqrt{f_{c}}$, with the average being approximately $3.6 \sqrt{\mathrm{f}_{\mathrm{c}}}$ and the standard deviation equal to 0.3 . Taking the average value minus two standard deviations yields $3 \sqrt{\mathrm{f}_{\mathrm{c}}}$. Subtracting two standard deviations from the mean corresponds to $3 \sqrt{f_{c}}$ being conservative for at least $95 \%$ of the specimens. The shear strength of the new joint can be conservatively estimated using $3 \sqrt{\mathrm{f}_{\mathrm{c}}}$. As noted, the lowest test result was $3.3 \sqrt{\mathrm{f}_{\mathrm{c}}}$.

The values produced by the New England joint specimens are presented in Table 4.6. However, because bond failure, not cracking of the panel section, was the primary cause of failure, the values are not valid for this comparison. However, they do illustrate the relative decrease in performance of this joint type.

Table 4.5: Computed coefficients of $\sqrt{\mathrm{f}_{\mathrm{c}}}$, new joint

\begin{tabular}{|c|c|c|}
\hline Specimen ID & Avg. shear stress (psi) & Coefficient of $\sqrt{\mathbf{f}_{\mathbf{c}}}$ \\
\hline $\mathrm{U}-6-1$ & 313 & 4.2 \\
\hline $\mathrm{U}-6-2$ & 242 & 3.3 \\
\hline $\mathrm{U}-8-1$ & 255 & 3.4 \\
\hline $\mathrm{U}-8-2$ & 284 & 3.8 \\
\hline $\mathrm{U}-8-3$ & 275 & 3.7 \\
\hline $\mathrm{U}-8-4$ & 302 & 4.1 \\
\hline S-6-1 & 288 & 3.9 \\
\hline S-6-2 & 272 & 3.7 \\
\hline S-6-3 & 258 & 3.5 \\
\hline S-6-4 & 252 & 3.4 \\
\hline S-8-1 & 248 & 3.3 \\
\hline S-8-2 & 256 & 3.5 \\
\hline Average & 270 & 3.6 \\
\hline
\end{tabular}


Table 4.6: Computed coefficients of $\sqrt{\mathrm{f}_{\mathrm{c}}}$, New England Joint

\begin{tabular}{|c|c|c|}
\hline Specimen ID & Avg. shear stress (psi) & Coefficient of $\sqrt{\mathbf{f}_{c}}$ \\
\hline C-0-1 & 108 & 1.4 \\
\hline C-0-2 & 139 & 1.9 \\
\hline C-0-3 & 192 & 2.6 \\
\hline Average & 146 & 2.0 \\
\hline
\end{tabular}

\subsection{Conclusions}

Using the new joint, failure was produced in the precast panels. However, in the New England system joint, failure occurred at the joint resulting in lower strength.

Several conclusions were drawn from the results of this phase of testing.

1. The new joint carried upwards of 78\% more load than the New England joint.

2. A 6 in. versus 8 in. radius has no appreciable effect on the strength of the new joint because both circular geometries resulted in failure of the panel concrete rather than the joint.

3. Sikadur 31 and Unitex Pro-Poxy SBA had similar performance because failure was controlled by the panel concrete rather than adhesion of the joint.

4. The shear strength of the new joint detail can be conservatively estimated using $3 \sqrt{f_{c}}$. Since the full shear strength of the member concrete was achieved (failure away from the joint), no calculations of joint strength are required. 


\subsection{Design Recommendation}

Based on the results of this phase of testing, the following design recommendations are provided.

1. Calculation of the shear strength of the joint is not required.

2. Either the 6 in. or 8 in. joint is recommended. However, the 8 in. joint may be preferable for constructability. It is less likely to chip at the edges. In addition, it would better accommodate variations in joint geometry.

3. Either Sikadur-31 or Unitex Pro-Poxy segmental bridge adhesive is recommended. 


\section{CHAPTER 5: FULL-DEPTH DECK SYSTEM}

\subsection{Introduction}

This phase of testing evaluates a new deck system developed as part of this research program. The new system consists of the improved panel-to-girder connection detail discussed in Chapter 3 as well as the new panel-to-panel connection discussed in Chapter 4. The system was developed to eliminate penetrations in the deck panels and minimize joint widths while increasing the speed of construction. In this phase of testing, a full-scale specimen was constructed using the new system so it could be evaluated to confirm its performance and constructability.

\subsection{Specimen Design}

To evaluate the structural behavior of the system and have a means of comparing new design details to current details, a large scale test was designed. The objectives of the testing was to evaluate the performance of the new panel-to-panel joint under cyclic loading, strength of the girder-to-panel connection, and composite behavior of the system. The test specimen was designed to be $42 \mathrm{ft}$ long using two modified HN36-49 prestressed concrete girders spaced 100 in. (8'- 4”) on center. The precast deck panels were designed to be $14 \mathrm{ft}$ in the transverse direction and $4 \mathrm{ft}$ in length. The specimen required ten deck panels. Each panel had double headed shear studs with a forged head embedded 5.5 in, as shown in Figure 5.1. The shear studs were spaced at 12 in., 18 in. and 24 in. increments along the length of the girders to create half spans in each girder with the following combinations of stud size and spacing: \#4 at 12 in., \#4 at 18 in., \#4 at 24 in., and \#5 at 24 in. Details of the girder and precast panel designs are presented in the following sections. 


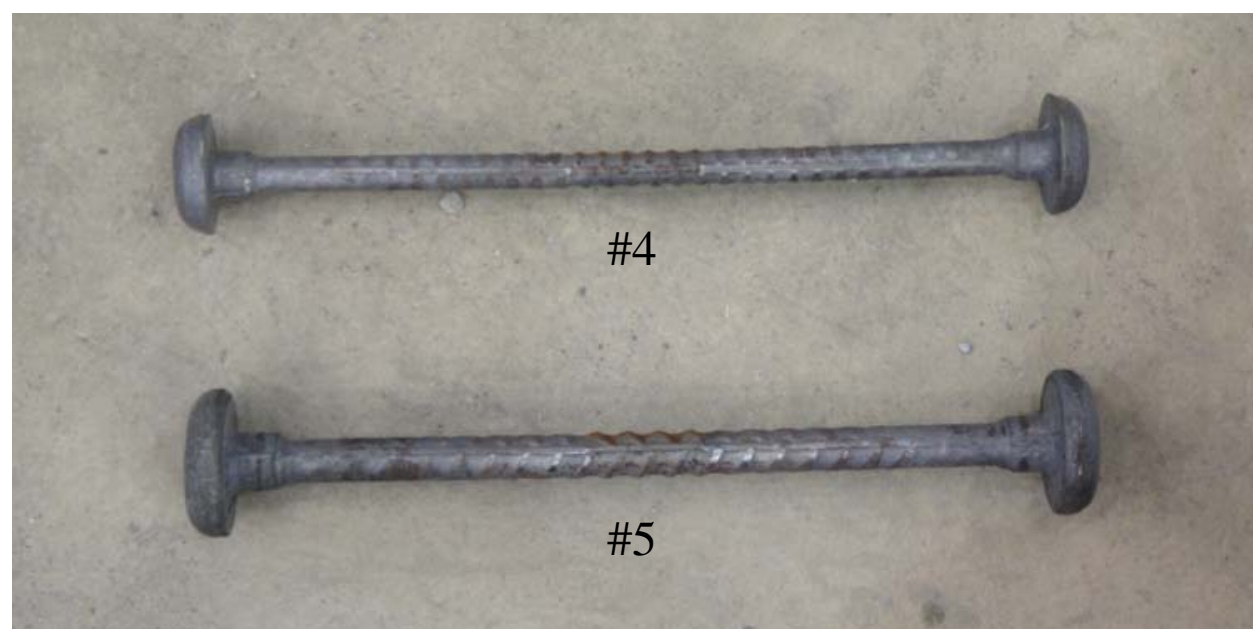

Figure 5.1: Double headed shear studs

\subsubsection{Girders}

The hybrid HN36-49 girders were designed with an overall length of $42 \mathrm{ft}$. A length of $42 \mathrm{ft}$ would allow for a $40 \mathrm{ft}$ simple span. The girder cross-section was chosen because it was the smallest standard cross-section available that would accommodate the new panel-to-girder connection detail. Cross-section details are provided in Figure 5.2. Prestressing steel was specified as Grade 270, 1/2 in.-special, 7-wire, low-lax strand and was placed on a 2 in. grid. 


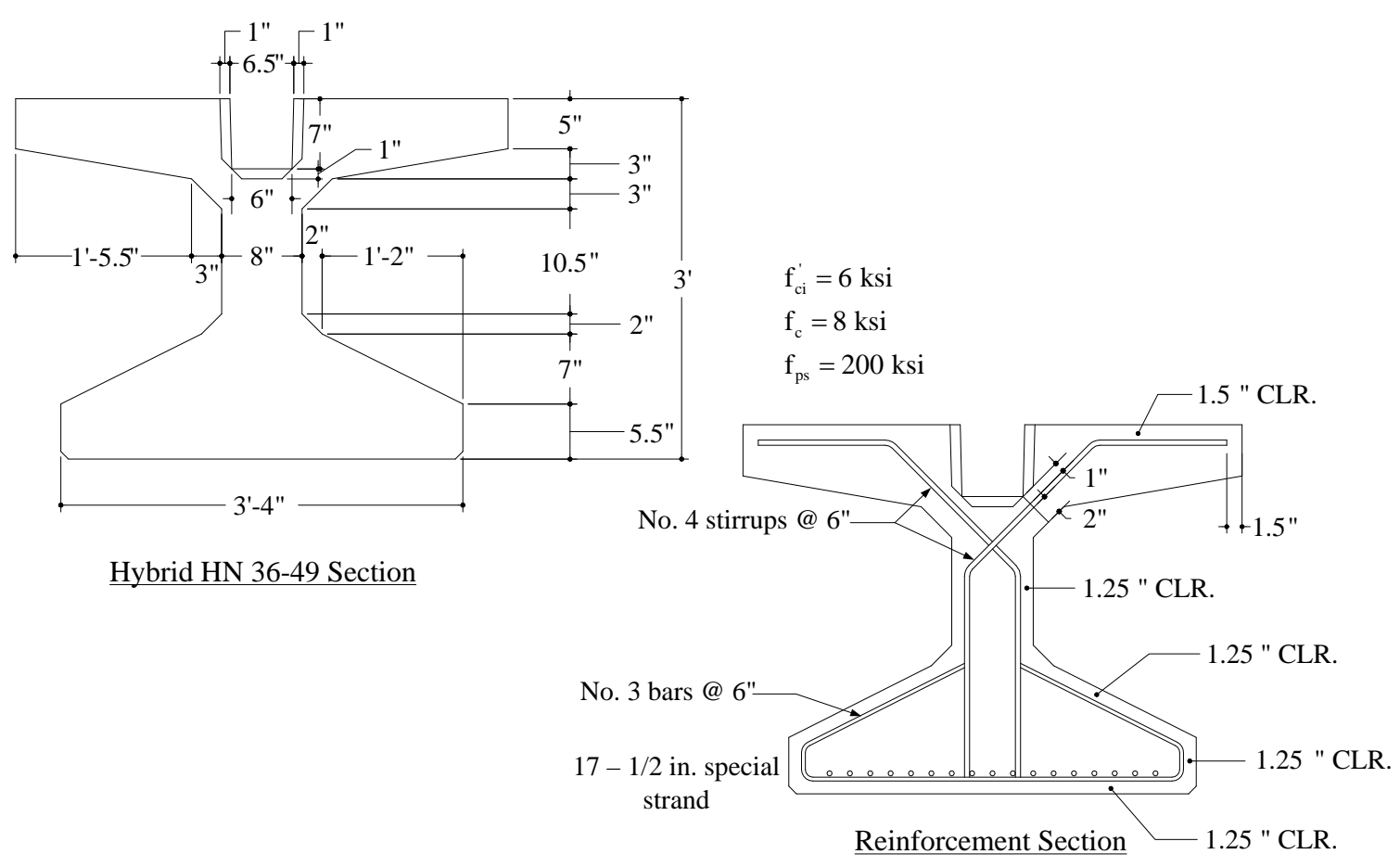

a) Elevation (cross-sections)

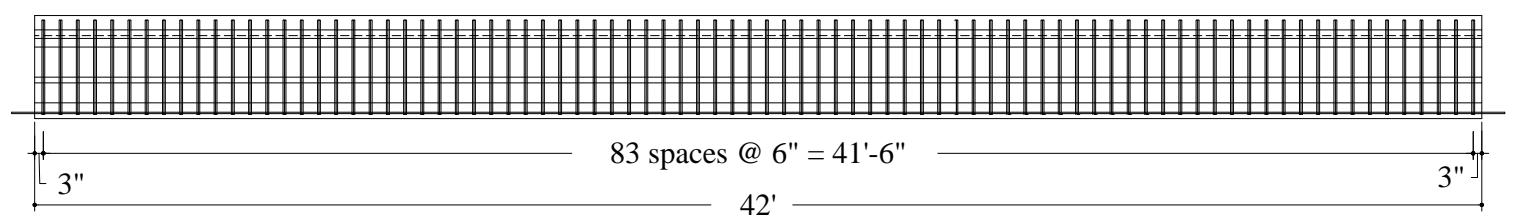

\section{b) Elevation (side)}

Figure 5.2: Girder cross-section and reinforcement layout.

\subsubsection{Precast panels}

The specimen required ten precast bridge deck panels. The precast deck panels were 49.5 in. in length, 168 in. in width, and 8 in. thick. Although an 8 in. radius joint may be preferable in setting the panels, a 6 in. radius joint was constructed because materials to form the joint were more readily available. The panels had shear studs spaced at different increments along the length depending on the panel position on the girders. The following combinations of stud size and spacing were established for this phase of testing: \#4 at 12 in., \#4 at 18 in., \#4 at 24 in., and \#5 at 24 in. The reinforcement in the deck panels consisted of two mats of \#4 and \#5 reinforcing bars. A detailed 
drawing showing the dimensions of the panels, shear stud spacing, and spacing of the mild reinforcement is presented in Figure 5.3.

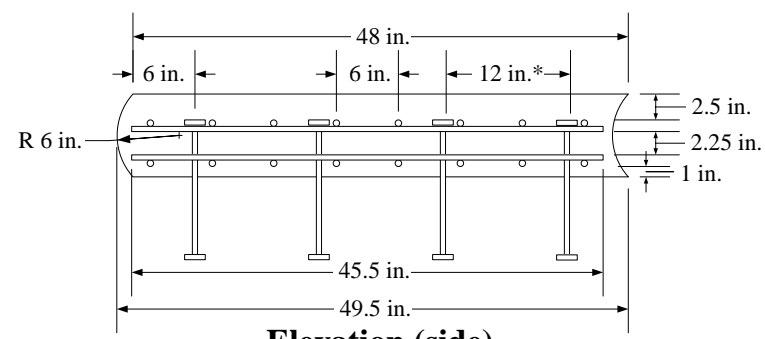

Elevation (side)

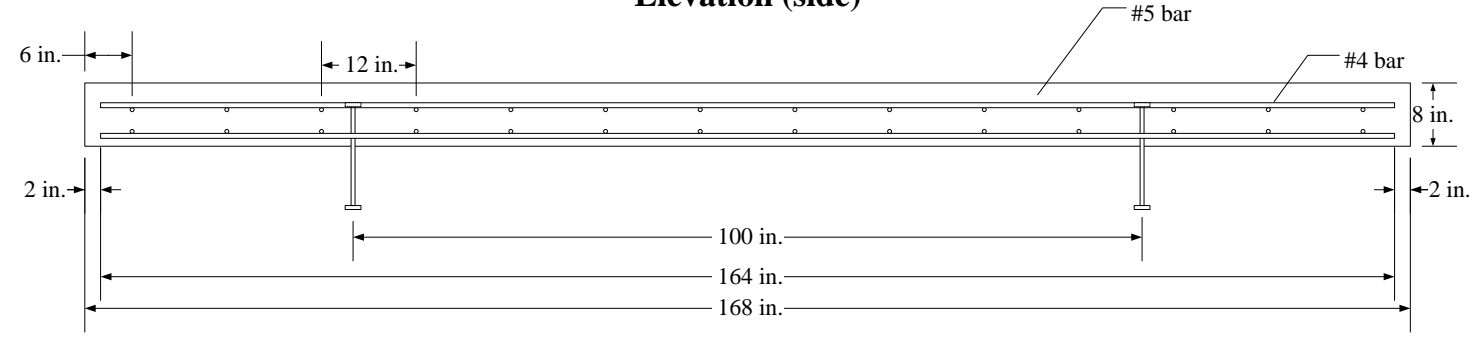

Elevation (front)

a) Elevation view

* Two stud sizes and four spacings were used in different panels. The locations within the specimen are presented in Section 5.5 .

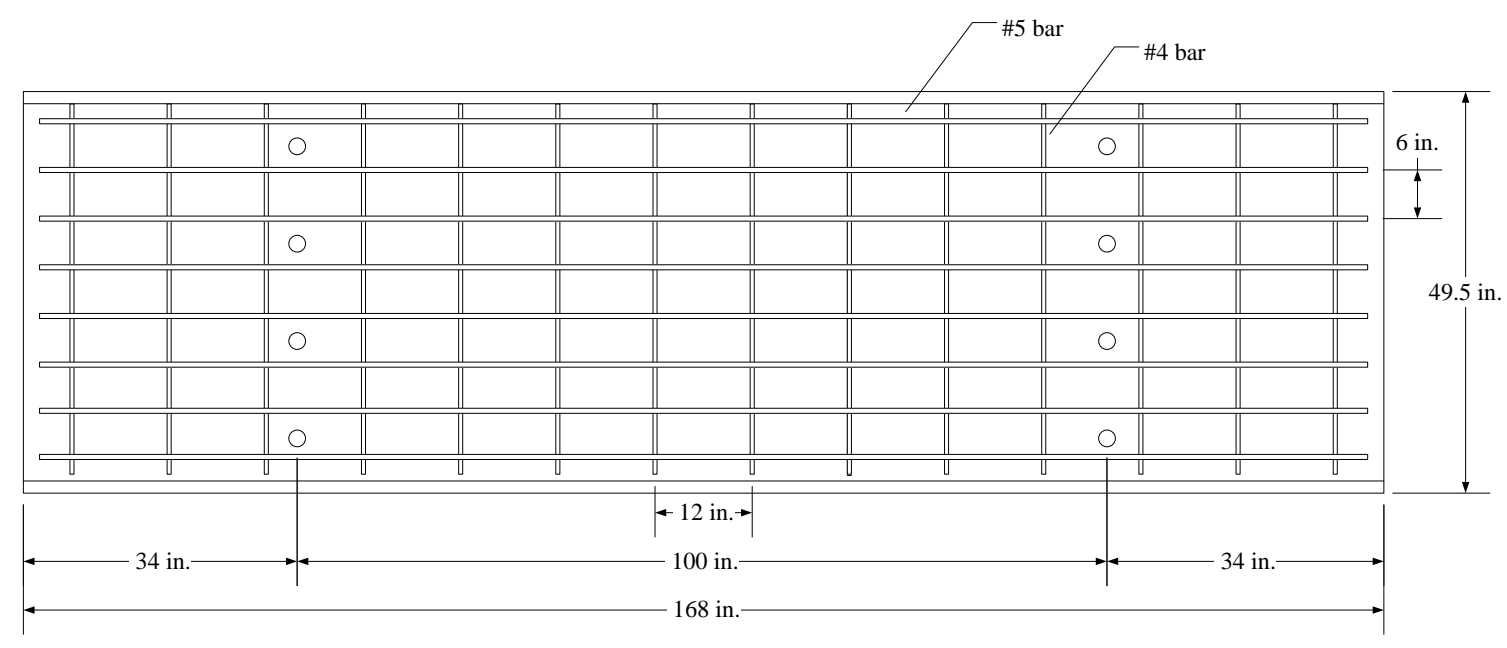

b) Plan view

Figure 5.3: Panel dimensions and reinforcement details 


\subsubsection{Test variables}

Test variables for the test series consisted of two parameters.

1. Size of shear stud: The shear stud size was varied to evaluate its influence on shear transfer strength. Two sizes were considered, \#4 and \#5 reinforcing bars.

2. Shear stud spacing: Three spacings were considered: 12 in., 18 in., and 24 in.

The girders were identified as G-1 and G-2. The shear studs size and spacing was varied on each girder half span because, depending on the failure mode, a second test of the opposite side of the girder may be possible to obtain additional information. Specimen labels and variables are presented in Table 5.1.

Table 5.1: Specimen variables.

\begin{tabular}{|c|c|c|}
\hline Specimens & Shear stud size & Shear stud spacing \\
\hline G-1 & $\# 4$ and $\# 5$ & 12 in. and 24 in. \\
\hline G-2 & $\# 4$ & 18 in. and 24 in. \\
\hline
\end{tabular}

\subsection{Construction}

The following subsections describe the processes by which the precast components required for each specimen were constructed. The construction process for the specimens is also described.

\subsubsection{Girders}

The girders were constructed by Prestress Services Industries LLC. The trough was formed using wood and shear keys cut from foam. Once casting was completed, the top surface of the girders received a flat float finish. The girders were cured for 3 days by covering the exposed surface with plastic sheeting. Once the concrete reached a nominal compressive strength of $6 \mathrm{ksi}$, the forms were removed and the strands were 
detensioned symmetrically. The trough was sandblasted to remove the remaining foam and laitance. Images from the girder construction process are presented in Figure 5.4.

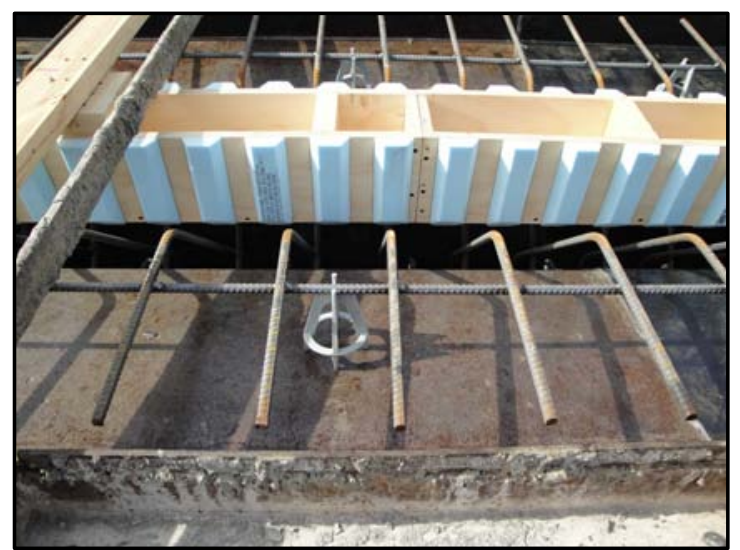

Trough and Reinforcement

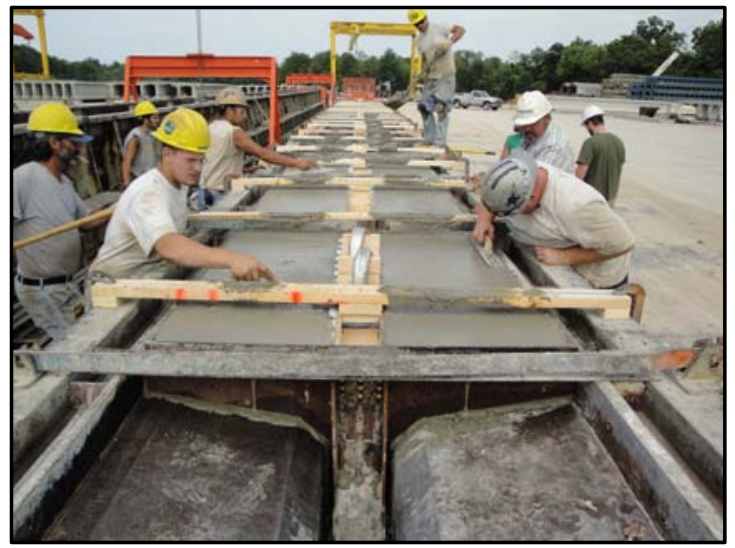

Finishing

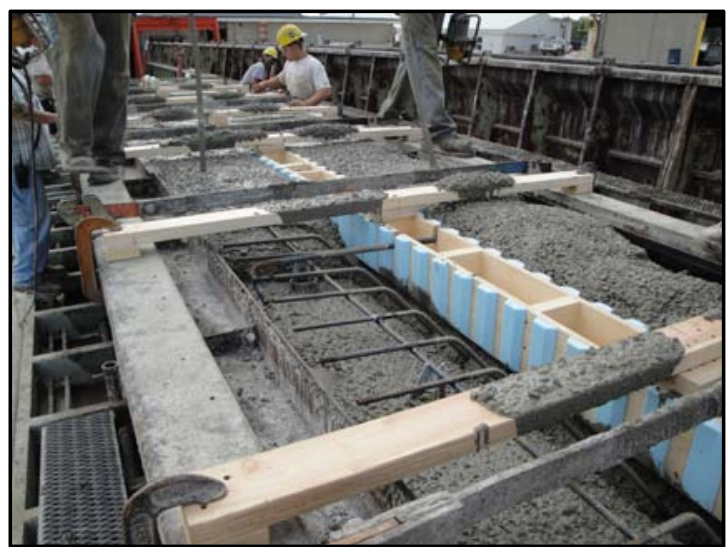

Casting

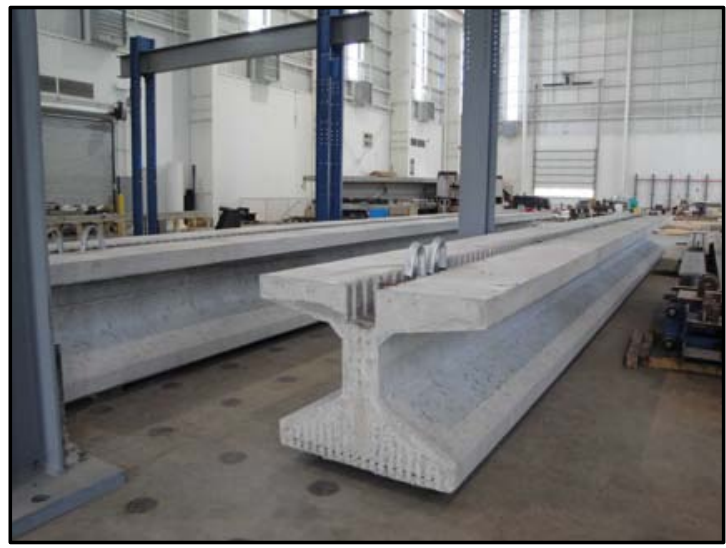

Completed Girders

Figure 5.4: Images of girder construction

\subsubsection{Precast deck panels}

The precast deck panels were constructed in the Bowen Laboratory at Purdue University on two separate occasions. One set of five panels were cast using the same batch of concrete. There were two casting beds for each set of five panels, as shown in Figure 5.5. The floor of the casting bed was elevated so shear studs could be placed through holes drilled in the floor. This allowed for the panels to be cast upright and the top surface to be finished as desired. The 6 in. radius panel-to-panel joint was formed using sections of 12 in. diameter PVC pipe. Once forming and rebar placement was complete, the concrete was obtained from a local ready-mix supplier. The mix specified 
for the precast panels was INDOT Class C, which has a minimum compressive strength of $4 \mathrm{ksi}$ at 28 days. After casting, the top surface received a flat float finish and the deck panels were wet cured for 7 days. Once removed from the formwork, the transverse joint surfaces were cleaned with a wire brush and compressed air to remove laitance. 


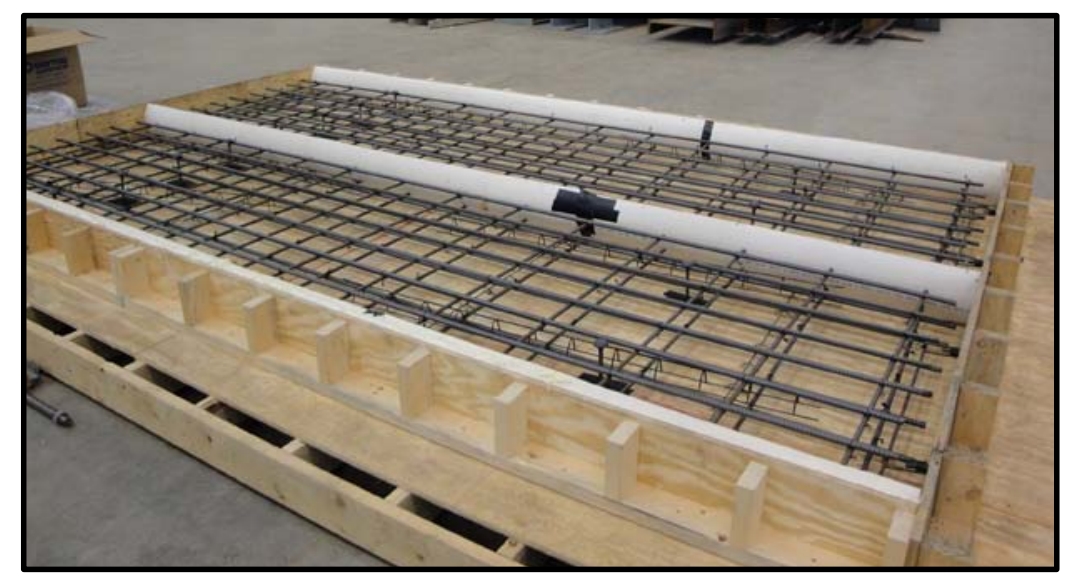

Two panel casting bed

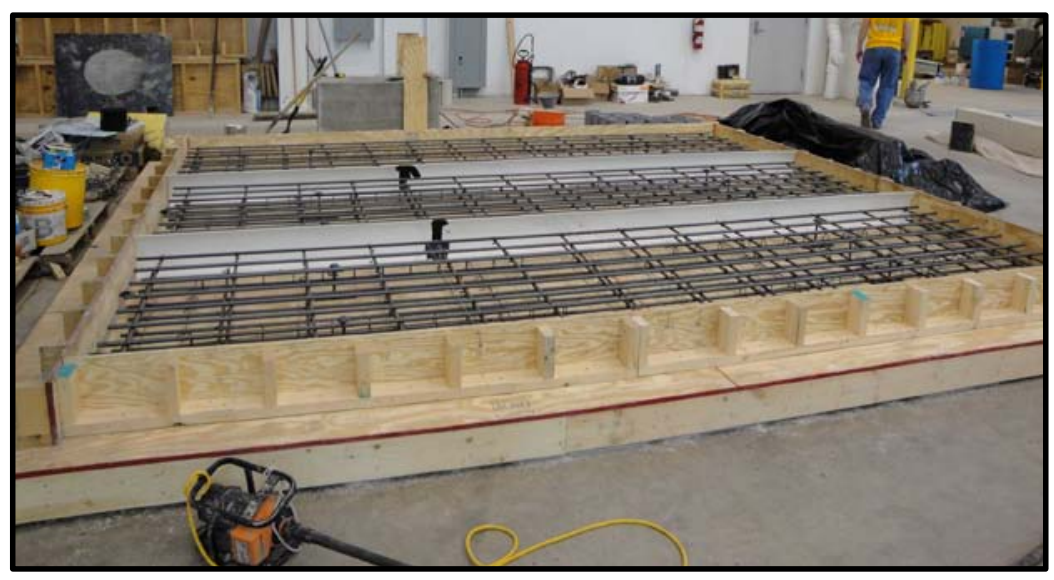

Three panel casting bed

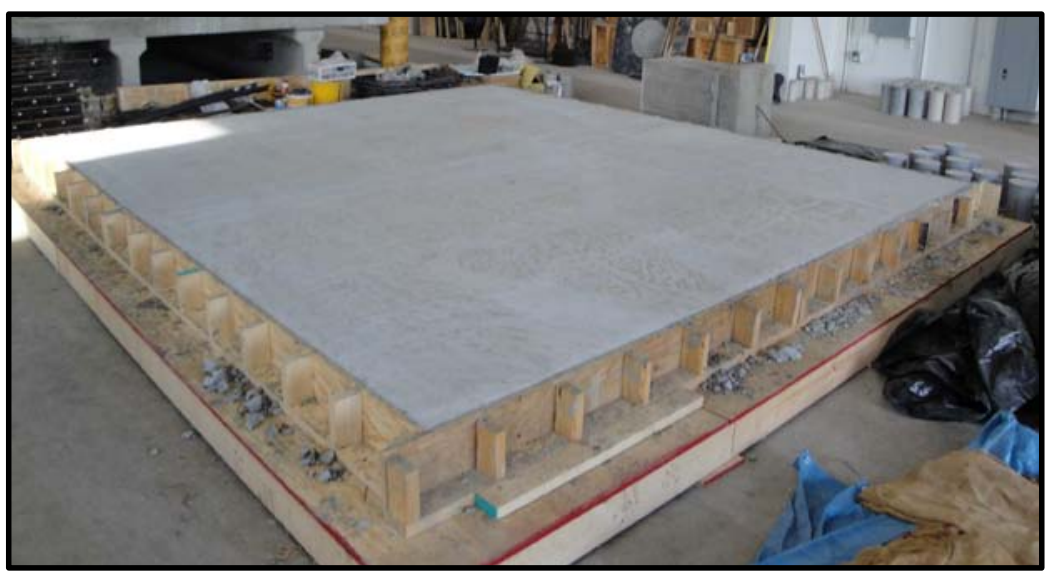

Completed panels

Figure 5.5: Panel construction 


\subsubsection{System}

Once the girders were placed on the supports, the precast deck panels were placed. Each successive panel was centered on the girders to within a 1/4 in. and leveled by shimming. Once centered, the panel was lifted and placed on top of the previously installed panel temporarily during placement of the trough concrete. Concrete for the trough was mixed in the laboratory and placed in the trough along a four foot section in each girder where the panel was to be placed. Once concrete was placed, the concrete was vibrated and additional concrete was added to each trough. The additional concrete was mounded to a height greater than $1 \mathrm{in}$. above the top surface of the girder to ensure contact with the bottom surface of the panel. Once the concrete was in place, approximately $0.15 \mathrm{gal} / \mathrm{ft}^{2}$ of the segmental bridge adhesive (SBA) was mixed and applied to the joint surface of the panel being placed. Then the panel was lifted and set into the trough concrete. The deck panels were elevated above the top surface of the girder using $3 / 4$ in. lengths of $2 \times 4$ lumber with two $1 / 8$ in. thick strips of Teflon to form a 1 in. haunch (Figure 5.6). The Teflon served as a low friction surface so the panels could be pressed together once the panel was set down. The panels were pressed together using two hydraulic rams that utilized the shear keys in the trough as a bearing point (Figure 5.7). The panels were pressed with a total force of 4 kips, resulting in approximately 3 psi across the joint surface. The pressure was sufficient to squeeze excess SBA from the joint. Once the panel was pressed against the previously set panel to ensure bonding of the transverse joint, the trough was vibrated again to consolidate the concrete around the studs. Then, the horizontal force on the panel was removed prior to setting of the concrete and SBA. The procedure described for panel placement is presented in Figure 5.8. Each panel took approximately 3 hours for one person to place. This includes time for aligning the panel, weighing and mixing the concrete, and proportioning and mixing the SBA. However, the process of placing the concrete and panel only took approximately 45 minutes. 

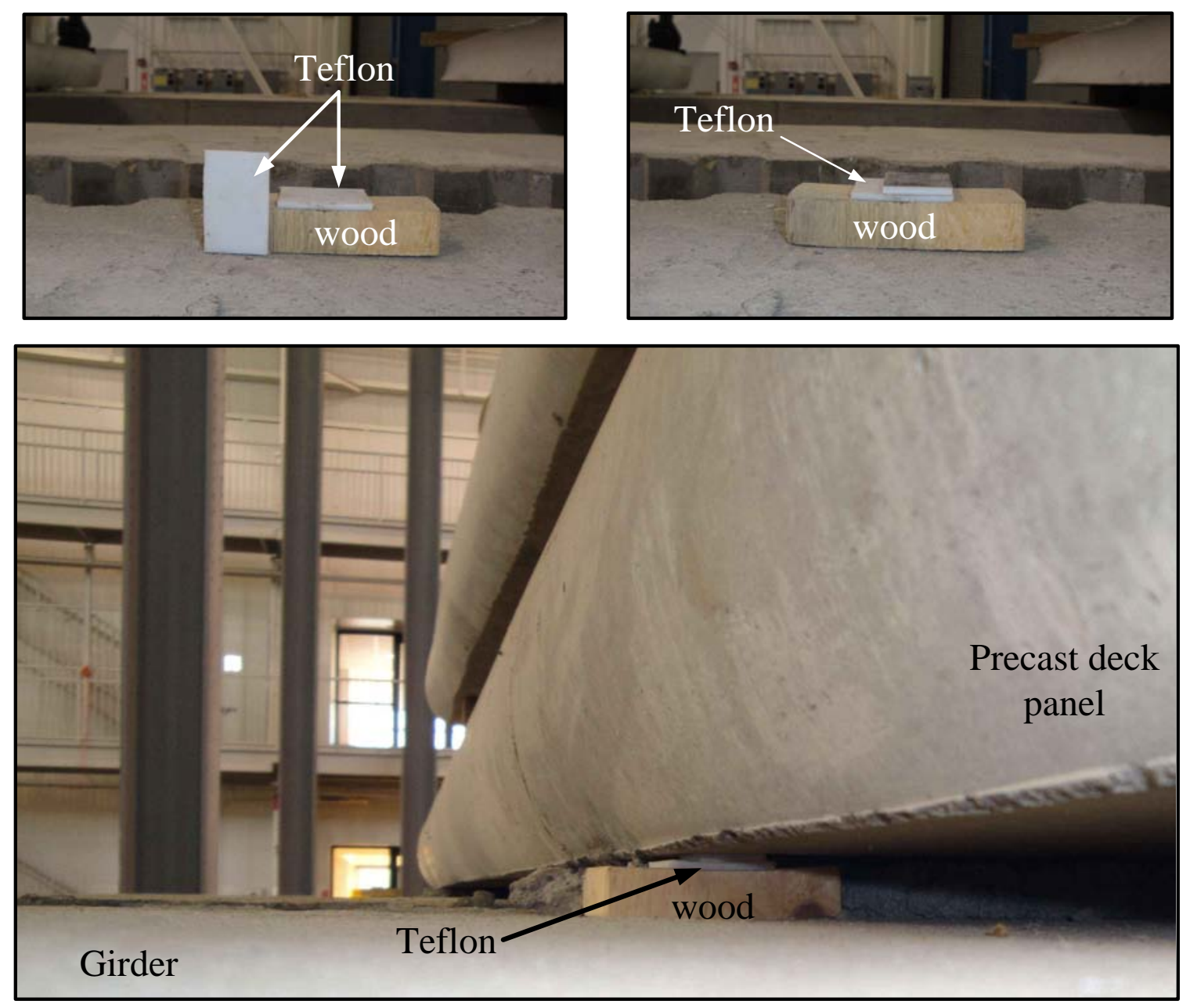

Figure 5.6: Teflon for panel placement 


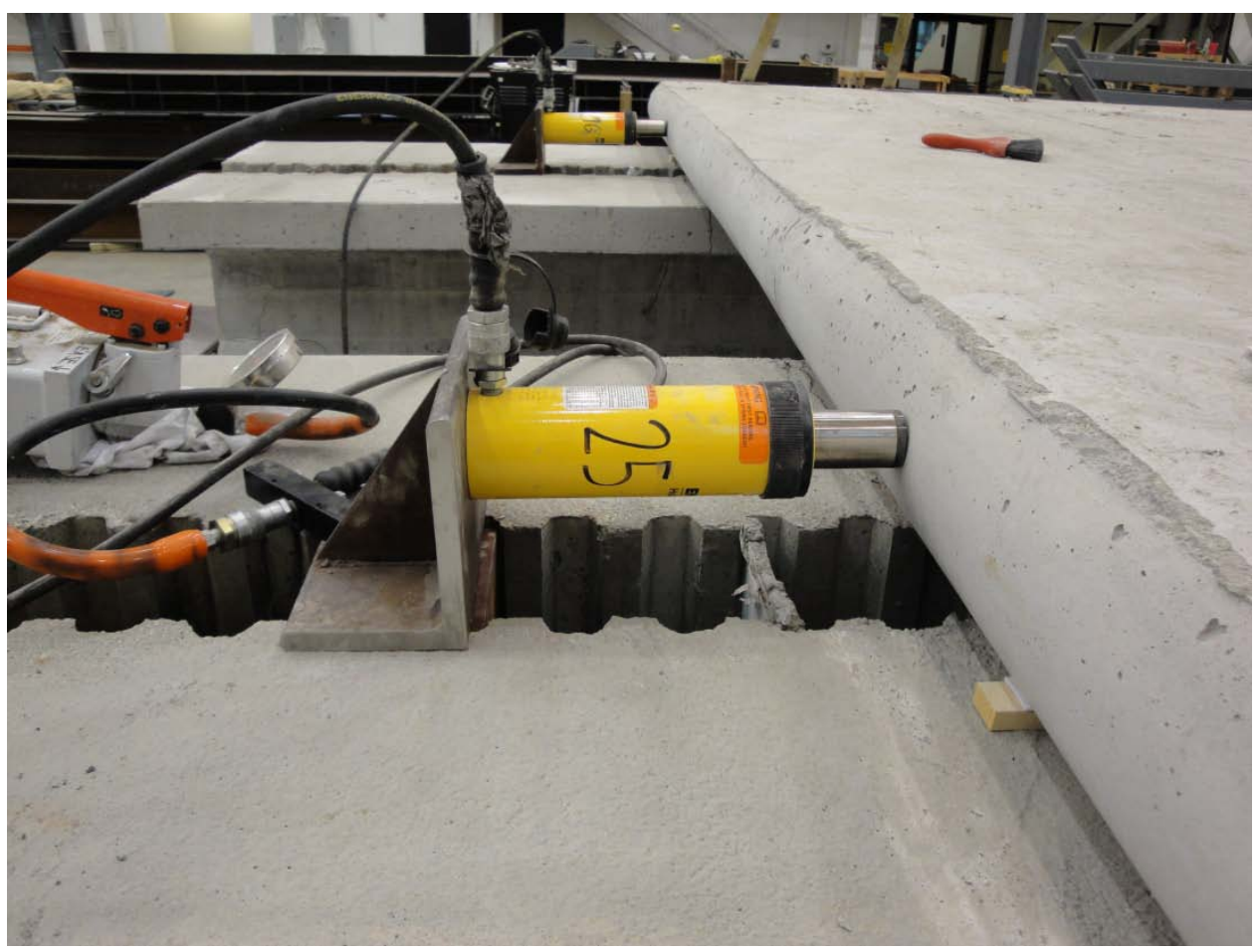

Figure 5.7: Hydraulic rams 


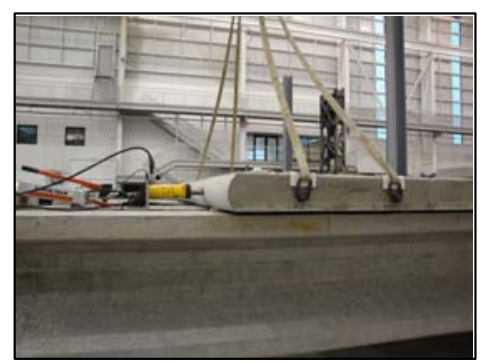

1. Initial fitting

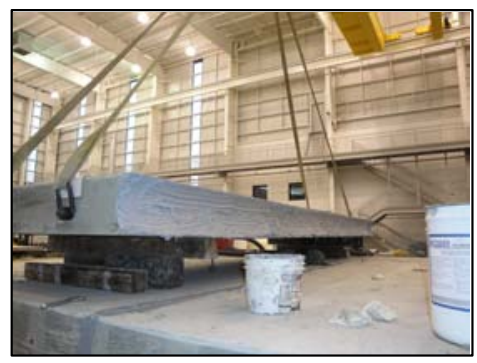

4. Apply SBA

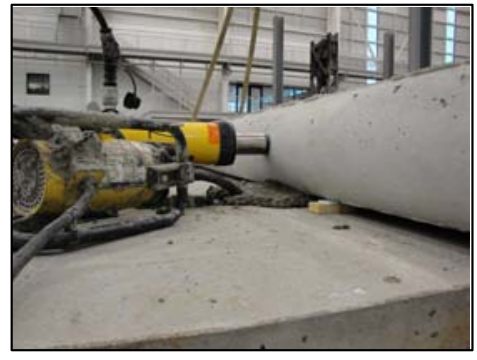

7. Vibrate trough concrete

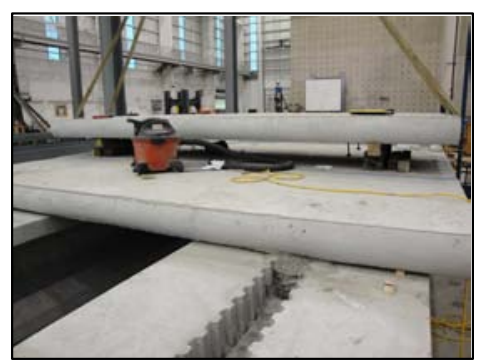

2. Panel staging

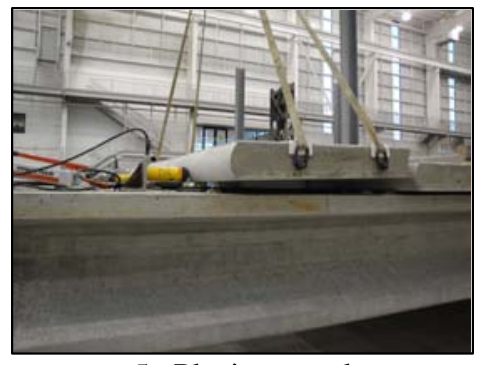

5. Placing panel

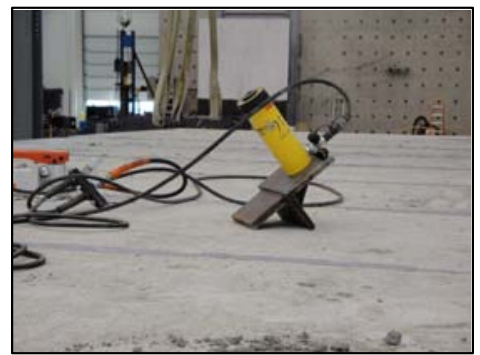

8. Remove hydraulic rams

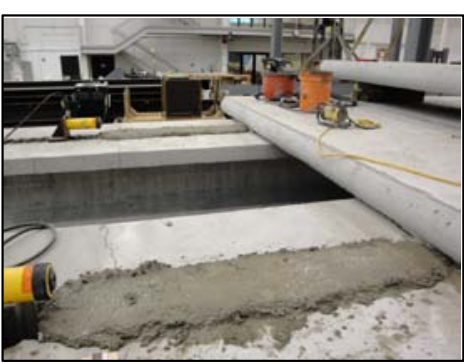

3. Fill trough

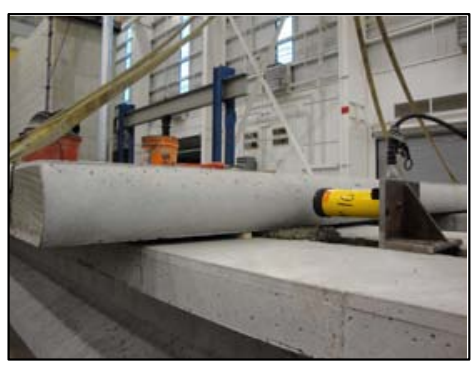

6. Press panels together

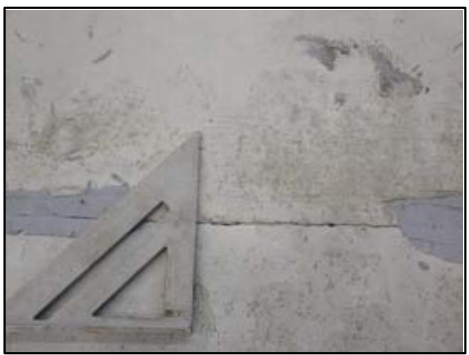

9. Transverse joint

Figure 5.8: Panel installation process

\subsection{Materials}

Standard strength testing was performed on the materials used in the construction of the specimens according to applicable ASTM standards. All testing was performed in the Bowen Laboratory at Purdue University.

\subsubsection{Concrete}

Concrete for the precast panels was obtained from a local ready-mix supplier. The concrete for the trough of the specimen was mixed in the Bowen Laboratory and that used for the girders was supplied by Prestress Services Industries LLC (PSI). Concrete mix proportions for the deck panels and trough are presented in Table 5.2. Concrete mix 
proportions provided by PSI are listed in Table 5.3. Compression tests were performed on $6 \times 12$ in. cylinders for the precast panels and $4 \times 8$ in. cylinders for the trough concrete. Both $6 \times 12$ in. and $4 \times 8$ in. cylinders were tested for the girder concrete, two $6 \times 12$ in. and one $4 \times 8$ in. for each compression test. The $6 \times 12$ in. cylinders were cast to have a point of comparison for the $4 \times 8$ in. cylinders, which were used for ease of transport from the casting site to the Bowen Lab. The strength-gain curves of the concrete compression tests are presented in Figure 5.9.

Table 5.2: Concrete mix proportions - Deck panels and Trough

\begin{tabular}{|c|c|c|c|c|}
\hline \multirow{2}{*}{ Material } & \multirow{2}{*}{ Unit } & \multicolumn{2}{|c|}{ Panels } & \multirow{2}{*}{$\frac{\text { Trough }}{\text { All }}$} \\
\hline & & Cast 1 & Cast 2 & \\
\hline Cement (Type I) & $\mathrm{lb} / \mathrm{cy}$ & 658 & 659 & 722 \\
\hline Pea-gravel & $\mathrm{lb} / \mathrm{cy}$ & --- & -- & 1588 \\
\hline \#8 stone & lb/cy & 1788 & 1784 & --- \\
\hline \#23 sand & lb/cy & 1244 & 1242 & --- \\
\hline Quikrete Medium Grade Sand & lb/cy & --- & --- & 1215 \\
\hline Fly-ash (Class C) & lb/cy & --- & --- & -- \\
\hline Super (Glenium ${ }^{\circledR} 3030$ NS) & oz/cy & 13.2 & 13.2 & --- \\
\hline Air (Micro Air ${ }^{\mathbb{B}}$ ) & oz/cy & 4.6 & 3.9 & -- \\
\hline Water & $\mathrm{lb} / \mathrm{cy}$ & 215 & 213 & 325 \\
\hline
\end{tabular}

Table 5.3: Concrete mix proportions - Girders

\begin{tabular}{|c|c|c|}
\hline Material & Unit & Girders \\
\hline Cement (Type III) & lb/cy & 752 \\
\hline Coarse Aggregate & lb/cy & 1717 \\
\hline Fine Aggregate & lb/cy & 1133 \\
\hline Super (Russtech 2000RM) & oz/100 wt. & 13 \\
\hline Reducer (Russtech LC-400R) & oz/100 wt. & 4 \\
\hline Air (Russtech RSA-10) & oz/cy & 5 \\
\hline Water & $\mathrm{lb} / \mathrm{cy}$ & 264 \\
\hline
\end{tabular}




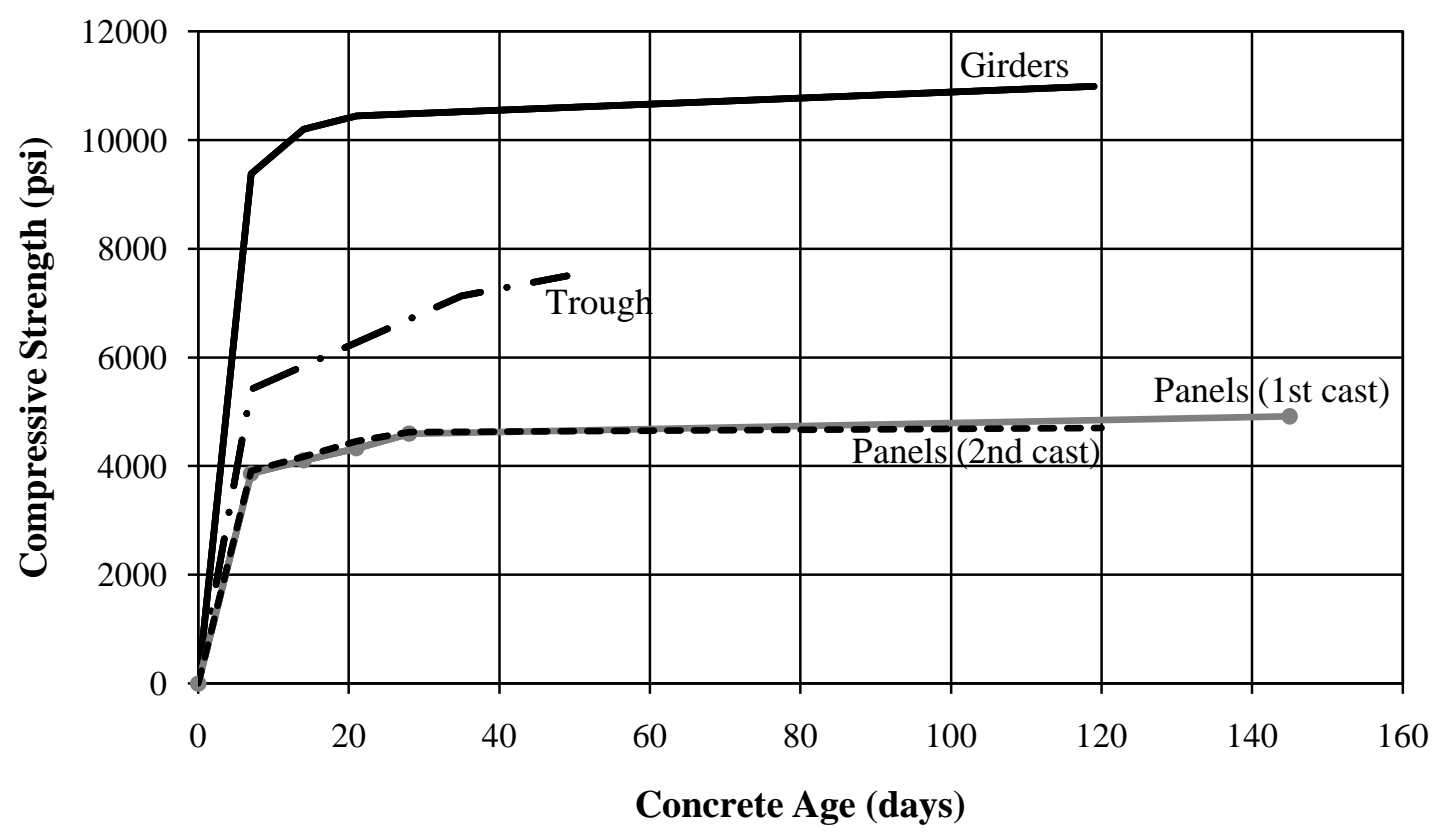

Figure 5.9: Concrete compressive strength gain

\subsubsection{Reinforcing Steel}

The mild steel used in the girder sections and precast panels was ASTM A615 Grade 60. The prestressing steel was ASTM A416 Grade 270 seven-wire strand. The seven-wire strand and mild steel used in the girder sections and precast panels was not tested because it was not a primary variable. However, certified mill test reports were provided for the seven-wire strand and mild steel used in the girder sections. A summary of those reports is presented in Table 5.4.

\subsubsection{Shear Studs}

Standard tension testing outlined in ASTM A370 was performed on the mild steel used for the shear studs. A total of two lots of rebar were used as shear studs in this test series. The stress-strain curves for each lot are presented in Figure 5.10, where the lots are identified by stud size. A summary of the yield and ultimate stress is presented in Table 5.5. 
Table 5.4: Summary of certified mill tests

\begin{tabular}{|c|c|c|c|}
\hline Steel & $\mathbf{f}_{\mathbf{y}}$ (ksi) & $\mathbf{f}_{\mathbf{u}}$ (ksi) & Elongation (\%) \\
\hline $\begin{array}{c}\text { Seven-wire strand } \\
\text { (1/2 in. special) }\end{array}$ & 252 & 275 & 5.0 \\
\hline \#3 bar & 69 & 109 & 11.0 \\
\hline \#4 bar & 69 & 102 & 13.8 \\
\hline
\end{tabular}

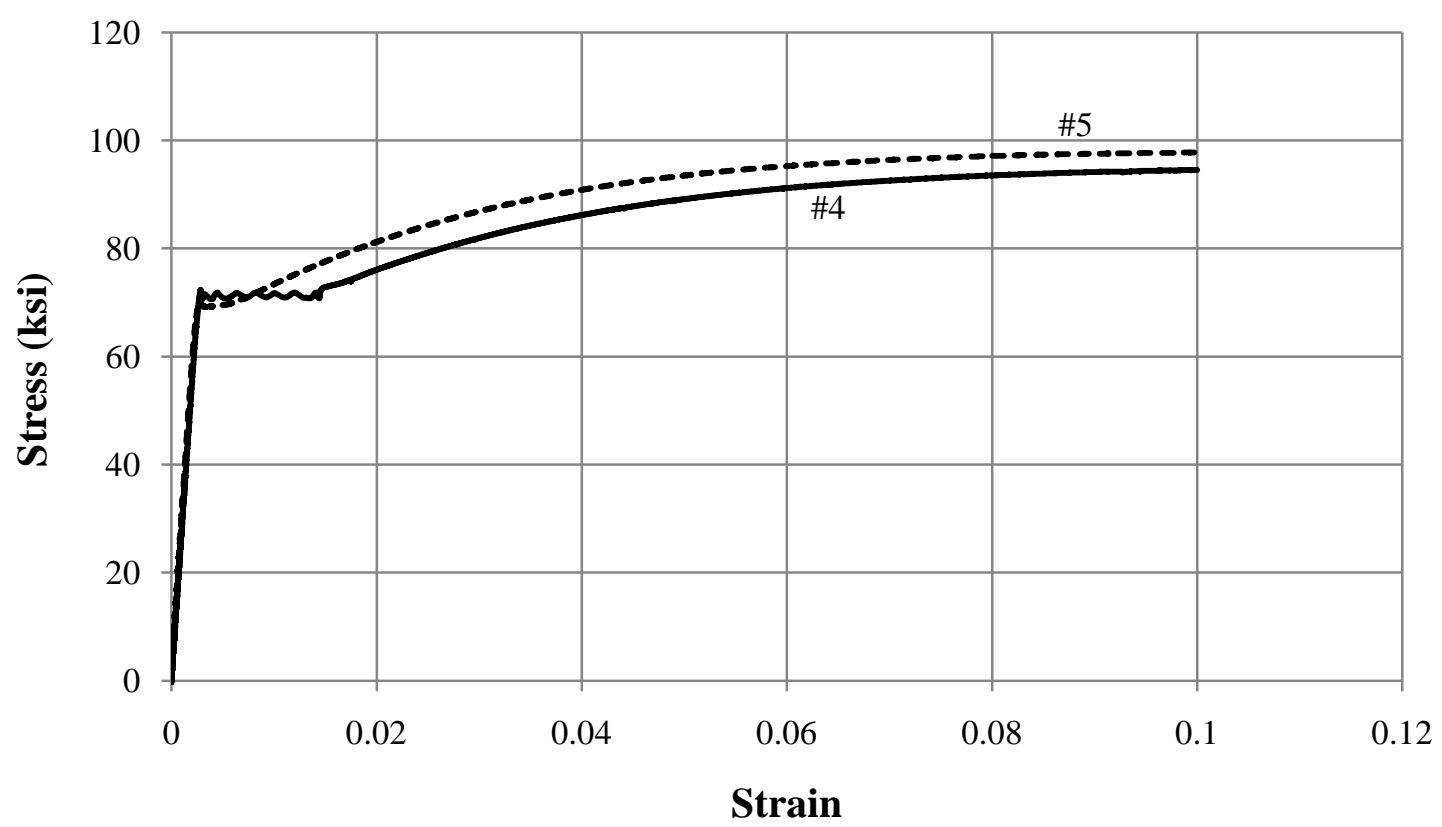

Figure 5.10: Shear stud stress-strain relationship

Table 5.5: Summary of results from tension tests

\begin{tabular}{|c|c|c|}
\hline Specimen & $\mathbf{f}_{\mathbf{y}}(\mathbf{k s i})$ & $\mathbf{f}_{\mathbf{u}}(\mathbf{k s i})$ \\
\hline$\# 4$ & 70 & 95 \\
\hline$\# 5$ & 67 & 97 \\
\hline
\end{tabular}

\subsubsection{Segmental Bridge Adhesive}

The SBA used for this phase of testing was Unitex Pro-Poxy SBA. Standard testing was not performed on the SBA because those results are provided by the 
manufacturer. However, the performance of the product was evaluated in a previous phase of testing, which is presented in Chapter 4 .

\subsection{Test Setup}

This phase of testing had two test setups. The first setup was designed for a cyclic load test of the new panel-to-panel joint, as presented in Figure 5.11. Upon completion of the test, the specimen was cut in two along its length resulting in two single girder specimens, as illustrated in Figure 5.12 and Figure 5.13. The second test setup was designed for a shear test of each girder specimen. Both test setups consisted of a loading system anchored to the strong floor and a support spaced $1 \mathrm{ft}$ from the end of each girder. Each girder had one support that was a roller and the other a pin, as illustrated in Figure 5.14, and the specimen was subjected to three point loading. 

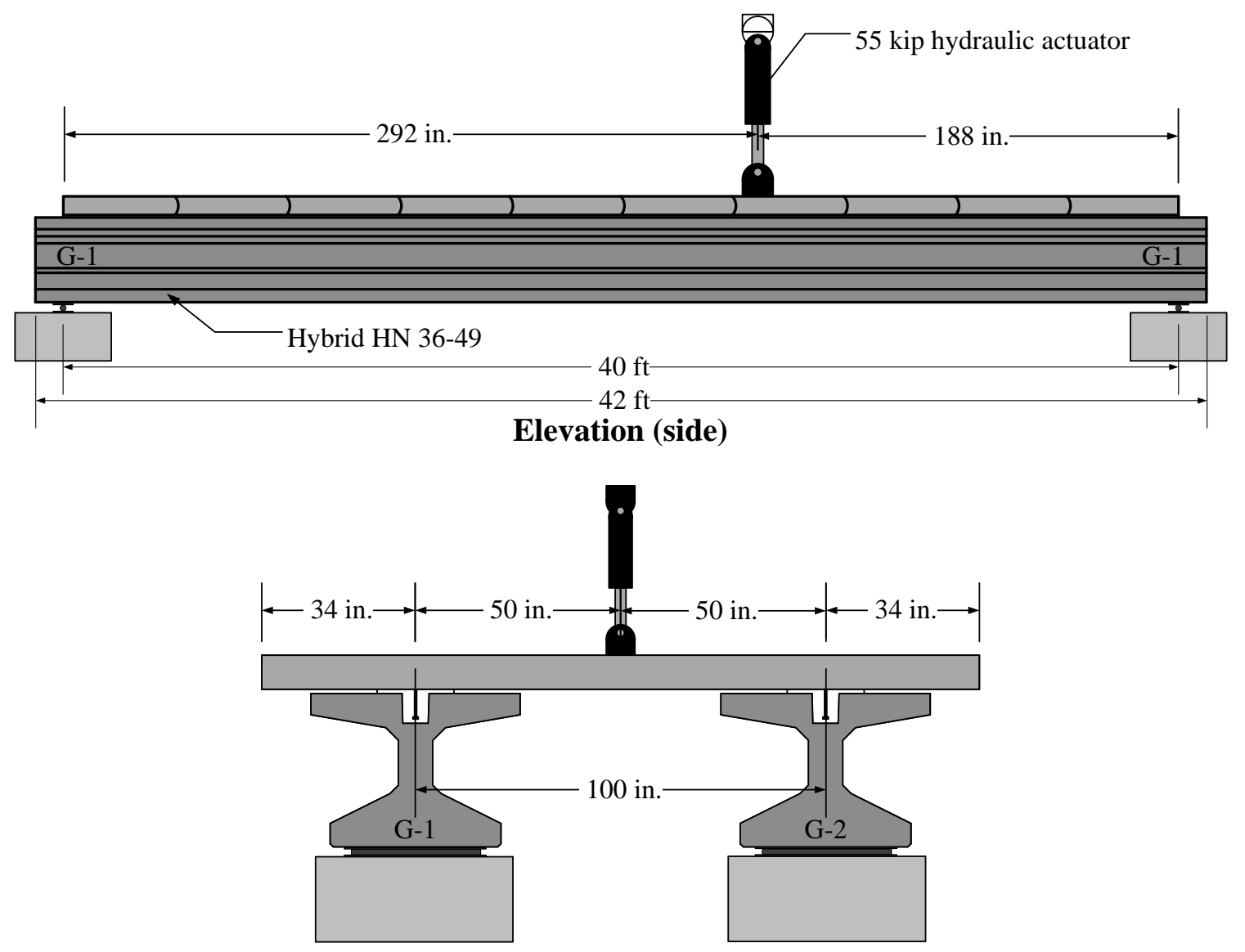

Elevation (front)

Figure 5.11: Cyclic load test setup 

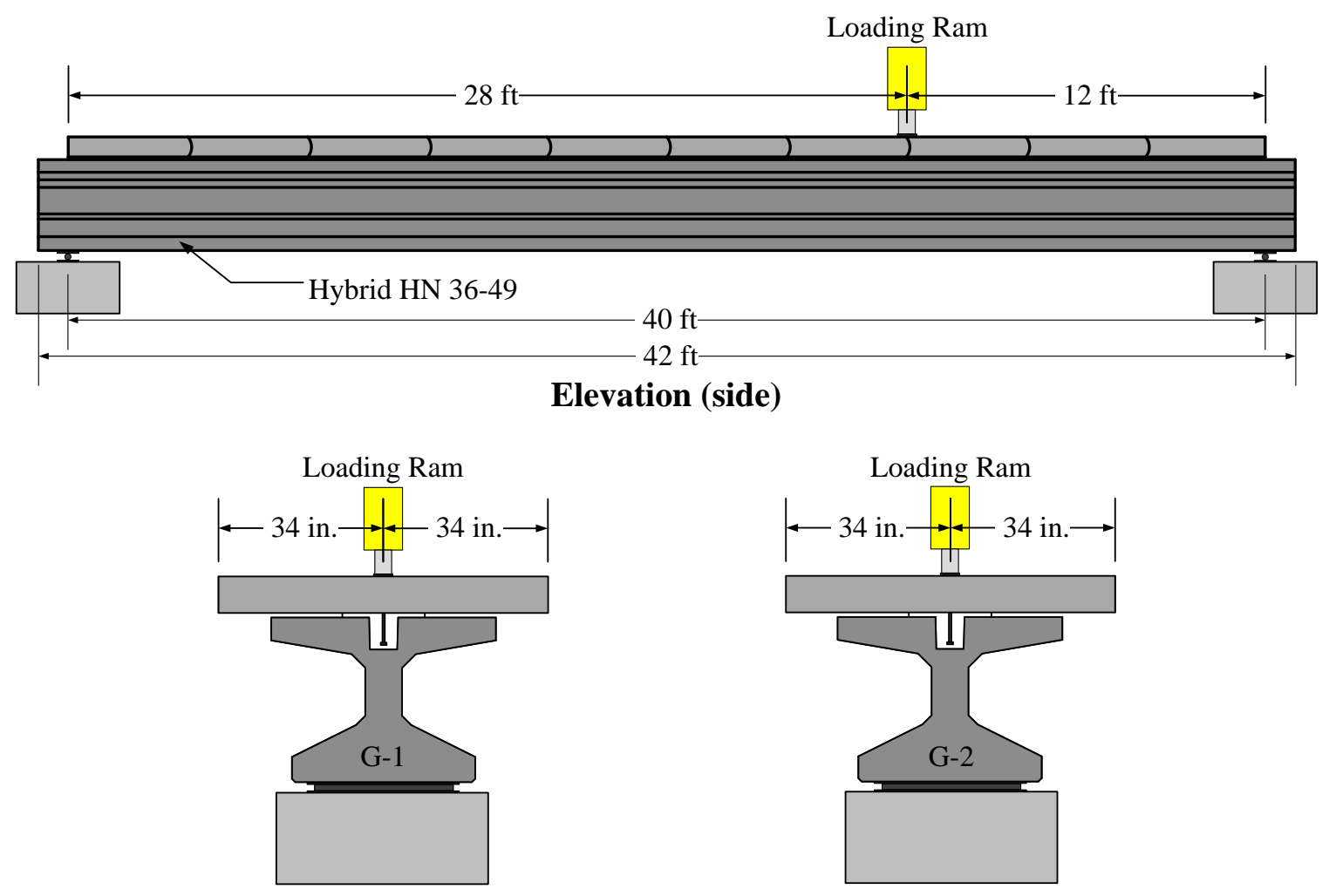

Elevation (front)

Figure 5.12: Shear test setup

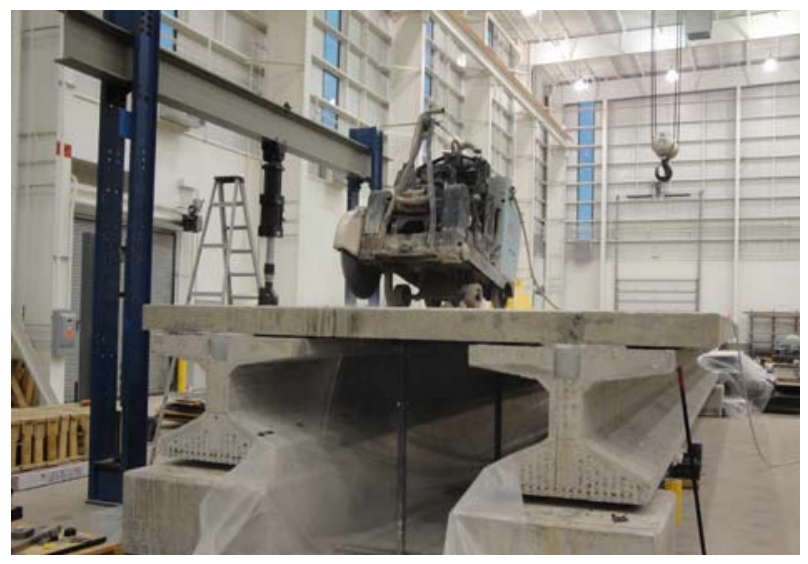

Cutting cyclic load specimen

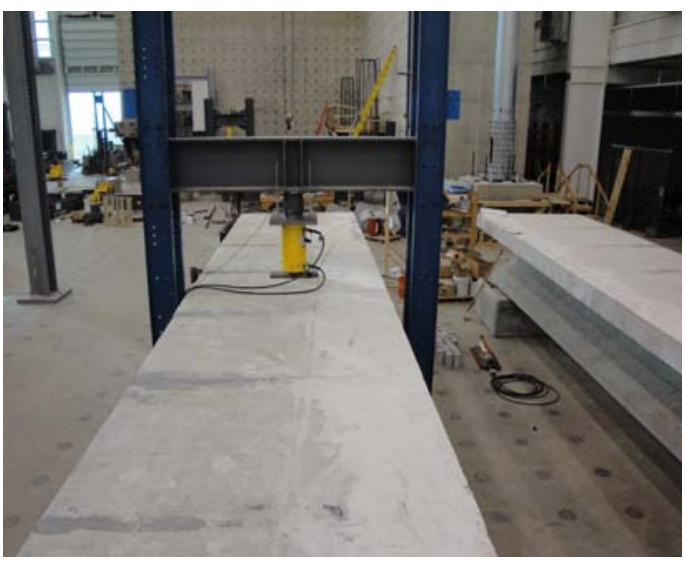

Girder Specimens G-1 and G-2

Figure 5.13: Cyclic load specimen to Specimens G-1 and G-2 


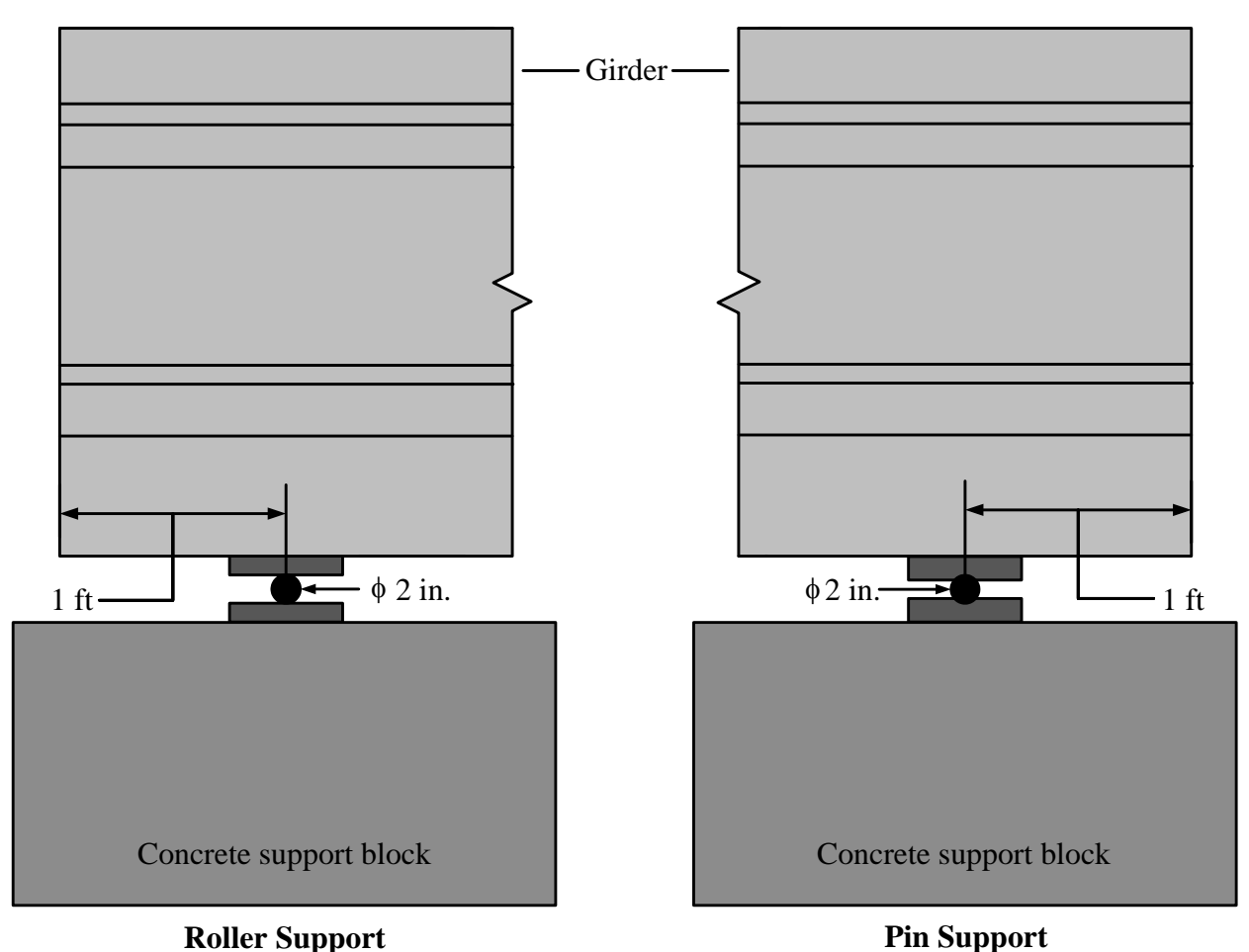

Figure 5.14: Roller and pin supports

\subsubsection{Cyclic Load Test Setup}

The specimen was loaded approximately $16 \mathrm{ft}$ from the support (Figure 5.11). This load location was chosen for the cyclic load test because it was the joint closest to midspan that was formed by two panels that were cast together. The joint at midspan was formed by panels made in two separate castings resulting in the joint being misaligned. The misalignment was due to the flexible PVC pipe used to form the radius. Because the midspan joint was not representative of the new joint detail, the next closest joint was chosen. Imperfections in joint geometry would be resolved if steel forms were used as is typical in standard precasting operations.

\subsubsection{Shear Test Setup}

The single girder specimens were loaded $12 \mathrm{ft}$ from the support. A reduced shear span on one side of the girder was used to subject the shear studs to higher shears and 
provide additional information regarding the behavior of both \#4 and \#5 studs. The south end of Specimen G-1and north end of Specimen G-2 was loaded because those were the half spans with the lowest interface shear strength.

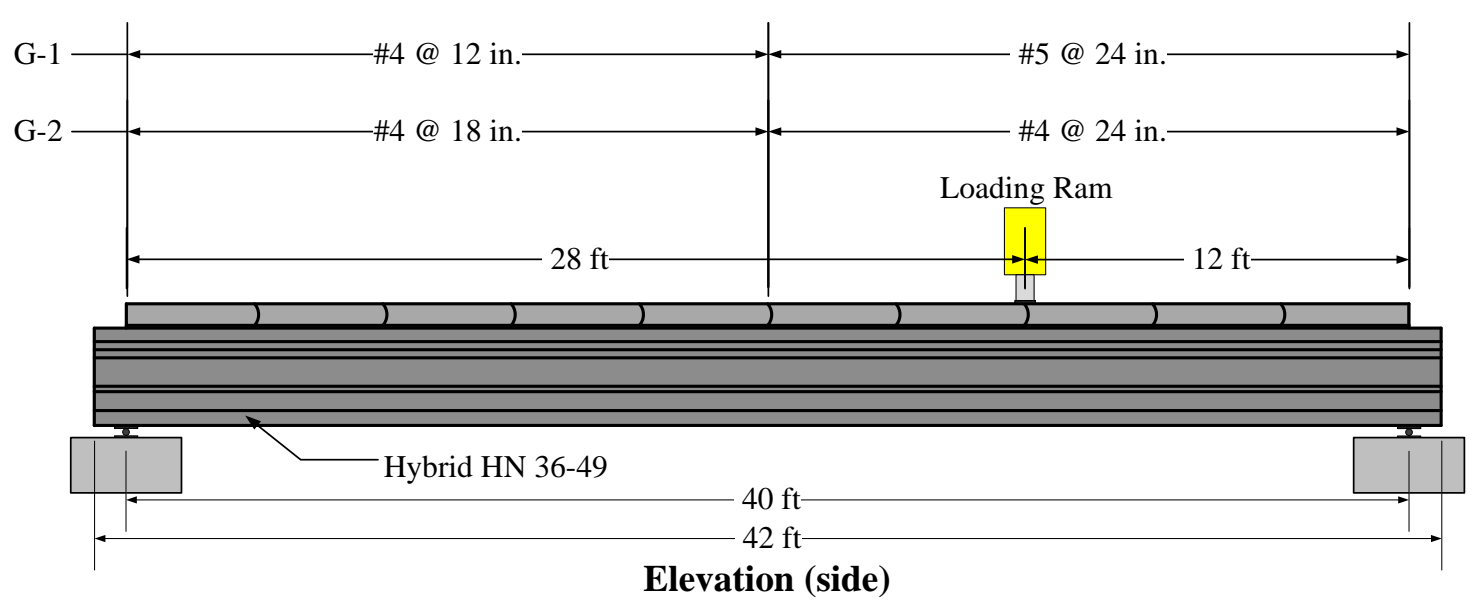

Figure 5.15: Stud size and spacing for ultimate load test

\subsubsection{Instrumentation}

Vertical displacement was measured from the girder bottom flange relative to the strong floor using 25 in. linear potentiometers. Horizontal displacement of the panels was measured relative to the top flange of the girder using $2 \mathrm{in}$. linear potentiometers. The 2 in. potentiometers were mounted to the top flange of the girder, and measurements were referenced to angle brackets mounted to the bottom of the panels. The hydraulic actuator had a 100 kip load cell mounted to the piston which was used to measure loads during the cyclic load test. For the shear test, loads were measured using a 300 kip load cell mounted between the ram and load frame. A total of 8 strain gauges were placed on the shear studs prior to specimen construction. All strain gauges were aligned along the longitudinal axis of the reinforcement to which they were attached. The locations of instrumentation used in the cyclic load test are presented in Figure 5.16. The location of instrumentation for the shear test of Specimens G-1 and G-2 differed and are presented in Figure 5.17. Potentiometers measuring horizontal slip were labeled sequentially from 1 to 8, as illustrated in Figure 5.17. 


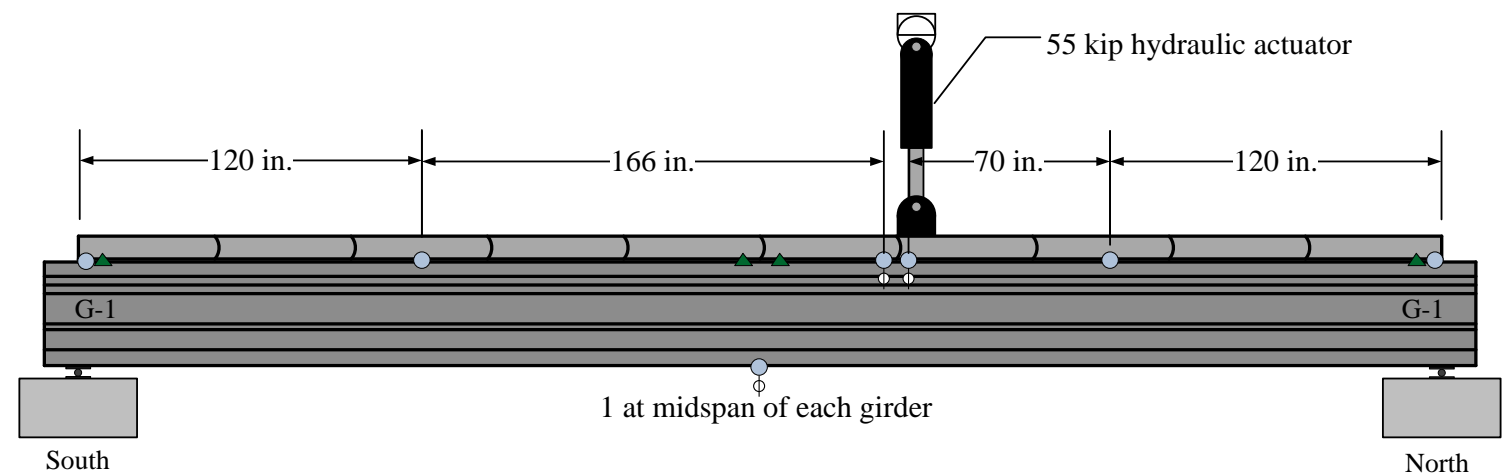

- Linear Potentiometer (12)

A - Strain gauge (8)

Elevation (side)

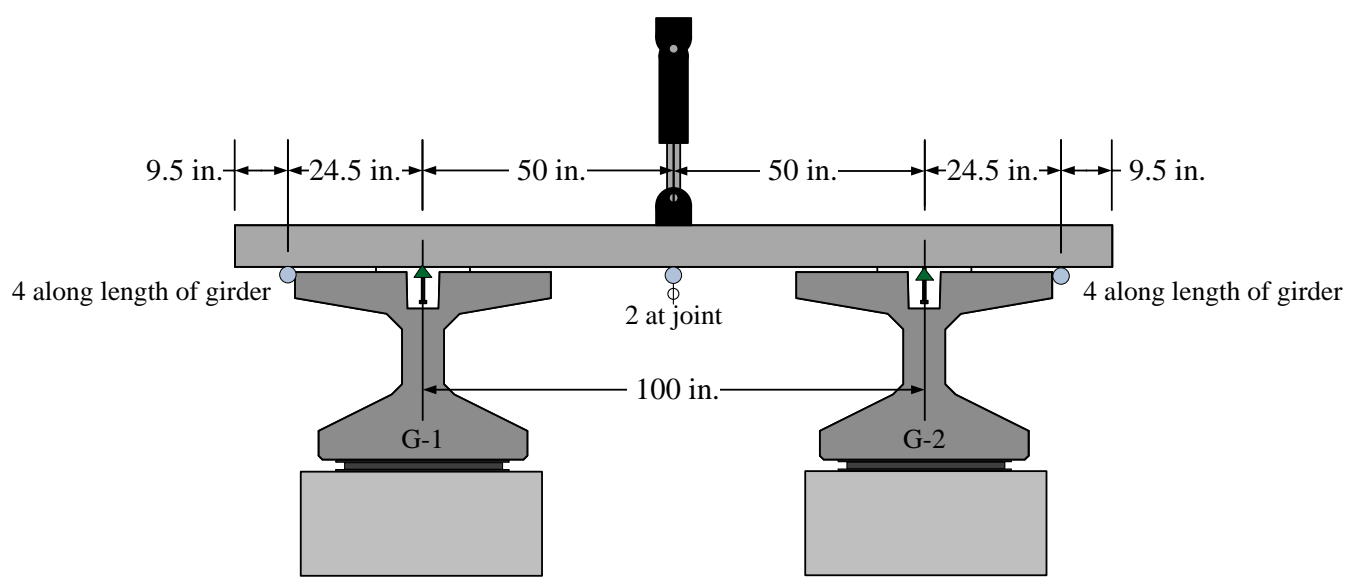

Elevation (front)

Figure 5.16: Instrumentation for cyclic load test

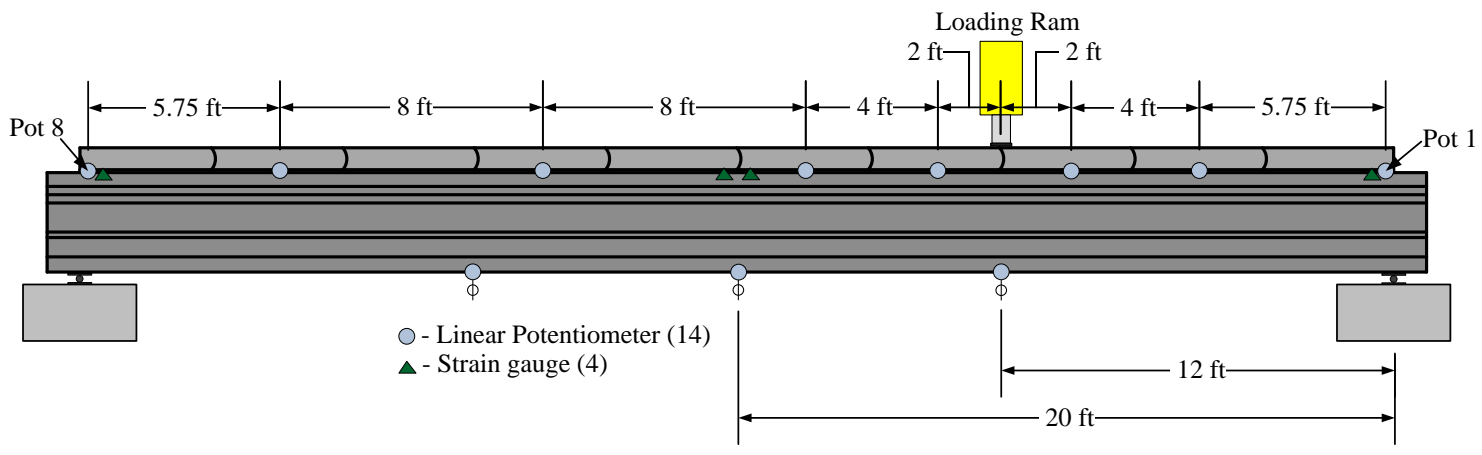

Figure 5.17: Instrumentation for shear test 


\subsubsection{Test protocol}

As previously discussed, the specimen was subjected to a cyclic load test of the new panel-to-panel joint. Upon completion of the cyclic load test, the specimen was cut in two, resulting in two single girder specimens. The single girder specimens were subjected to a shear test. The protocols for this phase of testing are discussed in the following subsections.

\subsubsection{Cyclic Load Test}

The specimen was loaded statically up to an AASHTO (2007) service wheel load of approximately 21.3 kips to obtain a baseline of behavior for comparison after cyclic loading. The wheel load was determined from the HS20 design truck wheel load (16 kips) given in AASHTO increased by an impact factor of 33\%. Following measurements from the static loading, it was removed, and the specimen was cyclically loaded using a 55 kip hydraulic actuator. Initially, loading was applied at a lower load and rate to monitor the test setup. Following the initial cyclic loading, load was applied at a frequency of $2 \mathrm{~Hz}$ in a sinusoidal pattern from 1 to 24 kips for two million cycles. Once two million cycles was completed, the specimen was loaded statically to approximately 21.3 kips to compare the behavior of the specimen from before and after the cyclic load test. In addition, the specimen was statically loaded to approximately 37.2 kips, which is the AASHTO ultimate wheel load. The number of cycles, associated frequency, load levels, and data collection rates are presented in Table 5.6. All instrumentation was monitored throughout testing and recorded at the rate presented in Table 5.6. 
Table 5.6: Test rates and loads

\begin{tabular}{|c|c|c|c|c|}
\hline Run & Cycles & $\begin{array}{c}\text { Frequency } \\
(\mathbf{H z})\end{array}$ & $\begin{array}{c}\text { Load Range } \\
\text { (kips) }\end{array}$ & $\begin{array}{c}\text { Data Collection } \\
\text { (scans:duration:increment) }\end{array}$ \\
\hline Static & --- & -- & $0-22$ & 5: continuous \\
\hline 1 & 18,000 & 0.5 & \multirow{5}{*}{$1-16$} & \multirow{2}{*}{ 10: 2 sec: $1 \mathrm{~min}$} \\
\hline 2 & 7,200 & 1 & & \\
\hline 3 & 10,800 & 1.5 & & \multirow{3}{*}{ 10: $1 \mathrm{sec}: 1 \mathrm{~min}$} \\
\hline 4 & 7,200 & \multirow{2}{*}{2} & & \\
\hline 5 & 21,600 & & & \\
\hline 6 & 115,200 & \multirow{3}{*}{2} & \multirow{3}{*}{$1-24$} & \multirow{2}{*}{ 10: 1 sec: 2 min } \\
\hline 7 & 7,200 & & & \\
\hline 8 & $1,877,600$ & & & 10: 1 sec: 4 min \\
\hline Static & --- & --- & $0-22$ & 5: continuous \\
\hline Static & --- & --- & $0-38$ & 5: continuous \\
\hline
\end{tabular}

\subsubsection{Shear Test}

The specimens were loaded using a 400 kip hydraulic ram until failure or excessive deflection occurred. Load was applied statically in specified load increments using a hydraulic pump. All instrumentation was monitored throughout testing and recorded at one second increments. In addition, cracks were monitored and marked at each load increment. 


\subsection{Test Results}

The following subsections present the results obtained from the test procedures described in Section 5.5. A summary of the results is provided for each specimen.

\subsubsection{Cyclic Load Test}

The load-deflection response for the specimen under the static loading of an AASHTO service wheel load before the cyclic load test is presented in Figure 5.18. As evident, the load-deflection response of the adjacent panels differed by approximately 0.004 in. at a load of 21.5 kips. This difference in response was due to the location of the potentiometers along the specimen length. The potentiometer north of the transverse joint being loaded was 2 in. north of the joint, positioning it under the actuator, while the potentiometer south of the joint was 2 in. south of the edge of the loading location. The load-deflection response of the girders was essentially identical.

The static service wheel load was applied to the specimen again following the completion of cyclic loading. The load-deflection response of the specimen is presented in Figure 5.19. The load-deflection response of the girders and panels differed by 0.001 in. and 0.004 in., respectively, at a load of 21.5 kips.

Following the second static service load, an ultimate wheel load was applied to the specimen. The load-deflection response is shown in Figure 5.20. The load-deflection response of the girders and panels differed by 0.002 in. and 0.007 in., respectively, at a load of 38.5 kips. It should be noted that the resolution of the instrumentation measuring deflection was \pm 0.001 in.

In addition to load and deflection, horizontal displacement at the girder-panel interface and shear stud strains were measured. No horizontal displacement was measured during the three static tests, and measured shear stud strains did not exceed $100 \mu \varepsilon$ ( $2.9 \mathrm{ksi})$. No cracking of the joint was observed during cyclic loading or static 
AASHTO wheel loading. In addition, there was no difference in joint appearance from before and after cyclic loading.

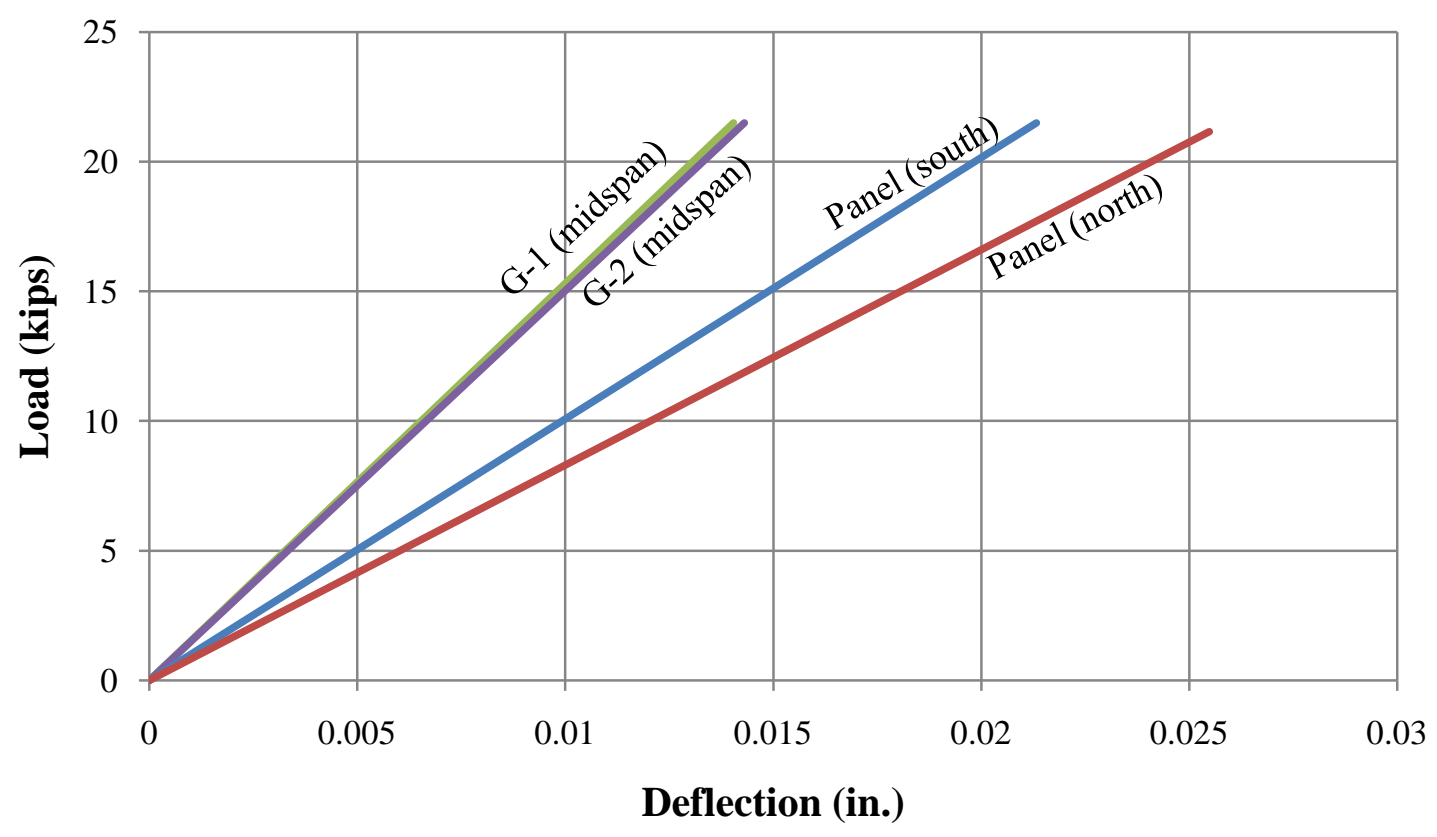

Figure 5.18: Static service wheel load-deflection response before cyclic loading

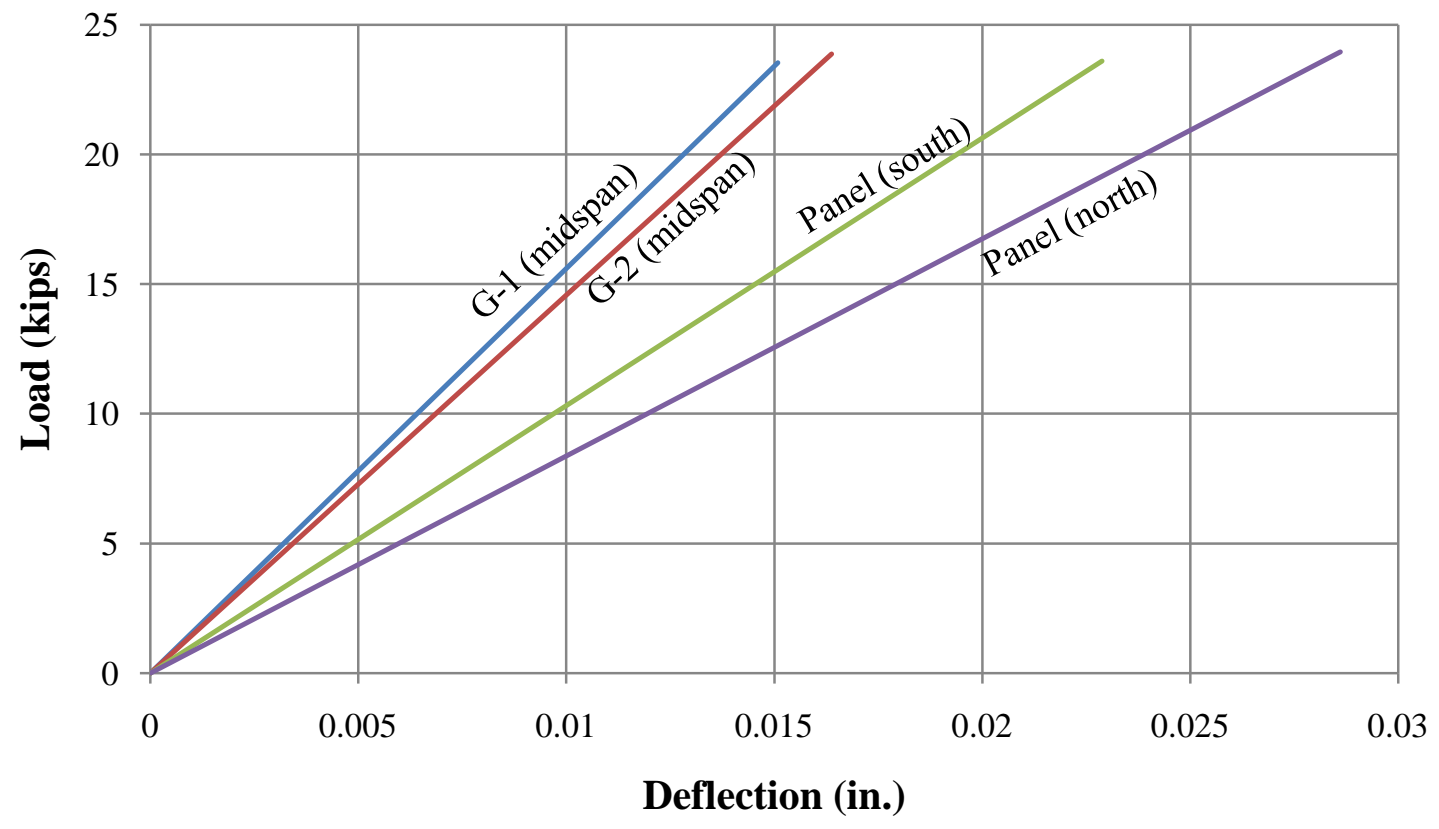

Figure 5.19: Static service wheel load-deflection response after cyclic loading 


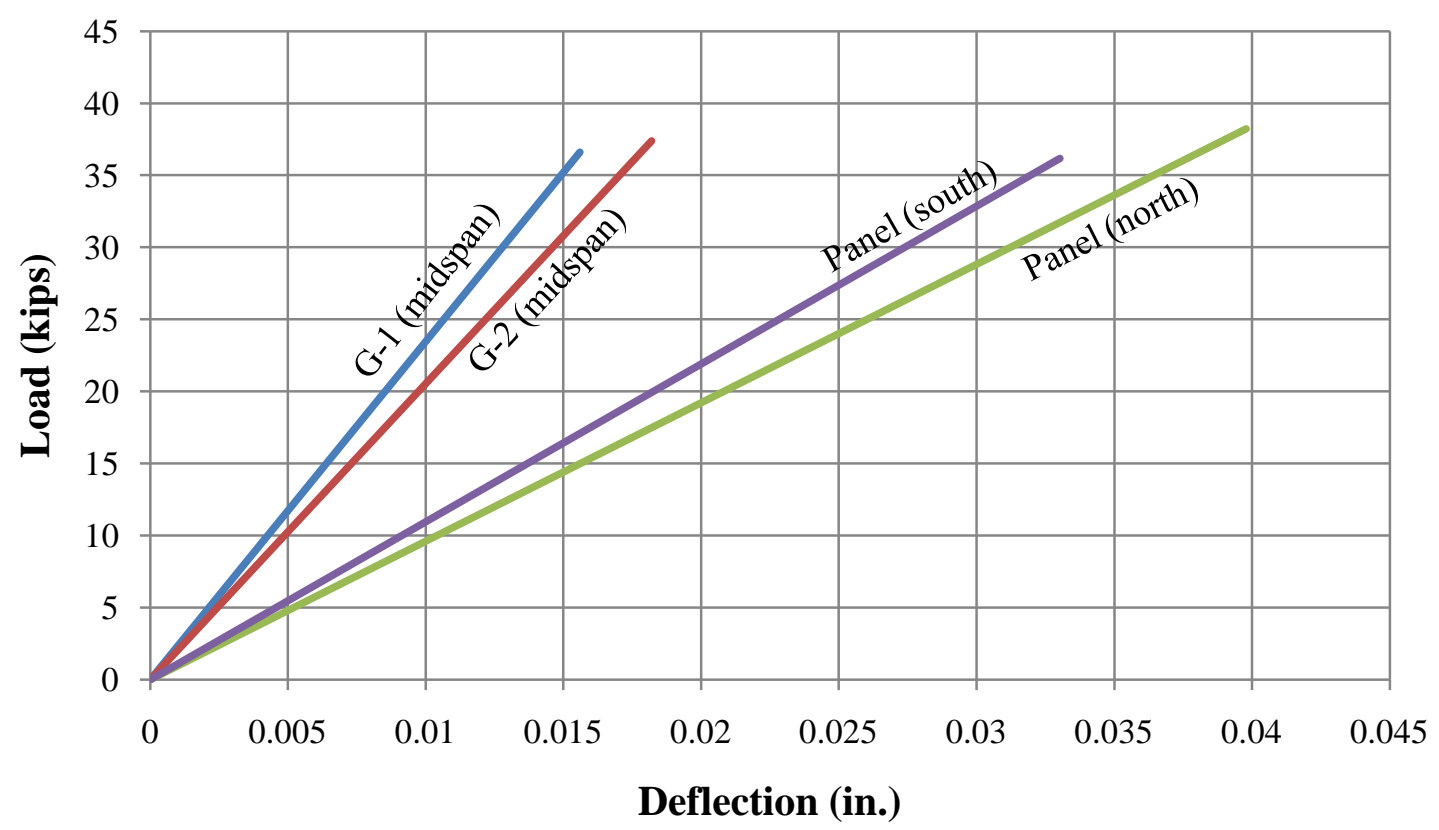

Figure 5.20: Static ultimate wheel load-deflection response

\subsubsection{Shear Test}

As previously discussed, the specimen was separated into two individual girders once the cyclic load test was complete. The south end of Specimen G-1and north end of Specimen G-2 was loaded $12 \mathrm{ft}$ from the support because those were the half spans with the lowest interface shear strength. Depending on the failure mode, it was considered that a second test of the opposite side of the girder may be possible to obtain additional information. In both tests, flexural failure of the girder occurred; consequently, testing the second half using the same loading setup was not possible.

\subsubsection{Specimen G-1}

The load-deflection response for Specimen G-1 is presented in Figure 5.21. There is no clear indication of bond failure from the load-deflection response. However, bond failure is evident in considering the horizontal slip on both the north and south sides of midspan (Figure 5.22 and Figure 5.23). In addition, bond failure on the north side of 
midspan is evident in considering the measured shear stud strains (Figure 5.24). A maximum measured slip of 0.72 in. occurred at the south slip gauge at a load of 255 kips. The higher slips on the south side are consistent in that this side was subjected to higher shear (70\% of applied load). Measured strains (Figure 5.24) indicate that the shear studs on the north side yielded prior to reaching the peak load. No strain measurements were obtained from the south side of midspan because the gauges were no longer functioning after construction of the specimen. Although there was no measured strain data from the south end, the measured slip indicates that the shear studs yielded because the slip on the south end was larger than that on the north end.

Final failure occurred in flexure due to crushing of the compression zone of the girder immediately followed by fracture of the prestressing strand (Figure 5.25). Flexural cracks were present at the bottom of the precast panel, indicating the girder and deck were not acting fully composite at this stage. Shear failure of shear studs was not observed.

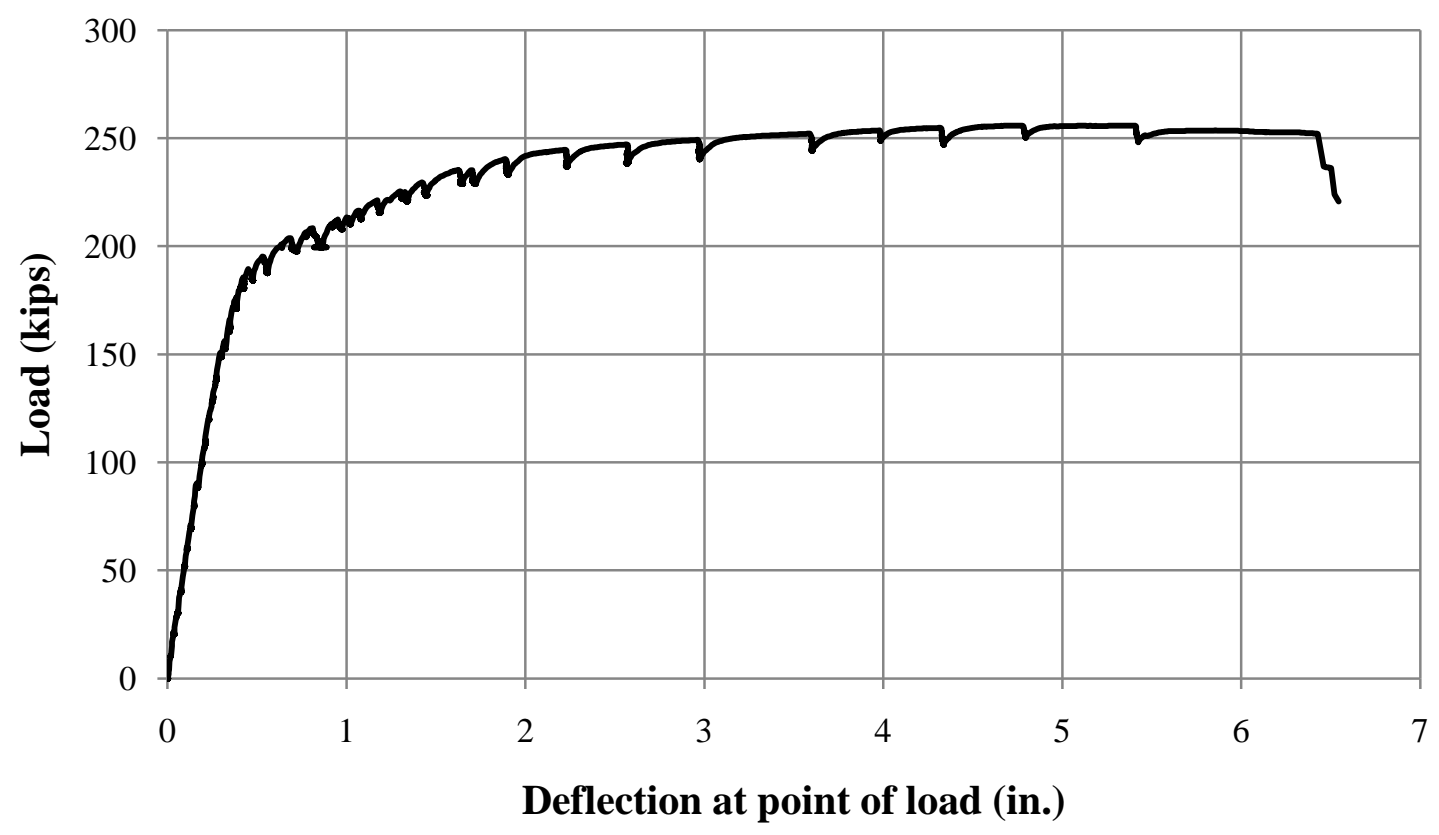

Figure 5.21: Load vs deflection - Specimen G-1 


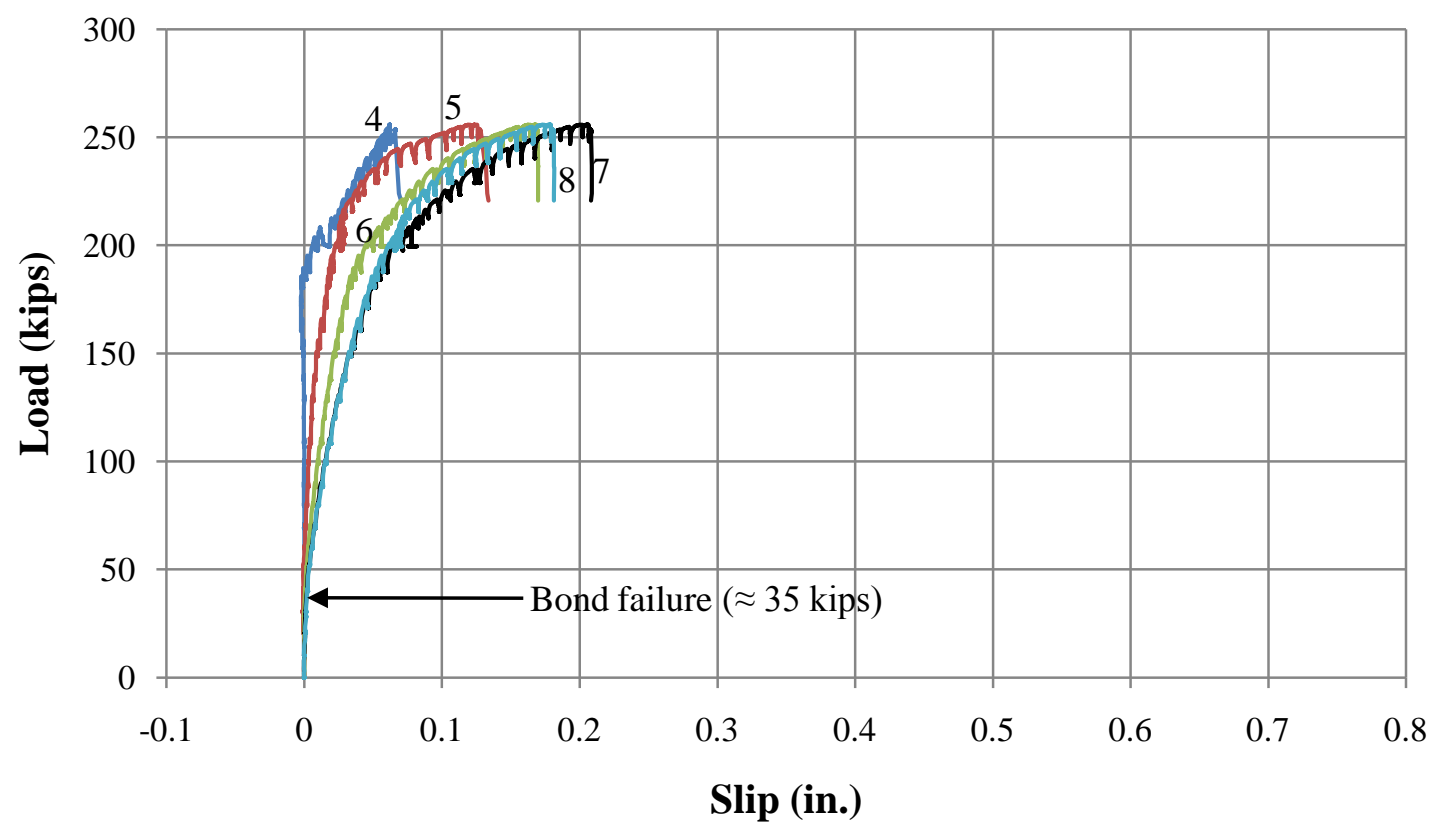

Figure 5.22: North horizontal slip - Specimen G-1

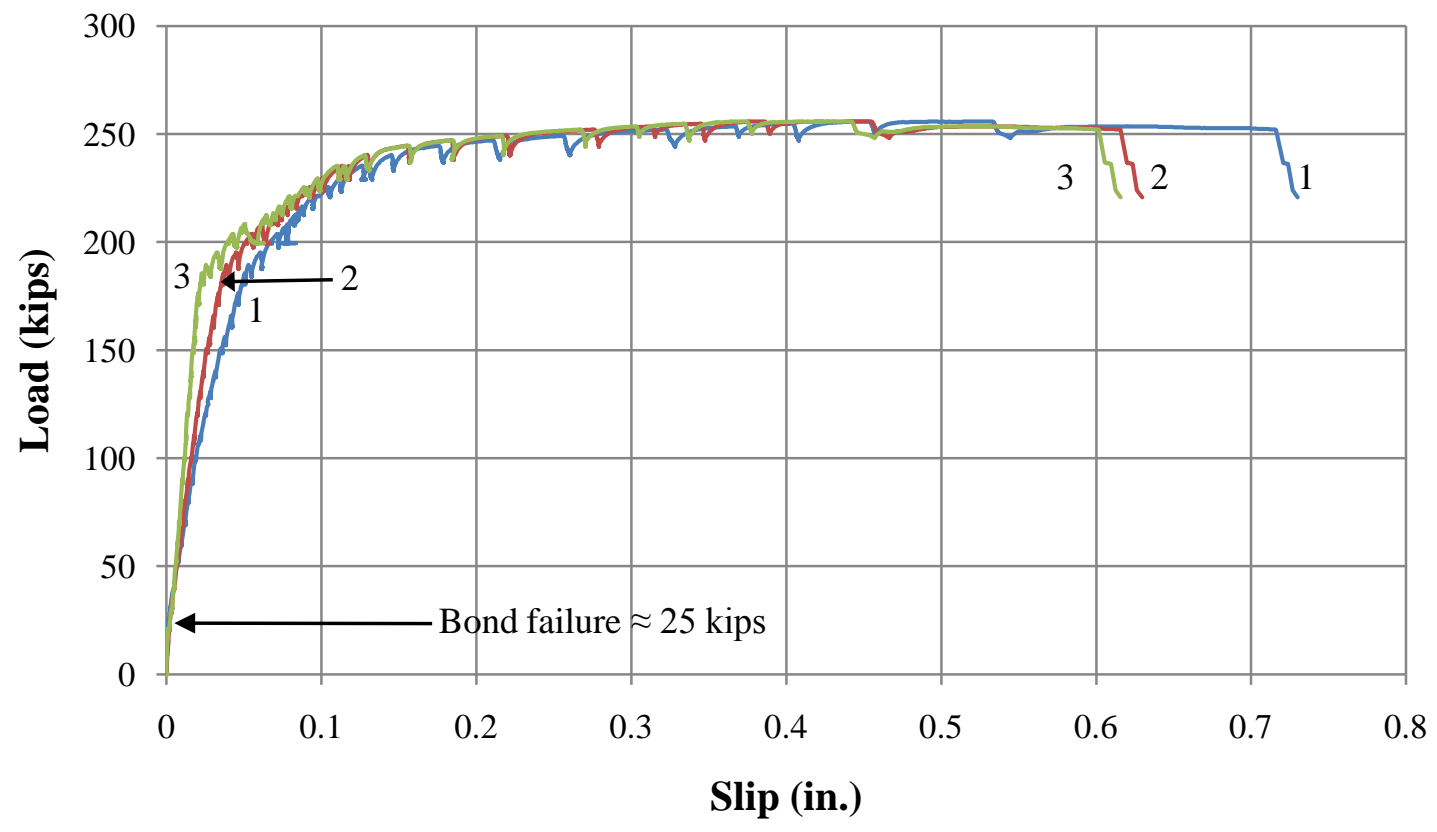

Figure 5.23: South horizontal slip - Specimen G-1 


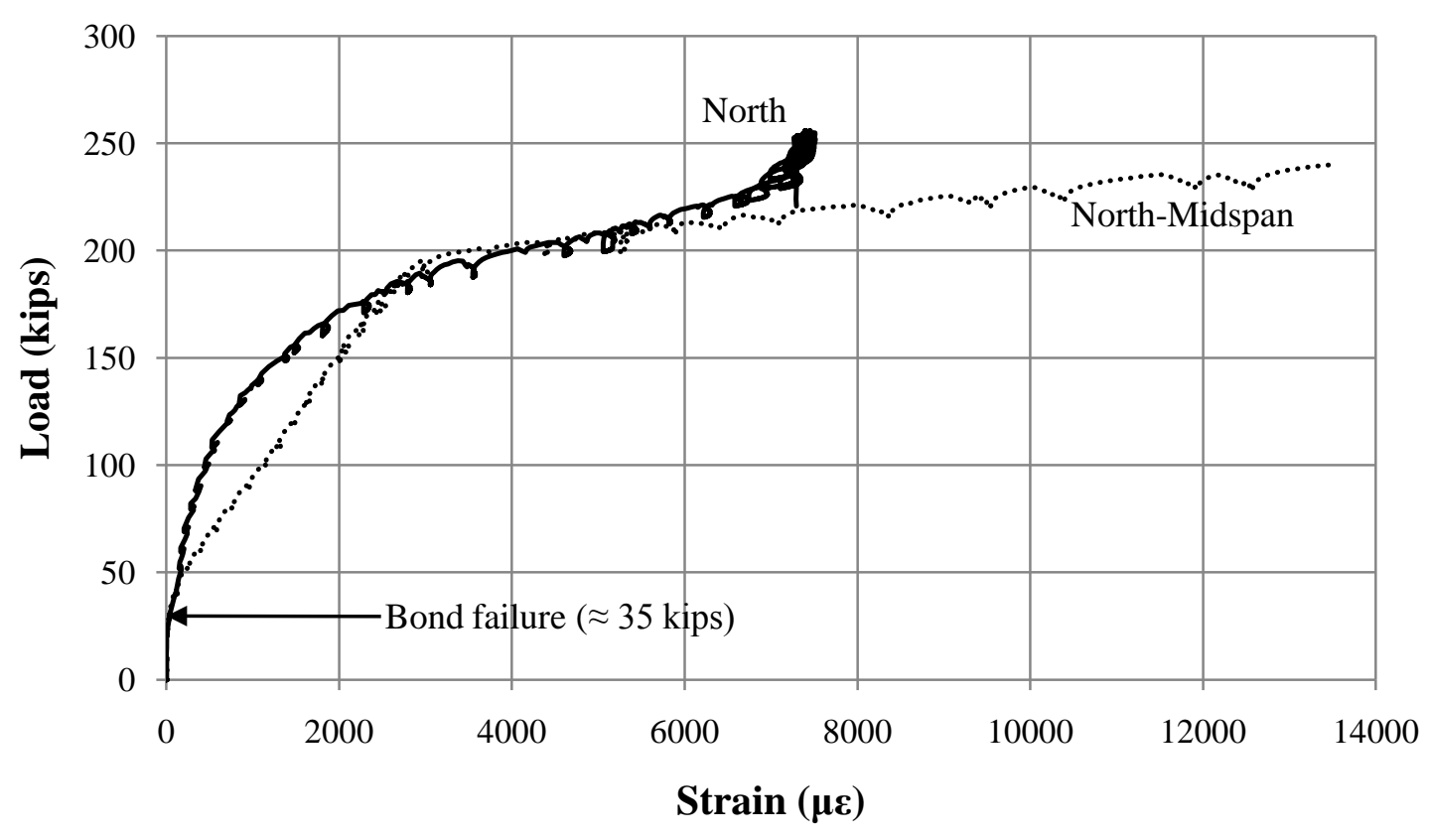

Figure 5.24: Measured strain in shear studs - Specimen G-1

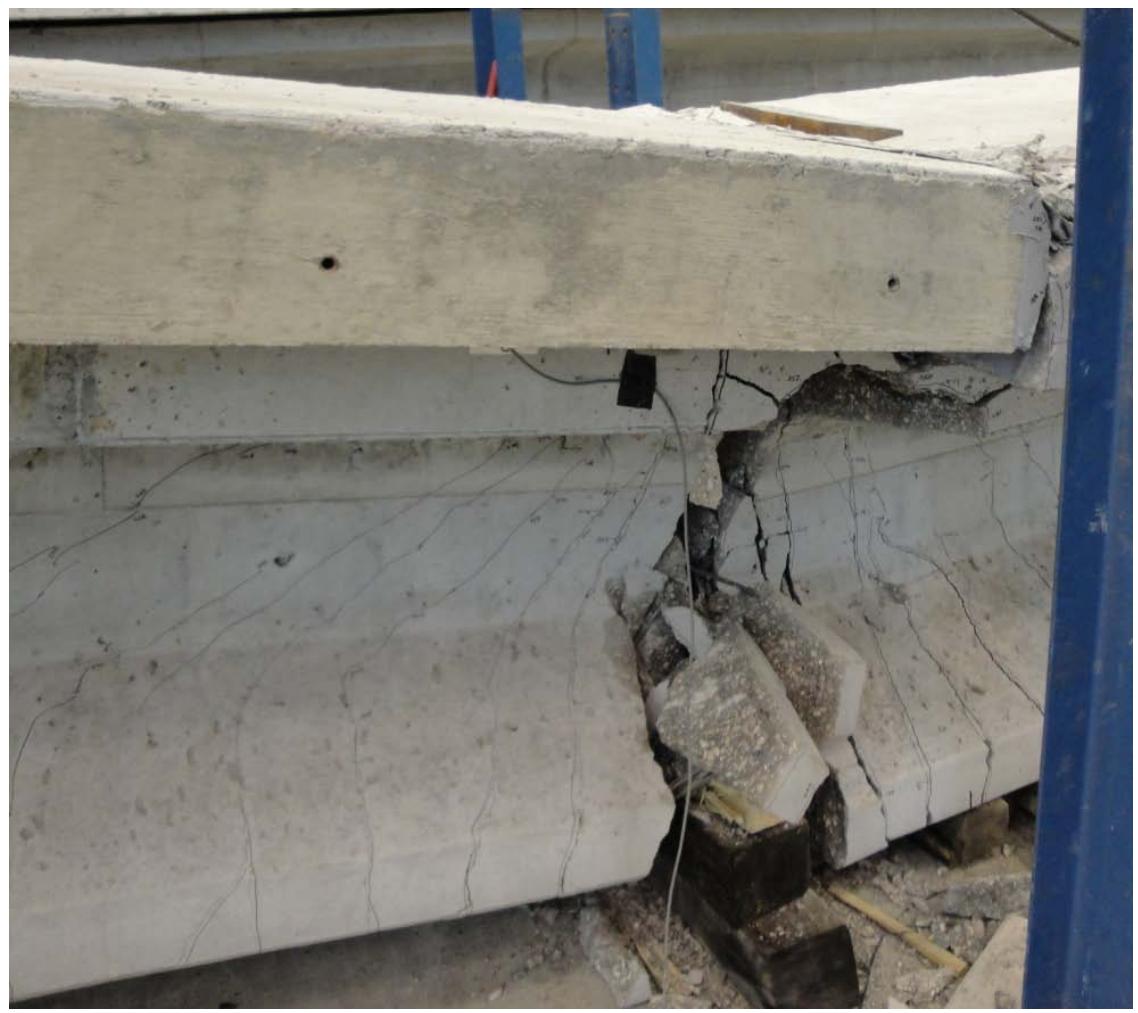

Figure 5.25: Failure of Specimen G-1 


\subsubsection{Specimen G-2}

The load-deflection response for Specimen G-2 is presented in Figure 5.26. There is indication of bond failure at approximately 25 kips. In addition, bond failure is evident in considering the horizontal slip and measured strains on both the north and south sides of midspan (Figure 5.27, Figure 5.28, and Figure 5.29). The north side experienced bond failure at approximately 25 kips while the south side bond failure at approximately 60 kips. A maximum measured slip of 0.33 in. occurred at the north slip gauge at a load of 255 kips. Higher slips were expected on the north side as this side was subjected to higher shear (70\% of applied load). Measured strains (Figure 5.29) and slip indicate that the shear studs yielded on both sides prior to reaching the peak load. Measured strain data from the midspan gauges was not available because the gauges were no longer functioning after construction. Final failure occurred in flexure due to crushing of the compressive zone in the top flange of the girder (Figure 5.30). Flexural cracks were present at the bottom of the precast panel, indicating the girder and deck were not acting fully composite at this stage. Shear failure of shear studs was not observed.

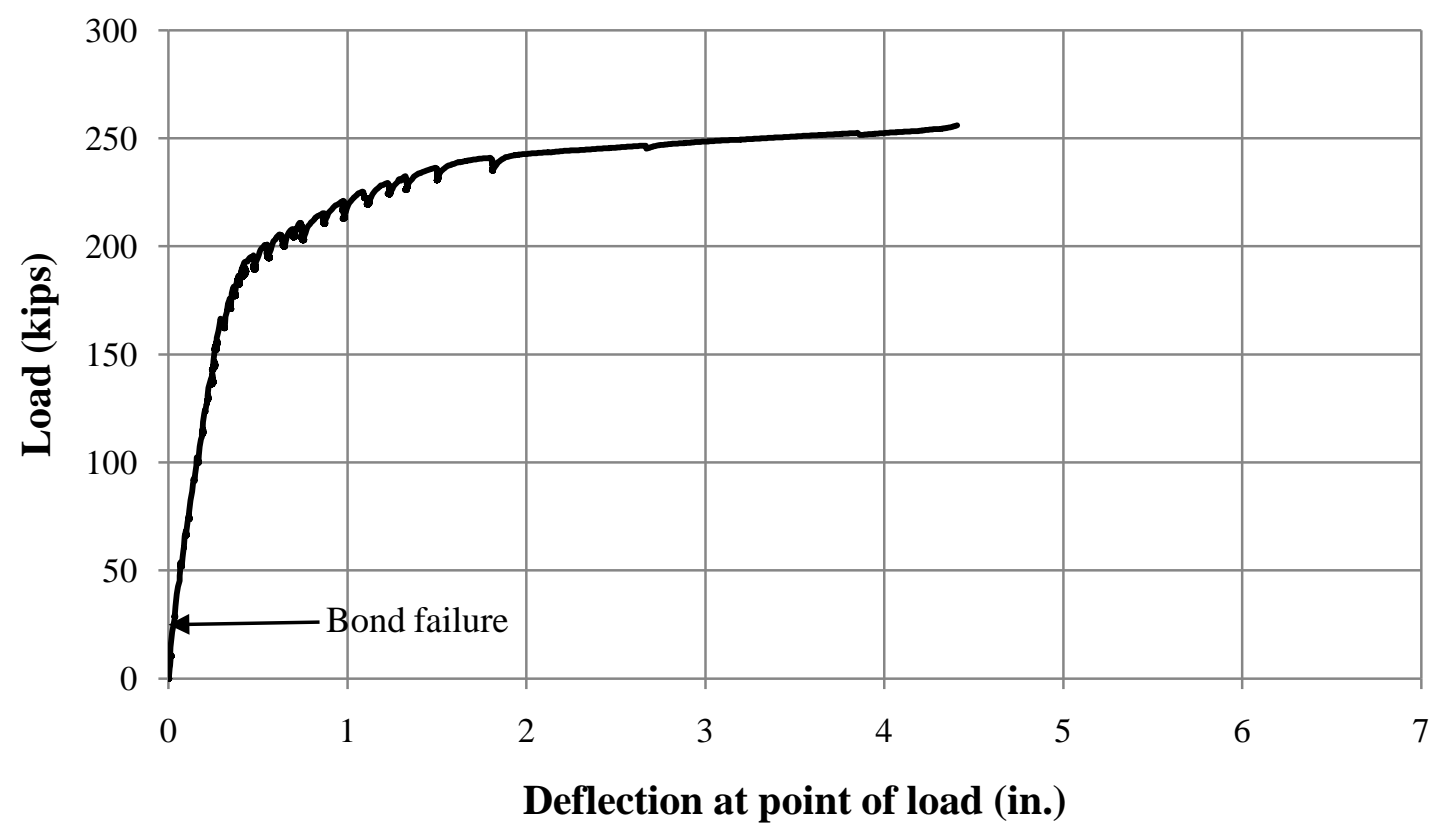

Figure 5.26: Load vs deflection - Specimen G-2 


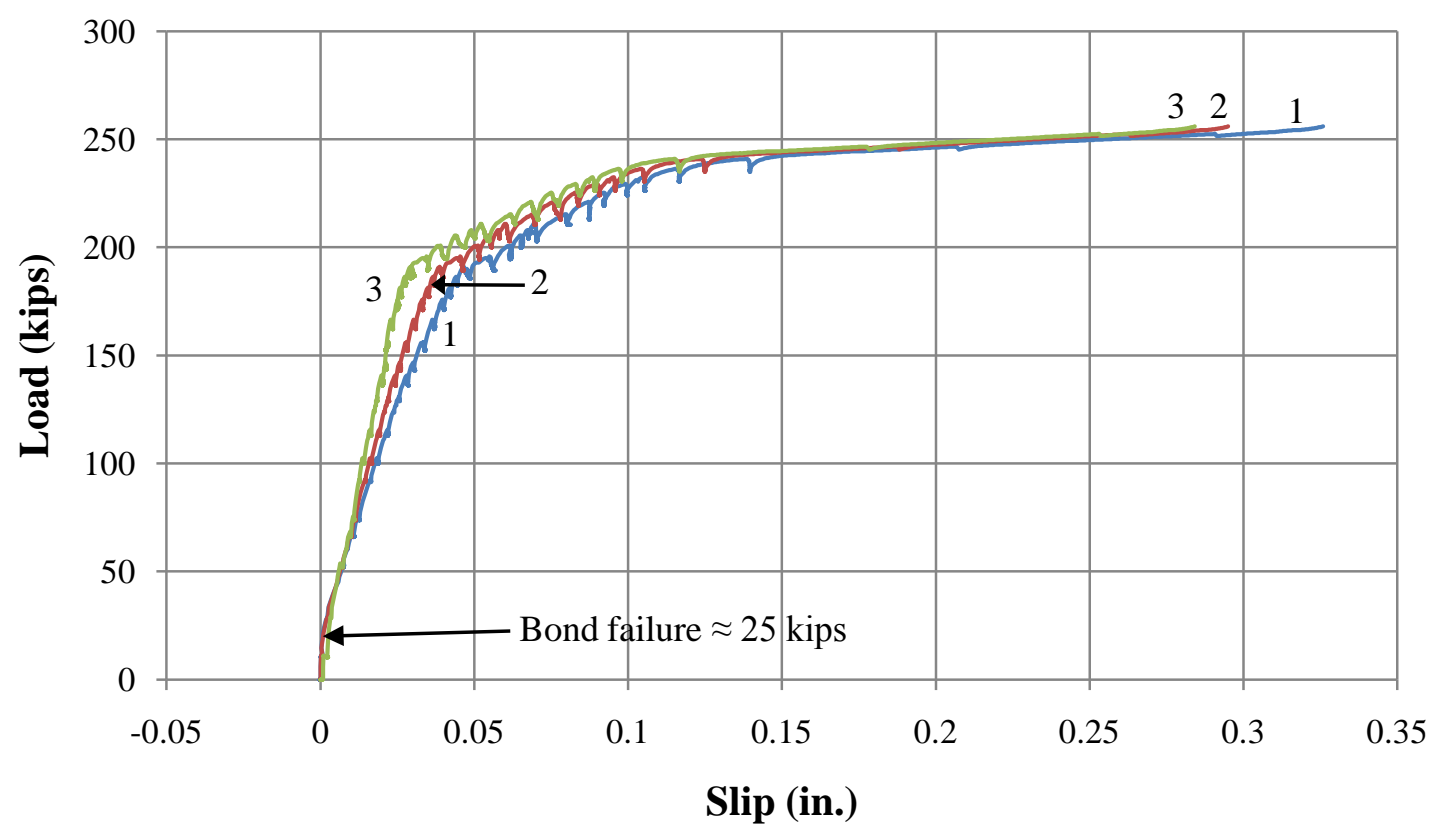

Figure 5.27: North horizontal slip - Specimen G-2

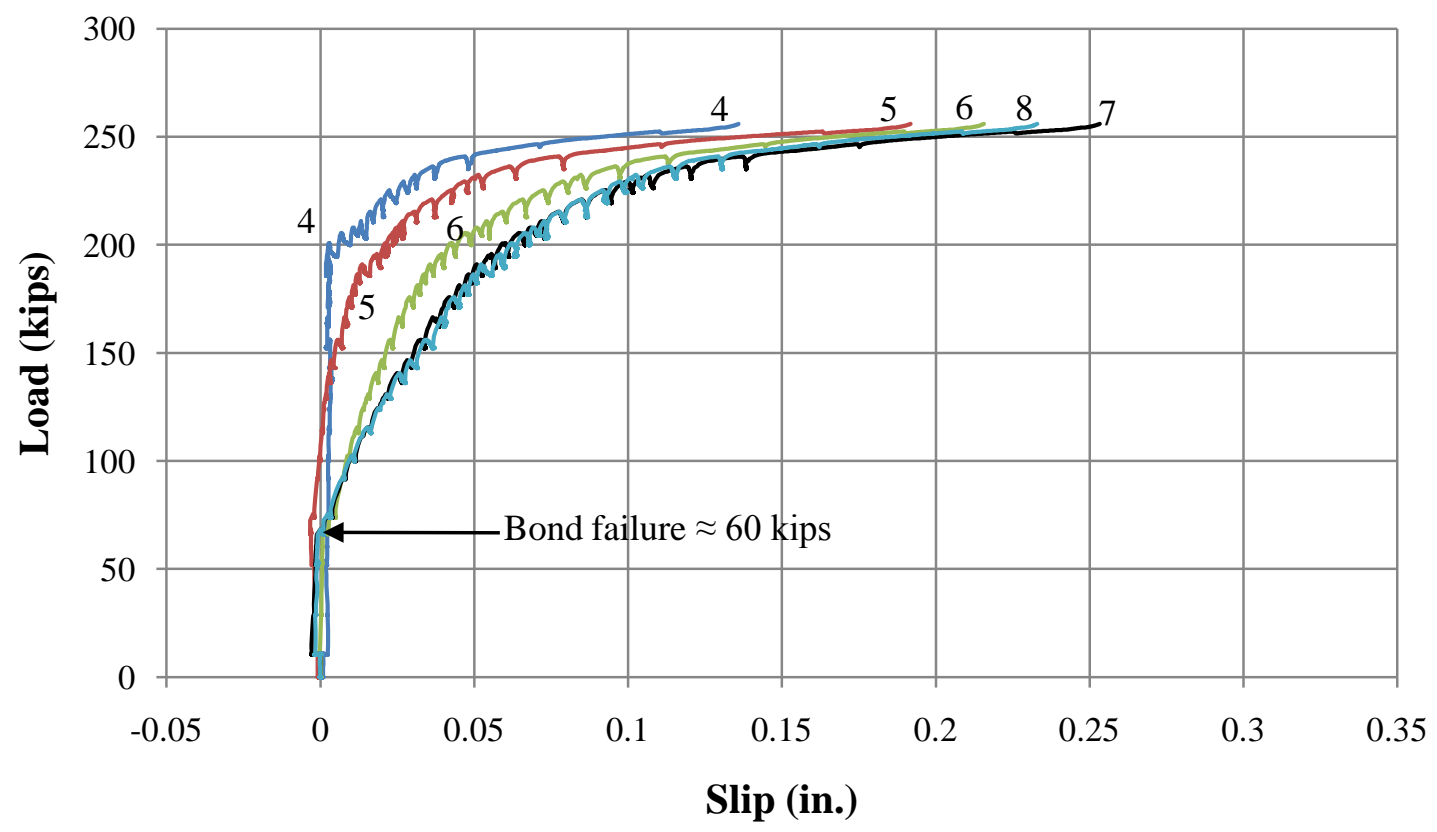

Figure 5.28: South horizontal slip - Specimen G-2 


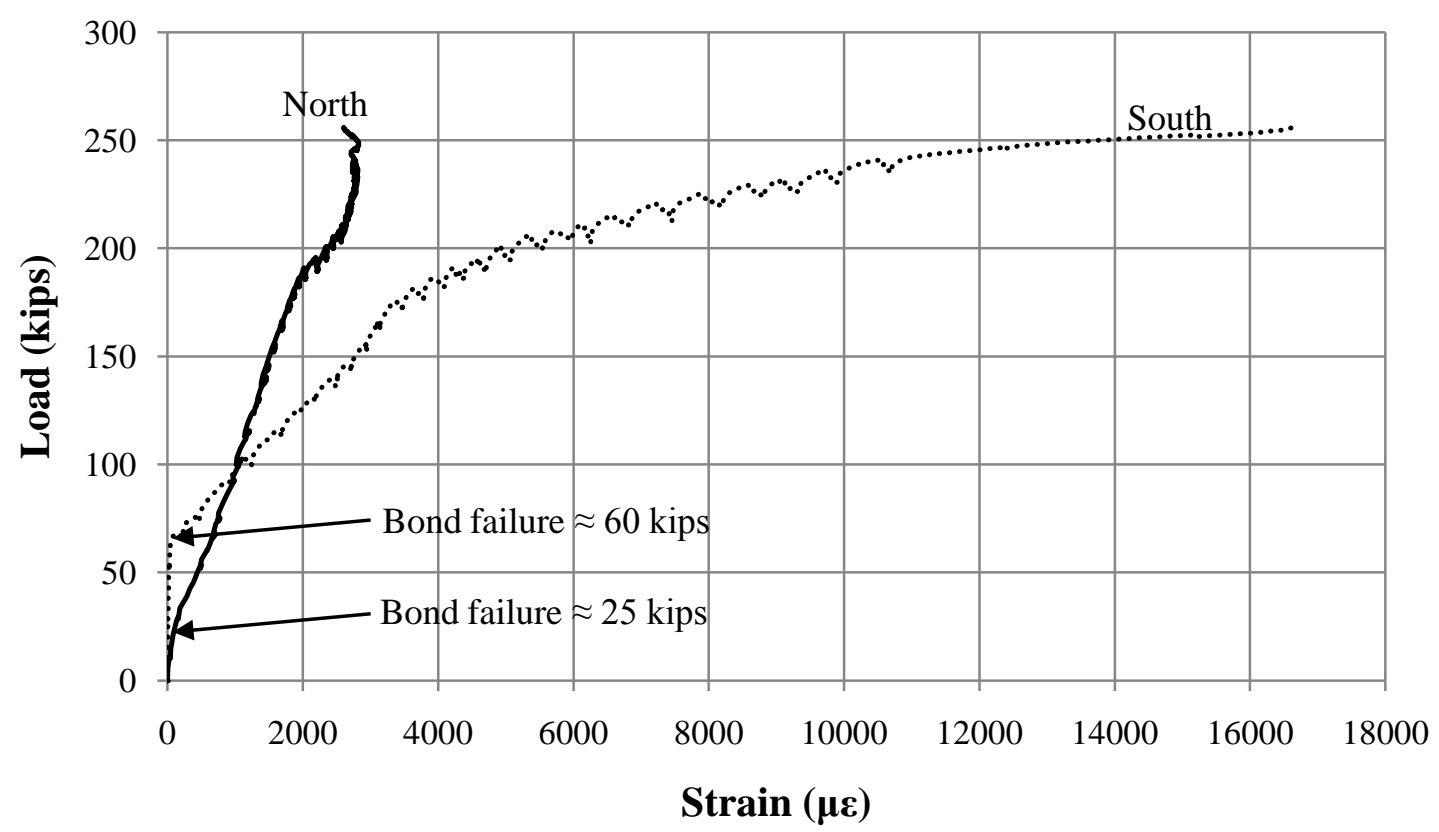

Figure 5.29: Measured strain in shear studs - Specimen G-2

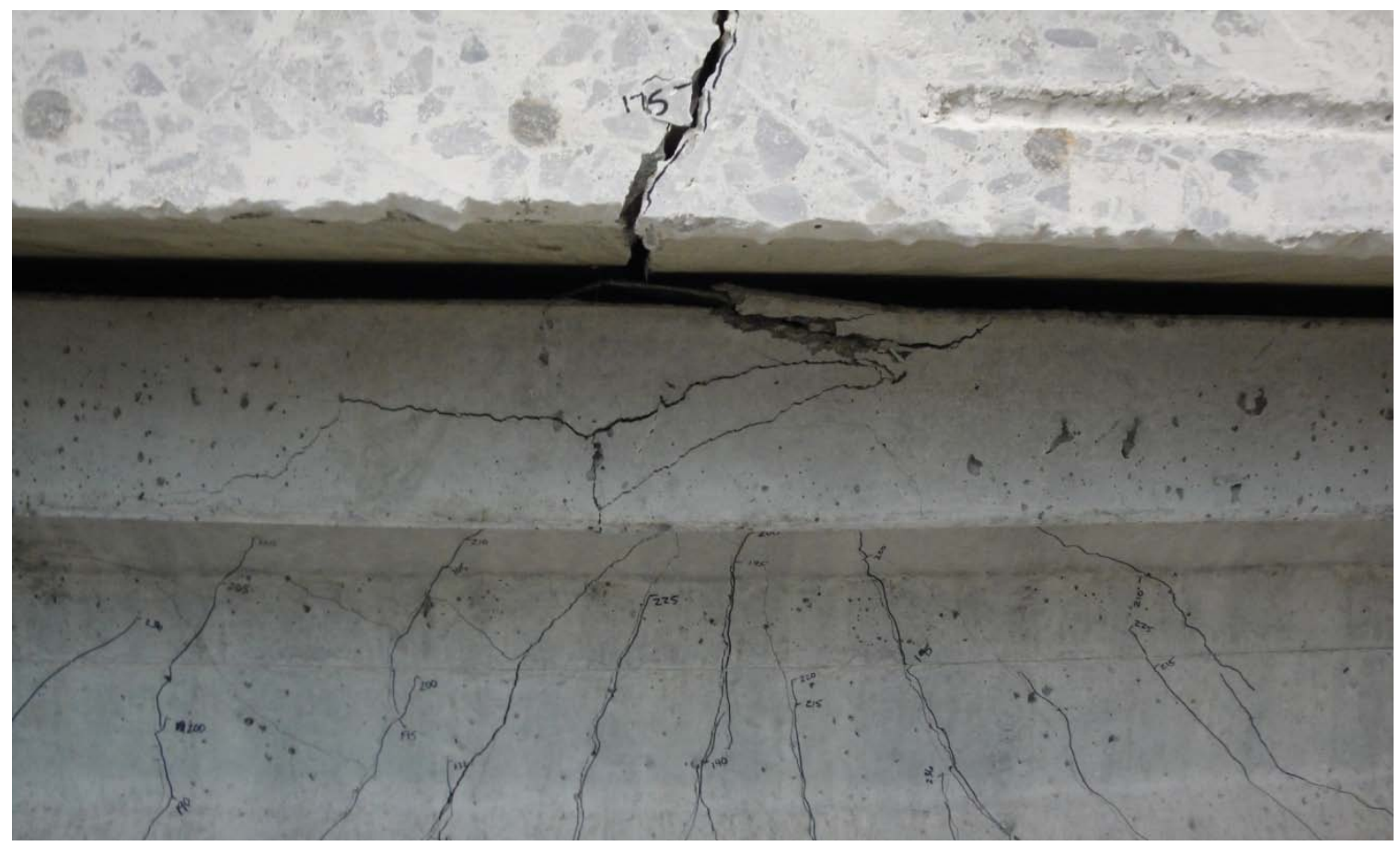

Figure 5.30: Failure of Specimen G-2 


\subsection{Analysis of Results}

The load-deflection results were evaluated to determine the effects of cyclic loading on the response of the system as well as the behavior of the composite section of each girder specimen. Analysis of the results for the cyclic load test and shear tests are presented in the following sections.

\subsubsection{Cyclic Load Test}

The load-deflection results for each static wheel load were compared to evaluate the effect of cyclic loading on the response of the system. The load-deflection response of the system under the AASHTO service wheel load before and after cyclic loading is presented in Figure 5.31 for the girder and Figure 5.32 for the panels. As evident, there is no appreciable effect on the load-deflection response of the system due to the cyclic load test. The results indicate that no deterioration occurred at the girder-panel connection or the panel-panel transverse joint. No slip at the horizontal interface occurred. A typical load-slip response is presented in Figure 5.33.

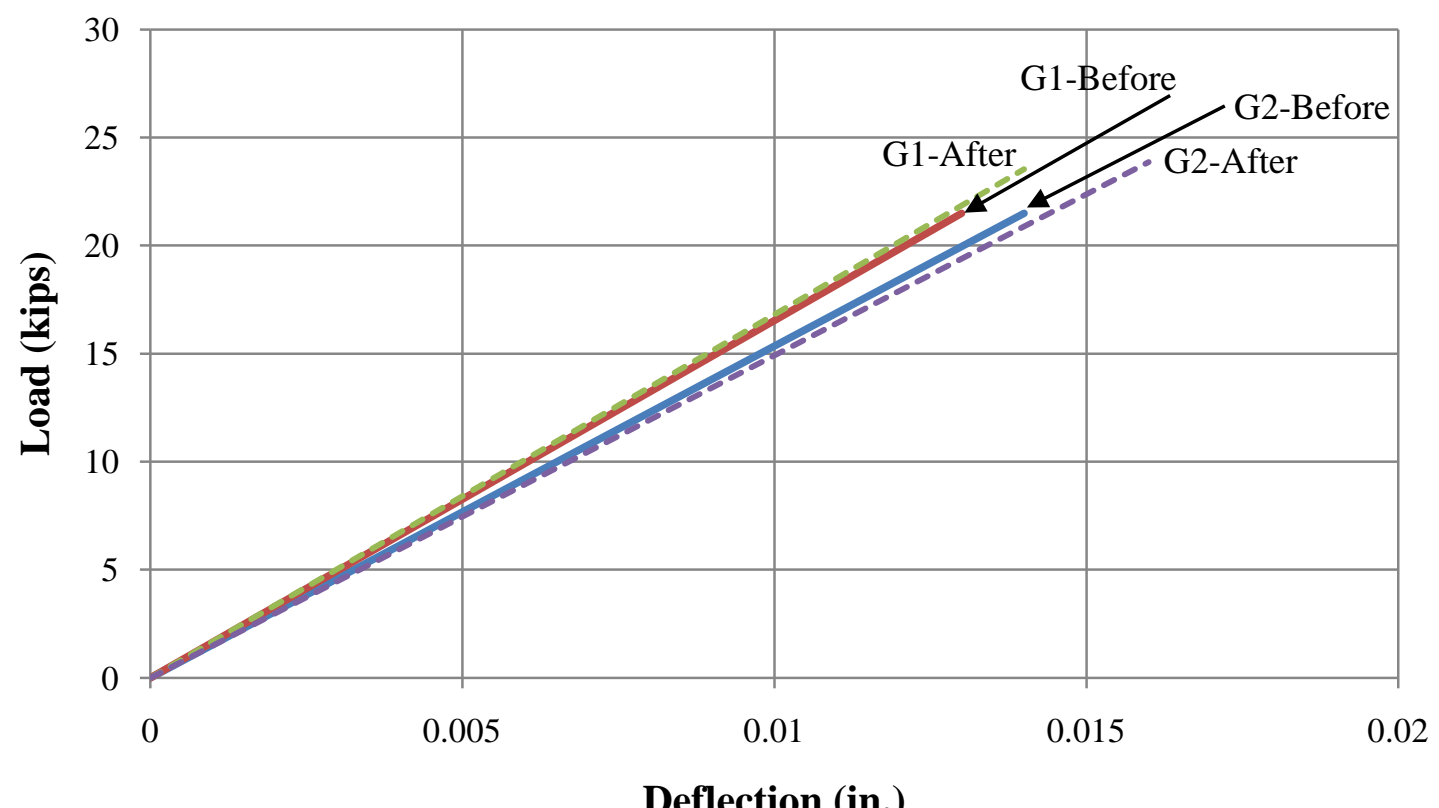

Figure 5.31: Girder static service load response comparison 


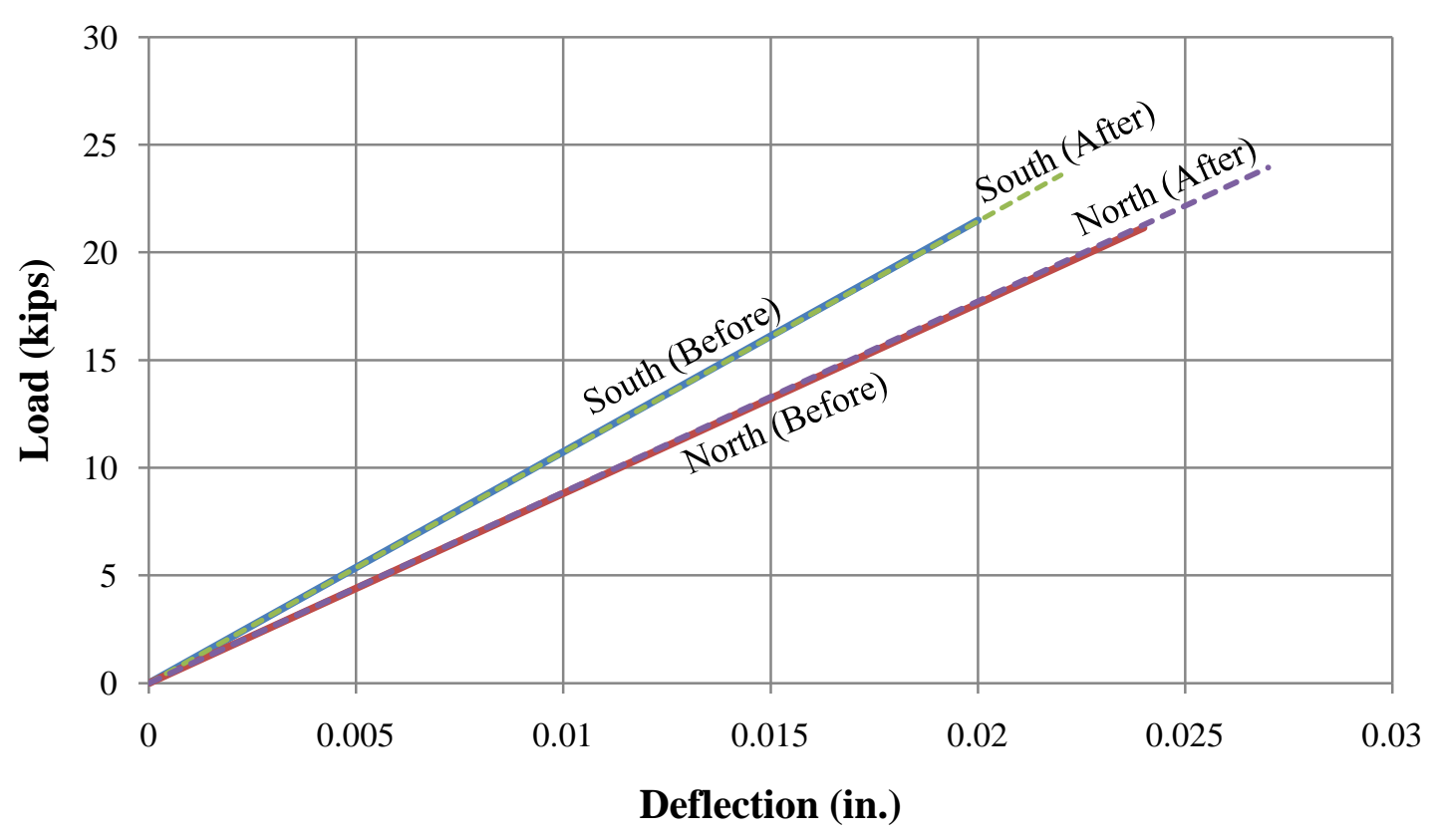

Figure 5.32: Panel static service load response comparison

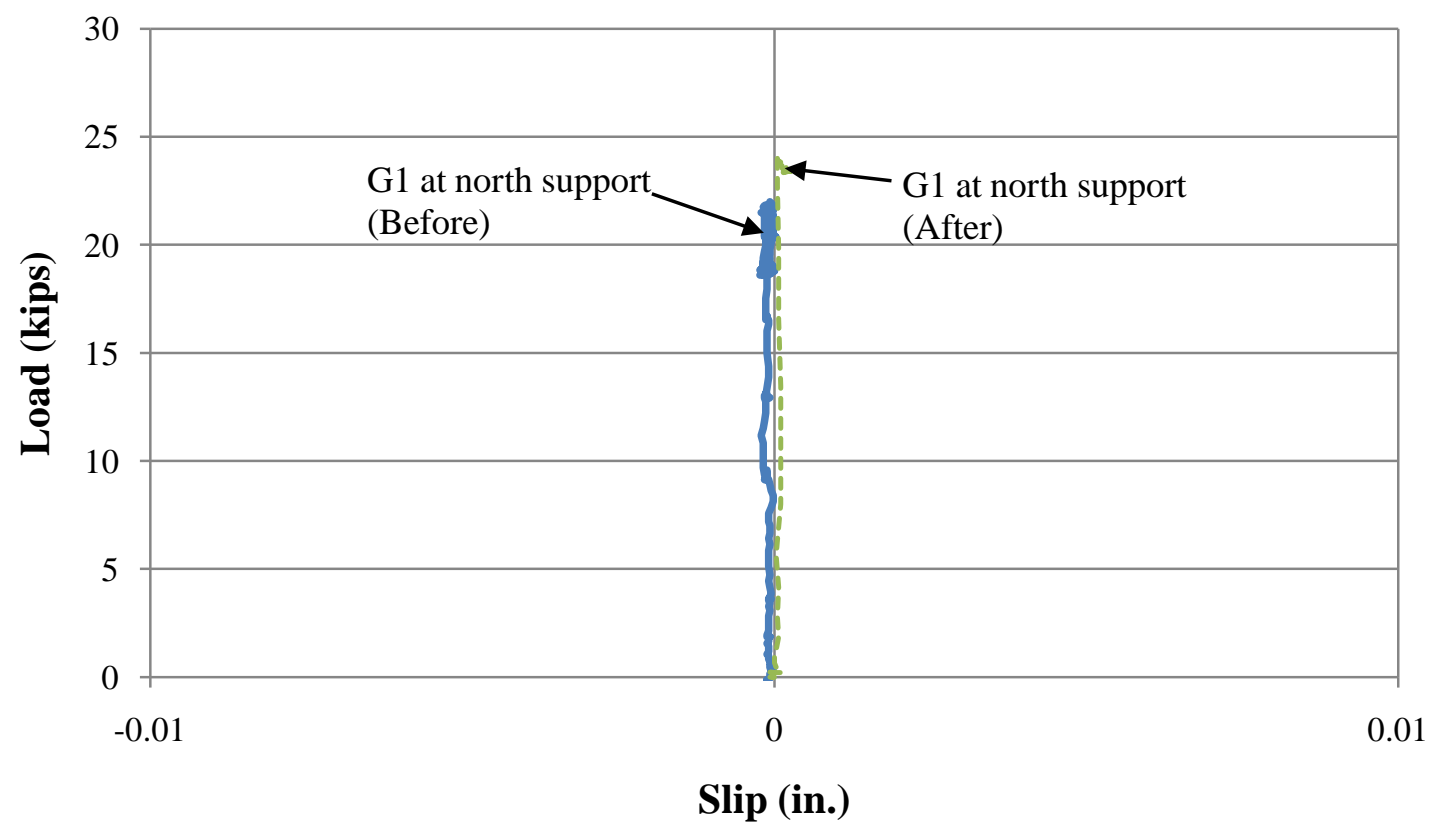

Figure 5.33: Typical horizontal slip response 


\subsubsection{Shear Tests}

The load-deflection results for each test were analyzed to evaluate the composite behavior of each specimen as well as the shear force resisted by the shear studs. A moment-curvature (MC) analysis was performed on the full-composite and girder crosssections to construct an upper and lower bound of the specimen response. A MC analysis of the partial-composite section was also performed (Section 2.7) to estimate the failure load of the test specimens using an estimated shear stud strength of $1.25 \mathrm{~A}_{\mathrm{s}} \mathrm{f}_{\mathrm{u}}$, where $f_{u}=90$ ksi. The shear stud strength from $1.25 A_{s} f_{u}$ was used because it provides a better estimate of strength for analytical purposes, while $1.0 \mathrm{~A}_{\mathrm{s}} \mathrm{f}_{\mathrm{u}}$ provides conservative values for design. Ritter's parabola, as presented by Hognestad (1951), was used in modeling the compressive stress-strain response, and the maximum concrete strain in the extreme compression fiber was assumed to be 0.004. A typical seven wire, low-relaxation strand stress-strain curve provided in the PCI Design Handbook (PCI 2004) was used in modeling the prestressing strand. The analysis results are presented in the following sections.

\subsubsection{Specimen G-1 (\#5 at $2 \mathrm{ft}$ )}

The load-deflection results were compared with the calculated load-deflection paths of the full-composite, partial-composite, and girder sections (Figure 5.34). As shown, the specimen did not reach the calculated full-composite section capacity of 266 kips. The maximum load applied to the specimen was 255.8 kips, approximately $96 \%$ of the ultimate capacity. The estimated partial-composite load capacity of the \#5 studs spaced at $2 \mathrm{ft}$ was 244 kips using an estimated horizontal interface force of 209 kips (34.8 kips/stud). The specimen, however, did not follow the analytical load-deflection path, and the measured response was less stiff than the computed response. This difference in behavior is not unexpected. In computing the partial-composite response, the specimen was assumed fully composite until flexural cracking, resulting in the same response up to the cracking load. For the specimen tested, however, it was unexpected that the response of the specimen was less stiff than the computed girder response in the linear region. The difference in the measured vs. computed girder response was 
approximately 0.03 in. at 140 kips. This small variation can be explained by support settlement. In particular permanent deformation of the bearing plates at the supports, caused by the steel rollers, was observed. To verify support settlement as the cause, the $28 \mathrm{ft}$ section of Specimen G-1, present after flexural failure, was placed on the same supports and loaded. The north support block of Specimen G-1 was not moved during the placement of the $28 \mathrm{ft}$ section in the test setup. In addition, the $28 \mathrm{ft}$ section was supported $1 \mathrm{ft}$ from its north end, as in the test of Specimen G-1. The load-deflection response of the north support is presented in Figure 5.35. This support deflection was subtracted from the load deflection response of Specimen G-1, resulting in the response presented in Figure 5.36. As evident, the linear load-deflection response now closely follows the calculated girder response.

The computed cracking load ( $\approx 180$ kips) and ultimate load were well estimated, differing by less than $5 \%$ from the test results. The test results indicate that the shear studs resisted 290 kips (48.3 kips/stud). To achieve full composite strength 375 kips (62.5 kips/stud) was required. No signs of deterioration of the trough material, shear keys, or girder section due to cracking at the base of the trough was observed. The overall behavior indicated that the new panel-to-girder joint had sufficient capacity to develop the ultimate strength of the section as limited by the strength of the shear studs. 


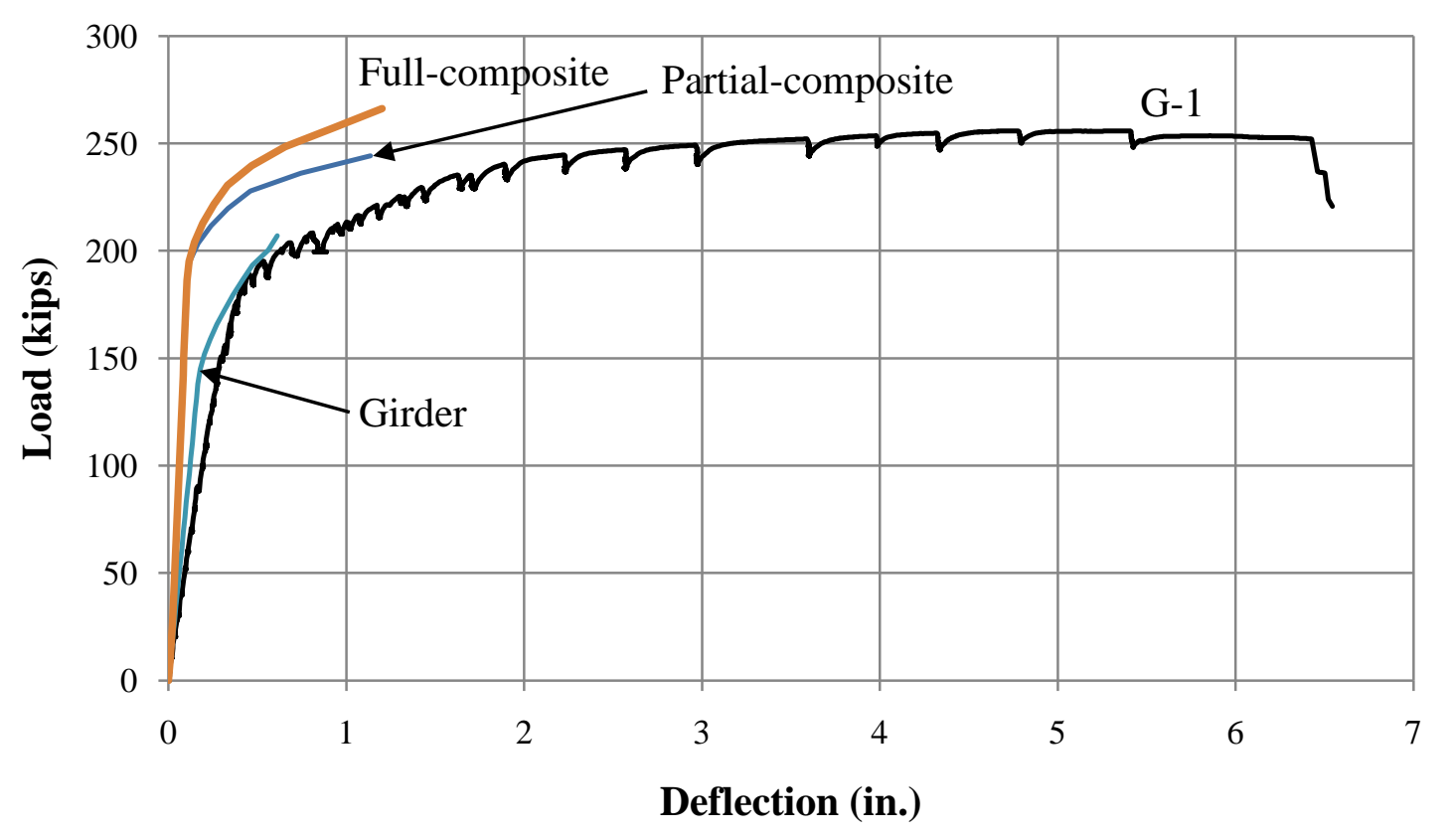

Figure 5.34: Specimen G-1 compared with calculated load-deflection paths

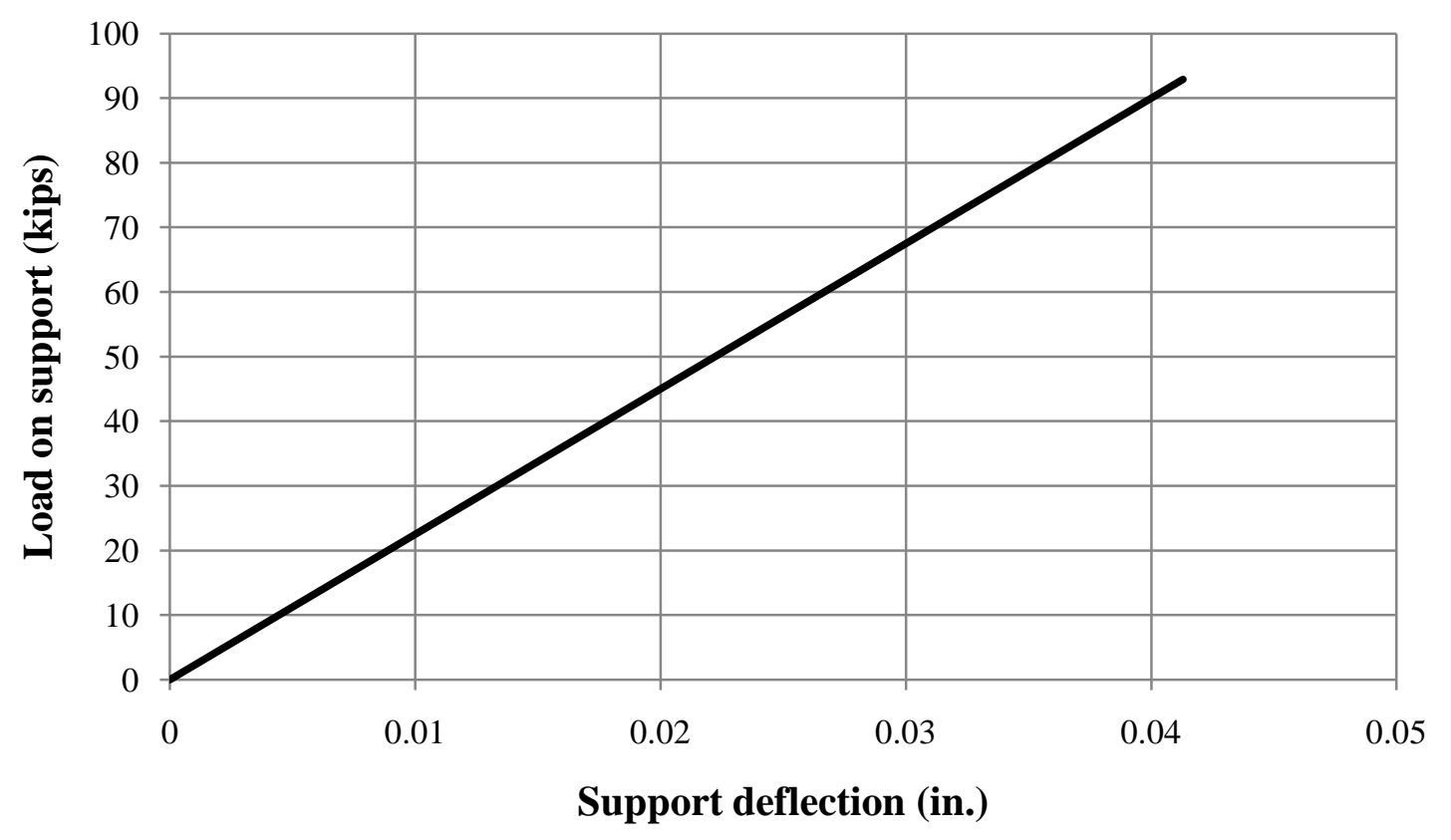

Figure 5.35: North support (28 ft section of Specimen G-1) 


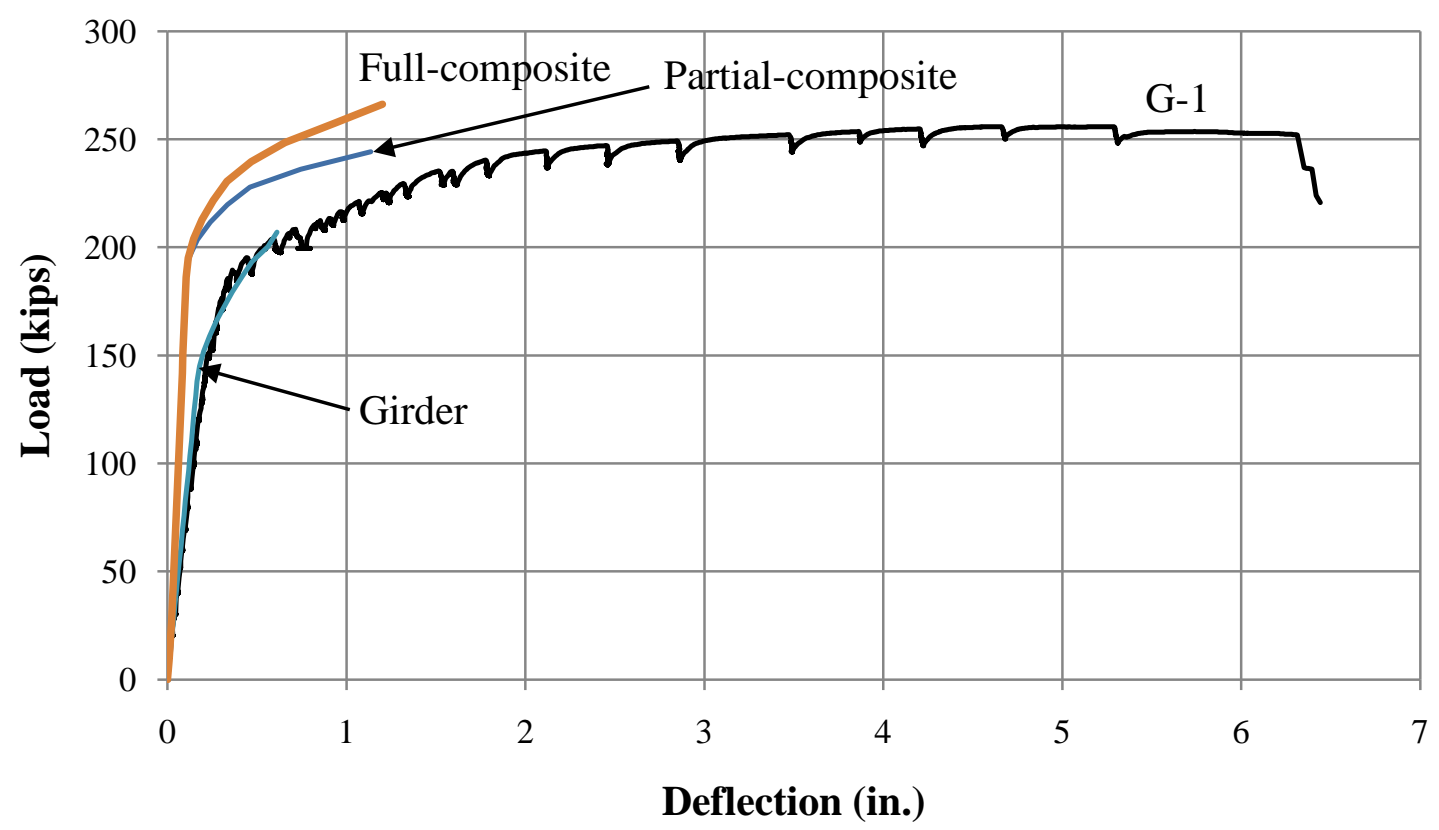

Figure 5.36: Adjusted response (Specimen G-1)

\subsubsection{Specimen G-2 (\#4 at $2 \mathrm{ft}$ )}

The load-deflection results were compared with the calculated load-deflection paths of the full-composite, partial-composite, and girder sections (Figure 5.37). The specimen did not reach the calculated full-composite section capacity of 266 kips. The maximum load applied to the specimen was $255.9 \mathrm{kips}$, approximately $96 \%$ of the ultimate capacity. The load-deflection response of Specimen G-1 was similar to G-2 (Figure 5.38). The estimated partial-composite load capacity of the \#4 studs spaced at 2 ft was 234 kips using an estimated horizontal interface force of 132 kips (22.0 kips/stud).

Similar to G-1, the specimen did not follow the analytical load-deflection path (Figure 5.37). The actual response of the specimen was less stiff than that computed for both the partial-composite and girder only response. The difference in the measured vs. computed girder response was approximately 0.01 in. at 140 kips. Again, support deflection was subtracted from the load-deflection response of Specimen G-2 as presented in Figure 5.39. The ultimate load of the specimen was estimated as 234 kips for the partial-composite though 256 kips was achieved, differing by approximately 9\%, 
due to influence from the test setup. This difference in calculated strength was higher than that observed for Specimen G-1 and is likely due to an inadvertent difference in the test setup. The loading ram was located on the north side of the transverse deck joint. This positioned the load on one of the three panels in the shorter shear span (12 ft), as illustrated Figure 5.40. The loading ram restrained the panels from moving horizontally as suggested by the decreased magnitude of horizontal slip when compared to Specimen G-1 (Figure 5.41). The horizontal slip measured by Pot 1 for Specimen G-2 was less than $50 \%$ of that measured for Specimen G-1, which is unexpected since the steel area crossing the interface is 35\% higher in Specimen G-1. In addition, when comparing slip at either end of Specimen G-1, it is evident that the shorter shear span (12 ft) accumulates more slip than the longer shear span (28 ft), as shown in Figure 5.42a. Similar results would be expected for Specimen G-2; however, the accumulated slip on either end differs by only 0.09 in. (Figure 5.42b). The added vertical restraint caused an increase in capacity to a load similar to that of Specimen G-1 even though the area of steel crossing the horizontal interface was 35\% less. The results indicate that the shear studs resisted 290 kips (48.3 kips/stud). However, this value is expected to be high considering the contribution of the vertical compression applied to the interface. To achieve full composite strength 375 kips (62.5 kips/stud) was required.

No signs of deterioration of the trough material, shear keys, or girder section due to cracking at the base of the trough was observed. The overall behavior indicated that the new panel-to-girder joint had sufficient capacity to develop the ultimate strength of the section as limited by the strength of the shear studs. 


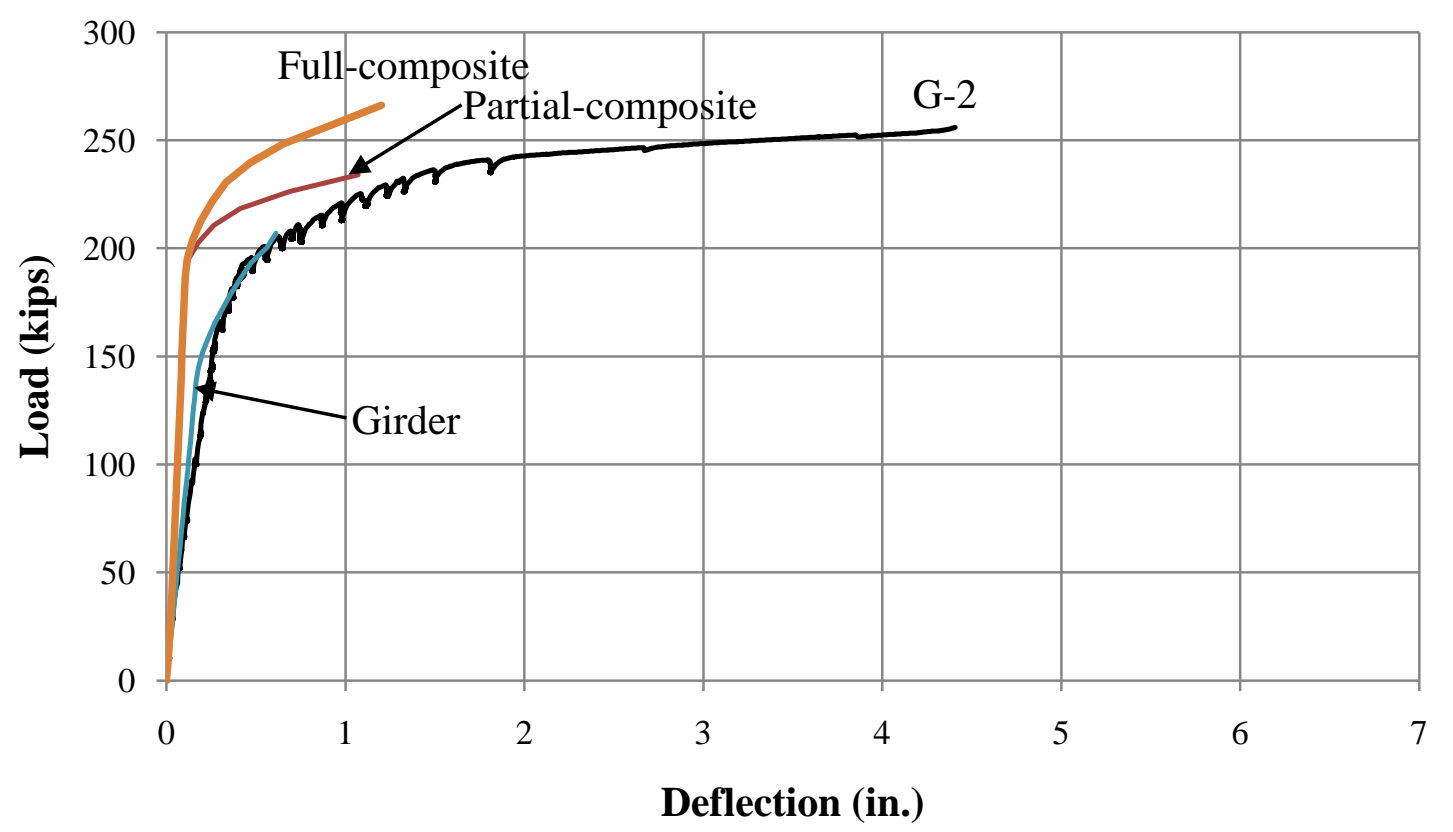

Figure 5.37: Specimen G-2 compared with calculated load-deflection paths

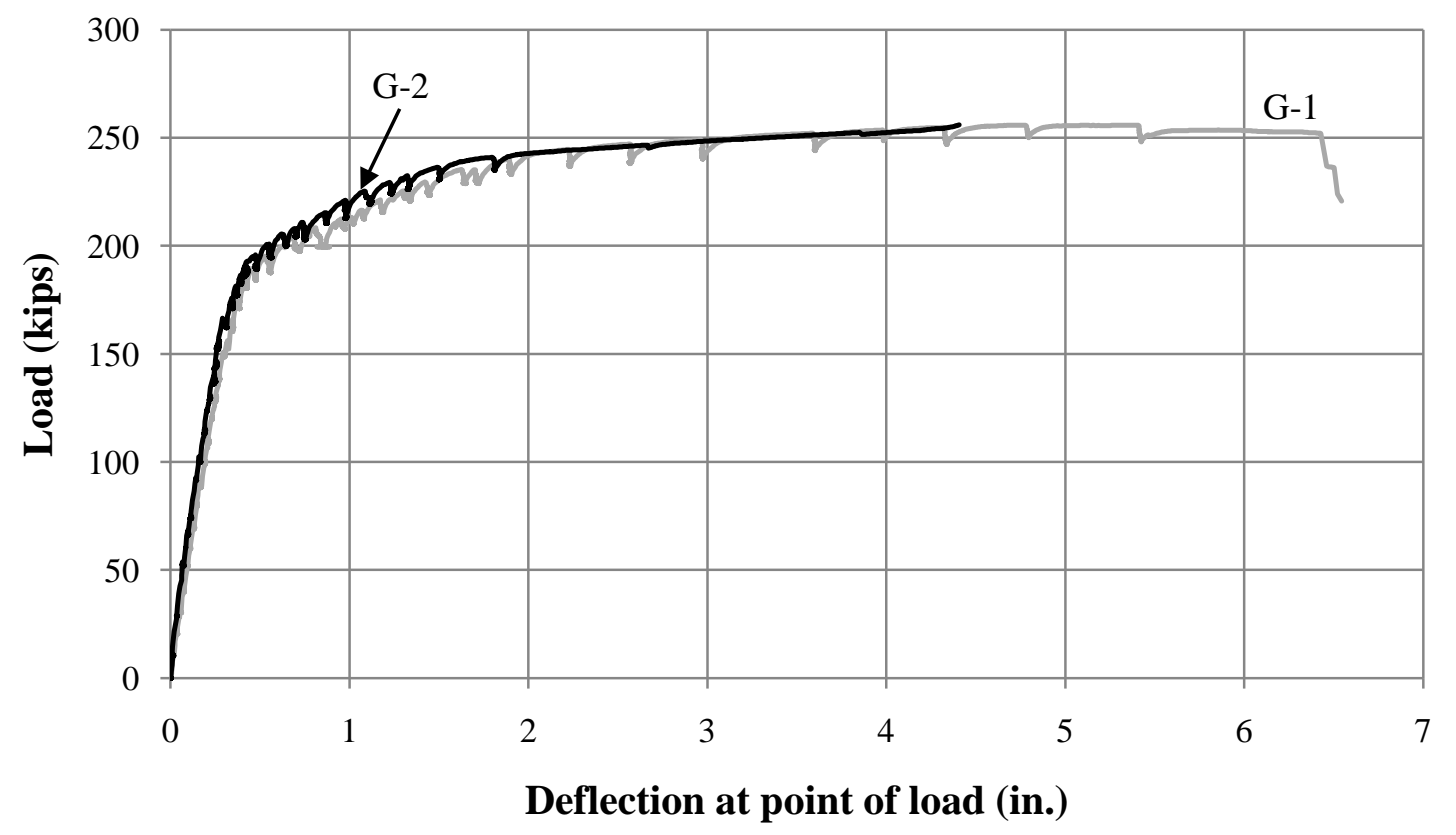

Figure 5.38: Specimen G-1 compared with G-2 


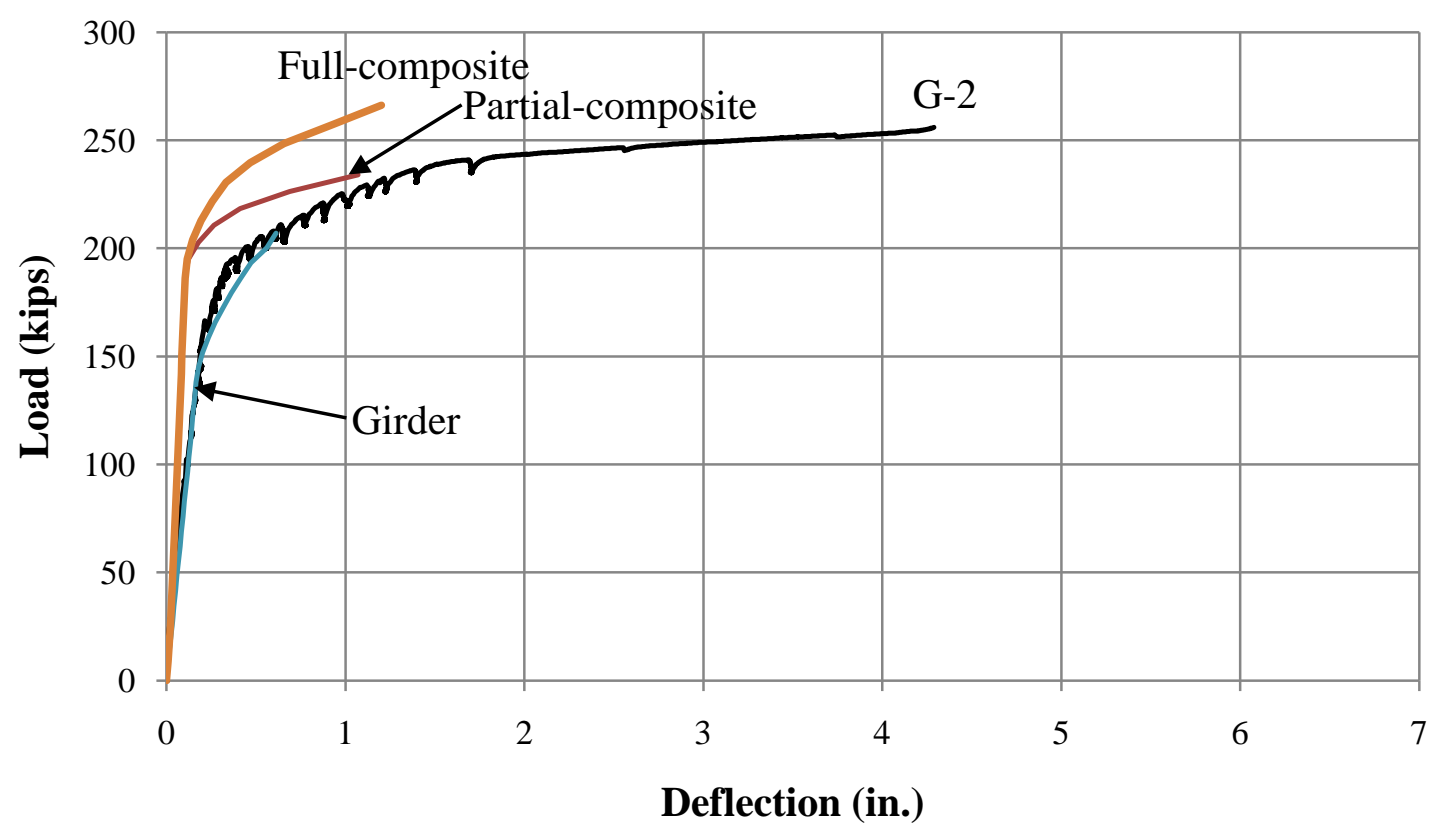

Figure 5.39: Adjusted response (Specimen G-2)

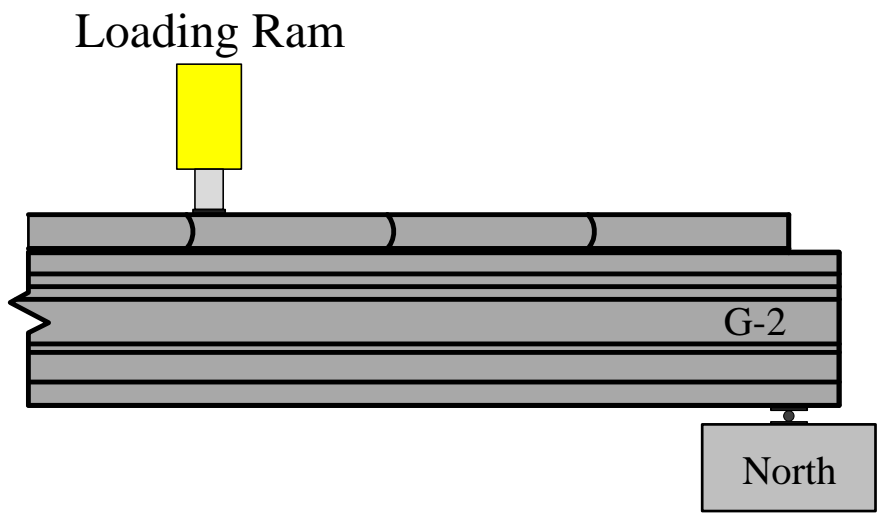

Figure 5.40: Load location-Specimen G-2 


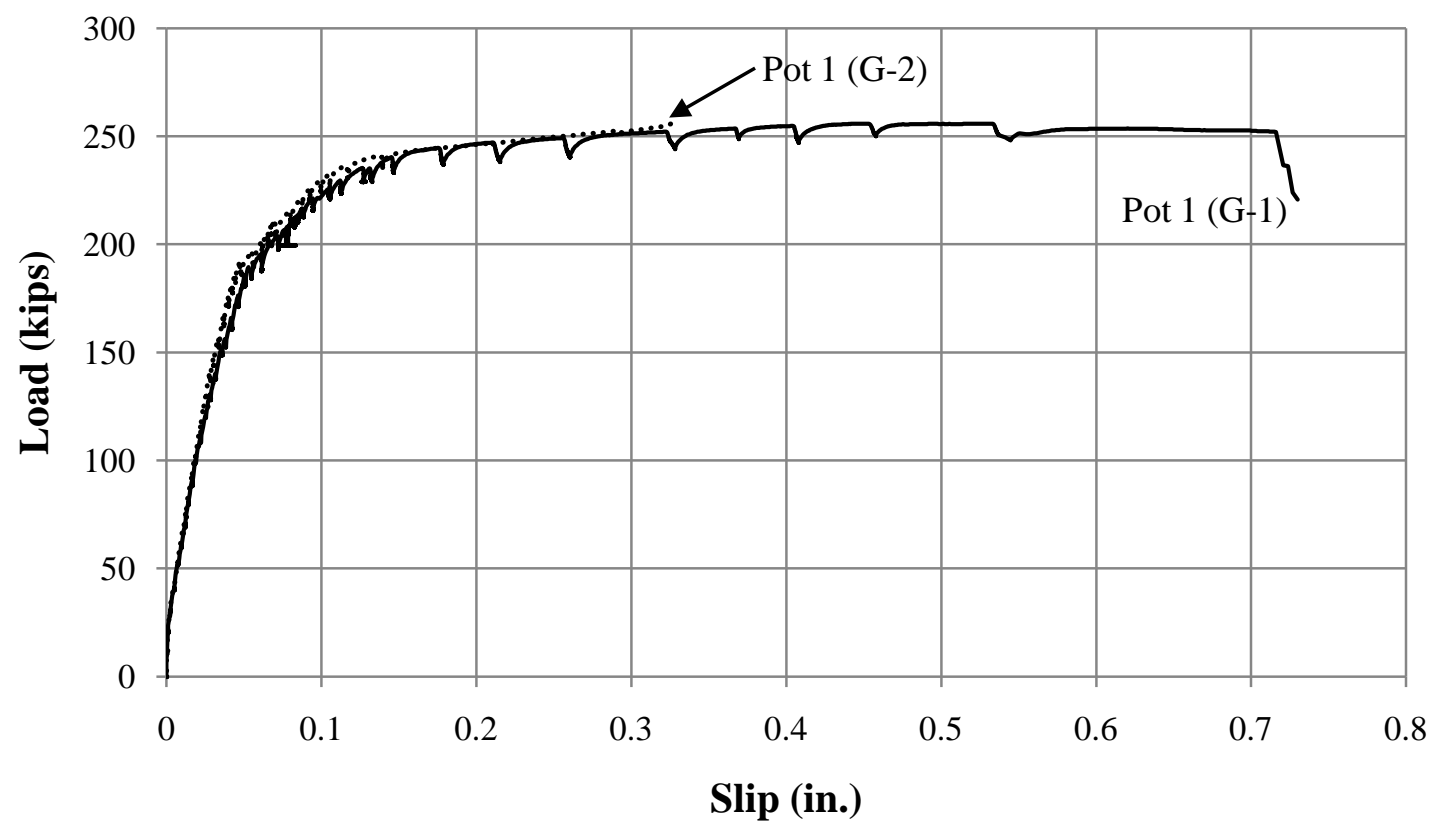

Figure 5.41: Slip response of Specimens G-1 and G-2 


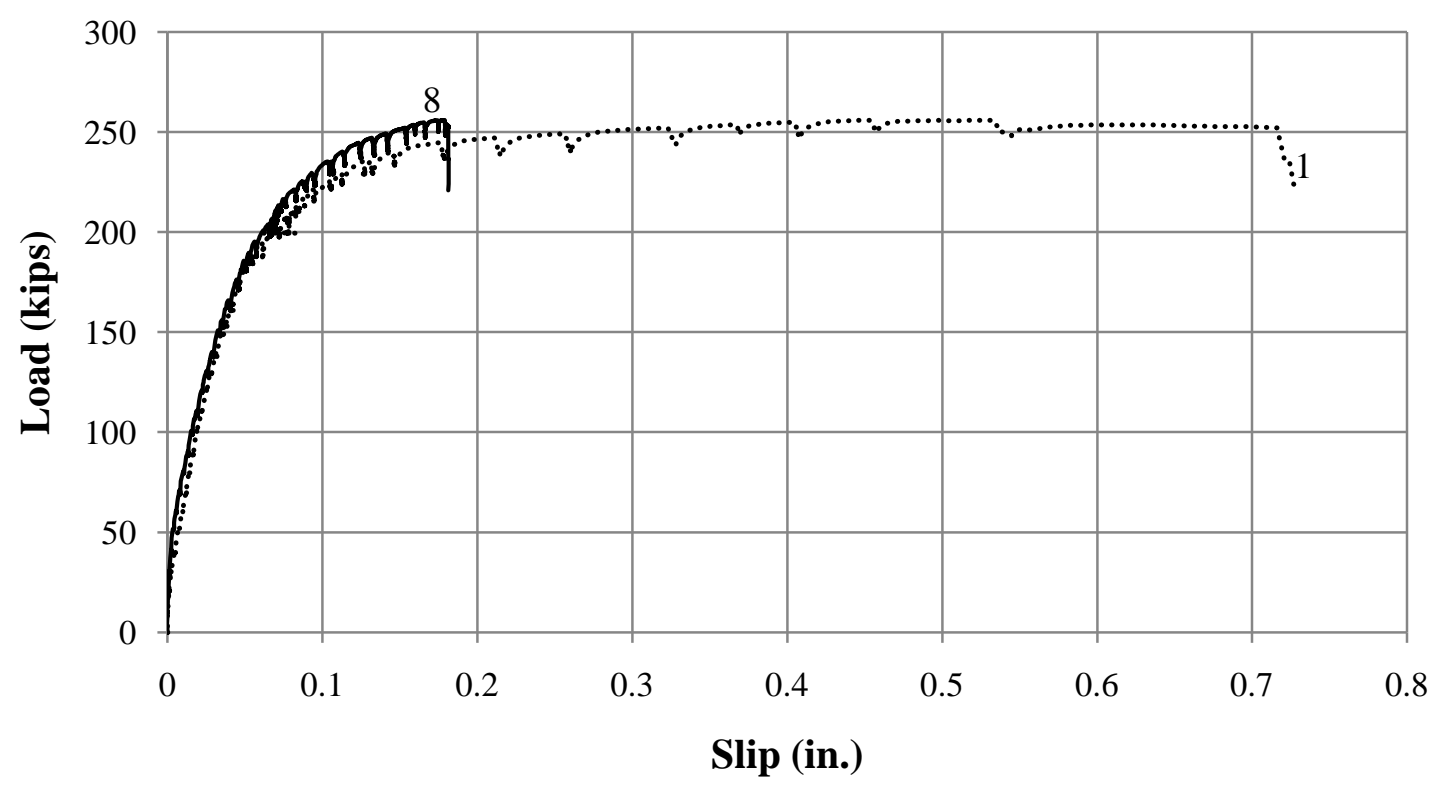

a) Specimen G-1

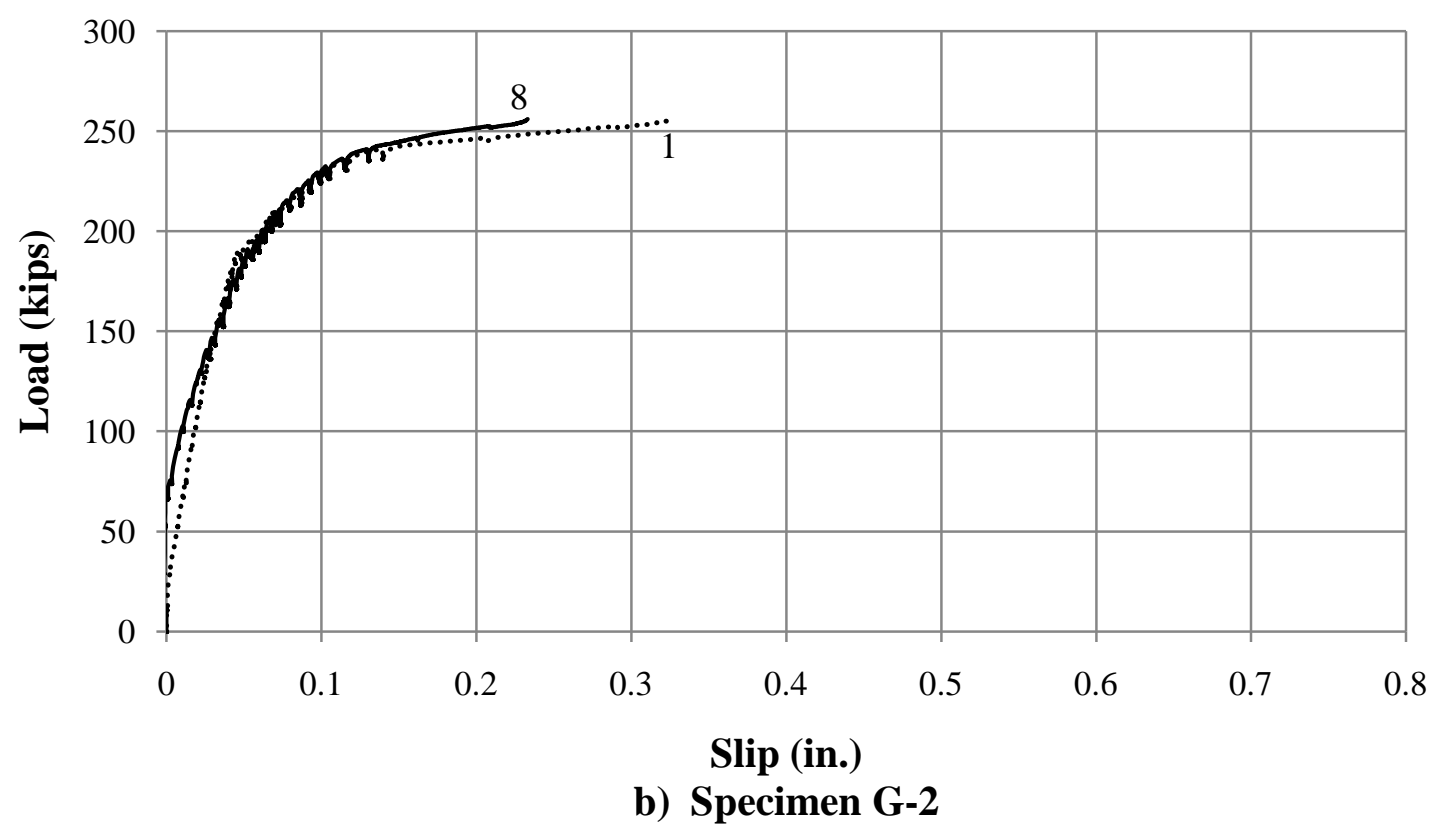

Figure 5.42: End slip of Specimens G-1 and G-2 


\subsection{Conclusions}

Several conclusions were drawn from the results of this series of tests.

1. The system was demonstrated to provide ease in constructability.

a. The precaster had no difficulties in forming the shear key or trough which are essential to the performance of the system.

b. Installation of one panel was achieved in 3 hours by one person, which included time for concrete mixing. In all, 30 man hours were required for installation of the panels, indicating that rapid construction is possible.

c. The shear keys provided an excellent means of compressing the panels after SBA application.

d. A trough width of 6 in. was more than sufficient to accommodate variation in stud or panel placement.

2. Cyclic loading to 2 million cycles of the AASHTO wheel load plus impact indicated that the new panel-to-panel joint as well as the overall system performed well. No deterioration in either the overall response or the joint was observed.

3. The panel-to-girder connection performed well in both cyclic and ultimate capacity tests. No deterioration or damage to the connection was observed.

4. The capacity of the system could be reliably estimated using partial-composite analysis.

a. Shear stud strength can be estimated using $1.25 \mathrm{~A}_{\mathrm{s}} \mathrm{f}_{\mathrm{u}}$ for Grade 60 reinforcement, $\mathrm{f}_{\mathrm{u}}=90 \mathrm{ksi}$. 


\section{CHAPTER 6: SUMMARY AND CONCLUSIONS}

\subsection{Introduction}

Interest in full-depth, precast bridge deck panels has been steadily increasing over the past 50 years because they offer several benefits over traditional cast-in-place construction. This type of system eliminates the need for cast-in-place formwork, which reduces cost, construction time, and environmental/economic impact. In addition, precast panels are constructed in a controlled environment which leads to a more durable, high quality product.

There has been a considerable amount of research and experience with full-depth precast concrete deck panels installed on steel girders. However, research on full-depth precast concrete deck panels installed on prestressed concrete girders has been limited. This research evaluated the use of precast bridge deck panels on new and existing precast, prestressed concrete girders. The New England Region system (PCINER 2002) was chosen for the evaluation because it represents the current geometry of full-depth precast deck panels. In addition, a new system was developed to address durability and ease of construction issues that are problematic with current joint details. Accordingly, the research program was conducted in four phases. First, the New England Region (NER) system was evaluated in a series of large scale tests in which the panels were placed on a $40 \mathrm{ft}$ prestressed concrete girder and subjected to three point loading to evaluate its constructability and composite behavior. Second, the strength and geometry of both the current and a new panel-to-girder joint detail were evaluated and compared in a series of direct shear tests. Third, the strength and geometry of both the current and a new panel-to-panel joint detail were evaluated and compared in a series of direct shear tests. Finally, a large scale specimen was designed, constructed, and evaluated to fully evaluate the new system. Each phase is summarized in the following sections. 


\subsection{New England System}

The connection details used in the New England Region (NER) system were extended for use with precast, prestressed concrete girders. To evaluate the structural behavior of the system with prestressed concrete girders and have a means of comparing new design details to current details, three large scale tests were designed and tested. The objective of the tests was to evaluate the strength of the girder-to-panel connection as well as the composite behavior of the system. Each of the three test specimens were $40 \mathrm{ft}$ long, consisting of an AASHTO Type-I prestressed concrete girder and precast deck panels. Both cast-in-place and post-installed shear studs were evaluated in the panel-to-

girder connection. Several conclusions were drawn from the results of this series of tests.

1. Once full-composite action was lost due to bond failure at the interface, shear studs across the interface yielded.

2. The ultimate strength of the \#4 studs were approximately 24 kips/stud for $f_{u}$ of $95 \mathrm{ksi}$. This corresponds to an ultimate capacity of approximately $1.25 \mathrm{~A}_{\mathrm{s}} \mathrm{f}_{\mathrm{u}}$.

3. Cast-in-place headed shear studs can be used successfully as a means of connecting precast deck panels to precast, prestressed concrete girders. The level of composite action can be varied based on the amount of reinforcement crossing the interface.

4. Post-installed shear studs performed similar to cast-in-place studs indicating the system could be used successfully in the redecking of existing bridges.

5. The area of steel required to achieve full-composite capacity of the section can be determined using the partial-composite MC analysis described in Section 2.7.

\subsection{Panel-to-Girder Connection}

New details for the connection between precast deck panels and precast, prestressed concrete girders were developed and evaluated. The objective of the tests was to develop a new connection between the precast deck panels and precast, prestressed girders with a focus on eliminating penetrations in the deck surface. To evaluate the behavior and strength of the new detail, direct shear tests were conducted. The NER system detail was also tested in the same manner to evaluate and compare 
behavior. Each of the test specimens for the new detail consisted of one concrete girder section with a trough and a precast deck panel with a shear stud. From the results, it was concluded that there are four main factors governing the behavior and strength of the new joint detail assuming the trough had a keyed surface and the stud was embedded at least 6 in. into the trough material:

1. Bond strength: A lower-bound value of $100 \mathrm{psi}$ can be used to estimate bond strength of the horizontal interface.

2. Confinement of trough concrete: Shear transfer occurring from the trough concrete to the girder section produces an outward lateral force on the girder section that must be resisted to provide confinement of the trough concrete. The reinforcement to resist the lateral force can be designed by using the approach presented in Section 3.8.2.

3. Trough concrete strength: A minimum of 4,000 psi should be used as this is the minimum tested.

4. Shear key capacity: Because the shear key capacity for a $1 \mathrm{ft}$ stud spacing in 4,000 psi concrete is approximately 82 kips, a maximum stud size of \#8 bar can be used without having to calculate shear key capacity.

5. Stud strength: Shear capacity was found to be $1.25 \mathrm{~A}_{s} \mathrm{f}_{\mathrm{u}}$ which can be used for analytical modeling purposes. For design purposes, the stud strength should be estimated as $\mathrm{V}_{\mathrm{n}}=\mathrm{A}_{\mathrm{s}} \mathrm{f}_{\mathrm{u}}$.

\subsection{Panel-to-Panel Connection}

New details for the connection between adjacent precast deck panels were developed and evaluated. The objective of the tests was to develop a new connection between precast deck panels with a focus on increasing the speed of construction, minimizing the use of grout, and minimizing joint width. To evaluate the behavior and strength of the new detail, direct shear tests were conducted. The New England System detail was also tested in the same manner to evaluate and compare behavior. The new joint detail consisted of a male-female, semi-circular shear key joined using segmental bridge adhesive (SBA). Several conclusions were drawn from the test results. 
1. Using the new joint detail produced failure in the precast panel concrete. However, in the New England system joint, failure occurred at the joint resulting in a significantly lower strength.

2. The new joint carried upwards of $78 \%$ more load than the New England joint.

3. A 6 in. versus 8 in. radius has no appreciable effect on the strength of the new joint because both circular geometries resulted in failure of the panel concrete rather than the joint.

4. Sikadur 31 and Unitex Pro-Poxy SBA had similar performance because failure was controlled by the panel concrete rather than adhesion of the joint.

5. The shear strength of the new joint detail can be conservatively estimated using $3 \sqrt{f_{c}}$. Since the full shear strength of the member concrete was achieved (failure away from the joint), no calculations of joint strength are required.

\subsection{Full-Depth Deck System}

The new full-depth deck system consists of the improved panel-to-girder connection detail developed in Phase 2 as well as the new panel-to-panel connection developed in Phase 3. The system was developed to eliminate penetrations in the deck panels and minimize joint widths, while increasing the speed of construction. A fullscale specimen was constructed using the new connection details and evaluated to confirm its performance and constructability. The objectives of the tests were to evaluate the performance of the new panel-to-panel joint under cyclic loading, strength of the girder-to-panel connection, and composite behavior of the system. The test specimen was $42 \mathrm{ft}$ long using two modified HN36-49 prestressed concrete girders spaced 100 in. on center. The precast deck panels were $14 \mathrm{ft}$ in the transverse direction and $4 \mathrm{ft}$ in length. The deck panels were secured together using segmental bridge adhesive (SBA). Following cyclic loading, the specimen was cut into two single girder specimens that were subsequently loaded to failure. Several conclusions were drawn from the results. 
1. The system was demonstrated to provide ease in constructability.

a. The precaster had no difficulties in forming the shear key or trough which are essential to the performance of the system.

b. Installation of one panel was achieved in 3 hours by one person, which included time for concrete mixing. In all, 30 man hours were required for installation of the panels. Indicating that rapid construction is possible.

c. The shear keys provided an excellent means of compressing the panels after SBA application.

d. A trough width of 6 in. was more than sufficient to accommodate variation in stud or panel placement.

2. Cyclic loading to 2 million cycles of the AASHTO wheel load plus impact indicated that the new panel-to-panel joint as well as the overall system performed well. No deterioration in either the overall response or the joint was observed.

3. The panel-to-girder connection performed well in both cyclic and ultimate capacity tests. No deterioration or damage to the connection was observed.

4. The capacity of the system could be reliably estimated using partial-composite analysis.

a. Shear stud strength can be estimated using $1.25 \mathrm{~A}_{\mathrm{s}} \mathrm{f}_{\mathrm{u}}$ for Grade 60 reinforcement, $\mathrm{f}_{\mathrm{u}}=90 \mathrm{ksi}$.

\subsection{Design and Construction Recommendations}

Based on the results of this research program, the following design and construction recommendations are provided:

\subsubsection{Girder Design}

1. The girder should be designed according to AASHTO for flexural and shear reinforcement.

2. The horizontal strength of the joint can be estimated based on the shear stud strength provided by $V_{n}=1.25 A_{s} f_{u}$ for analytical purposes. However, $1.0 A_{s} f_{u}$ 
should be used for design. A spacing of no less than $1 \mathrm{ft}$ should be used as that is the smallest stud spacing tested. While the shear strength is based on $f_{u}, f_{y}$ can be substituted for $f_{u}$ when computing stud strength if reduced slip is desired.

\section{Trough Design}

a. A keyed trough surface must be used to transfer shear force between the trough concrete and girder section. Trough details are provided in Section 3.2.1.

b. A minimum stud embedment of 6 in. should be used for \#4 - \#6 studs.

c. A minimum of 4,000 psi concrete strength should be used in the trough.

d. The girder section must be detailed to resist outward thrust as outlined in Section 3.8.2.

e. A trough width of 6 in. was more than sufficient to accommodate variation in stud or panel placement. A reduction in trough width to 4 in. would allow for use of the system in girders with smaller cross sections.

\subsubsection{Panel Design}

1. The deck should be designed according to AASHTO for flexural reinforcement in the transverse direction and for shrinkage and temperature steel as well as distribution reinforcement in the longitudinal direction. In addition, when using approximate methods of analysis described in Section 4.6.2 of AASHTO (2007), it is recommended that the strip width be limited to the panel width.

2. Calculation of the shear strength of the transverse joint is not required.

3. The shear studs should be embedded as far into the panel as possible taking into account reinforcement cover requirements provided by AASHTO.

4. Either the 6 in. or 8 in. joint radius is recommended. However, the 8 in. joint may be preferable for constructability. It is less likely to chip at the edges. In addition, it would better accommodate variations in joint geometry. 
5. Either Sikadur-31 or Unitex Pro-Poxy segmental bridge adhesive can be used for connection of adjacent panels.

\subsubsection{Construction}

1. Teflon can be used as a means of sliding the panels into position. This method proved successful and alleviates the need to tilt the panels during placement.

2. Leveling bolts should be considered for each panel since leveling panels by shimming can be time consuming in field applications.

3. The trough should not be filled with more than the required concrete. As the concrete spreads, due to the weight of the panel, the bearing area increases. If excessive concrete is present, the panel will not seat to the proper height. No more than the quantity of concrete required to fill the trough and create the desired haunch should be used.

4. The maximum size of aggregate in the trough concrete should be no more than 3/8 in. This dimension allows for proper consolidation within the keys and between the studs.

5. Approximately $0.15 \mathrm{gal} / \mathrm{ft}^{2}$ of adhesive should be used on the transverse deck joint. The adhesive can be applied with a gloved hand. Applying the adhesive to both sides of the joint is preferable to applying it to only one side.

6. Hydraulic rams bearing on the shear keys in the trough can be used as an effective means of squeezing the panel together.

7. If bond is desired between the trough concrete and panels, the bottom surface of the panels should be roughened. 


\subsection{Future Research}

Recommendations for future work include, but are not limited to, the following:

1. The use of reinforcing bars larger than \#6 as shear studs.

2. Further refinement of the proposed design process for trough confining reinforcement.

3. The use of shear stud groups.

4. Field evaluation of the deck system.

5. Use of a reduced trough width.

6. The use of other key dimensions. Only one key geometry was used in this research program.

7. Other trough geometries to reduce forming time and alleviate sharp corners at the base of the trough. 


\section{LIST OF REFERENCES}

AASHTO, 1999, Guide Specifications for Design and Construction of Segmental Concrete Bridges (2003 Interim), Second Edition, American Association of State Highway and Transportation Officials, Washington, DC.

AASHTO, 2007, AASHTO LRFD Bridge Design Specifications, 4th Edition, American Association of State Highway and Transportation Officials, Washington, DC.

ACI, 2008, Building Code Requirements for Structural Concrete (ACI 318-08) and Commentary, American Concrete Institute, Farmington Hills, MI, 465 pp.

Badie, S. S.; Baishya, M. C.; and Tadros, M. K., 1998, "NUDECK-An Efficient and Economical Precast Prestressed Bridge Deck System,” PCI Journal, V. 43, No. 5, Sep.-Oct., pp. 56-83.

Badie, S. S.; Tadros, M. K.; and Girgis, A. F., 2006, "Full-Depth Precast-Concrete Bridge Deck Panel Systems," Final Report No. NCHRP-12-65, National Cooperative Highway Research Program, Nov., 393 pp.

Barde, A.; Parameswaran, S.; Chariton, T.; Weiss, J.; Cohen, M. D.; and Newbolds, S., 2006, "Evaluation of Rapid Setting Cement-Based Materials for Patching and Repair," Final Report No. FHWA/IN/JTRP/2006-11, Joint Transportation Research Program, Purdue University, West Lafayette, IN, Oct., 144 pp.

Fallaha, S.; Chuanbing, S.; Lafferty, M. D.; and Tadros, M. K., 2004, "High Performance Precast Concrete NUDECK Panel System for Nebraska’s Skyline Bridge,” PCI Journal, V. 49, No. 5, Sept.-Oct., pp. 40-50. 
Frosch, R. J., 1996, “Seismic rehabilitation using precast infill walls,” Doctoral Dissertation, The University of Texas at Austin, Austin, TX, 234 pp.

Fuchs, W.; Eligehausen, R.; and Breen, J. E., 1995, “Concrete Capacity Design (CCD) Approach for Fastening to Concrete,” ACI Structural Journal, V. 92, No. 1, Jan.-Feb., pp 73-94.

Hognestad, E., 1951, “A Study of Combined Bending and Axial Load in Reinforced Concrete Members,” University of Illinois Engineering Experiment Station, University of Illinois-Urbana, Bulletin Series No. 399, V. 49, No. 22, Nov., 128 pp.

Issa, M. A.; Yousif, A. A.; Issa, M. A.; Kaspar, I. I.; and Khayyat, S. Y., 1995a, “Field Performance of Full Depth Precast Concrete Panels in Bridge Deck Reconstruction,” PCI Journal, V. 40, No. 3, May-June, pp. 82-108.

Issa, M. A.; Idriss, A.; Kaspar, I. I.; and Khayyat, S. Y., 1995b, “Full Depth Precast and Precast, Prestressed Concrete Bridge Deck Panels,” PCI Journal, V. 40, No. 1, Jan.-Feb., pp. 59-80.

Issa, M. A.; Yousif, A. A.; Issa, M. A.; Kaspar, I. I.; and Khayyat, S. Y., 1998, “Analysis of Full Depth Precast Concrete Bridge Deck Panels,” PCI Journal, V. 43, No. 1, Jan.-Feb., pp. 74-85.

Issa, M. A.; Yousif, A. A.; and Issa, M. A., 2000, "Experimental Behavior of Full-Depth Precast Concrete Panels for Bridge Rehabilitation,” ACI Structural Journal, V. 97, No. 3, May-June, pp. 397-407.

Issa, M. A.; Ribeiro do Valle, C. L.; Abdalla, H. A.; Islam, S., and Issa, M. A., 2003a, "Performance of Transverse Joint Grout Materials in Full-Depth Precast Concrete Bridge Deck Systems,” PCI Journal, V. 48, No. 4, July-Aug., pp. 92-103.

Issa, M. A.; Patton, T. A.; Abdalla, H. A., Yousif, A. A., and Issa, M. A., 2003b, “Composite Behavior of Shear Connections in Full-Depth Precast Concrete Bridge Deck Panels on Steel Stringers,” PCI Journal, V. 48, No. 5, Sept.-Oct., pp. 76-89. 
Issa, M. A.; Salas, J. S.; Shabila, H. I.; and Alrousan, R. Z., 2006, “Composite Behavior of Precast Concrete Full-Depth Panels and Prestressed Girders,” PCI Journal, V. 51, No. 5, Sept.-Oct., pp. 132-145.

Issa, M. A.; Anderson, R.; Domagalski, T.; Asfour, S.; and Islam, M. S., 2007a, "FullScale Testing of Prefabricated Full-Depth Precast Concrete Bridge Deck Panel System,” ACI Structural Journal, V. 104, No. 3, May-June, pp. 324-332.

Issa, M. A. and Abdalla, H. A., 2007b, "Structural Behavior of Single Key Joints in Precast Concrete Segmental Bridges,” Journal of Bridge Engineering, V. 12, No. 3, MayJune, pp. 315-324.

Kaneko, Y.; Connor, J. J.; Triantafillou, T. C.; and Leung, C. K., 1993, “Fracture Mechanics Approach for Failure of Concrete Shear Key. I: Theory,” Journal of Engineering Mechanics, V. 119, No. 4, Apr. pp. 681-700.

Kropp, P. K., 1973, “Use of Precast-Prestressed Concrete for Bridge Decks,” Interim Report No. 7, Joint Highway Research Project, Purdue University and Indiana State Highway Commission, (C-36-56N), March, 41 pp.

LaRose, K. and Elwood, K. J., 2006, “Performance of Headed Shear Stud Clusters for Precast Concrete Bridge Deck Panels,” 2006 Annual Conference of the Transportation Association of Canada, Charlottetown, Prince Edward Island, 13 pp.

Markowski, S. M., 2005, “Experimental and Analytical Study of Full-Depth Precast/Prestressed Concrete Deck Panels for Highway Bridges,” Master’s Thesis, University of Wisconsin-Madison, Madison, WI, 264 pp.

Menkulasi, F. and Roberts-Wollmann, C. L., 2005, “Behavior of Horizontal Shear Connections for Full-Depth Precast Concrete Bridge Decks on Prestressed I-Girders,” PCI Journal, V. 50, No. 3, May-June, pp. 60-73.

PCI, 2004, PCI Design Handbook: Precast and Prestressed Concrete, 6th Edition, MNL-120-04, Precast/Prestressed Concrete Institute, Chicago, IL. 
PCINER Technical Committee, 2002, “Full Depth Precast Concrete Deck Slabs,” Final Report No. PCINER-02-FDPCDS, Precast/Prestressed Concrete Institute New England Region, 18 pp.

Scholz, D. P.; Wallenfelsz, J. A.; Lijeron, C.; and Roberts-Wollmann, C. L., 2007, "Recommendations for the Connection Between Full-Depth Precast Bridge Deck Panel Systems and Precast I-Beams,” Final Report No. FHWA/VTRC 07-CR17, Virginia Transportation Research Council, June, pp. 78.

Sullivan, S., 2007, “Construction and Behavior of Precast Bridge Deck Panel Systems,” Doctoral Dissertation, Virginia Polytechnic Institute and State University, Blacksburg, VA, 331 pp.

The Fort Miller Co., Inc., 2002, “Precast Concrete Steel Composite Superstructure Units,” The Fort Miller Co., Inc., http://www.super-slab.com/pdf/precastconcrete.pdf (accessed December 3, 2009).

The Fort Miller Co., Inc., 2002, “Precast Composite Deck Systems,” The Fort Miller Co., Inc., http://www.super-slab.com/pdf/effideck.pdf (accessed December 3, 3009).

Versace, J. D., 2003, “Implementation of Full-Depth Precast Bridge Deck Panels,” Master's Thesis, Purdue University, West Lafayette, IN, 141 pp.

Wallenfelsz, J. A., 2006, “Horizontal Shear Transfer for Full-Depth Precast Concrete Bridge Deck Panels,” Master’s Thesis, Virginia Polytechnic Institute and State University, Blacksburg, VA, 111 pp.

Yamane, T.; Tadros, M. K.; Badie, S. S.; and Baishya, M. C., 1998, "Full Depth Precast, Prestressed Concrete Bridge Deck System,” PCI Journal, V. 43, No. 3, May-June, pp. 50-66. 
APPENDIX A 


\section{APPENDIX A}

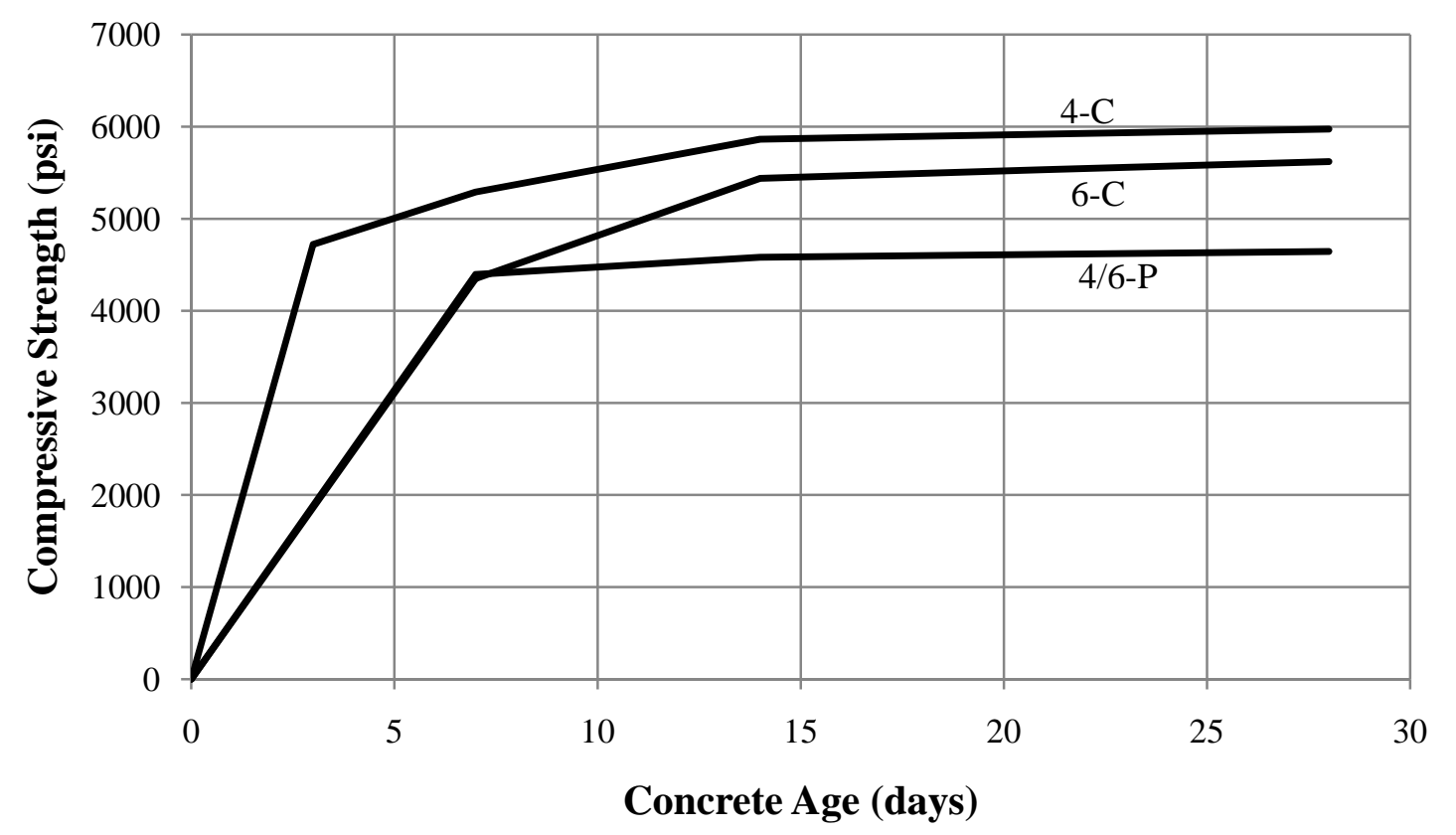

Figure A.1: Concrete compressive strength for Phase I deck panels

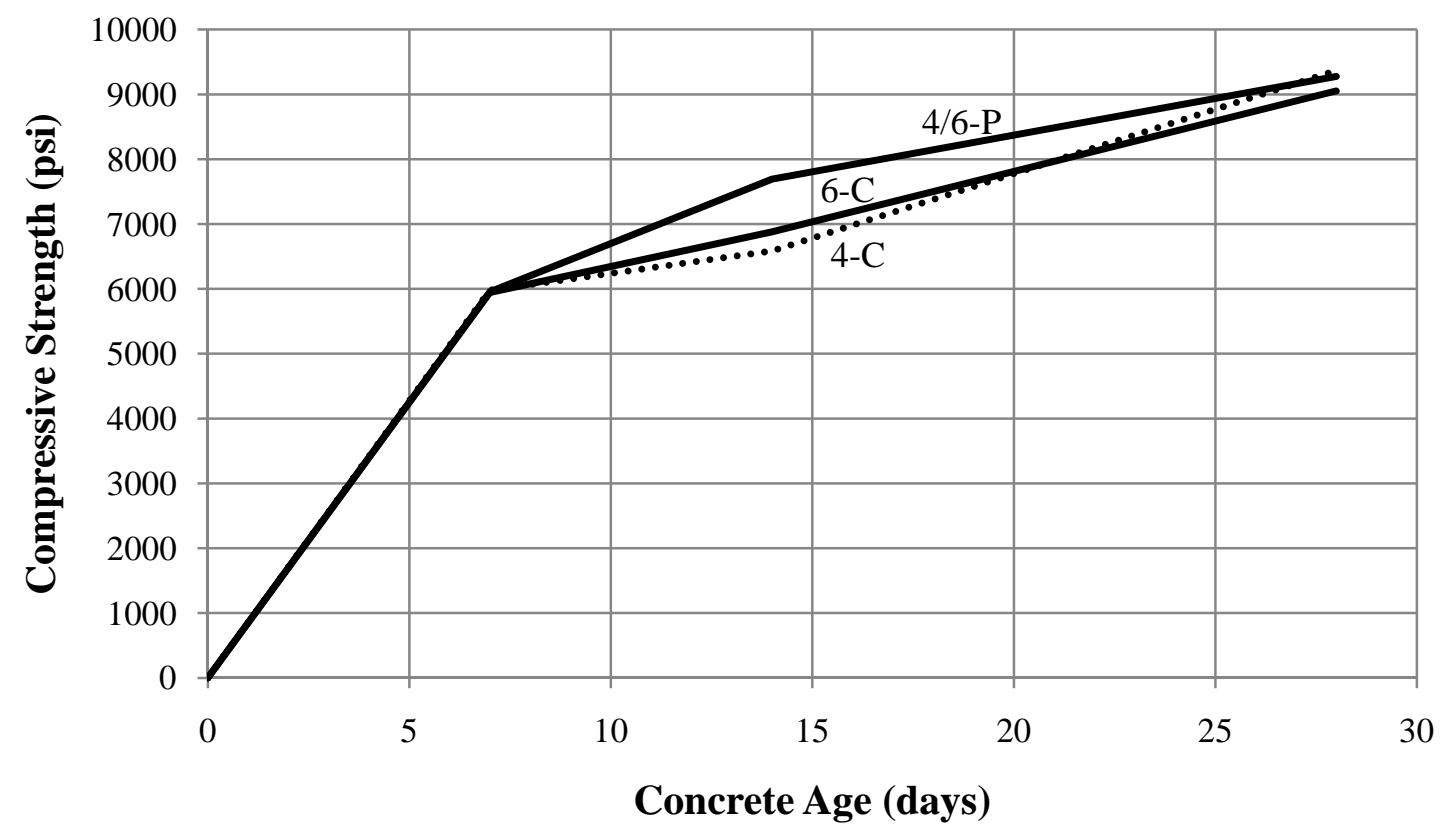

Figure A.2: Concrete compressive strength for Phase I girders 


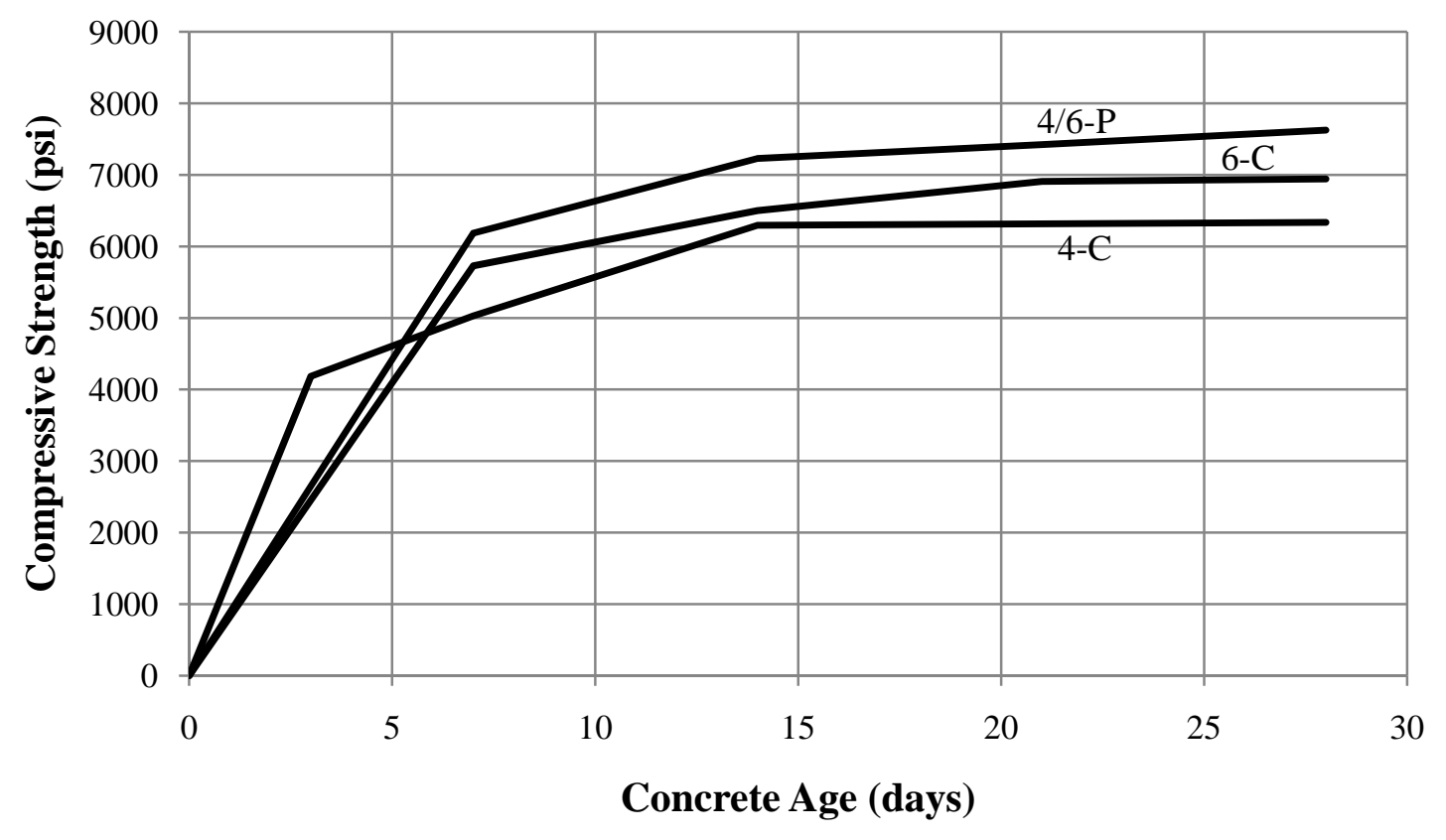

Figure A.3: Concrete compressive strength for Phase I SCC

Table A.1: Test day concrete compressive strength

Concrete compressive strength $\boldsymbol{f}_{c}$ (psi)

\begin{tabular}{|c|c|c|c|}
\hline Specimen & 4-C & 6-C & 4/6-P \\
\hline Panels & 6360 & 4660 & 4590 \\
\hline Girder & 9020 & 8320 & 8630 \\
\hline SCC & 5970 & 6860 & 7790 \\
\hline
\end{tabular}




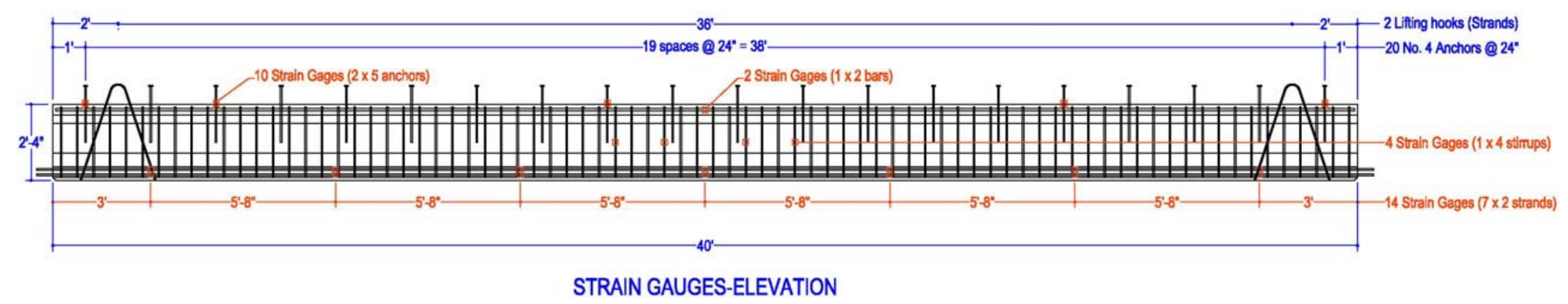

Figure A.5: Internal strain gauge layout (Phase I specimens) 


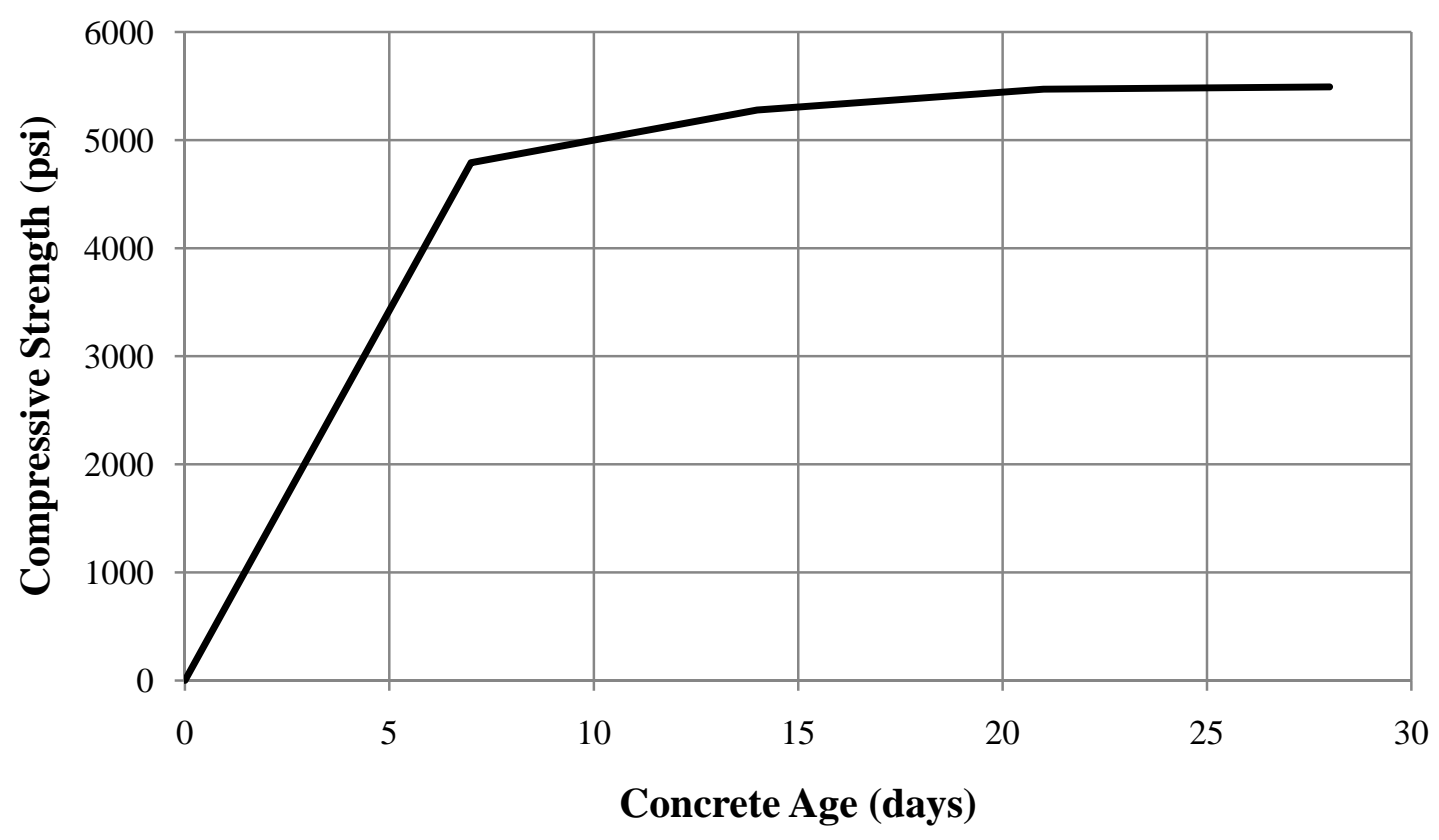

Figure A.6: Concrete compressive strength for Group 1 panel sections

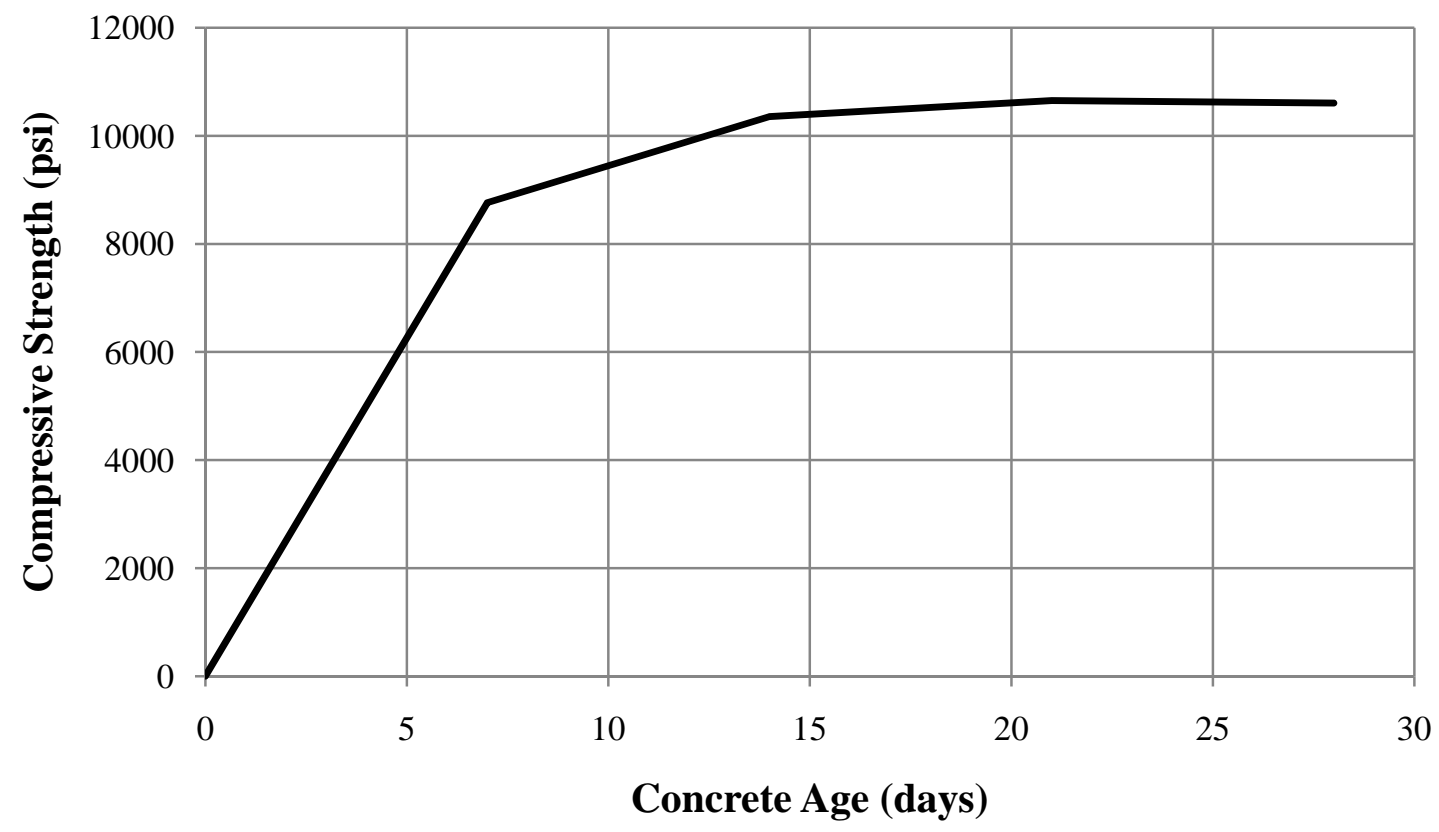

Figure A.7: Concrete compressive strength for Group 1 girder sections 


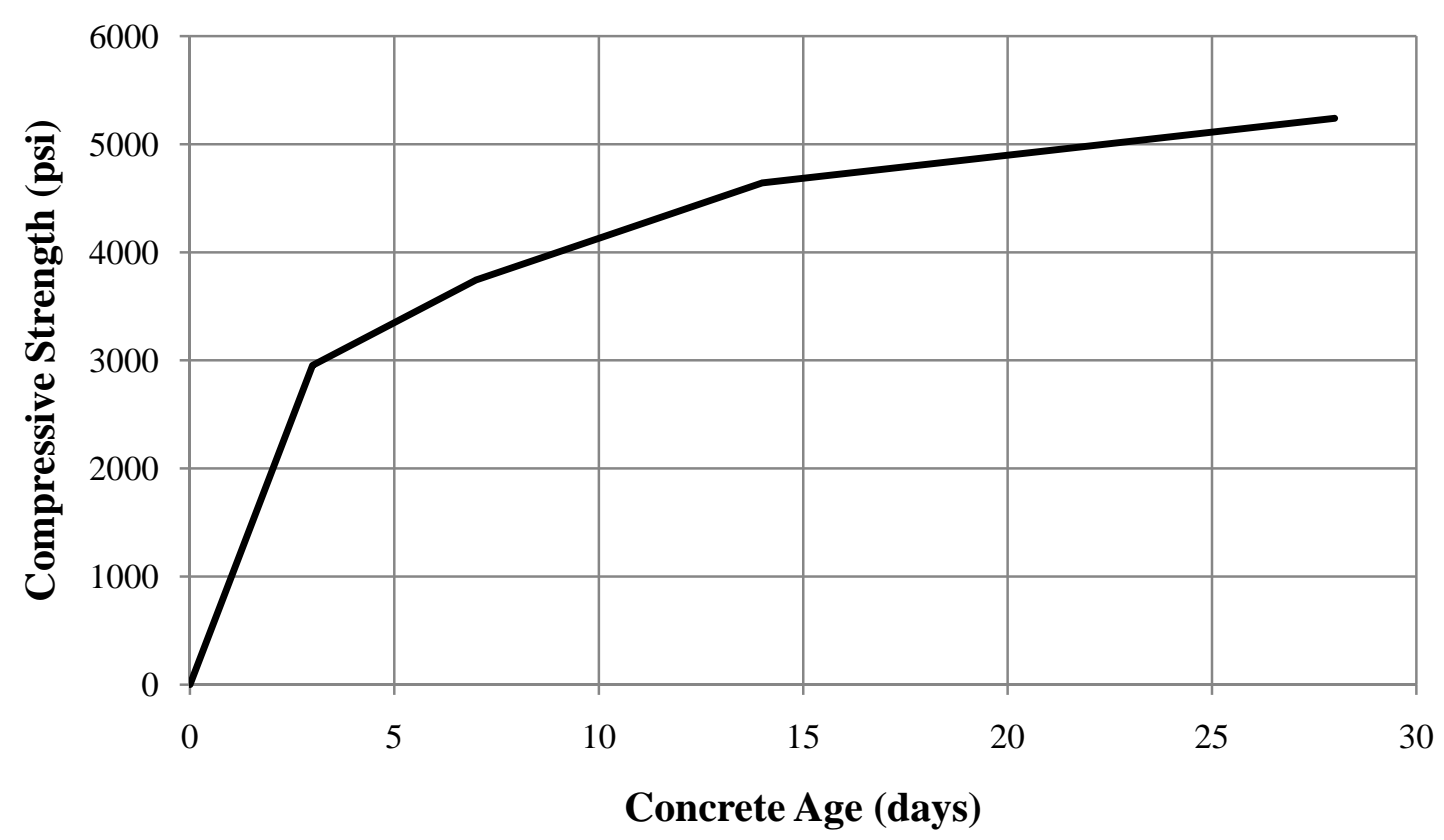

Figure A.8: Concrete compressive strength for $\mathbf{4 0 0 0}$ psi trough concrete

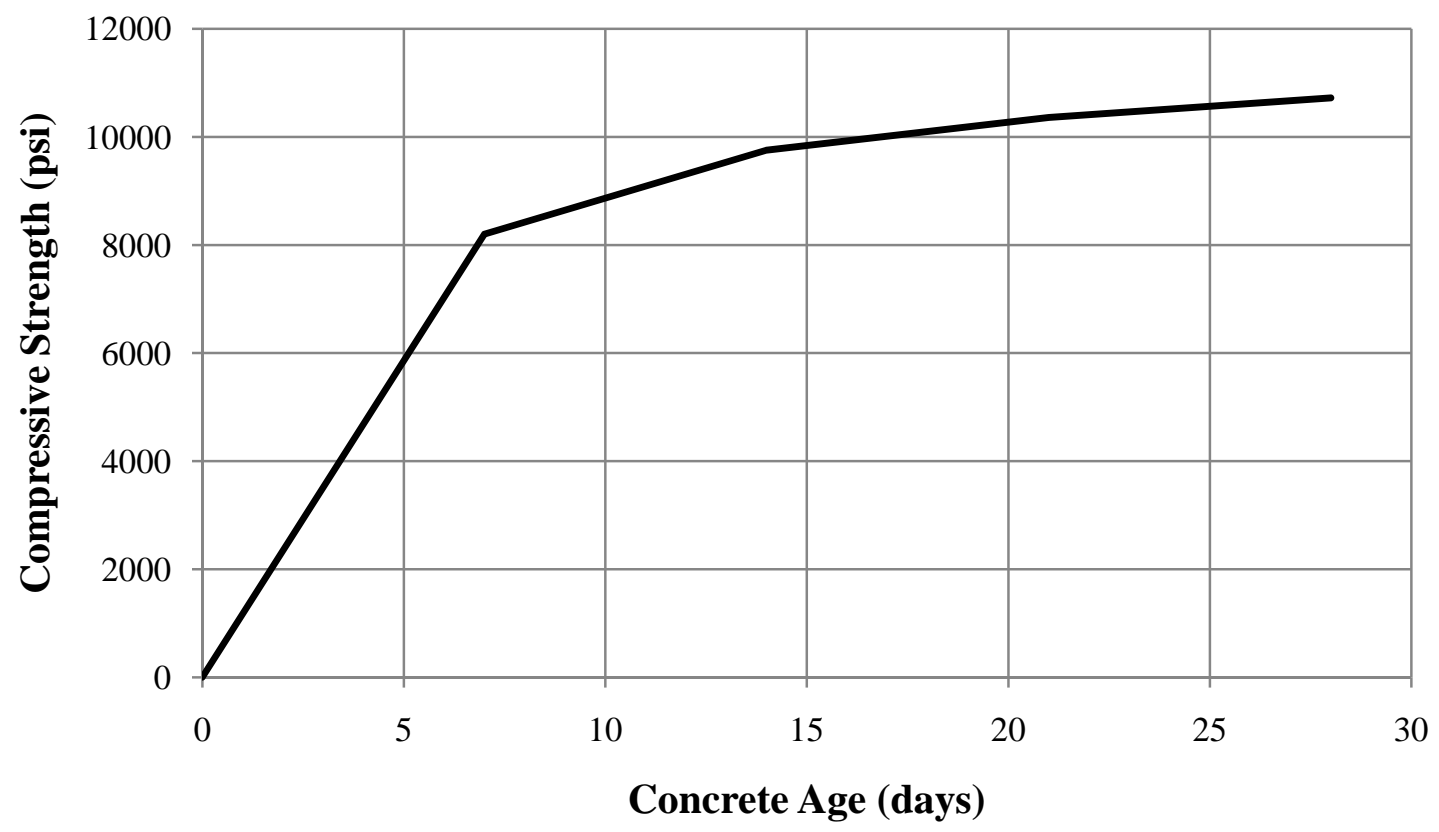

Figure A.9: Concrete compressive strength for Group 1, 8000 psi trough concrete and girder sections of Specimens 2-8000-6-k-6, 1-8000-6-k-4n, and 2-8000-6-k-6n 


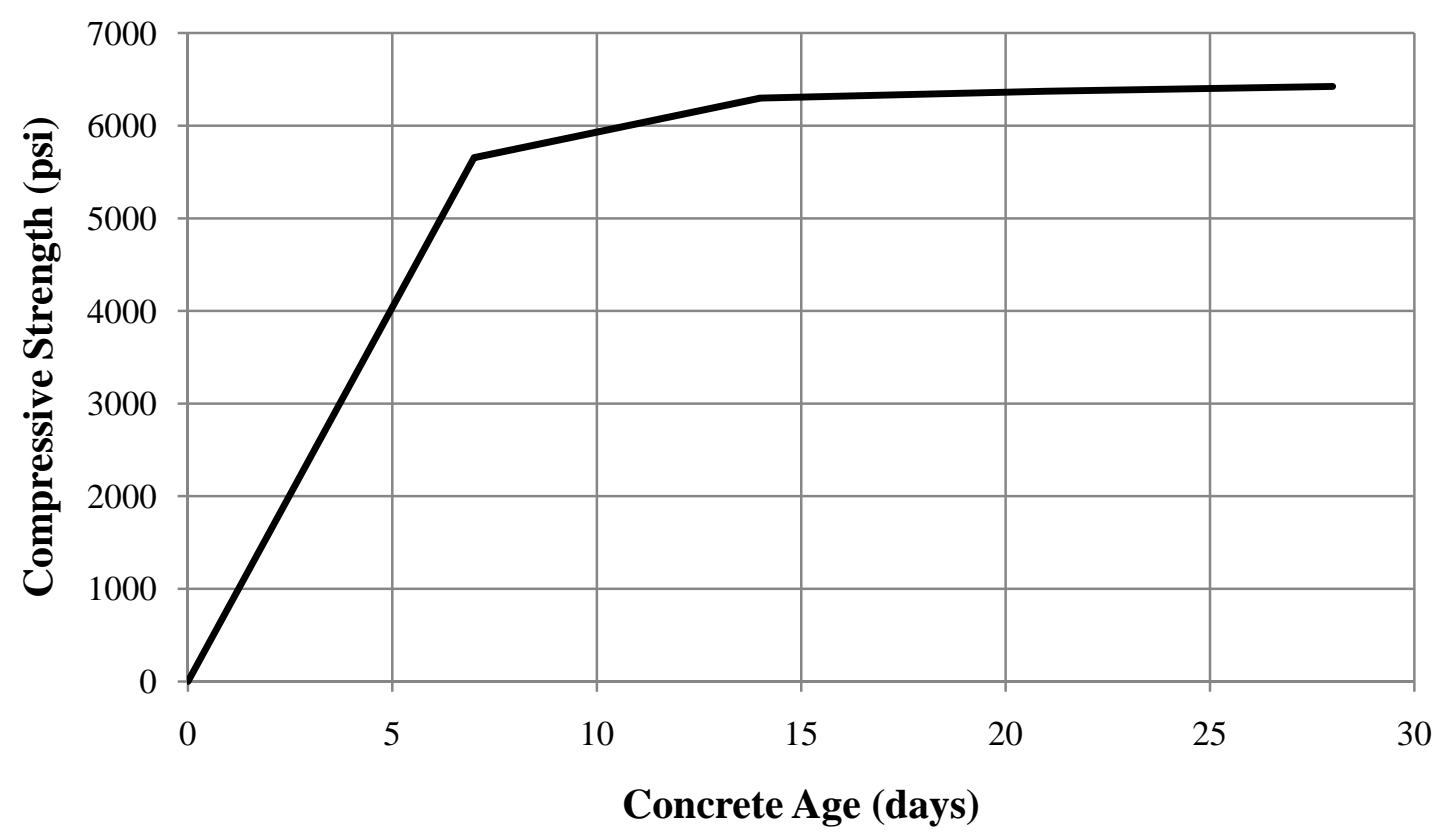

Figure A.10: Concrete compressive strength for panels of Specimens 2-8000-6-k-6, 1-8000-6-k-4n, and 2-8000-6-k-6n

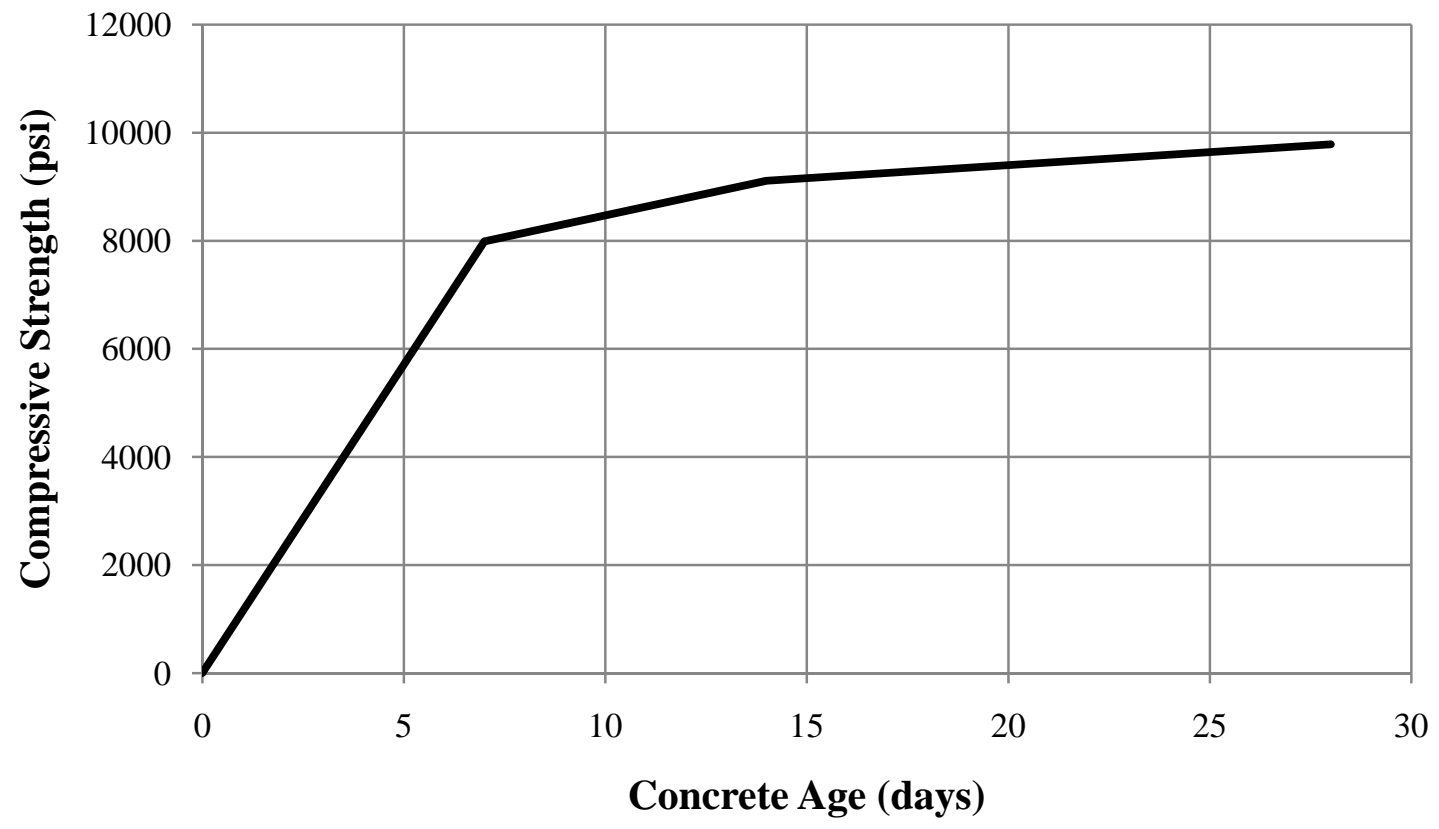

Figure A.11: Concrete compressive strength for New England specimen SCC and Specimen 2-4000-6-k-6n 


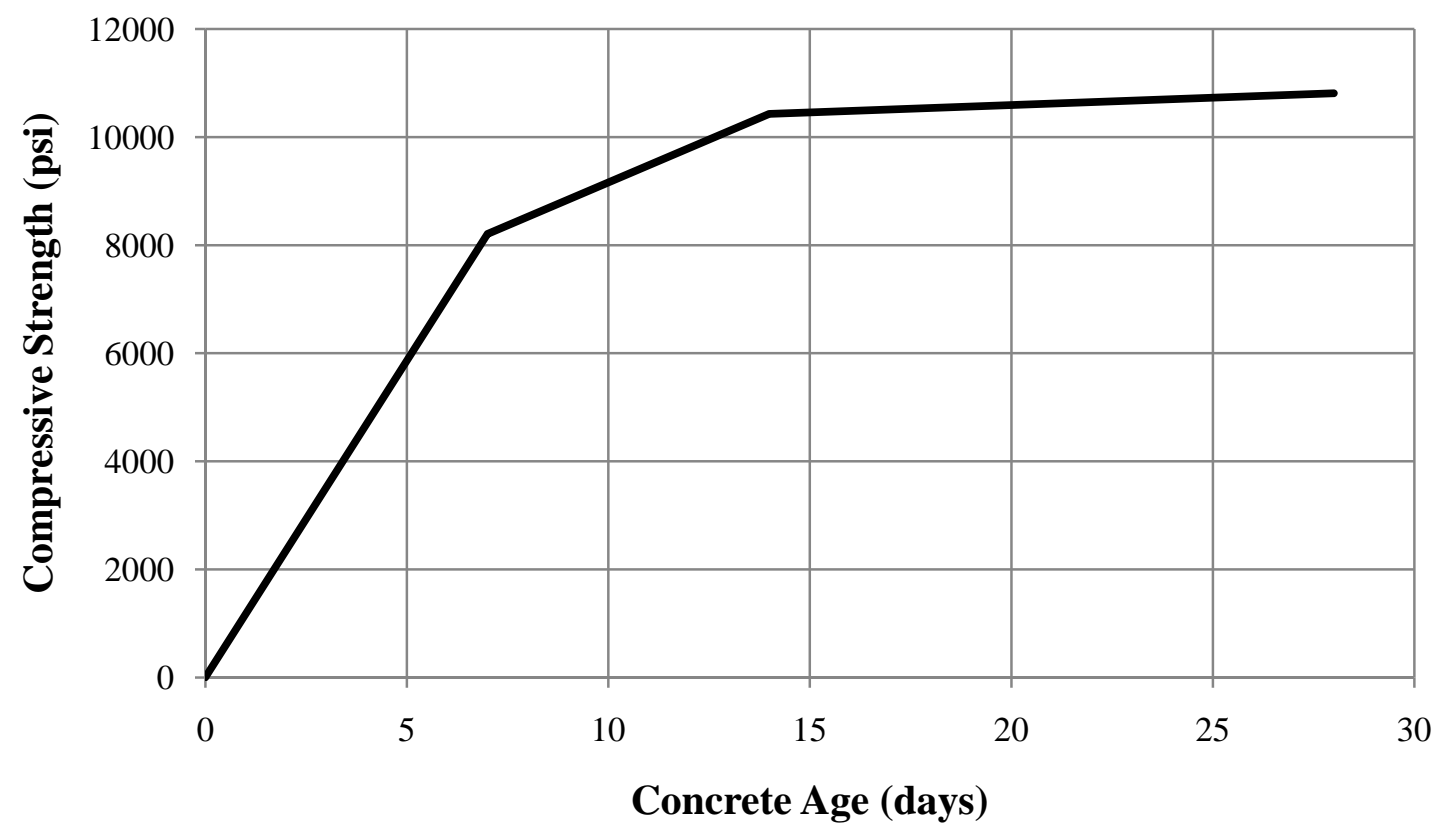

Figure A.12: Concrete compressive strength for Specimens 2-8000-6-k-6, 1-8000-6-k-4n, and 2-8000-6-k-6n

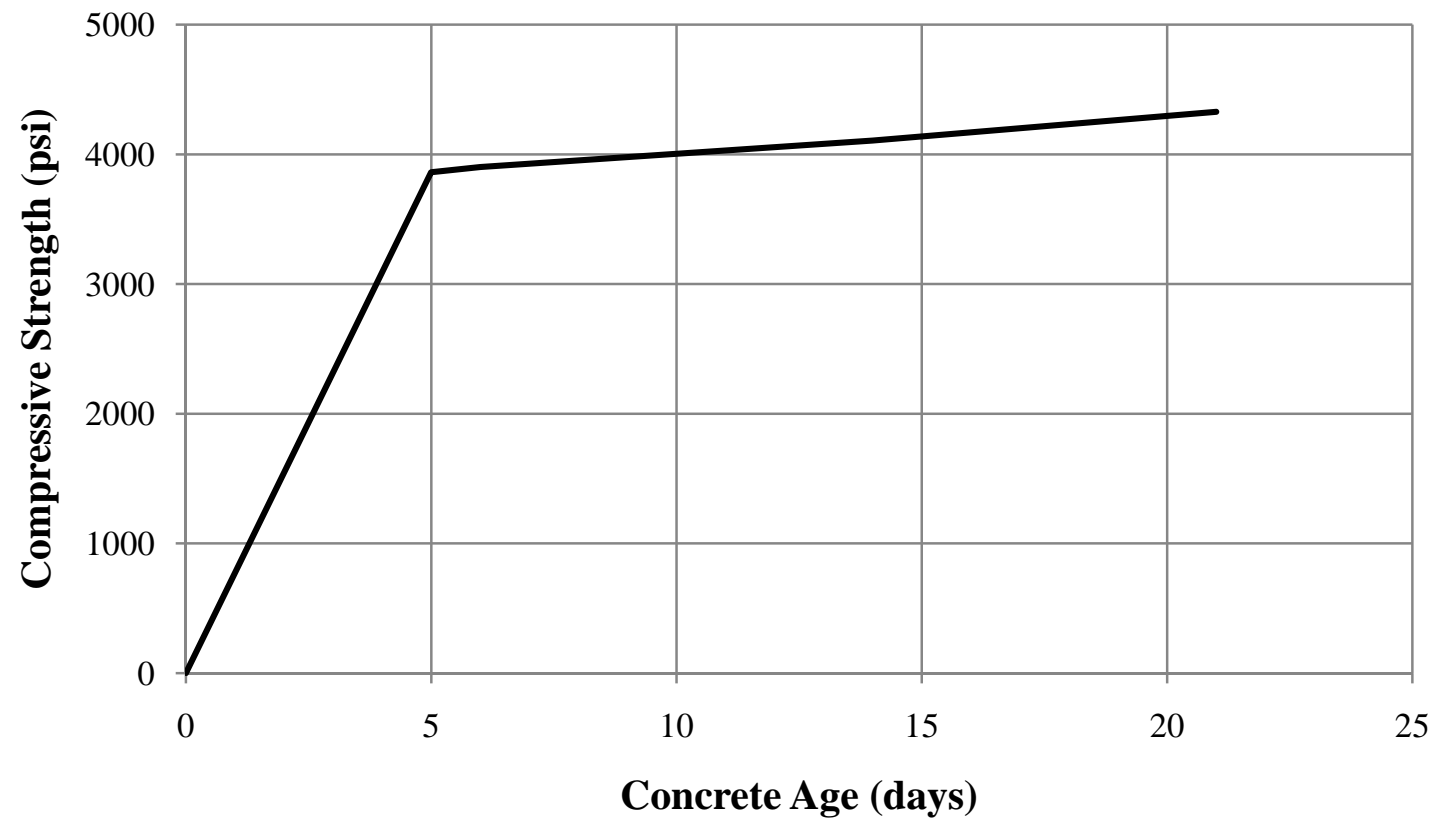

Figure A.13: Concrete compressive strength of trough concrete in Specimen 2-4000-6-k-6n 